AGE, MOVEMENTS, AND FEEDING ECOLOGY OF NORTHWEST ATLANTIC WHITE SHARKS ESTIMATED FROM

ECOGEOCHEMICAL PROFILES IN VERTEBRAE

\author{
By \\ Li Ling Hamady \\ B.A., University of California, Santa Barbara, 2006 \\ Submitted in partial fulfillment of the requirements for the degree of \\ Doctor of Philosophy \\ at the \\ MASSACHUSETTS INSTITUTE OF TECHNOLOGY \\ and the \\ WOODS HOLE OCEANOGRAPHIC INSTITUTION
}

February 2014

(C)2014 Li Ling Hamady

All rights reserved

The author hereby grants to MIT and WHOI permission to reproduce and to distribute publicly paper and electronic copies of this thesis document in whole or in part in any medium now known or hereafter created.

Signature of Author

Joint Program in Oceanography and Applied Ocean Science and Engineering Massachusetts Institute of Technology and Woods Hole Oceanographic Institution

Certified by January 30,2014

Dr. Simon R. Thorrold Thesis Supervisor

Accepted by

Professor Martin F. Polz

Chair, Joint Committee for Biological Oceanography Massachusetts Institute of Technology and Woods Hole Oceanographic Institution 


\title{
AGE, MOVEMENTS, AND FEEDING ECOLOGY OF NORTHWEST ATLANTIC WHITE SHARKS ESTIMATED FROM ECOGEOCHEMICAL PROFILES IN VERTEBRAE
}

\author{
By \\ Li Ling Hamady \\ Submitted to the MIT-WHOI Joint Program in Oceanography/Applied Ocean Science \\ and Engineering on January 30, 2014 in Partial Fulfillment of the Requirements for the \\ Degree of Doctor of Philosophy in Biological Oceanography
}

\begin{abstract}
White sharks (Carcharodon carcharias) are highly migratory, ecologically important, vulnerable, and understudied marine predators. Ecogeochemistry, which takes advantage of natural variations in chemical signatures recorded in body tissues, can help determine lifetime movement, age, and ontogenetic diet history in difficult to study species. Shark vertebrae are constructed of distinct layers of tissue laid down sequentially over an individual's lifetime and may preserve a chemical record of environmental exposure. In this thesis, I investigate the ecology of the understudied northwest Atlantic (NWA) white shark population by applying several ecogeochemistry techniques to their vertebrae. I generate the first radiocarbon $\left(\Delta^{14} \mathrm{C}\right)$ age estimates for adult white sharks, dramatically extending the maximum age and longevity compared to earlier age studies. $\Delta^{14} \mathrm{C}$ results also verify a lack of reworking of vertebral material and hint at possible sexual dimorphism in growth rates. Using amino acid and bulk stable isotope analyses, I show that individual sharks have marked variation in feeding and movement, and that pinnipeds do not constitute a large portion of their diet. Finally, I explore the utility of elemental chemistry to retrospectively infer movement. This work provides an important informational baseline for future NWA white shark ecological studies and conservation and management efforts.

Thesis Supervisor: Dr. Simon R. Thorrold

Title: Senior Scientist, Department of Biology, Woods Hole Oceanographic Institution
\end{abstract}




\section{ACKNOWLEDGEMENTS}

I received support from a National Science Foundation Graduate Research Fellowship and the WHOI Academic Programs Office. The research in this thesis was funded by a National Science Foundation Grant (OCE 0825148) to S. Thorrold. Additional support came from an ITCE (Inter-university Training for Continental-scale Ecology) Research in Residence Fellowship.

My advisor, Dr. Simon Thorrold, has been an absolutely amazing resource during my time as a graduate student and I cannot thank him enough. This work would not have been possible without his encouragement, support, guidance, and mentorship. I would like to thank my committee, Dr. Greg Skomal from MA Department of Marine Fisheries, Dr. Gareth Lawson from WHOI, Dr. Roger Summons from MIT, and my chair, Dr. Julie Kellner from WHOI, all of whom have been supportive and provided constructive critiques throughout the thesis process. Additionally, I would like to thank past and present Fish Ecology Lab members Leah Houghton, Dr. Kelton McMahon, Camrin Braun, Dr. Mike Polito, Dr. Joel Llopiz, and Dr. Michael Berumen for help in lab and scientific conversations.

Other scientists to whom I owe a great debt of gratitude include Dr. Lisa Natanson at NMFS for teaching me about the age and growth of sharks and, most critically, for the use of all the vertebrae; Mary Lardie at NOSAMS for her unwavering optimism, lab expertise, and friendship; Dr. Ann McNichol at NOSAMS for her guidance; Prof. Brian Popp and his lab at University of Hawaii, Manoa for being such gracious hosts while I learned the $\delta^{15} \mathrm{~N}$ amino acid technique; and Dr. Allen Andrews for many productive conversations and email exchanges regarding $\Delta^{14} \mathrm{C}$.

I have had many amazing people in my life during my time as a student and I am exceedingly grateful for the support I received and the love and memories that we shared. I could not have done this without my friends and family from both near and far. I especially want to acknowledge my parents, Joel and Darlene Hamady, who have provided me with unwavering love and encouragement and who have been with me since the earliest stages of my love affair with the ocean. This thesis is dedicated to them. 


\section{TABLE OF CONTENTS}

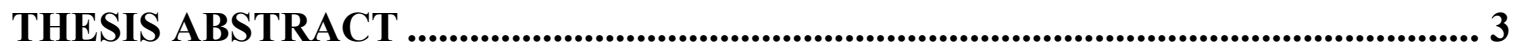

ACKNOWLEDGEMENTS ............................................................................................. 5

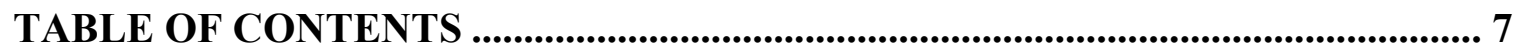

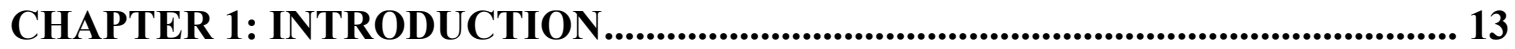

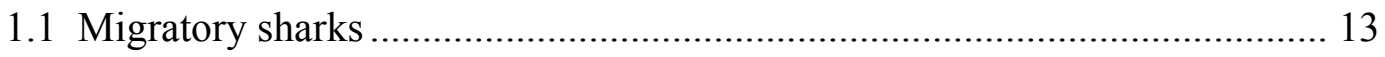

1.2 Traditional shark ecology techniques ......................................................... 13

1.2.1 Age

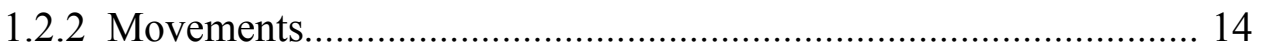

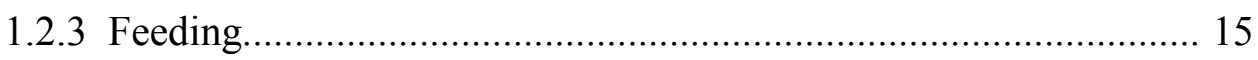

1.3 Complementary ecogeochemistry techniques................................................ 16

1.3.1 Bomb radiocarbon for age ...................................................... 16

1.3.2 Stable isotopes for movement and feeding .................................. 17

1.3.3 Elemental chemistry for movements ………………................... 18

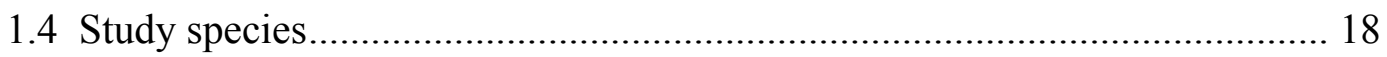

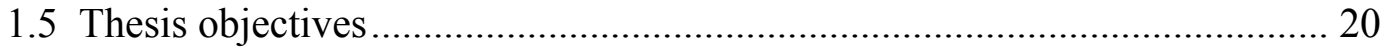

\section{CHAPTER 2: VERTEBRAL BOMB RADIOCARBON SUGGESTS EXTREME} LONGEVITY IN WHITE SHARKS ...................................................................... 21

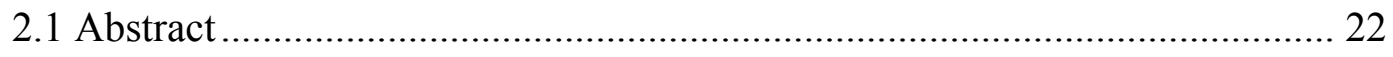

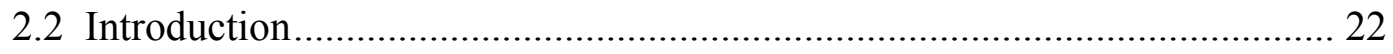

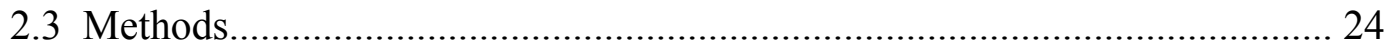

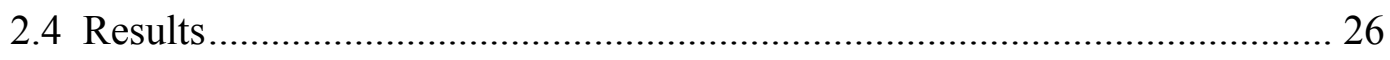

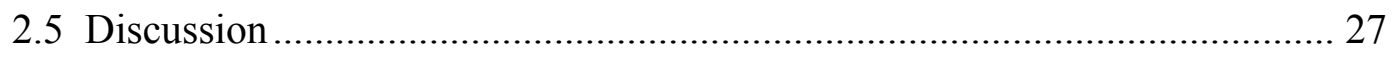

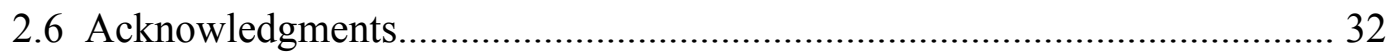


2.7 Tables

2.7.1 Collection and sampling information for individual sharks 33

2.8 Figures.

2.8.1 Photomicrographs of sectioned vertebrae 34

2.8.2 White shark $\Delta{ }^{14} \mathrm{C}$ results compared to three $\Delta^{14} \mathrm{C}$ reference chronologies 35

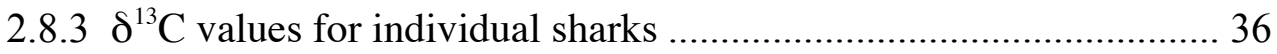

2.8.4 Bivariate plot of $\delta^{13} \mathrm{C}$ versus $\Delta^{14} \mathrm{C}$ for individual sharks ............... 37

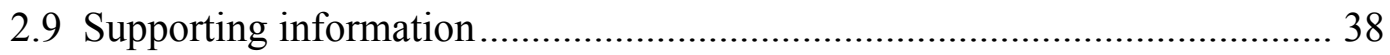

2.9.1 Linear trends fit to the $\Delta^{14} \mathrm{C}$ rise portion of the reference

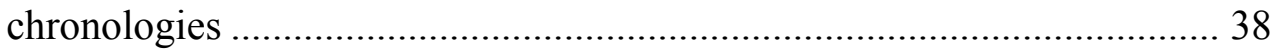

2.9.2 Phase lagged $\Delta^{14} \mathrm{C}$ shark values ............................................... 39

2.9.3 Calculating the summed squared differences for optimal

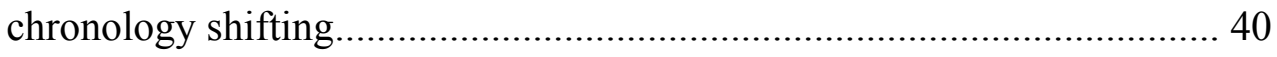

2.9.4 $\Delta^{14} \mathrm{C}$ and $\delta^{13} \mathrm{C}(\%)$ shark sample data listed by individual ............. 42

\section{CHAPTER 3: RETROSPECTIVELY INVESTIGATING WHITE SHARK ECOLOGY VIA BULK AND AMINO ACID STABLE ISOTOPE ANALYSIS .... 45}

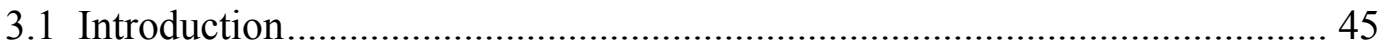

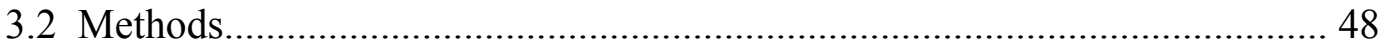

3.2.1 Tissue sampling ................................................................ 48

3.2.2 Bulk SIA ..................................................................... 48

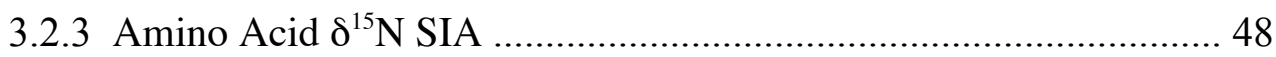

3.2.4 Data Analysis ............................................................... 49

3.2.4.1 Bulk SIA data ......................................................... 49

3.2.4.2 CSIA data ................................................................... 51 
3.3 Results.

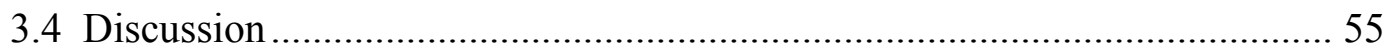

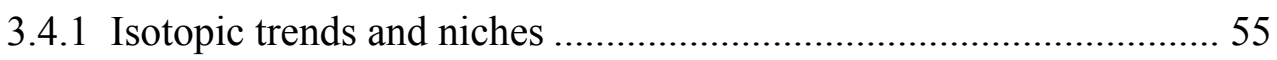

3.4.2 In context: the food web and other white shark studies ................... 57

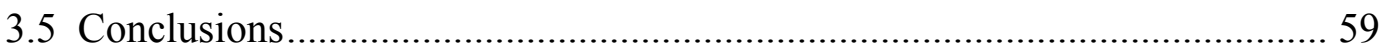

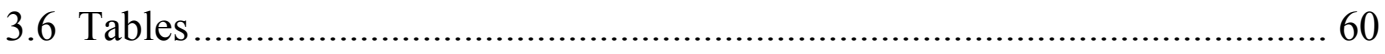

3.6.1 Collection and sampling information for individual sharks .............. 60

3.6.2 The known extent of the diet of NWA white sharks from stomach

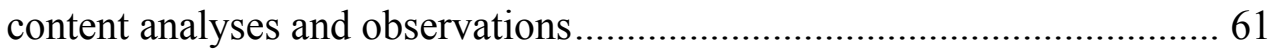

3.6.3 Stable isotope values for foodweb items from the NWA.................. 62

3.6.4 Calculating correction factors for shark tissue .................................. 68

3.6.5 White shark bulk isotopic niche space as measured by Bayesian

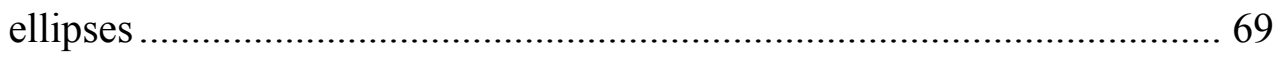

3.6.6 White shark CSI niche space as measured by Bayesian ellipses ..... 70

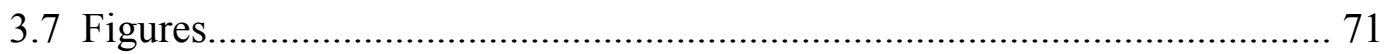

3.7.1 Uncorrected bivariate plot of $\delta^{13} \mathrm{C}$ and $\delta^{15} \mathrm{~N}$ values from white

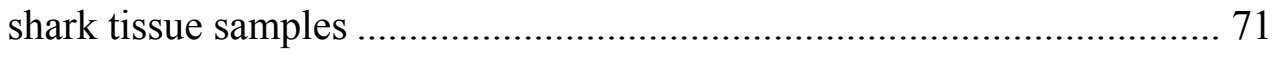

3.7.2 Corrected bivariate plot of $\delta^{13} \mathrm{C}$ and $\delta^{15} \mathrm{~N}$ values from white shark

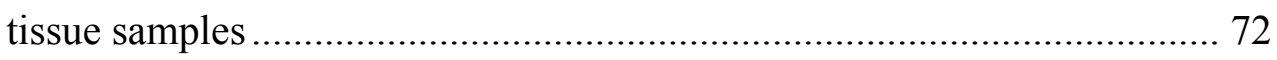

3.7.3 Bulk values from white shark tissues plotted by age ....................... 73

3.7.4 Bulk values from white shark tissues plotted by year ...................... 74

3.7.5 Lifetime niche width of individuals based on bulk values ............... 75

3.7.6 Northwest Atlantic foodweb …………………………………….... 76

3.7.7 Bivariate plot of average bulk $\delta^{13} \mathrm{C}$ and $\delta^{15} \mathrm{~N}$ values from white shark tissue samples from around the world ............................................... 77 
3.7.8 White shark trophic position ........................................................... 78

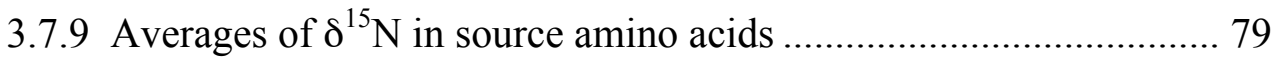

3.7.10 Lifetime isotopic niches of individuals based on CSIA ...................80

\section{CHAPTER 4: INFERRING MOVEMENTS OF WHITE SHARKS BASED ON}

VERTEBRAL ELEMENTAL CHEMISTRY ..................................................................81

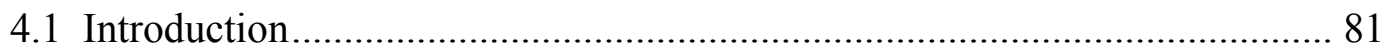

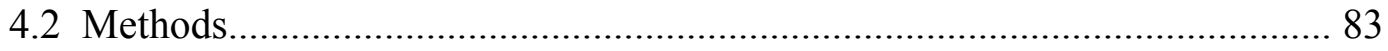

4.2.1 Vertebral sampling and preparation .............................................. 83

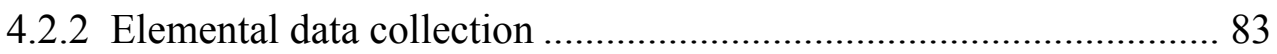

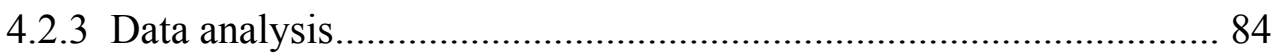

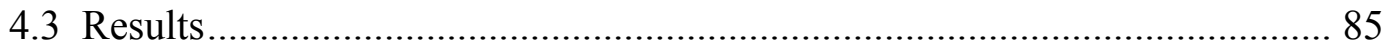

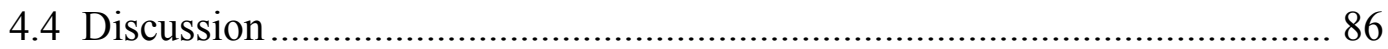

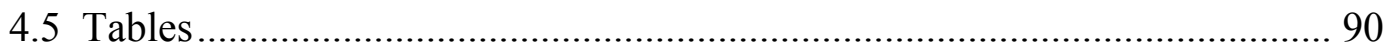

4.5.1 Collection and sampling information .............................................. 90

4.5.2 Elemental correlations .................................................................. 91

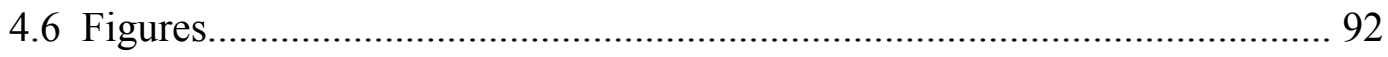

4.6.1 Example of parallel transects of elemental ratios............................ 92

4.6.2 Female pre-parturition white shark elemental transects................... 93

4.6.3 Male pre-parturition white shark elemental transects ...................... 97

4.6.4 Female lifetime white shark elemental transects............................. 101

4.6.5 Male lifetime white shark elemental transects ............................... 105

CHAPTER 5: CONCLUSIONS ................................................................................... 109

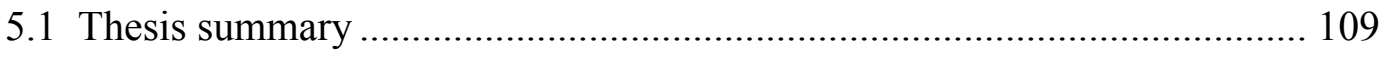

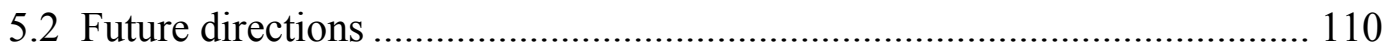


REFERENCES................................................................................................... 113 APPENDIX 1: A REVIEW OF ECOGEOCHEMISTRY APPROACHES TO ESTIMATING MOVEMENTS OF MARINE ANIMALS......................................... 129 APPENDIX 2: OCEAN ECOGEOCHEMISTRY: A REVIEW ................................ 149 APPENDIX 3: VALIDATED AGE AND GROWTH ESTIMATES FOR CARCHARHINUS OBSCURUS IN THE NWA OCEAN, WITH PRE- AND POST MANAGEMENT GROWTH COMPARISONS ........................................................... 203 


\section{CHAPTER ONE}

\section{Introduction}

\subsection{Migratory sharks}

Migratory sharks are some of the largest, most iconic, but paradoxically least understood of marine organisms. In recent decades, shark populations have experienced sharp declines due to overfishing (Baum 2003, Baum \& Myers 2004, Ferretti et al. 2008), which has, in some cases, caused unexpected consequences for the broader ecosystem (Myers et al. 2007). Many of these apex predators are vulnerable to even light fishing pressure (Dulvy et al. 2008, Ferretti et al. 2010) due to life history traits that typically include low fecundities and high age at first maturity (Smith et al. 1998, Rogers et al. 2013). Moreover, migratory sharks often pass through the jurisdictional zones of multiple countries, and are thus exposed to different levels of direct and indirect impacts of fishing. In international waters, outside the 200 nautical mile exclusive economic zone (EEZ) around countries, large international fleets are free to exploit many stocks without limit or regard to the management strategies undertaken inside nearby EEZs (Maguire et al. 2006). Unregulated fishing activity in international waters is problematic for conservation efforts because management in one area can be undermined by overexploitation in other locations.

\subsection{Traditional shark ecology techniques}

In order to develop feasible conservation plans for highly migratory species, it is first necessary to know when, where, and why individuals of a particular species move (Rubenstein \& Hobson 2004). Yet, for many sharks, even basic ecological information such as age, nursery grounds, and mating sites remains unknown. The following are several categories of fundamental importance to understanding shark ecology, the most commonly employed techniques used to study them, and some of the challenges with those techniques:

\subsubsection{Age}

Accurate aging of fish is fundamental to population assessment and management as it allows for the calculation of important demographic information such as longevity, growth rate, and age at sexual maturity. Knowledge of this demographic information is critical from a 
fisheries management perspective for general monitoring, as well as to develop plans for population recovery in the case of overfished species.

The primary method of aging fish relies on counting growth patterns in internally generated, accretionary material. In bony fish, otoliths, dorsal spines, vertebrae, and scales all show distinct rings which mark annual growth increments, similar to tree rings. These patterns, reflecting seasonal growth, have been observed for several centuries; Leeuwenhoek observed annual banding in fish scales in 1685, followed by Hederström in 1759 with fish vertebrae, and Reibisch in 1899 with otoliths (Jackson 2007). Elasmobranches lack many of the calcified parts that allow for aging in bony fish; instead, aging in sharks has been typically conducted by counting band pairs in vertebrae. Shark vertebrae are constructed of distinct layers of tissue, laid down sequentially over an individual's lifetime in an alternating light/dark banding pattern. One translucent and opaque pair makes up a band pair and is generally assumed to represent one year of growth (Goldman et al. 2012).

Counting and interpreting growth patterns in any accretionary material can be difficult. Age validation, whereby the observed banding pattern is confirmed by an outside method, is often necessary. In sharks, the boundaries between band pairs can blur, especially as sharks age, leading to possible underestimation of age. Additionally, while it has been assumed that most sharks show annual vertebral banding, Pacific angel sharks lay down band pairs based on the need for body structural support as girth increases (Natanson \& Cailliet 1990). Some sharks slow down their growth length-wise and substantially increase their girth as they get older and band counts can change from vertebra to vertebra along a vertebral column, with the highest counts corresponding to areas of widest body girth (L. Natanson, pers. comm). These observations call into question the validity of assuming annual banding in shark vertebrae and emphasize the need for age validation, which has yet to be done for most shark species.

\subsubsection{Movements}

Animal migrations are some of the most fascinating and impressive phenomena on the planet. While these movements are indeed often spectacular, migration patterns also have important demographic, ecological, and evolutionary implications for population and community structure in ocean ecosystems. For instance, movement rates determine colonization rates of new habitats, the resiliency of populations to natural and anthropogenic disturbances, and the likely effectiveness of marine protected areas and other spatial strategies for managing fisheries and 
preserving biodiversity. In contrast, a lack of gene flow among geographically separated subpopulations may allow for adaptation to local environmental conditions over evolutionary time scales.

Most studies of movement in marine organisms have been conducted using a variety of extrinsic tagging methods. Sharks are considerably more challenging to find and track than airbreathing marine species such as mammals and sea turtles because they may spend their entire lives without breaking the surface. A variety of tagging techniques including conventional, electronic transmitting, and electronic datalogging tags, have revealed ocean basin scale migrations (e.g. Kohler \& Turner 2001, Weng et al. 2005, Bonfil 2005, Skomal et al. 2009) as well as finer scale movements (e.g. Nelson et al. 1997, Weng et al. 2007a, Heupel et al. 2009) in numerous shark species. However, tagging has its limitations as some ontogentic stages are either unavailable or not amenable to tagging. Many electronic tags are routinely deployed for no more than 12 months and therefore provide only a small snapshot of lifetime movement of adult sharks that may live over 50 years. It has, therefore, proved very difficult to generate lifetime movement patterns of any shark species using tagging alone. This, in turn, makes it difficult to identify key habitats for conservation and protection of vulnerable shark populations.

\subsubsection{Feeding}

Typical investigations of diet and feeding rely on stomach content analysis (SCA), and opportunistic viewing of feeding events. SCA involves dissection of caught or stranded fish and identification and enumeration of the stomach contents and only captures the most recent meals of an individual. For migratory sharks that range into the open ocean for extensive time periods away from places where fishermen might catch them, this method biases their SCA data towards nearshore feeding events. Individuals are likely to feed on different prey items when migrating through oceanic waters compared to when they are close to shore. SCA can overestimate the contribution of organisms with hard parts that persist in the digestive tract (e.g. squid beaks, fish otoliths) over other more easily digestible food (Bowen and Iverson 2012), cause bias via the prevalence of unrecognized dietary items (Pinnegar et al. 2001) and regurgitation during capture (Renones et al. 2002). Additionally, SCA provides only a point sample in the lifetime of an organism and is impractical when species of interest are rare (Cortes 1997). Opportunistic viewing may similarly bias dietary analysis by overestimating the importance of nearshore, easily viewable surface feeding events (Fallows et al. 2013). 


\subsection{Complementary ecogeochemistry techniques}

Ecogeochemistry is the use of natural geochemical markers to reconstruct the ecological life history of animals. The method relies upon isotopic or trace element abundance differences across space or time that are recorded in the chemical composition of body tissues. The approach overcomes several significant difficulties with more traditional techniques. Geochemical markers are induced by the environment, rather than administered by the researcher, and therefore all animals within a specified location or time period are labeled without having to be captured and tagged. Similarly, because every individual is marked there is no need to "recapture" tagged animals. These approaches are therefore ideal for rare species that may be unavailable to researchers for some period of their life. The following are several ecogeochemical approaches that complement traditional shark ecology investigations:

\subsubsection{Bomb radiocarbon for age}

One method of age validation takes advantage of the large atmospheric ${ }^{14} \mathrm{C}$ spike that happened in the late 1950's and early 1960's due to atmospheric testing of thermonuclear weapons. The radiocarbon mixed into the ocean and became incorporated into the tissues of marine creatures through foodweb transmission. Tissues deposited before, during, and after the bomb testing initially incorporated the low natural levels of radiocarbon, followed by the peak and subsequent slow "decay" that continues to the present day as the enriched surface waters are diluted due to mixing. Metabolically inert accretionary tissues record the full magnitude of the bomb radiocarbon spike pattern. When collection date is known, it is possible to age the organism and determine the periodicity of band deposition in the tissue by matching the ${ }^{14} \mathrm{C}$ measurements from each band to a reference chronology (Kalish 1993). It is important to use a reference chronology for the specific habitat of interest, as radiocarbon is mixed into the various ocean basins differently, and ${ }^{14} \mathrm{C}$ values in deep water and shallow water differ as the signal in the deep sea is delayed (Appendix 2: McMahon et al. 2013). The method is generally considered to be the best age validation approach for long-lived fish (Campana 2001).

The radiocarbon validation technique has been used successfully on otoliths of a variety of fish species (e.g. Kalish 1993, Campana 1997, Andrews et al. 2013) and its application to elasmobranch vertebrae has raised some interesting questions. Annual deposition of band pairs has been confirmed in a handful of species (e.g. Campana et al. 2002, Ardizzone et al. 2006, Kneebone et al. 2008, Passerotti et al. 2010), but there is growing evidence for age 
underestimation via band counts for older sharks in several species (e.g. Francis et al. 2007, Andrews et al. 2011, Appendix 3: Natanson et al. 2013), making it critical to validate all species of concern. In addition to their usefulness as age indicators, vertebrae record the chemical signature of a shark's environment throughout its lifetime, similar to bony fish otoliths. Otoliths are archival tissues, and by analyzing stable isotopes or trace elements in otolith increments, researchers have been able to determine natal origins and population connectivity for a variety of bony fish (e.g. Thorrold et al. 2001, Rooker et al. 2008). Unlike otoliths, shark vertebrae are not acellular and material deposited at one time may be metabolized and replaced during a shark's lifetime. It is therefore necessary to determine the metabolic stability of shark vertebrae before analyzing individual growth increments, which is also possible through bomb radiocarbon analysis.

\subsubsection{Stable isotopes for movement and feeding}

In aquatic systems, habitat-specific differences create variability in baseline isotopic values, which then affect resultant values in the food web (Vander Zanden \& Rasmussen 1999). As migratory organisms feed and move through specific areas, their tissues record the isotope values of that location. When overlain on a map, the different baseline isotope values in different areas form an isotope landscape, or isoscape. Using isoscapes and analyzing two or more isotopes in concert (such as $\delta^{13} \mathrm{C}$ and $\delta^{15} \mathrm{~N}$ ) allows for a rough triangulation of the position at which the particular tissue was laid down. For food web studies, isotope analysis has the advantage of representing actually assimilated, not just ingested, prey; potentially covers the entire lifespan of an individual, depending on the tissue analyzed; and has been used on a variety of fish with success, including top predators like tuna (Estrada et al. 2005). Consumers generally show 0-1\% bulk $\delta^{13} \mathrm{C}$ (Michener and Schell 1994, DeNiro 1978) and 3.4\%o bulk $\delta^{15} \mathrm{~N}$ fractionation per trophic level above the baseline value (DeNiro \& Epstein 1981, Minigawa \& Wada 1984). Bulk $\delta^{13} \mathrm{C}$ values have been used to approximate geographical position, such as near shore versus open-ocean (Hobson 1999), as differences in $\delta^{13} \mathrm{C}$ value tend to indicate movement between different habitats (Cherel et al. 2007). Alternatively, $\delta^{15} \mathrm{~N}$ values have primarily been used to indicate trophic level, as eating higher up in the foodweb leads to readily measurable fractionation (DeNiro \& Epstein 1981). However, it can be difficult to interpret conventional bulk stable isotope data from highly migratory species that move through isotopically distinct food webs and shift diets seasonally and ontogenetically. 
Recent advances in compound-specific stable isotope analysis (e.g. individual amino acids [AAs]) have significantly reduced the influence of potentially confounding variables (shifting trophic position and different isotopic baselines) when investigating movement and diet of highly migratory species. Briefly, "trophic" amino acids undergo metabolic transamination processes that cause significant enrichment in ${ }^{15} \mathrm{~N}$ between trophic levels, while "source" amino acids retain the isotopic value of the base of the food web (McClelland and Montoya 2002, Chikaraishi et al. 2007). Recently, compound specific stable $\delta^{15} \mathrm{~N}$ has been used to examine the ecology of a variety of organisms (e.g. Hannides et al. 2009, Lorrain et al. 2009, Olson et al. 2010, Miller et al. 2012), including one elasmobranch (Dale et al. 2011), though studies have yet to look at lifetime records of movement and feeding.

\subsubsection{Elemental chemistry for movements}

Similar to stable isotopes, trace elements in the ocean can vary based on a variety of biotic and abiotic factors (McMahon et al. 2013). These elements can substitute for calcium in the matrix of actively accreting calcifying structures, creating an elemental fingerprint of an area. In marine systems, much of the work using trace elements markers as natural tags has been conducted on bony fish otoliths (Elsdon et al. 2008), though the technique holds promise for elasmobranchs (Smith 2013).

\subsection{Study Species}

White sharks (Carcharodon carcharias) are iconic, apex predators found in temperate and sub-tropical waters around the world, and seasonally in the waters off Cape Cod, Massachusetts. They are listed as "vulnerable" worldwide by the International Union for the Conservation of Nature (IUCN 2013) Red List of Threatened Species and are protected via international trade agreements including the Convention on International Trade in Endangered Species (CITES 2004) and the Convention on Migratory Species (CMS 2007). Despite protection in some locations, by-catch in long line and gillnet fisheries remains a significant threat, and direct fishing pressure includes sport fishing, shark finning, drum lines and nets for beach safety, and directed eradication (Compagno 2001).

Knowledge of white shark life history is surprisingly limited considering they are the third largest fish in the world's oceans. In the Pacific, population assessment based on dorsal fin photo identification estimated about 219 individuals in the population; much lower that previously thought (Jorgensen et al. 2011). In the northwest Atlantic, white sharks may have 
declined by almost $80 \%$ in the last 20 years (Baum et al. 2003). They are ovoviviparous, with gestation periods estimated at more than a year (Francis 1996) and pregnant white sharks and young juveniles are rarely seen, implying both rarity and spatial segregation. White sharks are also slow to grow and mature and have low fecundity, making them particularly vulnerable to fishing (Smith et al. 1998). Age validation studies have been attempted in South Africa (Wintner and Cliff 1999) and California (Kerr et al. 2006) but both studies proved inconclusive.

Though apex predators, white sharks are also highly opportunistic, eating everything from carrion to crabs, as well as fish, other elasmobranchs, and marine mammals (Compagno 2001). In areas with high marine mammal populations, like the Farallon Islands in California or Seal Island in South Africa, white sharks undergo an ontogenetic diet switch from feeding primarily on fish when less than $2 \mathrm{~m}$ in length, to feeding primarily on marine mammals such as seals when larger than 3m (Tricas \& McCosker 1984, Compagno 2001). However, this ontogenetic diet switch is not necessarily characteristic of all white shark populations, and is more likely a function of prey availability and an expanding predatory repertoire with size (Compagno 2001, Hammerschlag et al. 2012, Kim et al. 2012).

Along the US eastern seaboard prior to the $17^{\text {th }}$ century, gray seals were common and were likely an important diet of resident white sharks. However, human exploitation decimated populations via subsistence and bounty hunting (Wood Lafond 2009) until the passage of the Marine Mammal Protection Act (MMPA) in 1972 that has since seen gray seal populations rebound (Waring et al. 2011). For several centuries when gray seal populations were low, most large white sharks in the NWA likely fed at a significantly lower trophic position (TP), eating fish and scavenging cetacean carcasses (Skomal et al. 2012). Circumstantial evidence points to a possible recent diet switch in NWA white sharks, as sightings of sharks and reports of attacks on seals have increased dramatically in the last decade (Skomal et al. 2012). This type of dietary change has been reported in other locations following a pinniped population rebound (Pyle et al. 1996), but has yet to be demonstrated in NWA white sharks.

The white shark occupies one of the most varied habitat and temperature ranges of any fish, from sub-polar to temperate to tropical seas, and near-shore to open ocean environments worldwide (Compagno 2001). Tagging data from around the world indicates that white sharks undergo complex migrations and movements throughout their lifetime. In the Pacific, juveniles tend to stay in warmer, shallower areas, often distinct from adult habitat (Weng et al. 2007a). 
Meanwhile, adults tend to make deeper dives, and may exhibit long distance, cross-ocean basin migrations (Bonfil et al. 2005), but often predictably return to preferred coastal foraging areas via established migratory routes (Weng et al. 2007b, Jorgensen et al. 2010). Data on movements of northwest Atlantic white sharks from archival tags is just beginning to emerge from a study led by Dr. G. Skomal, but unpublished results suggest a diversity of movement patterns. Important life history events of white sharks occur seasonally, geographically, and ontogenetically, making it challenging to characterize movement and trophic ecology critical for designing effective conservation policies.

\subsection{Thesis objectives}

The goal of this thesis was to retrospectively investigate the lifetime ecology of white sharks from the northwest Atlantic Ocean using a variety of ecogeochemistry approaches on their vertebrae. Chapter 2 used bomb radiocarbon validation to generate the first ever validated ages for white sharks. Individuals were much older than age estimates from previous studies and band pair counts dramatically underestimated the age of the largest sharks. Validated ages from this study were used in subsequent chapters to put the ecological data into a time and age framework. Chapter 3 examined trophic ecology and migrations using bulk stable $\delta^{13} \mathrm{C}$ and $\delta^{15} \mathrm{~N}$ and amino acid $\delta^{15} \mathrm{~N}$ from vertebrae and muscle samples. Finally, Chapter 4 used trace element analysis to investigate white shark movements. Altogether, this thesis presents a glimpse into the lifetime ecology of the understudied northwest Atlantic white shark, and will provide a baseline of observations for ongoing conservation efforts for the species. 


\title{
CHAPTER TWO
}

\section{Vertebral Bomb Radiocarbon Suggests Extreme Longevity in White Sharks}

\author{
Li Ling Hamady \\ Massachusetts Institute of Technology/Woods Hole Oceanographic Institution Joint Program in \\ Oceanography/Applied Ocean Science and Engineering, Woods Hole, MA, USA \\ Lisa J. Natanson \\ Apex Predators Program, National Marine Fisheries Service, National Oceanic and Atmospheric \\ Administration, Narragansett, RI, USA \\ Gregory B. Skomal \\ Massachusetts Division of Marine Fisheries, New Bedford, MA, USA \\ Simon R. Thorrold \\ Biology Department, Woods Hole Oceanographic Institution, Woods Hole, MA, USA
}

This chapter consists of text and figures (modified to MIT/WHOI thesis standards) from an open-access article, free of all copyright, which may be freely reproduced, distributed, transmitted, modified, built upon, or otherwise used by anyone for any lawful purpose. The work is made available under the Creative Commons $\mathrm{CC} 0$ public domain dedication.

Hamady LL, Natanson LJ, Skomal GB, Thorrold SR (2014) Vertebral Bomb Radiocarbon Suggests Extreme Longevity in White Sharks. PLoS ONE 9(1): e84006.

doi:10.1371/journal.pone.0084006 


\subsection{Abstract}

Conservation and management efforts for white sharks (Carcharodon carcharias) remain hampered by a lack of basic demographic information including age and growth rates. Sharks are typically aged by counting growth bands sequentially deposited in their vertebrae, but the assumption of annual deposition of these band pairs requires testing. We compared radiocarbon $\left(\Delta^{14} \mathrm{C}\right)$ values in vertebrae from four female and four male white sharks from the northwestern Atlantic Ocean (NWA) with reference chronologies documenting the marine uptake of ${ }^{14} \mathrm{C}$ produced by atmospheric testing of thermonuclear devices to generate the first radiocarbon age estimates for adult white sharks. Age estimates were up to 40 years old for the largest female (fork length [FL]: $526 \mathrm{~cm}$ ) and 73 years old for the largest male (FL: 493cm). Our results dramatically extend the maximum age and longevity of white sharks compared to earlier studies, hint at possible sexual dimorphism in growth rates, and raise concerns that white shark populations are considerably more sensitive to human-induced mortality than previously thought.

\subsection{Introduction}

White sharks (Carcharodon carcharias) are wide ranging apex predators in coastal and offshore waters throughout the world's oceans. They are considered "vulnerable" worldwide by the International Union for the Conservation of Nature (IUCN 2013) Red List of Threatened Species and are protected via international trade agreements including the Convention on International Trade in Endangered Species (CITES 2004) and the Convention on Migratory Species (CMS 2007). Despite this attention, remarkably little demographic information is available for white shark populations. Age estimation is particularly important to the development of conservation and sustainable management strategies as most demographic variables required for adequate population assessments, such as longevity, growth rate, and age at sexual maturity, include an age component. The primary method of age estimation in fishes relies on counting growth increments in mineralized tissues, including otoliths, vertebrae, and fin rays (Campana 2001, Goldman et al. 2012). However, accurate interpretation of growth increments in these tissues is often difficult and, in the case of a species subjected to fisheries exploitation, misinterpretation may inadvertently lead to mismanagement (Fenton et al. 1991, Andrews et al. 2009). It is, therefore, necessary to validate age and growth estimates that are based on increment counts. 
The use of bomb radiocarbon to test the periodicity of increment formation and age is now well established and its use on sharks has increased considerably in recent years (Campana 2001, Goldman et al. 2012). The approach takes advantage of the pulse of radiocarbon above natural levels that was produced as a result of atmospheric testing of thermonuclear devices during the 1950s and '60s. This increase in atmospheric radiocarbon, measured as $\Delta^{14} \mathrm{C}$ (Stuiver and Polach 1977), mixed relatively quickly into the ocean and became incorporated in the tissues of marine organisms through uptake of dissolved inorganic carbon and subsequent dietary transmission through ocean foodwebs. The rapid rise in radiocarbon in the ocean can be used as a time stamp to determine the age of an organism that deposited layers in accretionary structures during this specific time period, and is generally considered the most diagnostic portion for $\Delta^{14} \mathrm{C}$ based age determination (Campana 2001, though see Andrews et al. 2013). Estimated ages based on band pair counts can then be independently confirmed by comparing $\Delta^{14} \mathrm{C}$ values from specific increments in the structure to a $\Delta^{14} \mathrm{C}$ reference chronology of known age material, typically from the same or nearby geographic area. First applied to bony fishes by comparing otolith $\Delta^{14} \mathrm{C}$ to a coral reference chronology (Kalish 1993), its use has since been extended to elasmobranch vertebrae (Campana et al. 2002, Ardizzone et al. 2006, Francis et al. 2007, Kneebone et al. 2008, Passerotti et al. 2010, Andrews et al. 2011, Appendix 3: Natanson et al. 2013).

Several studies have used vertebral band pairs to describe the age and growth of white sharks. Assuming annual deposition of growth bands, the oldest individuals identified to date from the northeastern Pacific (Cailliet et al. 1985, Kerr et al. 2006), western Indian (Wintner and Cliff 1999), and northwestern Pacific (Tanaka et al. 2011) oceans, were 18 (4.61 m total length, TL), 13 (3.73 m pre-caudal length, PCL), and 12 years (4.42 m TL), respectively. Two other papers described counts of 22 and 23 band pairs from the vertebrae of two large females, both over $5 \mathrm{~m}$ in total length, from the southwestern Pacific Ocean (Francis 1996) and western Indian Ocean (Mollet et al. 1996), respectively. None of the studies were, however, able to document annual periodicity of the band pairs used to assign age. Two of the studies (Wintner and Cliff 1999, Kerr et al. 2006) attempted to confirm annual periodicity of growth bands in white shark vertebrae, but results were inconclusive.

Our goal in the present study was to determine periodicity of band pair deposition in the vertebrae of white sharks from the northwest Atlantic Ocean (NWA) using the bomb radiocarbon 
signal. Once validated, band pair counts provide a method for providing minimum estimates of longevity in white shark populations.

\subsection{Methods}

Vertebrae were sampled from four female and four male white sharks caught in the NWA from 1967 to 2010 and archived at the National Marine Fisheries Service in Narragansett, RI. Vertebrae were loaned with permission to sample. With the exception of one individual (WS81), all vertebrae were taken from the abdominal section of the vertebral column. Abdominal vertebrae were unavailable from WS81 necessitating the use of a tail vertebra. The vertebrae were sectioned using a Ray Tech Gem Saw to approximately $0.6 \mathrm{~mm}$ in thickness. Larger vertebrae were sectioned through the corpus calcareum with a diamond blade using a Diamond Pacific Model TC-6 trim saw. Each section was digitally photographed with an MTI CCD 72 video camera attached to a SZX9 Olympus stereomicroscope using reflected light. Reference to trade names does not imply endorsement by NMFS. Two experienced readers (LJN and GBS) independently counted the growth bands. An opaque band through the intermedialia that continued to the corpus calcareum as a translucent band constituted a growth band. Definition of a band pair was similar to those used in earlier studies that confirmed the annual periodicity of band pairs in the porbeagle, Lamna nasus, and the shortfin mako, Isurus oxyrinchus (Campana et al. 2002, Natanson et al. 2002) which are closely related phylogenetically to the white shark.

The white shark vertebrae were characterized by narrow banding patterns that made it problematic to extract enough material from individual band pairs for $\Delta^{14} \mathrm{C}$ analysis. Therefore, sections were measured down the middle of the intermedialia from the central focus to the outer margin. Samples were cut along measured increments using a razor blade $(n=3$ to 23 per vertebra) and were aligned with their respective band pairs using annotated photographs of each section. Band pair deposition was initially assumed to be annual in periodicity and ages were assigned to sample sections based on back calculation from collection date. For WS105, the year of collection (1986) sample was thinly shaved from the outer vertebral surface, representing the material most recently deposited prior to the individual's death.

Radiocarbon analyses $(n=82)$ were conducted on collagen in the white shark vertebrae. Carbon isotope values in collagen reflect those of protein whereas the calcified inorganic component of vertebrae (hydroxyapatite) is composed of dietary carbon and dissolved inorganic carbon (DIC) (Ambrose and Norr 1993, Tieszen and Fagre 1993). Dietary and DIC pools have 
distinctive isotope values in ocean environments (Newsome et al. 2010, Appendix 1: McMahon et al. 2013a), which can cause problems when conducting bulk isotope analyses of vertebral material. Varying degrees of mineralization along a vertebra may lead to unequal carbon contributions from organic and inorganic pools to different material sampled longitudinally from a vertebra. Finally, $\Delta^{14} \mathrm{C}$ values in de-mineralized samples from white shark vertebrae have been shown to be lower than paired bulk samples (Kerr et al.2006), presumably due to the presence of carbon sourced from DIC in the bulk samples. Taken together, these observations provide a strong argument for performing collagen extraction before $\Delta^{14} \mathrm{C}$ analysis of vertebral samples.

Collagen extraction from vertebral samples was conducted following Tuross et al. (1988). Each sample consisted initially of approximately $0.5 \mathrm{~g}$ of tissue. Treatment was a series of steps: 1) overnight soak in a 3:1 chloroform methanol solution to remove lipids; 2) demineralization at room temperature with EDTA ( $\mathrm{pH}$ 8) for 7-20 days until soft; 3) rinsing 10 times with Milli-Q water and at least one overnight soak; 4) dissolution in Milli-Q water at $110^{\circ} \mathrm{C}$; and 5) filtration through muffled fritted glass filters. The filtrate from this process was frozen and lypholized. The purified collagen samples were then submitted as 'ready to burn' for $\delta^{13} \mathrm{C}$ and $\Delta^{14} \mathrm{C}$ analyses at the National Ocean Sciences Accelerator Mass Spectrometry Facility (NOSAMS) at the Woods Hole Oceanographic Institution (WHOI).

White sharks are highly migratory (Bonfil et al. 2005, Weng et al. 2007) with variable feeding habits (Compagno 2001, Kim et al. 2012). As a result, three reference chronologies from the NWA were considered to represent the ocean $\Delta^{14} \mathrm{C}$ rise profile for the region. A coral carbonate chronology from Florida (Druffel and Linick 1978) showed a more immediate uptake of bomb radiocarbon compared to the NWA otolith curve (Campana et al. 2008). The reference record from validated porbeagle shark data provided a reference for a potential phase lag between ocean radiocarbon curves and vertebral profiles (Campana et al. 2002). Radiocarbon values from white shark samples were plotted against the reference chronologies under the assumption of annual band pair deposition.

Where the $\Delta^{14} \mathrm{C}$ rise portion of the vertebral data was displaced to either the right or the left of the reference curves, we shifted the points to bring the entire white shark chronology into alignment. To optimize the alignment, we first fit a linear trend line to the $\Delta^{14} \mathrm{C}$ rise portion of the appropriate reference curve (Florida coral for WS134, and NWA otolith for WS81 and WS105) (Figure 2.9.1). Using the resulting equation, we entered each $\Delta^{14} \mathrm{C}$ data point from the 
vertebral $\Delta^{14} \mathrm{C}$ rise section and located the year corresponding to that point on the reference chronology (Table 2.9.2). We found the optimal alignment for each $\Delta^{14} \mathrm{C}$ data point by summing the squared differences between the reference $\Delta^{14} \mathrm{C}$ value for each year and the measured vertebral $\Delta^{14} \mathrm{C}$ from that same year. This calculation was repeated after moving the vertebral years step-wise one year closer each time to the reference years. We identified the optimal shift for each white shark chronology by minimizing the summed squared differences for all the points (Table 2.9.3). See supporting information for data and calculations.

Finally, $\delta^{13} \mathrm{C}$ values were also assayed in the collagen samples during the radiocarbon analysis. While $\delta^{13} \mathrm{C}$ values in the ocean did not increase along with radiocarbon values, carbon isoscapes do vary as a function of latitude and distance from the coast and can be a useful tracer of large scale movement patterns (Appendices 1 and 2: McMahon et al. 2013a,b). We therefore plotted $\delta^{13} \mathrm{C}$ values by radiocarbon adjusted age and radiocarbon value.

\section{$2.4 \quad$ Results}

Band pair counts in vertebral thin sections provided age estimates of 6-35 years for female white sharks and 9-52 years for male white sharks (Figure 2.8.1, Table 2.7.1). Radiocarbon values in vertebral samples from before the bomb $\Delta^{14} \mathrm{C}$ rise were generally consistent with regional $\Delta^{14} \mathrm{C}$ reference chronologies (mean=-62.5 $\pm 8.44 \%$ (SD)) (Figure 2.8.2A, $B, D)$. Post-peak radiocarbon values ranged from below the NWA otolith curve to nearly the same amplitude as the coral reference curve from Florida. Female white sharks displayed a broader range in both the absolute magnitude of the $\Delta^{14} \mathrm{C}$ rise and in $\Delta^{14} \mathrm{C}$ post-peak trajectories compared to males (Figure 2.8.2A, B, C, D).

We found good agreement between the reference curves and band pair counts in three sharks (WS57, WS100, WS28) with nominal ages of 44, 9, and 6 years, respectively. The two youngest white sharks (WS100 and WS28) aligned closely with the coral curve. An older shark (WS57) also aligned with the coral curve up to almost 30 years of age, with a good representation of pre- $\Delta^{14} \mathrm{C}$ rise levels, after which it matched well with the porbeagle reference curve, indicating that vertebral band pairs were indeed deposited on an annual basis (Figure 2.8.2A, C). Two other individuals (WS143, WS117) recorded radiocarbon values solely from the enriched post- $\Delta{ }^{14} \mathrm{C}$ rise period with values bracketed by the $\Delta^{14} \mathrm{C}$ reference chronologies (Figure 2.8.2A, C). The original $\Delta^{14} \mathrm{C}$ time series of one female (WS134) was plotted with a birth year three years prior to the most rapid increase in $\Delta^{14} \mathrm{C}$ documented, indicating a slight over- 
estimation of age by the band pair counting, based on the assumption that the coral record provided the best age calibration for this individual (Figure 2.8.2D). This assumption was likely appropriate given the similarity of the vertebral $\Delta^{14} \mathrm{C}$ values to the coral chronology, both of which were considerably higher than the other two reference chronologies. In the remaining two sharks - the largest female and male that we examined (WS81, WS105) - the original age estimates led to an offset $\Delta^{14} \mathrm{C}$ chronology for each of these individuals relative to the reference $\Delta^{14} \mathrm{C}$ data. Based on the limits provided by the NWA otolith $\Delta^{14} \mathrm{C}$ reference chronology, each was adjusted (by 7 and 21 years respectively) to a greater age than could be accounted for with the band pair counting. (Figure 2.8.2B, D). We kept the terminal data point of WS105 at the year of collection (1986) because it reflected the most recently deposited material in the vertebra. Moving the vertebral values back to the reference curves led to an increase of estimated age to 40 and 73 years for the female and male, respectively (Figure 2.8.2B, D).

Examining $\delta^{13} \mathrm{C}$ values as a function of estimated age, all pre-birth $\delta^{13} \mathrm{C}$ values, except for WS28, were clustered with a difference of $\sim 0.8 \%$. However, post-birth, $\delta^{13} \mathrm{C}$ values diverged with a tendency towards decline with age but no obvious trend $(\mathrm{R}=0.33)$ (Figure 3).

Interestingly, $\delta^{13} \mathrm{C}$ values were positively correlated with $\Delta^{14} \mathrm{C}$ values after $(\mathrm{R}=0.80)$ but not before $(\mathrm{R}=0.42)$ the bomb radiocarbon rise (Figure 2.8.4). The maximum difference in $\delta^{13} \mathrm{C}$ values across a single vertebra ranged from 0.33 to $1.84 \%$ (Table 2.9.4). Individual white shark $\Delta^{14} \mathrm{C}$ and $\delta^{13} \mathrm{C}(\%)$ sample values and deposition years are available online (Table 2.9.4).

\subsection{Discussion}

$\Delta^{14} \mathrm{C}$ profiles in vertebrae provided compelling evidence that white sharks are likely to live up to approximately 70 years in the NWA and may live longer. These data stand in contrast to earlier studies in the Pacific and Indian Oceans which suggested that the individual white sharks examined were no older than 23 years (Cailliet et al. 1985, Francis 1996, Mollet et al. 1996, Wintner and Cliff 1999) with concomitantly faster growth rates. Therefore, either white sharks are living significantly longer and growing slower in the NWA than either the Pacific or Indian Oceans or longevity has been underestimated in previous studies.

The only other study to attempt age validation in white shark vertebrae using $\Delta^{14} \mathrm{C}$ was conducted on samples from the northeastern Pacific Ocean (Kerr et al. 2006). Results from this earlier study were generally inconclusive for several reasons. The authors used known-age (1 year-old) samples to construct a species-specific $\Delta^{14} \mathrm{C}$ reference that they suggested showed a 
significant time lag with an otolith reference time series from the Pacific Ocean. However, this interpretation is questionable because no samples were analyzed from the time period between 1959 and 1977 when the $\Delta^{14} \mathrm{C}$ rise occured in the otolith reference chronologies. Kerr et al. (2006) did document a phase lag between otolith reference chronologies and samples from assays at the edge of the vertebrae that were assigned chronologically to the year of capture. The phase lag between year-of-capture samples and the $\Delta^{14} \mathrm{C}$ reference chronologies led the authors to suggest that white sharks were consuming some prey with depleted $\Delta^{14} \mathrm{C}$ values from deeper waters in the Pacific. However, the concept of missing growth in the outer margin was not considered because the idea had not yet been described (Francis et al. 2007).

Our results were substantively different from those derived from the Pacific samples. The NWA white sharks in our study with nominal ages up to 44 years aligned well with reference chronologies, confirming that these sharks deposited one band pair per year up to this age. Moreover, the prey base for NWA white sharks reflected $\Delta^{14} \mathrm{C}$ values commonly found in coastal and epipelagic zones (Appendix 2: McMahon et al. 2013b). This observation is consistent with results from the eastern Pacific that found juvenile white sharks tend to stay in shallow water close to the coast (Weng et al. 2007). Similar results have also been recently reported for great hammerhead (Passerotti et al. 2010), young tiger (Kneebone et al. 2008), and young sandbar (Andrews et al. 2011) sharks in the NWA, indicating that these sharks are also using shallow, well-mixed habitats in coastal or oceanic waters.

We found a significant phase lag in larger white sharks that, based on the alignment of young sharks with reference chronologies, was evidence for significant underestimation of age based on band pair counts in these individuals. The $\Delta^{14} \mathrm{C}$ chronologies from these individuals showed that the vertebrae are effectively missing time, on the order of one to two decades. This result is not necessarily surprising as band pair counts appear to also underestimate age in older individuals in other shark species (Kalish and Johnston 2001, Francis et al. 2007, Andrews et al. 2011, Appendix 3: Natanson et al. 2013). Given that band pairs are apparently laid down on an annual basis in small to medium sized NWA white sharks, we suggest that the largest individuals may experience a change in the rate of deposition of vertebral material at some point after maturity, or that the band pairs becomes so thin as to be unreadable. This second hypothesis was supported by the shaved terminal sample that we were able to extract from WS105 that was clearly post-bomb and close to the NWA reference value for the year of capture. Andrews et al. 
(2011) and Natanson et al. (2013, Appendix 3) came to a similar conclusion for sandbar and dusky sharks respectively, in the NWA. Kerr et al. (2006) found a similar phase lag in older northeastern Pacific white shark vertebrae that they argued could not be explained by age underestimation (though variable vertebral growth was mentioned as a possible factor), but rather by assimilation of $\Delta^{14} \mathrm{C}$-depleted carbon from dietary sources. An alternative interpretation of these data based on the fact that their results showed a phase shift as opposed to a lack of a $\Delta^{14} \mathrm{C}$ rise in the vertebrae suggests that ages may have been underestimated in these individuals. If the sharks were feeding on a significant amount of $\Delta^{14} \mathrm{C}$-depleted prey, we would expect a noticeably slowed and dampened response to the rise of $\Delta^{14} \mathrm{C}$ in the Pacific, which did not appear to be the case (Figure 1 in Kerr et al. 2006). We would also note that it is difficult to constrain the deposition date of material at the terminal edge of large white shark vertebrae even with the finescale sampling that we used here. Based on the available data, we cannot determine if the results of our study are applicable to white sharks in other locations as age and growth can vary between different shark populations (Campana et al. 2002, Francis et al. 2007), but further studies are clearly warranted.

While fish otoliths obtain most of their carbon through uptake from DIC (Kalish 1993, Thorrold et al. 1997) diet is likely the primary source of carbon in vertebral collagen of elasmobranchs (Kalish and Johnston 2001, Campana et al. 2002). This difference in carbon source may lead to problems when comparing radiocarbon curves between inorganic carbonate structures and organic cartilaginous tissues. Equilibration of carbon isotopes incorporated through trophic transfer is likely to be slower than uptake from DIC and this would, in turn, act to reduce the rate of increase and perhaps the amplitude of the radiocarbon rise depending on the variability of tissue turnover rates in food sources. This effect is likely to increase with the trophic level or age of the prey (Campana et al. 2002), at least to the degree that either variable correlates with carbon turnover rates in muscle tissue of individual prey species. However, NWA white shark records did not show any obvious reduction in the slope of the radiocarbon rise compared to carbonate reference chronologies (though attenuation may be possible and unresolvable in the post- $\Delta^{14} \mathrm{C}$ rise period). The synchronization between the coral reference chronology and WS28 and WS100 demonstrates that white sharks must quickly reach carbon isotopic equilibrium with their diet, or feed on prey that is isotopically equilibrated with ambient DIC. Vertebral samples from other shark species that lag carbonate reference chronologies 
(Campana et al. 2002) presumably reach isotopic equilibrium with their environment considerably more slowly than white sharks. Nonetheless, this observation further supports our contention that age under-estimation is the most likely cause of the phase lag between the reference chronologies and the vertebral profiles.

Atlantic white sharks are poorly studied in terms of diet and movement when compared to their Pacific, Australian, and South African counterparts. Post- $\Delta^{14} \mathrm{C}$ rise periods of the white shark profiles revealed some interesting differences among individuals and potentially between sexes that may be related to movement or diet shifts. The post $-\Delta^{14} \mathrm{C}$ rise signal of a location depends on oceanic conditions affecting the diffusion of atmospheric radiocarbon into the sea surface coupled with mixing rates and radiocarbon depth gradients and, therefore, varies significantly both within and across ocean basins (Appendix 2: McMahon et al. 2013b). These oceanic conditions as well as biotic factors also impact the $\delta^{13} \mathrm{C}$ signal of a location (Appendix 2: McMahon et al. 2013b). We found that male sharks aligned more closely with the NWA otolith reference record than the Florida coral record, suggesting that these individuals spent a significant amount of time in northern shelf waters. However, a similar pattern would also be observed if the sharks shifted to a diet of animals with $\Delta^{14} \mathrm{C}$-depleted values. Post- $\Delta^{14} \mathrm{C}$ rise radiocarbon values for two females (WS117 and WS 134) sat anywhere from 10-70\%o above the NWA otolith curve, suggesting residency in more southerly and tropical waters than the males in our study.

Our interpretation of habitat differences between sexes and among individuals in this study is reinforced by the post- $\Delta^{14} \mathrm{C}$ rise correlation between $\delta^{13} \mathrm{C}$ and $\Delta^{14} \mathrm{C}$ in the white shark vertebrae; less depleted $\delta^{13} \mathrm{C}$ values are indicative of lower latitudes in the Atlantic and more depleted $\delta^{13} \mathrm{C}$ values are indicative of more northern waters (Fig. 4) (Appendix 1: McMahon et al. 2013a). Sex-specific differences in habitat use have been documented for Pacific white sharks (Domeier and Nasby-Lucas 2012), as has individual diversity in feeding strategy. Using stable C and $\mathrm{N}$ isotopes in vertebrae, Kim et al. (2012) found a surprising degree of within and among individual variation attributable to a combination of both differences in diet and movement. Our $\delta^{13} \mathrm{C}$ data also hint at this, with general agreement in early growth, followed by individual differences (Fig 3). Kerr et al. (2006) noted a trend of lower $\delta^{13} \mathrm{C}$ values with increasing age and attributed this to differences in juvenile and adult habitat. While we did not consistently find this pattern, the two oldest individuals, both males (WS57, WS105), exhibited lower $\delta^{13} \mathrm{C}$ values as 
they aged. Changes in diet also affect $\delta^{13} \mathrm{C}$ values; an increase in trophic level generally corresponds to an enrichment of approximately 1\%o (Michener and Schell 1994). Based on bulk $\delta^{15} \mathrm{~N}$, which tends to be more sensitive to diet change than $\delta^{13} \mathrm{C}$, Estrada et al. (2006) found apparent size-based trophic shifts in NWA white sharks. It's likely that the variation in both $\Delta^{14} \mathrm{C}$ and $\delta^{13} \mathrm{C}$ in our study results from a combination of diet and movement differences; more work on the ecology of NWA white sharks is needed to understand and explain the observed variability.

White sharks in our study also displayed marked sexual dimorphism in size at age, assuming our age interpretations are correct. The largest male and female (WS105 and WS81) in this study were similar in size (FLs: $493 \mathrm{~cm}$ and $526 \mathrm{~cm}$ respectively), yet their ages, as estimated by radiocarbon analyses, differed by up to thirty-three years. WS81, the largest female, is almost a meter longer and yet still four years younger than the second largest male in our study (WS57). The smallest sharks in our study (males: WS100, WS143; female: WS28) are also very similar in size, yet the two males are 3 and 8 years older than the female, respectively. Sexual dimorphism in growth rates is common in lamnids (Francis et al. 2007), although it is usually thought that larger females are also older. While our sample is limited, the NWA white sharks in this study appear to show the opposite trend. Since the lifetimes and sampling dates of these sharks span several decades, changes in habitat quality may also have influenced this trend.

Assuming a lifespan estimate of 70 years or more, white sharks may be among the longest-lived chondrichthyan fishes (Cailliet and Goldman 2004). Population projections for white sharks based on earlier age and growth data will, therefore, need to be revisited in the NWA. Modeling of elasmobranch populations has found that age at maturity accounts for most of the variance in population growth rates; sharks that mature late, have long lifespans, and small litters have the lowest population growth rates and longest generation times (Smith et al. 1998, Cortés 2002). While increased overall longevity implies that each individual has greater potential lifetime productivity, modeling studies suggest that the ability of a shark species to recover from fishing pressure is little affected by overall longevity (Smith et al. 1998), and changes in juvenile survival actually have the greatest effect on population growth rates (Cortés 2002). We predict that age at maturity for NWA white sharks will be substantially higher than estimates from other areas, using our age data. Earlier work concluded that white sharks have low rebound potential when exposed to fishing pressure (Smith et al. 1998) and high intrinsic vulnerability to extinction 
(Rogers et al. 2013). Thus an increase in age at maturity would make white sharks even more sensitive to fishing pressure than previously thought. While already protected in many nations, even low levels of bycatch mortality are likely to have significant impacts (Dulvy et al. 2008) on attempts to rebuild white shark populations from historical over-fishing in the NWA (Baum et al. 2003 but see Burgess et al. 2005) and potentially other populations in the Pacific and Indian Oceans.

\subsection{Acknowledgements}

We thank M. Lardie Gaylord, A. McNichol, and other staff members at NOSAMS for help with sample preparation and processing. Thanks to the fishermen that allowed us to sample their catches and tournament officials that gave us the opportunity to sample at their events. We are grateful for discussions with A.H. Andrews and G. Cailliet; A.H. Andrews additionally provided valuable assistance with data interpretation and manuscript edits. We appreciate the helpful comments and suggestions provided by the editor and two anonymous reviewers. 
2.7.1 Collection and sampling information for individual sharks ${ }^{i}$

\begin{tabular}{cccccccc}
\hline Shark & $\begin{array}{c}\text { Year } \\
\text { collected }\end{array}$ & $\begin{array}{c}\text { FL } \\
(\mathrm{cm})\end{array}$ & Sex & Maturity $^{\text {iii }}$ & $\begin{array}{c}\text { Band } \\
\text { pairs }\end{array}$ & $\begin{array}{c}\text { Estimated } \\
\text { Bomb } \\
\Delta^{14} \text { C Age }\end{array}$ & $\begin{array}{c}\text { Estimated years } \\
\text { sampled }^{\text {iv }}\end{array}$ \\
\hline WS57 & 1981 & 442 & M & M & 44 & 44 & $1936.5-1979.5$ \\
WS100 & 1968 & 223.5 & M & N/A & 9 & 9 & $1958.5-1965$ \\
WS105 & 1986 & 493 & M & M & 52 & 73 & $1913-1986$ \\
WS143 & 2010 & 222.2 & M & I & 14 & 14 & $1995.5-2007$ \\
WS28 & 1967 & 220.9 & F & N/A & 6 & 6 & $1960.5-1966.5$ \\
WS81 & 1983 & 526 & F & N/A & 33 & 40 & $1943-1973$ \\
WS117 & 1988 & 330 & F & N/A & 21 & 21 & $1967-1987$ \\
WS134 & 1996 & 495.3 & F & N/A & 35 & 32 & $1964.5-1995$ \\
\hline
\end{tabular}

${ }^{\mathrm{i}}$ Discrepancies between band pair counts and bomb $\Delta^{14} \mathrm{C}$ age indicate instances where a shift was necessary to align sample $\Delta^{14} \mathrm{C}$ values to reference curves.

${ }_{\text {ii }} \mathrm{FL}$, fork length.

iii M: mature, I: immature, N/A: information not available.

${ }^{\text {iv }}$ Estimates based on band pair counts, and ages estimated from $\Delta^{14} \mathrm{C}$ values when shark trajectories required adjusting. 


\subsubsection{Photomicrographs of sectioned vertebrae}

A) Upper section of vertebra taken from WS105. B) WS 100 vertebra; first dot is the birth band. Visible band pairs are marked by dots on the corpus calcareum. The lines indicate the vertebral radius $(16.6 \mathrm{~mm})$. Vertebral radius is measured at the angle of the vertebra where the intermedialia meets the corpus calcareum.
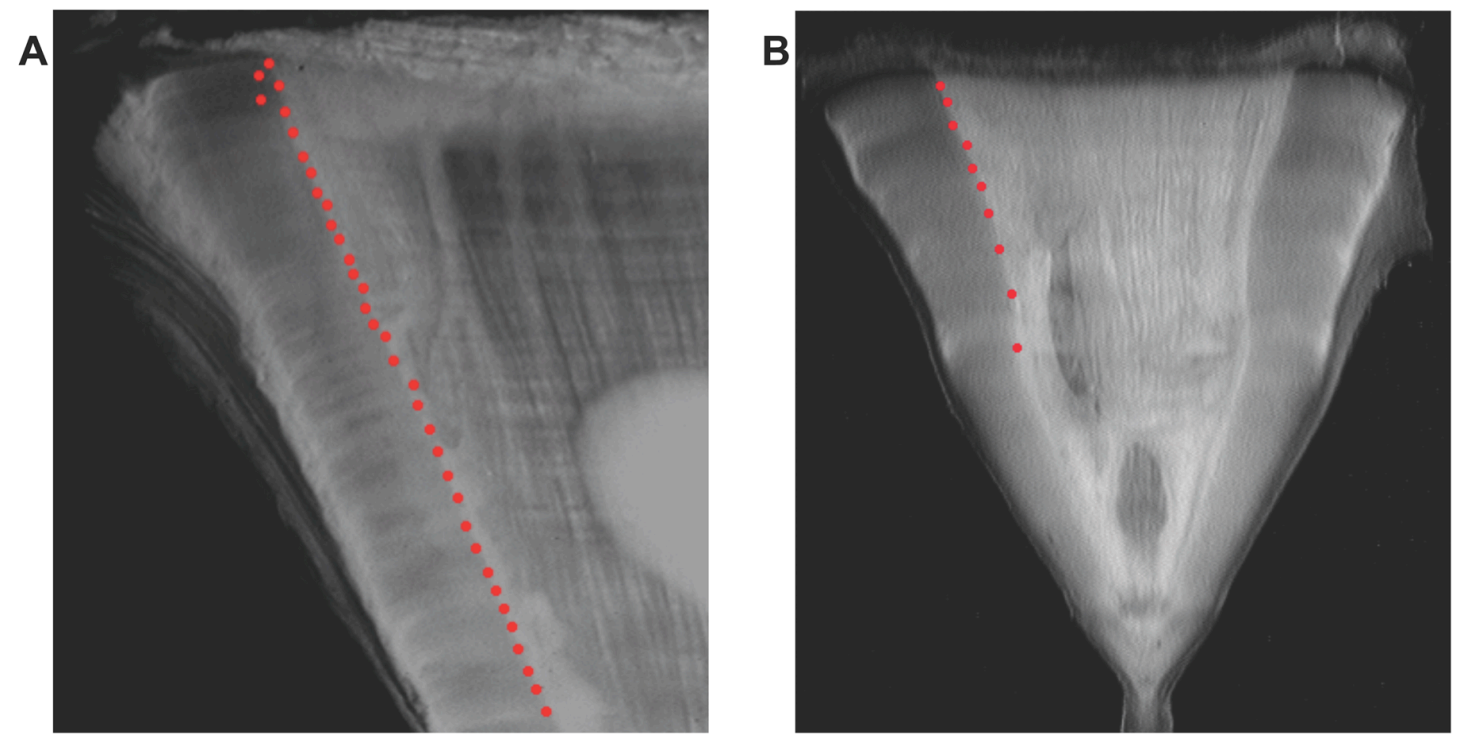


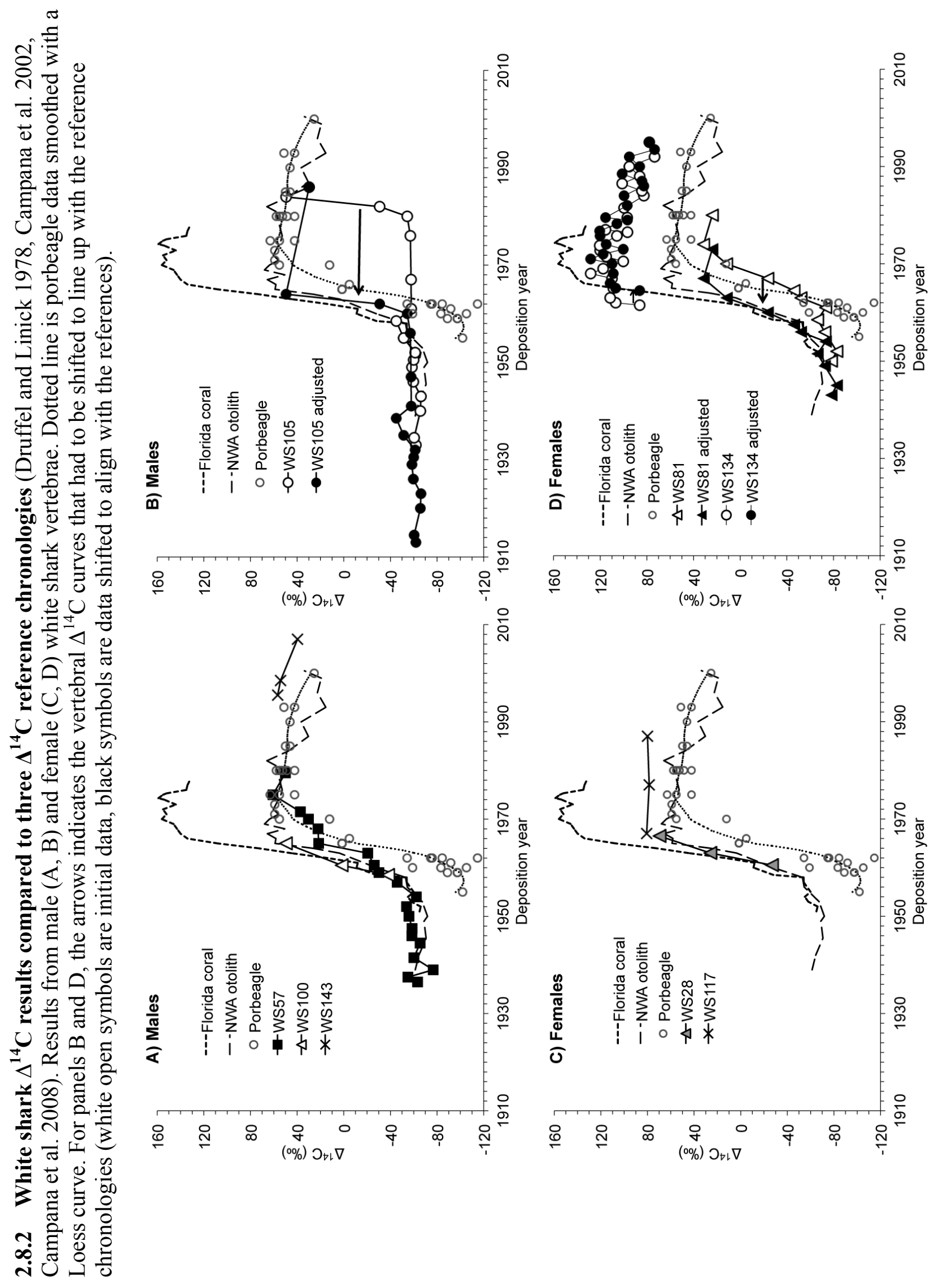


2.8.3 $\delta^{13} \mathrm{C}$ values for individual sharks

Plotted by age as corrected to fit the $\Delta^{14} \mathrm{C}$ reference curves.

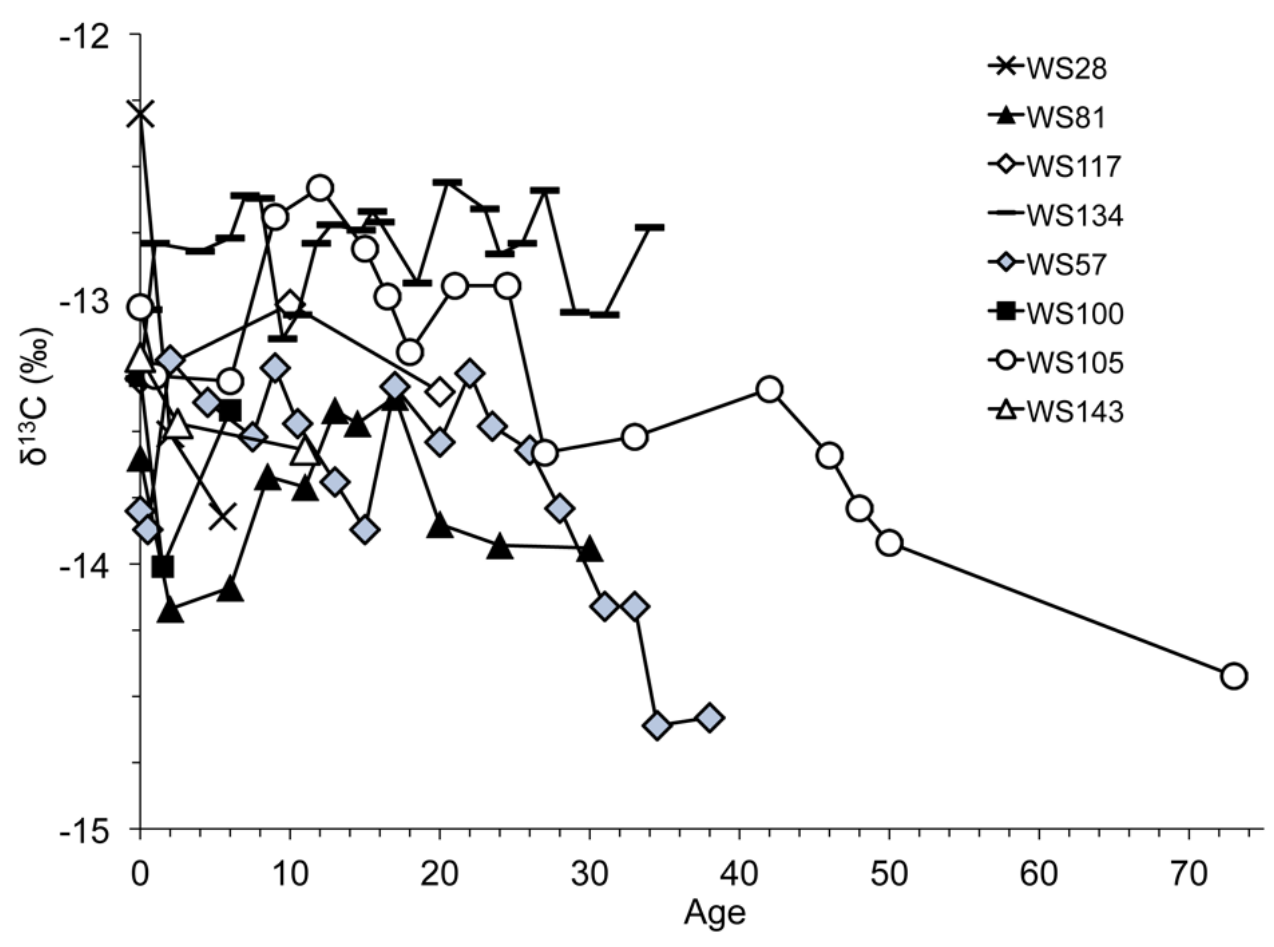


2.8.4 Bivariate plot of $\delta^{13} \mathrm{C}$ versus $\Delta^{14} \mathrm{C}$ for individual sharks

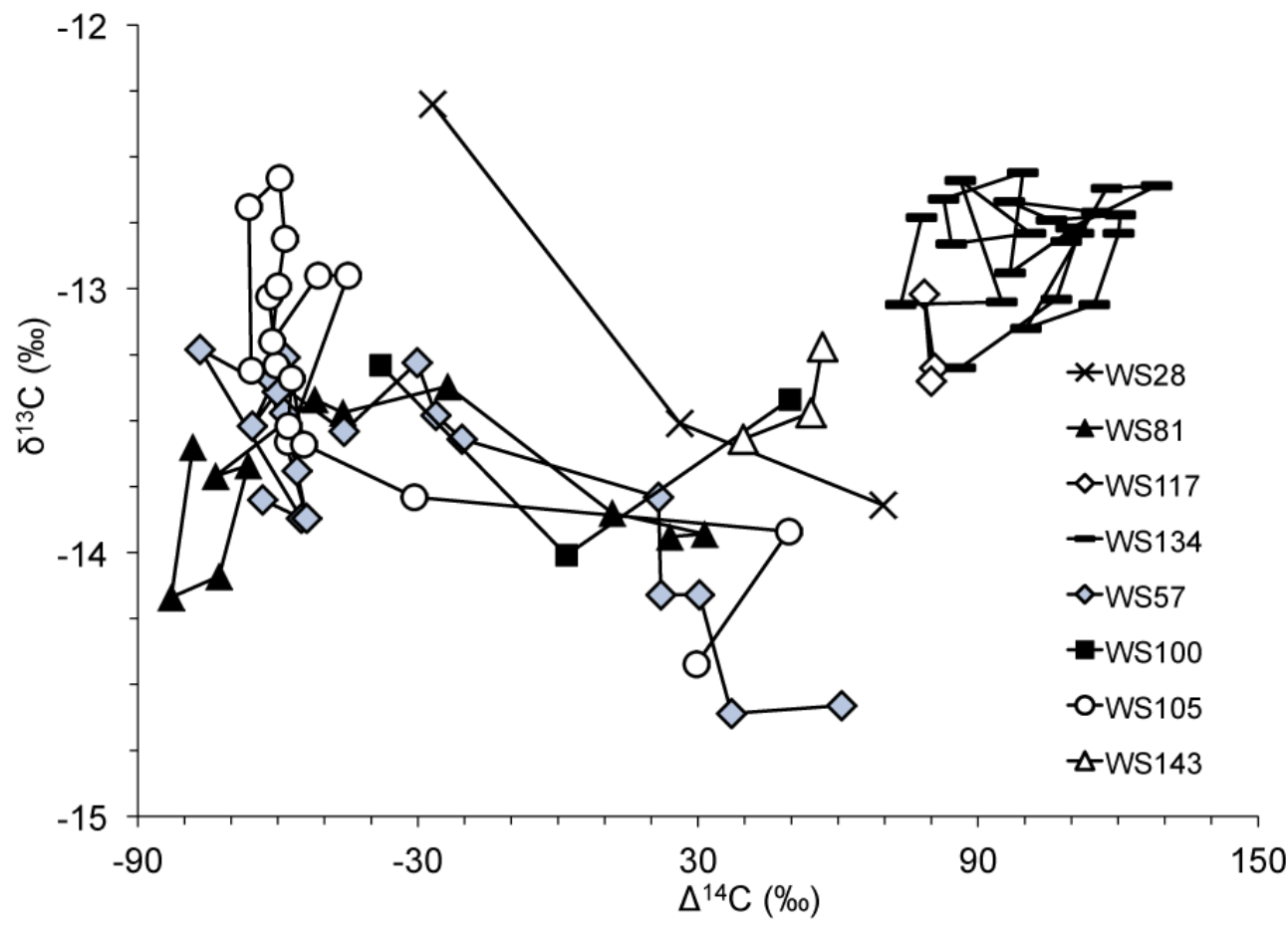




\subsubsection{Linear trends fit to the $\Delta^{14} \mathrm{C}$ rise portion of the reference chronologies}

A) Florida coral reference chronology, used to correct WS134. B) NWA otolith reference chronology, used to correct WS81 and WS105.

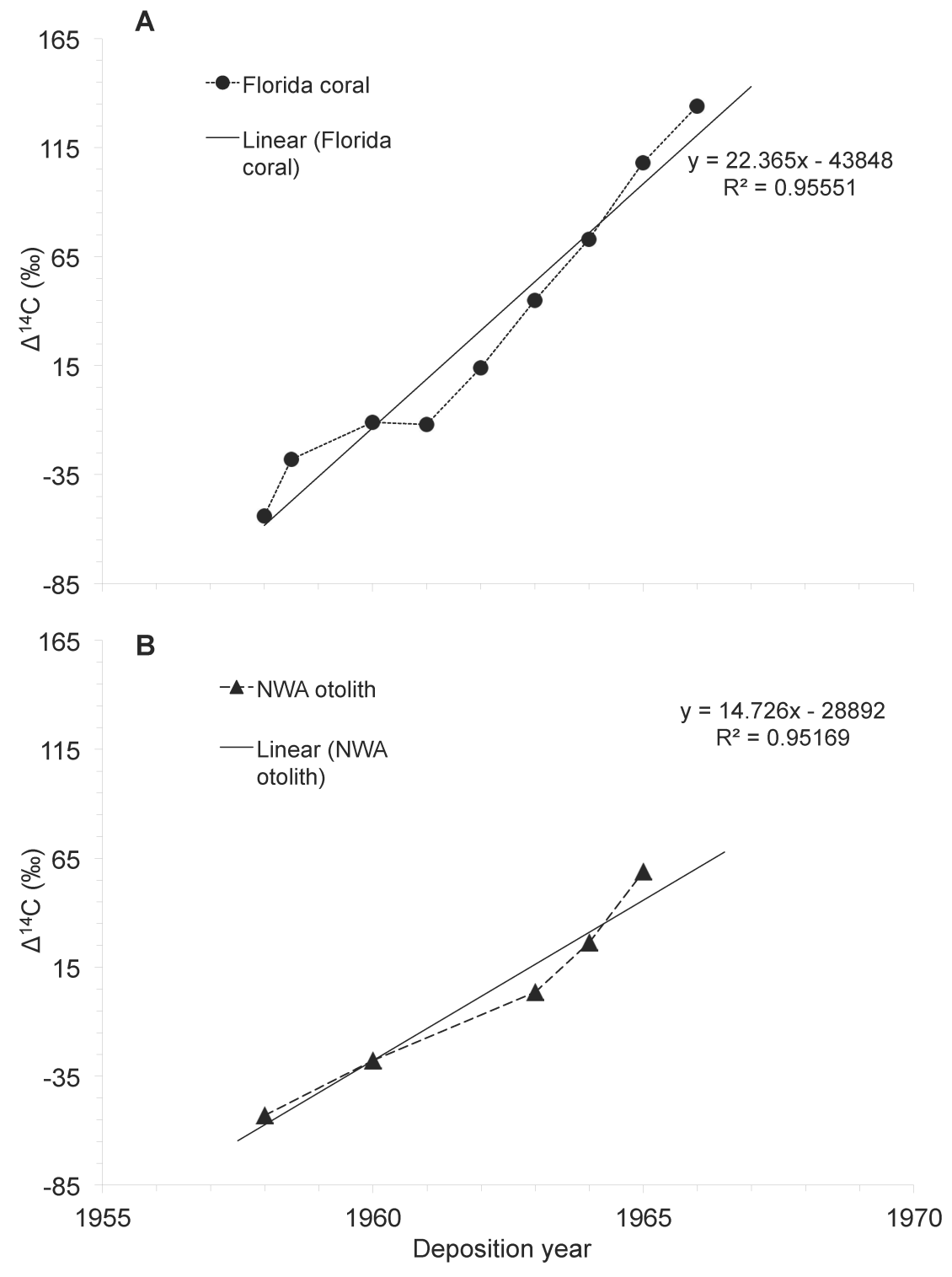




\subsubsection{Phase lagged $\Delta^{14} \mathrm{C}$ shark value}

\begin{tabular}{lcc}
\hline Shark & $\begin{array}{c}\text { Shark } \Delta^{\mathbf{1 4}} \mathbf{C} \\
\mathbf{( \% o )}^{\mathbf{i}}\end{array}$ & Year $^{\text {ii }}$ \\
\hline WS81 & -52.09 & 1957.88 \\
& -46.07 & 1958.29 \\
& -23.61 & 1959.82 \\
& 11.65 & 1962.21 \\
WS105 & -54.44 & 1957.72 \\
& -30.76 & 1959.33 \\
& 49.47 & 1964.78 \\
\hline WS134 & 86.19 & 1964.42 \\
& 106.79 & 1965.34 \\
\hline
\end{tabular}

${ }^{\mathrm{i}} \Delta^{14} \mathrm{C}$ values from shark samples that were initially misaligned with the bomb radiocarbon pulse as recorded in the reference chronologies, based on band pair counts.

ii The year on the reference trend line corresponding to the shark $\Delta{ }^{14} \mathrm{C}$ value, as determined using the equations from Figure 2.9.1. 


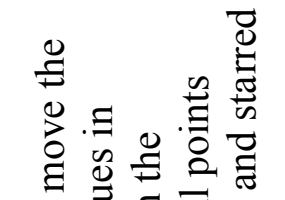

㻤

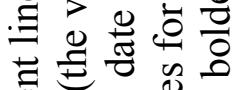

进

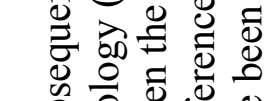

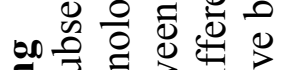

动

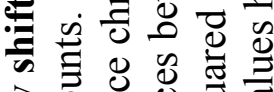

के

을.

음

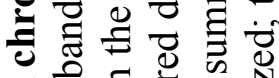

สี

.융 売

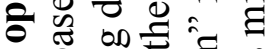

:

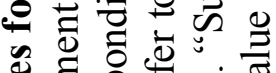

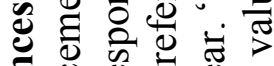

ప

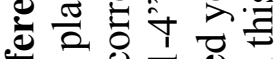

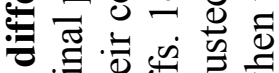

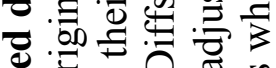

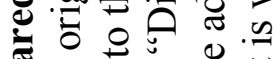

预.

ำ

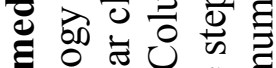

응

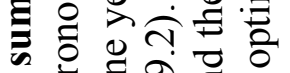

๖

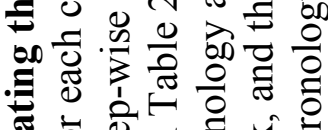

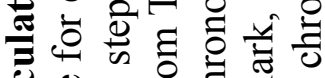

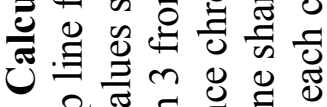

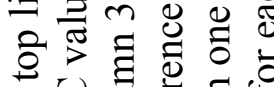

ตั

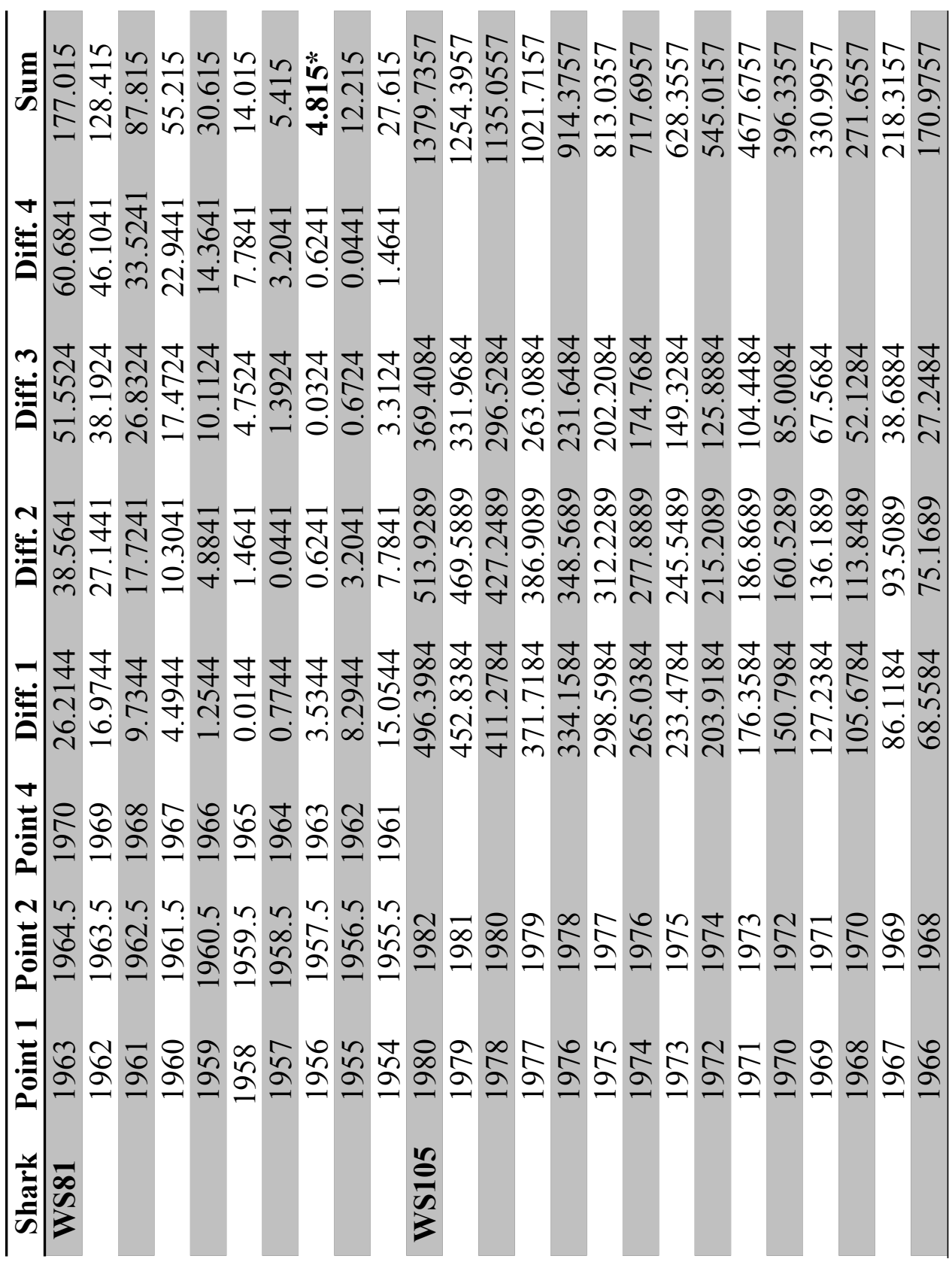




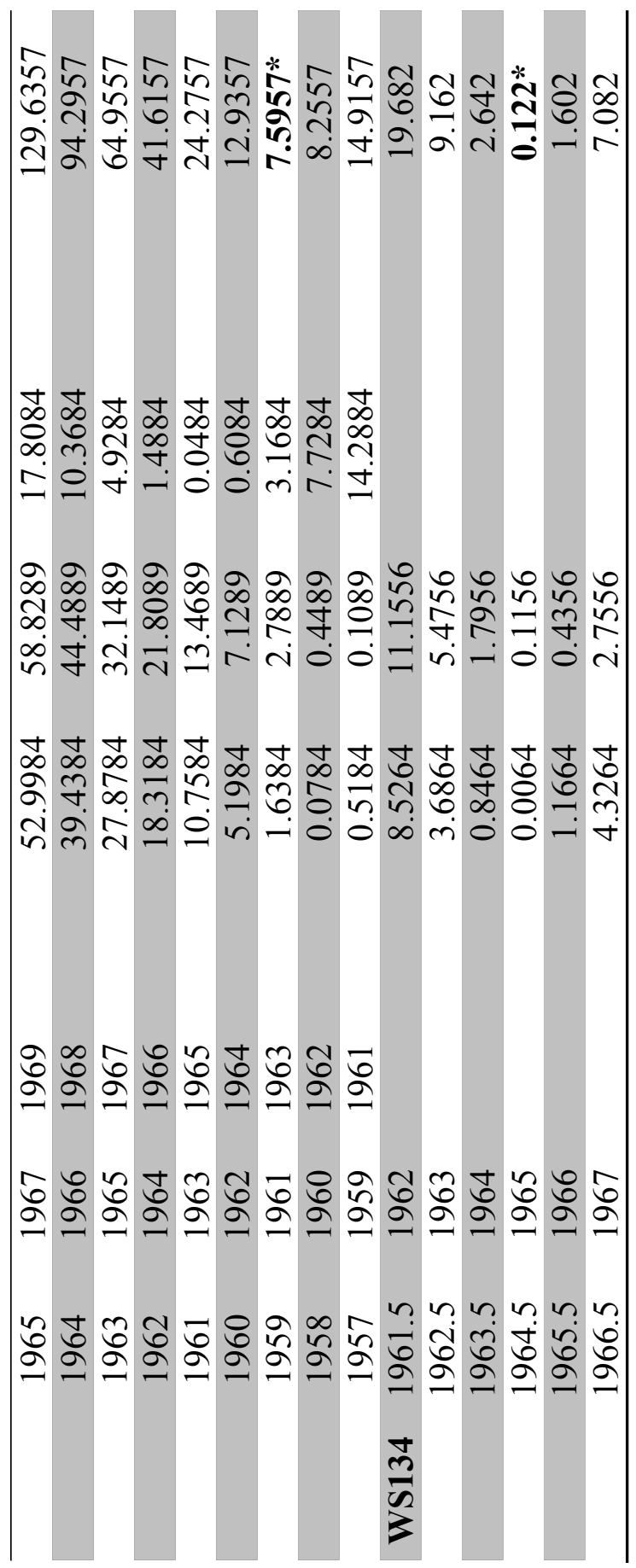




\subsection{4 $\quad \Delta^{14} \mathrm{C}$ and $\delta^{13} \mathrm{C}(\%$ ) shark sample data listed by individual}

\begin{tabular}{|c|c|c|c|c|c|c|}
\hline Shark & $\begin{array}{l}\text { Year }^{\mathrm{i}} \text { (band } \\
\text { pair) }\end{array}$ & $\begin{array}{l}\text { Year } \\
\left(\Delta^{14} \mathrm{C}\right)\end{array}$ & $\begin{array}{l}\text { Age of } \\
\text { formation ii }\end{array}$ & $\Delta^{14} \mathrm{C}(\%)$ & $\begin{array}{l}\delta^{13} C^{i i i} \\
(\%))^{i i i}\end{array}$ & $\begin{array}{l}\text { Overall difference in } \\
\delta^{13} \mathrm{C}(\% \circ)^{\mathrm{iv}}\end{array}$ \\
\hline \multirow[t]{20}{*}{ WS57 } & & 1936.5 & 0 & -63.27 & -12.62 & 1.49 \\
\hline & & 1937.5 & 1 & -54.97 & -13.3 & \\
\hline & & 1939 & 2.5 & -76.67 & -13.37 & \\
\hline & & 1941.5 & 4.5 & -60.13 & -12.73 & \\
\hline & & 1944.5 & 7.5 & -65.48 & -12.89 & \\
\hline & & 1946 & 9 & -58.44 & -13.02 & \\
\hline & & 1947.5 & 10.5 & -58.62 & -12.76 & \\
\hline & & 1950 & 13 & -55.90 & -12.97 & \\
\hline & & 1952 & 15 & -53.83 & -13.19 & \\
\hline & & 1954 & 17 & -62.25 & -13.37 & \\
\hline & & 1957 & 20 & -45.81 & -12.83 & \\
\hline & & 1959 & 22 & -30.16 & -13.04 & \\
\hline & & 1960.5 & 23.5 & -26.14 & -12.78 & \\
\hline & & 1963 & 26 & -20.54 & -12.98 & \\
\hline & & 1965 & 28 & 21.54 & -13.07 & \\
\hline & & 1968 & 31 & 22.07 & -13.29 & \\
\hline & & 1970 & 33 & 30.30 & -13.66 & \\
\hline & & 1971.5 & 34.5 & 37.20 & -13.66 & \\
\hline & & 1975 & 38 & 60.79 & -14.11 & \\
\hline & & 1979.5 & 42.5 & 50.05 & -14.08 & \\
\hline \multirow[t]{3}{*}{ WS100 } & & 1958.5 & 0 & -37.99 & -12.79 & 0.72 \\
\hline & & 1960.5 & 1.5 & 1.83 & -13.51 & \\
\hline & & 1965 & 6 & 49.69 & -12.92 & \\
\hline \multirow[t]{14}{*}{ WS105 } & 1933 & 1913 & 0 & -61.87 & -12.53 & 1.843 \\
\hline & 1934.5 & 1914.5 & 1 & -60.34 & -12.79 & \\
\hline & 1940 & 1920 & 6 & -65.67 & -12.81 & \\
\hline & 1943 & 1923 & 9 & -66.21 & -12.19 & \\
\hline & 1946 & 1926 & 12 & -59.65 & -12.08 & \\
\hline & 1949 & 1929 & 15 & -58.49 & -12.31 & \\
\hline & 1950.5 & 1930.5 & 16.5 & -59.96 & -12.49 & \\
\hline & 1952 & 1932 & 18 & -61.23 & -12.70 & \\
\hline & 1955 & 1935 & 21 & -51.37 & -12.45 & \\
\hline & 1958.5 & 1938.5 & 24.5 & -44.98 & -12.45 & \\
\hline & 1961 & 1941 & 27 & -57.85 & -13.08 & \\
\hline & 1967 & 1947 & 33 & -57.74 & -13.02 & \\
\hline & 1976 & 1956 & 42 & -57.07 & -12.84 & \\
\hline & 1980 & 1960 & 46 & -54.44 & -13.09 & \\
\hline
\end{tabular}

\footnotetext{
${ }^{\mathrm{i}}$ Year deposited according to band pair count only listed for samples requiring a shift in order to align sample $\Delta{ }^{14} \mathrm{C}$ values to reference curves.

${ }^{i i}$ Estimates based on band pair counts, and ages estimated from $\Delta{ }^{14} \mathrm{C}$ values when shark trajectories required adjusting.

${ }^{i i i}$ The $\delta^{13} \mathrm{C}$ values of the samples (mean $=-12.82 \pm 0.055 \%$ o $(\mathrm{SE})$ ) are typical of metabolically derived carbon $[11,35]$.

${ }^{\text {iv }}$ The overall difference in $\delta^{13} \mathrm{C}$ is the maximum difference between $\delta^{13} \mathrm{C}$ measurements on an individual vertebra.
} 


\begin{tabular}{|c|c|c|c|c|c|c|}
\hline & 1982 & 1962 & 48 & -30.76 & -13.29 & \\
\hline & 1984 & 1964 & 50 & 49.47 & -13.42 & \\
\hline & 1986 & 1986 & 73 & 29.71 & -13.92 & \\
\hline \multirow[t]{3}{*}{ WS143 } & & 1995.5 & 0 & 56.67 & -12.72 & 0.35 \\
\hline & & 1998.5 & 2.5 & 54.20 & -12.97 & \\
\hline & & 2007 & 11 & 39.71 & -13.07 & \\
\hline \multirow[t]{3}{*}{ WS28 } & & 1960.5 & 0 & -26.84 & -11.80 & 1.52 \\
\hline & & 1963 & 2 & 26.09 & -13.01 & \\
\hline & & 1966.5 & 5.5 & 69.66 & -13.32 & \\
\hline \multirow{11}{*}{ WS81 } & 1950 & 1943 & 0 & -78.20 & -13.10 & 0.8 \\
\hline & 1952 & 1945 & 2 & -82.82 & -13.67 & \\
\hline & 1956 & 1949 & 6 & -72.57 & -13.59 & \\
\hline & 1958.5 & 1951.5 & 8.5 & -66.36 & -13.17 & \\
\hline & 1961 & 1954 & 11 & -73.33 & -13.21 & \\
\hline & 1963 & 1956 & 13 & -52.09 & -12.92 & \\
\hline & 1964.5 & 1957.5 & 14.5 & -46.07 & -12.97 & \\
\hline & 1967 & 1960 & 17 & -23.61 & -12.87 & \\
\hline & 1970 & 1963 & 20 & 11.65 & -13.35 & \\
\hline & 1974 & 1967 & 24 & 31.40 & -13.43 & \\
\hline & 1980 & 1973 & 30 & 23.98 & -13.44 & \\
\hline \multirow[t]{3}{*}{ WS117 } & & 1967 & 0 & 80.68 & -12.80 & 0.33 \\
\hline & & 1977 & 10 & 78.47 & -12.52 & \\
\hline & & 1987 & 20 & 79.96 & -12.85 & \\
\hline \multirow[t]{23}{*}{ WS134 } & 1961.5 & 1964.5 & 0 & 86.19 & -12.8 & 0.71 \\
\hline & 1962 & 1965 & 1 & 106.79 & -12.54 & \\
\hline & 1963 & 1966 & 2 & 111.55 & -12.29 & \\
\hline & 1965 & 1968 & 4 & 108.89 & -12.32 & \\
\hline & 1967 & 1970 & 6 & 109.92 & -12.27 & \\
\hline & 1968 & 1971 & 7 & 128.24 & -12.11 & \\
\hline & 1969 & 1972 & 8 & 117.53 & -12.12 & \\
\hline & 1970.5 & 1973 & 9 & 100.27 & -12.65 & \\
\hline & 1971.5 & 1974 & 10 & 114.90 & -12.56 & \\
\hline & 1972.75 & 1975.75 & 11.75 & 120.11 & -12.29 & \\
\hline & 1973.75 & 1976.75 & 12.75 & 120.48 & -12.22 & \\
\hline & 1975.75 & 1978.25 & 14.25 & 105.75 & -12.24 & \\
\hline & 1976.5 & 1979 & 15 & 96.68 & -12.17 & \\
\hline & 1977 & 1979.5 & 15.5 & 115.45 & -12.21 & \\
\hline & 1979.5 & 1982 & 18 & 96.88 & -12.44 & \\
\hline & 1981.5 & 1984 & 20 & 99.60 & -12.06 & \\
\hline & 1984 & 1986 & 22 & 82.64 & -12.16 & \\
\hline & 1985 & 1987 & 23 & 84.30 & -12.33 & \\
\hline & 1986.5 & 1988.5 & 24.5 & 101.23 & -12.29 & \\
\hline & 1988 & 1990 & 26 & 86.20 & -12.09 & \\
\hline & 1990 & 1992 & 28 & 95.09 & -12.55 & \\
\hline & 1992 & 1993.5 & 29.5 & 73.43 & -12.56 & \\
\hline & 1995 & 1995 & 31 & 77.92 & -12.23 & \\
\hline
\end{tabular}




\section{CHAPTER THREE}

\section{Retrospectively Investigating White Shark Ecology \\ via Bulk and Amino Acid Stable Isotope Analysis}

\subsection{Introduction}

White sharks (Carcharodon carcharias) are iconic, apex predators found seasonally in the northwest Atlantic (NWA) waters off Cape Cod, Massachusetts. The status of the NWA white shark population is currently unknown, but globally the species is protected via international trade agreements including the Convention on Migratory Species (CMS 2007) and the Convention on International Trade in Endangered Species (CITES 2004), and are listed as vulnerable on the International Union for the Conservation of Nature Red List (IUCN 2013). Despite this protection, relatively little is known about the basic ecology of white sharks. Recent tagging efforts have confirmed seasonal and ontogenetic movements and behaviors that are vary geographically, making it challenging to characterize movement and trophic ecology critical for designing effective conservation policies. Understanding the movement and trophic ecology of white sharks is important because as apex predators, they are likely to have a disproportionate influence on food web structure in ocean ecosystems (Heithaus et al. 2008) and changes in white shark behavior can have important implications for public safety in coastal communities (Cliff 1991).

While white sharks remain under-studied throughout the global ocean, the Atlantic Ocean population is probably the least well characterized. Based on scant observations of feeding events and stomach content analysis (SCA) from individual fish, the breadth of the NWA white shark diet appears to be similar to individuals in other locations. Juveniles tend to eat mostly bony fish, and adults broaden their prey base to feed on elasmobranchs and a variety of marine mammals, including dead cetaceans as well as pinnipeds like gray seals (Halichoerus grypus) (Casey and Pratt 1985, Compagno 2001, Skomal et al. 2012). However, opportunistic viewing of feeding events and SCA also has inherent and problematic biases. Opportunistic viewing of feeding is biased towards near-shore and surface events like attacks at pinniped colonies (Hammerschlag et al. 2012). This may over emphasize their importance over other less easily 
viewable feeding events such as predation on demersal fish. Similarly, sharks available for SCA are typically caught in areas with high fishing pressure yet often spend considerable time away from these fished zones while undertaking extensive cross-ocean basin migrations (Bonfil 2005, Jorgensen et al. 2010). Individuals are likely to feed on different prey items when migrating through oceanic waters compared to when they are close to shore. Finally, white sharks became a prohibited species in 1999 under NOAA's Atlantic Highly Migratory Species Fishery Management Plan and very few individuals have been landed by fishermen since that date. Together, these factors have resulted in an ignorance of white shark trophic ecology. This lack of knowledge presents a significant impediment to researchers attempting to determine the effect of rebounding gray seal populations on white shark distributions along the northeast coast of the United States.

Stable isotope analysis of animal tissues may circumvent many of the problems associated with traditional observational and SCA analyses (Appendices 1 and 2: McMahon et al. 2013a,b). Following the adage, "you are what you eat," as an organism feeds and moves through a specific area, its tissues record the isotopic signature of that location. In aquatic systems, habitat-specific differences due to biotic and abiotic factors create variability in isotopic baselines which then affect resultant values in the food web (Vander Zanden \& Rasmussen 1999; Appendices 1 and 2: McMahon et al. 2013a, McMahon et al. 2013b). Consumers generally show $0-1 \%$ bulk $\delta^{13} \mathrm{C}$ (DeNiro 1978, Michener \& Schell 1994) and $\sim 3.4 \%$ bulk $\delta^{15} \mathrm{~N}$ fractionation per trophic level above the baseline value (DeNiro \& Epstein 1981, Minigawa \& Wada 1984). Bulk $\delta^{13} \mathrm{C}$ values have primarily been used to infer movement between different habitats (Cherel et al. 2007), while $\delta^{15} \mathrm{~N}$ values have been used to estimate TP (DeNiro 1978), though estimation or measurement of a $\delta^{15} \mathrm{~N}$ value at the base of the food web is necessary.

It can be challenging to interpret conventional bulk stable isotope data from highly migratory species such as white sharks that may move through isotopically distinct food webs and shift diets seasonally and ontogenetically (Appendices 1 and 2: McMahon et al. 2013a, McMahon et al. 2013b). One way around this problem is to analyze several tissues with different metabolic turnover rates that record an average dietary signature on a variety of temporal scales. This can at least potentially enable analysis of feeding ecology during times when an organism may be unavailable for observation or capture (e.g. Estrada et al. 2005, Dodge et al. 2011). A more promising approach relies upon advances in compound-specific stable isotope analysis 
(CSIA), and in particular amino acids (AAs) that may allow for a more thorough examination of an organism's diet and movement. For bulk $\delta^{15} \mathrm{~N}$, the typical enrichments due to trophic fractionation $(\sim 3.4 \%$ ) are in fact averaging much larger $(\sim 7 \%$ ) fractionation in "trophic" amino acids, while "source" amino acids show little or no fractionation (McClelland \& Montoya 2002). In consumers, trophic amino acids undergo metabolic transamination processes that cause significant enrichment in ${ }^{15} \mathrm{~N}$ between trophic levels. However, only photosynthetic organisms and bacteria can synthesize source amino acids de novo. Consumers must incorporate them directly from their diet, resulting in a source amino acid isotopic profile that is characteristic of the base of the food web (e.g. Chikaraishi et al. 2007). The ratio of $\delta^{15} \mathrm{~N}$ values in source AAs to that in trophic AAs allows calculation of trophic position from a single sample from the organism of interest, and requires fewer assumptions regarding the base of the food web and trophic discrimination. Recently, $\delta^{15} \mathrm{~N}$ values in amino acids have been used to examine trophic dynamics in yellowfin tuna (Popp et al. 2007), zooplankton (Hannides et al. 2009), eel larvae (Miller et al. 2012), and spiny lobsters (O’Malley et al. 2012); study foraging ecology in penguins (Lorrain et al. 2009) and stingrays (Dale et al. 2011); and spatial patterns in oceanic food webs focusing on copepods and yellowfin tuna (Olson et al. 2010).

Our goal in this study was to retrospectively examine the trophic ecology of NWA white sharks using both bulk $\delta^{15} \mathrm{~N}$ and $\delta^{13} \mathrm{C}$ and compound specific AA $\delta^{15} \mathrm{~N}$ analyses of vertebrae. Shark vertebrae are composed of calcified cartilage tissue that contains growth bands that can be seen when the vertebrae are sectioned. The isotopic composition of these band pairs may provide a temporal record of diet and foraging location throughout the lifetime of a shark when the frequency of band pair deposition in the vertebrae has been established (Kim et al. 2012). A previous study examined bulk $\delta^{15} \mathrm{~N}$ values in white sharks from the NWA (Estrada et al. 2006). However, without a validated chronological record from the vertebrae, it was impossible to assess the timing of any trends in relation to ontogeny or potential changes in the NWA ecosystem. We recently used the bomb radiocarbon technique (e.g. Campana et al. 2002) to estimate age and determine vertebral growth patterns in northwest Atlantic white sharks (Chapter 2: Hamady et al. 2014). The study provided an accurate chronological record from white shark vertebrae. These chronologies represent a unique opportunity to determine lifetime and longterm trends in the trophic ecology of NWA white sharks. In this study we compared NWA white shark isotopic niche space, constructed a NWA foodweb based on bulk isotope values, compared 
NWA white shark bulk isotope values to other populations from around the world, and looked for ontogenetic and long-term trends in the relative trophic position in the NWA white shark population.

\subsection{Methods}

\subsubsection{Tissue Sampling}

All vertebrae except for WS1201 and WS1202 were obtained from the collection of Dr. L. Natanson at the National Marine Fisheries Service in Narragansett, RI. Vertebrae and muscle samples from WS1201 and WS1202 were obtained from Dr. G. Skomal at the MA Department of Marine Fisheries. Muscle biopsy samples from three mature female white sharks were also obtained by Dr. G. Skomal during recent tagging studies in the NWA conducted by OCEARCH (www.OCEARCH.org). All muscle tissue and vertebrae were stored frozen. Table 3.6.1 lists shark collection information. Vertebrae were cut and sub sampled as described in Chapter 2 (Hamady et al. 2014) and both vertebrae and muscle samples were lypholized prior to SIA preparation. Birth was determined by the first opaque band distal to the focus, coinciding with an angle change on the corpus calcareum (Natanson and Skomal, submitted).

\subsubsection{Bulk SIA}

Muscle samples were run in pairs, with one sample lipid and urea extracted and the other unprocessed. Lipids and urea were removed from muscle tissue using petroleum ether followed by deionized water rinses [the manual extraction method described by Kim \& Koch (2011)], after which samples were lypholized. Vertebrae samples were not treated, as vertebral material is composed of mineralized cartilage with little to no lipid (Porter 2006) and bulk $\delta^{13} \mathrm{C}$ and $\delta^{15} \mathrm{~N}$ vertebral values are little affected by decalcification (Hussey et al. 2012). Each vertebrae or muscle sample consisted of $\sim 1.5 \mathrm{mg}$ of tissue weighed into a tin boat (4x6 mm, Costech). Samples were analyzed with a PDZ Europa ANCA-GSL elemental analyzer interfaced to a PDZ Europa 20-20 isotope ratio mass spectrometer (Sercon Ltd., Cheshire, UK) at the UC Davis Stable Isotope Facility, Davis, CA, USA. Laboratory standards run with the samples had SD values $<0.3 \%$ and $<0.2 \%$ for $\delta^{13} \mathrm{C}$ and $\delta^{15} \mathrm{~N}$, respectively.

\subsubsection{Amino Acid $\delta^{15}$ N SIA}

Each sample, consisting of either approximately $7.75 \mathrm{mg}$ (7.5 to $8.01 \mathrm{mg})$ of homogenized muscle tissue or approximately $16.5 \mathrm{mg}$ (16.17 to $16.85 \mathrm{mg}$ ) of homogenized vertebral tissue, was hydrolyzed using $6 \mathrm{~N}$ hydrochloric acid, followed by derivation to produce 
trifluoracetic amino acid esters using previously described methods (Popp et al. 2007, Hannides et al. 2009, Dale et al. 2011, O’Malley et al. 2012). Specific vertebral samples were selected to span the lifetime of each shark. Samples were analyzed at the Stable Isotope Biogeochemistry Laboratory at the University of Hawaii, Manoa, Honolulu, HI, USA, with either a Delta V (ThermoFisher Scientific) or a MAT 253 (ThermoFisher Scientific) interfaced to a Trace GC gas chromatograph (ThermoFisher Scientific) through a GC-C III combustion furnace $\left(980^{\circ} \mathrm{C}\right)$, reduction furnace $\left(650^{\circ} \mathrm{C}\right)$, and liquid nitrogen cold trap via a GC-C III interface. Muscle samples were analyzed in triplicate, while vertebral samples were analyzed in two sets of three,

with one set each at high and low concentration, in order to optimize peak height. Norleucine and aminoadipic acid were used as internal reference materials to normalize the sample $\delta^{15} \mathrm{~N}$ values. Standard deviations for all amino acids averaged $0.42 \%$ (range 0.12 to $1.2 \%$ ).

\subsubsection{Data Analysis}

WS57, WS81, and WS134 were previously aged using bomb radiocarbon analysis (Chapter 2: Hamady et al. 2014), allowing for direct age estimates of the stable isotope samples. WS1201 and WS1202 were not used in our earlier work, and ages and sample deposition dates were estimated based on the validated band pair counting criteria and were conducted by Drs. L. Natanson and G. Skomal.

Stable isotope ratios were expressed in standard delta $(\delta)$ notation:

$$
\delta^{h} X_{\text {sample }}=\left(\frac{R_{\text {sample }}}{R_{\text {standard }}}-1\right) \times 1000
$$

where $\mathrm{X}$ is the element of interest, $\mathrm{h}$ is the high mass number, and $\mathrm{R}$ is the high-mass to lowmass ratio. Units are parts per thousand (\%o), and the $\delta^{13} \mathrm{C}$ and $\delta^{15} \mathrm{~N}$ values were referenced to $\mathrm{V}$ PDB and Air, respectively.

\subsubsection{Bulk SIA Data}

Tissues within a single organism can have different isotopic values due to isotopic routing and different amino acid composition. To compare white shark muscle and vertebral values, we applied a tissue correction factor. A prior study on three species of NWA sharks found very similar across species offsets between vertebral cartilage and muscle tissue for both carbon and nitrogen (Table 3.6.4), which the authors attributed to the tissues recording a diet switch due to tissue turnover times (MacNeil et al. 2005). We were able to verify that the offsets 
reported by MacNeil and co-workers were very similar to those for white sharks by analyzing muscle and vertebral samples from the same individuals.

Tissues of potential marine mammal prey species were corrected to their equivalent muscle values based on previously published correction factors. Tooth dentin $\delta^{13} \mathrm{C}$ was corrected by $-2.00 \%$ based on corrections for bone collagen (Ramsay \& Hobson 1991) that were used in a prior white shark trophic study (Kim et al. 2012). Baleen $\delta^{13} \mathrm{C}$ and $\delta^{15} \mathrm{~N}$ were corrected by $1.90 \%$ and $-0.10 \%$ respectively based on corrections for keratin from harbor seal vibrissae based on previously published correction values (Ramsay \& Hobson 1991, Schell \& Hirons 1998). Since collagen and keratin may integrate diet over a longer time span than muscle, these correction factors assume that the potentially longer term diets recorded in these tissues are equivalent to the potentially shorter term diets reflected in muscle.

To compare individual white shark bulk isotopic niches, we used the package 'Stable Isotope Bayesian Ellipses in R' (SIBER) (Parnell et al. 2010), run in R 3.0.2 (R Core Team 2013) using RStudio 0.97.551 (RStudio 2013). Standard ellipse areas (SEA) of the white shark vertebral plus muscle chronologies were corrected for small sample sizes (SEAc), and convex hulls areas (CHA) were analyzed with Layman's metrics (Layman et al. 2007) for comparison with the Bayesian resampled standard ellipse areas (B SEA). B SEA was calculated by resampling 10,000 times, and 95\% upper and lower confidence intervals were calculated to determine statistical similarity. We used $\delta^{13} \mathrm{C}$ for the $\mathrm{x}$-axis, as a proxy for the spatial component of diet, and $\delta^{15} \mathrm{~N}$ for the $\mathrm{y}$-axis, as a proxy for trophic level. Niche sizes and overlap were calculated.

$\delta^{13} \mathrm{C}$ and $\delta^{15} \mathrm{~N}$ values were also plotted by both shark age and year of tissue deposition to examine ontogenetic trends as well as patterns through time.

To compare white shark isotopic space with that of the NWA foodweb, we compiled a list of known prey items (Table 3.6.2) and foodweb isotope values (Table 3.6.3) from the NWA. Known prey items were based on stomach content analysis or opportunistic feeding event observations. Because records of known NWA white shark diet are sparse, we included isotope values from a variety of organism from the NWA foodweb. Many of these species either occupy similar niches as confirmed prey species and may potentially be eaten by NWA white sharks, or are eaten by white sharks in other locations. Values from foodweb tissues other than muscle were corrected to resemble muscle as described below, except in the case of blubber since white 
sharks are known to preferentially feed on blubber of dead cetaceans (Carey et al. 1982, Casey \& Pratt 1985).

Average $\delta^{13} \mathrm{C}$ and $\delta^{15} \mathrm{~N}$ values from studies published on white sharks from around the world were plotted alongside the sharks from this study to compare isotopic niches and feeding. For several studies raw or averaged data was unavailable, so we used the online tool Web Plot Digitizer (http://arohatgi.info/WebPlotDigitizer/) to extract the data from the graphs.

\subsubsection{CSIA Data}

We tried two different equations to estimate trophic position from amino acid $\delta^{15} \mathrm{~N}$. The first was the original AA $\delta^{15} \mathrm{~N}$ equation (Chikaraishi et al. 2009):

$$
T P_{G l u}{ }_{P h e}=\left(\frac{\left(\delta^{15} N_{G l u}-\delta^{15} N_{P h e}\right)+\beta}{T E F}\right)+1,
$$

where $\delta^{15} \mathrm{~N}_{\text {Glu }}$ is the nitrogen value of glutamic acid (Glu) in the consumer of interest, $\delta^{15} \mathrm{~N}_{\text {Phe }}$ is the nitrogen value of phenylalanine (Phe) in the consumer of interest, $\beta$ is the difference between Glu and Phe in the primary producer (generally $-3.4 \%$ in aquatic photoautotrophs (Chikaraishi et al. 2009) and TEF is the trophic enrichment factor between trophic levels. We first used this equation with an assumed TEF of 7.6\%, following Chikaraishi et al. (2009), and also calculated TP using a TEF of 5\%, as per the only elasmobranch AA $\delta^{15} \mathrm{~N}$ study conducted thus far (Dale et al. 2011). We also estimated TP using a multi-TEF calculation based on Germain et al. (2013) and McMahon et al. (in review), under the assumption that white sharks in the NWA are feeding on seals. Under this assumption, we set up a four-level trophic chain with primary producers, fish, seals, and sharks, with three different TEF values; the typical 7.6\%o for phytoplankton to fish following Chikaraishi et al. (2009), 4.3\%o for fish to seals from Germain et al. (2013), and $5 \%$ for seals to sharks from Dale et al. (2011). $\beta$ was kept at $-3.4 \%$.

The equation was derived as follows:

$$
\begin{gathered}
T P_{\text {shark }}=\left(\frac{\Delta^{15} N_{G-P, \text { shark }}-\Delta^{15} N_{G-P, \text { seal }}}{T E F_{\text {shark }}}\right)+\left(\frac{\Delta^{15} N_{G-P, \text { seal }}-\Delta^{15} N_{G-P, f i s h}}{T E F_{\text {seal }}}\right)+\left(\frac{\Delta^{15} N_{G-P, \text { fish }}-3.4 \% 0}{7.6 \% 0}\right)+1 \\
\quad \text { if }\left(\frac{\Delta^{15} N_{G-P, \text { shark }}-\Delta^{15} N_{G-P, \text { seal }}}{T E F_{\text {shark }}}\right)=1 \text {, and }\left(\frac{\Delta^{15} N_{G-P, \text { seal }}-\Delta^{15} N_{G-P, \text { fish }}}{T E F_{\text {seal }}}\right)=1, \\
\text { then, } T P_{\text {shark }}=\left(\frac{\Delta^{15} N_{G-P, f i s h}-3.4 \% 0}{7.6 \% 0}\right)+3, \\
\text { and if } \Delta^{15} N_{G-P, \text { fish }}=\Delta^{15} N_{G-P, \text { seal }}-T E F_{\text {seal }}, \\
\text { and } \Delta^{15} N_{G-P, \text { seal }}=\Delta^{15} N_{G-P, \text { shark }}-T E F_{\text {shark }},
\end{gathered}
$$


and $T E F_{\text {shark }}=5$, and $T E F_{\text {seal }}=4.3$,

$$
\text { then } T P_{\text {shark }}=\left(\frac{\Delta^{15} N_{G-P, \text { shark }}-12.7 \% 0}{7.6 \% 0}\right)+3 \text {. }
$$

Trophic position was plotted by both shark age and year of tissue deposition to look for ontogenetic trends as well as patterns through time.

We took the average of all source amino acids (glycine, serine, lysine, and phenylalanine, as defined by McMahon et al., in review) and plotted these values by shark age and year of tissue deposition to look for changes in their isotopic baseline through time.

To compare individual white shark compound specific isotopic niches, we used the package 'Stable Isotope Bayesian Ellipses in R' (SIBER) (Parnell et al. 2010), run in R 3.0.2 (R Core Team 2013) using RStudio 0.97.551 (RStudio 2013). Standard ellipse areas (SEA) of the white shark vertebral plus muscle chronologies were corrected for small sample sizes (SEAc), and convex hulls areas (CHA) were analyzed with Layman's metrics (Layman et al. 2007) for comparison with the Bayesian resampled standard ellipse areas (B SEA). B SEA was calculated by resampling 10,000 times, and 95\% upper and lower confidence intervals were calculated to determine statistical similarity. We used the average $\delta^{15} \mathrm{~N}$ of all source AAs for the $\mathrm{x}$-axis as a proxy for the spatial component of diet, and trophic position for the y-axis. Niche sizes and overlap were calculated.

\subsection{Results}

Lipid extraction and rinsing enriched all $\delta^{13} \mathrm{C}$ and $\delta^{15} \mathrm{~N}$ muscle values by an average of $0.65 \pm 0.47 \%$ and $0.56 \pm 0.41 \%$ respectively. Because lipid and urea composition vary among individuals, we chose to use the lipid extracted muscle tissues for all analyses and comparisons. White shark muscle values were generally more $\delta^{15} \mathrm{~N}$-enriched than were the uncorrected vertebral samples (Figure 3.7.1) with muscle from Mary Lee plotting within the vertebral range and muscle from WS1201 and Lydia plotting just outside it. Uncorrected muscle samples also displayed a broader $\delta^{13} \mathrm{C}$ range, and were generally more depleted than vertebral samples. We

found a similar offset between muscle tissue and the most recently deposited sample of vertebral cartilage for WS1201 and WS1202, the two sharks for which we have both muscle and vertebral samples, for both carbon and nitrogen (Table 3.6.4, $\mathrm{C}$ mean $=-2.41 \%$ and nitrogen mean $=$ 
$1.33 \%$ ). Therefore we decided to correct all the vertebral samples by the average white shark muscle/cartilage offset, to allow for comparisons between muscle and vertebral samples.

Intra-individual differences for shark vertebrae plus muscle chronologies ranged from $0.48-1.41 \%$ and $1.37-3.36 \%$ for $\delta^{13} \mathrm{C}$ and $\delta^{15} \mathrm{~N}$ respectively. Among all sharks, $\delta^{13} \mathrm{C}$ ranged from - 17.34 to $-14.64 \%$ and $\delta^{15} \mathrm{~N}$ ranged from 13.46 to $16.83 \%$. Pre-birth $\delta^{15} \mathrm{~N}$ samples were depleted, in some cases markedly so, compared to samples at age 1 or 2 (Figure 3.7.3a). All sharks except WS57 had a peak in $\delta^{15} \mathrm{~N}$ values at age 1 or 2 followed by an immediate decline, with subsequent values rarely equaling the initial peak. Only WS81's terminal sample at age 32 surpassed its initial peak. WS57's values peaked and then remained fairly constant until a decline around age 13. All pre-birth $\delta^{13} \mathrm{C}$ values were within 1\%o of each other, except for WS134, which exhibited enriched $\delta^{13} \mathrm{C}$ values its entire life (Figure 3.7.3b). WS57, WS81, and WS1202 chronologies remained clustered within 1.5\% of each other, though WS1201 diverged from the other three, exhibiting the most depleted $\delta^{13} \mathrm{C}$ record of all the sharks for the rest of its lifespan. No clear patterns emerged when $\delta^{15} \mathrm{~N}$ and $\delta^{13} \mathrm{C}$ were plotted by year, as the overall trends from 1937 to 2013 remained relatively flat (Figure 3.7.4b).

Based on the bulk isotope Bayesian ellipse areas, WS134 had a statistically smaller niche space than either WS57 (0.97 probability) or WS1201 (0.995 probability), and all the other sharks were not significantly different from one another (Table 3.6.5, Figure 3.7.5). WS1202 exhibited a 53\% overlap with WS57 in Bayesian niche space, WS1202 overlapped WS81 by 40\%, and WS57 and WS81 overlapped by less than 1\% (Figure 3.7.5).

White sharks had enriched $\delta^{15} \mathrm{~N}$ and $\delta^{13} \mathrm{C}$ values compared to most other groups from our reconstructed NWA foodweb (Figure 3.7.6). The white shark values plotted close to a group of piscivorous fishes, gray seals and bottlenose dolphins. The white sharks were apparently feeding at a higher trophic level than NWA mako and blue sharks, but at a similar level to thresher sharks. Two distinct endmembers were visible at the base of this foodweb; a benthic endmember with higher $\delta^{13} \mathrm{C}$ values ranging from about -18 to $-16 \%$, and a pelagic endmember ranging from about -22 to $-19 \%$. However, there was a convergence of higher trophic levels and therefore it was impossible to determine which of these two endmembers contributed the most to the carbon incorporated by the white sharks that we sampled.

We next compared bulk $\mathrm{C}$ and $\mathrm{N}$ isotope values from our samples to those from white sharks reported by other studies in the Pacific and Indian Oceans (Figure 3.7.7). White sharks in 
the NWA were generally more depleted in $\delta^{15} \mathrm{~N}$ than sharks from California and Baja, but were similar to sharks from South Africa and others measured from the NWA. The $\delta^{15} \mathrm{~N}$ values from eastern Pacific white sharks were noticeably higher than those from the NWA, suggesting that these animals are feeding at a higher trophic level than the animals in our study. The eastern Pacific white sharks also had higher $\delta^{13} \mathrm{C}$ values which is at least consistent with feeding at a higher trophic level than the NWA individuals.

Compound-specific $\delta^{15} \mathrm{~N}$ values in a subset of the samples that we analyzed for bulk analyses provided an independent estimate of trophic position. Using equation 1 and a TEF value of 5, we estimated an average TP of $3.7 \pm 0.5$ (SD), with a minimum of 3.1 and a maximum of 4.8, for the NWA white sharks. Using the multi-step TEF calculation (equation 2), the average calculated TP was slightly lower at $3.6 \pm 0.29$ (SD), with a minimum of 3.2 and a maximum of 4.3. No comprehensive SCA studies from the NWA exist, but a recent SCA study from South Africa estimated TPs ranging from 4.2 to 5 (Hussey et al. 2012) and a synthesis of studies from around the world estimated a white shark TP of $4.5 \pm 0.7$ (SE) (Cortés 1999). Compared to the SCA studies, both of our equations generated TP values that seemed rather low. We used equation 1 and a TEF of 5 to estimate relative TP for all subsequent analyses as it gave slightly higher values, although the conclusions were similar from both approaches. Due to uncertainties regarding the proper TEF value, these TP values should be compared relative to one another and not necessarily to other TP calculations made in other populations or using other methods.

Relative TP showed no clear trend across the sampled ages and time period in the vertebrae (Figures 3.7.8a,b). The earliest sample from WS134 (age 2 in 1966) had the highest relative trophic level out of all samples. It is probably not an anomalous TP estimate as both its phenylalanine and glutamic acid values were similar to other source and trophic amino acid values within that sample and were also within the range of phenylalanine and glutamic values from other samples. Average $\delta^{15} \mathrm{~N}$ source amino acid values also showed no clear trends when plotted by age or year, though WS1202 showed the largest range in $\delta^{15} \mathrm{~N}$, with an overall increase in $4.1 \%$ over its lifetime (Figures 3.7.9a,b).

Finally, we constructed niche spaces for the sharks by plotting the relative trophic position from the ratio of glutamic acid and phenylalanine and the average source amino acid $\delta^{15} \mathrm{~N}$ values. Based on the Bayesian ellipse areas, the niche spaces of all sharks were not 
significantly different from one another with overlap ranging from between 14 and 80\% (Table 3.6.6, Figure 3.7.10).

\subsection{Discussion}

Stable isotope records in vertebrae and muscle tissue demonstrated that white sharks in the NWA exhibit spatial and diet variability within and among individuals. While the sample size of sharks is small, with 5 vertebral records ( 2 with corresponding muscle samples from the time of death) and 3 muscle samples from currently tagged sharks, this data set provides a unique look at the trophic and movement ecology of the understudied NWA white shark population. It provides a more nuanced view than a previous study in the NWA in which the largest white sharks occupied a significantly higher trophic position than smaller sharks (Estrada et al. 2006).

\subsubsection{Isotopic trends and niches}

Bulk and $\mathrm{AA} \delta^{15} \mathrm{~N}$ isotope analyses complemented each other to highlight variability in white shark life histories. Despite the lower resolution records, the AA data corroborated and further illuminated the trends in the bulk pre-birth $\delta^{15} \mathrm{~N}$ values and the $\delta^{15} \mathrm{~N}$ peak around age 2 . The AA $\delta^{15} \mathrm{~N}$ samples from WS1201 and WS1202 at age 0 and 0.5 showed relatively lower trophic positions than the next sampled band pair (Figure 3.7.8a), suggesting that the pattern seen in the bulk data was related to a change in trophic position. White sharks are ovoviviparous with intrauterine oophagy, and the difference between pre-birth and post birth values is indicative of a switch from a yolk to fish diet, as was seen in other white sharks from the NWA (Estrada et al. 2006) and CA (Kim et al. 2012). The bulk $\delta^{15} \mathrm{~N}$ peak around age 2 for WS134 and WS81 corresponded to a high TP, with WS134's value being the highest TP in our study, whereas WS 57 at age 2 had one of the lowest TPs. The relative range in TP (1.71) at age 2 between these sharks likely illustrates the generalist feeding behavior of NWA white sharks as a group. It seems counter-intuitive that a 2 year-old shark should have the highest TP, especially in comparison to the muscle samples taken from large individuals caught near Cape Cod seal colonies, but elevated $\delta^{15} \mathrm{~N}$ values found in some juvenile CA sharks have been attributed to possible scavenging of pinniped or large squid carcasses (Kim et al. 2012). Only one shark (WS57) showed a distinct increase in TP as measured by AA $\delta^{15} \mathrm{~N}$, increasing by about 1 TP over its lifetime. However, this individual did not show any significant increase in bulk $\delta^{15} \mathrm{~N}$ over the same time period. This emphasizes the utility of CSIA in teasing apart $\delta^{15} \mathrm{~N}$ variations generated 
by changes in trophic level from those caused by movement through waters with different $\delta^{15} \mathrm{~N}$ baselines.

Several individuals had interesting patterns in $\delta^{13} \mathrm{C}$ and $\mathrm{AA} \delta^{15} \mathrm{~N}$ values, demonstrating individual shark variability. Both the range in $\delta^{13} \mathrm{C}$ and AA $\delta^{15} \mathrm{~N}$ values, of $\sim 2.5$ and 3.5\% respectively, in juvenile sharks $<2$ years shows a wide range in either shark pupping/nursery habitat or seasonal or annual fluctuations in baseline isotopic values. WS134 had a more enriched $\delta^{13} \mathrm{C}$ record than the other sharks, but had a fairly depleted AA $\delta^{15} \mathrm{~N}$ value at age 2 , implying that this shark may have spent its early years in subtropical, offshore waters like the Sargasso Sea where $\delta^{13} \mathrm{C}$ is enriched and $\delta^{15} \mathrm{~N}$ is depleted (see Figure 1 in Appendix 1: McMahon et al. 2013a). The nearly annual resolution of WS134 and WS1202's $\delta^{13} \mathrm{C}$ records show a sawtooth pattern that may represent some sort of regular migration. Interestingly, these patterns are not of the same frequency; WS1202 has peaks every other year, while after age 2, WS134 peaks every 5 to 6 years. Based on size at capture, WS134 was a mature female, and bracketing previous size at maturity estimates with size and age data from our $\Delta^{14} \mathrm{C}$ samples (Chapter 2: Hamady et al. 2014) leads to a rough age at maturity estimate for females of 21 to 32 years. Considering the $\delta^{13} \mathrm{C}$ patterns started prior to WS134 reaching maturity, it seems unlikely that they were due to movements related to reproduction. Climatic conditions such as the North Atlantic Oscillation could also affect isotopic baselines and/or prey abundance and cause these patterns. It may be difficult to distinguish between shark movement and changes in isotopic baselines if oceanographic conditions and shark movements fluctuate contemporaneously. However, recent tagging showing large scale movements (Skomal et al. unpubl. data) and marked variation in the most recently deposited average AA $\delta^{15} \mathrm{~N}$ values from 2012 and 2013 suggest that the range in average $\mathrm{AA} \delta^{15} \mathrm{~N}$ and bulk $\delta^{13} \mathrm{C}$ is due to migration rather than oceanographic conditions affecting isotopic baselines. Improved spatial and temporal resolution in isoscapes combined with more tagging work to identify migration patterns may help answer these questions in the future.

Isotopic niches based on Bayesian ellipse areas varied between the traditional bulk $\delta^{15} \mathrm{~N}$ versus $\delta^{13} \mathrm{C}$ approach and the compound-specific methods that plotted TP estimated from the ratio of $\delta^{15} \mathrm{~N}$ values in glutamic acid to phenylalanine. Source $\mathrm{AA} \delta^{15} \mathrm{~N}$ and bulk $\delta^{13} \mathrm{C}$ values are both proxies for spatial movement but we would not expect their values to be correlated as 
baseline $\delta^{15} \mathrm{~N}$ and $\delta^{13} \mathrm{C}$ isoscapes are also not correlated in the NWA (Appendix 1: McMahon et al. 2013a). We therefore interpreted the differences in niche overlap and niche size as measured by the two methods to indicate that the different shark habitats had consistently overlapping $\delta^{15} \mathrm{~N}$ but not $\delta^{13} \mathrm{C}$ values. Nonetheless, both approaches found that white sharks had a larger range along the spatial axis than the trophic position axis, indicating more lifetime differences in movement than trophic level.

\subsubsection{In context: the food web and other white shark studies}

Based on stable isotope analysis, pinnipeds appear to constitute a fairly small portion of NWA white shark diets. Cape Cod gray seals eat groundfish, sandlance, small elasmobranchs, and cephalopods (Ampela 2009) and should occupy a trophic position similar to piscivorous northwest Atlantic sharks (Estrada et al. 2003). The only published stable isotope data for Cape Cod gray seals is a $\delta^{15} \mathrm{~N}$ value of $16.75 \pm 0.29 \%$ o that came from two stranded juvenile males (Bogomolni 2003). This value is higher than any other average in our compiled NWA foodweb, including adult gray seals from two locations in Canada and may represent lingering enrichment in values from nursing (Hobson \& Sease 1998) or catabolic tissue processing due to starvation or sickness (Hobson et al 1993). Alternately, nitrogen values at the base of the foodweb may have been anomalously high during their lifespan. Regardless, white sharks appear to share a similar or perhaps even lower TP than gray seals, which is indicative of two possible, not mutually exclusive scenarios:

1) Gray seals and white sharks in the NWA feed upon prey from similar trophic levels. This is corroborated by SCA, especially for juvenile white sharks (Casey \& Pratt 1985).

2) White sharks feed on a combination of seals and and lower trophic level prey. This may be more likely for large mature white sharks that have higher energy requirements and may switch between pinnipeds or dolphins and scavenging cetacean carcasses.

Unfortunately it is difficult if not impossible to test between these hypotheses using either bulk or AA isotope analyses that we used in the current study.

Observational bias has perhaps driven the tendency to focus on pinniped prey as the primary source of food for adult white sharks (Compagno 2001). As demonstrated by this study, as well as the stable isotope work done on the northeast Pacific population (Kim et al. 2012), the 
classic view of white sharks switching from a fish diet to a pinniped-dominated diet is likely too simplistic. Even morphological differences point towards a varied diet. Hubbell (1996) noted the now classic ontogenetic heterodonty in white sharks, but also that large, sexually mature individuals have fairly varied tooth structure, ranging from, "relatively long, narrow teeth," to "short wide teeth," with enough variation that, "were [tooth structure] the only criterion for identifying species, more than one species of extant white shark likely would have been named". Based on tagging information (Skomal et al. unpubl. data), NWA white sharks are spending months away from pinniped populations, meaning that other prey items must make a significant contribution to their diet.

Tissue turnover and deposition rates of muscle and vertebrae respectively may be a factor in identifying feeding on gray seals using SIA. In the first place, it is difficult to determine tissue turnover in a large, pelagic, elusive species that is nearly impossible to keep in captivity. Though turnover rates tend to decrease with increasing body size (Martinez del Rio et al. 2009), this may not be the case for all elasmobranchs. Matich et al. (2010) found relatively quick tissue turnover in large tiger sharks compared to the standard body size scaling predicted value (Carleton \& Del Rio 2010). Their genetic metabolic similarity to humans versus teleost fish (Richards et al. 2013), their partial endothermy, the close correspondence between vertebral $\Delta{ }^{14} \mathrm{C}$ and DIC $\Delta{ }^{14} \mathrm{C}$ chronologies (Chapter 2: Hamady et al. 2014), and a recent study on swimming energetics (Semmens et al. 2013) all imply that white sharks may have higher metabolic rates than previously supposed, suggesting that experimentally derived turnover rates from smaller species are applicable. Based on turnover rates in freshwater stingrays and sandbar sharks, muscle may represent an annual mean of diet $\delta^{15} \mathrm{~N}$, whereas blood reflects a diet switch within two or three months (MacNeil et al. 2006, Logan \& Lutcavage 2010). White shark vertebral band pairs are deposited on an annual basis, at least through maturity (Chapter 2: Hamady et al. 2014), and thus record isotopic values on a similar time scale as muscle. This is corroborated by the similarity between the vertebral edge material and muscle samples from WS1201 and WS1202. Comparison of tissues with quicker turnover times sampled in late summer or fall, like liver or blood, to tissues with slower turnover times, like muscle or vertebrae, may capture the increase in trophic level that a white shark would experience during a summer of feeding on gray seals off of Cape Cod. 
Using the only published elasmobranch TEF (Dale et al. 2011), we found an average white shark TP of 3.5-3.6. These values are somewhat lower than TP estimates of 4.2-5 from other studies (Cortés 1999, Hussey et al. 2012). However, it is difficult to compare $\delta^{15} \mathrm{~N}$ values and TPs between studies due to differences in isotopic baseline values and assumptions that are inherent to TP calculations, both for bulk and CSIA. Bulk TP estimation requires measuring or estimating a baseline $\delta^{15} \mathrm{~N}$ value, as well as assuming a TEF. Baseline values can vary in space and time, which is of concern when looking at records from highly migratory or long-lived species such as white sharks. CSIA has the advantage of measuring the baseline isotopic value

along with the trophic enrichment within the one sample, but there is still the need to estimate a TEF. Recent studies with higher trophic level organisms have found that TEFs vary, (Lorrain et al. 2009, Dale et al. 2011, Choy et al. 2012, Germain et al. 2013, Bradley et al. in press), and may be dependent on diet protein quality and quantity (Germain et al. 2013, McMahon et al. in review). Ideally, a TEF is calculated from controlled feeding studies, or is estimated using comprehensive SCA data or prior knowledge of diet (e.g. Lorrain et al. 2009, Dale et al. 2011). Neither of these two approaches were possible for NWA white sharks. We are, then, unable to conclude if NWA white sharks are feeding at a lower trophic level than white sharks in other locations, but further study is clearly warranted.

\subsection{Conclusions}

Bulk and CSIA of white shark vertebrae and muscle tissues provided evidence of variation in individual shark trophic position and movements over time. NWA white sharks generally clustered with piscivorous species in the foodweb, though behaviors and SCA indicate that feeding above and below this TP is not uncommon, and generalist feeding behavior may have led to intermediate TP values. This study is a valuable first step in providing historical feeding data on the understudied northwest Atlantic white shark population, and provides a baseline for future observations. Though we found no evidence for a recent diet switch to gray seals, the continued draw of this abundant food source may lead to continued increases in shark presence in near-shore Cape Cod waters, and future work on shark tissues with shorter turnover times may reveal a gray seal predation signal. 


\subsubsection{Collection and sampling information for individual sharks.}

$\mathrm{V}$, vertebra; M, muscle; FL, fork length. Maturity listed if known. Ages for WS57, WS81, and WS134 based on band pair counts as well as radiocarbon (Chapter 2: Hamady et al. 2014). Ages for WS1201 and WS1202 based solely on band pair counts.

\begin{tabular}{|c|c|c|c|c|c|c|}
\hline Shark & $\begin{array}{l}\text { Tissue(s) } \\
\text { collected }\end{array}$ & $\begin{array}{c}\text { Collection } \\
\text { date }\end{array}$ & $\begin{array}{c}\text { Collection } \\
\text { location }\end{array}$ & FL $(\mathbf{c m})$ & Sex & Age \\
\hline WS57 & V & 1981 & $\begin{array}{l}\text { Offshore New } \\
\text { England }\end{array}$ & 442 & $\mathrm{M}$, mature & 44 \\
\hline WS81 & V & 1983 & $\begin{array}{l}\text { Prince Edward } \\
\text { Island, Canada }\end{array}$ & 526 & $\mathrm{~F}$ & 40 \\
\hline WS134 & V & 1996 & $\begin{array}{l}\text { Offshore New } \\
\text { England }\end{array}$ & 495.3 & $\mathrm{~F}$ & 32 \\
\hline WS1201 & $\mathrm{V} \& \mathrm{M}$ & 2012 & Chatham, MA & 261 & $\begin{array}{c}\mathrm{M}, \\
\text { immature }\end{array}$ & 8 \\
\hline WS1202 & $\mathrm{V} \& \mathrm{M}$ & 2012 & Westport, RI & 377 & M, mature & 19 \\
\hline Genie & M & $13 / 9 / 2012$ & Cape Cod, MA & 419.1 & $\mathrm{~F}$, mature & unknown \\
\hline $\begin{array}{l}\text { Mary } \\
\text { Lee }\end{array}$ & M & $17 / 9 / 2012$ & Cape Cod, MA & 449.6 & $\mathrm{~F}$, mature & unknown \\
\hline Lydia & M & $3 / 3 / 2013$ & Jacksonville, FL & 416.7 & $\mathrm{~F}$ & unknown \\
\hline
\end{tabular}




\subsubsection{The known extent of the diet of northwest Atlantic white sharks from stomach content analyses and observations.}

\begin{tabular}{|c|c|c|}
\hline Category & Prey Item & Citation \\
\hline Invertebrate - benthic & Asterias sp. (seastars) & Casey and Pratt 1985 \\
\hline Invertebrate - benthic & Cancer sp. (crabs) & Casey and Pratt 1985 \\
\hline Invertebrate - benthic & Gastropoda (snails) & Casey and Pratt 1985 \\
\hline Squid & squid, unknown species & Bigelow and Schroeder 1948 \\
\hline Fish - Planktivore & Brevoortia tyrannus (Menhaden) & Casey and Pratt 1985 \\
\hline Fish - Planktivore & Peprilus triacanthus (Butterfish) & Casey and Pratt 1985 \\
\hline Groundfish & Chimaeroids & Bigelow and Schroeder 1948 \\
\hline Groundfish & Pleuronectidae (Flounders) & Casey and Pratt 1985 \\
\hline Groundfish & Prionotus sp. (Sea robins) & Casey and Pratt 1985 \\
\hline Groundfish & Raja sp. (Skates) & Casey and Pratt 1985 \\
\hline Groundfish & sturgeon, unknown species & Bigelow and Schroeder 1948 \\
\hline Groundfish & Urophycis sp. (Hakes) & Casey and Pratt 1985 \\
\hline $\begin{array}{l}\text { Fish - Opportunistic } \\
\text { generalist }\end{array}$ & Merluccius bilinearis (Silver hake) & Casey and Pratt 1985 \\
\hline Fish - Piscivore & $1.2-2.1 \mathrm{~m}$ sharks & Bigelow and Schroeder 1948 \\
\hline Fish - Piscivore & $\begin{array}{l}\text { Carcharinus plumbeus } \\
\text { (Sandbar shark) }\end{array}$ & $\begin{array}{l}\text { Bigelow and Schroeder 1948; Adams et } \\
\text { al. 1994; Castro } 2011\end{array}$ \\
\hline Fish - Piscivore & Mustelus canis (Smooth dogfish) & Casey and Pratt 1985 \\
\hline Fish - Piscivore & Pomatomus saltatrix (Bluefish) & Casey and Pratt 1985 \\
\hline Fish - Piscivore & $\begin{array}{l}\text { Squalus acanthias } \\
\text { (Spiny dogfish) }\end{array}$ & Schroeder 1938 \\
\hline Fish - Piscivore & tuna, unknown species & Bigelow and Schroeder 1948 \\
\hline Fish - Unknown & unidentified fish & $\begin{array}{c}\text { Schroeder 1938; Casey and Pratt 1985; } \\
\text { Castro } 2011\end{array}$ \\
\hline $\begin{array}{l}\text { Marine Mammal - } \\
\text { baleen }\end{array}$ & $\begin{array}{c}\text { Eubalaena glacialis (NA right } \\
\text { whale) }\end{array}$ & Taylor et al. 2012 \\
\hline $\begin{array}{l}\text { Marine Mammal - } \\
\text { baleen }\end{array}$ & dead fin whale & Carey et al. 1982 \\
\hline $\begin{array}{l}\text { Marine Mammal - } \\
\text { toothed }\end{array}$ & $\begin{array}{c}\text { Phocoena phocoena (Harbor } \\
\text { Porpoise) }\end{array}$ & Templeman 1963; Arnold 1972 \\
\hline Dolphin & dolphin, species not specified & Adams et al. 1994 \\
\hline $\begin{array}{l}\text { Marine Mammal - } \\
\text { unknown }\end{array}$ & dead whale, species not specified & $\begin{array}{l}\text { Ellis 1975; Casey and Pratt 1985; G. } \\
\text { Skomal, pers. comm. }\end{array}$ \\
\hline Pinniped & Halichoerus grypus (Gray Seal) & $\begin{array}{l}\text { Brodie and Beck 1983 } \text {; Skomal et al. } \\
\qquad 2012\end{array}$ \\
\hline Pinniped & Phoca vitulina (Harbor seal) & Lucas and Stobo 2000; Scattergood 1962 \\
\hline Other & garbage & Casey and Pratt 1985 \\
\hline Other & sea turtle, unknown species & Bigelow and Schroeder 1948 \\
\hline
\end{tabular}

${ }^{a}$ Attacks by unknown shark species, though white sharks are suspected due to bite patterns on some carcasses. 


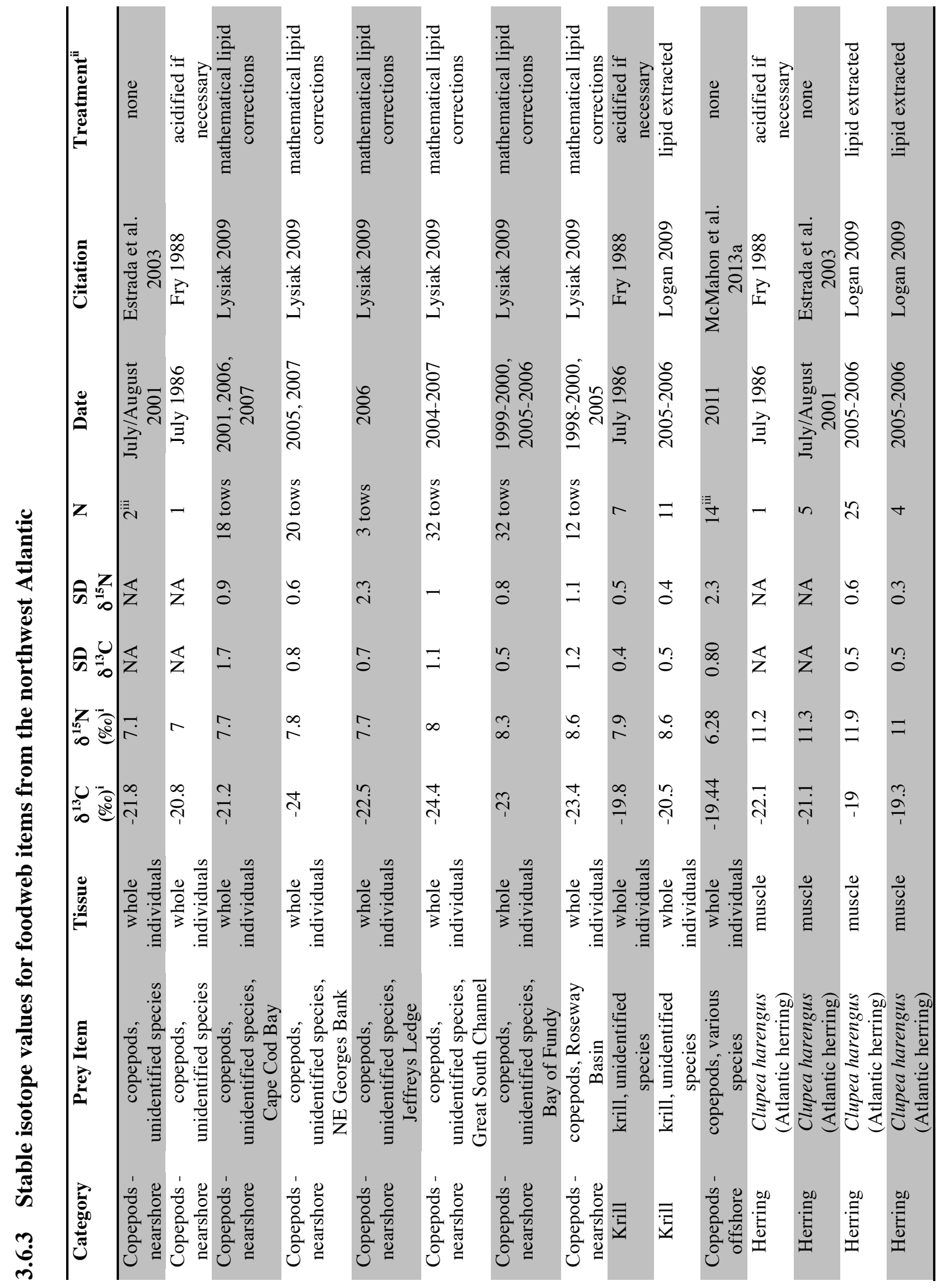




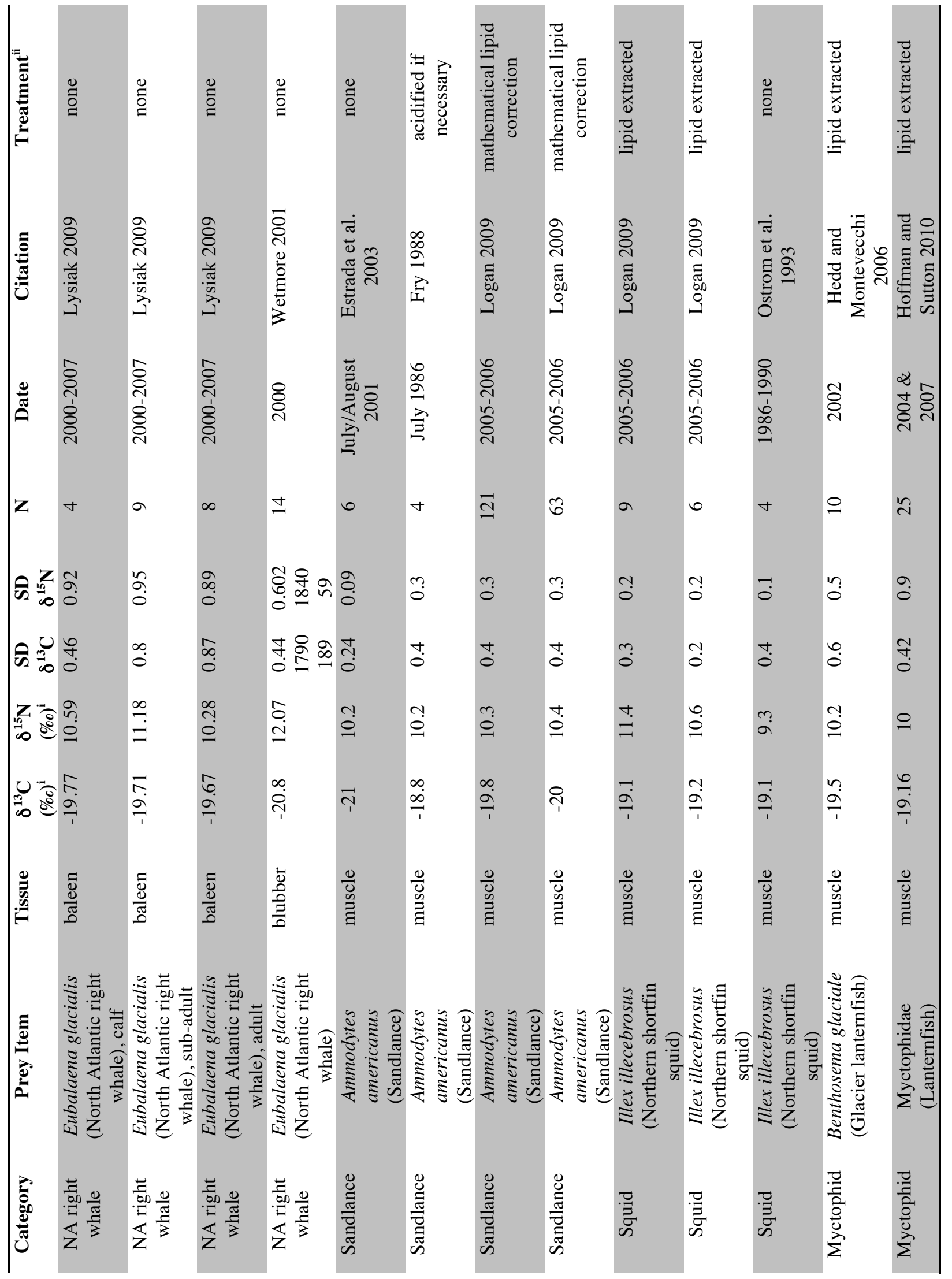




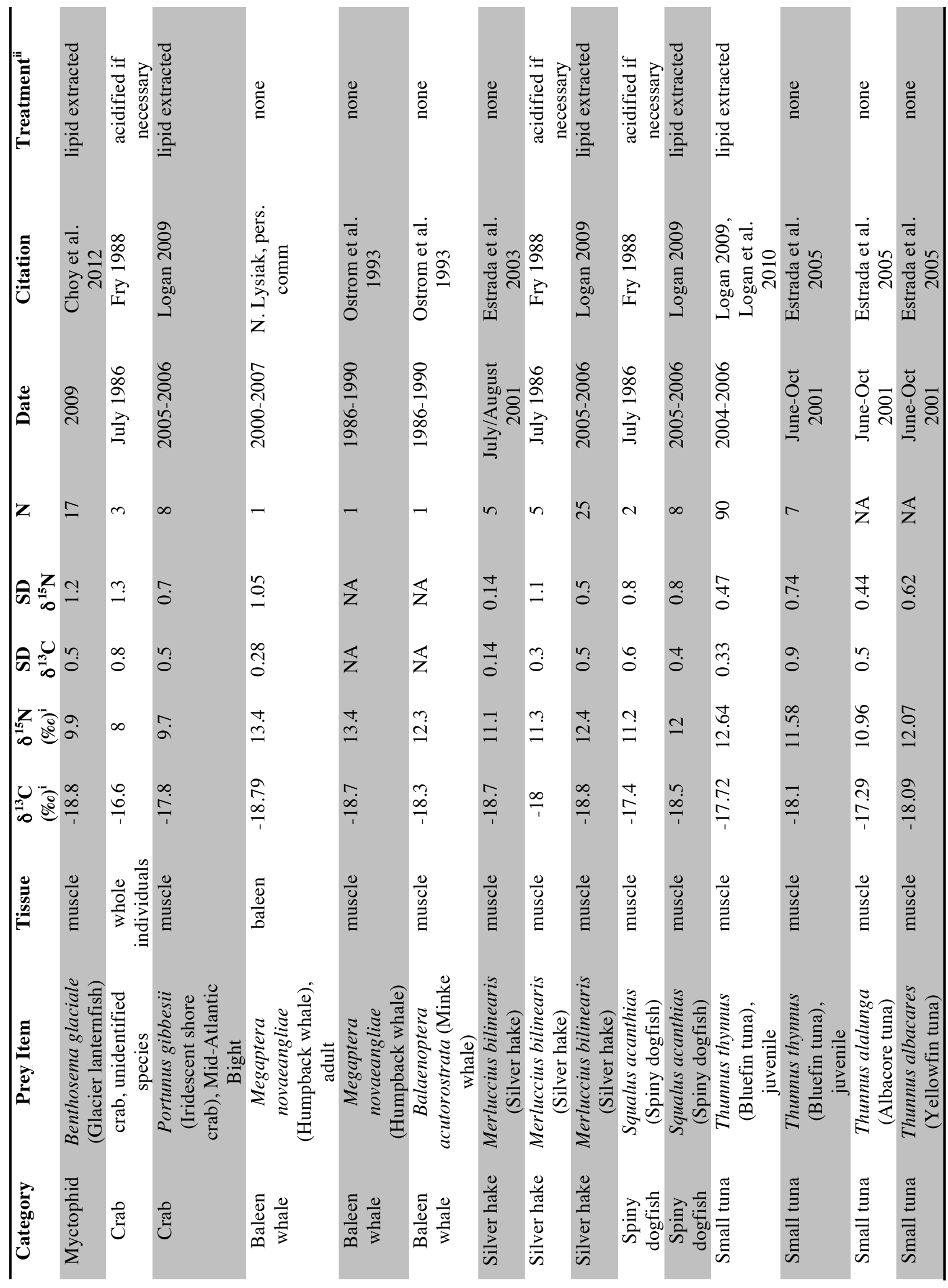




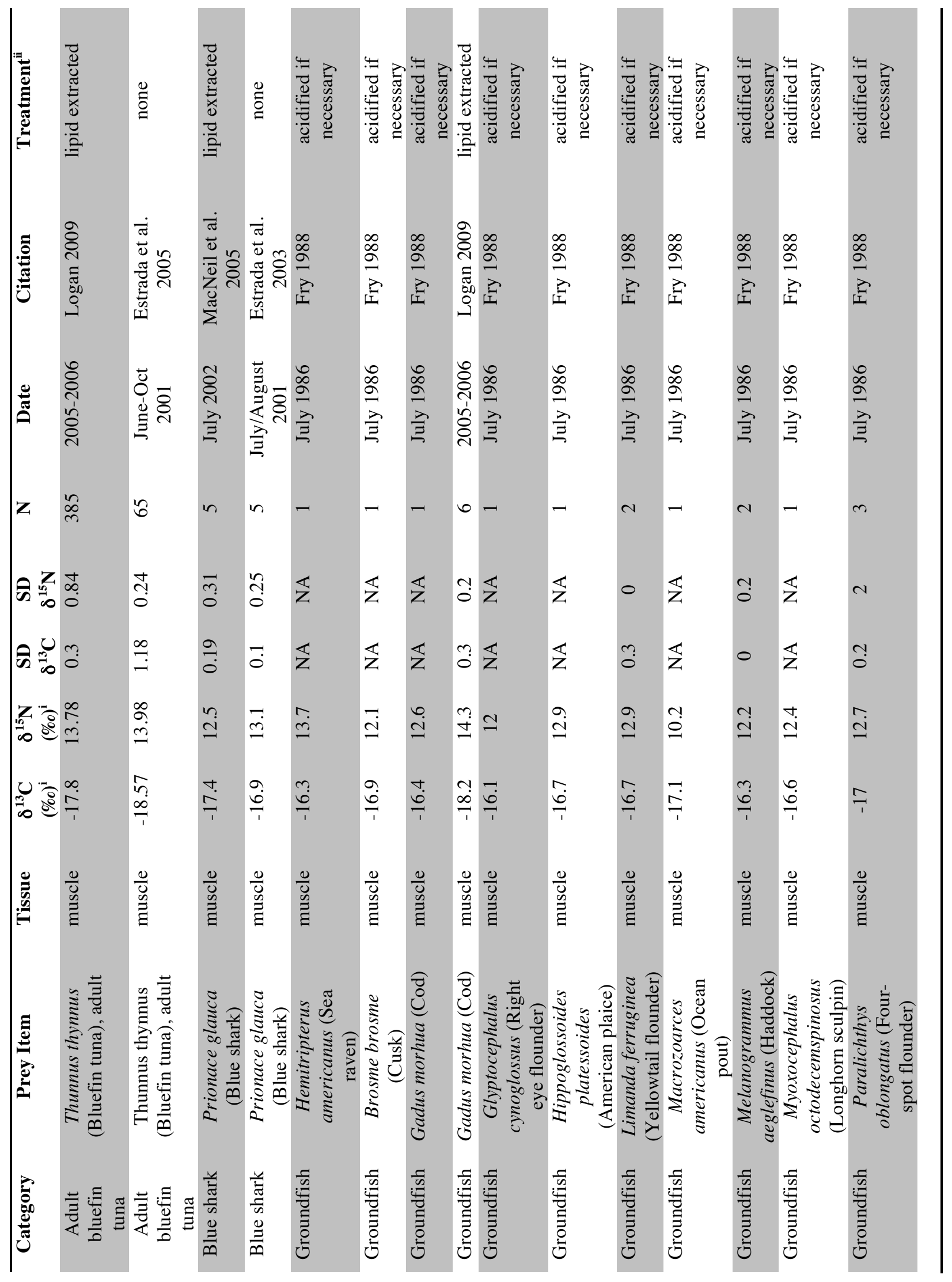




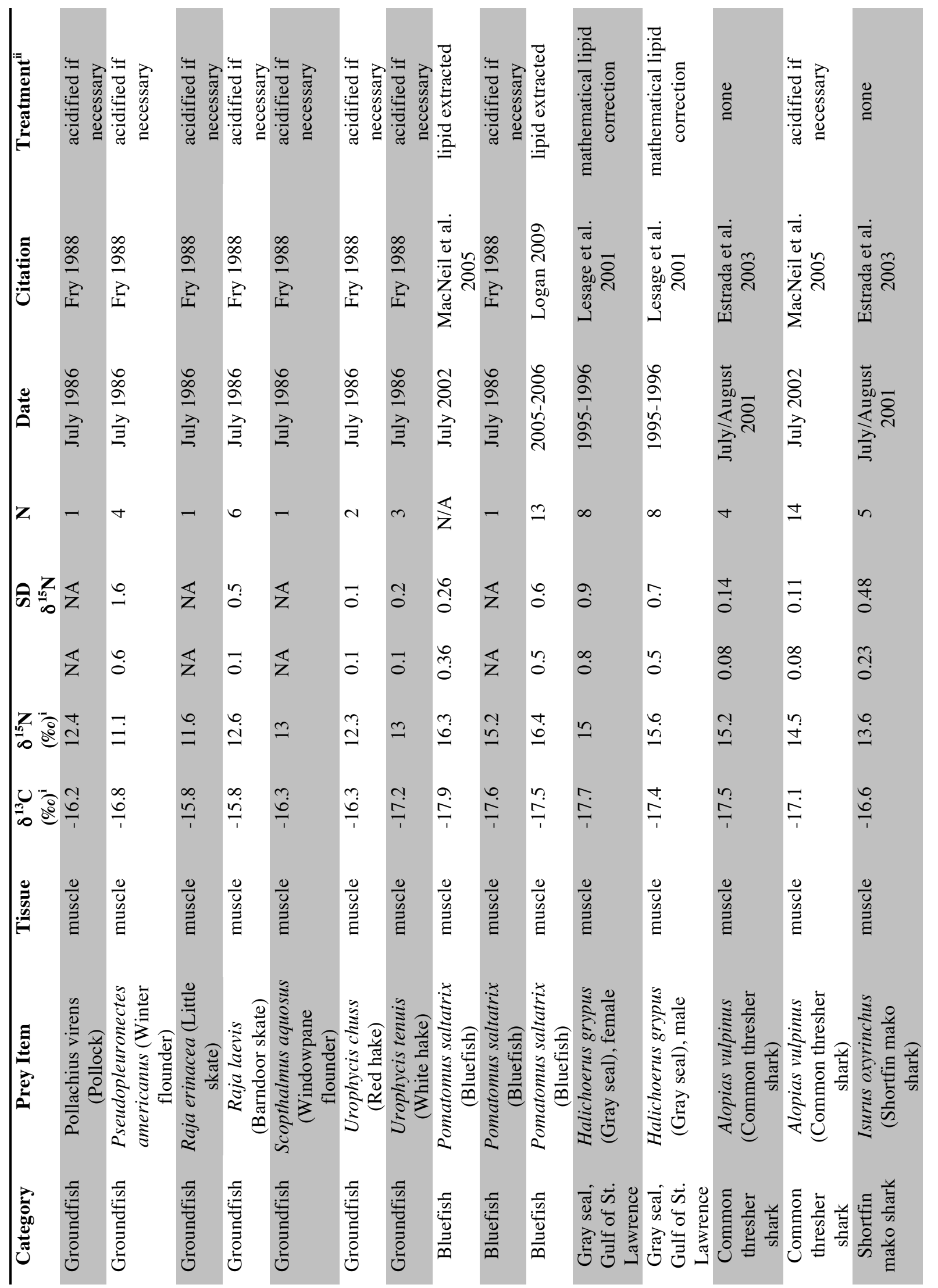




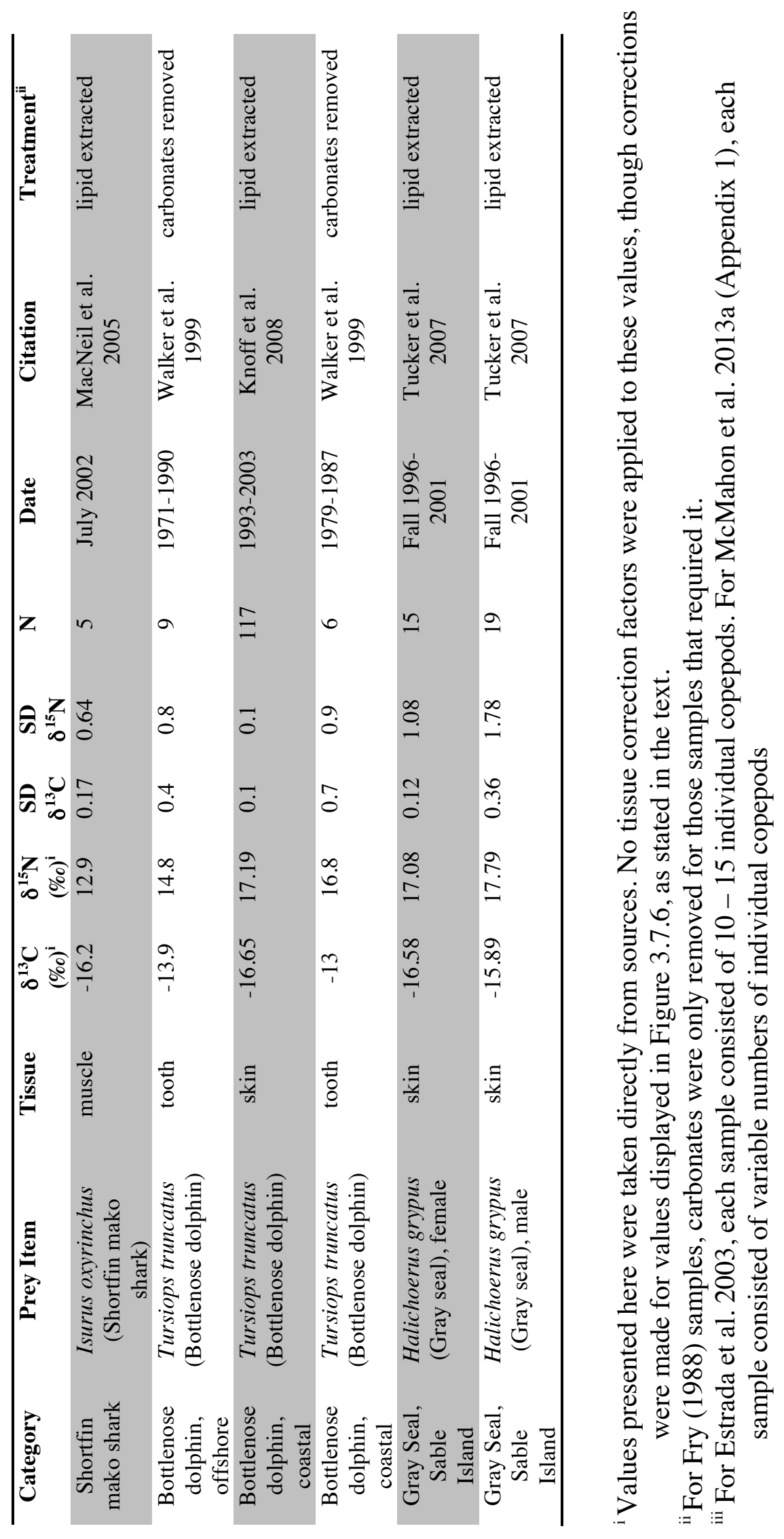




\subsubsection{Calculating correction factors for shark tissue}

Data from Isurus oxyrinchus, Prionace glauca, and Alopias vulpinus are mean non-parametric bootstrap estimates taken from MacNeil et al. 2005, Table 1. Due to the similarity of values between all four species, mean differences between the white shark cartilage and muscle were used to correct the white shark cartilage tissue samples to resemble muscle.

\begin{tabular}{c|cccc|ccc} 
Tissue & I. oxyrinchus & P. glauca & A. vulpinus & Mean & WS1201 & WS1202 & Mean \\
\hline $\boldsymbol{\delta}^{\mathbf{1 3}} \mathbf{C}(\%)$ & & & & & & & \\
Muscle & -16.20 & -17.37 & -17.06 & & -16.89 & -15.97 & \\
Cartilage & -13.71 & -14.93 & -14.4 & & -14.40 & -13.64 & \\
Difference & -2.49 & -2.44 & -2.66 & -2.53 & -2.48 & -2.34 & -2.41 \\
$\delta^{\mathbf{1 5}} \mathbf{N}(\%)$ & & & & & & & \\
Muscle & 12.93 & 12.48 & 14.50 & & 15.5 & 16.36 & \\
Cartilage & 11.79 & 11.67 & 12.76 & & 14.18 & 15.03 & \\
Difference & 1.14 & 0.81 & 1.74 & 1.23 & -1.32 & 1.33 & 1.33
\end{tabular}


3.6.5 White shark bulk isotopic niche space as measured by Bayesian ellipses Areas are measured in $(\%)^{2}$. CHA: convex hull area, SEAc; standard ellipse area corrected for small sample sizes; B SEA: Bayesian resampled standard ellipse area, resampled 10,000 times: CI: $95 \%$ confidence interval upper and lower bounds for the B SEA; Group: denotes statistical similarity in size.

\begin{tabular}{cccccc} 
Shark & CHA & SEAc & B SEA & CI & Group \\
\hline WS57 & 1.13 & 0.58 & 1.02 & $(0.65-1.54)$ & A \\
WS81 & 0.49 & 0.23 & 0.84 & $(0.51-1.31)$ & AB \\
WS134 & 0.98 & 0.3 & 0.57 & $(0.41-0.76)$ & B \\
WS1201 & 0.8 & 0.56 & 1.46 & $(0.83-2.42)$ & A \\
WS1202 & 0.48 & 0.21 & 0.81 & $(0.52-1.22)$ & AB
\end{tabular}




\subsubsection{White shark CSIA niche space as measured by Bayesian ellipses}

Areas are measured in (\%) ${ }^{2}$. CHA: convex hull area, SEAc; standard ellipse area corrected for small sample sizes; B SEA: Bayesian resampled standard ellipse area, resampled 10,000 times: CI: 95\% confidence interval upper and lower bounds for the B SEA; Group: denotes statistical similarity in size.

\begin{tabular}{cccccc} 
Shark & CHA & SEAc & B SEA & CI & Group \\
\hline WS57 & 0.86 & 1.37 & 2.29 & $(1.00-4.62)$ & A \\
WS81 & 0.30 & 1.10 & 3.26 & $(1.27-6.97)$ & A \\
WS134 & 1.35 & 1.06 & 2.11 & $(1.18-3.76)$ & A \\
WS1201 & 0.23 & 0.84 & 2.60 & $(1.01-5.63)$ & A \\
WS1202 & 2.25 & 2.44 & 3.46 & $(1.66-6.53)$ & A
\end{tabular}


3.7.1 Uncorrected bivariate plot of $\delta^{13} \mathrm{C}$ and $\delta^{15} \mathrm{~N}$ values from white shark tissue samples Values plotted without corrections (though muscle samples are lipid extracted). Convex hull lines delineate the outer bounds of each shark's vertebral isotopic niche space.

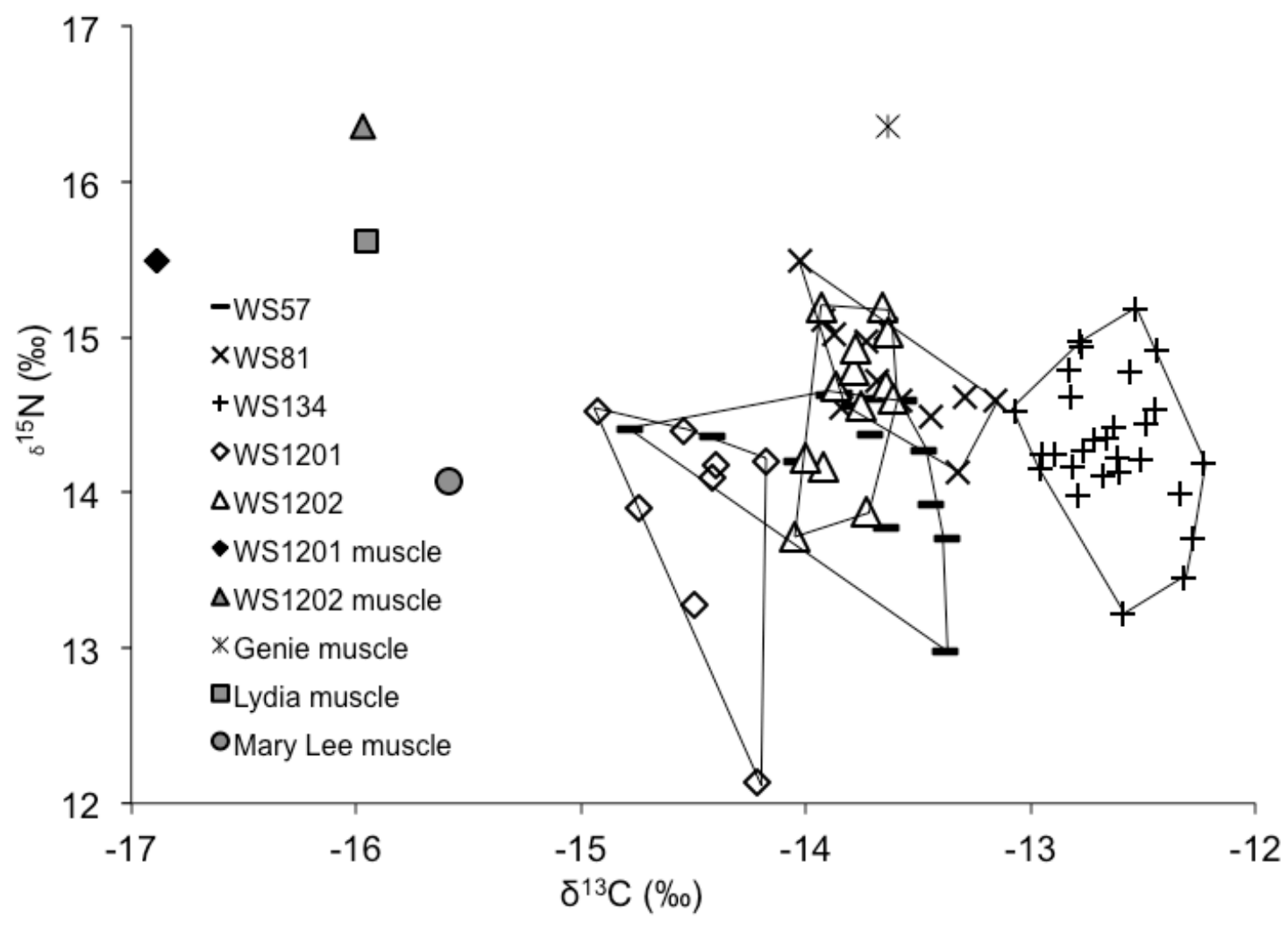




\subsubsection{Corrected bivariate plot of bulk $\delta^{13} \mathrm{C}$ and $\delta^{15} \mathrm{~N}$ values from white shark tissue samples}

Vertebral values corrected to resemble lipid extracted muscle values using the white shark specific vertebral to muscle tissue fractionation correction as determined in Table 3.6.4. Convex hull lines delineate the outer bounds of each shark's isotopic niche space.

Note the change in axes' range from the previous figure.

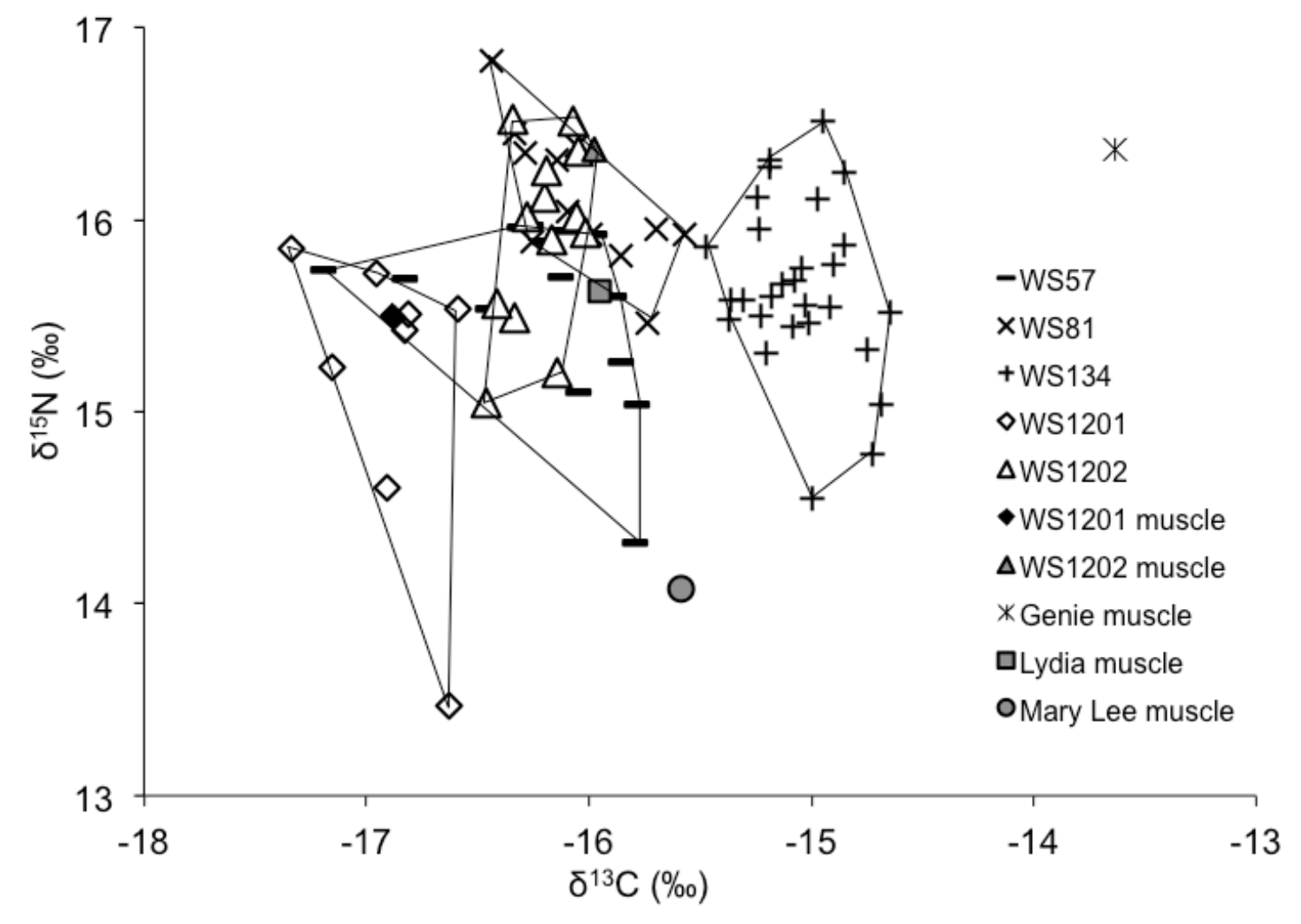




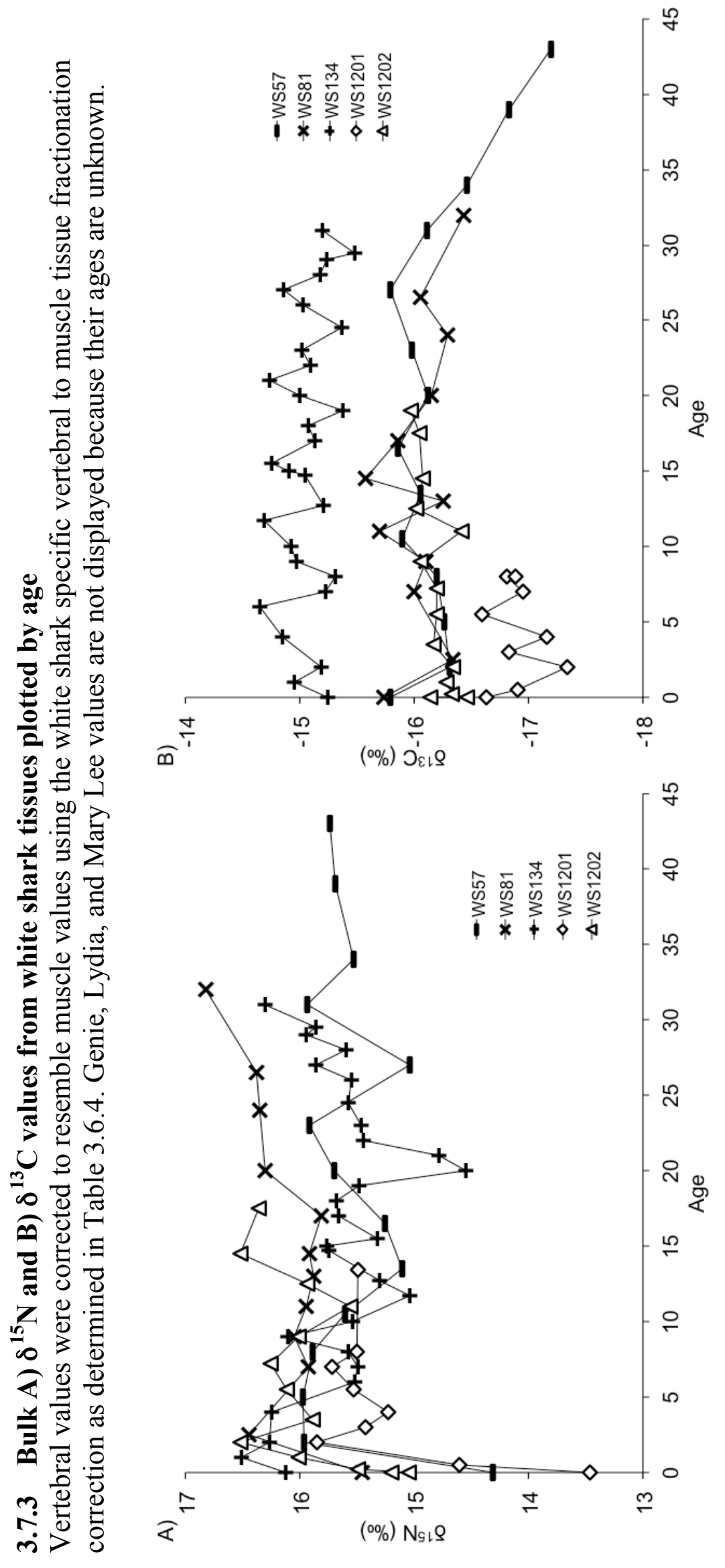




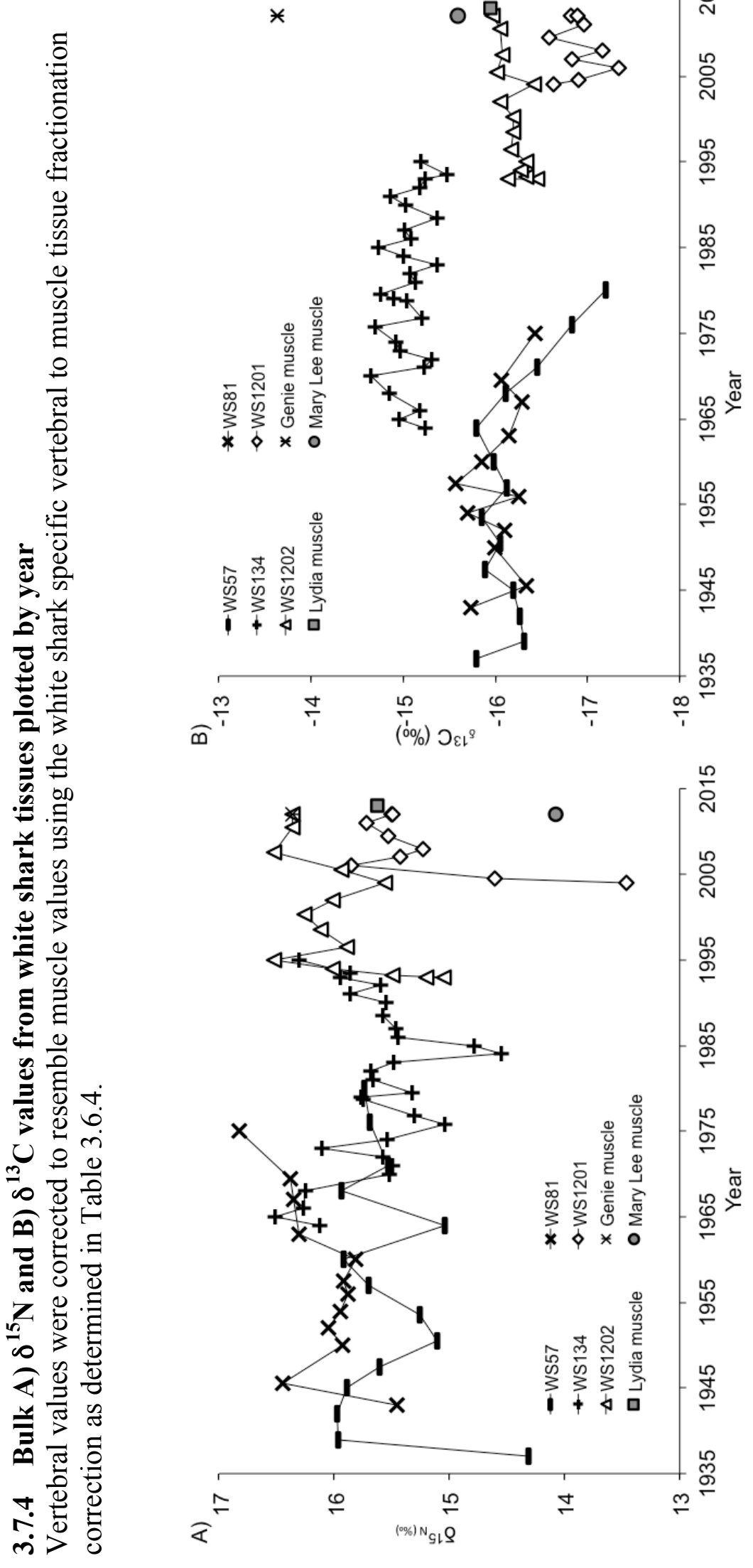




\subsubsection{Lifetime isotopic niches of individuals based on bulk $\delta^{13} \mathrm{C}$ and $\delta^{15} \mathrm{~N}$ values}

Vertebral values were corrected to resemble muscle values using the white shark specific vertebral to muscle tissue fractionation correction as determined in Table 3.6.4. Dotted convex hull lines delineate the outer bounds of each shark's isotopic niche space, and include the muscle samples for WS1201 and WS1202.

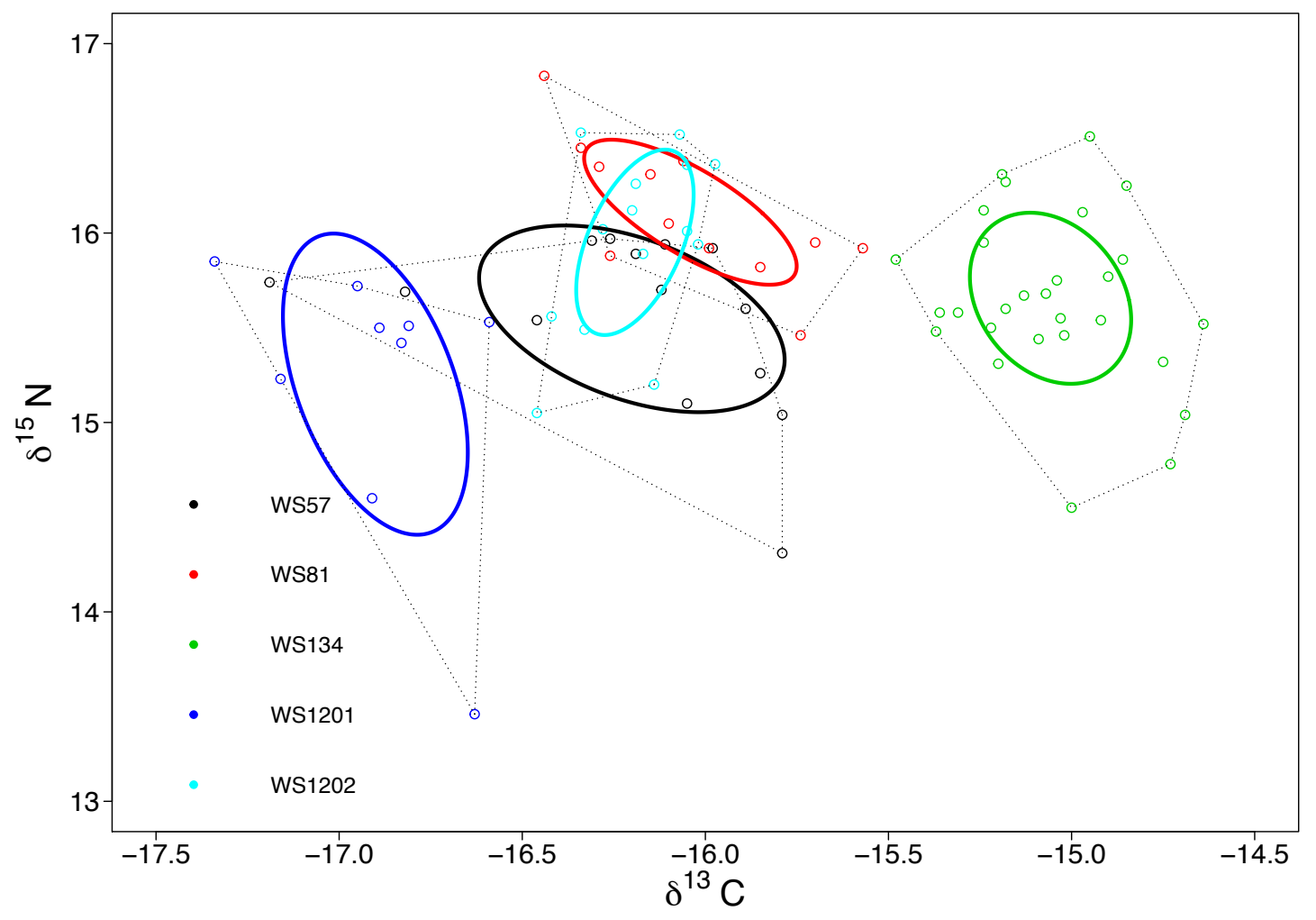




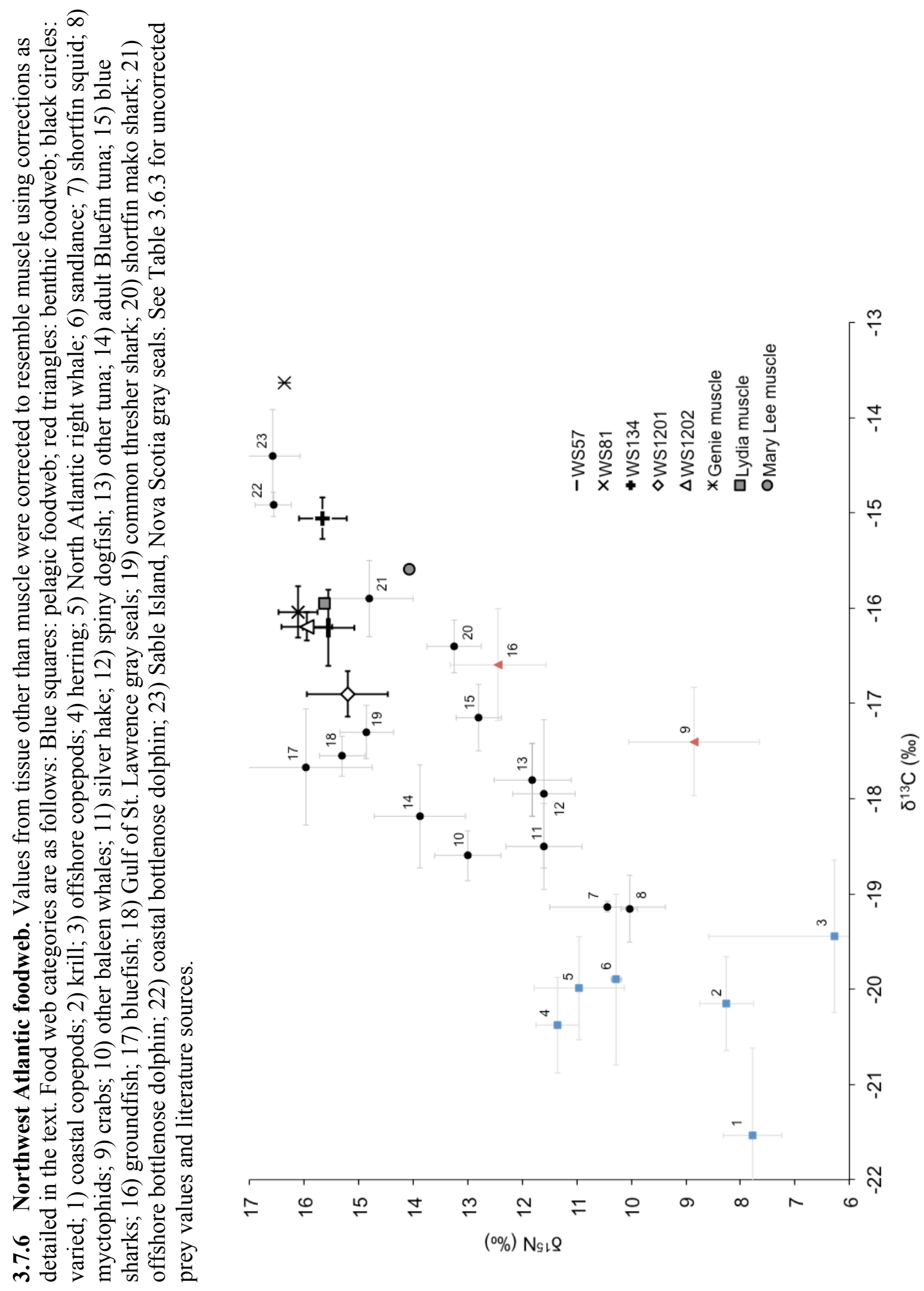



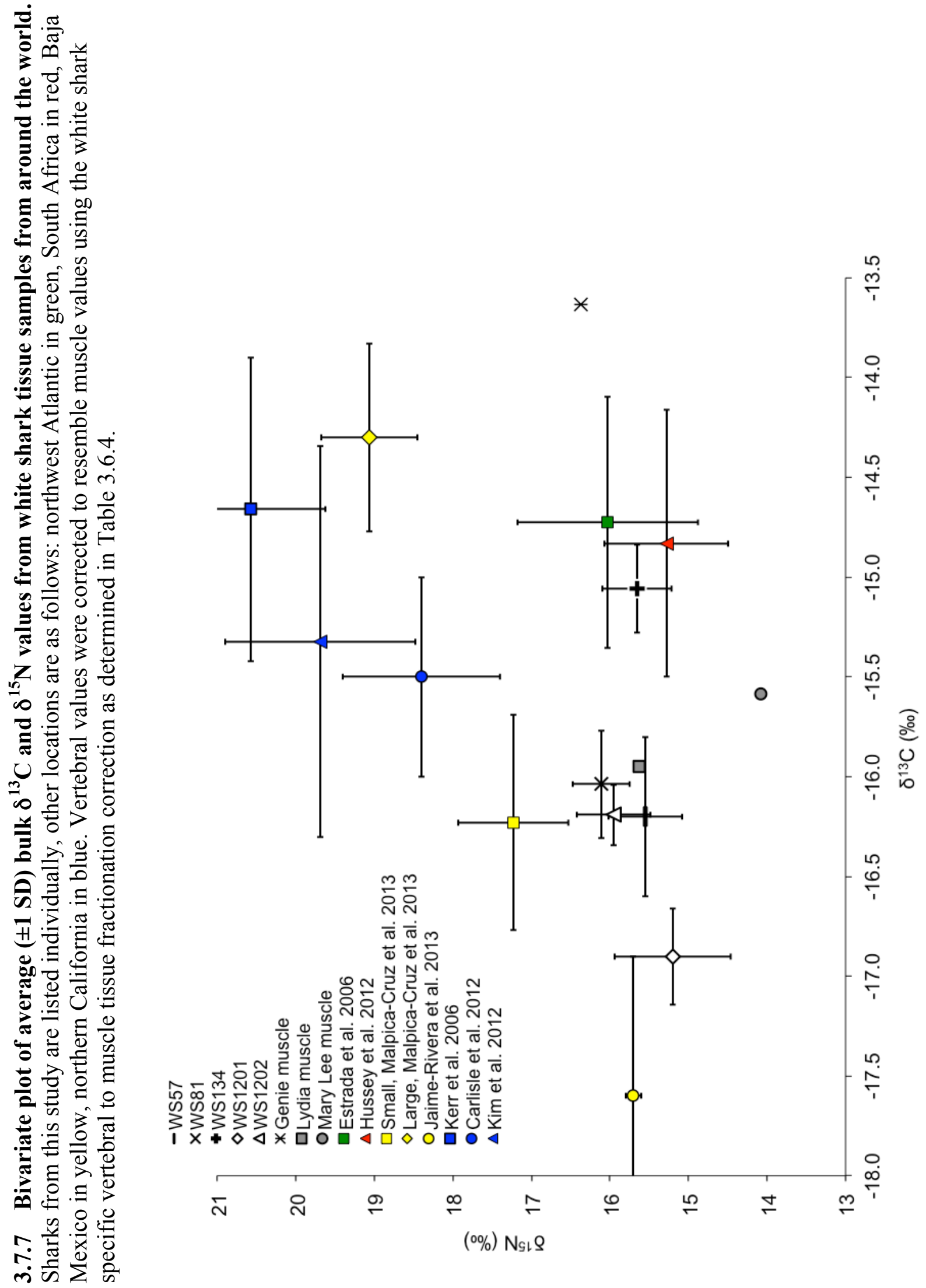


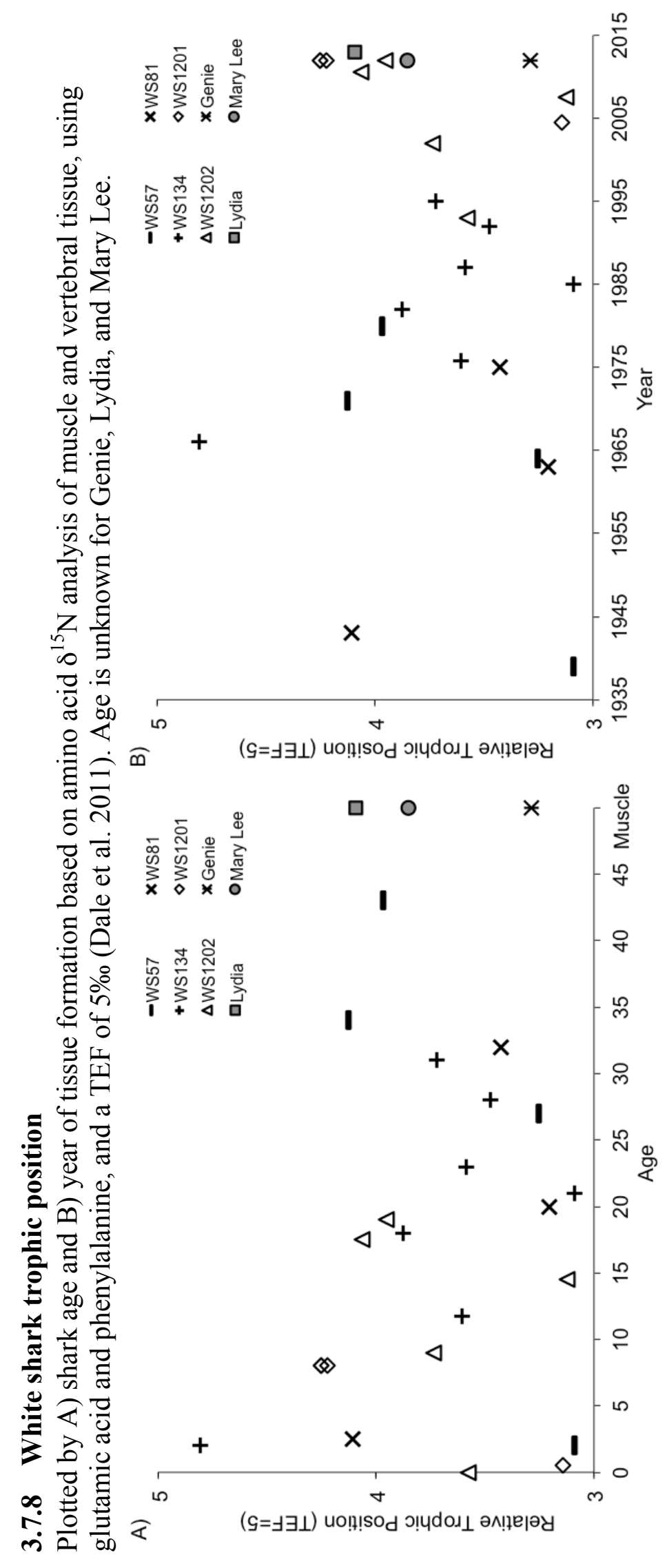




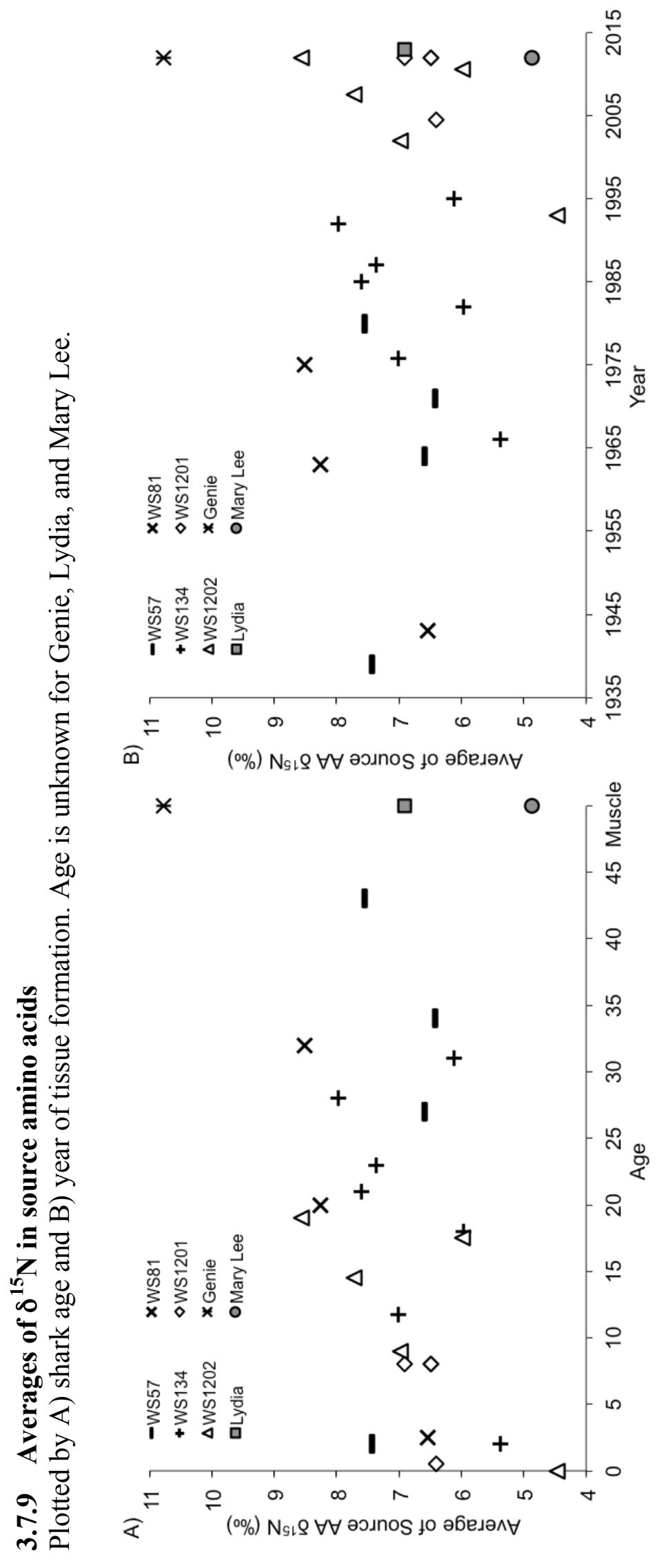




\subsubsection{Lifetime isotopic niches of individuals based on CSIA}

Based on averages of $\delta^{15} \mathrm{~N}$ in source amino acids and relative trophic positions from $\delta^{15} \mathrm{~N}$ CSIA of white shark tissue samples. Dotted convex hull lines delineate the outer bounds of each shark's isotopic niche space, and include the muscle samples for WS1201 and WS1202.

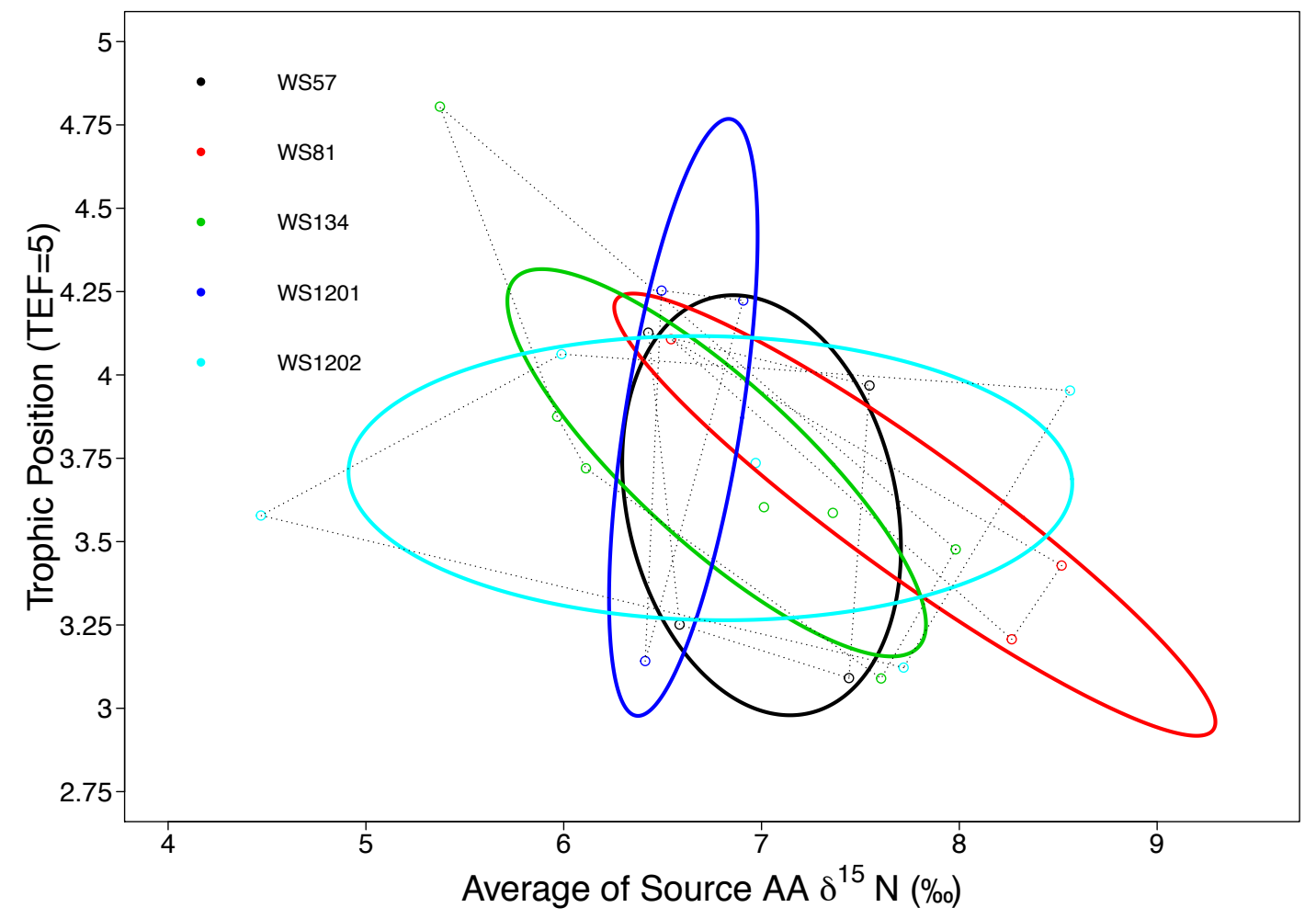




\section{CHAPTER FOUR}

\section{Inferring movements of white sharks \\ based on vertebral elemental chemistry}

\subsection{Introduction}

Animal movements have important demographic and ecological implications for population and community structure in ocean ecosystems. For instance, movement rates determine colonization rates of new habitats, the resiliency of populations to natural and anthropogenic disturbances, and the likely effectiveness of marine protected areas and other spatial strategies for managing fisheries and preserving biodiversity.

Pelagic sharks are some of the largest, most iconic species in the global ocean but we know remarkably little about their movements. This ignorance stems from the difficulties inherent when working on species that are capable or moving 1000's of kms through an opaque ocean on seasonal time scales. Advances in satellite tag technology have certainly helped to shed some light on these movements (Howey-Jordan et al 2013, Werry et al. 2014). For instance, pop-up satellite archival transmitting (PSAT) tags have typically used light level geolocation to determine positions of individuals during tag deployment, and have proved particularly useful

for species that spend most of their time in surface waters. However, PSAT tags have rarely deployed for more than 1 year and therefore cannot provide information on life-time movements of individuals.

Recently, new approaches using isotopic and elemental tags as natural markers have been developed that are likely to complement information available from satellite tags. Natural marking techniques rely upon geographic differences in stable isotope or trace element abundance that are recorded in the chemical composition of body tissues. For instance, isotopic tracers in bird feathers (Rubenstein et al. 2002), insect wings (Hobson et al. 1999) and fish bones (Kennedy et al. 1997) have been used to recover information on individual migratory histories that would have been difficult, if not impossible, using artificial tags. Elemental and isotope concentrations in ocean environments vary based on a variety of biotic and abiotic factors (Appendix 2: McMahon et al. 2013), and these markers get taken up by calcified structures that 
are actively accreting. The approach overcomes two significant difficulties with conventional tagging techniques. Geochemical signatures are induced by the environment, rather than administered by the researcher and all animals within a specified location are labeled without having to be captured and tagged, making this approach ideal for rare species that may be unavailable to researchers for some period of their life. Similarly, because every individual is marked there is no need to "recapture" tagged animals.

Elements in the ocean can be characterized by their distributions and are typically split into conservative, nutrient-type and scavenged-type categories. Conservative elements have long residence times and generally uniform distributions in the open ocean, and freshwater systems have generally very different levels of conserved elements like lithium, magnesium, and strontium; thus these elements may be useful tracers of movement between fresh and ocean environments (McMahon et al. 2013a, Appendix 1). Nutrient-type elements like barium are higher in coastal and riverine areas, as well as areas with upwelling of nutrient rich deep-water, while scavenged elements like lead and manganese have very strong particle interactions, leading to short residence times, and dust deposition and anthropogenic sources tend to primarily influence the distribution of these elements (McMahon et al. 2013b, Appendix 2).

In marine systems, most of the work using natural geochemical markers as tags has been conducted on fish otoliths (Elsdon et al. 2008). While sharks lack the otoliths of bony fishes, they do have calcified vertebrae that grow incrementally throughout their lifetime. Calcium counts in vertebrae have been used to infer age (Hale et al. 2006) with mixed success (Scharer et al. 2012), while other researchers have taken advantage of strontium variation correlating with salinity to determine age and growth (Scharer et al. 2012) and infer migration patterns (Werry et al. 2011, Tillett et al. 2011) in euryhaline elasmobranchs. A recent captive manipulation study on round stingrays (Urobatis halleri) found significant temperature effects on vertebral composition for $\mathrm{Mg}: \mathrm{Ca}, \mathrm{Mn}: \mathrm{Ca}$ and $\mathrm{Ba}: \mathrm{Ca}$, and noted that $\mathrm{Ba}: \mathrm{Ca}$ in vertebral were deposited in proportion to dissolved $\mathrm{Ba}$ in ambient water (Smith et al. 2013). This was the first study to provide experimental evidence that elasmobranch vertebrae have many of the same properties that have allowed researchers to use otoliths to retrospectively determine movement patterns and habitat use in teleost fishes (Elsdon et al. 2008).

Many elasmobranch populations, including white sharks (Carcharodon carcharias), have experienced sharp declines due to overfishing in recent decades (Baum 2003, Ferretti et al. 2008, 
Dulvy et al. 2008), leading to significant and unexpected ecosystem consequences (Myers et al. 2007, Ferretti et al. 2010). White sharks are vulnerable to even light fishing pressure due to life history traits that typically include low fecundities and high age at first maturity (Smith et al. 1998, Ferretti et al. 2010). In order to develop feasible conservation plans for white sharks it is first necessary to know where and when individuals of a particular species move (Rubenstein \& Hobson 2004). Electronic tagging of white sharks has revealed ocean basin scale migrations as well as more localized movements (Bonfil 2005, Weng et al. 2007a, Weng et al. 2007b, Jorgensen et al. 2010). However, some ontogenetic stages of white sharks are either unavailable or not amenable to tagging, and expense and tag failure of electronic tags restrict sample sizes (Hays et al. 2007, Musyl et al. 2011). The goal of the current study was to investigate potential movements of northwest Atlantic white sharks based on vertebral composition (MacMahon et al. 2013, Appendix 2). We analyzed the elemental chemistry of vertebral pair-bands based on chronologies provided by the bomb radiocarbon assays reported by Hamady et al. (2014, Chapter 2). The results represent a first attempt to estimate lifetime movements of white sharks in the northwest Atlantic using an ecogeochemistry approach (MacMahon et al. 2013, Appendix 2).

\subsection{Methods}

\subsubsection{Vertebral sampling and preparation}

All vertebrae were obtained from the collection of Dr. L. Natanson at the National Marine Fisheries Service in Narragansett, RI and were stored frozen. Table 4.5.1 lists shark collection information. Vertebrae were cut and sliced as described in Hamady et al. (2014, Chapter 2). Slices were polished with $30 \mu \mathrm{m}$ and $3 \mu \mathrm{m}$ lapping film. Triple rinsing and sonication in ultrapure water for 2 minutes was used to remove surface contaminants. Slices were then dried in a class 100 laminar flow hood. Cleaned and dried vertebral slices were mounted on petrographic slides using double-sided tape.

\subsubsection{Elemental data collection}

We analyzed elemental ratios in white shark vertebrae using a Thermo Finnigan Element2 single collector inductively coupled plasma mass spectrometer (ICP-MS) and a New Wave 193 $\mathrm{nm}$ excimer laser ablation system. Vertebral samples were analyzed for $\mathrm{Li}: \mathrm{Ca}, \mathrm{Mg}: \mathrm{Ca}, \mathrm{Mn}: \mathrm{Ca}$, $\mathrm{Sr}: \mathrm{Ca}, \mathrm{Ba}: \mathrm{Ca}$, Pb:Ca, Hg:Ca, and U:Ca by quantifying ${ }^{7} \mathrm{Li},{ }^{25} \mathrm{Mg},{ }^{48} \mathrm{Ca},{ }^{55} \mathrm{Mn},{ }^{88} \mathrm{Sr},{ }^{138} \mathrm{Ba},{ }^{208} \mathrm{~Pb}$,

${ }^{202} \mathrm{Hg}$, and ${ }^{238} \mathrm{U}$ in ablated vertebral material. The laser software was used to place $50 \mu \mathrm{m}$ spots every $60 \mu \mathrm{m}$ along the mid portion of the corpus calcareum, from the most recently deposited 
material down towards the focal region of the centrum. Laser parameters were as follows: Dwell time $=60$ seconds, repetition rate $=5 \mathrm{~Hz}$, and power $=80 \%$. Ablated material was transported via a He gas stream to the dual-inlet quartz spray chamber where it was mixed with a $2 \% \mathrm{HNO}_{3}$ aerosol from a self-aspirating perfluoroalkyoxy (PFA) nebulizer before being transported to the ICP-MS. Instrument blanks $\left(2 \% \mathrm{HNO}_{3}\right)$ were run after every 10 points, and a blank correction was calculated for each sample by linear interpolation of the measured blanks. A certified reference material (Sturgeon et al. 2005), dissolved in $2 \% \mathrm{HNO}_{3}$ and diluted to a $\mathrm{Ca}$ concentration of $40 \mathrm{mg} \cdot \mathrm{g}^{-1}$, was run every 10 samples and used to correct samples for instrument mass bias following Thorrold and Swearer (2009). External reproducibility was assessed using a second otolith certified reference material (Yoshinaga et al. 2000) that was also dissolved and also run every 10 samples and treated as an unknown. External precision (relative standard deviation) for each of the elemental ratios from the analyses of the second reference material $(\mathrm{n}=$ 380) were as follows: Li:Ca: 3.31, Mg:Ca: 1.19, Mn:Ca: 6.12, Sr:Ca: 0.62, Ba:Ca: 1.033, Pb:Ca: 2.44, Hg:Ca: 197.59, and U:Ca: 26.07\%. Blank to sample counts per second were as follows: Li: 8.81, Mg: 0.505, Ca: 0.492, Mn: 38.53, Sr: 0.334, Ba: 5.96, Pb: 15.03, Hg:Ca: 44.25, and U:Ca: $13.55 \%$. Finally, we ran duplicate analyses on several of the vertebrae to assess within-vertebra variation in elemental profiles. We used correlation analysis to assess the degree of reproducibility.

\subsubsection{Data analysis}

We initially removed obvious outliers (identified visually) and all negative ratios signifying measurements were below blank values. Elemental profiles were then smoothed using a LOESS 10-point locally weighted scatterplot smoothing curve in Microsoft Excel (Peltier 2009). Sharks were grouped by sex for comparison, as biological differences may mediate elemental patterns. Data from birth onward were plotted by lining up sampled profiles with deposition year and age using high resolution images, with time assigned to band pairs based on bomb radiocarbon age estimates (Hamady et al. 2014, Chapter 2). Birth was determined by the first opaque band distal to the focus, coinciding with an angle change on the corpus calcareum (Natanson and Skomal, submitted). Due to uncertainty regarding gestational period (Francis 1996), pre-parturition data points were plotted by spot number rather than time. Pre-parturition through 1-year old data were plotted to examine differences in pre-and post-natal vertebral chemistry. We examined correlations among the elemental ratios using correlation analysis with 
the Bonferroni correction to adjust a to account for multiple comparisons.

\subsection{Results}

We initially tested the reproducibility of vertebral profiles by analyzing parallel paths on several of the sectioned vertebrae (Figure 4.6.1). General patterns were very consistent between replicate profiles, with correlations ranging between 0.69 and 0.90 , suggesting little spatial variation in vertebral chemistry and good reproducibility among runs.

Linear vertebral growth rates were considerably higher during pre-parturition than postparturition, which made direct comparison between life history stages difficult (Fig. 4.6.2 and 4.6.3). Nonetheless, several general patterns were noteworthy. First, pre-parturition values were generally more variable, although not necessarily higher, than those following birth for all elements. Moreover, there were no obvious discontinuities in any of the elemental profiles that corresponded with the profiles at birth. One of the sharks (WS81) showed large peaks in $\mathrm{Pb} / \mathrm{Ca}$, $\mathrm{Hg} / \mathrm{Ca}$, and $\mathrm{U} / \mathrm{Ca}$ values that suggested significant heavy metal exposure well beyond that experienced by any of the other sharks. Two other sharks (WS105 and WS134) also showed elevated and correlated $\mathrm{Pb} / \mathrm{Ca}, \mathrm{Hg} / \mathrm{Ca}$, and $\mathrm{U} / \mathrm{Ca}$ values around the time of birth, although none were as high as WS81.

Post-parturition profiles of vertebral chemistry revealed variations over a number of different temporal scales (Figures 4.6.4d and 4.6.5d). Only one element ( $\mathrm{Sr} / \mathrm{Ca}$ ) showed a consistent trend with age (Fig. 4.6.4d and 4.6.5d), with values for both females and males declining throughout the shark lifespans. More commonly, elemental ratios showed oscillations with a range of periodicities from approximately 1-5 years. We observed high-frequency variations in $\mathrm{Li} / \mathrm{C}$ and $\mathrm{Mg} / \mathrm{Ca}$ ratios with periods of up to approximately 1 year in both females and males (Figures 4.6.4a,b and 4.6.5a, b). However, profiles for elements other than $\mathrm{Li} / \mathrm{Ca}$ and $\mathrm{Mg} / \mathrm{Ca}$ were characterized by oscillations at longer temporal scales of typically 3-5 years. One of the female sharks (WS134) displayed a pronounced pattern with high $\mathrm{Pb} / \mathrm{Ca}$ and $\mathrm{Hg} / \mathrm{Ca}$ levels at birth that declined through age 20, with another sharp peak in $\mathrm{Pb} / \mathrm{Ca}$ at age 32 (Figure 4.6.4f,g). The remaining female sharks, and all male sharks, displayed consistently low $\mathrm{Pb} / \mathrm{Ca}$ and $\mathrm{Hg} / \mathrm{Ca}$ values throughout their post-parturition lives (Figures 4.6.4f,g and 4.6.5f,g).

Finally, we produced correlations for all elemental ratio pairs to investigate if there may be common factors influencing vertebral composition of white sharks that would be manifested by significant correlations among elements (Table 4.5.2). The most consistent correlation was 
between $\mathrm{Pb} / \mathrm{Ca}$ and $\mathrm{Hg} / \mathrm{Ca}$ where correlations for seven sharks were significant and positive with $r$ values between 0.46 and 0.81 . Correlations were also significant and positive for $\mathrm{Ba} / \mathrm{Pb}$ for all except a single individual ( $r$ values ranging from 0.25 to 0.71 ). The remaining correlations among elements were either inconsistent (both positive and negative correlations for a single element pair) or insignificant.

\subsection{Discussion}

The geochemical records in white shark vertebrae represent a potentially powerful retrospective record of movement and trophic ecology of individuals throughout their lifetimes. However, several criteria need to be met before these profiles can be reliably used to recover life history information. Radiocarbon results provided the accurate chronology necessary to be able to place specific locations of vertebral material in time (Hamady et al. 2014, Chapter 2). Moreover, the fact that the amplitude of the bomb radiocarbon spike was accurately recorded in the vertebrae indicated that at least vertebral collagen is stable and metabolically inert after deposition. However, we still need to verify that the inorganic component of the vertebrae, where presumably at least some of elements are concentrated, is similarly stable. We found significant variability in elemental profiles both within and among profiles. These variations form the basis for revealing life history events in individual white sharks once we understand the mechanisms generating the observed elemental patterns.

A recent study lends support to the hypothesis that variations in at least some elemental ratios in round stingray vertebrae are generated by environmental variations experienced by individuals (Smith et al. 2013). The lack of clear changes in elemental ratios at female sexual maturity in our study, and similar patterns in a pregnant bull shark (Werry et al. 2011), further support the hypothesis that vertebral chemistry is predominantly dependent on the environment rather than by physiological status. Finally, Smith et al. (2013) noted that growth rates were not responsible for variation in elemental composition in round stingrays. Taken together, patterns of at least some elements in vertebral elemental composition likely reflect the physic-chemical properties of ambient water.

The elemental composition of otolith cores, formed during the embryonic stage of bony fishes, have been used in several studies to identify unique signatures for specific natal locations (e.g. Warner et al. 2005). In elasmobranchs, the part of the vertebral centrum below the birth band represents an analogous structure in ovoviviparous white sharks. Gestation estimates for 
white sharks range from a year to 18 months (Francis 1996). Based on the sharks in this study, there appears to be considerable variability in elemental deposition during this time period. Assuming that vertebrae record water chemistry or temperature (Smith et al. 2013) and that maternal influences and developmental effects are consistent over the pre-parturition growth period, white sharks experience relatively dynamic ocean chemistry while in utero. This may, in turn, reflect migratory behavior of the mother between different water masses, or it may reflect local elemental variability over seasonal time scales.

The relatively tight range in pre-parturition values for $\mathrm{Sr} / \mathrm{Ca}$ in females and $\mathrm{Mn} / \mathrm{Ca}$ in both females and males suggests a convergence in birthing location for northwest Atlantic white sharks. While little is known about their reproductive habits, catch records of young of the year near Cape Cod (Skomal 2007), and the larger region of the mid-Atlantic Bight (Casey and Pratt 1985 ) suggest a nursery area in these neritic waters. $\mathrm{Sr} / \mathrm{Ca}$ is not known to play a physiological role in fishes (Chowdhury and Blust 2012) and $\mathrm{Sr} / \mathrm{Ca}$ incorporation is not temperature-dependent in round stingrays (Smith et al. 2013), so variation in strontium values is most likely a function of dissolved $\mathrm{Sr} / \mathrm{Ca}$ levels in ambient water. In bony fishes (e.g. Secor \& Rooker 2000) and elasmobranchs (Werry et al. 2011, Tillett et al. 2011, Scharer et al. 2012), Sr/Ca values are usually positively correlated with changes in dissolved $\mathrm{Sr} / \mathrm{Ca}$ levels, which are in turn positively correlated with salinity. We found that $\mathrm{Sr} / \mathrm{Ca}$ values in white shark vertebrae were generally higher (all values $>1.8 \mu \mathrm{m} / \mathrm{mol}$ ) and less variable than those experienced by smalltooth sawfish in Florida (all values $<2 \mu \mathrm{m} / \mathrm{mol}$ ) that migrate between estuarine and coastal habitats. This pattern is again consistent with the hypothesis that vertebral $\mathrm{Sr} / \mathrm{Ca}$ is positively correlated with dissolved Sr/Ca levels (Tillett et al. 2011, Werry et al. 2011). However, it is likely that other elements are not causally linked to concentrations in the environment. For instance, manganese is an essential micronutrient enzymatic co-factor, playing an important role in many metabolic processes. Diet is the major contributor of Mn in elasmobranchs (Pentreath 1973), with less than $10 \%$ accumulation in soft tissues coming from uptake from seawater (Mathews et al. 2008). A convergence of $\mathrm{Mn}$ values at the time of birth in white sharks may indicate mediation by a physiological mechanism perhaps associated with hormones or development. Further studies to clarify the mechanisms of Mn incorporation are clearly needed.

The high levels of heavy metals in post-parturition samples from WS134 compared to the other individuals may reflect differences in habitat use. Oceanic $\mathrm{Pb}$ values are primarily due to 
natural dust deposition (Bergquist \& Boyle 2006) and deposition from anthropogenic sources like leaded gasoline burning and high-temperature industrial processes (Boyle et al. 1986, Wu \& Boyle 1997), which are latitudinally dispersed by prevailing wind patterns (Flegal \& Patterson 1983). However, for coastal locations, continental runoff has been found to be more important than atmospheric deposition (Couture et al. 2010) and advection of trace metal enriched water masses off of continental margins has been found to be important (Chever et al. 2010). The correlations between $\mathrm{Pb}$ and the other heavy metals suggest that water pollution may play a role in these signals in the vertebrae. The Atlantic seaboard has a large population living close to the coast, industrial activity, and minimal wetlands, all of which have contributed to poor benthic conditions, high levels of fish tissue contaminants, and fair water and sediment quality according to the latest EPA National Coastal Condition Report (2012). Ocean chemistry, especially for non-conservative scavenged-type elements like $\mathrm{Pb}$ (Flegal \& Patterson 1983), depends on changes in source input and can change dramatically on timescales from a week to several months (Boyle et al. 1986). Therefore, the extremely high heavy metal peak in WS81 preparturition, followed by non-detectable levels, may indicate residency around the time of birth in a nearshore environment following a particularly intense runoff or sediment re-suspension event, and then movement to and residency in an offshore area with minimal terrestrial input. One possible location is Long Island Sound, which has considerable $\mathrm{Pb}$ contamination in sediments especially in the western Sound (Mecray and Buchholtz ten Brink 2000). This also correlates with sightings as the greatest numbers of juvenile white sharks seen in the northwest Atlantic have been in the Sandy Hook/Western Long Island area (Casey and Pratt 1985). Post-parturition, WS134 had much higher lead levels than any of the other sharks until maturity, with a regular sawtooth pattern with a period of about every 3 years after age 2, and an overall declining trend (Figure 4.4f). If $\mathrm{Pb}$ is an indication of nearshore residency, this contrasts with WS134's stable isotope data from Chapter 3, which suggested residency in offshore waters. Dust input to open ocean waters from North Africa is one possible explanation (Prospero and Nees 1986). Dust from a known source region in Mali was found to have elevated lead concentrations, which were found in locations in the Caribbean following dust transport events, along with pesticides, microorganisms, and other pollutants (Garrison et al. 2006). However, further work is needed to test this hypothesis.

Based on the currently limited tagging data from northwest Atlantic white sharks, the lack 
of regular annual fluctuations in elements is not necessarily surprising. Tagged sharks have thus far not performed any regular, fixed pattern migrations (G. Skomal, pers. comm.), but the sample size in terms of both number of sharks and years of observation is low. In better studied white shark populations, males in the northeast Pacific appear to return to the Farallones in California annually, while the females return biannually (Anderson and Pyle 2003), and off Guadalupe Island in Baja Mexico, large females make return trips at multi year intervals (Domeier and Nasby-Lucas 2007). The cyclical patterns in many of the elements in our study could, therefore, reflect biannual or multi-year migrations between water masses with different chemical characteristics. For example, barium incorporation into round stingray vertebrae is strongly negatively correlated with temperature (Smith et al. 2013). The more extreme fluctuations in $\mathrm{Ba} / \mathrm{Ca}$ in some individuals (e.g. WS81, WS134, WS105) may reflect movements between warmer and cooler waters. Temperature also negatively affects $\mathrm{Mg}$ (Smith et al. 2013), and these two elements showed a significant correlation in five of the eight sharks (Table 4.2). However, without water chemistry data and a better idea of possible movements, it is difficult to narrow down where these migrations may be. Ba uptake is also dependent on water concentration, so this interaction with temperature may mediate the correlation.

The application of elemental chemistry to elasmobranch vertebrae is a new and developing area of research. Characterization of the unique chemical signatures in different water masses in the northwest Atlantic would allow for more specific interpretation of elemental signatures in white sharks and other fish species.

Manipulative experiments similar to those conducted by Smith et al. (2013) on pregnant female elasmobranchs are necessary to determine affects of in-utero exposure to elements. Additional manipulative experiments that should be performed include investigating trace metals like $\mathrm{Pb}, \mathrm{Hg}$, and $\mathrm{U}$, and their correlations with other elements. $\mathrm{Pb}$ isotopes may also prove interesting because different sources like leaded gasoline, wastewater treatment, metal refineries, and coal burning all have different ratios of ${ }^{206} \mathrm{~Pb} /{ }^{207} \mathrm{~Pb}$ which can be used to fingerprint sources of runoff, and therefore possible locations of residency (Spencer et al. 2000, Couture et al. 2010). 


\subsubsection{Collection and sampling information}

FL: fork length, M: mature, I: immature.

\begin{tabular}{cccccc}
\hline Shark & Year collected & $\begin{array}{c}\text { FL } \\
(\mathbf{c m})\end{array}$ & Sex & Maturity & $\begin{array}{c}\text { Bomb } \\
\Delta^{\mathbf{1 4}} \text { C Age }\end{array}$ \\
\hline WS28 & 1967 & 220.9 & $\mathrm{~F}$ & N/A & 6 \\
WS81 & 1983 & 526 & $\mathrm{~F}$ & N/A & 40 \\
WS117 & 1988 & 330 & $\mathrm{~F}$ & N/A & 21 \\
WS134 & 1996 & 495.3 & $\mathrm{~F}$ & N/A & 32 \\
WS57 & 1981 & 442 & $\mathrm{M}$ & $\mathrm{M}$ & 44 \\
WS100 & 1968 & 223.5 & $\mathrm{M}$ & $\mathrm{N} / \mathrm{A}$ & 9 \\
WS105 & 1986 & 493 & $\mathrm{M}$ & $\mathrm{M}$ & 73 \\
WS143 & 2010 & 222.2 & $\mathrm{M}$ & $\mathrm{I}$ & 14 \\
\hline
\end{tabular}




\subsubsection{Elemental correlations}

Grey highlights significant correlations at Bonferroni corrected $\mathrm{p}<0.05$.

\begin{tabular}{ccccccccc}
$\mathbf{C o r r e l a t i o n}$ & $\mathbf{W S 1 4 3}$ & $\mathbf{W S 1 0 0}$ & $\mathbf{W S 5 7}$ & $\mathbf{W S 1 0 5}$ & $\mathbf{W S 1 3 4}$ & $\mathbf{W S 1 1 7}$ & $\mathbf{W S 2 8}$ & WS81 \\
\hline \hline $\mathbf{L i} / \mathbf{M g}$ & -0.178 & -0.057 & -0.482 & -0.576 & 0.067 & 0.024 & 0.184 & -0.584 \\
$\mathbf{L i} / \mathbf{M n}$ & 0.129 & 0.300 & -0.032 & 0.292 & -0.079 & 0.192 & 0.940 & -0.589 \\
$\mathbf{L i} / \mathbf{S r}$ & -0.198 & 0.164 & 0.657 & 0.350 & 0.059 & 0.116 & 0.018 & 0.687 \\
$\mathbf{L i} / \mathbf{B a}$ & 0.328 & -0.577 & -0.266 & 0.436 & 0.254 & 0.096 & -0.131 & 0.016 \\
$\mathbf{L i} / \mathbf{P b}$ & 0.554 & -0.272 & -0.282 & 0.435 & -0.166 & 0.282 & -0.438 & $\mathrm{NA}$ \\
$\mathbf{L i} / \mathbf{H g}$ & 0.237 & -0.326 & 0.036 & 0.373 & -0.097 & 0.260 & -0.600 & $\mathrm{NA}$ \\
$\mathbf{L i} / \mathbf{U}$ & 0.300 & -0.469 & -0.099 & -0.539 & -0.043 & -0.274 & -0.138 & $\mathrm{NA}$ \\
$\mathbf{M g} / \mathbf{M n}$ & -0.310 & 0.346 & 0.428 & 0.218 & 0.249 & 0.220 & 0.258 & 0.469 \\
$\mathbf{M g} / \mathbf{S r}$ & -0.035 & 0.151 & -0.009 & 0.151 & -0.092 & 0.411 & 0.041 & -0.474 \\
$\mathbf{M g} / \mathbf{B a}$ & 0.208 & 0.408 & 0.675 & -0.430 & 0.178 & 0.315 & 0.395 & 0.030 \\
$\mathbf{M g} / \mathbf{P b}$ & -0.074 & -0.020 & 0.687 & 0.205 & 0.571 & 0.243 & 0.223 & NA \\
$\mathbf{M g} / \mathbf{H g}$ & -0.512 & 0.138 & 0.532 & 0.190 & 0.545 & -0.086 & -0.327 & NA \\
$\mathbf{M g} / \mathbf{U}$ & 0.504 & -0.092 & -0.068 & 0.288 & 0.490 & -0.197 & 0.492 & NA \\
$\mathbf{M n} / \mathbf{S r}$ & -0.224 & 0.195 & 0.396 & 0.507 & 0.063 & 0.028 & -0.094 & -0.605 \\
$\mathbf{M n} / \mathbf{B a}$ & -0.277 & 0.281 & 0.566 & 0.202 & -0.026 & 0.414 & -0.068 & 0.063 \\
$\mathbf{M n} / \mathbf{P b}$ & 0.189 & -0.025 & 0.485 & 0.667 & 0.202 & 0.428 & -0.404 & NA \\
$\mathbf{M n} / \mathbf{H g}$ & 0.371 & 0.193 & 0.538 & 0.577 & 0.354 & 0.327 & -0.683 & NA \\
$\mathbf{M n} / \mathbf{U}$ & -0.096 & -0.122 & 0.172 & -0.200 & 0.184 & -0.142 & -0.043 & NA \\
$\mathbf{S r} / \mathbf{B a}$ & -0.464 & -0.164 & 0.247 & 0.303 & 0.101 & 0.375 & -0.099 & -0.121 \\
$\mathbf{S r} / \mathbf{P b}$ & -0.324 & -0.437 & 0.151 & 0.493 & 0.040 & -0.065 & -0.332 & NA \\
$\mathbf{S r} / \mathbf{H g}$ & 0.251 & -0.253 & 0.459 & -0.296 & 0.231 & -0.194 & -0.081 & NA \\
$\mathbf{S r} / \mathbf{U}$ & -0.032 & -0.436 & -0.023 & 0.254 & 0.237 & -0.411 & -0.086 & NA \\
$\mathbf{B a} / \mathbf{P b}$ & 0.313 & 0.437 & 0.711 & 0.254 & -0.135 & 0.559 & 0.444 & NA \\
$\mathbf{B a} / \mathbf{H g}$ & -0.319 & 0.644 & 0.626 & 0.049 & -0.130 & 0.420 & 0.233 & NA \\
$\mathbf{B a} / \mathbf{U}$ & 0.511 & 0.540 & -0.074 & -0.248 & 0.420 & 0.056 & 0.696 & NA \\
$\mathbf{P b} / \mathbf{H g}$ & 0.461 & 0.787 & 0.657 & 0.525 & 0.716 & 0.819 & 0.515 & NA \\
$\mathbf{P b} / \mathbf{U}$ & 0.271 & 0.834 & -0.082 & -0.295 & 0.405 & 0.141 & 0.504 & NA \\
$\mathbf{H g} / \mathbf{U}$ & -0.146 & 0.686 & -0.052 & -0.246 & 0.323 & 0.228 & 0.259 & NA \\
\hline $\mathbf{N =}$ & 112 & 100 & 421 & 575 & 534 & 174 & 73 & 388
\end{tabular}




\subsubsection{Example of parallel transects of elemental ratios}

Plotted by age from WS143 with a LOESS curve through the complete lifelong transect (blue circles), with parallel transect plotted in green. Ratios measured in $\mathrm{mol} / \mathrm{mol}$.

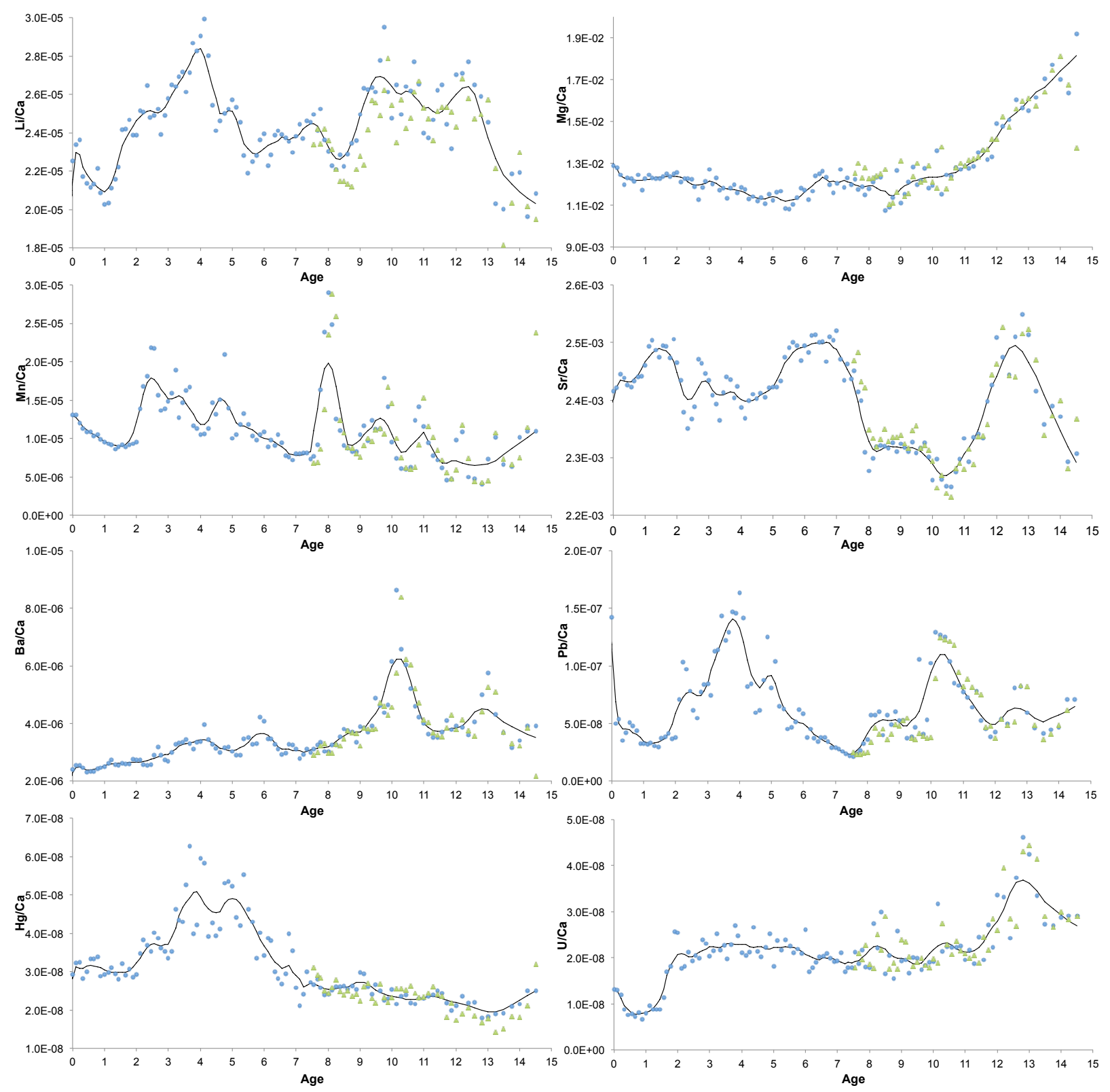




\subsection{2: Female pre-parturition white shark elemental transects}

Without smoothing, from pre-parturition through one year of age by spot number, where zero denotes birth. Different spot numbers pre- and post-parturition are due to differential vertebral growth. Gaps in transects were either bracketed by blanks and/or standards with issues, or contained negative values, signifying measurements below the detection limit. Listed by element: A) Li:Ca, B) Mg:Ca, C) Mn:Ca, D) Sr:Ca, E) Ba:Ca, F) Pb:Ca, G) Hg:Ca, and H) U:Ca. Ratios measured in $\mathrm{mol} / \mathrm{mol}$.

\subsection{2a}

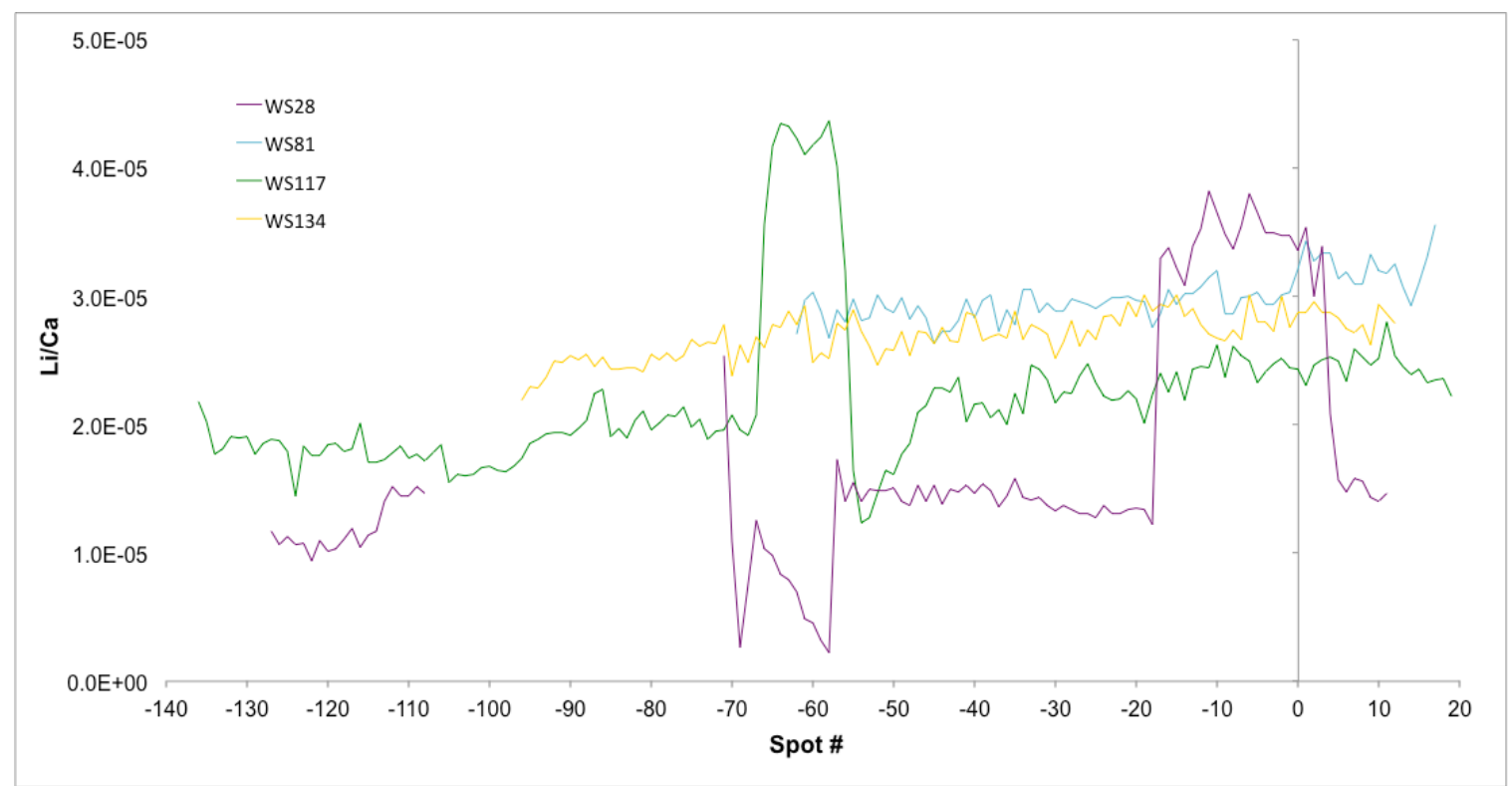

\subsection{2b}

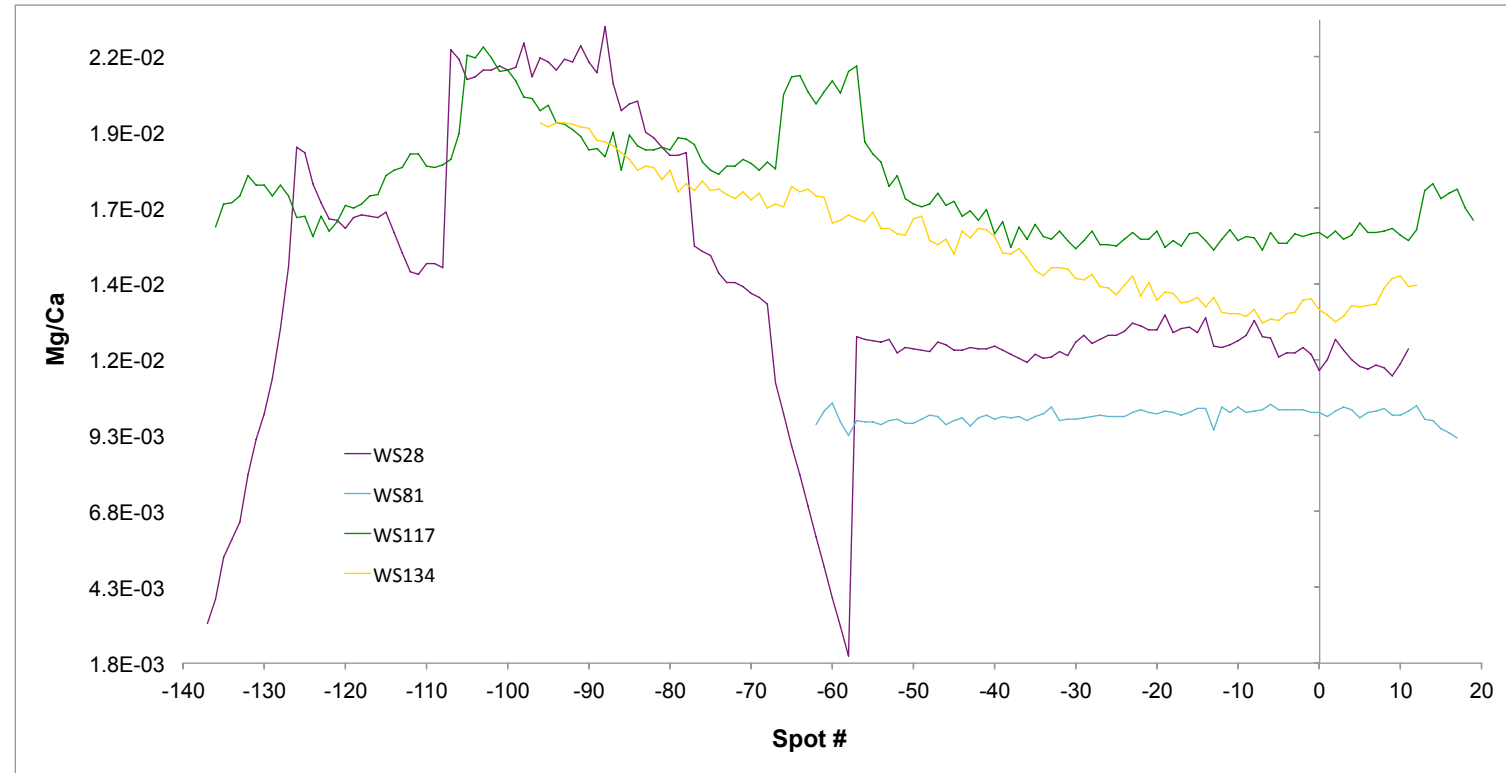




\subsection{2c}

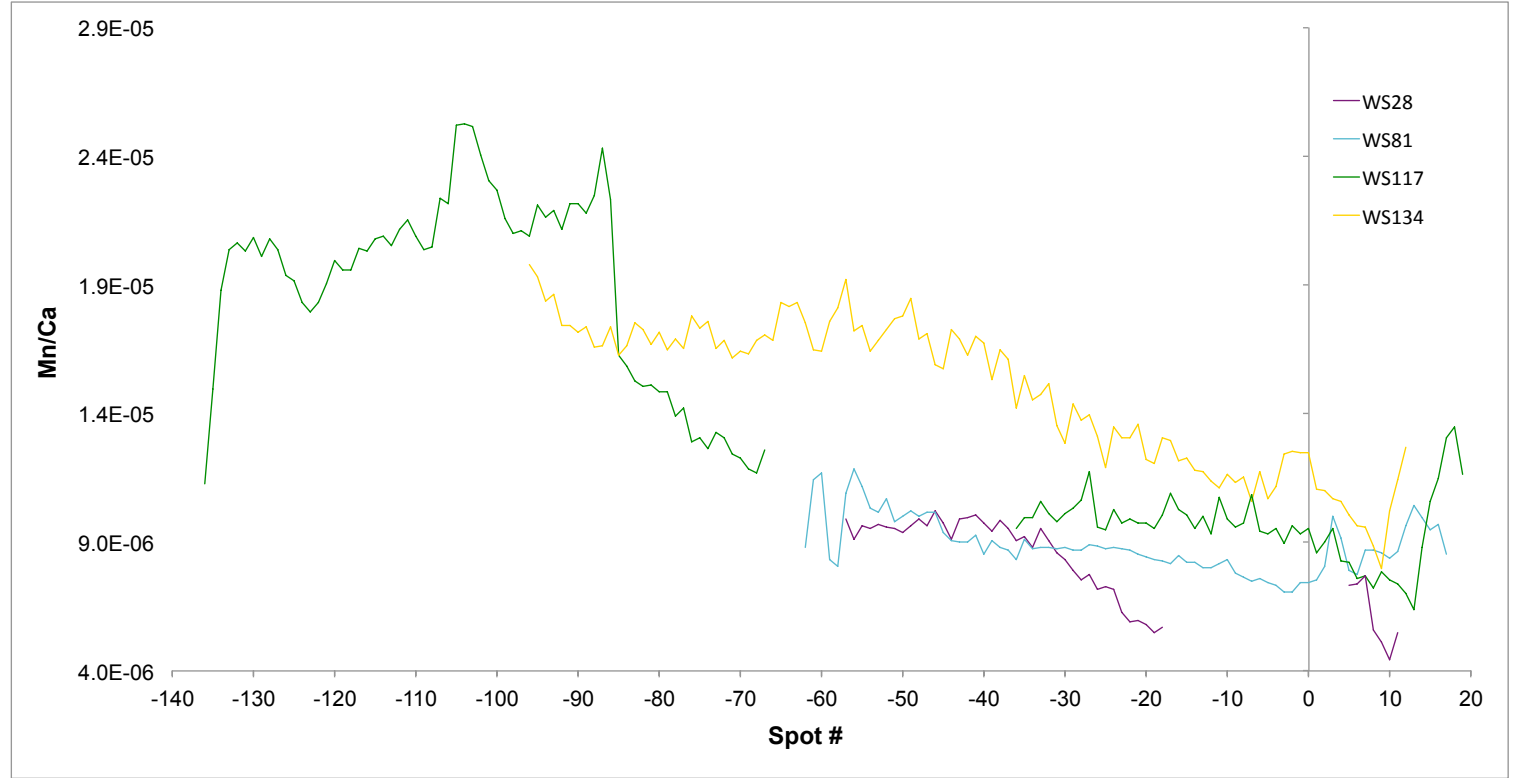

\subsection{2d}

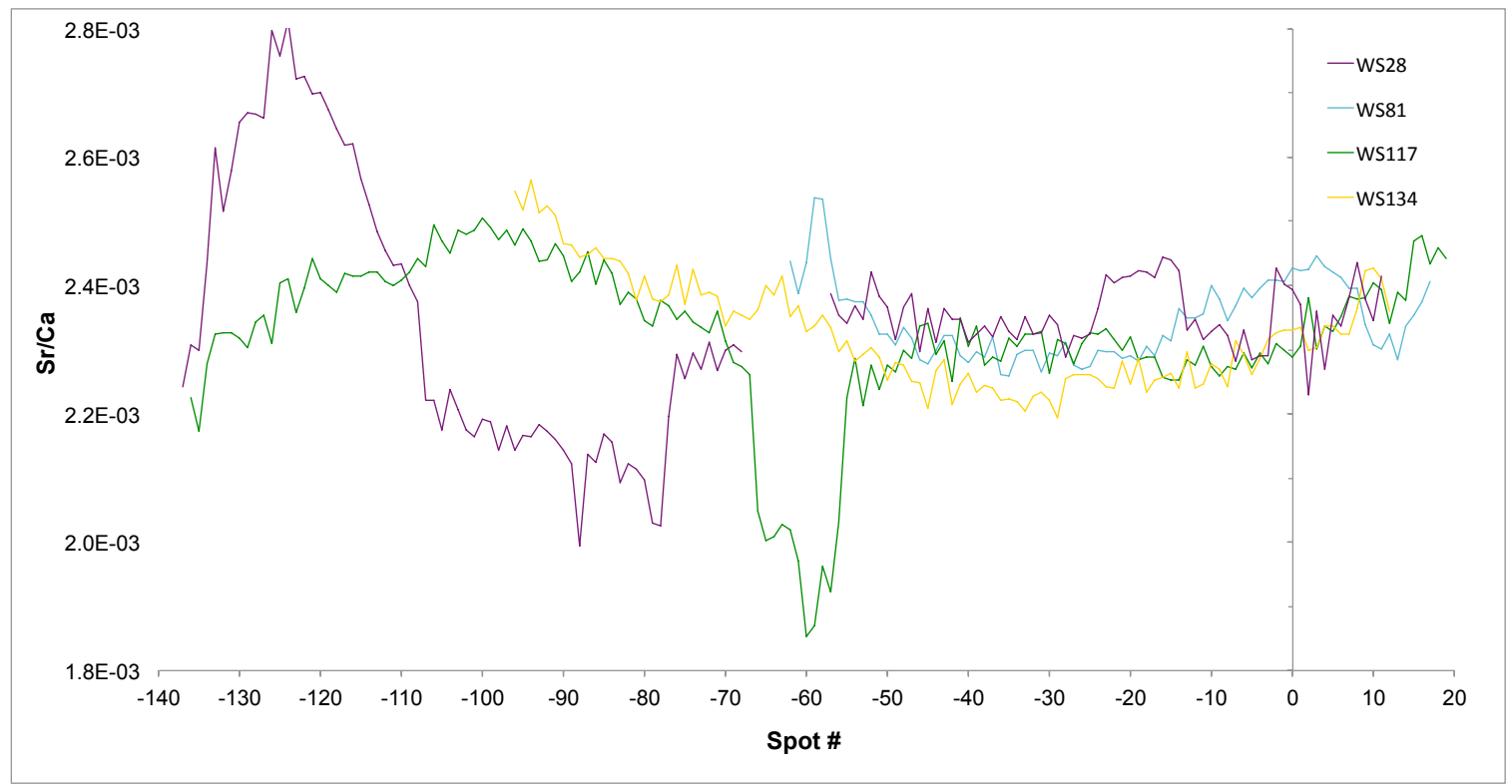


4.6.2e

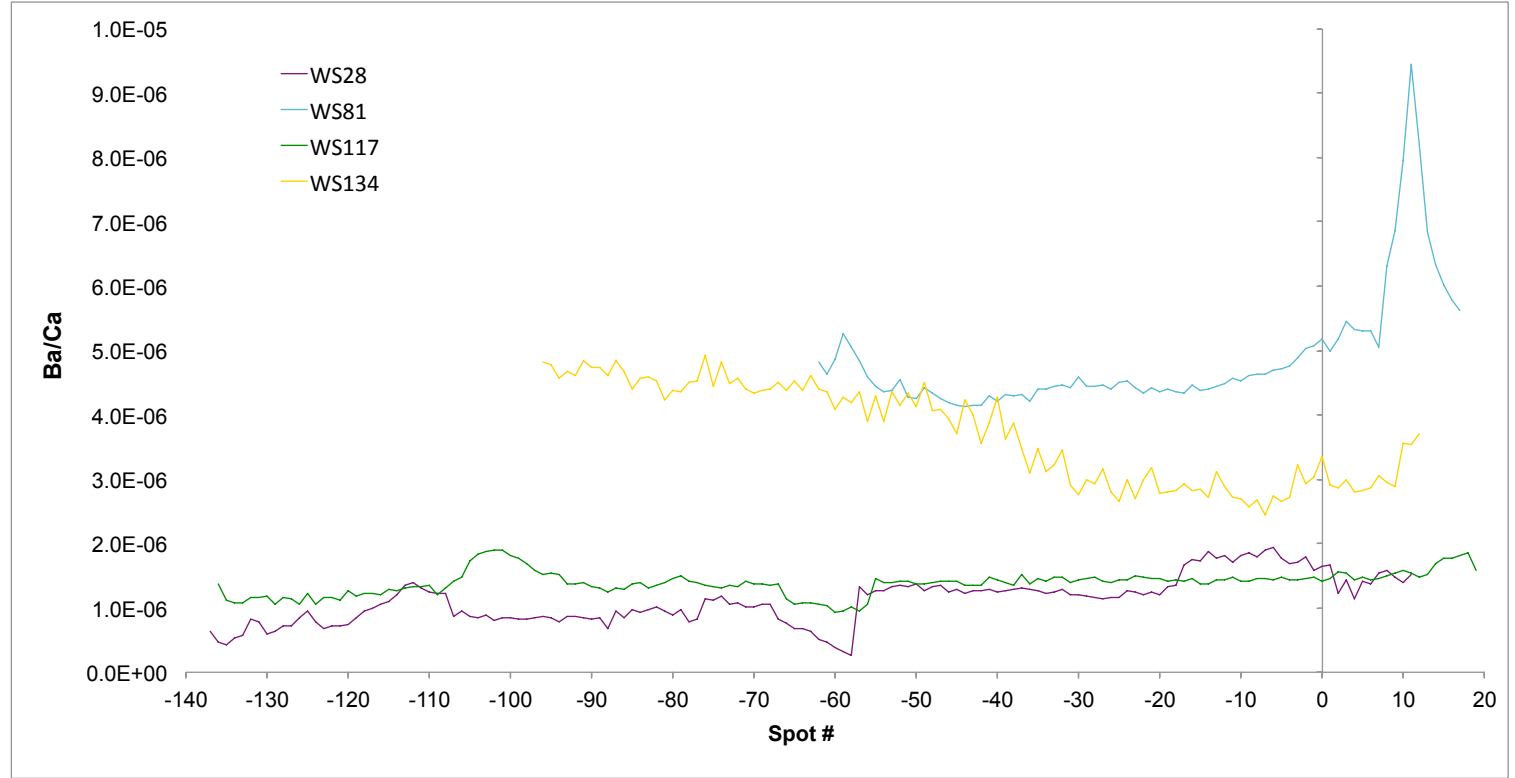

4.6.2f Note the different $y$-axis range on inset graph.

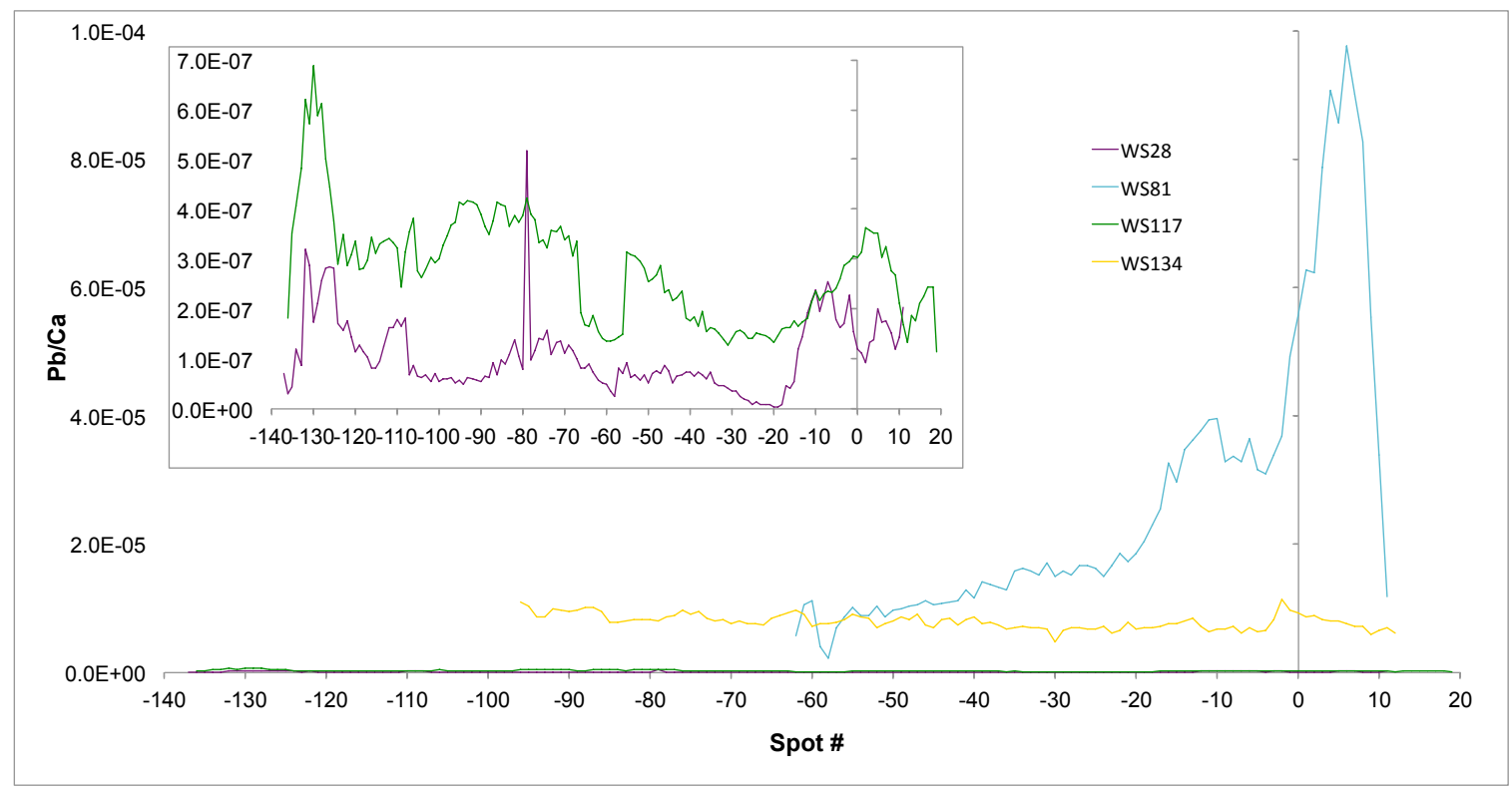


4.6.2g Note the different $y$-axis range on inset graph.

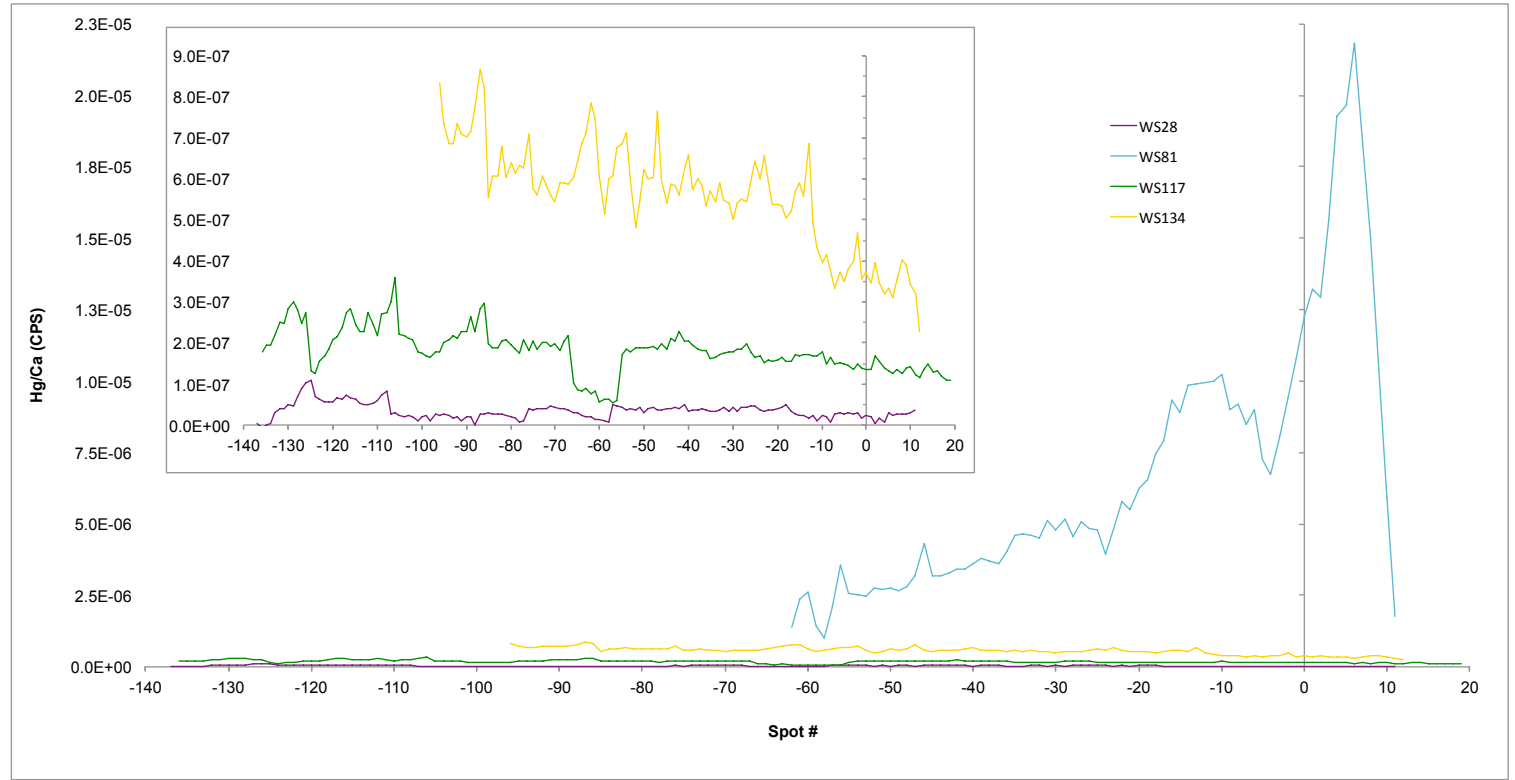

4.6.2h Note the different $y$-axis range on inset graph.

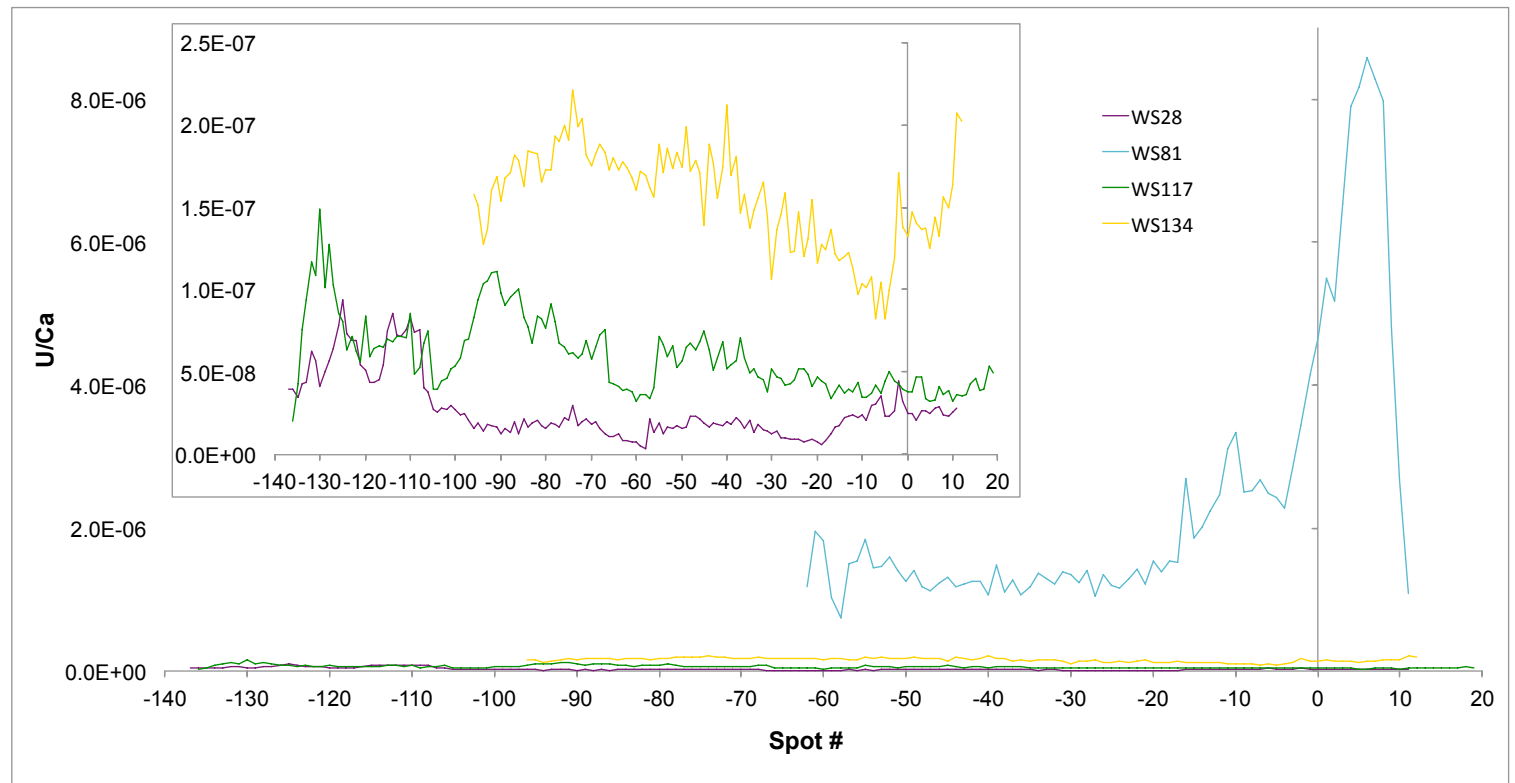




\subsection{3: Male pre-parturition white shark elemental transects}

Without smoothing, from pre-parturition through one year of age by spot number, where zero denotes birth. Different spot numbers pre- and post-parturition are due to differential vertebral growth. Gaps in transects were either bracketed by blanks and/or standards with issues, or contained negative values, signifying measurements below the detection limit. Listed by element: A) Li:Ca, B) Mg:Ca, C) Mn:Ca, D) Sr:Ca, E) Ba:Ca, F) Pb:Ca, G) Hg:Ca, and H) U:Ca. Ratios measured in $\mathrm{mol} / \mathrm{mol}$.

\subsection{3a}

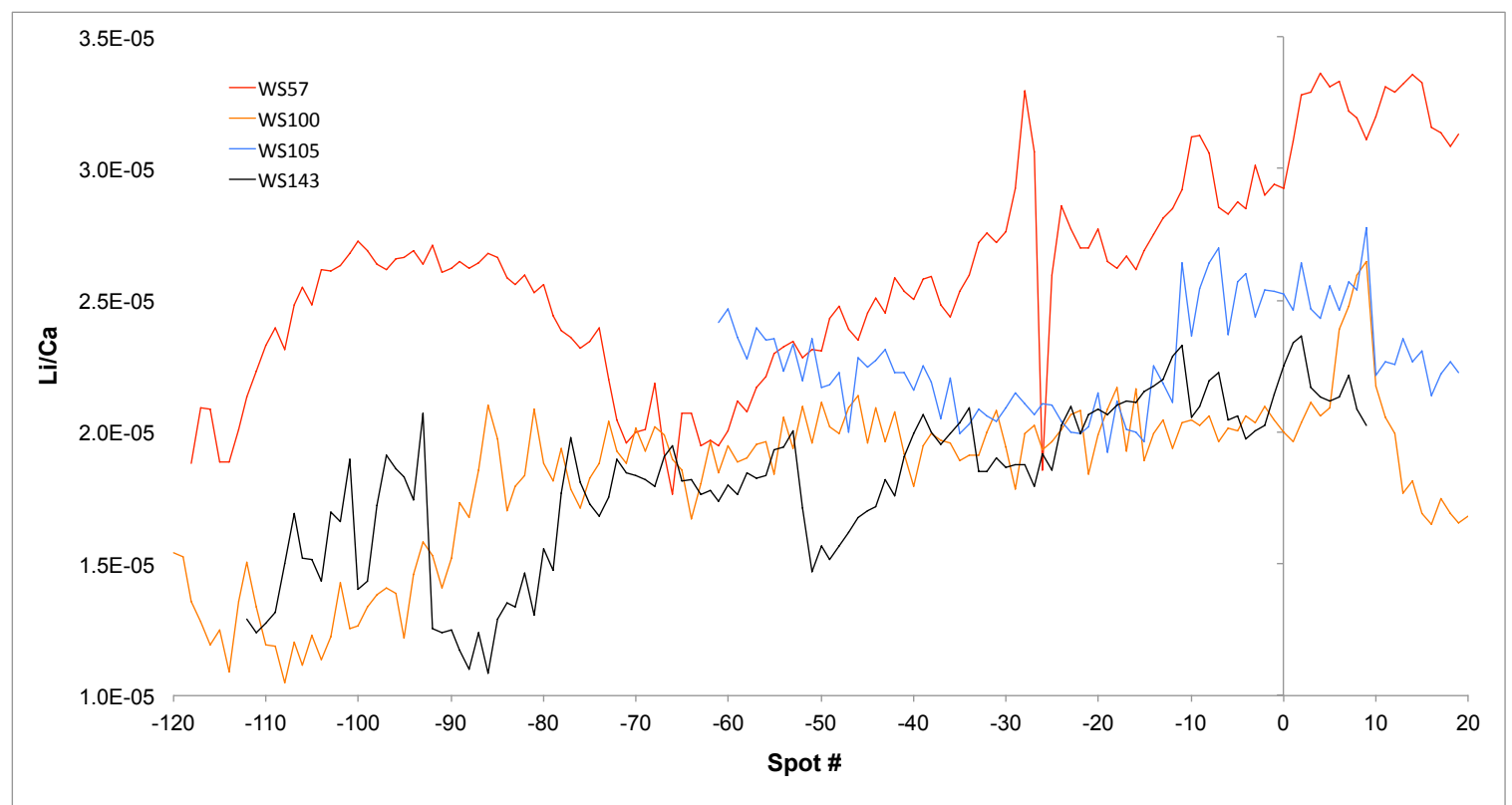

\subsection{3b}

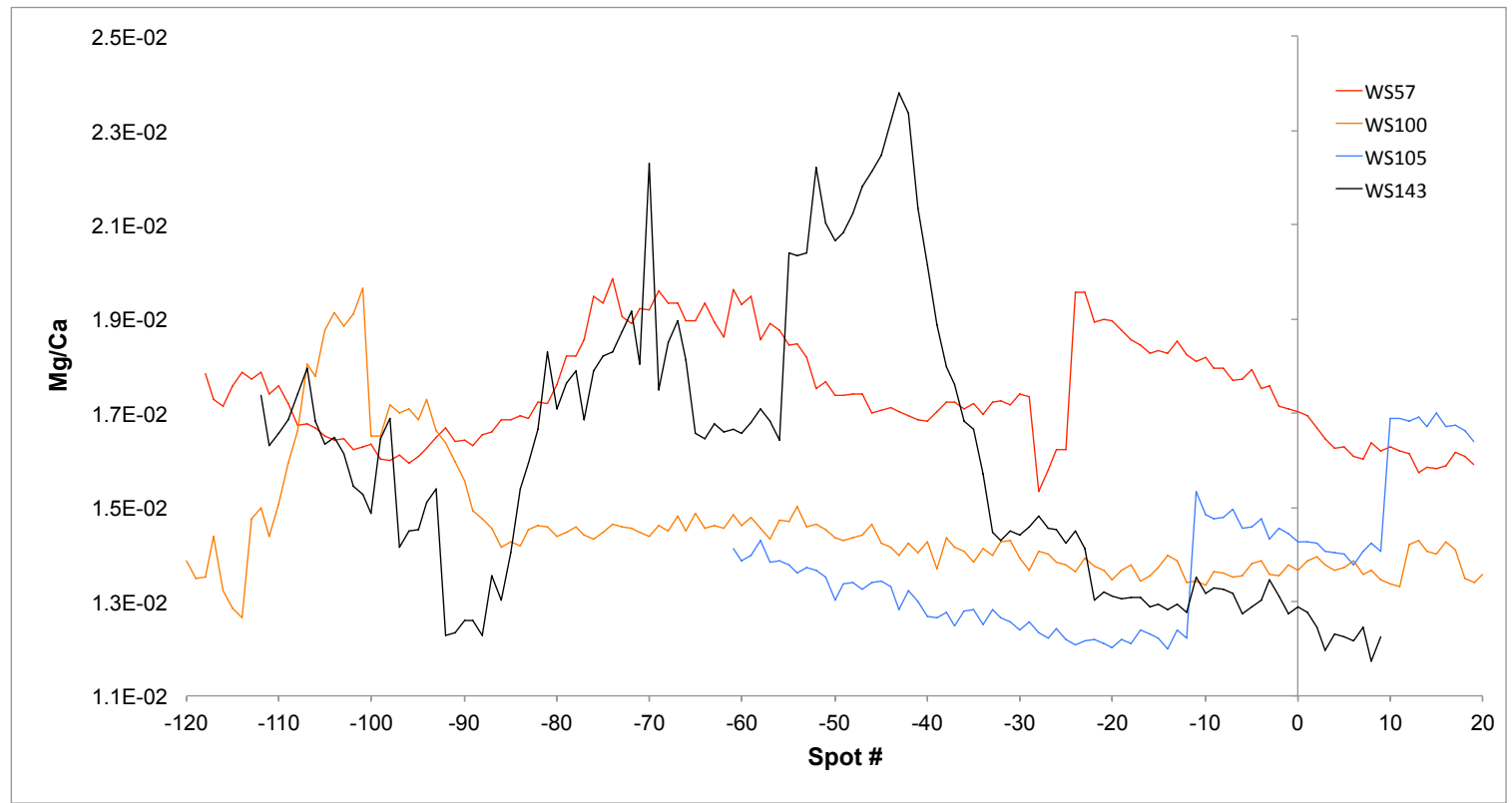




\subsection{3c}

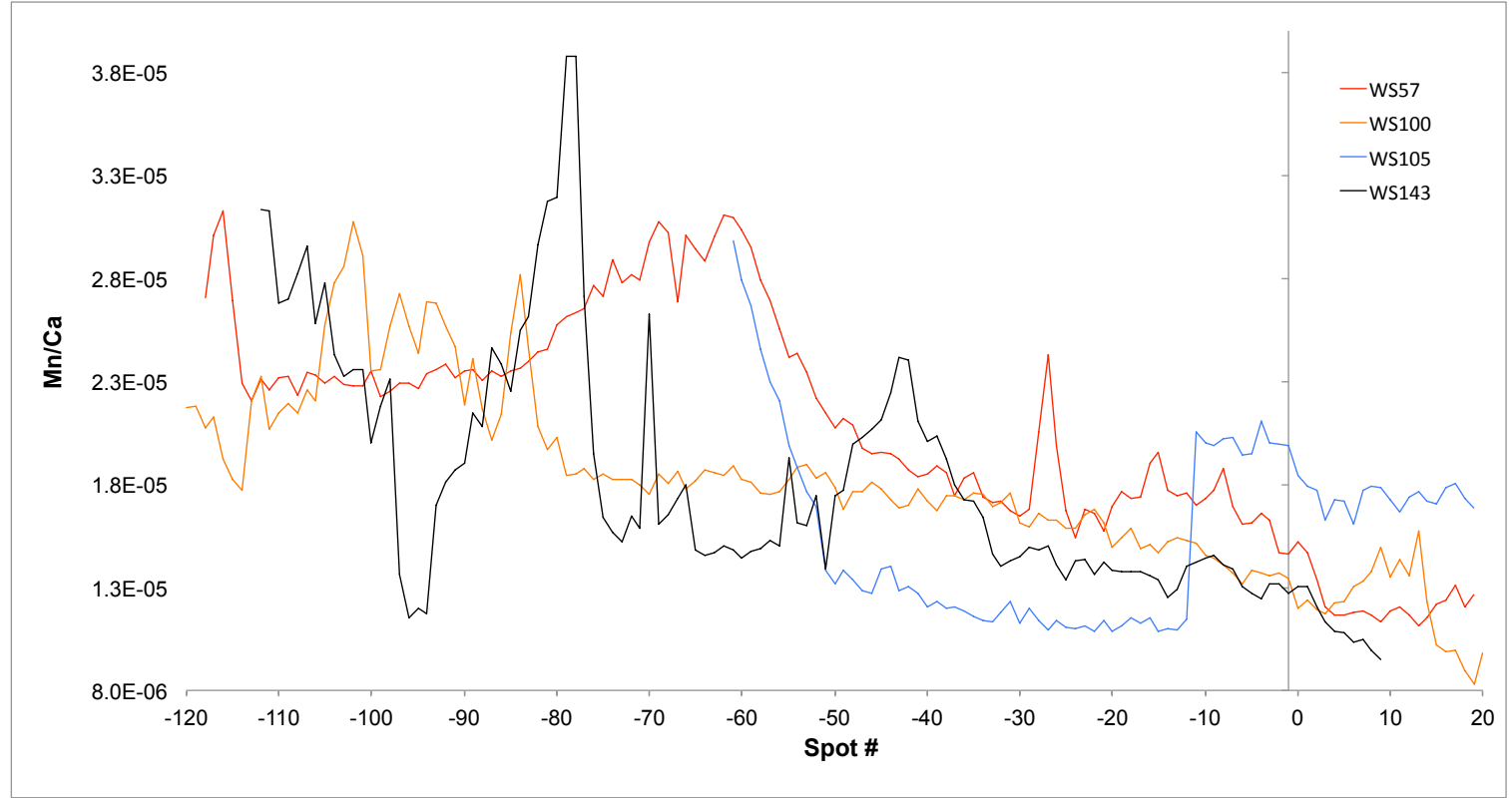

4.6.3d

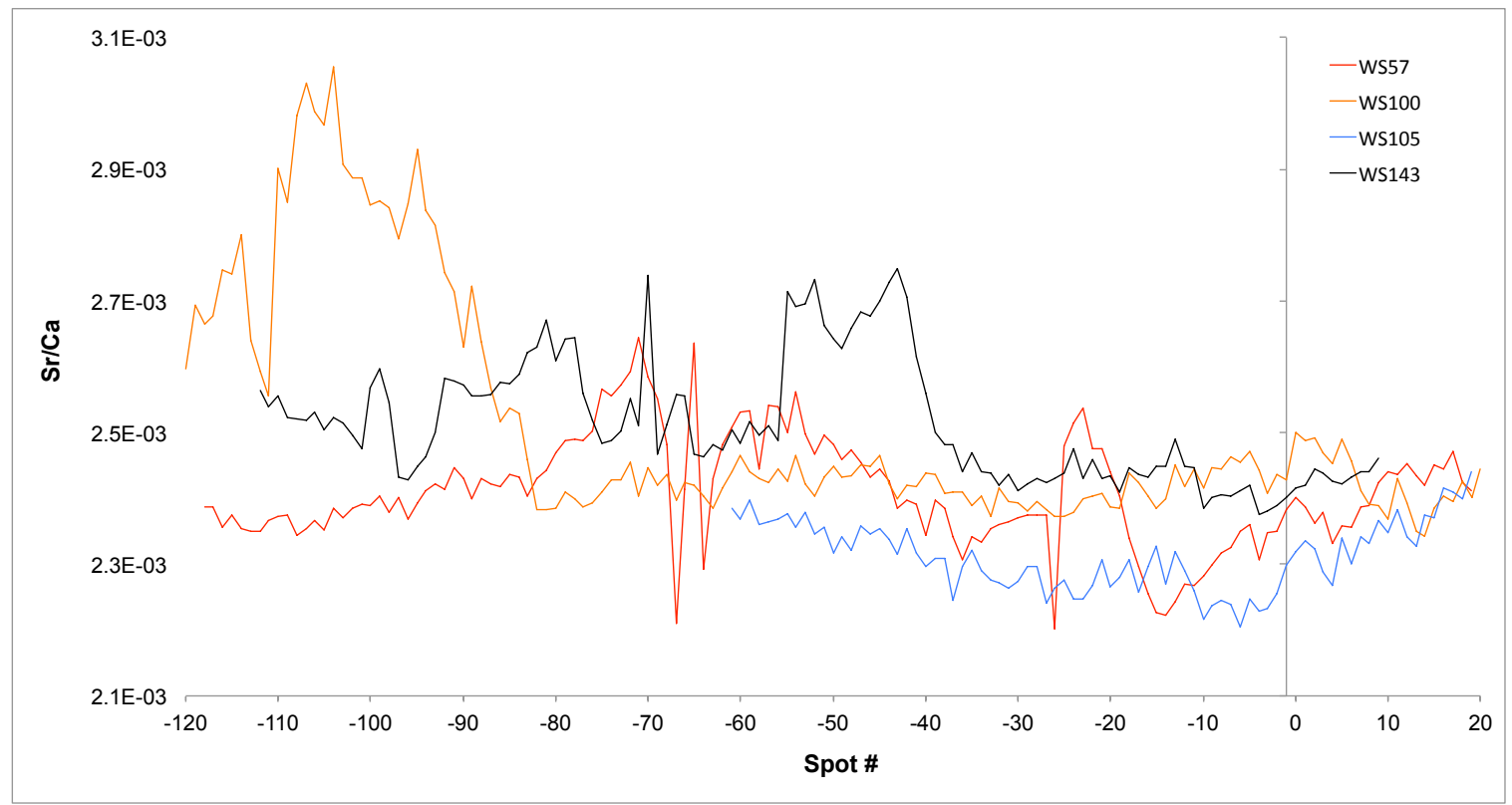




\subsection{3e}

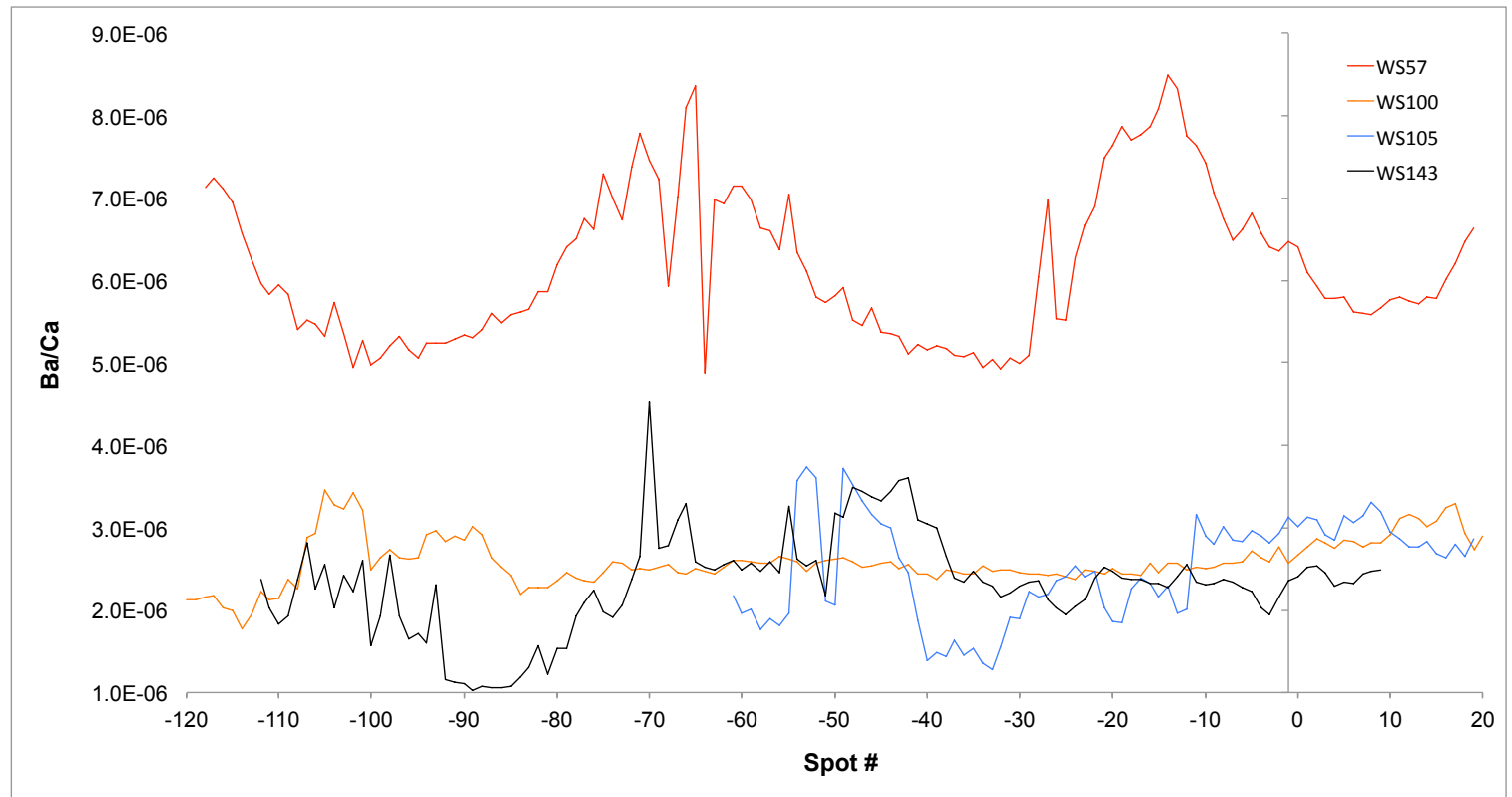

4.6.3f

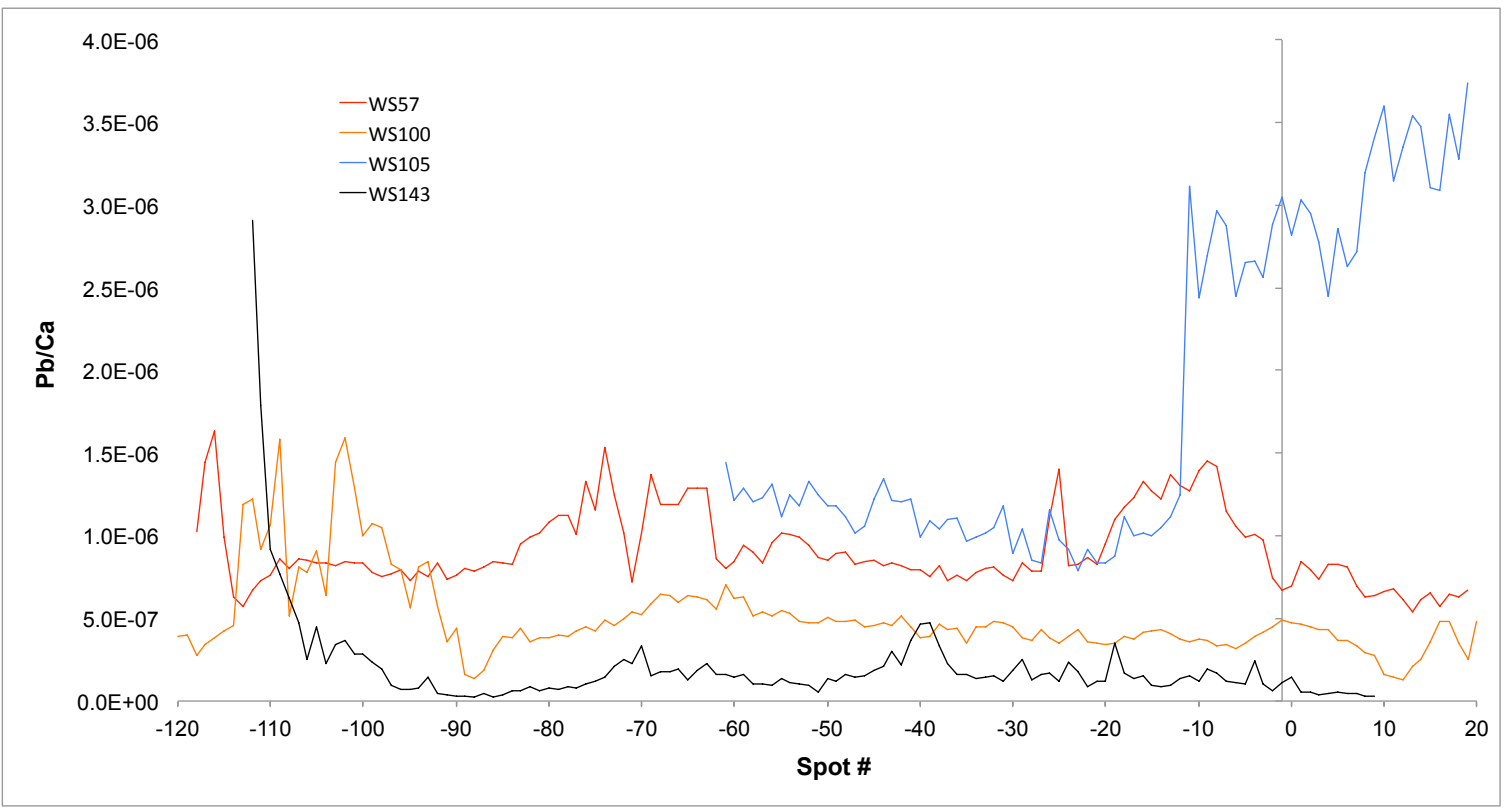




\subsection{3g}

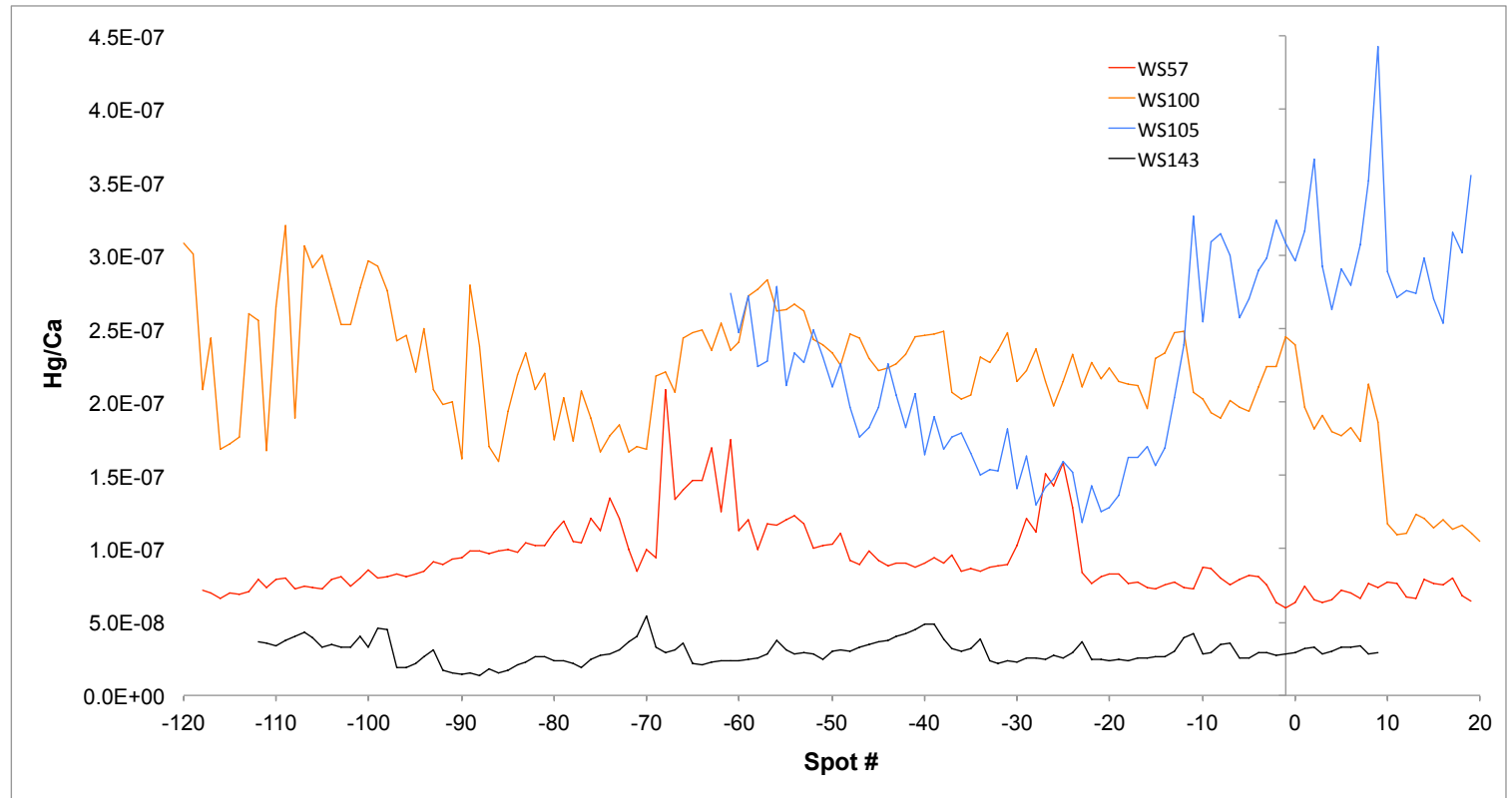

\subsection{3h}

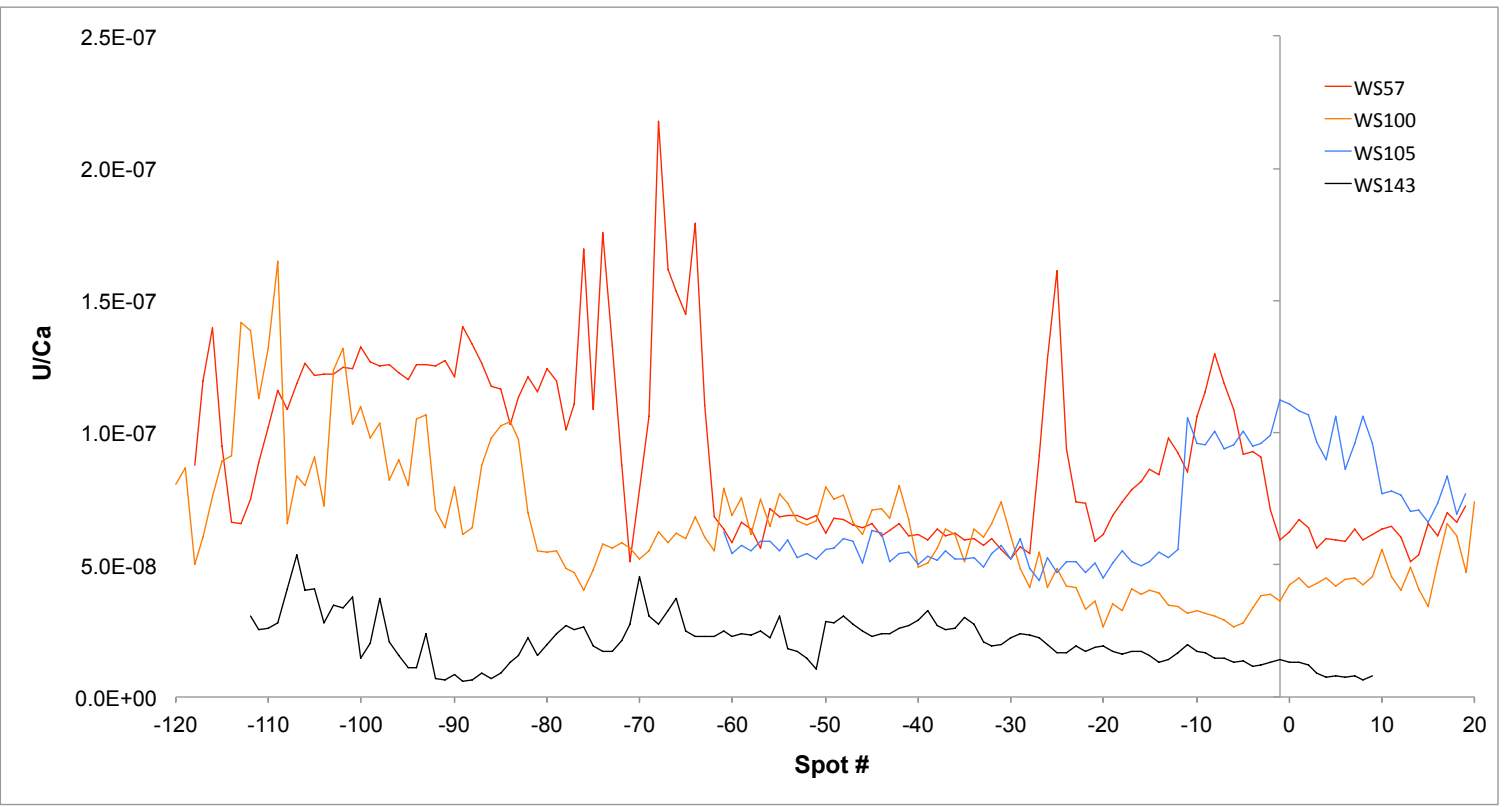




\subsection{4: Female lifetime white shark elemental transects}

Without smoothing. Gaps in transects were either bracketed by blanks and/or standards with issues, or contained negative values, signifying measurements below the detection limit. Listed by element: a) Li:Ca, b) Mg:Ca, c) Mn:Ca, d) $\mathrm{Sr}: \mathrm{Ca}$, e) $\mathrm{Ba}: \mathrm{Ca}, \mathrm{f}) \mathrm{Pb}: \mathrm{Ca}, \mathrm{g}) \mathrm{Hg}: \mathrm{Ca}$, and h) U:Ca. Ratios measured in $\mathrm{mol} / \mathrm{mol}$.

\subsection{4a}

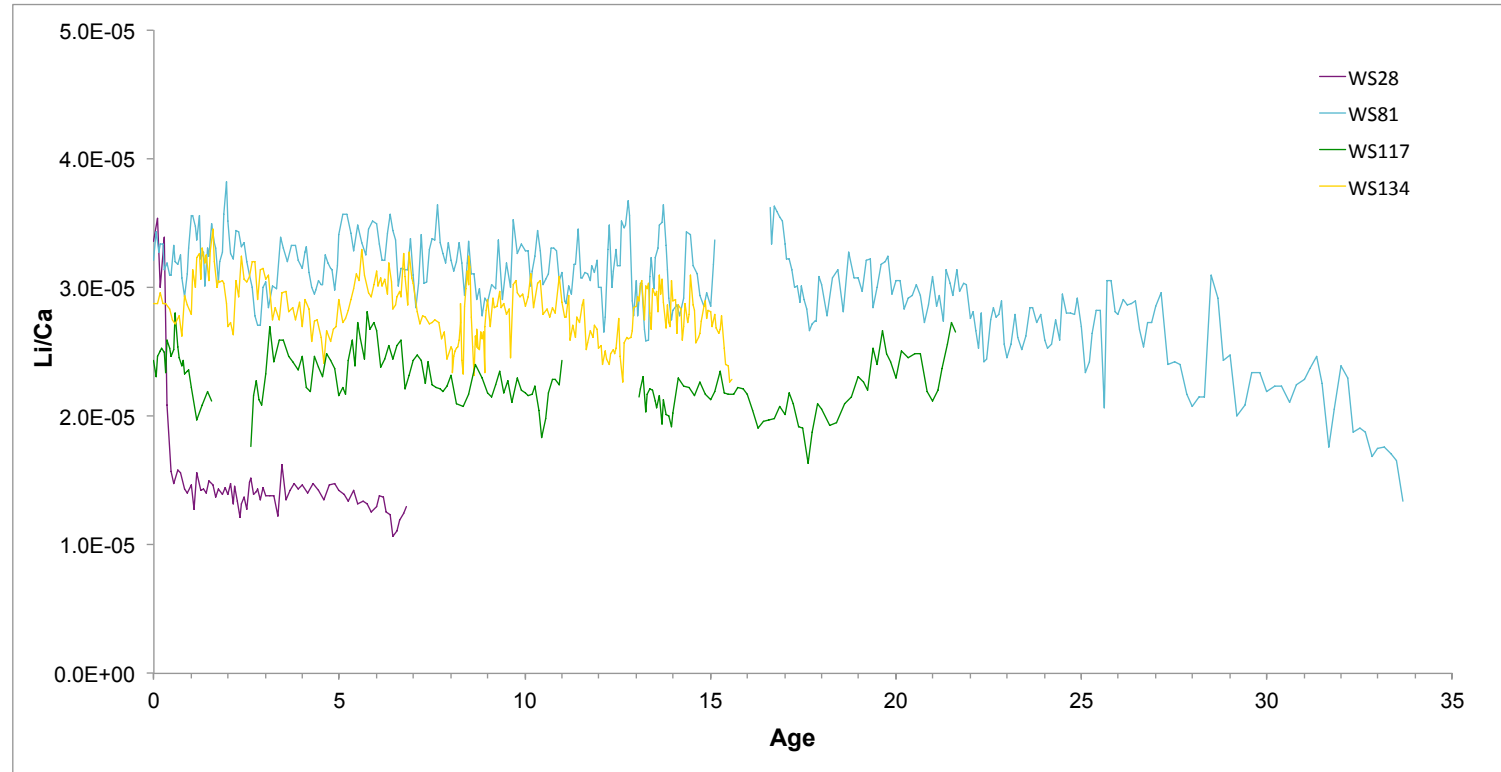

\subsection{4b}

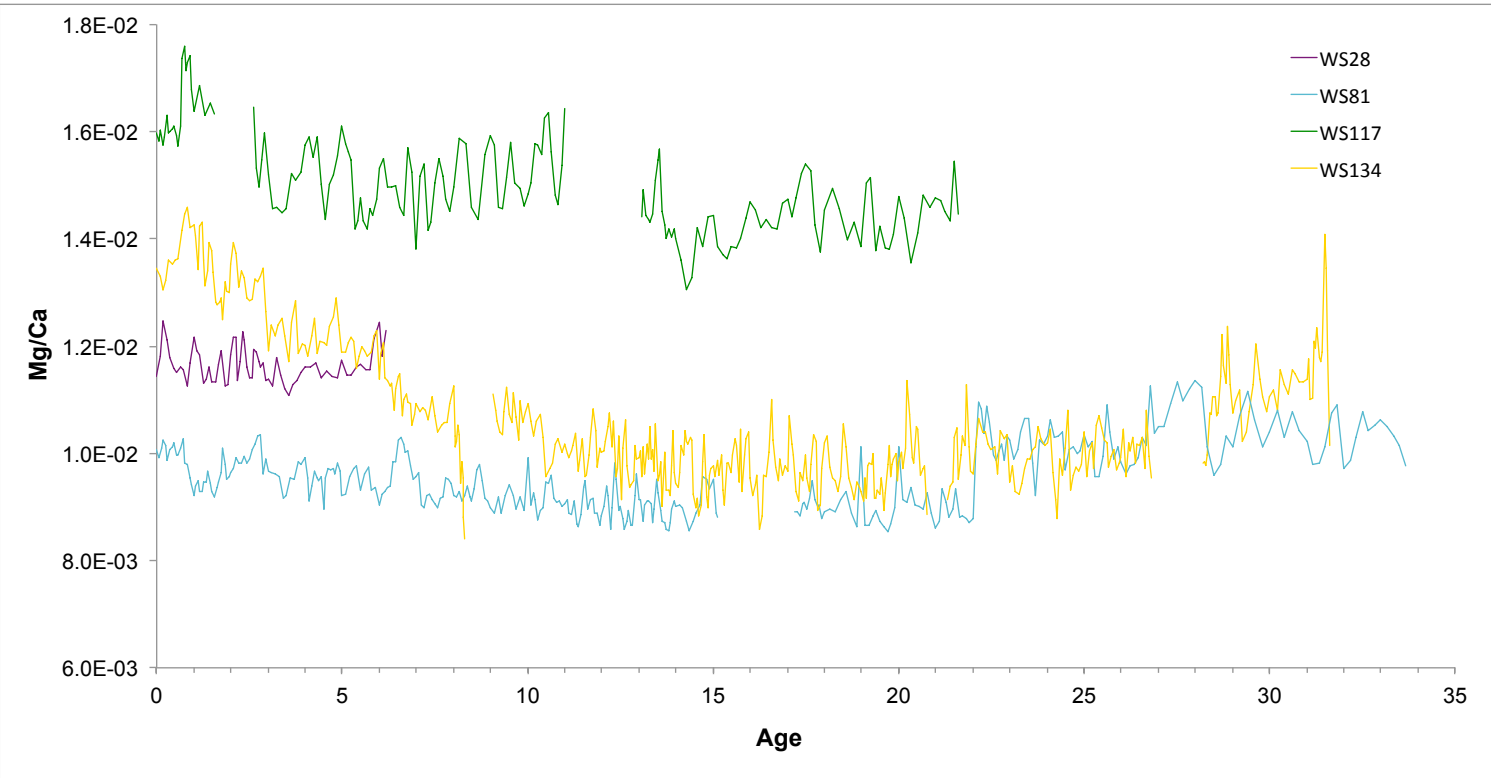




\subsection{4c}

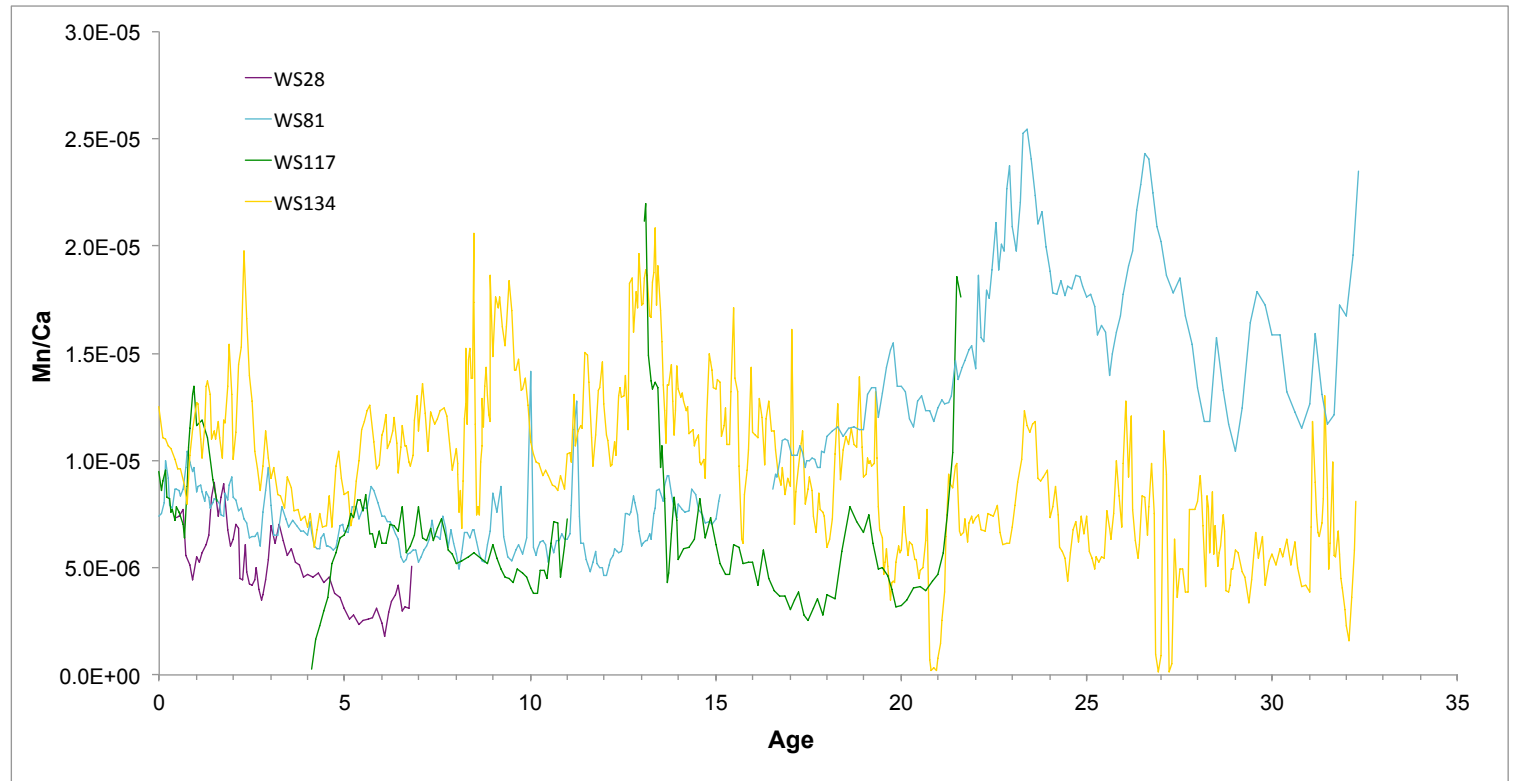

\subsection{4d}

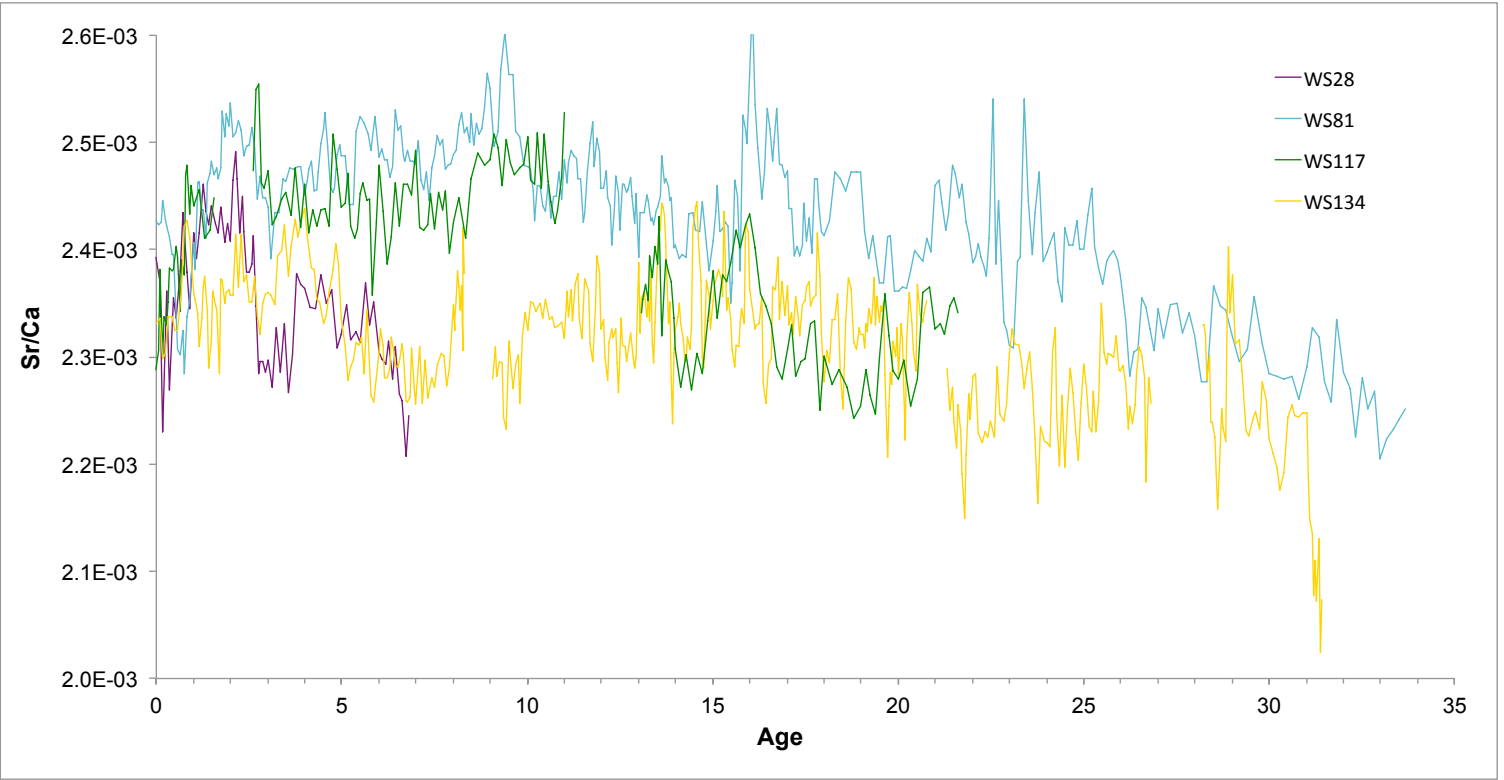




\subsection{4e}

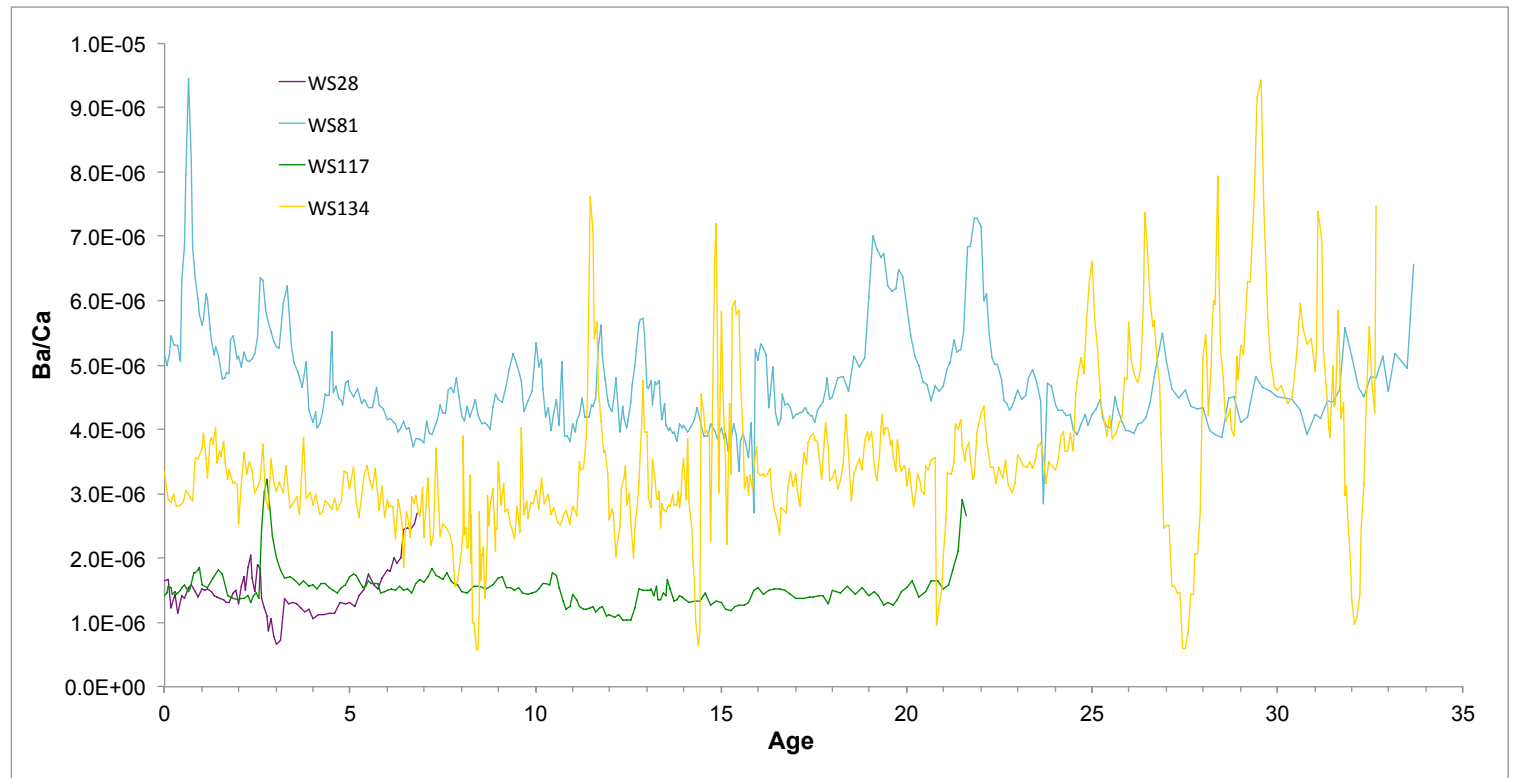

4.6.4f Note the different y-axis range on inset graph. Besides values within the first year (see Figure 4.6.2f), elemental levels for WS81 were consistently below the blank values, precluding their inclusion on the plot.

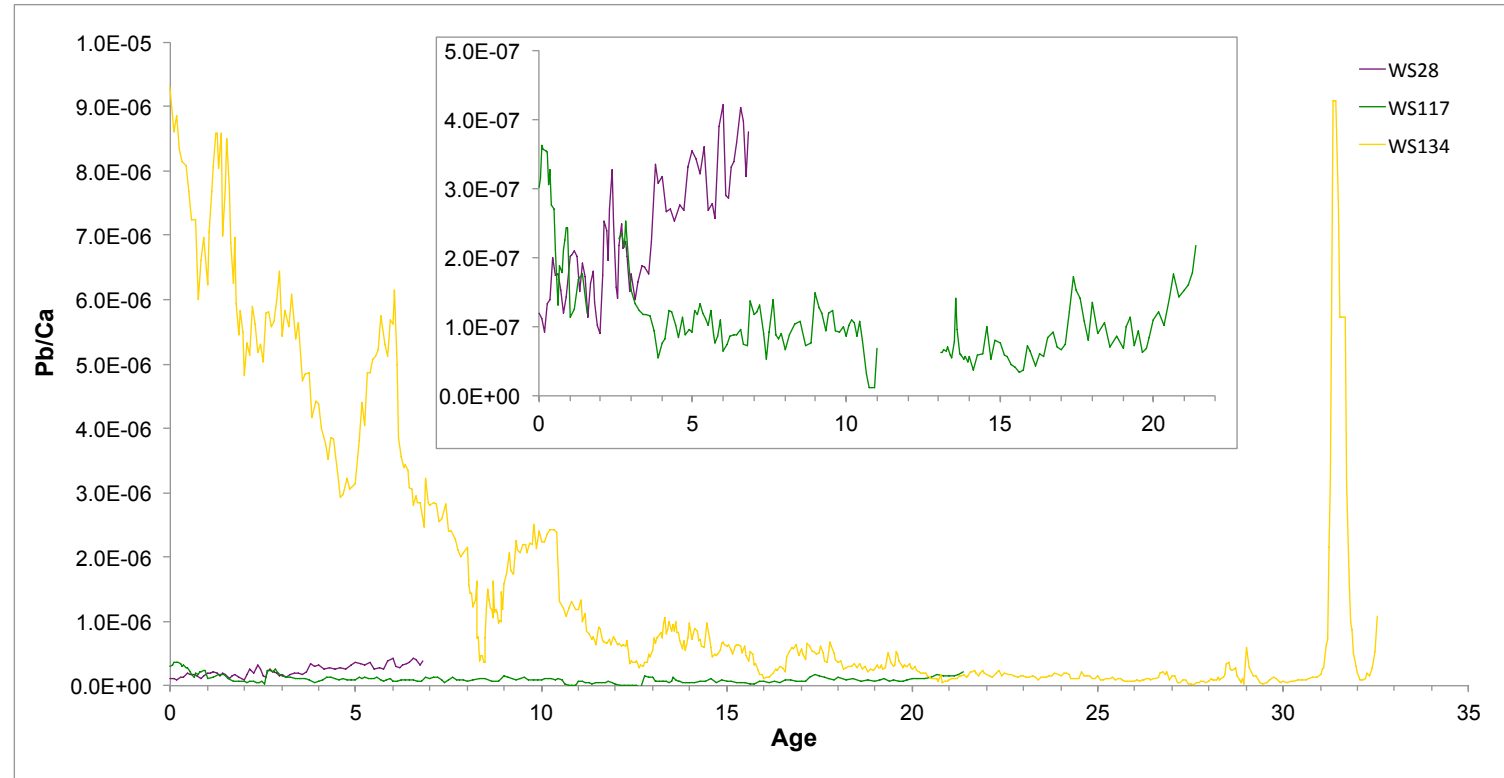


4.6.4g Note the different y-axis range on inset graph. Besides values within the first year (see Figure 4.6.2g), elemental levels for WS81 were consistently below the blank values, precluding their inclusion on the plot.

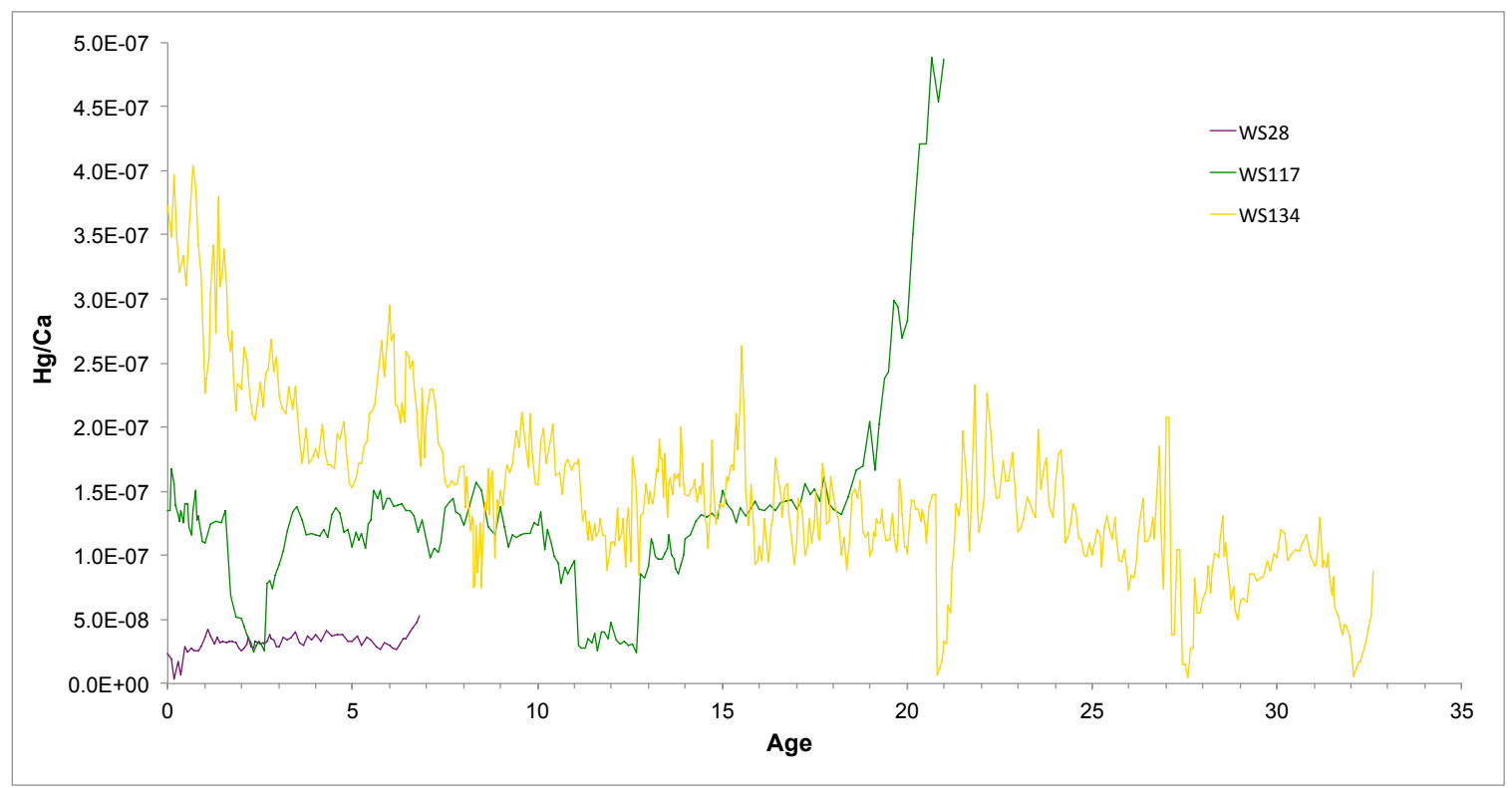

4.6.4h Note the different y-axis range on inset graph. Besides values within the first year (see Figure 4.6.2h), elemental levels for WS81 were consistently below the blank values, precluding their inclusion on the plot

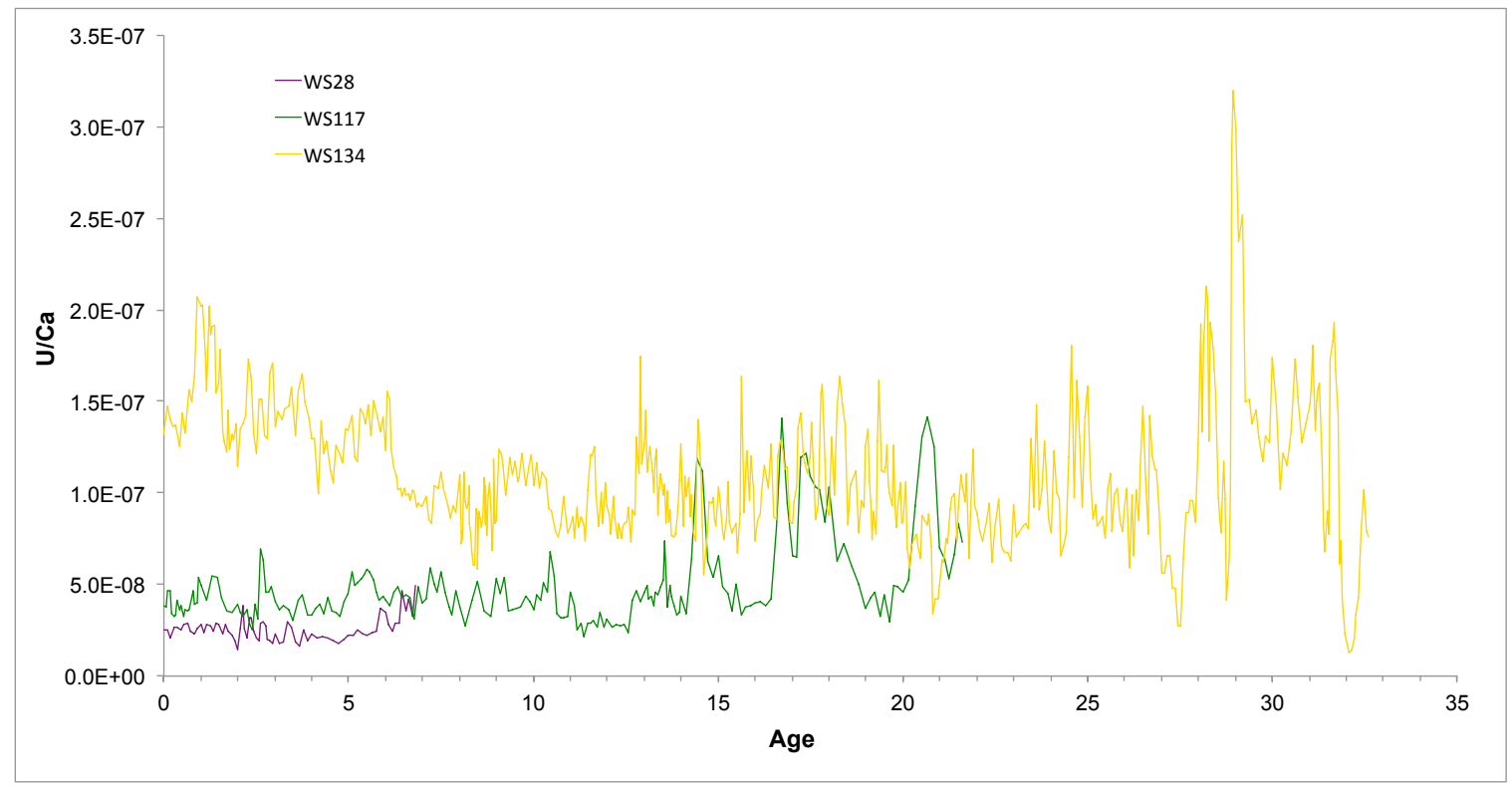




\subsection{5: Male lifetime white shark elemental transects}

Without smoothing. Gaps in transects were either bracketed by blanks and/or standards with issues, or contained negative values, signifying measurements below the detection limit. Listed by element: a) Li:Ca, b) Mg:Ca, c) Mn:Ca, d) $\mathrm{Sr}: \mathrm{Ca}$, e) $\mathrm{Ba}: \mathrm{Ca}, \mathrm{f}) \mathrm{Pb}: \mathrm{Ca}, \mathrm{g}) \mathrm{Hg}: \mathrm{Ca}$, and h) U:Ca. Ratios measured in $\mathrm{mol} / \mathrm{mol}$.

\subsection{5a}

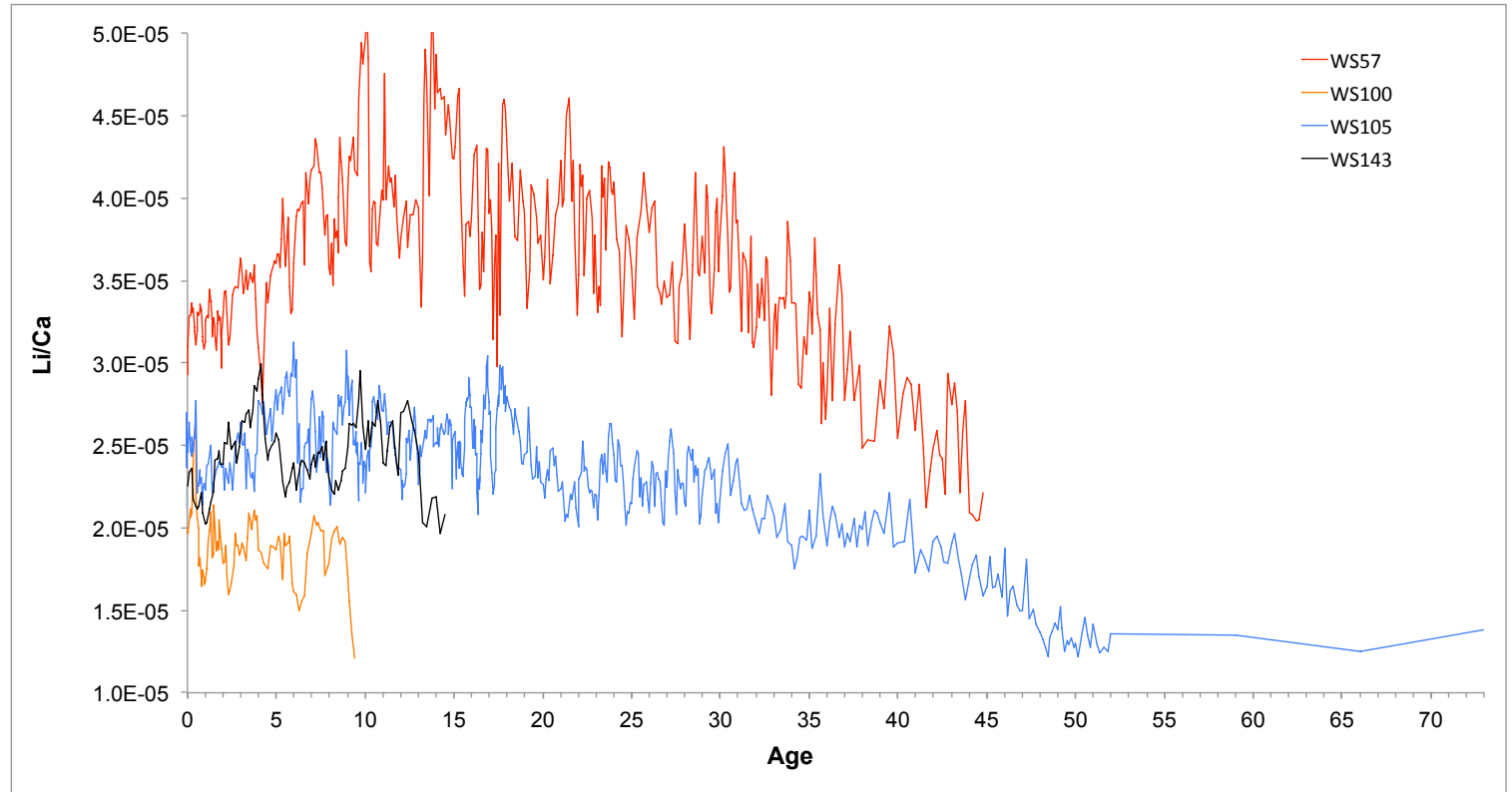

\subsection{5b}

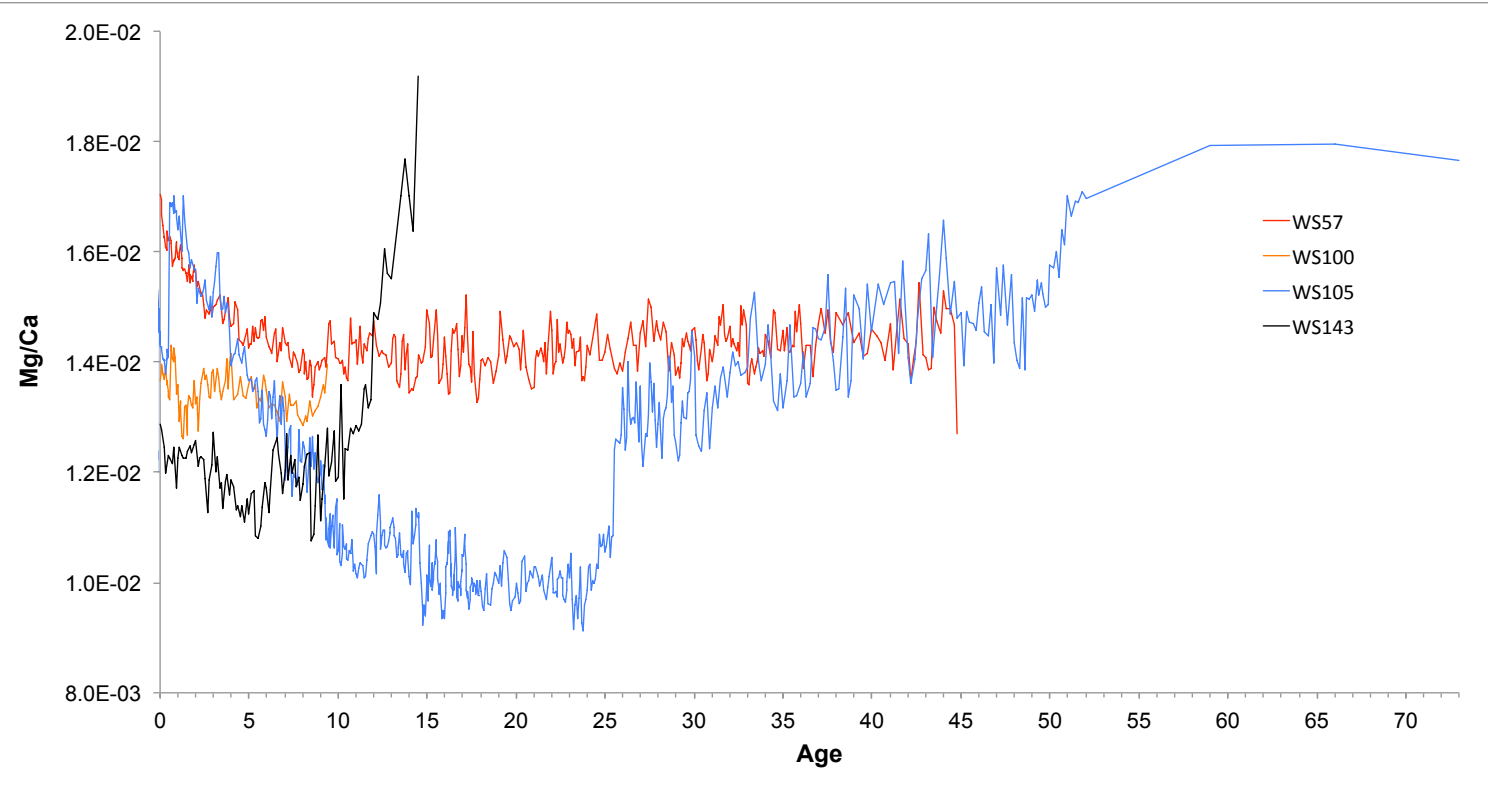




\subsection{5c}

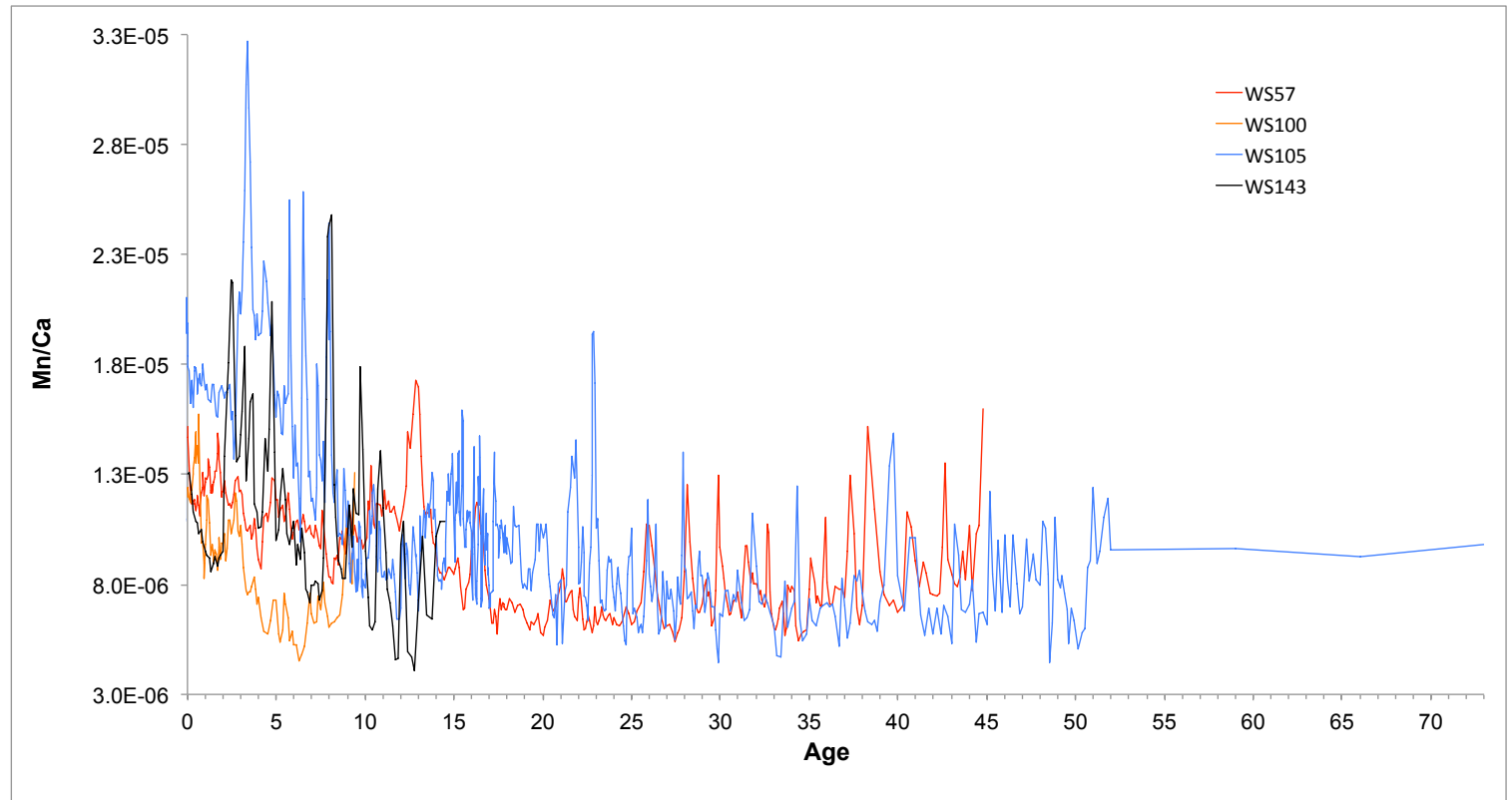

\subsection{5d}

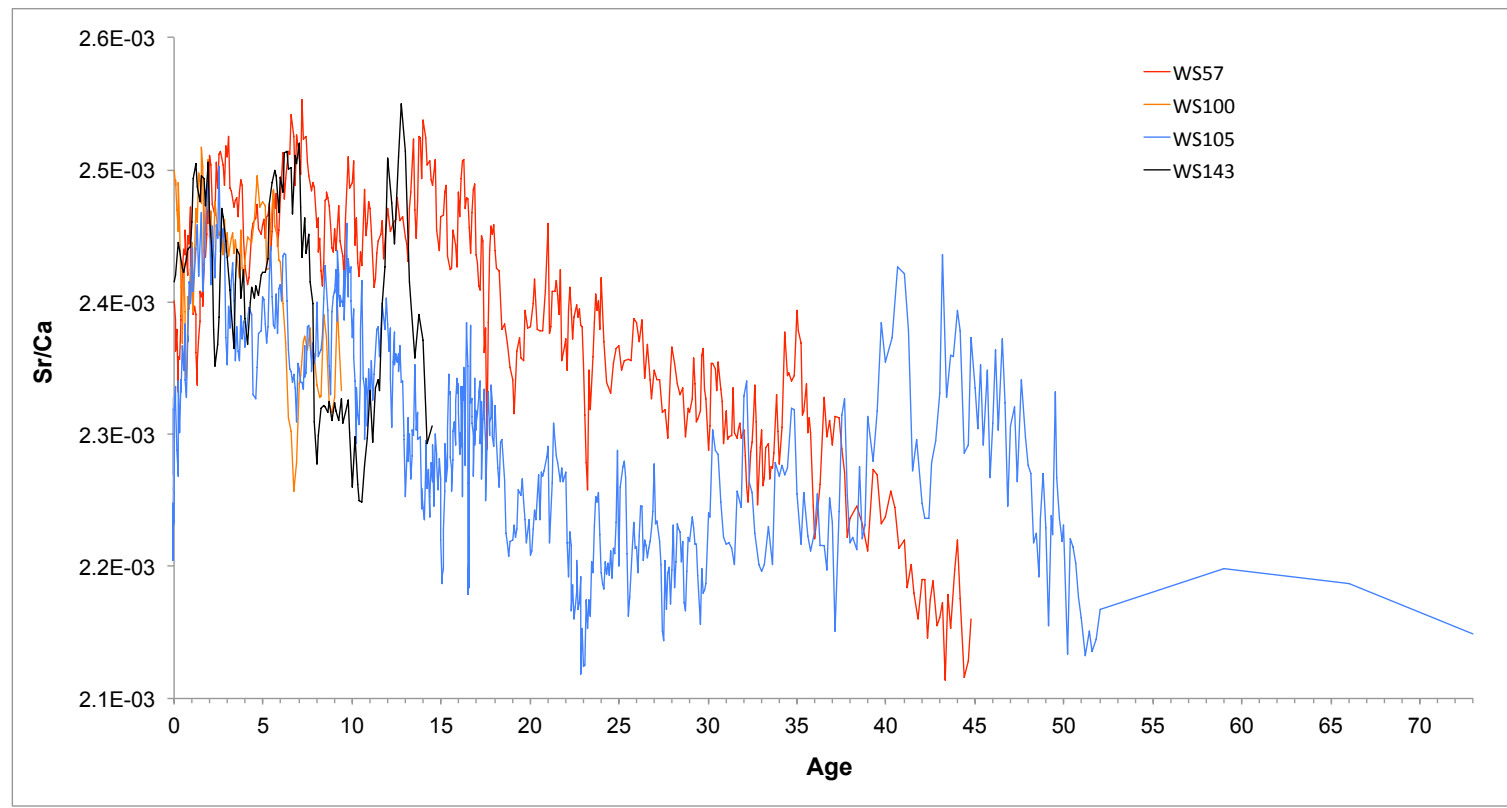




\subsection{5e}

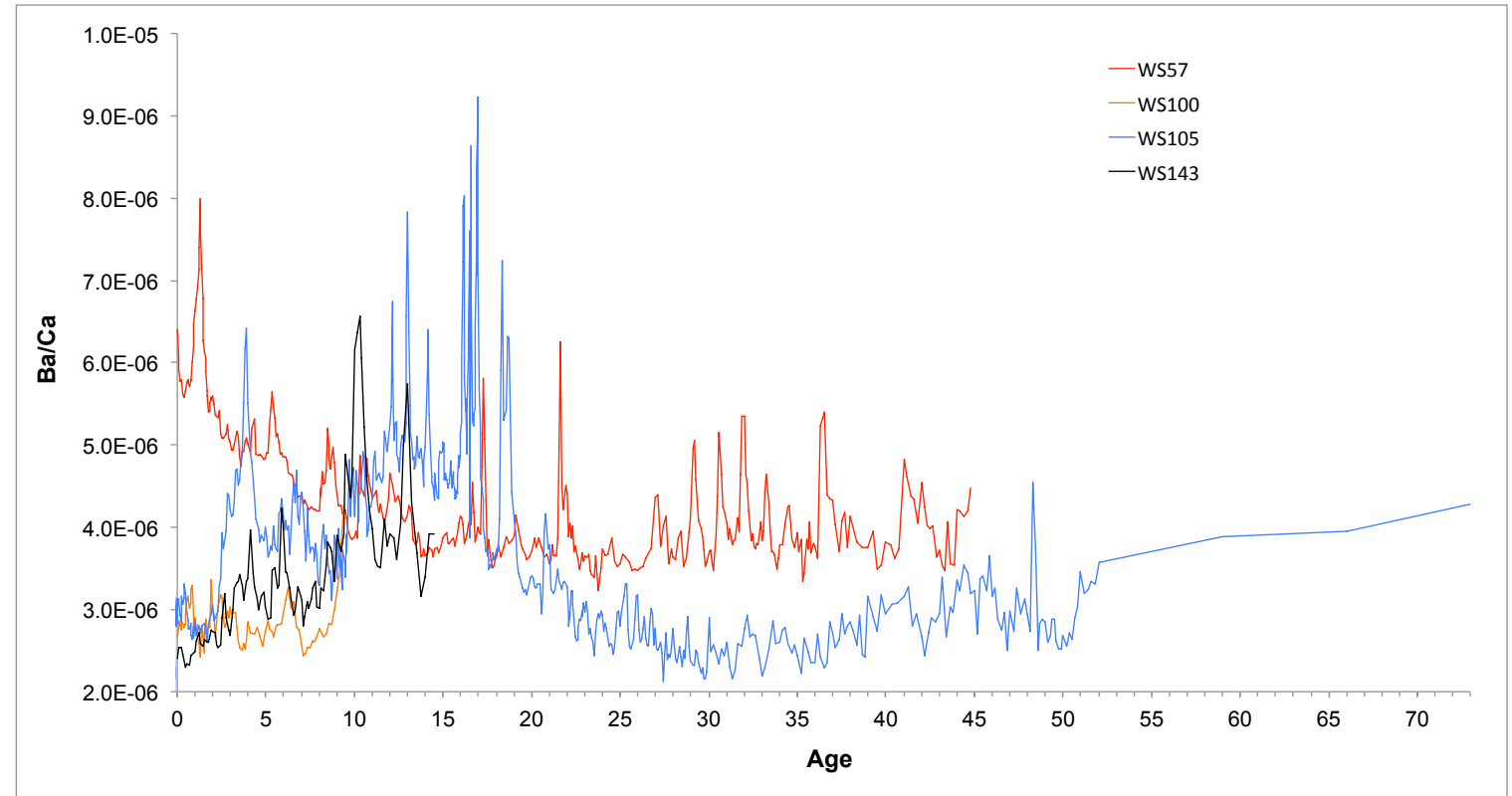

\subsection{5f}

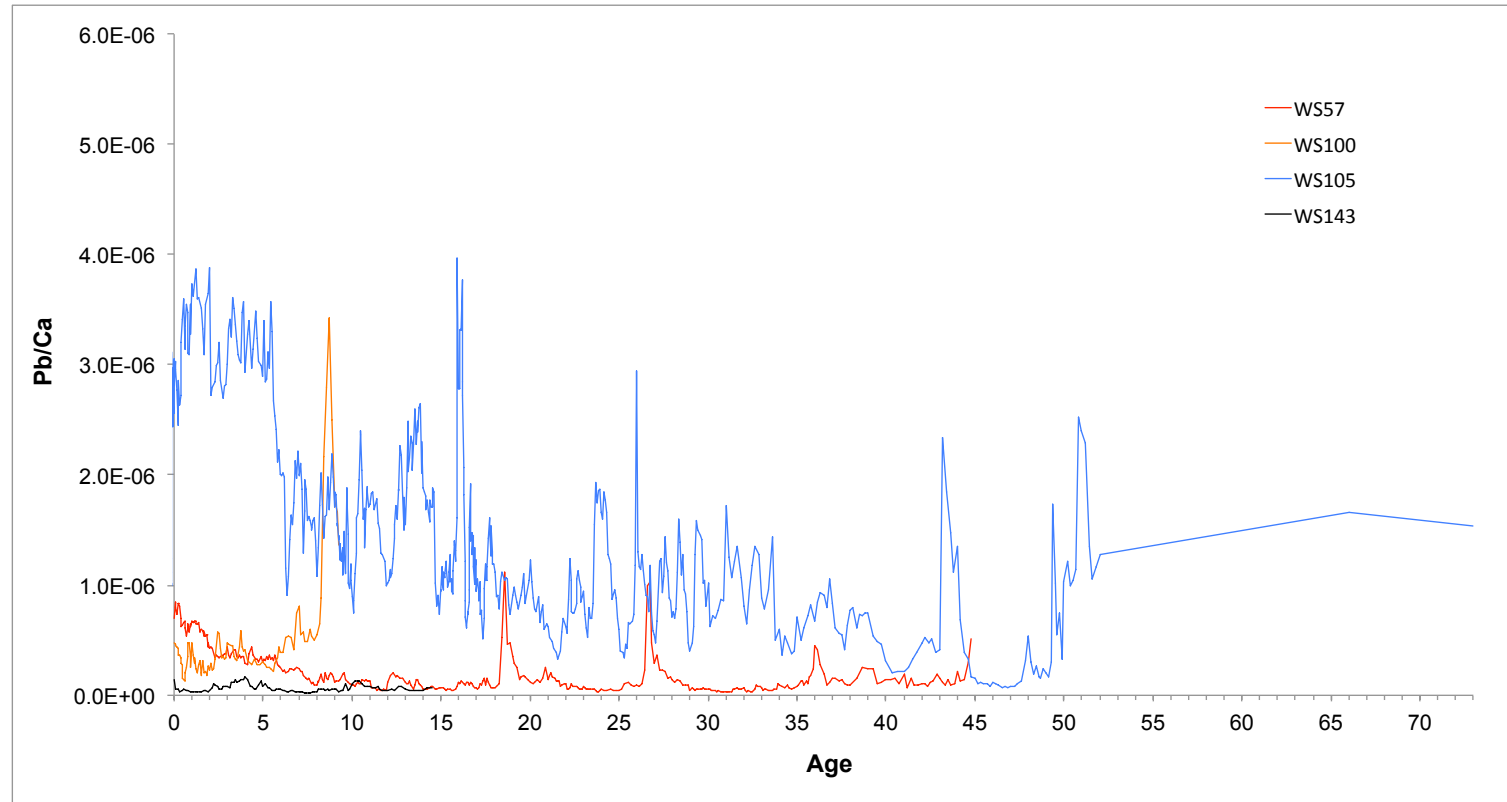




\subsection{5g}

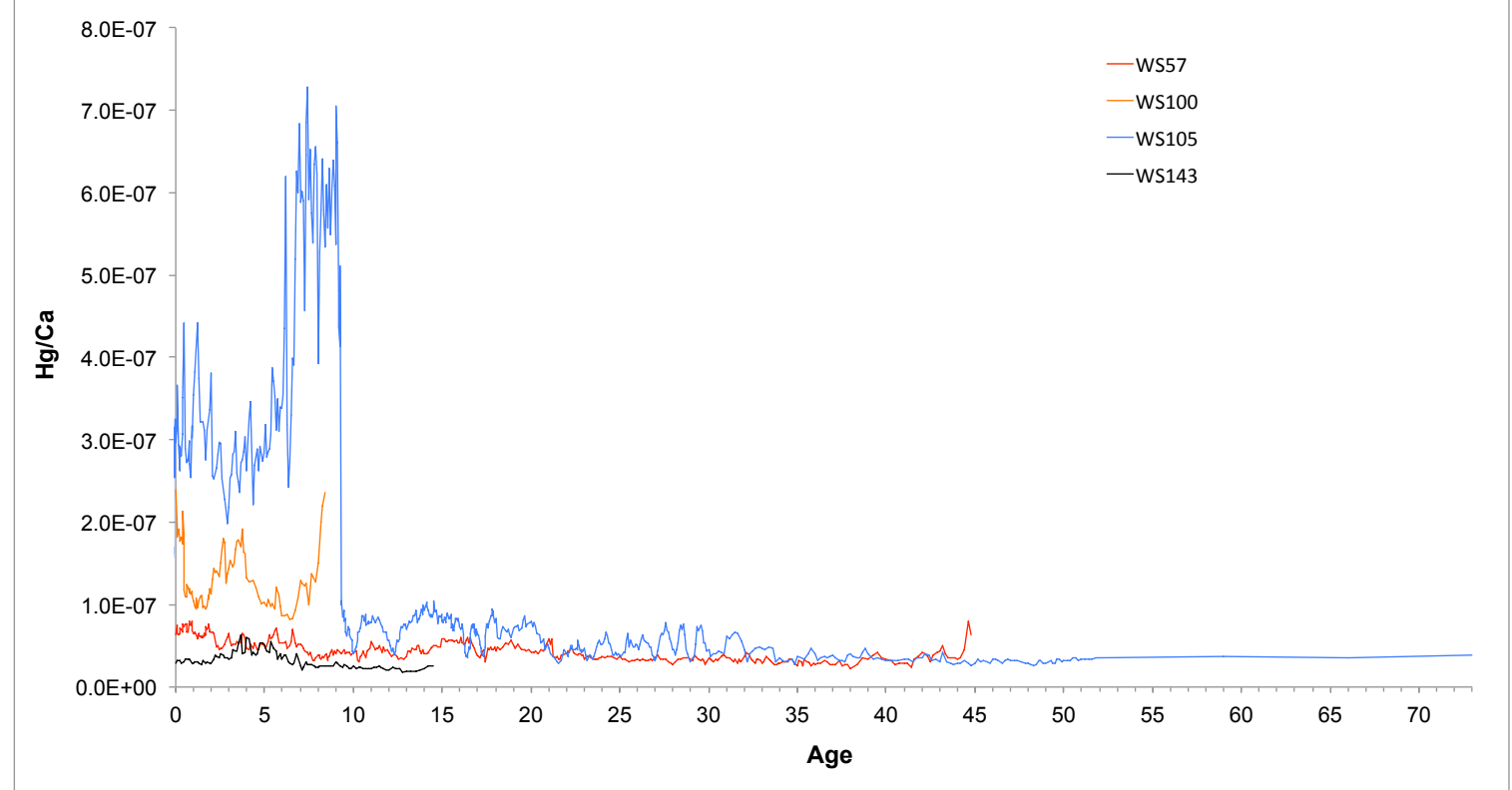

\subsection{5h}

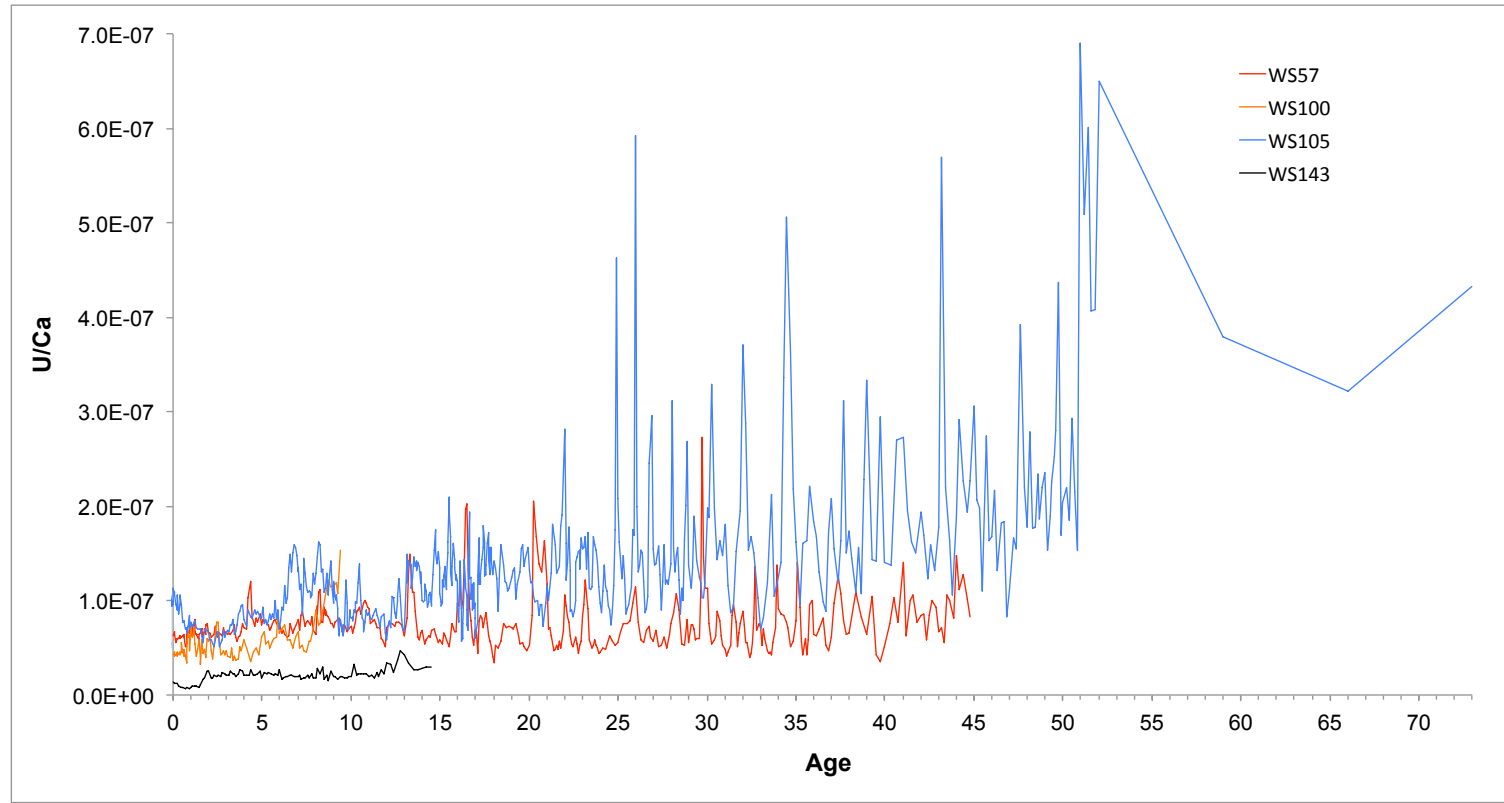




\section{CHAPTER FIVE}

\section{Conclusions}

\subsection{Thesis summary}

This thesis demonstrates the utility of white shark vertebrae as lifetime environmental recorders, enabling retrospective characterization of shark ontogeny. By using three different ecogeochemistry techniques on vertebrae, we expanded our knowledge of the ecology of the understudied northwest Atlantic (NWA) white shark population.

Bomb radiocarbon analyses in Chapter 2 confirmed the annual deposition of band pairs in white shark vertebrae, at least through age 30 for both sexes. At more advanced ages, band deposition either slows and/or the material becomes so thin as to render the different layers unreadable by current visual counting methods. This lead to an age underestimation of 21 years in the largest male, making that individual 73 years old. Based on this data, NWA white sharks are among the longest lived chondrichthyan fishes (Cailliet and Goldman 2004). The resultant increase in age at maturity (Natanson and Skomal, in review) has important implications for their conservation and management as changes in juvenile survival actually have the greatest effect on population growth rates (Cortés 2002). This makes white sharks even more vulnerable to any levels of bycatch or directed fishing, and considering their likely population decline in recent decades (Baum et al. 2003), raises concern regarding the conservation and management of the species.

In Chapter 3 we found evidence for individual variation in white shark feeding and movement over time using bulk and compound specific stable isotope analyses (SIA). There was no evidence for a regular ontogenetic trophic level increase as has been noted in other white shark populations (e.g. Ainley et al. 1985), nor was there evidence for a recent diet switch to gray seals. White sharks were trophically more similar to piscivorous species in the foodweb. This implies that white sharks feed on similar prey as pinnipeds and dolphins and/or they feed upon a combination of higher and lower trophic level prey. Individual variation has been seen in other white shark populations (Kim et al. 2012), implying that as a whole, the species may show more nuanced and generalist feeding behavior than previously supposed. This study also presents the first compound specific SIA from white sharks. Variation between bulk and compound 
specific SIA highlighted the utility of compound specific analyses in distinguishing between trophic isotopic baseline shifts. Trophic position calculations based on compound specific SIA were fairly low for an apex predator, adding to the growing body of knowledge that suggests that trophic enrichment factors vary for higher trophic level organisms (e.g. (Lorrain et al. 2009, Dale et al. 2011, Choy et al. 2012, Germain et al. 2013, Bradley et al. in press, McMahon et al. in review).

In Chapter 4 we found further evidence for variation in white shark movements using trace element analyses on white shark vertebrae. Laser ablation allowed for high resolution, subannual sampling, and results showed variation and regular patterns, likely attributable to environmental exposure. Several individual sharks had high levels of heavy metals at different times during ontogeny, which may correlate to residency in coastal waters that are subject to coastal runoff and pollution, while others with low metal concentrations may have spent more time in offshore waters.

\subsection{Future directions}

While Chapter 2 provides valuable longevity and age validation information for NWA white sharks, it raises questions about the applicability of these extended ages to other groups of white sharks. Separate populations can have dissimilar age and growth patterns. For instance, porbeagle sharks from New Zealand grow slower, are smaller, mature later, and live significantly longer than their NWA counterparts (Campana et al. 2002, Francis et al. 2007). An earlier study on northeast Pacific white sharks using bomb radiocarbon for validation was unsuccessful, which the authors attributed to white sharks feeding on radiocarbon depleted prey (Kerr et al. 2006). However, the band counting criteria in that study was different to the one applied here, and the shape of their "known capture year" curve and the estimated ages (Figure 1 in Kerr et al. 2006) which present a delayed rise in $\Delta^{14} \mathrm{C}$, may solely be a consequence of age underestimation via band counts. Reinvestigating their samples using the counting criteria from this study might clarify the issue. Further application of bomb radiocarbon analysis to vertebrae of sharks from other white shark population centers, including the western Indian and southwestern and northwestern Pacific Oceans is necessary to understand the age and growth of this threatened species. These studies would be especially timely as the Western Australian government moves to implement drum lines and culls of white sharks due to a recent spate of fatal attacks on 
beachgoers ${ }^{1}$.

We showed that gray seals likely do not constitute a significant fraction of the diet of NWA white sharks, yet tagging tracks and sightings indicate that some individuals spend the summer through the fall off the coast of Cape Cod (Skomal et al., unpubl. data). These individuals are likely feeding on gray seals but our data does not show this signature due to tissue turnover times and resolution. While vertebrae are metabolically stable and band pairs are deposited on an annual basis (Chapter 2: Hamady et al. 2014), vertebral tissue has low levels of nitrogen, necessitating relatively large sample sizes for bulk and amino acid stable isotope analyses. Muscle tissue also represents an annual mean of $\operatorname{diet} \delta^{15} \mathrm{~N}$ (Macneil et al. 2006, Logan and Lutcavage 2010); thus, the resolution of samples in this study is likely too coarse to reflect subannual dietary changes. Other tissues like blood and liver have quicker turnover times, reflecting a diet switch on the order of two or three months (Macneil et al. 2006, Logan and Lutcavage 2010). Analyses of these tissues sampled in early fall may capture an increase in trophic level that a white shark would experience during a summer of feeding on gray seals. Analysis of blood and plasma samples obtained by Dr. G. Skomal from white sharks tagged during recent OCEARCH (www.OCEARCH.org) expeditions in the NWA may resolve these dietary questions. Accurate characterization of prey values is also critical for evaluating relative position in a foodweb. The only currently available isotope samples from Cape Cod gray seals are bulk nitrogen from two stranded juveniles (Bogomolni 2003), which may be anomalously high due to lingering maternal effects, tissue catabolism, or high baseline nitrogen values. Recently sampled blood from a group of healthy Cape Cod gray seals (Dr. M Polito et al, unpubl. data) will give us more nitrogen values and the first carbon stable isotope values from Cape Cod gray seals for comparison with the white sharks.

At this point, results from Chapter 4 are rather speculative, but a more in depth characterization of the chemical environment in the NWA may help refine the conclusions we are able to draw from the data. Analysis and monitoring over time of different water bodies of known or suspected white shark residency would help our ability to interpret the data. To make sense of the interesting patterns seen in pre-parturition vertebral sections, it would be necessary

\footnotetext{
1 "Improving shark safety at popular WA beaches." Government of Western Australia Ministerial Media Statement, 27 December 2013. Accessed from: http://www.mediastatements.wa.gov.au/pages/StatementDetails.aspx?listName=StatementsBarne tt\&StatId=8039 on 6 January 2014.
} 
to conduct manipulative experiments, similar to those from Smith et al. (2013) on a shark species with similar gestational biology. Leopard sharks are also ovoviviparous (Compagno 2001) and are amenable to long-term rearing in captivity (e.g. Kim et al. 2012), making them a prime candidate species. Additional manipulative experiments that should be performed include investigating the behaviors of trace metals like $\mathrm{Pb}, \mathrm{Hg}$, and $\mathrm{U}$, and their correlations with other elements. For those individuals with high levels of $\mathrm{Pb}$, it may be valuable to investigate ${ }^{206} \mathrm{~Pb} /{ }^{207} \mathrm{~Pb}$ since different sources like leaded gasoline, wastewater treatment, metal refineries, and coal burning have different ratios which can be used to fingerprint sources of runoff, and therefore possible locations of residency (Spencer et al. 2000, Couture et al. 2010). 


\section{REFERENCES}

Adams DH, Mitchell ME, Parsons GR (1994) Seasonal Occurrence of the White Shark, Carcharodon carcharias, in Waters off the Florida West Coast, with Notes on its Life History. Mar Fish Rev 56:24-28

Ainley DG, Henderson AC, Huber HP, Boekelheide RJ, Allen SG, et al. (1985) Dynamics of white shark/pinniped interactions in the Gulf of the Farallones. In: (ed. Sibley G) Biology of the White Shark: A Symposium. S Cal Acad Sci 9:109-122

Ambrose SH, Norr L (1993) Experimental evidence for the relationship of the carbon isotope ratios of whole diet and dietary protein to those of bone collagen and carbonate. In: (eds. Lambert JB, Grupe G) Prehistoric Human Bone: Archaeology at the Molecular Level. New York: Springer-Verlag. pp 1-37

Ampela K (2009) The diet and foraging ecology of gray seals (Halichoerus grypus) in United States waters. Ph.D. dissertation, CUNY, Staten Island, New York

Anderson S, Pyle P (2003) A temporal, sex-specific occurrence pattern among white sharks at the South Farallon Islands, California. Calif Fish Game 89:96-101

Andrews AH, Tracey DM, Dunn MR (2009) Lead-radium dating of orange roughy (Hoplostethus altanticus): validation of a centenarian life span. Can J Fish Aquat Sci 66:1130-1140

Andrews AH, Natanson LJ, Kerr LA, Burgess GH, Cailliet GM (2011) Bomb radiocarbon and tag-recapture dating of sandbar shark (Carcharhinus plumbeus). Fish Bull 109:454-465

Andrews AH, Barnett BK, Allman RJ, Moyer RP, Trowbridge HD, Gillanders B (2013) Great longevity of speckled hind (Epinephelus drummondhayi), a deep-water grouper, with novel use of postbomb radiocarbon dating in the Gulf of Mexico. Can J Fish Aquat Sci 70:11311140

Ardizzone D, Cailliet GM, Natanson LJ, Andrews AH, Kerr LA, Brown TA (2006) Application of bomb radiocarbon chronologies to shortfin mako (Isurus oxyrinchus) age validation. Environ Biol Fishes 77:355-366

Arnold PW (1972) Predation on harbour porpoise, Phocoena phocoena, by a white shark, Carcharodon carcharias. Can J Fish Aquat Sci 29:1213-1214

Baum JK, Myers RA, Kehler DG, Worm B, Harley SJ, et al. (2003) Collapse and conservation of shark populations in the northwest Atlantic. Science 29:389-392

Baum JK, Myers RA (2004) Shifting baselines and the decline of pelagic sharks in the Gulf of Mexico. Ecol Lett 7:135-145

Beamish RJ, McFarlane GA (2000) Reevaluation of the interpretation of annuli from otoliths of a long-lived fish, Anoplopoma fimbria. Fish Res 46:105-111 
Bergquist BA, Boyle EA (2006) Dissolved iron in the tropical and subtropical Atlantic Ocean. Global Biogeochem Cycles 20: GB1015, doi:10.1029/2005GB002505

Bigelow HB, Schroeder WC (1948) Sharks. In: (eds. Tee-Van J, Breder CM, Hildebrand SF, Parr AE, Schroeder WC) Fishes of the Western North Atlantic. Part one. Lancelets, cyclostomes, sharks. Sears Foundation for Marine Research, Yale University, New Haven. pp 59-546

Bogomolni A (2003) Cytochrome P450 1A1, trophic status and contaminant profile of harp, harbor and grey seals of Cape Cod, MA. M.S. Thesis, Boston University Marine Program, Boston, MA, USA

Bonfil R, Meyer M, Scholl MC, Johnson R, O’Brien S, et al. (2005) Transoceanic Migration, Spatial Dynamics, and Population Linkages of White Sharks. Science 310:100-103

Bowen WD, Iverson SJ (2012) Methods of estimating marine mammal diets: A review of validation experiments and sources of bias and uncertainty. Mar Mam Sci 29:719-754

Boyle EA, Chapnick SD, Shen GT, Bacon MP (1986) Temporal variability of lead in the western North Atlantic. J Geophys Res Oceans 91:8573-8593

Burgess GH, Beerkircher LR, Cailliet GM, Carlson JK, Cortes E, et al. (2005) Is the collapse of shark populations in the northwest Atlantic Ocean and Gulf of Mexico real? Fisheries 30:2026.

Brodie P, Beck B (2013) Predation by sharks on the grey seal (Halichoerus grypus) in eastern Canada. Can J Fish Aquat Sci 40:267-271

Bradley CJ, Madigan DJ, Block BA, Popp BN (in press) Amino Acid Isotope Incorporation and Enrichment Factors in Pacific Bluefin Tuna, Thunnus orientalis. PLoS ONE

Cailliet GM, Natanson LJ, Welden BA, Ebert DA (1985) Preliminary studies on the age and growth of the white shark, Carcharodon carcharias, using vertebral bands. In: (ed. Sibley G) Biology of the White Shark: A Symposium. S Cal Acad Sci pp 49-59

Cailliet GM, Goldman KJ (2004) Age determination and validation in chondrichthyan fishes. In: (eds. Carrier JC, Musick JA, Heithaus MR) The Biology of Sharks and Their Relatives, Vol. 1. CRC Press, Boca Raton, FL, USA, pp 399-447

Campana S (1997) Use of radiocarbon from nuclear fallout as a dated marker in the otoliths of haddock Melanogrammus aeglefinus. Mar Ecol Prog Ser 150:49-56

Campana S (2001) Accuracy, precision and quality control in age determination, including a review of the use and abuse of age validation methods. J Fish Biol 59:197-242

Campana S, Natanson L, Myklevoll S (2002) Bomb dating and age determination of large pelagic sharks. Can J Fish Aquat Sci 59:450-455 
Campana SE, Casselman JM, Jones CM (2008) Bomb radiocarbon chronologies in the Arctic, with implications for the age validation of lake trout (Salvelinus namaycush) and other Arctic species. Can J Fish Aquat Sci. 65:733-743

Carey FG, Kanwisher JW, Brazier O, Gabrielson G, Case JG, Pratt HL Jr (1982) Temperature and Activities of a White Shark, Carcharodon carcharias. Copeia 2:254-260

Carleton SA, Del Rio CM (2010) Growth and catabolism in isotopic incorporation: a new formulation and experimental data. Funct Ecol 24:805-812

Carlisle AB, Kim SL, Semmens BX, Madigan DJ, Jorgensen SJ, Perle CR, Anderson SD, Chapple TK, Kanive PE, Block BA (2012) Using Stable Isotope Analysis to Understand the Migration and Trophic Ecology of Northeastern Pacific White Sharks (Carcharodon carcharias). PLoS ONE 7:e30492

Casey JG, Pratt HL Jr (1985) Distribution of the white shark, Carcharodon carcharias, in the western North Atlantic. South Calif Acad Sci Mem 9:2-14

Castro JI (2011) White Shark. In: Sharks of North America. Oxford University Press, USA. pp 258-269

Chapple TK, Jorgensen SJ, Anderson SD, Kanive PE, Klimley AP, Botsford LW, Block BA (2010) Philopatry and migration of Pacific white sharks. Biol Lett 7:581-583

Cherel Y, Hobson K, Guinet C (2007) Stable isotopes document seasonal changes in trophic niches and winter foraging individual specialization in diving predators from the Southern Ocean. J Anim Ecol 76:826-836

Chever F, Bucciarelli E, Sarthou G, Speich S, Arhan M, Penven P, Tagliabue A (2010) Physical speciation of iron in the Atlantic sector of the Southern Ocean, along a transect from the subtropical domain to the Weddell Sea Gyre. J Geophys Res Ocean, 115:C10059, doi:10.1029/2009JC005880

Chikaraishi Y, Kashiyama Y, Ogawa NO, Kitazato H, Ohkouchi N (2007) Metabolic control of nitrogen isotope composition of amino acids in macroalgae and gastropods: implications for aquatic food web studies. Mar Ecol Prog Ser 342:85-90

Chikaraishi Y, Ogawa NO, Kashiyama Y, Takano Y, Suga H, Tomitani A, Miyashita H, Kitazato H, Ohkouchi N (2009) Determination of aquatic food-web structure based on compound-specific nitrogen isotopic composition of amino acids. Limnol Oceanogr-Meth $7: 740-750$

Chowdhury MJ, Blust R (2012) Strontium. In: (eds. CM Wood, AP Farrell, CJ Brauner) Homeostasis and toxicology of non-essential metals, Fish Physiology Ser Vol 31B, Academic Press, Waltham, MA, USA 
Choy CA, Davison PC, Drazen JC, Flynn A, Gier EJ, Hoffman JC, McClain-Counts JP, Miller TW, Popp BN, Ross SW, Sutton TT (2012) Global Trophic Position Comparison of Two Dominant Mesopelagic Fish Families (Myctophidae, Stomiidae) Using Amino Acid Nitrogen Isotopic Analyses. PLoS ONE 7:e50133

CITES (2004) Proposal for the inclusion of Carcharodon carcharias in Appendix II. CoP13 Prop. 32 Rev. 1. Bangkok, Thailand, 39 pp www.cites.org/eng/cop/13/prop/index.shtml

Cliff G (1991) Shark attacks on the South African coast between 1960 and 1990. S Afr J Sci $87: 513-518$

CMS (2007) UNEP/CMS/Recommendation 8.16 Migratory sharks, Vol. 2005. United Nations Environment Programme, Convention on Migratory Species

Compagno LJV (2001) Carcharhiniformes. In: Sharks of the World: An Annotated and Illustrated Catalogue of Shark Species Known to Date. Rome: FAO Species Catalogue for Fishery Purposes, No. 1, Vol. 2. Rome, Italy. 269 pp

Cortés E (1997) A critical review of methods of studying fish feeding based on analysis of stomach contents: application to elasmobranch fishes. Can J Fish Aquat Sci 54:726-738

Cortés E (1999) Standardized diet compositions and trophic levels of sharks. ICES J Mar Sci 56:707-717

Cortés E (2002) Incorporating uncertainty into demographic modeling: Application to shark population and their conservation. Conserv Biol 16: 1048-1062

Couture R-M, Chiffoleau J-F, Auger D, Claisse D, Gobeil C, Cossa D (2010) Seasonal and Decadal Variations in Lead Sources to Eastern North Atlantic Mussels. Environ Sci Technol $44: 1211-1216$

Dale JJ, Wallsgrove NJ, Popp BN, Holland KN (2011) Nursery habitat use and foraging ecology of the brown stingray Dasyatis lata determined from stomach contents, bulk and amino acid stable isotopes. Mar Ecol Prog Ser 433:221-236

DeNiro M (1978) Influence of diet on the distribution of carbon isotopes in animals. Geochim Cosmochim Acta 42:495-506

DeNiro M, Epstein S (1981) Influence of diet on the distribution of nitrogen isotopes in animals. Geochim Cosmochim Acta 45:341-351

Dodge KL, Logan JM, Lutcavage ME (2011) Foraging ecology of leatherback sea turtles in the Western North Atlantic determined through multi-tissue stable isotope analyses. Mar Bio $158: 2813-2824$

Domeier M, Nasby-Lucas N (2007) Annual re-sightings of photo- graphically identified white sharks (Carcharodon carcharias) at an eastern Pacific aggregation site (Guadalupe Island, Mexico) Mar Biol 150:977-984, doi:10.1007/s00227-006-0380-7 
Domeier ML, Nasby-Lucas N (2012) Sex-specific migration patterns and sexual segregation of adult white sharks, Carcharodon carcharias, in the Northeastern Pacific. In: Domeier ML, editor. Global Perspectives on the Biology and Life History of the Great White Shark. Boca Raton: CRC Press. pp 133-146

Druffel ERM, Linick TW (1978) Radiocarbon in annual coral rings of Florida. Geophys Res Lett 5: 913-916

Dulvy NK, Baum JK, Clarke S, Compagno LJV, Cortes E, Domingo A, Fordham S, Fowler S, Francis MP, Gibson C, Martinez J, Musick JA, Soldo A, Stevens JD, Valenti S (2008) You can swim but you can't hide: the global status and conservation of oceanic pelagic sharks and rays. Aquat Conserv 18:459-482

Elsdon TS, Wells BK, Campana SE, Gillanders BM, Jones CM, Limburg KE, Secor DH, Thorrold SR, Walther BD (2008) Otolith chemistry to describe movements and life-history parameters of fishes: hypotheses, assumptions, limitations and inferences. Oceanogr Mar Biol Annu Rev 46:297-330

Environmental Protection Agency (2012) National Coastal Condition Report IV (EPA Publication No. 842-R-10-003) US Environmental Protection Agency, Office of Research and Development/Office of Water, Washington, DC, USA

Estrada J, Rice A, Lutcavage M, Skomal G (2003) Predicting trophic position in sharks of the north-west Atlantic Ocean using stable isotope analysis. J Mar Biol Assoc UK 83:13471350

Estrada JA, Lutcavage M, Thorrold S (2005) Diet and trophic position inferred from stable carbon and nitrogen isotopes of Atlantic bluefin tuna (Thunnus thynnus). Mar Bio 147:37-45

Estrada J, Rice A, Natanson L, Skomal G (2006) Use of isotopic analysis of vertebrae in reconstructing ontogenetic feeding ecology in white sharks. Ecology 87:829-834

Fallows C, Gallagher AJ, Hammerschlag N (2013) White Sharks (Carcharodon carcharias) Scavenging on Whales and Its Potential Role in Further Shaping the Ecology of an Apex Predator. PLoS ONE 8:e60797

Fenton GE, Short SA, Ritz DA (1991) Age determination of orange roughy, Hoplostethus atlanticus. (Pisces: Trachichthyidae) using ${ }^{210} \mathrm{~Pb}:{ }^{226} \mathrm{Ra}$ disequilibria. Mar Biol 109:197-202

Ferretti F, Myers RA, Serena F, Lotze HK (2008) Loss of large predatory sharks from the Mediterranean Sea. Conserv Biol 22:952-964

Ferretti F, Worm B, Britten GL, Heithaus MR, Lotze HK (2010) Patterns and ecosystem consequences of shark declines in the ocean. Ecol Lett 13:1055-1071

Flegal AR, Patterson CC (1983) Vertical concentration profiles of lead in the Central Pacific at $15^{\circ} \mathrm{N}$ and $20^{\circ} \mathrm{S}$. Earth Planet Sci Lett 64:19-32 
Fowler AJ (1990) Validation of annual growth increments in the otoliths of a small, tropical coral reef fish. Mar Ecol Prog Ser 64:25-38

Francis MP (1996) Observations on a pregnant white shark with a review of reproductive biology. In: (eds. Klimley P, Ainley DG) Great White Sharks: The biology of Carcharodon caracharias. Academic Press, San Diego, CA, USA, pp 157-172

Francis MP, Campana SE, Jones CM (2007) Age under-estimation in New Zealand porbeagle sharks (Lamna nasus): is there an upper limit to ages that can be determined from shark vertebrae? Mar Freshwater Res 58:10-23

Fry B (1988) Food web structure on Georges Bank from stable C, N, and S isotopic compositions. Limnol Oceanogr 33:1182-1190

Garrison VH, Foreman WT, Genualdi S, Griffin DW, Kellogg CA, Majewski MS, Mohammed A, Ramsubhag A, Shinn EA, Simonich SL, Smith GW (2006) Saharan dust - a carrier of persistent organic pollutants, metals and microbes to the Caribbean? Int J Trop Biol Conserv $54: 9-21$

Goldman KJ, Cailliet GM, Andrews AH, Natanson LJ (2012) Chapter 14: Assessing the Age and Growth of Chondrichthyan Fishes. In: (eds. Carrier J, Musick JA, Heithaus MR) Biology of Sharks and their Relatives. CRC Press, Boca Raton, FL, USA pp 423-451

Hale LF, Dudgeon JV, Mason AZ, Lowe CG (2006) Elemental signatures in the vertebral cartilage of the round stingray, Urobatis halleri, from Seal Beach, California. Environ Biol Fish 77:317-325

Hamady LL, Natanson LJ, Skomal GB, Thorrold SR (2014) Vertebral Bomb Radiocarbon Suggests Extreme Longevity in White Sharks. PLoS ONE 9: e84006, doi:10.1371/journal.pone.0084006

Hammerschlag N, Martin RA, Fallows C, Collier RS, Lawrence R (2012) Investigatory Behavior toward Surface Objects and Nonconsumptive Strikes on Seabirds by White Sharks, Carcharodon carcharias, at Seal Island, South Africa (1997-2010). In: (ed. Domeier ML) Global Perspectives on the Biology and Life History of the White Shark. CRC Press, Boca Raton, Florida, USA, pp 1-14

Hannides, S CC, Popp BN, Landry MR, Graham BS (2009) Quantification of zooplankton trophic position in the North Pacific Subtropical Gyre using stable nitrogen isotopes. Limnol Oceanogr 54:50-61

Hedd A, Montevecchi WA (2006) Diet and trophic position of Leach's storm-petrel Oceanodroma leucorhoa during breeding and moult, inferred from stable isotope analysis of feathers. Mar Ecol Prog Ser 322:291-301

Heithaus MR, Frid A, Wirsin AJ, Worm B (2008) Predicting ecological consequences of marine top predator declines. Trends Ecol Evol 23:202-210 
Heupel MR, Yeiser BG, Collins AG, Ortega L, Simpfendorfer CA (2009) Long-term presence and movement patterns of juvenile bull sharks, Carcharhinus leucas, in an estuarine river system. Mar Freshwater Res 61:1-10

Hobson KA, Alisauskas RT, Clark RG (1993) Stable-nitrogen isotope enrichment in avian tissues due to fasting and nutritional stress: implications for isotopic analyses of diet. Condor 95:388-394

Hobson KA, Sease JL (1998) Stable isotope analyses of tooth annuli reveal temporal dietary records: an example using Steller sea lions. Mar Mam Sci 14:116-129

Hobson KA (1999) Tracing origins and migration of wildlife using stable isotopes: a review. Oecologia 120:314-326

Hobson KA, Wassenaar LI, Taylor OR (1999) Stable isotopes ( $\delta \mathrm{D}$ and $\left.\delta^{13} \mathrm{C}\right)$ are geographic indicators of natal origins of monarch butterflies in eastern North America. Oecologia 120:397-404

Hoffman JC, Sutton TT (2010) Lipid correction for carbon stable isotope analysis of deep-sea fishes. Deep Sea Res Pt I 57:956-964

Howey-Jordan LA, Brooks EJ, Abercrombie DL, Jordan LKB, Brooks A, Williams S, Gospodarczyk E, Chapman DD (2013) Complex Movements, Philopatry and Expanded Depth Range of a Severely Threatened Pelagic Shark, the Oceanic Whitetip (Carcharhinus longimanus) in the Western North Atlantic. PLoS ONE 8:e56588, doi:10.1371/ journal.pone. 0056588

Hubbell G. Using Tooth Structure to Determine the Evolutionary History of the White Shark. In: (eds. AP Klimley \& DG Ainley) Great White Sharks: The Biology of Carcharodon carcharias. Academic Press, San Diego, pp 9-18

Hussey NE, MacNeil MA, Olin JA, McMeans BC, Kinney MJ, Chapman DD, Fisk AT (2012) Stable isotopes and elasmobranchs: tissue types, methods, applications and assumptions. J Fish Biol 80:1449-1484

Hussey NE, McCann HM, Cliff G, Dudley SF, Wintner SP, Fisk AT (2012) Size-based analysis of diet and trophic position of the white shark (Carcharodon carcharias) in South African waters. In: (ed. Domeier ML) Global Perspectives on the Biology and Life History of the White Shark. CRC Press, Boca Raton, FL, USA, pp 27-49

IUCN (2013) IUCN Red List of Threatened Species, v. 1. Available: http://www.iucnredlist.org. Accessed 15 February 2013.

Jackson J (2007) Earliest references to age determination of fishes and their early application to the study of fisheries. Fisheries 32:321-328 
Jorgensen SJ, Reeb CA, Chapple TK, Anderson S, Perle C, Van Sommeran SR, Fritz-Cope C, Brown AC, Klimley AP, Block BA (2010) Philopatry and migration of Pacific white sharks. Proc R Soc B Biol Sci 277:679-688

Kalish J (1993) Pre-and post-bomb radiocarbon in fish otoliths. E Earth Planet Sci Lett 114: 549554

Kalish JM, Johnston J (2001) Determination of school shark age based on analysis of radiocarbon in vertebral collagen. In: Kalish JM, editor. Use of the Bomb Radiocarbon Chronometer to Validate Fish Age: Final Report, FDRC Project 93/109. Canberra: Fisheries Research and Development Corporation. pp. 116-122

Kennedy BP, Folt CL, Blum JD, Chamberlain CP (1997) Natural isotope markers in salmon. Nature 387:766-767

Kerr LA, Andrews AH, Cailliet GM, Brown TA, Coale KH (2006) Investigations of $\Delta^{14} \mathrm{C}, \delta^{13} \mathrm{C}$, and $\delta^{15} \mathrm{~N}$ in vertebrae of white shark (Carcharodon carcharias) from the eastern North Pacific Ocean. Environ Biol Fishes 77:337-353

Kim SL, Koch PL (2011) Methods to collect, preserve, and prepare elasmobranch tissues for stable isotope analysis. Environ Biol Fish 95:53-63

Kim SL, del Rio CM, Casper D, Koch PL (2012) Isotopic incorporation rates for shark tissues from a long-term captive feeding study. J Exp Biol 215:2495-2500

Kim SL, Tinker MT, Estes JA, Koch PL (2012) Ontogenetic and Among-Individual Variation in Foraging Strategies of Northeast Pacific White Sharks Based on Stable Isotope Analysis. PLoS ONE 7:e45068

Kneebone J, Natanson LJ, Andrews AH, Howell WH (2008) Using bomb radiocarbon analyses to validate age and growth estimates for the tiger shark, Galeocerdo cuvier, in the western North Atlantic. Mar Biol 154:423-434

Knoff A, Hohn A, Macko S (2008) Ontogenetic diet changes in bottlenose dolphins (Tursiops truncatus) reflected through stable isotopes. Mar Mam Sci 24:128-137

Kohler N, Turner P (2001) Shark tagging: a review of conventional methods and studies. Environ Biol Fish 60:191-224

Layman CA, Arrington DA, Montaña CG, Post DM (2007) Can stable isotope ratios provide for community-wide measures of trophic structure? Ecology 88:42-48

Lesage V, Hammill MO, Kovacs KM (2001) Marine mammals and the community structure of the Estuary and Gulf of St Lawrence, Canada: evidence from stable isotope analysis. Mar Ecol Prog Ser 210:203-221

Logan JM, Lutcavage ME (2010) Stable isotope dynamics in elasmobranch fishes. Hydrobiologia 644:231-244 
Lorrain A, Graham B, Ménard F, Popp B, Bouillon S, Van Breugel P, Cherel Y (2009) Nitrogen and carbon isotope values of individual amino acids: a tool to study foraging ecology of penguins in the Southern Ocean. Mar Ecol Prog Ser 391:293-306

Lucas Z, Stobo WT (2000) Shark-inflicted mortality on a population of harbour seals (Phoca vitulina) at Sable Island, Nova Scotia. J Zoology 252:405-414

Lysiak N (2008) Migration patterns and trophic status of North Atlantic right whales. Ph.D. Thesis, Boston University Marine Program

MacNeil M, Skomal G, Fisk A (2005) Stable isotopes from multiple tissues reveal diet switching in sharks. Mar Ecol-Prog Ser 302:199-206

MacNeil MA, Drouillard KG, Fisk AT (2006) Variable uptake and elimination of stable nitrogen isotopes between tissues in fish. Can J Fish Aquat Sci 63:345-353

Maguire JJ, Sissenwine M, Csirke J, Grainger R, Garcia S (2006) The state of the world highly migratory, straddling and other high seas fish stocks. FAO Fisheries Technical Paper 495

Martinez del Rio C, Wolf N, Carleton SA, Gannes LZ (2009) Isotopic ecology ten years after a call for more laboratory experiments. Biol Rev 84:91-111

Mathews T, Fisher NS, Jeffree RA, Teyssié JL (2008) Assimilation and retention of metals in teleost and elasmobranch fishes following dietary exposure. Mar Ecol Prog Ser 360:1-12

Matich P, Heithaus MR, Layman CA (2010) Contrasting patterns of individual specialization and trophic coupling in two marine apex predators. J Animal Ecol 80:294-305

McClelland JW, Montoya JP (2002) Trophic relationships and the nitrogen isotopic composition of amino acids in plankton. Ecology 83:2173-2180

McMahon KW, Hamady LL, Thorrold SR (2013a) A review of ecogeochemistry approaches to estimating movements of marine animals. Limnol Oceanogr 58:697-714

McMahon KW, Hamady LL, Thorrold SR (2013b) Ocean Ecogeochemistry: A Review. Oceanography and Marine Biology: An Annual Review 51:327-374

McMahon KW, Thorrold SR, Elsdon TS, McCarthy M (in review) Nitrogen isotope fractionation of amino acids in fish muscle reflects the food web baseline and trophic position-specific trophic fractionation

Mecray EL, Buchholtz ten Brink MR (2000) Contaminant Distribution and Accumulation in the Surface Sediments of Long Island Sound. J Coast Res 16:575-590

Michener RH, Schell DM (1994) Stable isotopes as tracers in marine aquatic food webs. In: (eds. Lajtha K, Michener RH) Stable Isotopes in Ecology and Environmental Science. Blackwell Scientific, Oxford, UK, pp 138-157 
Miller MJ, Chikaraishi Y, Ogawa NO, Yamada Y, Tsukamoto K, Ohkouchi N (2012) A low trophic position of Japanese eel larvae indicates feeding on marine snow. Biol Lett 9:20120826-20120826

Minigawa M, Wada E (1984) Stepwise enrichment of ${ }^{15} \mathrm{~N}$ along food chains: Further evidence and the relation between $\delta^{15} \mathrm{~N}$ and animal age. Geoch Cosmochim Acta 48:1135-1140

Mollet HFD, Cailliet GM, Klimley AP, D.A. Ebert, A.D. Testi, et al. (1996) A review of length validation methods and protocols to measure large white sharks. In: (eds. Klimley P, Ainley DG) Great White Sharks: The biology of Carcharodon caracharias. Academic Press, San Diego, CA, USA pp 91-108

Musyl MK, Domeier ML, Nasby-Lucas N, Brill RW, McNaughton LM, Swimmer JY, Lutcavage MS, Wilson SG, Galuardi B, Liddle JB (2011) Performance of pop-up satellite archival tags. Mar Ecol Prog Ser 433:1-28

Myers R, Baum J, Shepherd T, Powers S, Peterson C (2007) Cascading effects of the loss of apex predatory sharks from a coastal ocean. Science 315:1846

Natanson L, Cailliet G (1990) Vertebral Growth Zone Deposition in Pacific Angel Sharks. Copeia 1990:1133-1145

Natanson LJ, Gervelis BJ, Winton MV, Hamady LL, Gulak SJB, Carlson JK (2013) Validated age and growth estimates for Carcharhinus obscurus in the northwestern Atlantic Ocean, with pre- and post management growth comparisons. Environ Biol Fish 10.1007/s10641013-0189-4

Natanson LJ, Skomal GB (in review) Validated age and growth of the White Shark, Carcharodon carcharias, in the western North Atlantic Ocean. Mar Biol

Nelson DR, McKibben JN, Strong WR Jr., Lowe CG, Sisneros JA, Schroeder DM, Lavenberg RJ (1997) An acoustic tracking of a megamouth shark, Megachasma pelagios: a crepuscular vertical migrator. Env Biol Fish 49:389-399

Newsome SD, Clementz MT, Koch PL (2010) Using stable isotope biogeochemistry to study marine mammal ecology. Mar Mamm Science 26:509-572

Olson RJ, Popp BN, Graham BS, Lopez-Ibarra GA, Galvan-Magana F, Lennert-Cody CE, Bocanegra-Castillo N, Wallsgrove NJ, Gier E, Alatorre-Ramirez V, Ballance LT, Fry B (2010) Food-web inferences of stable isotope spatial patterns in copepods and yellowfin tuna in the pelagic eastern Pacific Ocean. Prog Oceanogr 86:124-138

Ostrom PH, Lien J, Macko SA (1993) Evaluation of the diet of Sowerby's beaked whale, Mesoplodon bidens, based on isotopic comparisons among northwestern Atlantic cetaceans. Can J Zool 71:858-861 
O’Malley JM, Drazen JC, Popp BN, Gier E, Toonen RJ (2012) Spatial variability in growth and prey availability of lobsters in the northwestern Hawaiian Islands. Mar Ecol Prog Ser 449:211-220

Parnell, A.C., Inger R., Bearhop, S. \& Jackson, A.L. 2010. Source partioning using stable isotopes: coping with too much variation. PLoS ONE 5(3): e9672. doi:10.1371/journal.pone.0009672

Passerotti MS, Carlson JK, Piercy AN, Campana SE (2010) Age validation of great hammerhead shark (Sphyrna mokarran), determined by bomb radiocarbon analysis. Fish Bull 108:346351

Peltier J. (2009) LOESS Utility. Accessed from: http://peltiertech.com/WordPress/loess-utilityawesome-update/

Pentreath RJ (1973) The accumulation from sea water of ${ }^{65} \mathrm{Zn},{ }^{54} \mathrm{Mn},{ }^{58} \mathrm{Co}$ and ${ }^{59} \mathrm{Fe}$ by the thornback ray, Raja clavata L. J Exp Mar Biol Ecol 12:327-334

Pinnegar JK, Campbell N, Polunin NVC (2001) Unusual stable isotope fractionation patterns observed for fish host-parasite trophic relationships. J Fish Biol 59:494-503

Popp BN, Graham BS, Olson RJ, Hannides CCS, Lott MJ, Lopez-Ibarra GA, Galvan-Magana F, Fry B (2007) Insight into the trophic ecology of yellowfin tuna, Thunnus albacares, from compound-specific nitrogen isotope analysis of protenaceous amino acids. In: (eds. Dawson T, Siegwolf R) Stable Isotopes as Indicators of Ecological Change, Elsevier/Academic Press, New York, New York, USA, pp 173-190

Porter ME (2006) Material properties and biochemical composition of mineralized vertebral cartilage in seven elasmobranch species (Chondrichthyes). J Exp Biol 209:2920-2928

Pratt HL Jr, Casey JG, Conklin RB (1982) Observations on large white sharks, Carcharodon carcharias, off Long Island, New York. Fish Bull 8:153-156

Prospero JM, Nees RT (1986) Impact of the North African drought and El Niño on mineral dust in the Barbados trade winds. Nature 320:735-738

Pyle P, Anderson SD, Ainley DG (1996) Trends in white shark predation at the south Farallon Islands. In: (eds. Klimley AP, Ainley DG) Great White Sharks: The Biology of Carcharodon carcharias. Academic Press, San Diego, CA, USA, pp 375-379

R Core Team (2013). R: A language and environment for statistical computing. R Foundation for Statistical Computing, Vienna, Austria. URL http://www.R-project.org/.

Ramsay MA, Hobson KA (1991) Polar bears make little use of terrestrial food webs: evidence from stable-carbon isotope analysis. Oecologia 86:598-600 
Renones O, Polunin NVC, Goni R (2002) Size related dietary shifts of Epinephelus marginatus in a western Mediterranean littoral ecosystem: an isotope and stomach content analysis. J Fish Biol 61:122-137

Richards VP, Suzuki H, Stanhope MJ, Shivji MS (2013) Characterization of the heart transcriptome of the white shark (Carcharodon carcharias). BMC Genomics 14:697-711

Rogers PJ, Huveneers C, Goldsworthy SD, Cheung WWL, Jones GK, Mitchell JG, Seuront L (2013) Population metrics and movement of two sympatric carcharhinids: a comparison of the vulnerability of pelagic sharks of the southern Australian gulfs and shelves. Mar Freshwater Res 64:20-30

Rooker JR, Secor DH, De Metrio G, Schloesser R, Block BA, Neilson JD (2008) Natal Homing and Connectivity in Atlantic Bluefin Tuna Populations. Science 322:742-744

RStudio (2012). RStudio: Integrated development environment for R (Version 0.97.551) [Computer software]. Boston, MA. Retrieved September 27, 2013. Available from http://www.rstudio.org/

Rubenstein DR, Chamberlain CP, Holmes RT, Ayres MP, Waldbauer JR, Graves GR, Tuross $\mathrm{NC}$ (2002) Linking breeding and wintering ranges of a migratory songbird using stable isotopes. Science 295:1062-1065

Rubenstein D, Hobson K (2004) From birds to butterflies: animal movement patterns and stable isotopes. Trends in Ecology \& Evolution 19:256-263

Scattergood LW (1962). White Sharks, Carcharodon carcharias, in Maine, 1959-1960. Copeia 2:446-447

Scharer RM, Patterson WF III, Carlson JK, Poulakis GR (2012) Age and Growth of Endangered Smalltooth Sawfish (Pristis pectinata) Verified with LA-ICP-MS Analysis of Vertebrae. PLoS ONE 7(10): e47850. doi:10.1371/journal.pone.0047850

Schell DM, Hirons AC (1997) Isotope ratio studies of marine mammals in Prince William Sound, Exxon Valdez Oil Spill Restoration Project Annual Report (Restoration Project 97 170), Alaska Department of Fish and Game, Habitat and Restoration Division, Anchorage, Alaska

Schroeder WC (1938) Records of Carcharodon carcharias (Linnaeus) and Pseudopriacanthus altus (Gill) from the Gulf of Maine, Summer of 1937. Copeia 1:46

Secor DH, Rooker JR (2000) Is otolith strontium a useful scalar of life cycles in estuarine fishes? Fish Res 46:359-371

Semmens JM, Payne NL, Huveneers C, Sims DW, Bruce BD (2013) Feeding requirements of white sharks may be higher than originally thought. Sci Rep 3:1-4 
Skomal G (2007) Shark nursery areas in the coastal waters of Massachusetts. Am Fish Soc Symp 50:17-33

Skomal GB, Zeeman SI, Chisholm JH, Summers EL, Walsh HJ, McMahon KW, Thorrold SR (2009) Transequatorial Migrations by Basking Sharks in the Western Atlantic Ocean. Current Biology 19:1019-1022

Skomal GB, Chisholm J, Correia SJ (2012) Implications of increasing pinniped populations on the diet and abundance of white sharks off the coast of Massachusetts. In: (ed. Domeier ML) Global Perspectives on the Biology and Life History of the White Shark, CRC Press, Boca Raton, FL, USA, pp 405-418

Smith SE (1984) Timing of Vertebral-Band Deposition in Tetracycline-Injected Leopard Sharks. Trans Am Fish Soc 113:308-313

Smith SE, Au DW, Show C (1998) Intrinsic rebound potentials of 26 species of Pacific sharks. Mar Freshwater Res 49:663-678

Smith WD (2013) Vertebral elemental markers in elasmobranchs: potential for reconstructing environmental history and population structure. Ph.D. dissertation, Oregon State University, Corvallis, OR, USA

Smith WD, Miller JA, Heppell SS (2013) Elemental Markers in Elasmobranchs: Effects of Environmental History and Growth on Vertebral Chemistry (D Steinke, Ed.). PLoS ONE 8(10): e62423. doi:10.1371/journal.pone.0062423

Spencer K, Shafer DJ, Gauldie RW, DeCarlo EH (2000) Stable lead isotope ratios from distinct anthropogenic sources in fish otoliths: a potential nursery ground stock marker. Comp Biochem Phys A 127:273-284

Stuiver M, Polach HA (1977) Discussion: reporting of ${ }^{14} \mathrm{C}$ data. Radiocarbon 19:355-363.

Sturgeon RE, Willie SN, Yang L, Greenberg R, Spatz RO, Chen Z, Scriver C, Clancy V, Lam JW, Thorrold S (2005) Certification of a fish otolith reference material in support of quality assurance for trace element analysis. J Anal At Spectrom 20:1067

Tanaka S, Kitamura T, Mochizuki T, Kofuji K (2011) Age, growth and genetic status of the white shark (Carcharodon carcharias) from Kashima-nada, Japan. Mari Freshw Res 62: $548-556$

Taylor JKD, Mandelman JW, McLellan WA, Moore MJ, Skomal GB, Rotstein DS, Kraus SD (2012) Shark predation on North Atlantic right whales (Eubalaena glacialis) in the southeastern United States calving ground. Mar Mam Sci 29:204-212

Templeman W (1963) Distribution of Sharks in the Canadian Atlantic (with special reference to Newfoundland waters). Bull Fish Res Board Can 140:1-77 
Thorrold SR, Campana SE, Jones CM, Swart PK (1997) Factors determining $\delta^{13} \mathrm{C}$ and $\delta^{18} \mathrm{O}$ fractionation in aragonitic otoliths of marine fish. Geochim Cosmochim Acta 61: 2909-2919

Thorrold SR, Swearer SE (2009) Otolith chemistry. In: (eds. Green BS, Begg GA, Carlos G, Mapstone B) Tropical fish otoliths: Information for assessment, management and ecology. Springer, Netherlands pp 249-296

Thorrold S, Latkoczy C, Swart P, Jones C (2001) Natal homing in a marine fish metapopulation. Science 291:297-299

Tieszen LL, Fagre T (1993) Effect of diet quality and composition on the isotopic composition of respiratory $\mathrm{CO} 2$, bone collagen, bioapatite, and soft tissues. In: (eds. Lambert JB, Grupe G) Prehistoric Human Bone: Archaeology at the Molecular Level. Springer-Verlag, New York, New York, USA pp 121-155

Tillett BJ, Meekan MG, Parry D, Munksgaard N, Field IC, Thorburn D, Bradshaw CJ (2011) Decoding fingerprints: elemental composition of vertebrae correlates to age-related habitat use in two morphologically similar sharks. Mar Ecol Prog Ser 434:133-142

Tricas TC, McCosker JE (1984) Predatory Behavior of the White Shark (Carcharodon carcharias) with Notes on Its Biology. Proc of the Cal Acad Sci 43:221-238

Tucker S, Bowen WD, Iverson SJ (2007) Dimensions of diet segregation in grey seals Halichoerus grypus revealed through stable isotopes of carbon $\left(\delta^{13} \mathrm{C}\right)$ and nitrogen $\left(\delta^{15} \mathrm{~N}\right)$. Mar Ecol Prog Ser 339:271-282

Tuross N, Fogel ML, Hare PE (1988) Variability in the preservation of the isotopic composition of collagen from fossil bone. Geochim Cosmochim Acta 52: 929-935

Vander Zanden M, Rasmussen J (1999) Primary consumer $\delta^{15} \mathrm{~N}$ and $\delta^{13} \mathrm{C}$ and the trophic position of aquatic consumers. Ecology 80:1395-1404

Walker JL, Potter CW, Macko SA (1999) The diets of modern and historic bottlenose dolphin populations reflected through stable isotopes. Mar Mam Sci 15:335-350

Waring GT, Josephson E, Maze-Foley K, Rosel, PE, eds. (2011) U.S. Atlantic and Gulf of Mexico Marine Mammal Stock Assessments. NOAA Tech Mem NMFS-NE-221, 319 pp

Warner RR, Swearer SE, Caselle JE, Sheehy M, Paradis G (2005) Natal trace-elemental signatures in the otoliths of an open-coast fish. Limnol Oceanogr 50:1529-1542

Weng KC, Castilho P, Morrissette J (2005) Satellite tagging and cardiac physiology reveal niche expansion in salmon sharks. Science 310:104-106

Weng KC, O'Sullivan J, Lowe C, Winkler C, Dewar H, Block B (2007a) Movements, behavior and habitat preferences of juvenile white sharks Carcharodon carcharias in the eastern Pacific. Mar Ecol Prog Ser 338:211-224 
Weng KC, Boustany AM, Pyle P, Anderson SD, Brown A, Block BA (2007b) Migration and habitat of white sharks (Carcharodon carcharias) in the eastern Pacific Ocean. Mar Biol 152:877-894

Werry JM, Lee SY, Otway NM, Hu Y, Sumpton W (2011) A multi-faceted approach for quantifying the estuarine-nearshore transition in the life cycle of the bull shark, Carcharhinus leucas. Mar Freshwater Res 62:1421-1431

Werry JM, Planes S, Berumen ML, Lee KA, Braun CD, Clua E (2014) Reef-Fidelity and Migration of Tiger Sharks, Galeocerdo cuvier, across the Coral Sea. PLoS ONE 9: e83249, doi:10.1371/journal.pone.0083249

Wetmore SE (2001) Stable Isotopic Investigations into the Foraging Ecology of North Atlantic Right Whales. MS dissertation, University of Massachusetts Boston

Wintner S, Cliff G (1999) Age and growth determination of the white shark, Carcharodon carcharias, from the east coast of South Africa. Fish Bull 97:153-169

Wood LaFond S (2009) Dynamics of recolonization: A study of the gray seal (Halichoerus grypus) in the northeast U.S. Ph.D. dissertation, University of Massachusetts, Boston, MA, USA

Wu J, Boyle EA (1997) Lead in the western North Atlantic Ocean: Completed response to leaded gasoline phaseout. Geochim Cosmochim Acta 61:3279-3283

Yoshinaga J, Nakama A, Morita M, Edmonds JS (2000) Fish otolith reference material for quality assurance of chemical analyses. Mar Chem 69:91-97 


\title{
APPENDIX ONE
}

\section{A Review of Ecogeochemistry Approaches to Estimating Movements of Marine Animals}

\author{
Kelton W. McMahon
}

Biology Department, Woods Hole Oceanographic Institution, Woods Hole, MA, USA Red Sea Research Center, King Abdullah University of Science and Technology, Thuwal, Kingdom of Saudi Arabia

Li Ling Hamady

Massachusetts Institute of Technology/Woods Hole Oceanographic Institution Joint Program in Oceanography/Applied Ocean Science and Engineering, Woods Hole, MA, USA

Simon R. Thorrold

Biology Department, Woods Hole Oceanographic Institution, Woods Hole, MA, USA

McMahon KW, LL Hamady, SR Thorrold (2013) A review of ecogeochemistry approaches to estimating movements of marine animals. Limnology and Oceanography. 58(2): 697-714

Reprinted with permission from Limnology and Oceanography (C2013 the Association for the Sciences of Limnology and Oceanography, Inc. 


\title{
A review of ecogeochemistry approaches to estimating movements of marine animals
}

\author{
Kelton W. McMahon, a,b,1,* Li Ling Hamady, a and Simon R. Thorrold a \\ a Biology Department, Woods Hole Oceanographic Institution, Woods Hole, Massachusetts \\ ${ }^{\mathrm{b}}$ Red Sea Research Center, King Abdullah University of Science and Technology, Thuwal, Kingdom of Saudi Arabia
}

\begin{abstract}
Ecogeochemistry - the application of geochemical techniques to fundamental questions in population and community ecology — has been used in animal migration studies in terrestrial environments for several decades; however, the approach has received far less attention in marine systems. This review includes comprehensive meta-analyses of organic zooplankton $\delta^{13} \mathrm{C}$ and $\delta^{15} \mathrm{~N}$ values at the base of the food web, dissolved inorganic carbon $\delta^{13} \mathrm{C}$ values, and seawater $\delta^{18} \mathrm{O}$ values to create, for the first time, robust isoscapes for the Atlantic Ocean. These isoscapes present far greater geographic variability in multiple geochemical tracers than was previously thought, thus forming the foundation for reconstructions of habitat use and migration patterns of marine organisms. We review several additional tracers, including trace-element-to-calcium ratios and heavy element stable isotopes, to examine anadromous migrations. We highlight the value of the ecogeochemistry approach by examining case studies on three components of connectivity: dispersal and natal homing, functional connectivity, and migratory connectivity. We also discuss recent advances in compound-specific stable carbon and nitrogen isotope analyses for tracking animal movement. A better understanding of isotopic routing and fractionation factors, particularly of individual compound classes, is necessary to realize the full potential of ecogeochemistry.
\end{abstract}

Animal migrations are among nature's most spectacular and biologically significant phenomena (Dingle 1996). In an evolutionary context, the ability to move determines the genetic structure of geographically separated populations. For instance, homing to natal populations may lead to genetic isolation and significant adaptation to local environments, but only if dispersal is sufficiently low to allow local genetic variation to occur. The demographic implications of migration and dispersal to populations are equally compelling. Movement rates will determine colonization patterns of new habitats, the resiliency of populations to harvest, and the effectiveness of spatial management options designed to reverse declines in ocean biodiversity and marine-capture fisheries. The importance of an understanding of migration and connectivity is particularly timely as organisms are faced with adapting to global climate change (Roessig et al. 2004; Munday et al. 2009).

Most classic examples of long-distance migration come from terrestrial environments. In contrast, marine ecologists have, at least until recently, known remarkably little about migration, dispersal, and migratory connectivity in marine organisms (Cowen et al. 2007). This ignorance stems from the inherent logistic challenges when working in a vast and largely opaque environment and with animals capable of traveling thousands of kilometers on seasonal time scales. New archival tag technology is shedding light on some remarkable long-distance migrations by large tunas (Block et al. 2005) and sharks (Skomal et al. 2009). Acoustic tags are similarly expanding our knowledge of fish movements over smaller spatial scales (Parsons et al. 2003; Luo et al. 2009). However, not all marine species, or life

\footnotetext{
*Corresponding author:kmcmahon@whoi.edu

${ }^{1}$ Present address: Ocean Sciences Department, University of California, Santa Cruz, Santa Cruz, California
}

stages, are amenable to archival or acoustic tags. Many marine fish and invertebrates begin life as microscopic larvae that are difficult, if not impossible, to tag using conventional artificial markers (Thorrold et al. 2002). Similarly, even the most basic aspects of the early life history of many elasmobranches remain unknown, largely because neonates of many species are so rarely observed (Sims et al. 1997; Wilson and Martin 2004). Quantifying animal movement, therefore, remains a major challenge for researchers applying spatially explicit population models to conservation and management questions in marine environments (Botsford et al. 2009).

Recently, new approaches using isotopic and elemental tags as natural markers have been developed that may provide new insights on animal movements in ocean ecosystems (Graham et al. 2010; Hobson et al. 2010; Ramos and Gonzalez-Solis 2012). These techniques represent a new direction for the field of ecogeochemistry, a term first used to describe the application of stable carbon (C) and nitrogen $(\mathrm{N})$ isotopes to infer diet and trophic structure in bats (Mizutani et al. 1991). The expansion of ecogeochemistry to include the use of geochemical markers in movement studies is logical as both types of studies use many of the same isotope systems and associated analytical techniques. The term "ecogeochemical markers," therefore, refers to elemental and isotope ratios in biological tissues that are used to reconstruct movement or dietary histories of animals, and is similar to an earlier term "biogeochemical markers" reviewed by Schlesinger (1997) and discussed in the context of animal migration by Rubenstein and Hobson (2004). Our terminology is, however, less ambiguous as biogeochemistry more accurately refers to the study of biotic controls on chemical transformations in the environment (Elder 1988; Dittmar and Kattner 2003).

Ecogeochemistry is a potentially valuable approach to delineate metapopulation structure that is necessary for 
successful spatial management of many marine-capture fisheries (Crowder and Norse 2008). Natural tagging techniques rely upon geographic differences in isotope or trace element abundance that are recorded in the chemical composition of body tissues. The approach overcomes several significant difficulties with conventional techniques for studying movement (Thorrold et al. 2002). Ecogeochemical markers are induced by the environment, rather than administered by the researcher, and therefore all animals within a specified location are labeled without having to be captured and tagged. Similarly, because every individual is marked there is no need to recapture tagged animals. The approach is therefore well suited for rare species that may be unavailable to researchers for significant periods of their life history. Artificial tags also come with significant tagging and handling effects that limit their use to large-bodied animals. Natural ecogeochemical markers, on the other hand, do not affect behavior or mortality rates (Thorrold et al. 2002).

Whereas natural geochemical tags have been used to track movements of animals in terrestrial systems, there has been comparatively little use of the technique in ocean environments. One reason for this apparent oversight is that the degree of geographic variation in isotope and element abundances across marine environments may not be fully appreciated (Hobson 1999; Rubenstein and Hobson 2004). We present the results of a comprehensive meta-analysis of $\delta^{13} \mathrm{C}$ and $\delta^{15} \mathrm{~N}$ values at the base of the food web and seawater $\delta^{13} \mathrm{C}$ and $\delta^{18} \mathrm{O}$ values to create, for the first time, robust isoscapes for the Atlantic Ocean. We review several additional tracers, including trace-elementto-calcium ratios and trace element stable isotopes, to examine diadromous migrations. We also discuss recent advances in compound-specific stable carbon and nitrogen isotope analyses for tracking animal movement. We conclude by highlighting the value of an ecogeochemistry approach by examining case studies on population connectivity including dispersal and natal homing, functional connectivity, and migratory connectivity.

\section{Geographic variation}

To be successfully applied in the field, an ecogeochemistry approach must do each of the following (Hobson et al. 2010): (1) establish a geochemical map that characterizes distinct geochemical signatures in different habitats, (2) constrain tissue turnover rates that determine the period of spatial integration of geochemical signatures for a particular animal tissue, and (3) identify isotope or elemental fractionation factors between consumer and diet, or between animals and the ambient environment, that may offset geochemical signatures in animal tissues from baseline isoscape values. Whereas terrestrial isoscapes have been used to track long-distance migrations of birds and mammals for many years (Hobson 1999; Rubenstein and Hobson 2004), the degree of geographic variation in marine isotopes has only recently been recognized (West et al. 2010).

Here we synthesize geographic variability in inorganic (dissolved inorganic carbon [DIC] $\delta^{13} \mathrm{C}_{\mathrm{DIC}}$ and seawater $\delta^{18} \mathrm{O}_{\mathrm{SW}}$ ) and organic (zooplankton $\delta^{13} \mathrm{C}_{\mathrm{PLK}}$ and $\delta^{15} \mathrm{~N}_{\mathrm{PLK}}$ ) isoscapes of the Atlantic Ocean, and discuss the primary mechanisms generating this isoscape variability. These maps are necessarily constrained over space and time scales by the available data coverage. Caution should therefore be used when interpreting isoscape patterns in areas with low sample densities. All $\delta^{18} \mathrm{O}_{\mathrm{Sw}}$ data are available on the Global Oxygen-18 Database (Schmidt et al. 1999). Similarly, seawater DIC $\delta^{13} C_{\text {DIC }}$ data were mined from the Global Data Analysis Project (Key et al. 2004). Data for both the $\delta^{18} \mathrm{O}_{\mathrm{Sw}}$ and $\delta^{13} \mathrm{C}_{\mathrm{DIC}}$ isoscapes were limited to the top $100 \mathrm{~m}$ of the Atlantic Ocean. Zooplankton $\delta^{13} \mathrm{C}$ and $\delta^{15} \mathrm{~N}$ values were collated from extensive searches of Institute for Scientific Information Web of Science, Google Scholar, the Open Access library Pangaea (www. pangaea.de), and several other online data repositories. We limited the zooplankton isoscape search to samples described as net plankton $(<1 \mathrm{~mm})$, collected in the euphotic $(<150 \mathrm{~m}$ depth) and not preserved in formalin. The zooplankton isoscapes comprise a range of species, but consisted predominantly of copepods and similar-sized zooplankton. In order to achieve the best spatial coverage, no attempts were made to sort data temporally, either by season or year. However, most samples were collected no earlier than 1990. References for the data presented in the isoscapes are organized by isotope in Tables 1 and 2 .

Isoscapes were generated using Ocean Data View (ODV) version 4.5.0 (Brown 1998; Schlitzer 2002). Isotope data were displayed as color-shaded maps based on contouring of the original data using the Data Interpolating Variational Analysis (DIVA) gridding software (Barth et al. 2010). DIVA gridding takes into account coastlines, subbasins, and advection. Calculations rely on a finiteelement resolution and take into account the distance between analysis and data (observation constraint), the regularity of the analysis (smoothness constraint), and physical laws (behavior constraint).

The gridding algorithms used in ODV provided estimations of isotope values at arbitrary $(x, y)$ points based on observational data values at sampling locations $(x i, y i), i=$ $1 \ldots n$. We used misfit plots to assess the accuracy of the gridding algorithm. Misfits represent the difference between the observational data and the associated modeled value at the same location calculated by the gridding algorithm. In general, misfits should show no systematic spatial patterns, the mean of the misfits should be close to zero, and the standard deviation of the misfits close to the error in the data. We plotted gridding misfits onto the isoscape maps to visually assess the spatial distribution and magnitude of the misfits.

Inorganic $\delta^{13} \mathrm{C}$ and $\delta^{18} \mathrm{O}$ isoscapes-The $\delta^{13} \mathrm{C}$ values of DIC in surface ocean waters are influenced by physical and biological processes that create noticeable latitudinal gradients in the inorganic carbon isoscape (Figs. 1A, 2A). Air-sea gas exchange causes fractionation via two equilibration processes: the slow, $\sim 10 \mathrm{yr}$ process (Broecker and Peng 1974) of equilibration between atmospheric $\mathrm{CO}_{2}$ and oceanic DIC that includes all the inorganic carbon species, and the relatively quick equilibration process of $\mathrm{CO}_{2}$ alone. 
Table 1. Regional breakdown of references and sample sizes for the dissolved inorganic carbon $\delta^{13} \mathrm{C}_{\mathrm{DIC}}(\mathrm{Figs} .1 \mathrm{~A}, 2 \mathrm{~A})$ and seawater $\delta^{18} \mathrm{O}_{\mathrm{SW}}$ (Figs. 1B, 2B) inorganic isoscapes of the Atlantic Ocean. na $=$ no data available.

\begin{tabular}{|c|c|c|c|c|c|c|}
\hline \multirow[b]{2}{*}{ Region } & \multirow[b]{2}{*}{ Latitude range } & \multirow[b]{2}{*}{ Longitude range } & \multicolumn{2}{|c|}{ Sample size $(n)$} & \multicolumn{2}{|c|}{ References } \\
\hline & & & $\delta^{13} \mathrm{C}_{\mathrm{DIC}}$ & $\delta^{18} \mathrm{O}_{\mathrm{SW}}$ & $\delta^{13} \mathrm{C}_{\mathrm{DIC}}$ & $\delta^{18} \mathrm{O}_{\mathrm{SW}}$ \\
\hline \multirow[t]{2}{*}{ Northwest Atlantic } & $80^{\circ} \mathrm{N}$ to $35^{\circ} \mathrm{N}$ & $80^{\circ} \mathrm{W}$ to $45^{\circ} \mathrm{W}$ & 53 & 1998 & Key et al. 2004 & Schmidt et al. 1999 \\
\hline & $35^{\circ} \mathrm{N}$ to $23^{\circ} \mathrm{N}$ & $80^{\circ} \mathrm{W}$ to $70^{\circ} \mathrm{W}$ & 30 & 61 & Key et al. 2004 & Schmidt et al. 1999 \\
\hline \multirow[t]{2}{*}{ Northeast Atlantic } & $80^{\circ} \mathrm{N}$ to $35^{\circ} \mathrm{N}$ & $45^{\circ} \mathrm{W}$ to $20^{\circ} \mathrm{E}$ & 563 & 1694 & Key et al. 2004 & Schmidt et al. 1999 \\
\hline & $35^{\circ} \mathrm{N}$ to $23^{\circ} \mathrm{N}$ & $30^{\circ} \mathrm{W}$ to $5^{\circ} \mathrm{W}$ & 131 & 7 & Key et al. 2004 & Schmidt et al. 1999 \\
\hline Mediterranean Sea & $43^{\circ} \mathrm{N}$ to $30^{\circ} \mathrm{N}$ & $5^{\circ} \mathrm{W}$ to $20^{\circ} \mathrm{E}$ & na & 474 & Key et al. 2004 & Schmidt et al. 1999 \\
\hline Sargasso Sea & $35^{\circ} \mathrm{N}$ to $23^{\circ} \mathrm{N}$ & $70^{\circ} \mathrm{W}$ to $30^{\circ} \mathrm{W}$ & 578 & 14 & Key et al. 2004 & Schmidt et al. 1999 \\
\hline Gulf of Mexico & $30^{\circ} \mathrm{N}$ to $20^{\circ} \mathrm{N}$ & $100^{\circ} \mathrm{W}$ to $80^{\circ} \mathrm{W}$ & na & 75 & Key et al. 2004 & Schmidt et al. 1999 \\
\hline Tropical Atlantic & $23^{\circ} \mathrm{N}$ to $23^{\circ} \mathrm{S}$ & $90^{\circ} \mathrm{W}$ to $15^{\circ} \mathrm{E}$ & 512 & 747 & Key et al. 2004 & Schmidt et al. 1999 \\
\hline Southern Atlantic & $23^{\circ} \mathrm{S}$ to $55^{\circ} \mathrm{S}$ & $70^{\circ} \mathrm{W}$ to $20^{\circ} \mathrm{E}$ & 392 & 136 & Key et al. 2004 & Schmidt et al. 1999 \\
\hline Southern Ocean & $55^{\circ} \mathrm{S}$ to $80^{\circ} \mathrm{S}$ & $70^{\circ} \mathrm{W}$ to $20^{\circ} \mathrm{E}$ & 248 & 798 & Key et al. 2004 & Schmidt et al. 1999 \\
\hline Total & & & 2507 & 6004 & & \\
\hline
\end{tabular}

In areas of $\mathrm{CO}_{2}$ invasion, such as the North Atlantic, surface waters have relatively low $\delta^{13} \mathrm{C}$ due to the introduction of isotopically light atmospheric $\mathrm{CO}_{2}$. In areas of outgassing, like equatorial upwelling zones, surface waters become ${ }^{13} \mathrm{C}$ enriched (Lynch-Stieglitz et al. 1995).

Photosynthetic marine organisms preferentially take up the lighter carbon isotope $\left({ }^{12} \mathrm{C}\right)$ with a $\delta^{13} \mathrm{C}$ fractionation value of approximately $-19 \%$ between $\delta^{13} \mathrm{C}_{\text {DIC }}$ and fixed organic carbon (Lynch-Stieglitz et al. 1995). Organic material is then remineralized as it sinks and water masses at depth are therefore low in $\delta^{13} \mathrm{C}_{\text {DIC }}$ value relative to surface waters, typically approaching $0 \%$. Upwelling events can result in significant, low surface $\delta^{13} \mathrm{C}_{\mathrm{DIC}}$ value anomalies (Kroopnick 1985).

The observed variation in $\delta^{13} \mathrm{C}_{\mathrm{DIC}}$ is much smaller than the potential range if the effects of the dominant regional processes acted in isolation. Photosynthetic organisms prefer to incorporate ${ }^{12} \mathrm{C}$, leading to isotopically heavier DIC values in surface vs. deep waters, with variation in nutrient availability driving the amount of photosynthesis and therefore the amount of fractionation. However, this pattern is nearly offset due to temperature-driven air-sea gas exchange fractionation, leading to a relatively small range of geographic variation (Lynch-Stieglitz et al. 1995; Gruber et al. 1999). In terms of large-scale trends, there is a maximum in surface-water $\delta^{13} C_{\text {DIC }}$ values near the subAntarctic Front due to photosynthetic activity, and minimum surface-water $\delta^{13} \mathrm{C}_{\text {DIC }}$ values in the Southern Ocean due to upwelling (Gruber et al. 1999). Worldwide, anthropogenic input of isotopically light $\mathrm{CO}_{2}$ into the atmosphere has depleted surface ocean $\delta^{13} \mathrm{C}_{\text {DIC }}$ values, with a decrease of about $0.2 \%$ per decade in the Atlantic Ocean (Quay et al. 2003). The largest changes in $\delta^{13} C_{\text {DIC }}$ can be seen in the equatorial and polar regions, with little or no change in the Southern Ocean. On seasonal time scales, sub-Arctic latitudes $\left(>50^{\circ} \mathrm{N}\right)$ experience summertime $\delta^{13} \mathrm{C}_{\text {DIC }}$ increases of up to $1 \%$, and in the Sargasso Sea, near Bermuda, time-series data show annual oscillations in $\delta^{13} \mathrm{C}$ values of $0.2 \%$ to $0.3 \%$ due to changes in net community production, air-sea exchange, and vertical transport (Gruber et al. 1999).

Oxygen isotope values of seawater $\left(\delta^{18} \mathrm{O}_{\mathrm{Sw}}\right)$ show substantial regional and ocean basin-scale variability that can facilitate tracking habitat use and movement in the marine environment on a variety of scales (Figs. 1B, 2B). Seawater $\delta^{18} \mathrm{O}$ values are generally linearly correlated with salinity due to the combined effects of evaporation and freshwater input (Epstein and Mayeda 1953). Evaporation acts to move water molecules with light oxygen isotopes into the vapor phase more quickly than the heavy isotopologues, and at the same time increases surface-water salinity. Meteoric water $\delta^{18} \mathrm{O}$ values are also lower than $\delta^{18} \mathrm{O}_{\mathrm{SW}}$ values, with the magnitude of the effect dependent on the water source (Gat 1996). For instance, $\delta^{18} \mathrm{O}$ values in river waters along the east coast of the U.S.A. vary from $-2 \%$ (Vienna Standard Mean Ocean Water) in the St. Johns River, Florida, to $-11 \%$ in the Connecticut River (Walther and Thorrold 2008). Freshwater discharge, in turn, lowers $\delta^{18} \mathrm{O}_{\mathrm{SW}}$ values of coastal ocean waters and, in the case of large rivers like the Amazon and the Orinoco in the tropics and the MacKenzie and $\mathrm{Ob}$ in the Arctic, can produce anomalously low $\delta^{18} \mathrm{O}_{\mathrm{SW}}$ values that penetrate hundreds of kilometers into the Atlantic Ocean (Cooper et al. 2005). However, some coastal regions, particularly shallow, enclosed or semi-enclosed bays with limited freshwater input, can become hypersaline and produce anomalously high $\delta^{18} \mathrm{O}$ values (Lloyd 1966).

More positive $\delta^{18} \mathrm{O}_{\mathrm{SW}}$ values are typically observed in highly evaporative subtropical gyres and semi-enclosed marginal basins, including the Mediterranean Sea (maximum $\delta^{18} \mathrm{O}_{\mathrm{SW}}=1.7 \%$ [Rohling and Rijk 1999]) and the Red Sea (maximum $\delta^{18} \mathrm{O}_{\mathrm{SW}}=\sim 1.6 \%$ [Ganssen and Kroon 1991]). The most negative $\delta^{18} \mathrm{O}$ values are often found at high latitudes (nearly $-20 \%$ in the Arctic Ocean) and regions of extensive freshwater input. There are, however, at least two exceptions to the general pattern of decreasing $\delta^{18} \mathrm{O}_{\mathrm{SW}}$ values with latitude. The California Current exhibits relatively low $\delta^{18} \mathrm{O}_{\mathrm{Sw}}$ values for its latitude, due to advection of ${ }^{18} \mathrm{O}$-depleted subpolar water toward the equator along the eastern boundary of the North Pacific Ocean. Conversely, the northeastern North Atlantic exhibits high $\delta^{18} \mathrm{O}_{\mathrm{Sw}}$ values for its latitude due to poleward advection of ${ }^{18} \mathrm{O}$-enriched low-latitude water via the Gulf Stream. Vertical profiles of $\delta^{18} \mathrm{O}$ generally tend to show less variation than the horizontal surface variation, trending towards 0\%o with depth (Schmidt et 
Table 2. Regional breakdown of references and sample sizes for the zooplankton $\delta^{13} \mathrm{C}_{\mathrm{PLK}}$ (Figs. $\left.1 \mathrm{C}, 2 \mathrm{C}\right)$ and $\delta^{15} \mathrm{~N}_{\mathrm{PLK}}$ (Figs. $1 \mathrm{D}$, 2D) organic isoscapes of the Atlantic Ocean.

\begin{tabular}{|c|c|c|c|c|c|c|}
\hline \multirow[b]{2}{*}{ Region } & \multirow[b]{2}{*}{ Latitude range } & \multirow[b]{2}{*}{ Longitude range } & \multicolumn{2}{|c|}{ Sample size $(n)$} & \multicolumn{2}{|c|}{ References } \\
\hline & & & $\delta^{13} \mathrm{C}_{\mathrm{PLK}}$ & $\delta^{15} \mathrm{~N}_{\text {PLK }}$ & $\delta^{13} \mathrm{C}_{\mathrm{PLK}}$ & $\delta^{15} \mathrm{~N}_{\mathrm{PLK}}$ \\
\hline Northwest Atlantic & $80^{\circ} \mathrm{N}$ to $35^{\circ} \mathrm{N}$ & $80^{\circ} \mathrm{W}$ to $45^{\circ} \mathrm{W}$ & 203 & 69 & $\begin{array}{l}\text { Peterson and Howarth } \\
\text { 1987; Fry 1988; Fry } \\
\text { and Quinones 1994; } \\
\text { France et al. 1995; } \\
\text { Calvert 2000; Lesage } \\
\text { et al. 2001; Hobson } \\
\text { et al. 2002; Lamb and } \\
\text { Swart 2008; Lysiak } \\
\text { 2009; Pomerleau et al. } \\
\text { 2011; K. McMahon } \\
\text { unpubl. data }\end{array}$ & $\begin{array}{l}\text { Peterson and Howarth } \\
\text { 1987; Fry 1988; Hobson } \\
\text { and Montevecchi 1991; } \\
\text { Fry and Quinones 1994; } \\
\text { Calvert 2000; Waser } \\
\text { et al. 2000; Tittlemier } \\
\text { et al. 2000; Lesage et al. } \\
\text { 2001; Hobson et al. } \\
\text { 2002; Montoya et al. } \\
\text { 2002; Estrada et al. } \\
\text { 2003; Lamb and Swart } \\
\text { 2008; Lysiak 2009; } \\
\text { Pomerleau et al. 2011; } \\
\text { K. McMahon unpubl. } \\
\text { data }\end{array}$ \\
\hline Northeast Atlantic & $\begin{array}{l}35^{\circ} \mathrm{N} \text { to } 23^{\circ} \mathrm{N} \\
80^{\circ} \mathrm{N} \text { to } 35^{\circ} \mathrm{N}\end{array}$ & $\begin{array}{l}80^{\circ} \mathrm{W} \text { to } 70^{\circ} \mathrm{W} \\
45^{\circ} \mathrm{W} \text { to } 20^{\circ} \mathrm{E}\end{array}$ & $\begin{array}{l}12 \\
72\end{array}$ & $\begin{array}{r}2 \\
68\end{array}$ & $\begin{array}{l}\text { Hobson et al. 1995; } \\
\text { Calvert 2000; } \\
\text { Hofmann et al. 2000; } \\
\text { Polunin et al. 2001; } \\
\text { Sato et al. 2002; Das } \\
\text { et al. 2003; Le Loc'h } \\
\text { and Hily 2005; } \\
\text { Tamelander et al. } \\
\text { 2006; Le Loc'h et al. } \\
\text { 2008; Petursdottir } \\
\text { et al. 2008, 2010; } \\
\text { Hirch 2009; Pajuelo } \\
\text { et al. 2010; Kurten } \\
\text { et al. 2012; K. } \\
\text { McMahon unpubl. } \\
\text { data }\end{array}$ & $\begin{array}{l}\text { Hobson et al. 1995; } \\
\text { Waser et al. 2000; } \\
\text { Calvert 2000; Sato et al. } \\
\text { 2002; Bode et al. 2003, } \\
\text { 2007; Jennings and } \\
\text { Warr 2003; Mahaffey } \\
\text { et al. 2004; } \\
\text { Kiriakoulakis et al. } \\
\text { 2005; Sommer et al. } \\
\text { 2005; Tamelander et al. } \\
\text { 2006; Le Loc'h et al. } \\
\text { 2008; Petursdottir et al. } \\
\text { 2008, 2010; Hirch } \\
\text { 2009; Pajuelo et al. } \\
\text { 2010; Kurten et al. } \\
\text { 2012; K. McMahon } \\
\text { unpubl. data }\end{array}$ \\
\hline Mediterranean Sea & $\begin{array}{l}35^{\circ} \mathrm{N} \text { to } 23^{\circ} \mathrm{N} \\
43^{\circ} \mathrm{N} \text { to } 30^{\circ} \mathrm{N}\end{array}$ & $\begin{array}{l}30^{\circ} \mathrm{W} \text { to } 5^{\circ} \mathrm{W} \\
5^{\circ} \mathrm{W} \text { to } 20^{\circ} \mathrm{E}\end{array}$ & $\begin{array}{l}17 \\
13\end{array}$ & $\begin{array}{l}41 \\
15\end{array}$ & $\begin{array}{l}\text { Pinnegar et al. 2000; } \\
\text { Polunin et al. 2001; } \\
\text { Stuck et al. 2001; } \\
\text { Carlier et al. 2007; } \\
\text { Harmelin-Vivien et al. } \\
\text { 2008; Fanelli et al. } \\
\text { 2009, 2011 }\end{array}$ & $\begin{array}{l}\text { Pinnegar et al. 2000; } \\
\text { Stuck et al. 2001; Bode } \\
\text { et al. 2007; Carlier et } \\
\text { al. 2007; Harmelin- } \\
\text { Vivien et al. 2008; } \\
\text { Fanelli et al. 2009, } \\
2011\end{array}$ \\
\hline Sargasso Sea & $35^{\circ} \mathrm{N}$ to $23^{\circ} \mathrm{N}$ & $70^{\circ} \mathrm{W}$ to $30^{\circ} \mathrm{W}$ & 9 & 3 & $\begin{array}{l}\text { Sackett et al. 1965; } \\
\text { Fry and Quinones } \\
\text { 1994; Hofmann et al. } \\
\text { 2000; K. McMahon } \\
\text { unpubl. data }\end{array}$ & $\begin{array}{l}\text { Altabet and Small 1990; } \\
\text { Fry and Quinones } \\
\text { 1994; Montoya et al. } \\
\text { 2002; K. McMahon } \\
\text { unpubl. data }\end{array}$ \\
\hline Gulf of Mexico & $30^{\circ} \mathrm{N}$ to $20^{\circ} \mathrm{N}$ & $100^{\circ} \mathrm{W}$ to $80^{\circ} \mathrm{W}$ & 29 & 12 & $\begin{array}{l}\text { Macko et al. 1984; } \\
\text { Holl et al. 2007; } \\
\text { Lamb and Swart } \\
2008\end{array}$ & $\begin{array}{l}\text { Thayer et al. 1983; } \\
\text { Macko et al. 1984; } \\
\text { Holl et al. 2007; } \\
\text { Lamb and Swart } \\
2008\end{array}$ \\
\hline Tropical Atlantic & $23^{\circ} \mathrm{N}$ to $23^{\circ} \mathrm{S}$ & $90^{\circ} \mathrm{W}$ to $15^{\circ} \mathrm{E}$ & 53 & 69 & $\begin{array}{l}\text { Sackett et al. 1965; } \\
\text { Hofmann et al. } 2000\end{array}$ & $\begin{array}{l}\text { Checkley and Entezroth } \\
\text { 1985; Calvert 2000; } \\
\text { Montoya et al. 2002; } \\
\text { McClelland et al. 2003; } \\
\text { Mahaffey et al. 2004; } \\
\text { Abed-Navandi and } \\
\text { Dworschak 2005; K. } \\
\text { McMahon unpubl. } \\
\text { data }\end{array}$ \\
\hline
\end{tabular}


Table 2. Continued.

\begin{tabular}{|c|c|c|c|c|c|c|}
\hline \multirow[b]{2}{*}{ Region } & \multirow[b]{2}{*}{ Latitude range } & \multirow[b]{2}{*}{ Longitude range } & \multicolumn{2}{|c|}{ Sample size $(n)$} & \multicolumn{2}{|c|}{ References } \\
\hline & & & $\delta^{13} \mathrm{C}_{\mathrm{PLK}}$ & $\delta 15 \mathrm{~N}_{\text {PLK }}$ & $\delta^{13} \mathrm{C}_{\mathrm{PLK}}$ & $\delta^{15} \mathrm{~N}_{\text {PLK }}$ \\
\hline Southern Atlantic & $23^{\circ} \mathrm{S}$ to $55^{\circ} \mathrm{S}$ & $70^{\circ} \mathrm{W}$ to $20^{\circ} \mathrm{E}$ & 68 & 35 & $\begin{array}{l}\text { Sackett et al. 1965; } \\
\text { Matsuura and Wada } \\
\text { 1994; Hofmann et al. } \\
\text { 2000; Schmidt et al. } \\
\text { 2003; Quillfeldt et al. } \\
\text { 2005; Laakmann and } \\
\text { Auel 2010; Kohler et al. } \\
\text { 2011 }\end{array}$ & $\begin{array}{l}\text { Matsuura and Wada } \\
\text { 1994; Sigman et al. } \\
\text { 1999; Schmidt et al. } \\
\text { 2003; Mahaffey et al. } \\
\text { 2004; Quillfeldt et al. } \\
\text { 2005; Laakmann and } \\
\text { Auel 2010; Kohler et al. } \\
\text { 2011; K. McMahon } \\
\text { unpubl. data }\end{array}$ \\
\hline Southern Ocean & $55^{\circ} \mathrm{S}$ to $80^{\circ} \mathrm{S}$ & $70^{\circ} \mathrm{W}$ to $20^{\circ} \mathrm{E}$ & 70 & 51 & $\begin{array}{l}\text { Wada et al. 1987; } \\
\text { Hofmann et al. 2000; } \\
\text { Dunton 2001; Nyssen et } \\
\text { al. 2002; Corbisier et al. } \\
\text { 2004; Quillfeldt et al. } \\
\text { 2005; Stowasser et al. } \\
\text { 2012 }\end{array}$ & $\begin{array}{l}\text { Wada et al. 1987; Sigman } \\
\text { et al. 1999; Dunton } \\
\text { 2001; Nyssen et al. } \\
\text { 2002; Schmidt et al. } \\
\text { 2003; Quillfeldt et al. } \\
\text { 2005; Stowasser et al. } \\
\text { 2012 }\end{array}$ \\
\hline
\end{tabular}

al. 1999). However, as with horizontal variation, vertical profiles of $\delta^{18} \mathrm{O}$ generally follow the salinity profile patterns.

Organic isoscapes-We synthesized results from published organic stable carbon and nitrogen isotope data for zooplankton in the Atlantic Ocean (Table 2). Isoscapes of zooplankton carbon $\left(\delta^{13} \mathrm{C}_{\mathrm{PLK}}[\right.$ Figs. $\left.1 \mathrm{C}, 2 \mathrm{C}]\right)$ and nitrogen $\left(\delta^{15} \mathrm{~N}_{\text {PLK }}\right.$ [Figs. 1D, 2D]) show substantial variation spatially, on regional and ocean basin scales. The $\delta^{13} \mathrm{C}$ value of primary producers is strongly influenced by the $\delta^{13} \mathrm{C}_{\text {DIC }}$ value of the local DIC pool (Fig. 1A), and thus spatial variability in $\delta^{13} \mathrm{C}$ at the base of the food web $\left(\delta^{13} \mathrm{C}_{\mathrm{Base}}\right)$ is primarily driven by the same physical parameters (temperature and $\left[\mathrm{CO}_{2}\right]_{\mathrm{aq}}$ ) that influence $\delta^{13} \mathrm{C}_{\text {DIC }}$ values. However, internal biological parameters can also influence phytoplankton $\delta^{13} \mathrm{C}$ values and thus obscure these patterns (Fry and Wainright 1991; Hinga et al. 1994; Kelly 2000). Nearshore and benthic systems with higher nutrient concentrations, and thus higher productivity, are typically more ${ }^{13} \mathrm{C}$ enriched than offshore, pelagic systems (France 1995). This gradient can be particularly pronounced in regions of strong upwelling or seasonal coastal phytoplankton blooms (Pancost et al. 1997). In addition, tighter terrestrial-littoral and benthic-pelagic coupling in nearshore systems can increase inputs from ${ }^{13} \mathrm{C}$-heavy benthic algae and $\mathrm{C}_{4}$ marsh plants (France 1995).

While nitrogen isotopes are commonly used to calculate trophic position of consumers in the marine environment, the microalgae that support marine food webs typically have $\delta^{15} \mathrm{~N}_{\text {Base }}$ values that change spatially and seasonally due to incomplete consumption of nitrogenous nutrients (Altabet and Francois 2001; Lourey et al. 2003), and differential utilization of nitrogen sources (nitrate, ammonium, $\mathrm{N}_{2}$ ) in space and time (Dugdale and Goering 1967; Caraco et al. 1998; Dore et al. 2002). In the Atlantic Ocean, the lowest $\delta^{15} \mathrm{~N}_{\text {PLK }}$ values are found in the oligotrophic
Sargasso Sea, where diazotrophic cyanobacteria fix $\mathrm{N}_{2}$ $(0 \%)$ into organic nitrogen (Montoya et al. 2002). In the higher latitudes of the Atlantic, $\mathrm{NO}_{3}^{-}(\sim 5 \%)$ is the major source of nitrogen for marine phytoplankton. Decomposition of particulate organic matter (POM) results in preferential losses in ${ }^{14} \mathrm{~N}$ and creates a gradient of increasing $\delta^{15} \mathrm{~N}_{\text {POM }}$ with depth in the ocean that is particularly evident in areas of high productivity (Saino and Hattori 1980).

There can be significant variability in $\delta^{15} \mathrm{~N}_{\mathrm{POM}}$ and $\delta^{15} \mathrm{~N}_{\text {PLK }}$ values on smaller spatial scales as well. Anthropogenic sources of nitrogen, including fertilizers, sewage and agricultural animal waste, and atmospheric deposition via fossil fuel burning, can have significant effects on coastal $\delta 15 \mathrm{~N}_{\text {POM }}$ (Heaton 1986; Hansson et al. 1997). Local eutrophication from fertilizers and increased urbanization can lead to increases in primary production and denitrification, both of which generate an enriched $\delta^{15} \mathrm{~N}_{\text {POM }}$ isotopic signal (McClelland et al. 1997) that can be reflected in the $\delta^{15} \mathrm{~N}$ values of tissues in resident fishes and invertebrates (Griffin and Valiela 2001).

Both $\delta^{13} \mathrm{C}_{\text {PLK }}$ and $\delta^{15} \mathrm{~N}_{\text {PLK }}$ values at the base of coastal food webs can also show significant temporal variability (Fig. 3), owing to changes in primary productivity and nutrient sources, microbial nitrogen cycling, temperature, and phytoplankton species growth rates and composition (Cifuentes et al. 1988; Goering et al. 1990; Ostrom et al. 1997; Caraco et al. 1998). Temporal variability can be pronounced on small spatial scales, as shown in the seasonal patterns of $\delta^{13} \mathrm{C}_{\mathrm{POM}}$ and $\delta^{15} \mathrm{~N}_{\mathrm{POM}}$ values in the Delaware Estuary (Cifuentes et al. 1988). In early spring, POM reached a maximum of $-17 \%$ in $\delta^{13} \mathrm{C}$ and a minimum of $+2.3 \%$ in $\delta^{15} \mathrm{~N}$. By summer, after the spring bloom had passed, the $\delta^{13} \mathrm{C}_{\mathrm{POM}}$ maximum disappeared and more negative values, down to $-26 \%$, were recorded within the estuary, whereas a $\delta^{15} \mathrm{~N}_{\text {POM }}$ maximum of $+18.7 \%$ was located in the central portion of the estuary. The large seasonal variability was associated with shifts in available $\mathrm{N}$ sources, as $\mathrm{NH}_{4}^{+}$ 

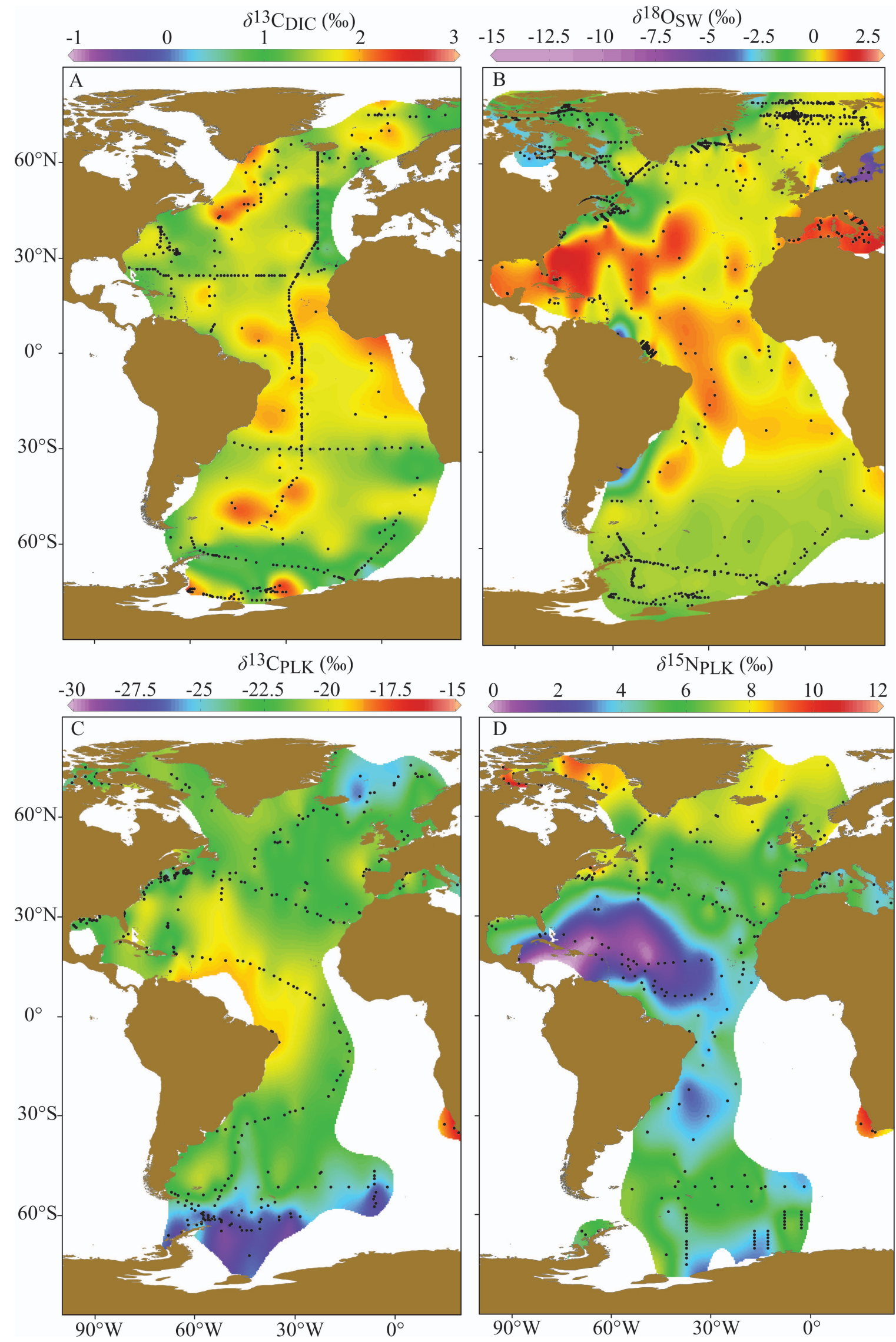
utilization far exceeded $\mathrm{NO}_{3}^{-}$in the winter, and increases in productivity and decreases in nutrient availability during the spring bloom. The transfer of temporal variability in isotope values at the base of food webs to upper trophic consumers tends to diminish with increasing trophic level. Relatively slow tissue turnover rates in higher-trophic-level consumers may effectively lead to temporal averaging of much of the observed seasonal variability baseline values (Goering et al. 1990; O'Reilly et al. 2002). However, there is evidence that seasonal differences in $\delta^{13} \mathrm{C}$ and $\delta^{15} \mathrm{~N}$ can be observed in upper-trophic-level consumers in at least some situations (Goering et al. 1990; Riera and Richard 1997; Vizzini and Mazzola 2003).

Seasonal variability in isoscape structure can even be seen at regional and ocean basin scales. In general, seasonal variability is higher at high latitudes, with larger variations in temperature and productivity compared to low-latitude, tropical systems. Seasonal deviations in copepod $\delta^{13} \mathrm{C}$ and $\delta^{15} \mathrm{~N}$ values between the highly productive late-winter and early-spring months compared to the summer and early-fall months were similar on the western and eastern sides of the North Atlantic (Fig. 3). $\delta^{13} \mathrm{C}$ values varied seasonally by $2 \%$ to $3 \%$, whereas $\delta^{15} \mathrm{~N}$ values varied by upwards of $6 \%$. This variability obviously needs to be considered when using isoscapes to track movement of animals through different habitats, particularly where animals may be selectively using different habitats during different times of the year.

Diadromous isoscapes - Quantifying movements of fishes between marine and freshwater environments has proved to be particularly amenable to ecogeochemistry approaches. Significant compositional differences between freshwater and ocean water generate distinctive isoscape gradients across the two systems. Stable carbon and oxygen isotopes provide perhaps the best tracer of diadromous movements, as spatial and temporal variability of freshwater endmembers are generally higher than the relevant seawater end-members. Both $\delta^{13} \mathrm{C}_{\mathrm{DIC}}$ and $\delta^{18} \mathrm{O}_{\mathrm{H} 2 \mathrm{O}}$ are lower in almost all freshwater systems compared to the coastal ocean (Kerr et al. 2007; Walther and Thorrold 2008). Moreover, as mentioned earlier, salinity is generally linearly correlated with $\delta^{18} \mathrm{O}_{\mathrm{H} 2 \mathrm{O}}$ and therefore may allow for more subtle reconstructions of estuarine habitat use beyond a binary distinction between marine and freshwater habitats. Interestingly, Kerr et al. (2007) found that $\delta^{13} \mathrm{C}_{\text {DIC }}$ was both tightly correlated with salinity and showed less seasonal and interannual variability than $\delta^{18} \mathrm{O}_{\mathrm{H} 2 \mathrm{O}}$ in a Chesapeake Bay tributary. Based on a high correlation between $\delta^{13} \mathrm{C}_{\mathrm{DIC}}$ and otolith $\delta^{13} \mathrm{C}$ values, $\delta^{13} \mathrm{C}$ was a better tracer of habitat use as a function of salinity for fish populations, at least in the Patuxent River.

Several elemental ratios also differ significantly among freshwater and ocean waters. Notably, the concentrations of those elements in calcified tissues reflect dissolved concentrations of the elements in the ambient environment (Bath et al. 2000; Elsdon and Gillanders 2004; Dorval et al. 2005). Strontium ( $\mathrm{Sr}$ ) remains the most widely used element to track diadromous migrations (Elsdon et al. 2008). The size of the oceanic reservoirs of $\mathrm{Sr}$ and calcium $(\mathrm{Ca})$, along with residence times of millions of years, results in relatively invariant seawater $\mathrm{Sr}: \mathrm{Ca}$ ratios $\left(8.5 \mathrm{mmol} \mathrm{mol}^{-1}\right.$; De Villiers 1999), and similarly invariant ${ }^{87} \mathrm{Sr}:{ }^{86} \mathrm{Sr}$ ratios of 0.70198 (Ando et al. 2010). Alternatively, freshwater values show significant geographic and temporal variability, with $\mathrm{Sr}: \mathrm{Ca}$ ratios ranging from 0.27 to $19.18 \mathrm{mmol} \mathrm{mol}^{-1}$ (Brown and Severin 2009). Similarly, ${ }^{87} \mathrm{Sr}:{ }^{86} \mathrm{Sr}$ ratios reflect bedrock values of watersheds and typically vary from $\sim 0.704$ in basaltic drainages to at least 0.75 in older highly radiogenic granites (Barnett-Johnson et al. 2010; Muhlfeld et al. 2012). It remains, therefore, necessary to quantify $\mathrm{Sr}: \mathrm{Ca}$ and ${ }^{87} \mathrm{Sr}:{ }^{86} \mathrm{Sr}$ ratios in freshwater endmembers in the systems of interest. Nonetheless, profiles of $\mathrm{Sr}: \mathrm{Ca}$ and ${ }^{87} \mathrm{Sr}:{ }^{86} \mathrm{Sr}$ across archival tissues, including fish otoliths and scales, have often revealed unambiguous evidence of fish movement between freshwater and marine habitats (Tzeng and Tsai 1994; Limburg 2001; McCulloch et al. 2005).

Dissolved barium (Ba) concentrations also often differ significantly between freshwater and coastal marine waters. In seawater, Ba typically follows a nutrient-like distributions with relatively high concentrations in riverine and coastal areas compared to slope and oceanic waters (Shen and Sanford 1990). Freshwater dissolved Ba concentrations vary by nearly an order of magnitude globally around a worldwide riverine average of $0.10 \mu \mathrm{mol} \mathrm{L}-1$ (Gaillardet et al. 2003). Conversely, open-ocean surface values are typically 0.01 to $0.02 \mu \mathrm{mol} \mathrm{L}^{-1}$, increasing to $0.03 \mu \mathrm{mol} \mathrm{L}-1$ and $0.09 \mu \mathrm{mol} \mathrm{L}^{-1}$ at $3 \mathrm{~km}$ depth in the North Atlantic and deep North Pacific, respectively (Bruland and Lohan 2004). Therefore, episodic upwelling of the relatively high $\mathrm{Ba}$ concentrations found in colder, nutrient-rich deep waters can also be a significant source of $\mathrm{Ba}$ variability to the ocean surface waters (Lea et al. 1989; Kingsford et al. 2009). Similarly, episodic coastal flooding events may also significantly increase dissolved Ba levels in coastal waters over relatively short time scales (Alibert et al. 2003). While $\mathrm{Ba}: \mathrm{Ca}$ and $\mathrm{Ba}: \mathrm{Sr}$ ratios have been used to infer diadromous movements in at least one species (McCulloch et al. 2005), interpretation of Ba data is more difficult than

Fig. 1. (A) Dissolved inorganic carbon $\left(\delta^{13} \mathrm{C}_{\mathrm{DIC}}\right)$ isoscape of seawater $(n=2507)$ from the upper $100 \mathrm{~m}$ of the Atlantic Ocean. (B) Oxygen $\left(\delta^{18} \mathrm{O}_{\mathrm{SW}}\right)$ isoscape of seawater $(n=6004)$ from the upper $100 \mathrm{~m}$ of the Atlantic Ocean and Mediterranean Sea. $(\mathrm{C}) \mathrm{Zooplankton}$ organic carbon $\left(\delta^{13} \mathrm{C}_{\mathrm{PLK}}\right)$ isoscape $(n=546)$ from the upper $150 \mathrm{~m}$ of the Atlantic Ocean and Mediterranean Sea. (D) Zooplankton organic nitrogen $\left(\delta^{15} \mathrm{~N}_{\mathrm{PLK}}\right)$ isoscape $(n=365)$ from the upper $150 \mathrm{~m}$ of the Atlantic Ocean and Mediterranean Sea. Contour plots were generated in Ocean Data View (Schlitzer 2002) from a meta-analysis of published data (regional breakdown and references in Tables 1 and 2). Black dots indicate sample locations. 

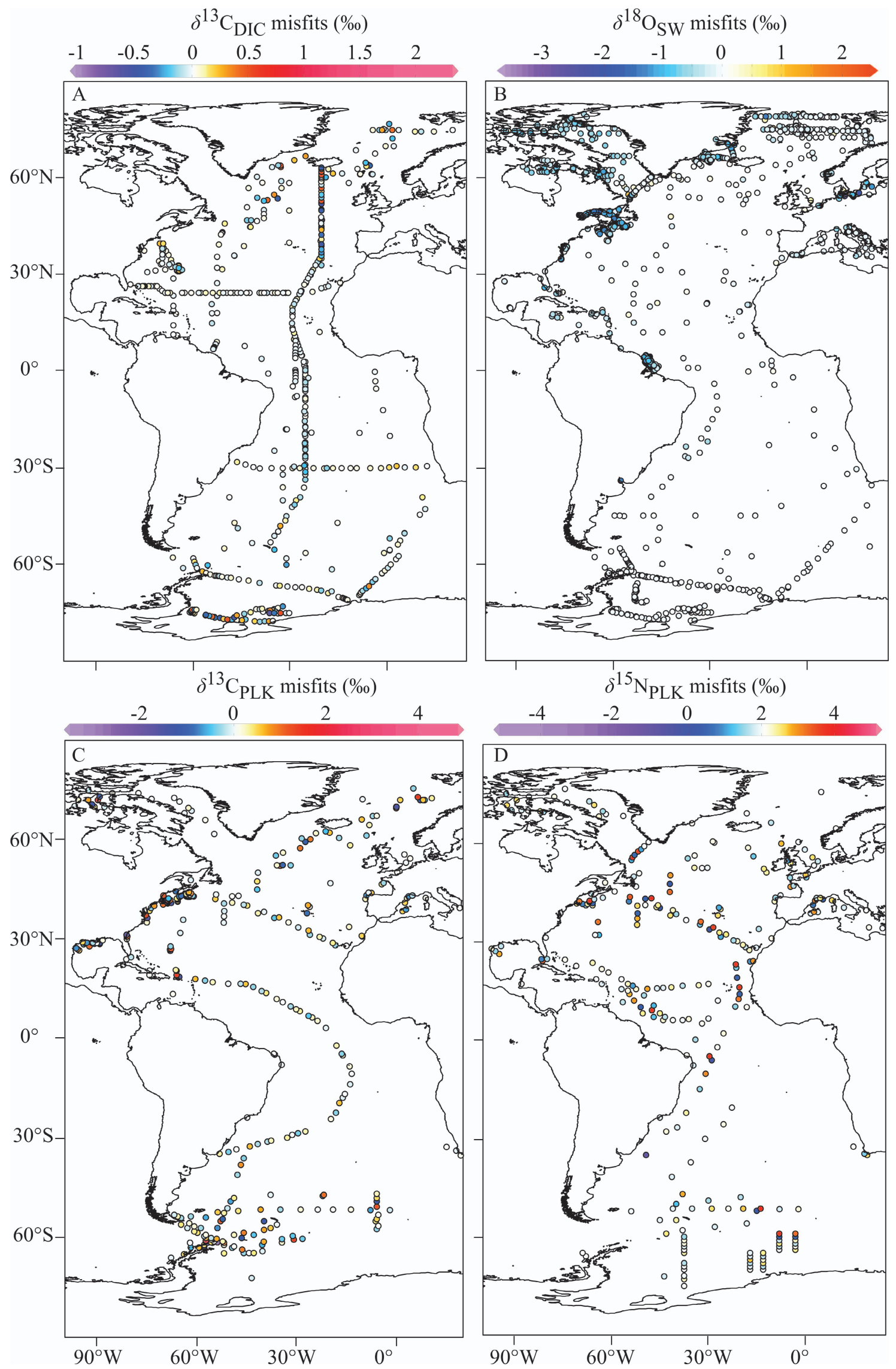

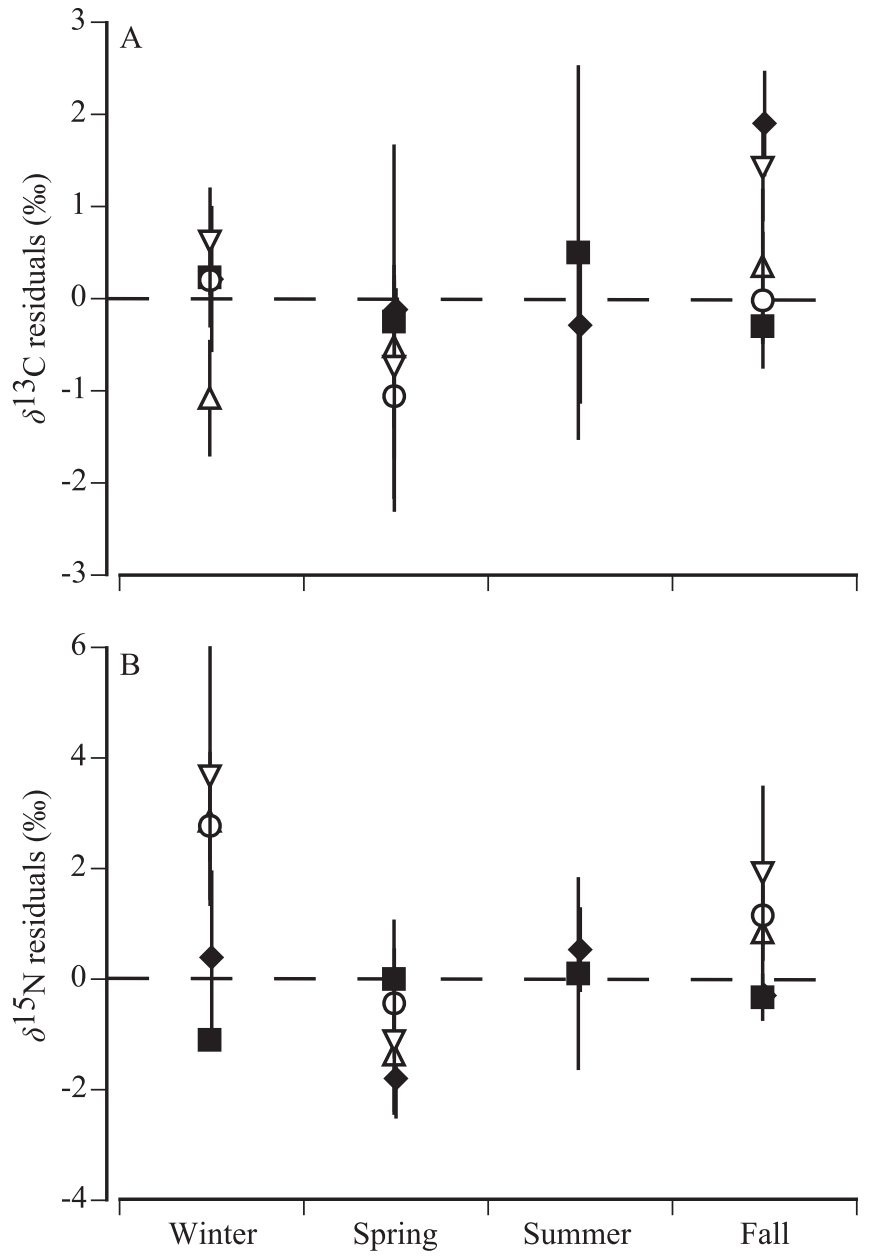

Fig. 3. Seasonal variability (residuals from the mean) in zooplankton (A) $\delta^{13} \mathrm{C}$ values and (B) $\delta^{15} \mathrm{~N}$ values from the Northwest Atlantic Ocean (filled symbols; Lysiak 2009) and Northeast Atlantic Ocean (open symbols; Kurten et al. 2012). Different symbols represent different sites within a region.

for $\mathrm{Sr}$ because of the confounding influence of these shortterm temporal variations in dissolved $\mathrm{Ba}$ concentrations.

While $\mathrm{Sr}$ and $\mathrm{Ba}$ are typically the most commonly used trace elements, there are a number of other elements, including magnesium $(\mathrm{Mg})$, potassium $(\mathrm{K})$, manganese $(\mathrm{Mn})$, copper $(\mathrm{Cu})$, zinc $(\mathrm{Zn})$, and lead $(\mathrm{Pb})$ that have been used to examine habitat use and movement patterns between fresh and marine environs (Thorrold et al. 1998a; Milton and Chenery 2001). Variations in several of these other trace elements (both the isotope values and element-to-calcium ratios) can reflect natural, watershed variability and anthropogenic point sources. In the large Fly River, Papua New Guinea, water contaminated by a nearby copper mine can have mean total dissolved copper concentrations reach $20 \mu \mathrm{g} \mathrm{L}^{-1}$ at the confluence of the Ok Tedi and Fly Rivers $800 \mathrm{~km}$ from the coast and remain as high as $8 \mu \mathrm{g} \mathrm{L}^{-1} 400 \mathrm{~km}$ downstream (Storey and Figa 1998). Geffen et al. (1998) showed that the uptake of mercury and lead into fish otoliths was related to water concentrations of these metals.

\section{Applications}

In its most basic sense, ecological connectivity represents the movement of individuals between spatially distinct locations (Harrison and Bjorndal 2006). Animals travel among habitats over daily, seasonal, and ontogenetic time scales, which play an important role in the ecology of individuals and populations, as well as the resilience of ecosystem structure and functioning. Here, we illustrate the use of ecogeochemistry to address three components of connectivity: dispersal and natal homing, functional connectivity, and migratory connectivity. We define these terms as follows to avoid any confusion. Dispersal is the intergenerational spread of propagules away from their natal location, whereas natal homing represents the return of individuals to their place of birth after moving away from the place that they were spawned. Functional connectivity is the movement of individuals among spatially separated habitats resulting from interactions between behavioral processes and seascape configuration. Finally, migratory connectivity refers to movement of individuals between locations due to shifts in some key resource, such as food availability or breeding requirements, often on seasonal time scales.

Natal origins-Theoretical studies suggest that the proportion of pelagic larvae retained within or transported among geographically separated subpopulations is a critical determinant of processes that drive local and meta-population dynamics of marine species (Cowen and Sponaugle 2009). Tracking larval dispersal in marine fishes is challenging because many marine species are highly fecund, producing millions of tiny offspring that are difficult to tag without introducing significant handling effects. In addition, the high mortality rate of early life history stages makes the probability of recovering tagged individuals extremely low. Dealing with these limitations over the potentially large spatial and temporal scales at which these linkages occur makes the use of conventional mark-recapture techniques daunting (Thorrold et al. 2002).

$\leftarrow$

Fig. 2. (A) Gridded misfits for the dissolved inorganic carbon $\left(\delta^{13} \mathrm{C}_{\mathrm{DIC}}\right)$ isoscape $(n=2507)$ from the upper $100 \mathrm{~m}$ of the Atlantic Ocean (Fig. 1A). Mean gridded misfits $=0.02 \%$, root mean square $=0.29 \%$. (B) Gridded misfits for the oxygen $\left(\delta^{18} \mathrm{O}_{\text {sw }}\right)$ isoscape $(n=$ 6004) from the upper $100 \mathrm{~m}$ of the Atlantic Ocean and Mediterranean Sea (Fig. 1B). Mean gridded misfits $=0.2 \%$, root mean square $=$ $1.14 \%$. (C) Gridded misfits for the zooplankton organic carbon $\left(\delta^{13} \mathrm{C}_{\mathrm{PLK}}\right)$ isoscape $(n=546)$ from the upper $150 \mathrm{~m}$ of the Atlantic Ocean and Mediterranean Sea (Fig. 1C). Mean gridded misfit $=0.01 \%$, root mean square $=0.89 \%$. (D) Gridded misfits for the zooplankton organic nitrogen $\left(\delta^{15} \mathrm{~N}_{\mathrm{PLK}}\right)$ isoscape $(n=365)$ from the upper $150 \mathrm{~m}$ of the Atlantic Ocean and Mediterranean Sea (Fig. 1D). Mean gridded misfits $=0.01 \%$, root mean square $=0.43 \%$. All gridded misfits were calculated in Ocean Data View (Schlitzer 2002). 
A number of studies have employed ecogeochemistry as a natural tracer technique to track larval dispersal and natal homing (Elsdon et al. 2008).

Swearer et al. (1999) used growth histories and trace element profiles from bluehead wrasse (Thalassoma bifasciatum) otoliths as archival recorders of potential dispersal pathways. The authors hypothesized that larvae retained in the nutrient-rich, productive coastal water masses around St. Croix would have faster growth rates and larger size at settlement than individuals dispersing to St. Croix from nutrient-poor, open-ocean waters. In addition, the larvae retained around St. Croix would also have high concentrations of particle-reactive trace elements (particularly lead $[\mathrm{Pb}])$ in their otoliths, reflecting the locally elevated trace element concentrations relative to oceanic waters. The authors found that a high proportion of larvae recruiting to reefs on the leeward side of St. Croix, particularly in the summer, were large, fast-growing individuals with high $\mathrm{Pb}$ concentrations in their otoliths that, together, were characteristic of local retention around St. Croix. Conversely, fall recruitment events on the windward side of the island were composed primarily of small, slow-growing individuals whose otoliths had a threefold lower $\mathrm{Pb}$ concentration, characteristic of dispersal from nutrient-depleted offshore environs.

Thorrold et al. $(1998 b, 2001)$ used elemental ratios and stable carbon and oxygen isotopes in otoliths to examine natal homing in weakfish (Cynoscion regalis). During its annual migration along the east coast of the United States, C. regalis moves from overwintering grounds south and offshore of Cape Hatteras to spawning locations in estuaries throughout the species' range (Florida to Maine). The authors found that geochemical values in otoliths of juvenile weakfish varied significantly among five estuaries along the east coast of the United States. Using these estuarine-specific signatures, Thorrold et al. (2001) showed high levels of natal homing in spawning weakfish $(60 \%$ to $81 \%$ ), with straying largely confined to locations adjacent to natal estuaries. These findings were in contrast to earlier population genetics work on $C$. regalis that showed little genetic structuring throughout the region.

More recently, ecogeochemistry approaches have been used to identify natal origins of ocean-phase anadromous fish (Walther and Thorrold 2010) and to locate marine feeding grounds of anadromous fish caught upon returning to natal rivers to spawn (MacKenzie et al. 2011). Walther and coworkers initially identified unique geochemical signatures in otoliths of young-of-the-year American shad (Alosa sapidissima) from a total of 20 rivers along the east coast of the United States (Walther and Thorrold 2008). They then used river-specific values in $\delta^{18} \mathrm{O},{ }^{87} \mathrm{Sr}:{ }^{86} \mathrm{Sr}$, $\mathrm{Sr}: \mathrm{Ca}$, and $\mathrm{Ba}: \mathrm{Ca}$ in the core region of adult otoliths to determine natal origins of ocean-phase subadults collected in the Gulf of Maine (Walther and Thorrold 2010). Almost all of the fish were assigned to one of only two rivers, suggesting that shad did not mix extensively during ocean residency. Rather, immature fish from river populations appear to exhibit diverse migratory behaviors and therefore are likely to encounter variable ocean conditions and predators while resident in coastal oceans. MacKenzie and colleagues studied the inverse problem of identifying marine feeding grounds of Atlantic salmon (Salmo salar) from collections of adults returning to spawn in natal rivers after 3 to $5 \mathrm{yr}$ of ocean residency. MacKenzie et al. (2011) found that fish returning to different rivers around the U.K. over an $18 \mathrm{yr}$ period had consistently distinct $\delta^{13} \mathrm{C}$ values in scale material deposited during ocean residency. Based on a correlation between sea surface temperature and scale $\delta^{13} \mathrm{C}$ values, they inferred that fish from the different rivers must have been spatially segregated on marine feeding grounds in the North Atlantic. Conventional tagging studies had been unable to resolve questions of the location of ocean residency despite a million salmon tagged since the 1950s in English and Welsh rivers (MacKenzie et al. 2011).

Functional connectivity-Marine seascapes are complex mosaics of patchily distributed habitats, including coastal wetlands, nearshore habitats, and offshore systems that are linked through fish movement. Recently, attention has been directed at the issue of preserving critical seascape functions as well as habitat types, with particular emphasis on functional connectivity (McCook et al. 2009). Initially developed in landscape ecology, functional connectivity is an emergent property of species-seascape interactions and is a particularly useful concept for assessing functional linkages among juvenile nursery habitats and coral reefs using ecogeochemistry.

Fry et al. (1999) used a bulk stable isotope approach to identify the importance of juvenile nursery habitats in shallow seagrass meadows and mangrove-lined bays to pink shrimp (Farfantepenaeus duorarum) caught offshore in the Tortugas and Sanibel fisheries. Shrimp from seven seagrass meadows had $\delta^{13} \mathrm{C}$ values $(-15 \%$ to $-9 \%$ ) that were distinct from those collected in 12 mangrove-lined bays $(-29 \%$ to $-18 \%$ ). Approximately $60 \%$ of juvenile individuals captured in the offshore fisheries had similar signatures to the offshore residents. The other $40 \%$ of juvenile shrimp were classified as recent immigrants, most of which showed seagrass values with only a few showing mangrove values. These results supported the hypothesis that the major spring peak of pink shrimp recruitment into the South Florida offshore fisheries is fueled by ontogenetic migration from seagrass meadows.

Nakamura et al. (2008) used a similar bulk muscle $\delta^{13} \mathrm{C}$ approach to infer black-tail snapper (Lutjanus fulvus) movement from coastal mangroves to coral reefs around Ishigaki Island, Japan. The authors identified distinct mangrove $(-23 \%$ to $-17 \%)$ and coral reef $(-16 \%$ to $-8 \%$ ) habitat signatures using local prey and congeneric resident fish, mangrove red snapper (Lutjanus argentimaculatus) and humpback red snapper (Lutjanus gibbus), respectively. The majority of small L. fulvus (88\%) on coral reefs had muscle $\delta^{13} \mathrm{C}$ values indicative of residence in the mangrove habitat, suggesting recent immigration from a coastal wetland nursery. Due to the fast turnover rate of muscle tissue, those juvenile nursery habitat signatures transitioned quickly to local reef signatures. As a result, it was difficult to distinguish individuals that were lifetime reef residents from those that may have arrived from a 
coastal wetland nursery sufficiently beyond the half-life of the tissue turnover rate.

To overcome the challenges of tissues with fast turnover rates, some researchers have used accretionary tissues, including fish otoliths, that provide a chronological record that is metabolically inert post-deposition. Mateo et al. (2010) used bulk $\delta^{13} \mathrm{C}$ and $\delta^{18} \mathrm{O}$ analysis, coupled with elemental profiles, to estimate post-settlement movement of French grunts (Haemulon flavolineatum) and schoolmaster snapper (Lutjanus apodus) from coastal mangrove lagoons and seagrass beds to coral reefs around two Caribbean Islands. In this instance, the authors classified adult fish collected on offshore coral reefs to either the mangrove or seagrass nursery habitat based on the geochemistry of the core region of otoliths that corresponded to the time period when the fish were resident in juvenile habitats. Between $40 \%$ and $68 \%$ of French grunt subadults collected from fore-reef stations in St. Croix, and 70\% and 74\% in Puerto Rico spent their juvenile period in mangrove nurseries. By contrast, nearly $100 \%$ of schoolmaster on both islands resided as juveniles in mangrove habitats.

Targeting the juvenile core of otoliths, which preserves an isotopic record of juvenile habitat residence, avoids the potential problem of tissue turnover obscuring the juvenile habitat signature in adult muscle tissue. However, McMahon et al. (2011b) showed that it is not always possible to distinguish residence in mangrove and seagrass nursery habitats using bulk otolith stable isotope analysis (SIA). Conventional bulk otolith and muscle SIA and essential amino acid (AA) SIA were conducted on snapper collected from seagrass beds, mangroves, and coral reefs in the Red Sea, Caribbean Sea, and Pacific coast of Panama. The authors found that while bulk stable isotope values in otoliths showed regional differences, it was not always possible to distinguish nursery residence on local scales. Essential AA $\delta^{13} \mathrm{C}$ values in otoliths, on the other hand, varied as a function of habitat type and provided a better tracer of residence in different juvenile nursery habitats than conventional bulk otolith SIA alone.

Migration connectivity-Several studies have taken advantage of large-scale (thousands of kilometers) geographic variation in carbon, nitrogen, and oxygen to track the ocean basin-scale migration of large pelagic animals, including cetaceans, pinnipeds, teleost fishes, and marine birds. Schell et al. (1989) and Best and Schell (1996) exploited the large high-latitude $\delta^{13} \mathrm{C}_{\mathrm{POM}}$ gradients in the North Pacific Ocean and Southern Ocean, respectively, to track annual migration patterns of mysticete whales. Both studies showed that baleen $\delta^{13} \mathrm{C}$ varied seasonally, corresponding to geographic variations in the $\delta^{13} C_{\mathrm{PLK}}$ of prey organisms consumed along the annual migratory route between wintering and summering grounds. Cyclical $\delta^{15} \mathrm{~N}$ patterns in baleen growth plates were consistent with an annual migratory starvation and recovery cycle. Killingley (1980) took a unique approach to track California gray whale (Eschrichtius robustus) migrations from the Arctic Pacific in spring and summer to Baja California, Mexico, in winter. This study used $\delta^{18} \mathrm{O}$ analysis of growth bands from the epizoic barnacle (Cryptolepas rhachianecti) that encrust gray whales as a proxy for local water $\delta^{18} \mathrm{O}_{\mathrm{Sw}}$ values in which the whale resided during the time of barnacle growth band formation. Killingley compared the expected barnacle $\delta^{18} \mathrm{O}$ values, calculated from regional salinity $-\delta^{18} \mathrm{O}_{\mathrm{SW}}$ relationships and temperature along the known migration route, to the actual $\delta^{18} \mathrm{O}$ values of barnacles collected from a gray whale in San Ignacio Lagoon. Modeled and observed $\delta^{18} \mathrm{O}$ values agreed well, indicating that latitudinal gradients in $\delta^{18} \mathrm{O}_{\mathrm{SW}}$ were accurately reflected in the barnacle growth bands, thus serving as a tracer of migration pathways.

Newsome et al. (2007) used $\delta^{13} \mathrm{C}$ and $\delta^{15} \mathrm{~N}$ analysis of archaeological seal bones to examine foraging patterns and population distributions of northern fur seals (Callorhinus ursinus) on the eastern Pacific Ocean. Northern fur seals are a common pinniped species in archaeological sites from southern California to the Aleutian Islands, yet today they breed almost exclusively on offshore islands at high latitudes. Prehistoric populations of adult female northern fur seals had significantly lower $\delta^{13} \mathrm{C}$ values than harbor seals (Phoca vitulina), a nonmigratory species that feeds nearshore. Consistently low $\delta^{13} \mathrm{C}$ values in fur seals likely represent feeding in deep, offshore waters. The prehistoric adult female northern fur seals clustered into three latitudinal foraging groups based upon their $\delta^{13} \mathrm{C}$ and $\delta^{15} \mathrm{~N}$ values: a southern group (California) with high isotope values, a northern group (eastern Aleutian, Gulf of Alaska, and Pacific Northwest) with intermediate values, and a western Aleutian group with very low isotope values. These data also confirmed that prehistoric northern fur seals from California were not immigrants from northern waters but instead were year-round residents.

Mendes et al. (2007) used a similar approach with $\delta^{13} \mathrm{C}$ and $\delta^{15} \mathrm{~N}$ analysis of the teeth of sperm whales (Physeter macrocephalus) in the Northeastern Atlantic to examine ontogenetic shifts in movement and trophic ecology. Stable isotope profiles showed a trend of decreasing $\delta^{13} \mathrm{C}$ and increasing $\delta^{15} \mathrm{~N}$ with age, punctuated by marked declines in $\delta^{13} \mathrm{C}$ values around 9 to $10 \mathrm{yr}$ and again around $20 \mathrm{yr}$ for many individuals. These authors attributed the first marked decline to male segregation from natal groups in low latitudes following the onset of puberty between 4 and $15 \mathrm{yr}$ and the gradual movement poleward into ${ }^{13} \mathrm{C}$-depleted temperate waters. The second decline around age 20 likely reflected movement into further ${ }^{13} \mathrm{C}$-depleted, productive high latitudes to facilitate the spurt of accelerated growth rate observed around that age. Interestingly, the periodic migrations back to low-latitude breeding grounds were not reflected in the $\delta^{13} \mathrm{C}$ profiles, most likely due to the short residence time at low latitude relative to the time spent in high-latitude feeding grounds. The observed increase in $\delta^{15} \mathrm{~N}$ with age is likely to be caused by an ontogenetic shift in trophic level coupled with movement from low latitudes with a low $\delta^{15} \mathrm{~N}_{\text {Base }}$ to high latitudes with a correspondingly high $\delta^{15} \mathrm{~N}_{\text {Base }}$.

Trophic and geographic stable isotope structure-Ecogeochemistry has been employed, in some form or another, for many years to examine migration or trophic dynamics in the marine environment, primarily using bulk tissue 
SIA (Peterson and Fry 1987; Hobson 1999; Post 2002). However, with conventional bulk SIA it can be difficult to tease apart differences in consumer stable isotope values due to movement through habitats with different baseline stable isotope values from those due to shifts in trophic position (Post 2002). This challenge is particularly true for highly migratory species with life histories characterized by large-scale movements and variable or shifting diets (Estrada et al. 2005; Kerr et al. 2006; Lorrain et al. 2009).

Recent advances in compound-specific SIA of individual biological compounds, including AAs and fatty acids (Meier-Augenstein 1999; Sessions 2006), have opened the door for more complex studies of connectivity and trophic dynamics than was possible with conventional markrecapture and feeding observation techniques (Popp et al. 2007; Lorrain et al. 2009; McMahon et al. 2011b). Modest $\delta^{13} \mathrm{C}$ fractionation between diet and bulk tissue often reflects relatively large trophic fractionation $\left(\delta^{13} \mathrm{C}\right)$ for many nonessential AAs and little to no fractionation for all essential AAs (Hare et al. 1991; Jim et al. 2006; McMahon et al. 2010). Although plants and bacteria can synthesize the essential AAs de novo, most animals have lost the necessary enzymatic pathways to synthesize these AAs at a rate sufficient for normal growth and must incorporate them directly from their diet (Borman et al. 1946; Reeds 2000 ). As a result, $\delta^{13} \mathrm{C}$ fractionation of essential AAs is typically near $0 \%$. Consumer essential AA $\delta^{13} \mathrm{C}$ values represent the isotopic fingerprints of $\delta^{13} \mathrm{C}$ values at the base of the food web in which the animal is feeding and therefore provides a promising tool to track animal movement through isotopically distinct food webs.

Moderate increases in bulk $\delta^{15} \mathrm{~N}$ with trophic position reflect an averaging of large increases in the $\delta^{15} \mathrm{~N}$ of some AAs, termed trophic AAs, and little or no change in others, referred to as source AAs (McClelland and Montoya 2002; Chikaraishi et al. 2007). Trophic AAs, such as alanine, aspartic acid, glutamic acid, isoleucine, leucine, proline, and valine, can either be synthesized by animals or undergo significant transamination and deamination reactions, resulting in larger $\delta^{15} \mathrm{~N}$ fractionation between tissue and diet upwards of $7 \%$. Fractionation of trophic AAs represents a more robust indicator of changes in trophic level than bulk SIA (McClelland and Montoya 2002; Chikaraishi et al. 2007). Conversely, source AAs are those that animals cannot synthesize themselves, and must incorporate directly from their diet. These AAs, including glycine, phenylalanine, serine, and threonine, exhibit little to no trophic fractionation and provide a fingerprint of $\delta^{15} \mathrm{~N}_{\text {Base }}$. Compound-specific SIA makes use of the differences in fractionation of trophic and source AAs to provide an internally indexed indicator of trophic position that normalizes for $\delta^{15} \mathrm{~N}_{\text {Base. }}$. In addition, source AA $\delta^{15} \mathrm{~N}$ values can act as a valuable tool to track animal movements across isotopically distinct marine environments, for example, from coastal to oceanic waters or from tropical to high latitudes.

Compound-specific SIA provides a complementary approach to traditional bulk stable isotope techniques for tracking animal migrations in the marine environment, and in many instances, provide more in-depth information about habitat use and movement patterns. Stable isotope analyses of AAs and fatty acids have previously been used to examine detailed information about diet (Fantle et al. 1999; Popp et al. 2007; Chikaraishi et al. 2009), the sources of complex mixtures of organic matter (Uhle et al. 1997; McCarthy et al. 2004), and more recently, habitat use and movement patterns (Lorrain et al. 2009; McMahon et al. 2011a). The ability to assess both the $\delta^{15} \mathrm{~N}_{\text {Base }}$ isotope signature as well as trophic position from a single analysis avoids one of the biggest confounding variables of bulk SIA. Compound-specific SIA therefore represents a powerful tool for future ecogeochemistry applications and clearly warrants greater attention from the ecological community.

Ecogeochemistry relies, in large part, on the presence of isoscapes that represent spatiotemporal composites of the chemical, physical, and biological processes structuring marine ecosystems. The isoscapes we presented in this review revealed a great deal more geographic variation in key elements than was previously appreciated. Advances in statistical tools have allowed for more accurate assignments to populations or specific habitats by combining isotope and other data types, including conventional tagging and population genetics, in a Bayesian framework (Smith and Campana 2010; Van Wilgenburg and Hobson 2011; Chabot et al. 2012). However, the ecogeochemistry approach is not without its own limitations and inherent challenges. If animals reside in geochemically indistinguishable habitats, or move through habitats faster than the local signature can be recorded, then the ecogeochemistry approach may underestimate habitat use or fail to fully resolve movement patterns. Therefore, to enhance the utility of isoscapes, we need continued field collections for SIA, both in space and time. The development of timeexplicit isoscapes is particularly important in light of the growing effects of climate change and ocean acidification on the biological, chemical, and physical processes of the world's oceans (Bowen 2010). The effects of climate change on the biology (e.g., temperature effects on productivity and species composition and distribution), chemistry (e.g., hypoxic effects on denitrification) and hydrography (e.g., climate effects on evaporation rates and circulation) will potentially have far-reaching effects on baseline isoscapes, both spatially and temporally. Given the logistical challenges of generating extensive spatial and temporal coverage of observational data, the development of robust isoscapes would be greatly improved with a more mechanistic understanding of what establishes and maintains isoscape structure. This will likely require developing process-based, coupled biogeochemical-physical ocean models to reconstruct baseline marine isoscapes (Schmittner et al. 2008; Somes et al. 2010). Enhanced knowledge of isotopic routing and fractionation factors, particularly of individual compound classes, is also necessary to fully realize the potential of ocean ecogeochemistry.

Finally, we were struck by the results from a recent review that found $>40 \%$ of published studies analyzing $\delta^{13} \mathrm{C}$ or $\delta^{15} \mathrm{~N}$ were conducted in marine ecosystems (Boecklen et al. 2011). Despite these efforts, we have not yet fulfilled the promise of SIA in ocean ecosystems. An ecogeochemistry approach, based on the documentation of 
isoscapes and the use of compound-specific SIA to distinguish movements through isoscapes and changes in diet, provides a powerful framework to significantly advance the field over the next decade.

\section{Acknowledgments}

We thank all of the researchers who contributed published data to the meta-analyses used to generate our isoscapes, N. Lysiak and G. Lawson at Woods Hole Oceanographic Institution for providing unpublished zooplankton samples for the organic isoscapes, the Ocean Isotope Ecology BIO7.431 class in the Massachusetts Institute of Technology-Woods Hole Oceanographic Institution Joint Program in Oceanography Applied Ocean Science and Engineering for initial discussion of the topic that led to this review, and four anonymous reviewers for comments on the manuscript. We were supported by funding from the National Science Foundation (Division of Ocean Sciences-0825148 to S.R.T.), Award USA 00002 and KSA 00011 from the King Abdullah University of Science and Technology (to S.R.T.), and a National Science Foundation Graduate Research Fellowship (to L.H.).

\section{References}

Abed-Navandi, D., and P. C. Dworschak. 2005. Food sources of tropical thalassinidean shrimps: A stable-isotope study. Mar. Ecol. Prog. Ser. 291: 159-168, doi:10.3354/meps291159

Alibert, C., L. P. J. Kinsley, S. J. Fallon, M. T. McCulloch, R. Berkelmans, and F. McAllister. 2003. Source of trace element variability in Great Barrier Reef corals affected by the Burdekin flood plumes. Geochim. Cosmochim. Acta 67: 231-246, doi:10.1016/S0016-7037(02)01055-4

Altabet, M. A., and R. Francois. 2001. Nitrogen isotope biogeochemistry of the Antarctic Polar Frontal Zone at $170^{\circ} \mathrm{W}$. DeepSea Res. II 48: 4247-4273, doi:10.1016/S0967-0645(01)00088-1

—, AND L. F. SMall. 1990. Nitrogen isotopic ratios in fecal pellets produced by marine zooplankton. Geochim. Cosmochim. Acta 54: 155-163, doi:10.1016/0016-7037(90)90203-W

Ando, A., T. Nakano, H. Kawahata, Y. Yokoyama, and B.-K. KнIм. 2010. Testing seawater $\mathrm{Sr}$ isotopic variability on a glacial-interglacial time scale: An application of latest highprecision thermal ionization mass spectrometry. Geochem. J. 44: $347-357$.

Barnett-Johnson, R., D. J. Teel, and E. Castillas. 2010. Genetic and otolith isotopic markers identify salmon populations in the Columbia River at broad and fine geographic scales. Environ. Biol. Fish. 89: 533-546, doi:10.1007/s10641010-9662-5

Barth, A., A. Alvera Azcarate, C. Troupin, M. Ouberdous, and J.-M. Beckers. 2010. A web interface for griding arbitrarily distributed in situ data based on Data-Interpolating Variational Analysis (DIVA). Adv. Geosci. 28: 29-37, doi:10.5194/ adgeo-28-29-2010

Bath, G. E., S. R. Thorrold, C. M. Jones, S. E. Campana, J. W. Mclaren, and J. W. H. Lam. 2000. Strontium and barium uptake in aragnitic otoliths of marine fish. Geochim. Cosmochim. Acta 64: 1705-1714, doi:10.1016/S0016-7037(99)00419-6

Best, P. B., And D. M. Schell. 1996. Stable isotopes in southern right whale (Eubalaena australis) baleen as indicators of seasonal movements, feeding, and growth. Mar. Biol. 124: 483-494, doi:10.1007/BF00351030

Block, B. A., AND OTHERs. 2005. Electronic tagging and populations structure of Atlantic bluefin tuna. Nature 434: 1121-1127, doi:10.1038/nature03463
Bode, A., M. T. Alvarex-Ossorio, M. E. Cunha, S. Garrido, P. B. Peleteiro, L. Valdes, and M. Varela. 2007. Stable nitrogen isotope studies of the pelagic food web on the Atlantic shelf of the Iberian Peninsula. Prog. Oceanogr. 74: 115-131, doi:10.1016/j.pocean.2007.04.005

, P. Cerrera, and S. Lens. 2003. The pelagic foodweb in the upwelling ecosystem of Galicia (NW Spain) during spring: Natural abundance of stable carbon and nitrogen isotopes. J. Mar. Sci. 60: 11-22.

Boecklen, W. J., C. T. Yarnes, B. A. Cook, and A. C. James. 2011. On the use of stable isotopes in trophic ecology. Annu. Rev. Ecol. Evol. Syst. 42: 411-440, doi:10.1146/annurevecolsys-102209-144726

Borman, A., T. R. Wood, H. C. Black, E. G. Anderson, M. J. Oesterling, M. Womack, And W. C. Rose. 1946. The role of arginine in growth with some observations on the effects of argininic acid. J. Biol. Chem. 166: 585-594.

Botsford, L. W., AND OTHers. 2009. Connectivity and resilience of coral reef metapopulations in marine protected areas: Matching empirical efforts to predictive needs. Coral Reefs 28: 327-337, doi:10.1007/s00338-009-0466-z

Bowen, G. J. 2010. Isoscapes: Spatial pattern in isotopic biogeochemistry. Annu. Rev. Earth Planet. Sci. 38: 161-187, doi:10.1146/annurev-earth-040809-152429

Broecker, W. E., And T. H. Peng. 1974. Gas exchange rates between air and sea. Tellus 26: 21-35, doi:10.1111/j.2153-3490.1974. tb01948.x

Brown, M. 1998. Ocean Data View 4.0. Oceanography 11: 19-21, doi:10.5670/oceanog.1998.04

Brown, R. J., AND K. P. SEverin. 2009. Otolith chemistry analyses indicate that water $\mathrm{Sr}: \mathrm{Ca}$ is the primary factor influencing otolith $\mathrm{Sr}: \mathrm{Ca}$ for freshwater and diadromous fish but not for marine fish. Can. J. Fish. Aquat. Sci. 66: 1790-1808, doi:10.1139/F09-112

BRuland, K. W., AND M. C. LoHAN. 2004. The control of trace metals in seawater, p. 23-47. In H. Elderfield [ed.], The oceans and marine geochemistry. Treatise on geochemistry, v. 6. Elsevier.

Calvert, S. E. 2000. Stable isotope data from sediment traps and net tows in the Atlantic and Northeast Pacific Oceans. JGOFS Canada Data Sets 1989-1998. Marine Environmental Data Service, Department of Fisheries and Oceans, Canada.

Caraco, N. F., G. Lampman, J. J. Cole, K. E. Limburg, M. L. Pace, AND D. FISCHER. 1998. Microbial assimilation of DIN in a nitrogen rich estuary: Implications for food web quality and isotope studies. Mar. Ecol. Prog. Ser. 167: 59-71, doi:10.3354/meps167059

CArlier, A., And Others. 2007. A seasonal survey of the food web in the Lapalme Lagoon (northwestern Mediterranean) assessed by carbon and nitrogen stable isotope analysis. Estuar. Coast. Shelf Sci. 73: 299-315, doi:10.1016/j.ecss.2007.01.012

Сhabot, A. A., K. A. Hobson, S. L. Van Wilgenburg, G. J. McQuat, and S. C. Lougheed. 2012. Advances in linking wintering migrant birds to their breeding-ground origins using combined analyses of genetic and stable isotope markers. PLoS One 7: e43627, doi:10.1371/journal.pone.0043627

Checkley, C. M., and L. C. Entzeroth. 1985. Elemental and isotopic fractionation of carbon and nitrogen by marine, planktonic copepods and implications to the marine nitrogen cycle. J. Plankton Res. 7: 553-568, doi:10.1093/plankt/7.4.553

Chikaraishi, Y., Y. Kashiyama, N. O. Ogawa, H. Kitazato, and N. Oнкоусhi. 2007. Metabolic control of nitrogen isotope composition of amino acids in macroalgae and gastropods: Implications for aquatic food web studies. Mar. Ecol. Prog. Ser. 342: 85-90, doi:10.3354/meps342085

— AND OTHERs. 2009. Determination of aquatic food-web structure based on compound-specific nitrogen isotopic composition of amino acids. Limnol. Oceanogr.: Methods 7: 740-750, doi:10.4319/lom.2009.7.740 
Cifuentes, L. A., J. H. Sharp, and M. L. Fogel. 1988. Stable carbon and nitrogen isotope biogeochemistry in the Delaware Estuary. Limnol. Oceanogr. 33: 1102-1115, doi:10.4319/ 10.1988.33.5.1102

COOPER, L. W., AND OTHERs. 2005. Linkages among runoff, dissolved organic carbon, and the stable oxygen isotope composition of seawater and other water mass indicators in the Arctic Ocean. J. Geophys. Res. 110: G02013, doi:10. 1029/2005JG000031

Corbisier, T., M. V. Petti, R. P. Skowronski, and T. S. Brito. 2004. Trophic relationships in the nearshore zone of Martel Inlet (King George Island, Antarctic): $\delta^{13} \mathrm{C}$ stable-isotope analysis. Polar Biol. 27: 75-82, doi:10.1007/s00300-0030567-z

Cowen, R. K., G. G. Gawarkiewicz, J. Pineda, S. R. Thorrold, AND F. E. Werner. 2007. Population connectivity in marine systems: An overview. Oceanography 20: 14-21, doi:10.5670/ oceanog.2007.26

—, And S. Sponaugle. 2009. Larval dispersal and marine population connectivity. Annu. Rev. Mar. Sci. 1: 443-466, doi:10.1146/annurev.marine.010908.163757

Crowder, L., AND E. Norse. 2008. Essential ecological insights for marine ecosystem-based management and marine spatial planning. Mar. Policy 32: 772-778, doi:10.1016/j.marpol. 2008.03.012

Das, K., G. Lepoint, L. Yann, and J. M. Bouquegneau. 2003. Marine mammals from the southern North Sea: Feeding ecology from $\delta^{13} \mathrm{C}$ and $\delta^{15} \mathrm{~N}$ measurements. Mar. Ecol. Prog. Ser. 263: 287-298, doi:10.3354/meps 263287

DE Villiers, S. 1999. Seawater strontium and $\mathrm{Sr} / \mathrm{Ca}$ variability in the Atlantic and Pacific Oceans. Earth Planet. Sci. Lett. 171: 623-634.

Dingle, H. 1996. Migration: The biology of life on the move. Oxford Univ. Press.

Dittmar, T., And G. Kattner. 2003. The biogeochemistry of the river and shelf ecosystem of the Arctic Ocean: A review. Mar. Chem. 83: 103-120, doi:10.1016/S0304-4203(03)00105-1

Dore, J. E., J. R. Brum, L. M. Tupas, and D. M. Karl. 2002. Seasonal and interannual variability in sources of nitrogen supporting export in the oligotrophic subtropical North Pacific Ocean. Limnol. Oceanogr. 47: 1595-1607, doi:10.4319/ 10.2002.47.6.1595

Dorval, E., C. M. Jones, and R. Hannigan. 2005. Chemistry of surface waters: Distinguishing fine-scale differences in sea grass habitats of Chesapeake Bay. Limnol. Oceanogr. 50: 1073-1083, doi:10.4319/1o.2005.50.4.1073

Dugdale, R. C., And J. J. Goering. 1967. Uptake of new and regenerated forms of nitrogen in primary productivity. Limnol. Oceanogr. 12: 196-206, doi:10.4319/1o.1967. 12.2.0196

Dunton, K. H. 2001. $\delta^{15} \mathrm{~N}$ and $\delta^{13} \mathrm{C}$ measurements of Antarctic peninsula fauna: Trophic relationships and assimilation of benthic seaweeds. Integr. Comp. Biol. 41: 99-112, doi:10. 1093/icb/41.1.99

Elder, J. F. 1988. Metal biogeochemistry in surface-water systems: A review of principles and concepts. Circular 1013. U.S. Geological Survey.

Elsdon, T. S., And B. M. Gillanders. 2004. Fish otolith chemistry influenced by exposure to multiple environmental variables. J. Exp. Mar. Biol. Ecol. 313: 269-284, doi:10.1016/ j.jembe.2004.08.010

- AND OTHERS. 2008. Otolith chemistry to describe movements and life-history parameters of fishes: Hypotheses, assumptions, limitations and inferences. Oceanogr. Mar. Biol.: Annu. Rev. 46: 297-330, doi:10.1201/9781420065756.ch7
Epstein, S., And T. MayedA. 1953. Variation of $\mathrm{O}^{18}$ content of waters from natural sources. Geochim. Cosmochim. Acta 4: 213-224, doi:10.1016/0016-7037(53)90051-9

Estrada, J. A., M. Lutcavage, and S. R. Thorrold. 2005. Diet and trophic position of Atlantic bluefin tuna (Thunnus thynnus) inferred from stable carbon and nitrogen isotope analysis. Mar. Biol. 147: 37-45, doi:10.1007/s00227-004-1541-1

- A. N. Rice, M. E. Lutcavage, and G. B. Skomal. 2003. Predicting trophic position in sharks of the north-west Atlantic Ocean using stable isotope analysis. J. Mar. Biol. Assoc. UK 83: 1347-1350, doi:10.1017/S0025315403008798

Fanelli, E., J. E. Cartes, and V. Papiol. 2011. Food web structure of deep-sea macrozooplankton and micronecton off the Catalan slope: Insight from stable isotopes. J. Mar. Syst. 87: 79-89, doi:10.1016/j.jmarsys.2011.03.003

P. Rumolo, AND M. SPROVIERI, 2009 . Food-web structure and trophodynamics of mesopelagic-suprabenthic bathyal macrofauna of the Algerian Basin based on stable isotopes of carbon and nitrogen. Deep-Sea Res. I 56: 1504-1520, doi:10.1016/j.dsr.2009.04.004

Fantle, M. S., A. I. Dittel, S. M. Schwalm, C. E. Epifanio, and M. L. Fogel. 1999. A food web analysis of the juvenile blue crab, Callinectes sapidus, using stable isotopes in whole animals and individual amino acids. Oecologia 120: 416-426, doi:10.1007/s004420050874

France, R. L. 1995. Carbon-13 enrichment in benthic compared to planktonic algae: Foodweb implications. Mar. Ecol. Prog. Ser. 124: 307-312, doi:10.3354/meps 124307

FRY, B. 1988. Food web structure on Georges Bank from stable C, $\mathrm{N}$, and $\mathrm{S}$ isotopic compositions. Limnol. Oceanogr. 33: 1182-1190, doi:10.4319/lo.1988.33.5.1182

, P. Mumford, And M. RobbleE. 1999. Stable isotope studies of pink shrimp (Farfantepenaeus duorarum Burkenroad) migrations on the southwestern Florida shelf. Bull. Mar. Sci. 65: 419-430.

, AND R. B. Quinones. 1994. Biomass spectra and stable isotope indicators of trophic level in zooplankton of the northwest Atlantic. Mar. Ecol. Prog. Ser. 112: 201-204, doi:10.3354/meps 112201

, AND S. C. WAINRIGHT. 1991. Diatom sources of ${ }^{13}$ C-rich carbon in marine food webs. Mar. Ecol. Prog. Ser. 76: 149-157, doi:10.3354/meps076149

Gaillardet, J., J. Viers, And B. Dupré. 2003. Trace elements in river waters, p. 225-272. In J. I. Drever [ed.], Treatise on geochemistry. Pergamon.

Ganssen, G., And D. Kroon. 1991. Evidence for Red Sea circulation from oxygen isotopes of modern surface waters and planktonic foraminiferal tests. Paleoceanography 6: 73-82, doi:10.1029/90PA01976

GAT, J. R. 1996. Oxygen and hydrogen isotopes in the hydrologic cycle. Annu. Rev. Earth Planet. Sci. 24: 225-262, doi:10.1146/ annurev.earth.24.1.225

Geffen, A. J., N. J. Pearce, and W. T. Perkins. 1998. Metal concentrations in fish otoliths in relation to body composition after laboratory exposure to mercury and lead. Mar. Ecol. Prog. Ser. 165: 235-245, doi:10.3354/meps 165235

Goering, J., V. Alexander, And N. Haubenstock. 1990. Seasonal variability of stable carbon and nitrogen isotope ratios of organisms in a North Pacific bay. Estuar. Coast. Shelf Sci. 30: 239-260, doi:10.1016/0272-7714(90)90050-2

Graham, B. S., P. L. Koch, S. D. Newsome, K. W. McMahon, and D. Aurioles. 2010. Using isoscapes to trace the movements and foraging behavior of top predators in oceanic ecosystems, p. 299-318. In J. West, G. J. Bowen, T. E. Dawson, and K. P. Tu [eds.], Isoscapes: Understanding movement, pattern, and process on Earth through isotope mapping. Springer-Verlag. 
Griffin, M. P. A., AND I. Valiela. 2001. $\delta^{15} \mathrm{~N}$ isotope studies of life history and trophic position of Fundulus heteroclitus and Menidia menidia. Mar. Ecol. Prog. Ser. 214: 299-305, doi:10. 3354/meps214299

Gruber, N., AND OTHERs. 1999. Spatiotemporal patterns of carbon-13 in the global surface oceans and the oceanic Suess effect. Global Biogeochem. Cycles 13: 307-335, doi:10.1029/ 1999GB900019

Hansson, S., J. E. Hobbie, R. Elmgren, U. Larsson, B. Fry, and S. JOHANSSON. 1997. The stable nitrogen isotope ratio as a marker of food-web interactions and fish migration. Ecology 78: 2249-2257, doi:10.1890/0012-9658(1997)078[2249:TSNIRA]2.0.CO;2

Hare, P. E., M. L. Fogel, T. W. Stafford, A. D. Mitchell, and T. C. Hoering. 1991. The isotopic composition of carbon and nitrogen in individual amino acids isolated from modern and fossil proteins. J. Archaeol. Sci. 18: 277-292, doi:10.1016/ 0305-4403(91)90066-X

Harmelin-Vivien, M., AND others. 2008. Comparison of C and N stable isotope ratios between surface particulate organic matter and microphytoplankton in the Gulf of Lions (NW Mediterranean). Cont. Shelf Res. 28: 1911-1919, doi:10.1016/j.csr.2008.03.002

Harrison, A. L., and K. A. BJorndal. 2006. Connectivity and wide-ranging species in the ocean, p. 213-232. In K. R. Crooks and M. Sanjayan [eds.], Connectivity conservation. Cambridge Univ. Press.

Heaton, T. H. E. 1986. Isotopic studies of nitrogen pollution in the hydrosphere and atmosphere: A review. Chem. Geol. 59: 87-102, doi:10.1016/0168-9622(86)90059-X

Hinga, K. R., M. A. Arthur, M. E. Pilson, and D. Whitaker. 1994. Carbon isotope fractionation by marine phytoplankton in culture: The effects of $\mathrm{CO}_{2}$ concentration, $\mathrm{pH}$, temperature and species. Global Biogeochem. Cycles 8: 91-102, doi:10. 1029/93GB03393

Hirch, S. 2009. Trophic interactions at seamounts. Ph.D. thesis. Univ. Hamburg.

Hobson, K. A. 1999. Tracing origins and migration of wildlife using stable isotopes: A review. Oecologia 120: 314-326, doi:10.1007/s004420050865

- W. G. Ambrose, And P. E. Renaud. 1995. Sources of primary production, benthic-pelagic coupling, and trophic relationships within the Northeast Water Polynya: Insights from $\delta^{13} \mathrm{C}$ and $\delta^{15} \mathrm{~N}$ analysis. Mar. Ecol. Prog. Ser. 128: $1-10$, doi:10.3354/meps 128001

$\longrightarrow$, R. Barnett-Johnson, and T. Cerling. 2010. Using isoscapes to track animal migration, p. 273-298. In J. West, G. J. Bowen, T. E. Dawson, and K. P. Tu [eds.], Isoscapes: Understanding movement, pattern, and process on Earth through isotope mapping. Springer-Verlag.

- A. Fisk, N. Karnovsky, M. Holst, J. M. Gagnon, and M. Fortier. 2002. A stable isotope $\left(\delta^{13} \mathrm{C}, \delta^{15} \mathrm{~N}\right)$ model for the North Water food web: Implications for evaluating trophodynamics and the flow of energy and contaminants. Deep-Sea Res. II 49: 5131-5150, doi:10.1016/S0967-0645(02)00182-0

—, AND W. A. Montevecchi. 1991. Stable isotopic determination of the trophic relationships of Great Auks. Oecologia 87: 528-531, doi:10.1007/BF00320416

Hofmann, M., D. A. Wolf-Gladrow, T. Takahashi, S. C. Sutherland, K. D. Six, And E. Maier-Reimer. 2000. Stable carbon isotope distribution of particulate organic matter in the ocean: A model study. Mar. Chem. 72: 131-150, doi:10.1016/S0304-4203(00)00078-5

Holl, C. M., T. A. Villareal, C. D. Payne, T. D. Clayton, C. Hart, and J. P. Montoya. 2007. Trichodesmium in the western Gulf of Mexico: lil;gd $\backslash r \mid 15 \mathrm{~N}_{2}$-fixation and natural abundance stable isotope evidence. Limnol. Oceanogr. 52: 2249-2259, doi:10.4319/1o.2007.52.5.2249
JenNings, S., AND K. J. WARR. 2003. Environmental correlates of large-scale spatial variation in the $\delta^{15} \mathrm{~N}$ of marine animals. Mar. Biol. 142: 1131-1140.

Jim, S., V. Jones, S. H. Ambrose, and R. P. Evershed. 2006. Quantifying dietary macronutrient sources of carbon for bone collagen biosynthesis using natural abundance stable carbon isotope analysis. Br. J. Nutr. 95: 1055-1062, doi:10.1079/ BJN20051685

Kelly, J. F. 2000. Stable isotopes of carbon and nitrogen in the study of avian and mammalian trophic ecology. Can. J. Zool. 78: 1-27, doi:10.1139/z99-165

Kerr, L. A., A. H. Andrews, G. M. Cailiet, T. A. Brown, And K. H. CoAle. 2006. Investigations of $\delta^{14} \mathrm{C}, \delta^{13} \mathrm{C}$, and $\delta^{15} \mathrm{~N}$ in vertebrae of white shark (Carcharodon carcharias) from the eastern North Pacific Ocean. Environ. Biol. Fish. 77: 337-353, doi:10.1007/s10641-006-9125-1

- D. H. Secor, and T. T. Kraus. 2007. Stable isotope $\left(\delta^{13} \mathrm{C}\right.$ and $\delta^{18} \mathrm{O}$ ) and $\mathrm{Sr} / \mathrm{Ca}$ composition of otoliths as proxies for environmental salinity experienced by an estuarine fish. Mar. Ecol. Prog. Ser. 349: 245-253, doi:10.3354/meps07064

Key, R. M., AND OTHERs. 2004. A global ocean carbon climatology: Results from GLODAP. Global Biogeochem. Cycles 18: GB4031, doi:10.1029/2004GB002247

Killingley, J. S. 1980. Migrations of California gray whales tracked by oxygen-18 variations in their epizoic barnacles. Science 207: 759-760, doi:10.1126/science.207.4432.759

Kingsford, M. J., J. M. Hughes, and H. M. Patterson. 2009. Otolith chemistry of the non-dispersing reef fish Acanthochromis polyacanthus: Cross-shelf patterns form the central Great Barrier Reef. Mar. Ecol. Prog. Ser. 377: 279-288, doi:10.3354/meps07794

Kiriakoulakis, K., E. Fisher, G. A. Wolff, A. Freiwald, A. Grehan, AND J. M. Roberts. 2005. Lipids and nitrogen isotopes of two deep-water corals from the North-East Atlantic: Initial results and implications for their nutrition, p. 715-729. In A. Freiwald and J. M. Roberts [eds.], Coldwater corals and ecosystems. Springer-Verlag.

Kohler, S. A., And others. 2011. Geographic variation in the trophic ecology of an avian rocky shore predator, the African black oystercatcher, along the southern African coastline. Mar. Ecol. Prog. Ser. 435: 235-249, doi:10.3354/meps09215

Kroopnick, P. M. 1985. The distribution of ${ }^{13} \mathrm{C}$ of $\Sigma \mathrm{CO}_{2}$ in the world oceans. Deep-Sea Res. 32: 57-84.

Kurten, B., S. J. Painting, U. Struck, N. V. C. Polunin, and J. J. Middelburg. 2012. Tracking seasonal changes in North Sea zooplankton trophic dynamics using stable isotopes. Biogeochemistry 2012: 1-21, doi:10.1007/s10533-011-9630-y

LaAKmann, S., AND H. Auel. 2010. Longitudinal and vertical trends in stable isotope signatures $\left(\delta^{13} \mathrm{C}\right.$ and $\left.\delta^{15} \mathrm{~N}\right)$ of omnivorous and carnivorous copepods across the South Atlantic Oceanogr. Mar. Biol. 157: 463-471, doi:10.1007/s00227-009-1332-9

Lamb, K., and P. K. Swart. 2008. The carbon and nitrogen isotopic values of particulate organic material from the Florida Keys: A temporal and spatial study. Coral Reefs 27: 351-362, doi:10.1007/s00338-007-0336-5

Le Loc'h, F., And C. Hily. 2005. Stable carbon and nitrogen isotope analysis of Nephrops norvegicus/Merluccius merluccius fishing grounds in the Bay of Biscay (Northeast Atlantic). Can. J. Fish. Aquat. Sci. 62: 123-132, doi:10.1139/f04-242

- $\longrightarrow$ AND J. Grall. 2008. Benthic community and food web structure on the continental shelf of the Bay of Biscay (North Eastern Atlantic) revealed by stable isotope analysis. J. Mar. Syst. 72: 17-34, doi:10.1016/j.jmarsys.2007.05.011

Lea, D. W., G. T. Shen, And E. A. Boyle. 1989. Coralline barium records temporal variability in equatorial Pacific upwelling. Nature 340: 373-376, doi:10.1038/340373a0 
Lesage, V., M. O. Hammill, and K. M. Kovacs. 2001. Diet-tissue fractionation of stable carbon and nitrogen isotopes in phocid seals. Mar. Mammal Sci. 18: 182-193, doi:10.1111/j.17487692.2002.tb01027.x

Limburg, K. E. 2001. Through the gauntlet again: Demographic restructuring of American shad by migration. Ecology 82: 1584-1596, doi:10.1890/0012-9658(2001)082[1584:TTGADR] 2.0.CO;2

Lloyd, R. M. 1966. Oxygen isotope enrichment of sea water by evaporation. Geochim. Cosmochim. Acta 30: 801-814, doi:10.1016/0016-7037(66)90133-5

Lorrain, A., B. Graham, F. Menard, B. Popp, S. Boulllon, P. van Bruegel, AND Y. Cherel. 2009. Nitrogen and carbon isotope values of individual amino acids: A tool to study foraging ecology of penguins in the Southern Ocean. Mar. Ecol. Prog. Ser. 391: 293-306, doi:10.3354/meps08215

Lourey, M. J., T. W. Trull, and D. M. Sigman. 2003. Sensitivity of $\delta^{15} \mathrm{~N}$ of nitrate, surface suspended and deep sinking particulate nitrogen to seasonal nitrate depletion in the Southern Ocean. Global Biogeochem. Cycles 17: 1081-1099, doi:10.1029/2002GB001973

Luo, J., J. E. Serafy, S. Sponaugle, P. B. Teare, and D. KIECKBUSCH. 2009. Movement of gray snapper Lutjanus griseus among subtropical seagrass, mangrove, and coral reef habitats. Mar. Ecol. Prog. Ser. 380: 255-269, doi:10.3354/meps07911

Lynch-Stieglitz, J., T. F. Stocker, W. S. Broecker, and R. G. FAIRBANKS. 1995. The influence of air-sea exchange on the isotopic composition of oceanic carbon: Observations and modeling. Global Biogeochem. Cycles 9: 653-665, doi:10. 1029/95GB02574

LYSIAK, N. S. 2009. Investigating the migration and foraging ecology of North Atlantic right whales with stable isotope geochemistry of baleen and zooplankton. Ph.D. thesis. Boston Univ.

MacKenzie, K. M., M. R. Palmer, A. Moore, A. T. Ibbotson, W. R. C. Beaumont, D. J. S. Poulter, and C. N. Trueman. 2011. Locations of marine animals revealed by carbon isotopes. Sci. Rep. 1: 1-21, doi:10.1038/srep00021

Macko, S. A., L. Entzeroth, and P. L. Parker. 1984. Regional differences in nitrogen and carbon isotopes on the continental shelf of the Gulf of Mexico. Naturwissenschaften 71: 374-375, doi:10.1007/BF00410746

Mahaffey, C., R. G. Williams, and G. A. WolfF. 2004. Physical supply of nitrogen to phytoplankton in the Atlantic Ocean. Global Biogeochem. Cycles 18: GB1034, doi:10.1029/2003GB 002129

Mateo, I., AND others. 2010. Role of mangroves as nurseries for French grunt Haemulon falvolineatum and schoolmaster Lutjanus apodus assessed by otolith elemental fingerprints. Mar. Ecol. Prog. Ser. 402: 197-212, doi:10.3354/meps08445

Matsuura, Y., AND E. WadA. 1994. Carbon and nitrogen isotope ratios in marine organic matters of the coastal ecosystem in Ubatuba, southern Brazil. Cienc. Cult. 46: 141-146.

McCarthy, M. D., R. Benner, C. Lee, J. I. Hedges, and M. L. Fogel. 2004. Amino acid carbon isotope fractionation patterns in oceanic dissolved matter: An unaltered photoautotrophic source for dissolved organic nitrogen in the ocean? Mar. Chem. 92: 123-134, doi:10.1016/j.marchem.2004.06.021

McClelland, J. W., C. M. Holl, and J. P. Montoya. 2003. Relating low $\backslash$ il; gd $\backslash r \mid{ }^{15} \mathrm{~N}$ values of zooplankton to $\mathrm{N}_{2}$-fixation in the tropical North Altantic: Insights provided by stable isotope ratios of amino acids. Deep Sea Res. 50: 849-861, doi:10.1016/s0967-0637(03)00073-6

—, AND J. P. Montoya. 2002. Trophic relationships and the nitrogen isotopic composition of amino acids in plankton Ecology 83: 2173-2180, doi:10.1890/0012-9658(2002)083 [2173:TRATNI]2.0.CO;2
I. Valiela, and R. H. Michener. 1997. Nitrogen-stable isotope signatures in estuarine food webs: A record of increasing urbanization in coastal watersheds. Limnol. Oceanogr. 42: 930-937, doi:10.4319/lo.1997.42.5.0930

McCOOK, L. J., AND OTHERs. 2009. Management under uncertainty: Guide-lines for incorporating connectivity into the protection of coral reefs. Coral Reefs 28: 353-366, doi:10. 1007/s00338-008-0463-7

McCulloch, M. T., M. Cappo, J. Aumend, and W. Muller. 2005. Tracing the life history of individual barramundi using laser ablation MC-ICP-MS Sr-isotopic and $\mathrm{Sr} / \mathrm{Ba}$ ratios in otoliths. Mar. Freshwater Res. 56: 637-644, doi:10.1071/MF04184

McMahon, K. W., M. L. Berumen, I. Mateo, T. S. Elsdon, and S. R. Thorrold. 2011a. Carbon isotopes in otolith amino acids identify residency of juvenile snapper (Family: Lutjanidae) in coastal nurseries. Coral Reefs 30: 1135-1145, doi:10.1007/s00338-011-0816-5

_, M. L. Fogel, T. S. Elsdon, and S. R. Thorrold. 2010. Carbon isotope fractionation of amino acids in fish muscle reflects biosynthesis and isotopic routing from dietary protein. J. Anim. Ecol. 79: 1132-1141, doi:10.1111/j.13652656.2010.01722.x

B. J. Johnson, L. A. Houghton, And S. R. ThORRold. 2011b. A new method to reconstruct fish diet and movement patterns from $\delta^{13} \mathrm{C}$ values in otolith amino acids. Can. J. Fish. Aquat. Sci. 68: 1330-1340, doi:10.1139/f2011-070

Meier-Augenstein, W. 1999. Applied gas chromatography coupled to isotope ratio mass spectrometry. J. Chromatogr. A 842: 351-371, doi:10.1016/S0021-9673(98)01057-7

Mendes, S., J. Newton, R. J. Reid, A. F. Zuur, and G. J. Pierce. 2007. Stable carbon and nitrogen isotope ratio profiling of sperm whale teeth reveals ontogenetic movements and trophic ecology. Oecologia 151: 605-615, doi:10.1007/s00442-006-0612-z

Milton, D. A., AND S. R. Chenery. 2001. Sources and uptake of trace metals in otoliths of juvenile barramundi (Lates calcarifer). J. Exp. Mar. Biol. Ecol. 264: 47-65, doi:10.1016/ S0022-0981(01)00301-X

Mizutani, H., Y. Kabaya, and E. Wada. 1991. Nitrogen and carbon isotope compositions relate linearly in cormorant tissues and its diet. Isotopenpraxis 27: 166-168, doi:10.1080/ 10256019108622500

Montoya, J. P., E. J. Carpenter, and D. G. Capone. 2002. Nitrogen fixation and nitrogen isotope abundances in zooplankton of the oligotrophic North Atlantic. Limnol. Oceanogr. 47: 1617-1628, doi:10.4319/1o.2002.47.6.1617

Muhlfeld, C. C., S. R. Thorrold, T. E. McMahon, and B. Marotz. 2012. Estimating westslope trout (Oncorhynchus clarkii lewisi) movements in a river network using strontium isoscapes. Can. J. Fish. Aquat. Sci. 69: 906-915, doi:10.1139/ f2012-033

Munday, P. L., J. M. Leis, J. M. Lough, C. B. Paris, M. J. Kingsford, M. L. Berumen, and J. Lambrechts. 2009. Climate change and coral reef connectivity. Coral Reefs 28: 379-395, doi:10.1007/s00338-008-0461-9

NakAmura, Y., AND OTHERs. 2008. Evidence of ontogenetic migration from mangroves to coral reefs by black-tail snapper Lutjanus fulvus: Stable isotope approach. Mar. Ecol. Prog. Ser. 355: 257-266, doi:10.3354/meps07234

Newsome, S. D., AND OTHERs. 2007. The shifting baseline of northern fur seal ecology in the northeastern Pacific Ocean. Proc. Natl. Acad. Sci. USA 104: 9709-9714, doi:10.1073/ pnas.0610986104

Nyssen, F., T. Brey, G. Lepoint, J. M. Bouquegneau, C. de Broyer, And P. Dauby. 2002. A stable isotope approach to the eastern Weddell Sea trophic web: Focus on benthic amphipods. Polar Biol. 25: 280-287. 
O’Reilly, C. M., R. E. Hecky, A. S. Cohen, and P.-D. Plisnier. 2002. Interpreting stable isotope in food webs: Recognizing the role of time averaging at different trophic levels. Limnol. Oceanogr. 47: 306-309, doi:10.4319/lo.2002.47.1.0306

Ostrom, N. E., S. A. Macko, D. Deibel, and R. J. Thrompson. 1997. Seasonal variation in the stable carbon and nitrogen isotope biogeochemistry of a coastal cold ocean environment. Geochim. Cosmochim. Acta 61: 2929-2942, doi:10.1016/ S0016-7037(97)00131-2

Pajuelo, M., K. A. Buorndal, J. Alfaro-Shigueto, J. A. Seminoff, J. C. Mangel, and A. B. Bolten. 2010. Stable isotope variation in loggerhead turtles reveals Pacific-Atlantic oceanographic differences. Mar. Ecol. Prog. Ser. 417: 277-285, doi:10.3354/meps08804

Pancost, R. D., K. H. Freeman, S. G. Wakeham, and C. Y. Roberston. 1997. Controls on carbon isotope fractionation by diatoms in the Peru upwelling region. Geochim. Cosmochim. Acta 61: 4983-4991, doi:10.1016/S0016-7037(97)003517

Parsons, D. M., R. D. Babcock, R. K. S. Hankin, T. J. Willis, J. P. Aitken, R. K. O’Dor, And G. D. Jackson. 2003. Snapper Pagrus auratus (Sparidae) home range dynamics: Acoustic tagging studies in a marine reserve. Mar. Ecol. Prog. Ser. 262: 253-265, doi:10.3354/meps 262253

Peterson, B. J., And B. Fry. 1987. Stable isotopes in ecosystem studies. Annu. Rev. Ecol. Syst. 18: 293-320, doi:10.1146/ annurev.es.18.110187.001453

-, AND R. W. Howarth. 1987. Sulfur, carbon, and nitrogen isotopes used to trace organic matter flow in the salt-marsh estuaries of Sapelo Island, Georgia. Limnol. Oceanogr. 32: 1195-1213, doi:10.4319/1o.1987.32.6.1195

Petursdottir, H., S. Falk-Petersen, H. Hop, and A. Gislason. 2010. Calanus finmarchicus along the northern Mid-Atlantic Ridge: Variation in fatty acid and alcohol profiles and stable isotope values, $\delta^{15} \mathrm{~N}$ and $\delta^{13} \mathrm{C}$. J. Plankton Res. 32: 1067-1077, doi:10.1093/plankt/fbq036

—, A. Gislason, S. Falk-Petersen, H. Hop, and J. Svavarsson. 2008. Trophic interactions of the pelagic ecosystem over the Reykjanes Ridge as evaluated by fatty acids and stable isotope analyses. Deep-Sea Res. II 55: 83-93, doi:10.1016/j.dsr2.2007.09.003

Pinnegar, J. K., And others. 2000. Trophic cascades in benthic marine ecosystems: Lessons for fisheries and protected-area management. Environ. Conserv. 27: 179-200, doi:10.1017/ S0376892900000205

Polunin, N. V. C., B. Morales-Nin, W. E. Pawsey, J. E. Cartes, J. K. Pinnegar, And J. Moranta. 2001. Feeding relationships in Mediterranean bathyal assemblages elucidated by stable nitrogen and carbon isotope data. Mar. Ecol. Prog. Ser. 220: 13-23, doi:10.3354/meps220013

Pomerleau, C., G. Winkler, A. R. Sastri, R. J. Nelson, S. Vagle, V. Lesage, and S. H. Ferguson. 2011. Spatial patterns in zooplankton communities across the eastern Canadian sub-Arctic and Arctic waters: Insights from stable carbon $\left(\delta^{13} \mathrm{C}\right)$ and nitrogen $\left(\delta^{15} \mathrm{~N}\right)$ isotope ratios. J. Plankton Res. 33: 1779-1792, doi:10.1093/plankt/fbr080

Popp, B. N., AND OTHERs. 2007. Insight into the trophic ecology of yellowfin tuna, Thunnus albacares, from compound-specific nitrogen isotope analysis of proteinaceous amino acids, p. 173-190. In T. D. Dawson and R. T. W. Siegworlf [eds.], Stable isotopes as indicators of ecological change. Elsevier/ Academic Press.

Post, D. M. 2002. Using stable isotopes to estimate trophic position: Models, methods, and assumptions. Ecology 83: 703-718, doi:10.1890/0012-9658(2002)083[0703:USITET]2.0.CO;2
Quay, P., R. Sonnerup, T. Westby, J. Stutsman, and A. MCNichol. 2003. Changes in the ${ }^{13} \mathrm{C} /{ }^{12} \mathrm{C}$ of dissolved inorganic carbon in the ocean as a tracer of anthropogenic $\mathrm{CO}_{2}$ uptake. Global Biogeochem. Cycles 17: 1004-1024, doi:10.1029/2001GB001817

Quillfeldt, P., R. A. R. McGill, and R. W. Furnes. 2005. Diet and foraging areas of Southern Ocean seabirds and their prey inferred from stable isotopes: Review and case study of Wilson's storm-petrel. Mar. Ecol. Prog. Ser. 295: 295-304, doi:10.3354/meps 295295

Ramos, R., And J. Gonzalez-Solis. 2012. Trace me if you can: The use of intrinsic biogeochemical markers in marine top predators. Front. Ecol. Environ. 10: 258-266, doi:10.1890/ 110140

Reeds, P. 2000. Dispensable and indispensable amino acids for humans. J. Nutr. 130: 1835S-1840S.

Riera, P., AND P. Richard. 1997. Temporal variation of $\delta^{13} \mathrm{C}$ in particulate organic matter and oyster Crassostrea gigas in Marennes-Oleron Bay (France): Effect of freshwater inflow. Mar. Ecol. Prog. Ser. 147: 105-115, doi:10.3354/ meps 147105

Roessig, J. M., C. M. Woodley, J. J. Ceeh, and L. J. Hansen. 2004. Effects of global climate change on marine and estuarine fishes and fisheries. Rev. Fish Biol. Fish. 14: 251-275, doi:10.1007/s11160-004-6749-0

Rohling, E. J., AND S. D. RiJk. 1999. Holocene climate optimum and last glacial maximum in the Mediterranean: The marine oxygen isotope record. Mar. Geol. 153: 57-75, doi:10.1016/ S0025-3227(98)00020-6

Rubenstein, D. R., And H. A. Hobson. 2004. From birds to butterflies: Animal movement patterns and stable isotopes. Trends Ecol. Evol. 19: 256-263.

Sackett, W. M., W. R. Eckelmann, M. L. Bender, and A. W. H. BE. 1965. Temperature dependence of carbon isotope composition in marine plankton and sediments. Science 148: 235-237, doi:10.1126/science.148.3667.235

SAino, T., AND A. HatTori. $1980 .{ }^{15} \mathrm{~N}$ natural abundance in oceanic suspended particulate matter. Nature 283: 752-754, doi: $10.1038 / 283752 \mathrm{a} 0$

Sato, T., H. Sasaki, and M. Fukuchi. 2002. Stable isotopic compositions of overwintering copepods in the arctic and subarctic waters and implications to the feeding history. J. Mar. Syst. 38: 165-174, doi:10.1016/S0924-7963(02)00175-6

Schell, D. M., S. M. SAupe, and N. Haubenstock. 1989. Bowhead whale (Balaena mysticetus) growth and feeding as estimated by $\delta^{13} \mathrm{C}$ techniques. Mar. Biol. 103: 433-443, doi:10.1007/BF00399575

Schlesinger, W. H. 1997. Biogeochemistry: An analysis of global change, 2nd ed. Academic Press.

SChlitzer, R. 2002. Interactive analysis and visualization of geosciences data with Ocean Data View. Comp. Geosci. 28: 1211-1218, doi:10.1016/S0098-3004(02)00040-7

Schmidt, G. A., G. R. BigG, And E. J. Rohling. 1999. Global seawater oxygen-18 database-version 1.21 [Internet]. New York (New York): National Aeronautics and Space Administration, [accessed 2012 September 01]. Available from http:// data.giss.nasa.gov/o18data/

Schmidt, K., A. Atrinson, D. Stubing, J. W. McClelland, J. P. MontoyA, And M. Voss. 2003. Trophic relationships among Southern Ocean copepods and krill: Some uses and limitation of a stable isotope approach. Limnol. Oceanogr. 48: 277-289, doi:10.4319/1o.2003.48.1.0277

Schmittner, A., A. Oschlies, H. D. Matthews, and E. D. Galbraith. 2008. Future changes in climate, ocean circulation, ecosystems, and biogeochemical cycling simulated for a 
business-as-usual $\mathrm{CO}_{2}$ emission scenario until year $4000 \mathrm{AD}$. Global Biogeochem. Cycles 22: GB1013, doi:10.1029/2007GB 002953

Sessions, A. L. 2006. Isotope-ratio detection for gas chromatography. J. Sep. Sci. 29: 1946-1961, doi:10.1002/jssc.200600002

Shen, G. T., AND C. L. SANFORD. 1990. Trace-element indicators of climate variability in reef-building corals, p. 255-283. In P. W. Glynn [ed.], Global ecological consequences of the 1982-83 El Nino-Southern Oscillation. Elsevier.

Sigman, D. M., M. A. Altabet, D. C. McCorkle, R. Francois, AND G. Fisher. 1999. The $\delta^{15} \mathrm{~N}$ of nitrate in the southern ocean: Consumption of nitrate in surface waters. Global Biogeochem. Cycles 113: 1149-1166, doi:10.1029/1999GB 900038

Sims, S. W., A. M. Fox, And D. A. Merrett. 1997. Basking shark occurrence off south-west England in relation to zooplankton abundance. J. Fish Biol. 51: 436-440, doi:10.1111/j.10958649.1997.tb01677.x

Skomal, G. B., S. I. Zeeman, J. G. Chisholm, E. L. Summers, H. J. Walsh, K. W. McMahon, and S. R. Thorrold. 2009. Transequatorial migrations of basking sharks in the western Atlantic Ocean. Curr. Biol. 19: 1019-1022, doi:10.1016/j.cub. 2009.04.019

Smith, S. J., AND S. E. CAmpana. 2010. Integrated stock mixture analysis for continuous and categorical data, with application to generic-otolith combinations. Can. J. Fish. Aquat. Sci. 67: 1533-1548, doi:10.1139/F10-078

Somes, C. J., AND others. 2010. Simulating the global distribution of nitrogen isotopes in the ocean. Global Biogeochem. Cycles 24: GB4019, doi:10.1029/2009GB003767

Sommer, F., A. Saage, B. Santer, T. Hansen, and U. Sommer. 2005. Linking foraging strategies of marine calanoid copepods to patterns of nitrogen stable isotope signatures in a mesocosm study. Mar. Ecol. Prog. Ser. 286: 99-106, doi:10.3354/meps 286099

Storey, A. W., AND B. Figa. 1998. Effects of the Ok Tedi copper mine on the benthic macroinvertebrate fauna of forest-fringed oxbow lakes of the Fly River system, Papua New Guinea. Int. J. Ecol. Environ. Sci. 24: 193-206.

Stowasser, G., A. Atkinson, R. A. R. McGill, R. A. Phillips, M. A. Collins, And D. W. Pond. 2012. Food web dynamics in the Scotia Sea in summer: A stable isotope study. Deep-Sea Res. II. 59-60: 208-221, doi:10.1016/j.dsr2.2011.08.004

Stuck, U., K. -C. Emeis, M. Vob, M. D. Krom, and G. H. Rua. 2001. Biological productivity during sapropel S5 formation in the Eastern Mediterranean Sea: Evidence from stable isotopes of nitrogen and carbon. Geochim. Cosmochim. Acta 65: 3249-3266.

Swearer, S. E., J. E. Caselle, D. W. Lea, and R. R. Warner. 1999. Larval retention and recruitment in an island population of a coral-reef fish. Nature 402: 799-802, doi:10.1038/ 45533

Tamelander, T., P. E. Renaud, H. Hop, M. L. Carroll, W. G. Ambrose, And A. Hobson. 2006. Trophic relationships and pelagic-benthic coupling during summer in the Barents Sea Marginal Ice Zone, revealed by stable carbon and nitrogen isotope measurements. Mar. Ecol. Prog. Ser. 310: 33-46, doi: $10.3354 /$ meps 310033

Thorrold, S. R., C. M. Jones, S. E. Campana, J. W. Mclaren, AND J. W. H. LAm. 1998a. Trace element signatures in otoliths record natal river of juvenile American shad (Alosa sapidissima). Limnol Oceanogr. 43: 1826-1835.
P. K. Swart, and T. E. Targett. 1998b. Accurate classification of juvenile weakfish Cynoscion regalis to estuarine nursery areas based on chemical signatures in otoliths. Mar. Ecol. Prog. Ser. 173: 253-265, doi:10.3354/meps 173253

, C. Latkoczy, P. K. Swart, and C. M. Jones. 2001. Natal homing in a marine fish metapopulation. Science 291: 297-299, doi:10.1126/science.291.5502.297

—, AND OTHERS. 2002. Quantifying larval retention and connectivity in marine populations with artificial and natural markers. Bull. Mar. Sci. 70: 291-308.

Tittlemier, S. A., A. T. Risk, K. A. Hobson, and R. J. Norstrom. 2000. Examination of the bioaccumulation of halogenated dimethyl bipyrroles in an Arctic marine food web using stable nitrogen isotope analysis. Environ. Pollut. 116: 85-93, doi:10.1016/S0269-7491(01)00144-0

Tzeng, W. N., And Y. C. Tsai. 1994. Changes in otolith microchemistry of the Japanese eel, Anguilla japonica, during its migration from the ocean to the rivers of Taiwan. J. Fish Biol. 45: 671-683.

Uhle, M. E., S. A. Macko, S. A. Spero, M. H. Engel, and D. W. LEA. 1997. Sources of carbon and nitrogen in modern plankton foraminifera: The role of algal symbionts as determined by bulk and compound specific stable isotope analysis. Org. Geochem. 27: 103-113, doi:10.1016/S01466380(97)00075-2

Van Wilgenburg, S. L., and K. A. Hobson. 2011. Combining stable-isotope $(\delta \mathrm{D})$ and band recovery data to improve probabilistic assignment of migratory birds to origin. Ecol. Appl. 21: 1340-1351, doi:10.1890/09-2047.1

Vizzini, S., And A. Mazzola. 2003. Seasonal variations in the stable carbon and nitrogen isotope ratios $\left({ }^{13} \mathrm{C} /{ }^{12} \mathrm{C}\right.$ and ${ }^{15} \mathrm{~N} /{ }^{14} \mathrm{~N}$ ) of primary producers and consumers in a western Mediterranean coastal lagoon. Mar. Biol. 142: 1009-1018.

Wada, E., M. Terazaki, Y. Kabaya, and T. Nemoto. 1987. ${ }^{15} \mathrm{~N}$ and ${ }^{13} \mathrm{C}$ abundances in the Antarctic Ocean with emphasis on the biogeochemical structure of the food web. Deep-Sea Res. 34: 829-841.

Walther, B. D., And S. R. Thorrold. 2010. Limited diversity in natal origins of an anadromous fish during ocean residency. Can. J. Fish. Aquat. Sci. 67: 1699-1707, doi:10.1139/F10-086

Walther, D. B., and S. R. Thorrold. 2008. Continental-scale variation in otolith geochemistry of juvenile American shad (Alosa sapidissima). Can. J. Fish. Aquat. Sci. 65: 2623-2635, doi:10.1139/F08-164

Waser, N. A. D., W. G. Harrison, E. J. H. Head, B. Nielsen, V. A. Lutz, and S. E. Calvert. 2000. Geographic variations in the nitrogen isotope composition of surface particulate nitrogen and new nitrogen production across the North Atlantic Ocean. Deep-Sea Res. I 47: 1207-1226, doi:10.1016/ S0967-0637(99)00102-8

West, J., G. J. Bowen, T. E. Dawson, and K. P. Tu [eds.]. 2010. Isoscapes: Understanding movement, pattern, and process on Earth through isotope mapping. Springer-Verlag.

Wilson, S. G., AND A. R. Martin. 2004. Body markings of the whale shark, vestigial or functional. West. Aust. Nat. 124: $118-134$.
Associate editor: Jonathan J. Cole

Received: 01 October 2012 Accepted: 23 December 2012 Amended: 24 December 2012 


\title{
APPENDIX TWO
}

\section{Ocean Ecogeochemistry: A Review}

\author{
Kelton W. McMahon \\ Biology Department, Woods Hole Oceanographic Institution, Woods Hole, MA, USA \\ Red Sea Research Center, King Abdullah University of Science and Technology, \\ Thuwal, Kingdom of Saudi Arabia \\ Li Ling Hamady \\ Massachusetts Institute of Technology/Woods Hole Oceanographic Institution Joint Program in \\ Oceanography/Applied Ocean Science and Engineering, Woods Hole, MA, USA \\ Simon R. Thorrold \\ Biology Department, Woods Hole Oceanographic Institution, Woods Hole, MA, USA
}

Reprinted with permission from Oceanography and Marine Biology: An Annual Review (C2013 Roger N. Hughes, David Hughes, and I. Philip Smith, Editors. Taylor and Francis.

McMahon KW, LL Hamady, SR Thorrold (2013) Ocean Ecogeochemistry: A Review. Oceanography and Marine Biology: An Annual Review. 51: 327-374 


\title{
OCEAN ECOGEOCHEMISTRY: A REVIEW
}

\author{
KELTON W. MCMAHON ${ }^{1,2,3}$, LI LING HAMADY ${ }^{1} \&$ SIMON R. THORROLD ${ }^{1}$
}

\author{
${ }^{1}$ Biology Department, Woods Hole Oceanographic Institution, \\ MS50, Woods Hole, MA 02543, USA \\ E-mail:kmcmahon@whoi.edu (corresponding author), lhamady@whoi.edu \\ ${ }^{2}$ Red Sea Research Center, King Abdullah University of Science and Technology, \\ Thuwal, Kingdom of Saudi Arabia \\ E-mail: sthorrold@whoi.edu \\ ${ }^{3}$ Ocean Sciences Department, University of California-Santa Cruz, SantaCruz, CA 95064, USA
}

\begin{abstract}
Animal movements and the acquisition and allocation of resources provide mechanisms for individual behavioural traits to propagate through population, community and ecosystem levels of biological organization. Recent developments in analytical geochemistry have provided ecologists with new opportunities to examine movements and trophic dynamics and their subsequent influence on the structure and functioning of animal communities. We refer to this approach as ecogeochemistry - the application of geochemical techniques to fundamental questions in population and community ecology. We used meta-analyses of published data to construct $\delta^{2} \mathrm{H}, \delta^{13} \mathrm{C}, \delta^{15} \mathrm{~N}$, $\delta^{18} \mathrm{O}$ and $\Delta^{14} \mathrm{C}$ isoscapes throughout the world's oceans. These maps reveal substantial spatial variability in stable isotope values on regional and ocean-basin scales. We summarize distributions of dissolved metals commonly assayed in the calcified tissues of marine animals. Finally, we review stable isotope analysis (SIA) of amino acids and fatty acids. These analyses overcome many of the problems that prevent bulk SIA from providing sufficient geographic or trophic resolution in marine applications. We expect that ecologists will increasingly use ecogeochemistry approaches to estimate animal movements and trace nutrient pathways in ocean food webs. These studies will, in turn, help provide the scientific underpinning for ecosystem-based management strategies in marine environments.
\end{abstract}

\section{Introduction}

The acquisition and allocation of resources are fundamental requirements for all animals and significantly influence behaviour, population dynamics and ecosystem functioning. Animal movement plays a critical role in resource acquisition and the transfer of these resources among locations. Trophic and movement ecology are therefore inextricably linked across a range of spatiotemporal scales within and among food webs. This connection extends to the techniques used to study connections among habitats and trophic groups. Stable isotope analysis (SIA) and other geochemical methods have been used extensively in food web studies and, more recently, to trace animal movements across habitats with distinctive isotopic signatures (Hobson 1999, Boecklen et al. 2011). This convergence represents a new direction for the field of ecogeochemistry, a term first used by Mizutani et al. (1991) to describe the use of SIA to infer diets of bats and subsequently expanded to include a range of geochemical approaches applied to ecological studies of food web dynamics and movement (McMahon et al. 2013). 
Ecologists have embraced the use of SIA in studies of marine food webs. A recent review found that nearly $60 \%$ of trophic ecology studies using SIAs published between 2007 and 2009 were conducted in marine or estuarine environments (Boecklen et al. 2011). However, while stable isotopes have been used in animal migration studies in terrestrial environments for several decades (Hobson 1999, Rubenstein \& Hobson 2004), the approach has received far less attention in marine systems (Fry 1981, Schell et al. 1989, Best \& Schell 1996). This lack of effort may be due, at least in part, to a failure to recognize the degree of geographic variation in isotope and element abundances across marine environments (Hobson 1999, Rubenstein \& Hobson 2004). Compilations of maps showing spatial variation in isotope values have identified marine isoscapes that are clearly sufficient for use in movement studies over ocean-basin scales (West et al. 2010, McMahon et al. 2013).

The use of ecogeochemical approaches to examine trophic dynamics and movement patterns of animals offers significant advantages over traditional methods in marine environments. For instance, the use of stable isotopes has overcome at least some of the problems associated with stomach content analysis to determine diets (Michener \& Schell 1994). Ecogeochemistry has also been employed to overcome problems associated with conventional tagging methods of the early life-history stages of marine animals (Thorrold et al. 2002, Becker et al. 2007). Finally, in some instances isotope analyses of ancient calcified tissues have provided a means of investigating ecological processes over millennial timescales (Limburg et al. 2011). Taken together, ecogeochemistry may allow for significant progress in a number of important, but as yet unresolved, questions in ocean ecology.

In this review, we outline the processes controlling isotope and elemental fractionation and summarize geographic gradients in isotope and elemental distributions in ocean and estuarine environments. We assemble global ocean isoscapes for key elements in marine ecogeochemistry, including seawater hydrogen $\left(\delta^{2} \mathrm{H}_{\mathrm{SW}}\right)$, dissolved inorganic carbon (DIC) $\left(\delta^{13} \mathrm{C}_{\mathrm{DIC}}\right)$, seawater radiocarbon $\left(\Delta^{14} \mathrm{C}_{\mathrm{SW}}\right)$, plankton carbon $\left(\delta^{13} \mathrm{C}_{\mathrm{PLK}}\right)$, plankton nitrogen $\left(\delta^{15} \mathrm{~N}_{\mathrm{PLK}}\right)$ and seawater oxygen $\left(\delta^{18} \mathrm{O}_{\mathrm{SW}}\right)$. We summarize distributions of those minor and trace elements that are consistently and accurately analysed in the calcified tissues of marine fish and invertebrates and used as natural geochemical tags of natal origin (Thorrold et al. 1997). Finally, we highlight the potential for compound-specific stable isotope analyses, acknowledging that more research is needed in terms of understanding the processes controlling stable isotope fractionation of individual amino acids and fatty acids.

\section{Data sources and isoscape methods}

In this review, we have assembled isoscapes for a number of key elements in the marine environment. The data used to generate the isoscapes were collected from meta-analyses of published isotope data. For $\delta^{2} \mathrm{H}_{\mathrm{SW}}$ and $\delta^{18} \mathrm{O}_{\mathrm{SW}}$, all data were available on the Global Oxygen-18 Database (Schmidt et al. 1999) on the National Aeronautics and Space Administration website (http://data. giss.nasa.gov/o18data/). Similarly, seawater radiocarbon $\left(\Delta^{14} \mathrm{C}_{\mathrm{SW}}\right)$ data were mined from the Global Data Analysis Project (GLODAP) (Key et al. 2004). Seawater DIC $\delta^{13} C_{\text {DIC }}$ data were collected from GLODAP (Key et al. 2004), the Open Access library Pangaea (http://www.pangaea.de), and extensive searches of Google Scholar and Web of Science. Date for both $\Delta^{14} \mathrm{C}_{\mathrm{SW}}$ and $\delta^{13} \mathrm{C}_{\mathrm{DIC}}$ were predominantly more recent than the $1990 \mathrm{~s}$. The $\delta^{13} \mathrm{C}_{\mathrm{DIC}}$ data in the horizontal isoscape were from the top $100 \mathrm{~m}$ of the world's oceans. Horizontal isoscapes of plankton $\delta^{13} \mathrm{C}_{\mathrm{PLK}}$ and $\delta^{15} \mathrm{~N}_{\mathrm{PLK}}$ values were mined from extensive searches of Google Scholar, Web of Science, and several online data repositories, including Pangaea. We limited the plankton isoscape search to samples described as net plankton $(<1 \mathrm{~mm})$ collected in the euphotic zone $(<150 \mathrm{~m}$ depth) and not preserved in formalin. The plankton isoscapes comprise a range of species but consist predominantly of copepods and similar zooplankton. To achieve the best spatial coverage, no attempts were made to sort data temporally. However, most data presented are more recent than the 1990s. In addition to papers cited individually elsewhere in this review, data were obtained from the work of Sackett et al. (1965); 
Degens et al. (1968); Wada \& Hattori (1976); Fontugne \& Duplessy (1978); Rau et al. (1982, 1983, 2003); Shadsky et al. (1982); Fry et al. (1983); Thayer et al. (1983); Macko et al. (1984); Mullin et al. (1984); Rodelli et al. (1984); Checkley \& Entzeroth (1985); Peterson \& Howarth (1987); Wada et al. (1987); Fry (1988); Libes \& Deuser (1988); Checkley \& Miller (1989); Dunton et al. (1989); Altabet \& Small (1990); Hobson \& Montevecchi (1991); Sholto-Douglas et al. (1991); Mackensen et al. (1993, 1996); Fry \& Quinones (1994); Hobson et al. (1994, 1995, 2002); Keeling \& Guenther (1994); Matsura \& Wada (1994); Laws et al. (1995); Yamamuro et al. (1995); Boon et al. (1997); Sydeman et al. (1997); Bentaleb et al. (1998); France et al. (1998); Millero et al. (1998); Schell et al. (1998); Gruber et al. (1999); Popp et al. (1999); Sigman et al. (1999); van Woesik et al. (1999); Wu et al. (1999); Calvert (2000); Hofmann et al. (2000); Kaehler et al. (2000); Koppelmann \& Weikert (2000); Pinnegar et al. (2000); Tittlemier et al. (2000); Villinski et al. (2000); Waser et al. (2000); Dunton (2001); Lesage et al. (2001); Mackensen (2001); Polunin et al. (2001); Stuck et al. (2001); Devenport \& Bax (2002); Hoekstra et al. (2002, 2003); Nyssen et al. (2002); Sato et al. (2002); Schlitzer (2002); Smith et al. (2002); Bode et al. (2003, 2004, 2007); Das et al. (2003); Estrada et al. (2003); Jennings \& Warr (2003); Kang et al. (2003); McClelland et al. (2003); Quay et al. (2003); Schmidt et al. (2003); Corbisier et al. (2004); Mahaffey et al. (2004); Abed-Navandi \& Dworschak (2005); Iken et al. (2005); Kiriakoulakis et al. (2005); Le Loc'h \& Hily (2005); Quillfeldt et al. (2005); Sommer et al. (2005); Galimov et al. (2006); Goni et al. (2006); Tamelander et al. (2006); Carlier et al. (2007); Holl et al. (2007); Cianco et al. (2008); Harmelin-Vivien et al. (2008); Lamb \& Swart (2008); Le Loc'h et al. (2008); Petursdottir et al. (2008, 2010); Fanelli et al. (2009, 2011); Frederich et al. (2009); Hirch (2009); Lysiak (2009); Richoux \& Froneman (2009); Laakmann \& Auel (2010); Miller et al. (2010); Olson et al. (2010); Pajuelo et al. (2010); Forest et al. (2011); Hill \& McQuaid (2011); Kohler et al. (2011); Kolasinski et al. (2011); Kurten et al. (2011); Pomerleau et al. (2011); Stowasser et al. (2012); and Wyatt (2011).

Isoscapes were generated using Ocean Data View (ODV) version 4.5.0 (Brown 1998, Schlitzer 2002, http://odv.awi.de/). Data are displayed as colour-shaded maps based on contouring of the original data using the Data Interpolating Variational Analysis (DIVA) gridding software. DIVA software was designed to interpolate data spatially (Barth et al. 2010). DIVA gridding takes into account coastlines, subbasins and advection. Calculations are highly optimized and rely on a finite-element resolution. In particular, the finite-element method takes into account the distance between analysis and data (observation constraint), the regularity of the analysis (smoothness constraint) and physical laws (behaviour constraint). Information about the DIVA gridding software used by ODV can be found at http://modb.oce.ulg.ac.be/mediawiki/index.php/DIVA. Details of the algorithms employed by DIVA gridding can be found at http://modb.oce.ulg.ac.be/mediawiki/index.php/DIVA_method.

\section{Systematics}

To be successfully applied in the field, an ecogeochemistry approach must do each of the following (Hobson et al. 2010): (1) establish a baseline isoscape that characterizes distinct geochemical signatures in different habitats or food web end members; (2) constrain tissue isotope turnover rates that determine the period of integration of geochemical signatures for a particular tissue; and (3) identify isotope or elemental fractionation factors between consumer and diet, or between animals and the ambient environment, that offset animal geochemical signatures from the baseline isotope values. The isotopic composition of elements in the marine environment is influenced by a variety of physical, chemical and biological processes that together produce unique geographic distributions, termed isoscapes (West et al. 2010). Next, we provide a brief overview of the dominant sources of fractionation for elements commonly used in ecogeochemistry studies and discuss the resulting geographic distributions in the marine and estuarine environments. Common reference standards for the elements discussed can be found in Table 1. 
Table 1 Common isotope ratios, their percentage abundances, reference standards, substance types, and $\delta$ values

\begin{tabular}{|c|c|c|c|c|}
\hline $\begin{array}{l}\text { Isotope } \\
\text { ratio }\end{array}$ & $\begin{array}{c}\text { Abundance } \\
(\%)\end{array}$ & Standard & Type & Value \\
\hline${ }^{2} \mathrm{H} /{ }^{1} \mathrm{H}$ & $0.01 / 99.98$ & SMOW (Standard Mean Ocean Water) & Water & $\delta \mathrm{D}(\mathrm{SMOW})=0.00 \%$ \\
\hline${ }^{2} \mathrm{H} /{ }^{1} \mathrm{H}$ & $0.01 / 99.98$ & SLAP (Standard Light Antarctic Precipitation) & Water & $\delta \mathrm{D}(\mathrm{SMOW})=-428.00 \%$ \\
\hline${ }^{13} \mathrm{C} /{ }^{12} \mathrm{C}$ & $1.10 / 98.90$ & PDB (PeeDee Belemnite) & Calcite & $\delta^{13} \mathrm{C}(\mathrm{PDB})=0.00 \% 0$ \\
\hline${ }^{13} \mathrm{C} /{ }^{12} \mathrm{C}$ & $1.10 / 98.90$ & NBS-19 (National Bureau of Standards-19) & Calcite & $\delta^{13} \mathrm{C}(\mathrm{PDB})=1.95 \%$ \\
\hline${ }^{14} \mathrm{C} /{ }^{12} \mathrm{C}$ & $<0.01 / 98.90$ & $\begin{array}{l}\text { NBS HOx1 (National Bureau of Standards } \\
\text { Oxalic Acid I) }\end{array}$ & Oxalic acid & \\
\hline${ }^{15} \mathrm{~N} /{ }^{14} \mathrm{~N}$ & $0.36 / 99.64$ & Atmospheric AIR & Air & $\delta^{15} \mathrm{~N}(\mathrm{AIR})=0.00 \%$ \\
\hline${ }^{18} \mathrm{O} /{ }^{16} \mathrm{O}$ & $0.20 / 99.76$ & SMOW (Standard Mean Ocean Water) & Water & $\delta^{18} \mathrm{O}(\mathrm{SMOW})=0.00 \%$ \\
\hline${ }^{18} \mathrm{O} /{ }^{16} \mathrm{O}$ & $0.20 / 99.76$ & SLAP (Standard Light Antarctic Precipitation) & Water & $\delta^{18} \mathrm{O}(\mathrm{SMOW})=-55.50 \%$ \\
\hline${ }^{18} \mathrm{O} /{ }^{16} \mathrm{O}$ & $0.20 / 99.76$ & PDB (PeeDee Belemnite) & Calcite & $\delta^{18} \mathrm{O}(\mathrm{SMOW})=0.27 \%$ \\
\hline${ }^{18} \mathrm{O} /{ }^{16} \mathrm{O}$ & $0.20 / 99.76$ & NBS-19 (National Bureau of Standards-19) & Calcite & $\delta^{18} \mathrm{O}(\mathrm{SMOW})=28.64 \% \circ$ \\
\hline${ }^{34} \mathrm{~S} /{ }^{32} \mathrm{~S}$ & $4.21 / 95.02$ & CDT (Canyon Diablo Troilite) & Iron sulphide & $\delta^{18} \mathrm{O}(\mathrm{SMOW})=0.00 \% \circ$ \\
\hline
\end{tabular}

Note: For a complete set of standards, see Coplen et al. (2002).

\section{Hydrogen isotopes}

\section{Hydrogen isotope fractionation}

Hydrogen has the largest mass difference between isotopes relative to mass and hence the greatest variability of $\delta$ values of any element on Earth. Physical-chemical processes governing hydrogen isotope fractionation in the marine environment include evaporation, precipitation, mixing and exchange reactions (Friedman 1953). Evaporation from a number of sources, including clouds, water bodies, soil and plant and animal respiration, forms an important basis for fractionation of hydrogen isotopes in the hydrologic cycle. Fractionation of hydrogen isotopes during evaporation is largely a kinetic process that depends on a number of factors and can, in turn, be quite large. Vapour pressures of the isotopologues of water decrease with decreasing molecular weight; therefore, the heavy isotope $\left({ }^{2} \mathrm{H}\right)$ will favour that part of the system in which it is more strongly bound, that is, the liquid phase (Gat 1996). The same is true for condensation; therefore, during evaporation and condensation in an open system, the liquid phase of water becomes progressively enriched in ${ }^{2} \mathrm{H}$, while the vapour phase becomes progressively depleted. This process is known as Rayleigh distillation (Gat 1996). Rayleigh distillation has important implications for latitudinal gradients in ocean $\delta^{2} \mathrm{H}$ values of seawater $\left(\delta^{2} \mathrm{H}_{\mathrm{SW}}\right)$ as described in the next section. Hydrogen isotope fractionation factors for phase transitions of water are so large that even in high-temperature systems like hydrothermal vents, significant variation in $\delta^{2} \mathrm{H}_{\mathrm{SW}}$ can be seen (Horita \& Wesolowski 1994). Further fractionation of hydrogen isotopes can take place at hydrothermal vents and deep-water cold seeps during oxidation of $\mathrm{H}_{2}$ and $\mathrm{CH}_{4}$ to $\mathrm{H}_{2} \mathrm{O}$ and $\mathrm{CO}_{2}$. The pressure (depth) at which these reactions take place can also have an impact on hydrogen isotope fractionation (Horita 1999).

Hydrogen isotopes can also be fractionated by biological processes, including bacterially mediated production of hydrogen gas and methane, both of which tend to be depleted in ${ }^{2} \mathrm{H}$ (Krichevsky et al. 1961). Hydrogen isotope fractionation during photosynthesis typically results in organic matter that is relatively depleted in ${ }^{2} \mathrm{H}$; however, the individual steps involved in fractionation are still unclear (White 1989). It is important to note that at low temperatures water hydrogen will exchange quickly and reversibly with labile organic hydrogen bound in organic nitrogen, sulphur and oxygen compounds (Werstiuk \& Ju 1989). Water at neutral pH and low temperature in the absence of a catalyst, however, does not readily exchange with most carbon-bound hydrogen (Sternberg 1988), particularly hydrocarbons and lipids. Therefore, it is important to choose appropriate tissues that 
contain non-exchangeable hydrogen or correct for exchange with suitable standards when attempting to examine animal migration with stable hydrogen isotopes (Kelly et al. 2009).

\section{Hydrogen isotope geographic variability}

Surface $\delta^{2} \mathrm{H}_{\mathrm{SW}}$ values range from approximately $-60 \%$ in the Arctic Ocean to approximately $12 \%$ o in parts of the Mediterranean Sea (Figure 1). Rayleigh distillation is a fundamental process controlling latitudinal gradients in $\delta^{2} \mathrm{H}_{\mathrm{Sw}}$. As water vapour travels polewards and cools, some of the vapour condenses out as enriched precipitation, leaving the remaining vapour further depleted relative to its source. The water vapour becomes more depleted as the fraction of vapour remaining becomes smaller, until it is finally deposited as highly ${ }^{2} \mathrm{H}$-depleted snow at the poles. This depletion can be modelled as follows:

$$
{ }^{2} \mathrm{H} /{ }^{1} \mathrm{H}_{\mathrm{V}}={ }^{2} \mathrm{H} /{ }^{1} \mathrm{H}_{\mathrm{V}_{\mathrm{o}}} f^{(\alpha-1)},
$$

where $f$ is the fraction of vapour remaining, $\alpha$ is the equilibrium fractionation factor for the water-vapour phase transition, and ${ }^{2} \mathrm{H} /{ }^{1} \mathrm{H}_{\mathrm{V}}$ and ${ }^{2} \mathrm{H} /{ }^{1} \mathrm{H}_{\mathrm{V}_{\mathrm{o}}}$ are the hydrogen isotope ratios of the current and initial water vapour fractions, respectively. This process results in a gradient of $\delta^{2} \mathrm{H}_{\mathrm{SW}}$ values that are more negative with increasing latitude. $\delta^{2} \mathrm{H}_{\mathrm{SW}}$ values that are more negative also occur in regions of river run-off from large drainage basins. Riverine and groundwater sources typically have $\delta^{2} \mathrm{H}$ values that reflect the average isotope composition of precipitation that fell relatively recently into watersheds or recharge sites for that area (Kendall \& Coplen 2001). These freshwater sources introduce unique $\delta^{2} \mathrm{H}$ signatures into coastal areas that are consistently lower than $\delta^{2} \mathrm{H}_{\mathrm{SW}}$ values. The mouths of large rivers like the Amazon can introduce anomalously low $\delta^{2} \mathrm{H}$ values that penetrate hundreds of kilometres into the Atlantic Ocean. Similarly, deuterium can be a valuable tracer of subsurface groundwater sources (Sonntag et al. 1983), resulting in unique nearshore $\delta^{2} \mathrm{H}_{\mathrm{Sw}}$ signatures that could be used to track animal migration within and among nearshore habitats. More positive $\delta^{2} \mathrm{H}_{\mathrm{SW}}$ values are typically observed in highly evaporative sites, such as the subtropical gyres, the Mediterranean Sea and the Arabian Sea. Vertical profiles of $\delta^{2} \mathrm{H}_{\mathrm{Sw}}$ generally tend to show less variation than the horizontal surface variation and covary with salinity.

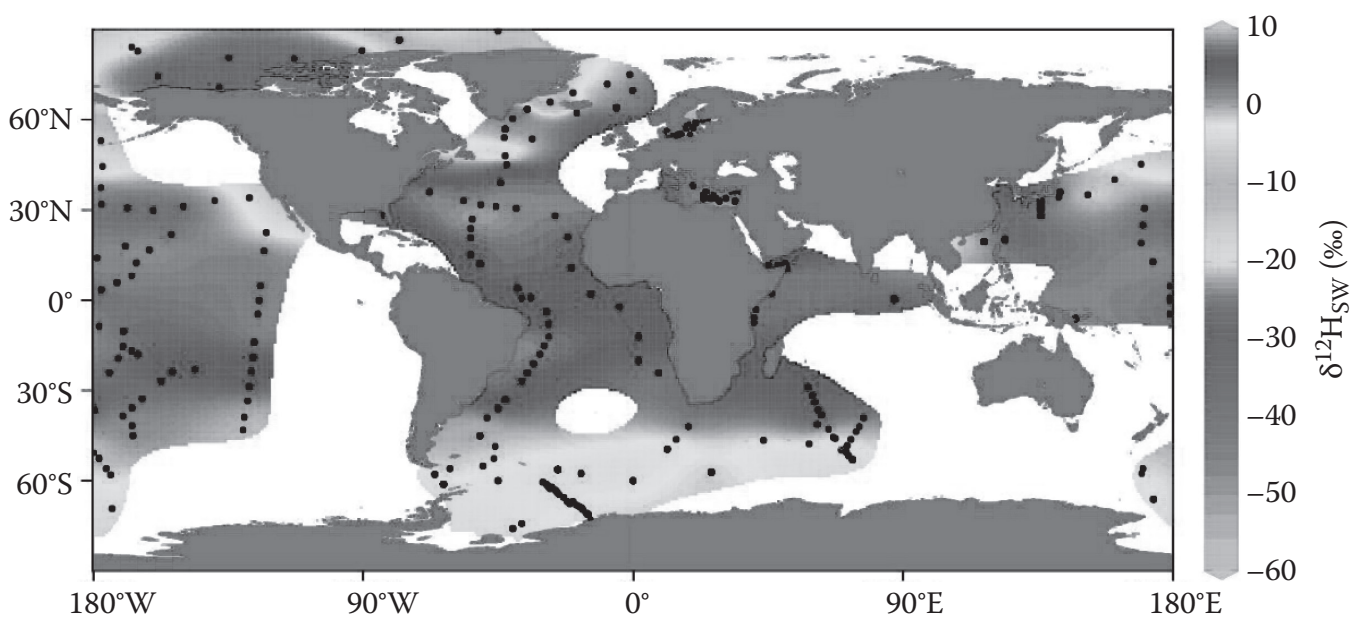

Figure 1 (See also colour figure in the insert) Horizontal isoscape of published seawater $\delta^{2} \mathrm{H}_{\mathrm{SW}}$ values in the surface waters (top $100 \mathrm{~m}$ ) of the world's oceans ( $n=360$ data points). Data were collected from the Global Seawater Oxygen-18 database (Schmidt et al. 1999). Isoscapes were generated in Ocean Data View (Schlitzer 2011). Black dots indicate the sample locations. 
It is interesting to note two exceptions to the patterns described. In the Pacific Ocean, the California Current exhibits $\delta^{2} \mathrm{H}_{\mathrm{SW}}$ values that are more negative than would be predicted based on latitude due to advection of ${ }^{2} \mathrm{H}$-depleted subpolar water towards the equator along the eastern Pacific Ocean. Conversely, the north-eastern North Atlantic exhibits enriched $\delta^{2} \mathrm{H}_{\mathrm{SW}}$ values for its latitude due to polewards advection of ${ }^{2} \mathrm{H}$-enriched low-latitude water via the Gulf Stream.

\section{Carbon isotopes}

\section{Carbon-13 $\left({ }^{13} \mathrm{C}\right)$}

${ }^{13} \mathrm{C}$ fractionation Carbon isotopes are fractionated during several reactions as they move through the environment and into food webs. The first of these fractionation processes is caused by equilibration of $\mathrm{CO}_{2}$ between the atmosphere and the surface ocean DIC pool (Boutton 1991). The dissolution of $\mathrm{CO}_{2}$ in seawater occurs through the following reactions:

$$
\mathrm{CO}_{2(\mathrm{~atm})} \rightleftharpoons \mathrm{CO}_{2(\mathrm{aq})}+\mathrm{H}_{2} \mathrm{O} \rightleftharpoons \mathrm{H}_{2} \mathrm{CO}_{2} \rightleftharpoons \mathrm{H}^{+}+\mathrm{HCO}_{3}^{-} \rightleftharpoons 2 \mathrm{H}^{+}+\mathrm{CO}_{3}^{2-}
$$

Although the equilibration of $\mathrm{CO}_{2}$ alone is relatively fast (approximately 1 year), exchange between atmospheric $\mathrm{CO}_{2}$ and DIC that includes all the inorganic carbon species is a slower process, on the order of about 10 years (Broecker \& Peng 1974). At a typical surface seawater $\mathrm{pH}$ of 8.2, seawater DIC has $91 \%$ bicarbonate ion, $8 \%$ carbonate ion, and $1 \%$ dissolved $\mathrm{CO}_{2}$. There is also significant temperature-dependent fractionation of carbon isotopes among the various dissolved carbon species (Zeebe \& Wolf-Gladrow 2001). The $\delta^{13} \mathrm{C}$ value of $\mathrm{CO}_{2(\mathrm{~atm})}$ is approximately $-8 \%$ o (Keeling et al. 2005). At $25^{\circ} \mathrm{C}$, carbon isotope fractionation between $\mathrm{CO}_{2(\mathrm{~atm})}$ and $\mathrm{CO}_{2(\mathrm{aq})}$ is $1.3 \%$, and fractionation between $\mathrm{CO}_{2(\mathrm{aq})}$ and bicarbonate ions is -9\%o (Mook 1986, Zhang et al. 1995). Finally, fractionation between bicarbonate and carbonate ions was reported by Mook (1986) to be $0.4 \%$, although the value is not particularly well constrained (Zeebe \& Wolf-Gladrow 2001).

Photosynthetic marine organisms take up the lighter carbon isotope $\left({ }^{12} \mathrm{C}\right)$ at a faster rate, with a $\delta^{13} \mathrm{C}$ fractionation value of approximately $-19 \%$ o between $\delta^{13} \mathrm{C}_{\mathrm{DIC}}$ and fixed organic carbon (Lynch-Stieglitz et al. 1995). Internal biological parameters of primary producers, such as biosynthesis rate, enzymatic activity and cell lipid content, can significantly influence their $\delta^{13} C_{\text {PLK }}$ values (Fry \& Wainright 1991, Hinga et al. 1994). The most prominent example of this differential fractionation during photosynthesis can be seen in the $\delta^{13} \mathrm{C}$ values of $\mathrm{C}_{3}$ and $\mathrm{C}_{4}$ plants. Plants using the $\mathrm{C}_{4}$ photosynthetic pathway typically have $\delta^{13} \mathrm{C}$ values that are more positive, ranging from $-8 \%$ o to $-12 \%$ o, than $\mathrm{C}_{3}$ plants $(-22 \%$ o to $-28 \%$ o) (see review by Farquhar et al. 1989). This difference is due to $\mathrm{C}_{4}$ plants using a different primary carboxylating enzyme, phosphenolpyruvate (PEP) carboxylase, and a different species of inorganic carbon than $\mathrm{C}_{3}$ plants that use ribulose-bisphosphate carboxylase-oxygenase (Rubisco). During photosynthesis, phytoplankton take up DIC, and after moderate kinetic fractionation, phytoplankton obtains a $\delta^{13} \mathrm{C}$ value between $-16 \%$ and $-24 \%$ o (Peterson \& Fry 1987).

${ }^{13} \mathrm{C}$ geographic variability Temperature is a key physical parameter that influences $\delta^{13} \mathrm{C}$ variability of $\mathrm{CO}_{2}$ globally. The dissolved $\mathrm{CO}_{2}$ concentration of the surface mixed layer $\left[\mathrm{CO}_{2}\right]_{\mathrm{aq}}$ is inversely related to sea-surface temperature (SST) (Weiss 1974), and cold waters with higher $\left[\mathrm{CO}_{2}\right]_{\mathrm{aq}}$ tend to have lower $\delta^{13} \mathrm{C}$ values than warm waters. This process establishes a strong latitudinal gradient in surface ocean $\delta^{13} \mathrm{C}$ values of $\mathrm{CO}_{2}$ and DIC (Figure 2). Introduction of ${ }^{13} \mathrm{C}$-depleted atmospheric $\mathrm{CO}_{2}$ in regions of the ocean with prominent $\mathrm{CO}_{2}$ invasion, such as the North Atlantic, results in relatively low surface water $\delta^{13} \mathrm{C}_{\mathrm{DIC}}$ values. Conversely, outgassing of $\mathrm{CO}_{2}$ in equatorial upwelling zones gives surface waters more positive $\delta^{13} \mathrm{C}$ values (Lynch-Stieglitz et al. 1995). Organic material is remineralized as it sinks; therefore, water masses at depth are low in $\delta^{13} \mathrm{C}_{\mathrm{DIC}}$ value relative to surface waters, 


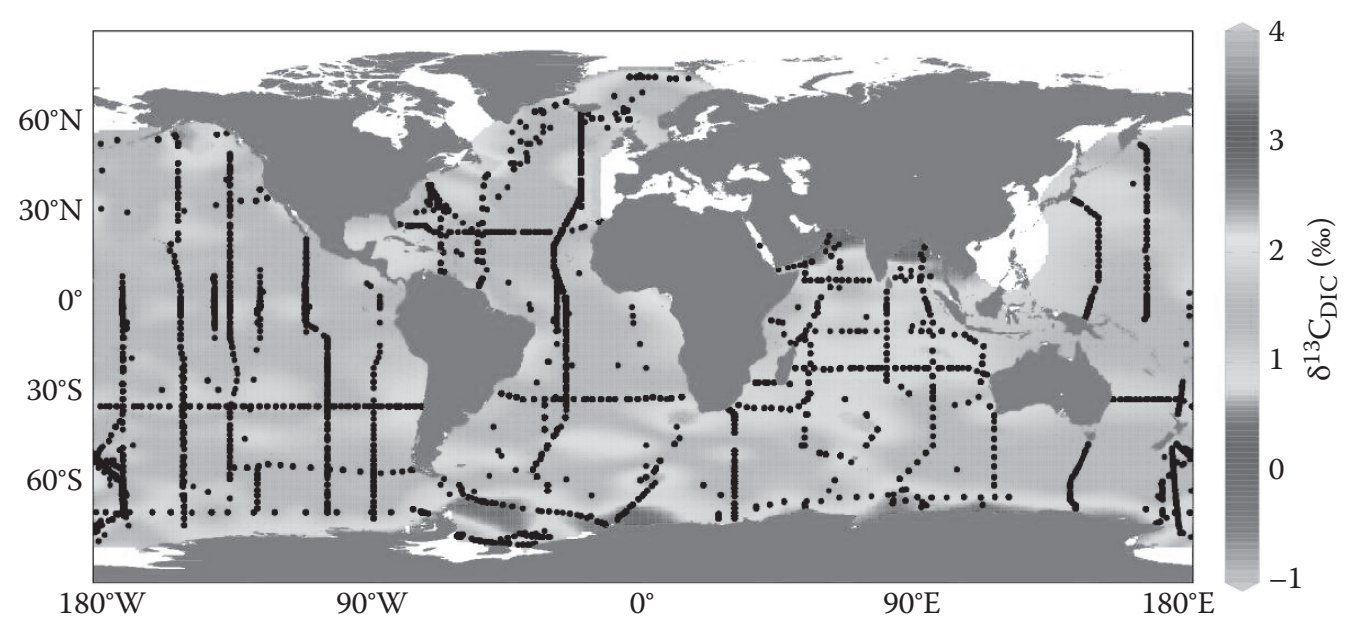

Figure 2 (See also colour figure in the insert) Horizontal isoscape of published seawater dissolved inorganic carbon (DIC) $\delta^{13} C_{\text {DIC }}$ values in the surface waters (top $100 \mathrm{~m}$ ) of the world's oceans $(n=5501$ data points). Data were collected from the GLODAP database (Key et al. 2004). Isoscapes were generated in Ocean Data View (Schlitzer 2011). Black dots indicate the sample locations.

with values typically approaching $0 \%$ (Figure 3 ). Upwelling events can also be a significant source of anomalously low surface $\delta^{13} C_{\text {DIC }}$ values (Kroopnick 1985).

The $\delta^{13} \mathrm{C}$ value of primary producers $\left(\delta^{13} \mathrm{C}_{\mathrm{PLK}}\right)$ is strongly influenced by the $\delta^{13} \mathrm{C}$ value of the local DIC pool; thus, spatial variability in $\delta^{13} \mathrm{C}_{\mathrm{PLK}}$ is primarily driven by the same physical parameters (temperature and $\left[\mathrm{CO}_{2}\right]_{\mathrm{aq}}$ ) that influence $\delta^{13} \mathrm{C}_{\mathrm{DIC}}$ values (Figure 4). For example, Goericke $\&$ Fry (1994) demonstrated that phytoplankton $\delta^{13} \mathrm{C}$ values generally decreased with increasing latitude as the $\delta^{13} \mathrm{C}$ of particulate organic carbon (POC) weakly tracked with temperature on a global scale. However, as mentioned, biological processes can also influence phytoplankton $\delta^{13} \mathrm{C}_{\mathrm{PLK}}$ values and thus decouple these patterns in some situations (Fry \& Wainright 1991, Hinga et al. 1994, Kelly 2000).

Nearshore and benthic systems are typically more ${ }^{13} \mathrm{C}$-enriched than oceanic systems due to higher nutrient concentrations near shore causing greater overall productivity (France 1995). In addition, tighter terrestrial and benthic-pelagic coupling in nearshore systems can increase inputs from ${ }^{13} \mathrm{C}$-enriched benthic macrophytes and $\mathrm{C}_{4}$ marsh plants (France 1995). In contrast, pelagic waters are ${ }^{13} \mathrm{C}$-depleted owing to lower nutrient availability, lower phytoplankton growth rates and overall productivity and reduced contributions from benthic macrophytes. As a result, there are often steep gradients in $\delta^{13} \mathrm{C}_{\text {base }}$ values from nearshore to offshore and benthic to pelagic habitats. This gradient can be particularly pronounced in regions of strong upwelling or seasonal coastal phytoplankton blooms (Pancost et al. 1997).

There can also be significant seasonal variability in $\delta^{13} \mathrm{C}$ values at the base of marine food webs $\left(\delta^{13} \mathrm{C}_{\text {base }}\right)$ in many ocean ecosystems (Gearing et al. 1984, Cifuentes et al. 1988, Goering et al. 1990, Ostrom et al. 1997). There are a number of factors that can contribute to seasonal variability in $\delta^{13} \mathrm{C}_{\text {base }}$, including seasonal changes in water mass properties and fluctuations in terrestrial run-off, temperature and associated $\left[\mathrm{CO}_{2}\right]_{\mathrm{aq}}$, phytoplankton productivity and growth rate and primary producer species composition. In general, seasonal variability is larger at high latitudes, with large variations in temperature and productivity, compared to low-latitude, tropical systems. Cifuentes et al. (1988) showed that the pattern of $\delta^{13} \mathrm{C}$ in suspended particulate matter varied by nearly $9 \%$ on seasonal timescales in the Delaware Estuary. Goering et al. (1990) found a similar pattern with more than a $4 \%$ difference in net phytoplankton $\delta^{13} C_{\mathrm{PLK}}$ values between April and May alone 


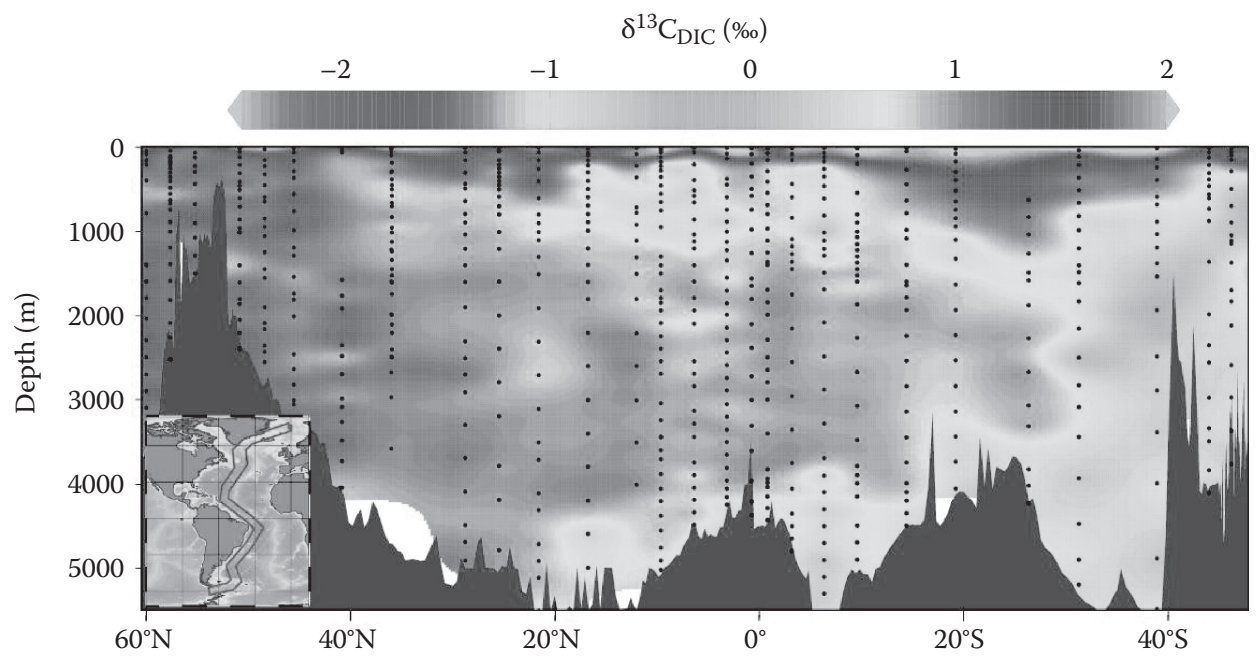

(A)

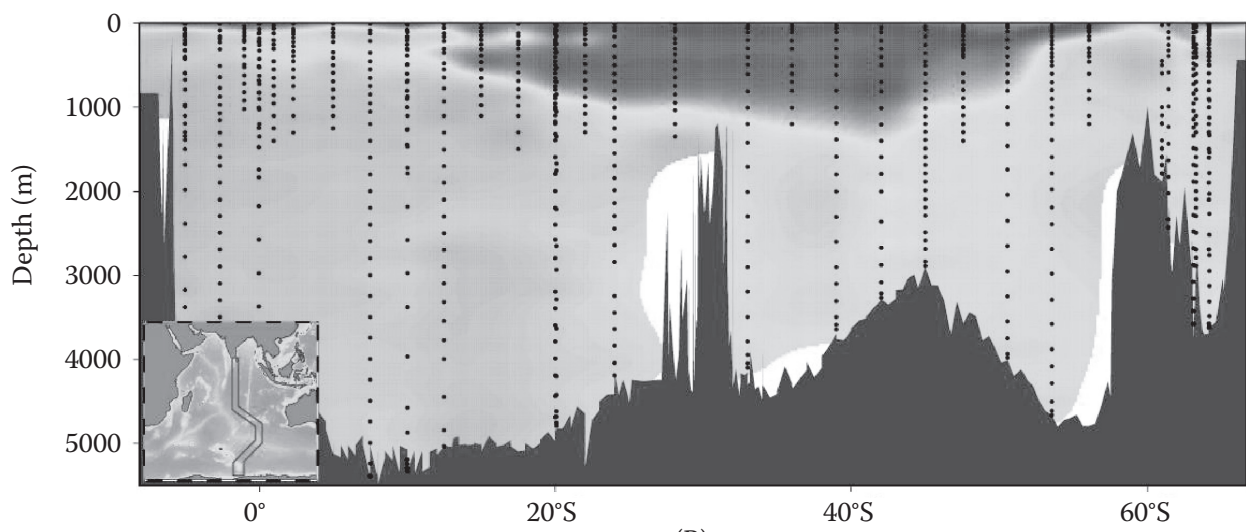

(B)

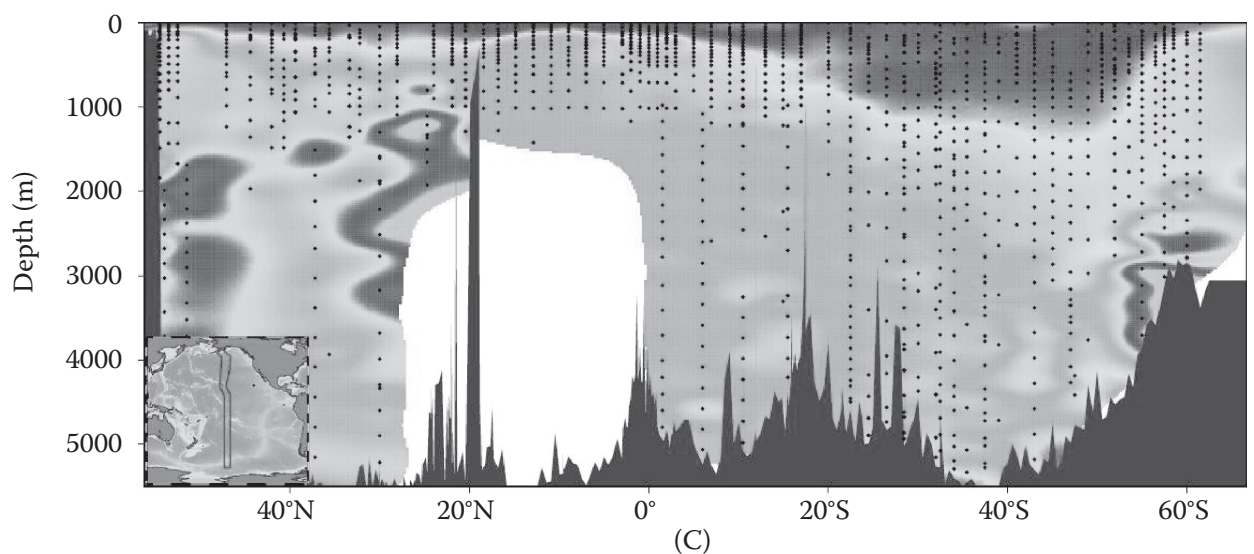

Figure 3 (See also colour figure in the insert) Vertical isoscapes of published seawater dissolved inorganic carbon (DIC) $\delta^{13} \mathrm{C}_{\text {DIC }}$ values from (A) Atlantic Ocean $(n=659$ data points); (B) Indian Ocean $(n=809$ data points); and (C) Pacific Ocean ( $n=1353$ data points). Data were collected from an extensive search on Web of Knowledge and the GLODAP database (Key et al. 2004). Isoscapes were generated in Ocean Data View (Schlitzer 2011). Black dots indicate the sample locations. 


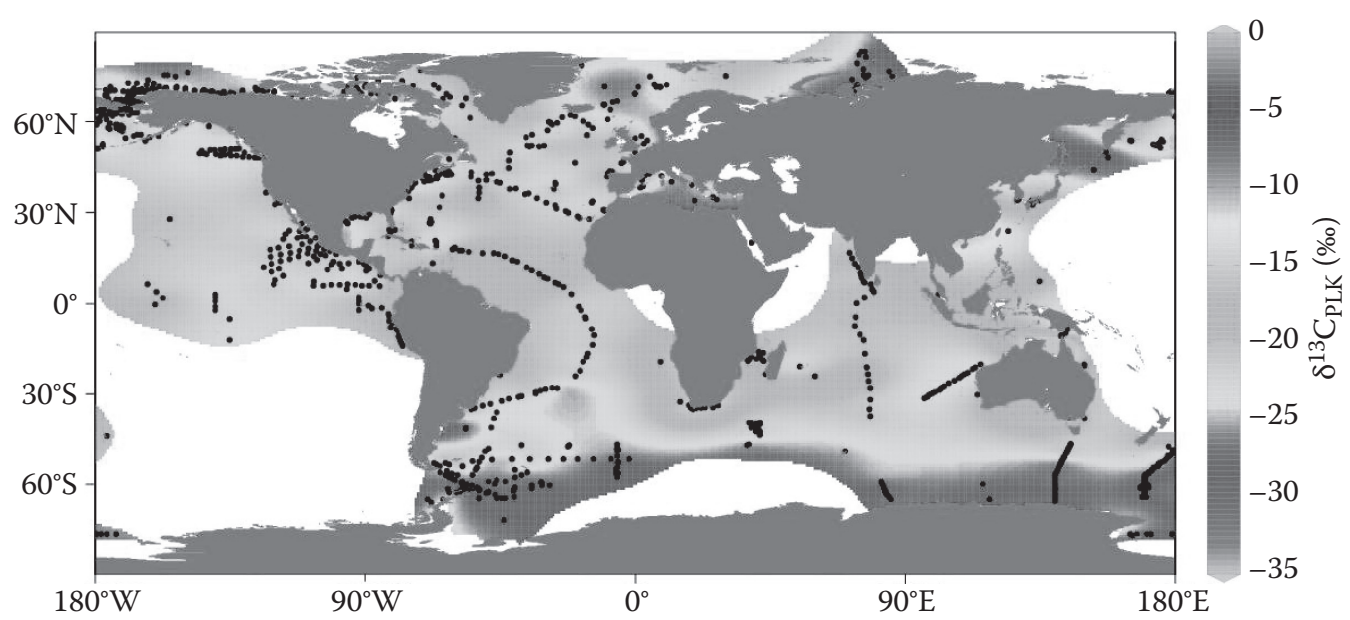

Figure 4 (See also colour figure in the insert) Horizontal isoscape of published surface plankton $\delta^{13} \mathrm{C}_{\mathrm{PLK}}$ values in the surface waters (top $200 \mathrm{~m}$ ) of the world's oceans ( $n=1434$ data points). Data were collected from an extensive search on Web of Knowledge and several online data repositories. Isoscapes were generated in Ocean Data View (Schlitzer 2011). Black dots indicate the sample locations.

during the seasonal spring bloom in coastal Alaska. These seasonal fluctuations in $\delta^{13} \mathrm{C}$ can be passed on to higher trophic levels as well, particularly for primary consumers with fast turnover rates (Gearing et al. 1984, Simenstad \& Wissmar 1985, Goering et al. 1990, Riera \& Richard 1997). The transfer of such variability to consumers at the upper trophic level tends to diminish with increasing trophic level as a result of time averaging due to slower tissue turnover rates and feeding on multiple food sources, potentially across multiple food webs for highly mobile species (Goering et al. 1990, O'Reilly et al. 2002). For instance, in the Goering et al. (1990) study, zooplankton had a similar, although smaller, seasonal variability $\left(\delta^{13} \mathrm{C}_{\mathrm{PLK}}\right.$ about $3 \%$ ) to net phytoplankton.

\section{Carbon-14 $\left({ }^{14} \mathrm{C}\right)$}

${ }^{14} \mathrm{C}$ fractionation Carbon has a naturally occurring, radiogenic isotope, ${ }^{14} \mathrm{C}$ (radiocarbon), that may be a useful tracer of habitat use in the marine environment. Radiocarbon is created by cosmic ray bombardment of nitrogen in the atmosphere. In living organisms, radiocarbon exists at levels in isotopic equilibrium with their surroundings; when an organism dies, the ${ }^{14} \mathrm{C}$ begins to decay at a predictable and measurable rate. This makes radiocarbon analysis useful for dating organic matter. In modern times, several anthropogenic perturbations have altered natural radiocarbon levels. Fossil fuel emissions introduced old, 'dead' radiocarbon into the atmosphere and led to a decrease of about 20\% in atmospheric $\Delta^{14} \mathrm{C}$ values from 1890 to 1950 (Suess 1955, Levin \& Hesshaimer 2000). In addition, atmospheric testing of atomic bombs in the 1950s and early 1960s resulted in a rapid and well-documented increase in radiocarbon in the atmosphere, leading to disequilibrium with the world's oceans and biosphere (Druffel \& Linick 1978). The initial rise of bomb radiocarbon in surface ocean waters from prebomb levels (approximately $-50 \%$ in the Pacific Ocean and $-65 \%$ o to $-45 \%$ in the Atlantic Ocean) occurred in $1959 \pm 1$ year, and ${ }^{14} \mathrm{C}$ levels rose relatively rapidly to peak $\Delta^{14} \mathrm{C}$ values between 1967 and 1970 (approximately 210\%o in the Pacific Ocean and 270\%o in the Atlantic Ocean), with a subsequent slow but steady declining trend since then (Ostlund et al. 1974, Stuiver et al. 1981, Nydal 1998). This bomb radiocarbon chronology is almost synchronous around the world in biogenic carbonates, such as coral skeletons, bivalve shells and fish otoliths (Druffel \& Linick 1978, Kalish 1993, Weidman \& Jones 1993), thus serving as a dated marker in calcified structures exhibiting periodic growth bands (Figure 5). 


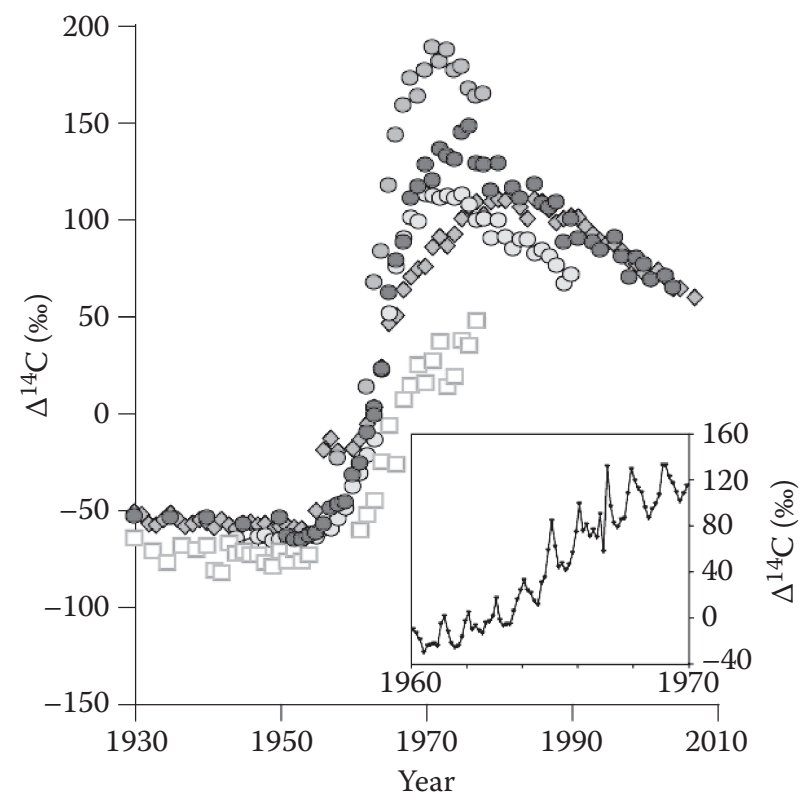

Figure 5 (See also colour figure in the insert) Radiocarbon $\left(\Delta^{14} \mathrm{C}\right)$ chronologies from marine corals in the world's oceans from 1930 to 2010. Blue circles: Porites sp., French Frigate Shoals, Pacific Ocean (Druffel 1987). Blue squares: Pavona clavus, Galapagos Islands, Pacific Ocean (Druffel 1981). Blue diamonds: Porites lutea, Palmyra Atoll, Pacific Ocean (Druffel-Rodriguez et al. 2012). Red circles: Porites lutea, Puerto Rico, Atlantic Ocean (Kilbourne et al. 2007). Yellow circles: Porites sp., Mentawai Islands, Indian Ocean (Grumet et al. 2004). Inset: seasonal variability in Porites lutea $\Delta^{14} \mathrm{C}$ values from the South Makassar Strait, Indonesia, between 1960 and 1970 (Fallon \& Guilderson 2008).

${ }^{14} \mathrm{C}$ geographic variability The distribution of ${ }^{14} \mathrm{C}_{\mathrm{DIC}}$ in the ocean is largely determined by air-sea exchange of $\mathrm{CO}_{2}$ and ocean circulation (Siegenthaler 1989). Due to initial asymmetrical atmospheric input, the $\Delta^{14} \mathrm{C}_{\mathrm{SW}}$ maximum values peaked 1-2 years earlier in the Northern Hemisphere compared to the Southern Hemisphere (Linick 1978). Deep-water masses that are isolated from the atmosphere and transported to depth via thermohaline circulation have $\Delta^{14} \mathrm{C}_{\mathrm{SW}}$ values that become more negative with increasing residence time in the ocean (Broecker et al. 1985, Jain et al. 1995) (Figure 6). For instance, the relatively young deep waters of the Atlantic Ocean have $\Delta^{14} \mathrm{C}_{\mathrm{Sw}}$ values on the order of $-140 \%$, while the $\Delta^{14} \mathrm{C}_{\mathrm{SW}}$ values of older deep North Pacific waters are approximately $-250 \%$ (Siegenthaler 1989, but see Druffel \& Williams 1990).

Seawater $\Delta^{14} \mathrm{C}$ values also can vary on regional scales, both horizontally and vertically. Subtropical gyres that entrain water at the surface and possess a strong thermocline with limited vertical mixing typically have high sea-surface $\Delta^{14} \mathrm{C}_{\mathrm{SW}}$ values. Conversely, subpolar gyres and areas of divergence and upwelling bring older, more negative $\Delta^{14} \mathrm{C}_{\mathrm{SW}}$ waters to mix at the surface. In the Pacific, maximal $\Delta^{14} \mathrm{C}$ values occur in midlatitudes around $30^{\circ}$ north and south; at the peak, these regions registered $210 \%$ or $260 \%$ above prebomb levels, whereas equatorial waters reached $50 \%$ or $110 \%$ above prebomb levels (Linick 1978). These $\Delta^{14} \mathrm{C}_{\mathrm{SW}}$ surface patterns translate down through the mixed layer, although values drop off quickly below that and remain relatively constant below about $1000 \mathrm{~m}$ in all areas (Key et al. 2004). The vertical $\Delta{ }^{14} \mathrm{C}_{\mathrm{SW}}$ gradients observed in the North Pacific and North Atlantic may potentially be used as a depth tracer in the context of animal movements if the analysed tissue is primarily derived from DIC (Pearcy \& Stuiver 1983, Rau et al. 1986). Upwelling can cause significant variability in sea-surface $\Delta^{14} C_{\mathrm{SW}}$ values on regional and seasonal scales (Figure 5). For instance, strong upwelling around the Galapagos Islands brings old 


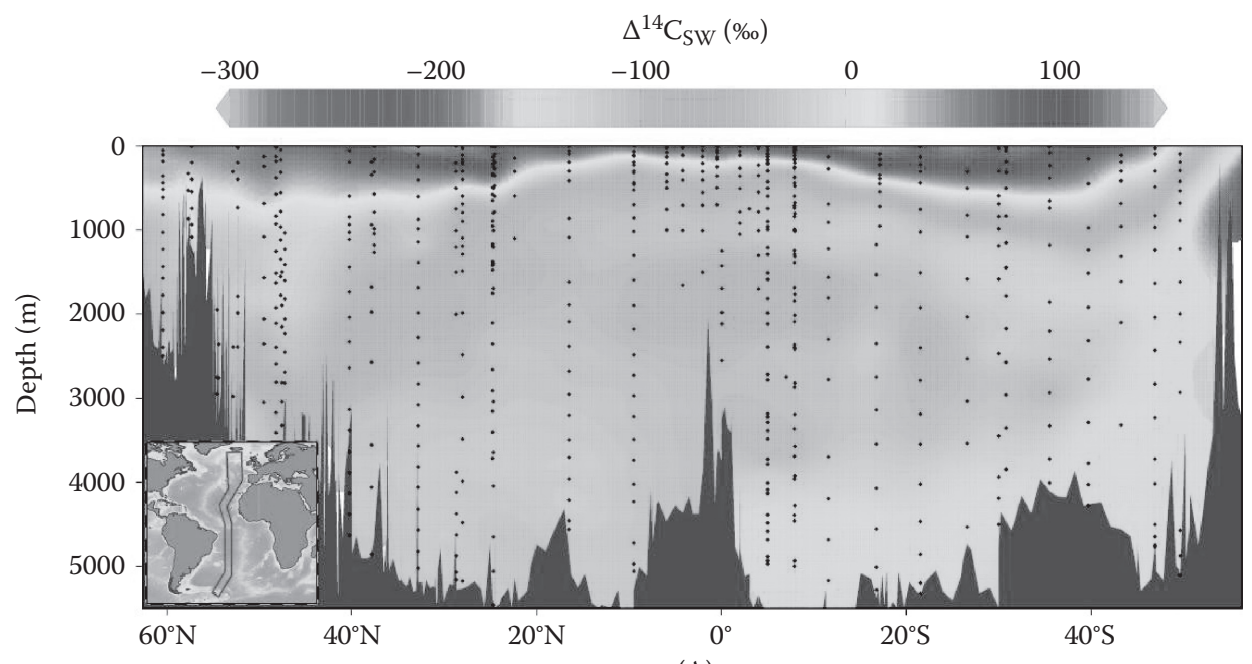

(A)

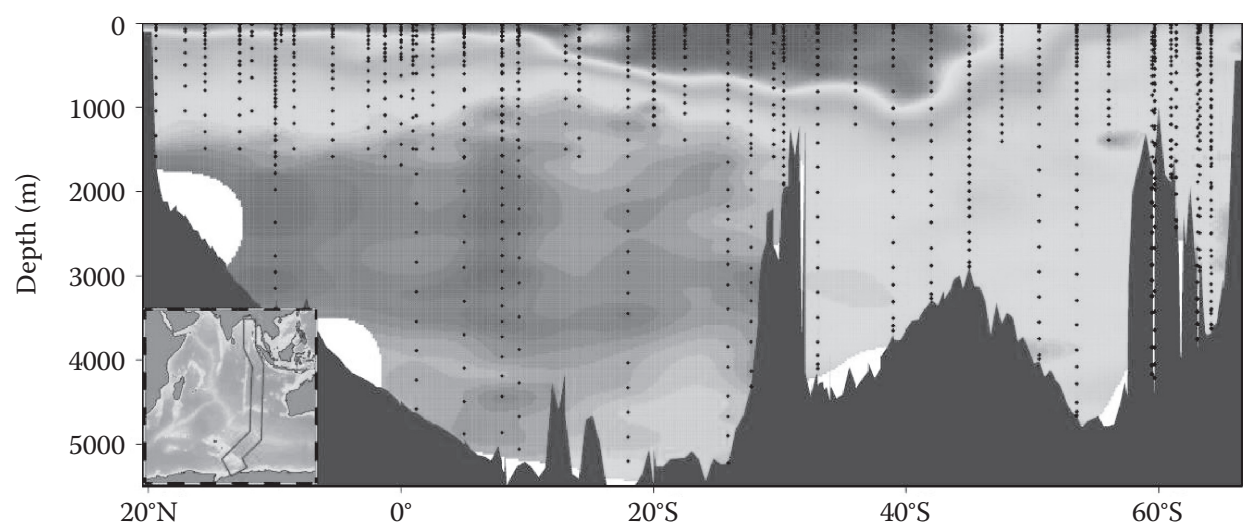

(B)

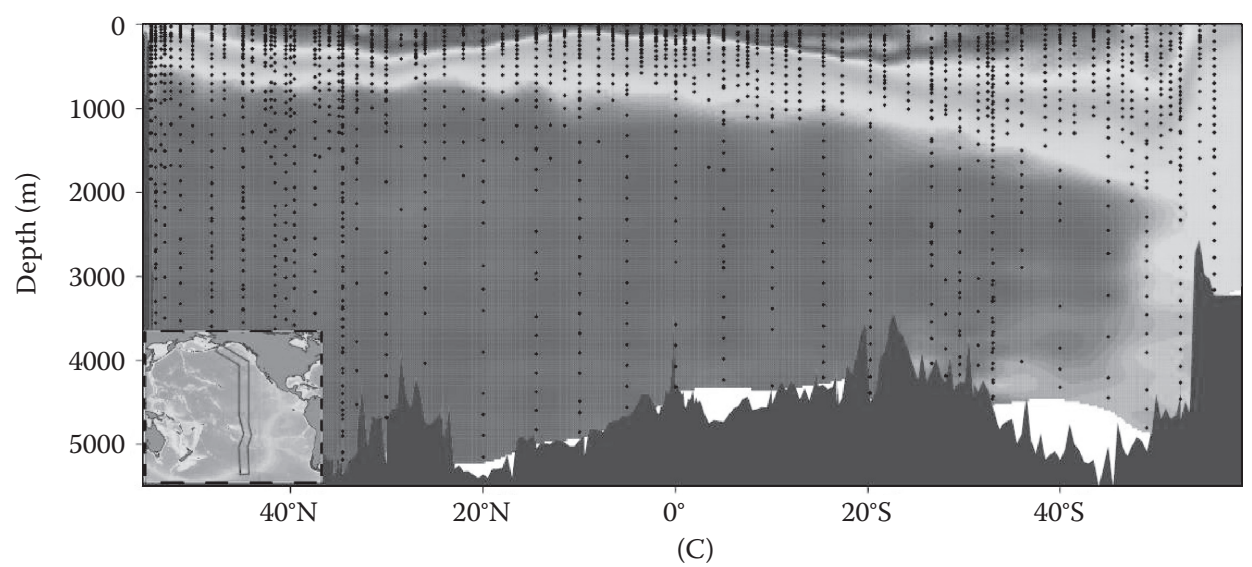

Figure 6 (See also colour figure in the insert) Vertical isoscapes of published seawater $\Delta^{14} \mathrm{C}$ values from (A) Atlantic Ocean ( $n=645$ data points); (B) Indian Ocean ( $n=1026$ data points); and (C) Pacific Ocean ( $n=1878$ data points). Data were collected from the GLODAP database (Key et al. 2004). Isoscapes were generated in Ocean Data View (Schlitzer 2011). Black dots indicate the sample locations. 
'dead' carbon up from depth that significantly reduces regional surface $\Delta^{14} \mathrm{C}$ values (Druffel 1981). Similarly, the South Makassar Strait in Indonesia exhibits significant seasonal variability, in the range of $10 \%$ o to $20 \%$ seasonally, associated with upwelling that overlays the interannual trend of increasing $\Delta^{14} \mathrm{C}$ value with time after the initial bomb spike (Fallon \& Guilderson 2008).

\section{Nitrogen isotopes}

\section{Nitrogen isotope fractionation}

Although only a small fraction of the global nitrogen reservoir is contained in living matter, organic nitrogen is of tremendous importance for nitrogen isotope distributions because almost all nitrogen isotope fractionation results from metabolically related processes (Hübner 1986). Fractionation associated with nitrogen fixation is typically small, with the average isotope effect between atmospheric $\mathrm{N}_{2}$ and fixed nitrogen near 0\%o (Hoering \& Ford 1960, Fogel \& Cifuentes 1993). Mineralization of organic matter to ammonium also has a relatively small fractionation factor $(0 \% \pm \pm 1 \%$ o $)$, but concurrent nitrification of ammonium to nitrate, particularly in vent and seep environments with high concentrations of ammonium, can result in large fractionations ( $-18 \%$ o to $-42 \%$ o) (Hoch et al. 1992, Fogel \& Cifuentes 1993). Assimilation of $\mathrm{NH}_{4}{ }^{+}, \mathrm{NO}_{2}{ }^{-}$, and $\mathrm{NO}_{3}{ }^{-}$by microorganisms can cause significant and often highly variable fractionation ( $-27 \%$ o to $0 \%$ ), regulated by nitrogen availability and reaction rates (Fogel \& Cifuentes 1993). Denitrification produces $\mathrm{N}_{2}$ gas, which if lost to the atmosphere by diffusional processes can produce large isotope effects owing to classic Rayleigh fractionation (as discussed previously). Denitrification produces $\mathrm{N}_{2}$ gas that can be upwards of $40 \%$ o lower in $\delta^{15} \mathrm{~N}$ relative to dissolved nitrate, leaving the remaining nitrate relatively ${ }^{15} \mathrm{~N}$-enriched (Cline \& Kaplan 1975).

\section{Nitrogen isotope geographic variability}

The $\delta^{15} \mathrm{~N}$ of nitrogenous species in seawater is determined by the balance of nitrogen sources and sinks, as well as fractionation resulting from biologically mediated processes. Sources of nitrogen to the marine environment include river run-off, atmospheric deposition, and $\mathrm{N}_{2}$ fixation by cyanobacteria, while the major sinks are burial in sediments and denitrification. The Atlantic and Pacific Oceans both show large-scale, albeit opposite, geographic relationships between $\delta^{15} \mathrm{~N}$ of plankton $\left(\delta^{15} \mathrm{~N}_{\mathrm{PLK}}\right)$ and latitude (Figure 7). A meta-analysis of published zooplankton $\delta^{15} \mathrm{~N}_{\mathrm{PLK}}$ values from the upper ocean of the North Atlantic shows a pattern of enrichment with increasing latitude. The lowest $\delta^{15} \mathrm{~N}_{\text {PLK }}$ values are found in the oligotrophic gyres, particularly the Sargasso Sea, where diazotrophic cyanobacteria fix $\mathrm{N}_{2}\left(0 \%\right.$ ) into organic nitrogen (Montoya et al. 2002). $\delta^{15} \mathrm{~N}_{\text {PLK }}$ values increase with increasing latitude as $\mathrm{NO}_{3}{ }^{-}(5 \%$ ) becomes the major fixed nitrogen source for marine phytoplankton. In the Pacific Ocean, however, the $\delta^{15} \mathrm{~N}_{\mathrm{PLK}}$-latitude correlation is reversed, with the highest $\delta^{15} \mathrm{~N}_{\text {PLK }}$ values recorded in the eastern tropical and central gyre (Saino \& Hattori 1987). This is because (1) the Pacific is generally iron limited and thus lacks significant $\mathrm{N}_{2}$ fixation in the surface ocean and (2) year-round stratification and large oxygen minimum zones result in significant amounts of denitrification and thus nitrate ${ }^{15} \mathrm{~N}$ enrichment (Saino \& Hattori 1987). For example, the $\delta^{15} \mathrm{~N}$ of dissolved nitrate in Antarctic Intermediate Water can be upwards of $12.5 \%$ lower than that of active denitrification zones in the North Pacific Ocean (Cline \& Kaplan 1975). Particulate organic matter decomposition and respiration, resulting in faster losses in ${ }^{14} \mathrm{~N}$, can create a gradient of increased $\delta^{15} \mathrm{~N}$ with depth in the ocean (Saino \& Hattori 1980). This is particularly evident over areas of high productivity, where large diatoms at the base of the euphotic zone may substantially affect vertical $\delta^{15} \mathrm{~N}$ gradients (Kalansky et al. 2011).

There can also be significant variability in $\delta^{15} \mathrm{~N}$ values on smaller spatial scales. Anthropogenic sources of nitrogen, including fertilizers, sewage and agricultural animal waste, and atmospheric deposition via fossil fuel burning, are all important point sources that can have a significant 


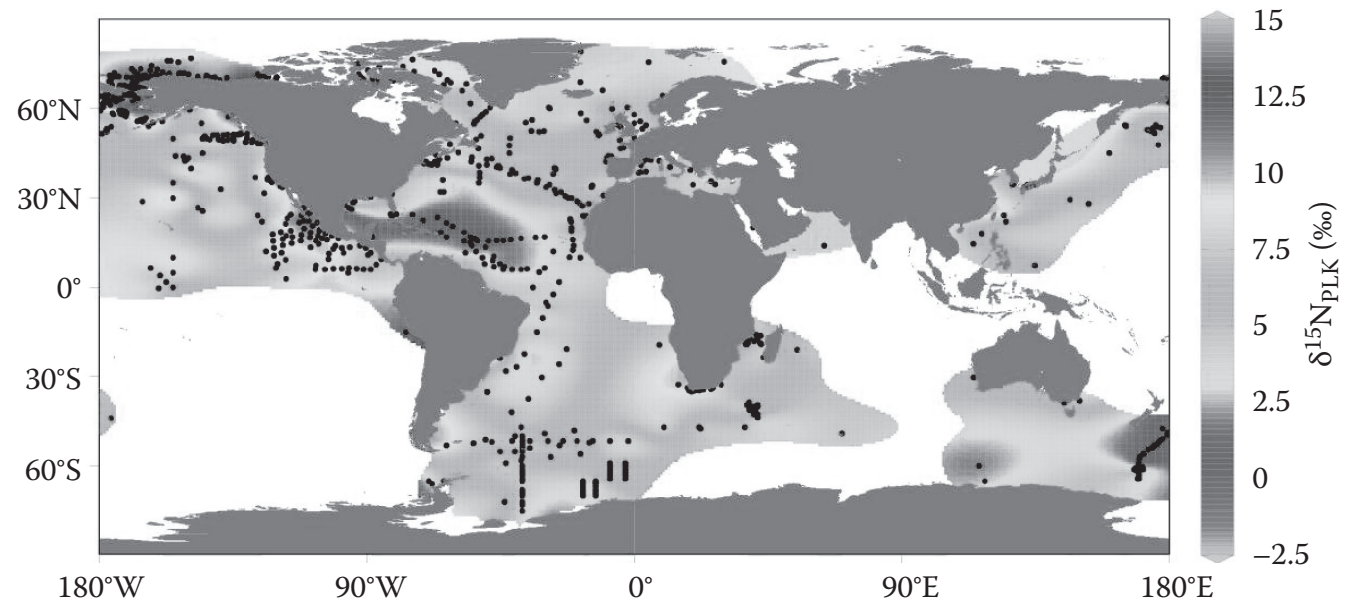

Figure 7 (See also colour figure in the insert) Horizontal isoscape of published surface plankton $\delta^{15} \mathrm{~N}_{\text {PLK }}$ values in the surface waters (top $200 \mathrm{~m}$ ) of the world's oceans ( $n=1088$ data points). Data were collected from an extensive search on Web of Knowledge and several online data repositories. Isoscapes were generated in Ocean Data View (Schlitzer 2011). Black dots indicate the sample locations.

impact on coastal $\delta^{15} \mathrm{~N}_{\text {POM }}$ (Heaton 1986). For instance, sewage discharge into coastal estuaries has provided enriched $\delta^{15} \mathrm{~N}$ isotopic point sources due to isotope fractionation during treatment, which is reflected in the $\delta^{15} \mathrm{~N}$ values of resident organisms (Hansson et al. 1997, Dierking et al. 2012). Similarly, excess nutrients in wastewater associated with diffuse source anthropogenic activities, such as urban run-off and lawn/field fertilization, have led to eutrophication in coastal bays (McClelland et al. 1997). This can result in an increase in primary production and subsequent denitrification, both of which also provide an enriched $\delta^{15} \mathrm{~N}$ isotopic signal that is reflected in the tissue $\delta^{15} \mathrm{~N}$ values of local fishes and invertebrates (Griffin \& Valiela 2001).

Plankton $\delta^{15} \mathrm{~N}_{\text {PLK }}$ values can also vary temporally, particularly on seasonal timescales, due to changes in primary productivity associated with shifts in nutrient sources and concentrations, microbial nitrogen cycling and phytoplankton species growth rates and composition (Cifuentes et al. 1988, Goering et al. 1990, Ostrom et al. 1997, Vizzini \& Mazzola 2003). Seasonal changes in $\delta^{15} \mathrm{~N}$ at the base of food webs $\left(\delta^{15} \mathrm{~N}_{\text {base }}\right)$ can be quite large. Cifuentes et al. (1988) found that the $\delta^{15} \mathrm{~N}$ value of suspended particulate matter in the Delaware Estuary in winter alone ranged from $+5.5 \%$ o to $+12.2 \%$ o. The authors observed $\delta^{15} \mathrm{~N}$ values as low as $+2.3 \%$ o in early spring, and just 3 weeks later, a $\delta^{15} \mathrm{~N}$ maximum of $+18.7 \%$ o was located in the central portion of the estuary. This large seasonal variability was associated with seasonal shifts in available nitrogen sources, as $\mathrm{NH}_{4}{ }^{+}$ utilization far exceeded $\mathrm{NO}_{3}{ }^{-}$in the winter, and with increases in productivity and decreases in nutrient availability during the spring bloom. Large shifts in baseline stable isotope values will have a cascading effect on upper trophic levels. As a result, seasonal variation must be considered when constructing and using isoscapes to address questions of connectivity and trophic dynamics in the marine environment.

\section{Oxygen isotopes}

\section{Oxygen isotope fractionation}

Fractionation of oxygen isotopes is temperature dependent (Urey 1947, Gat 1996), and $\delta^{18} \mathrm{O}$ analyses of marine carbonates have routinely been used as a proxy for temperature in both palaeoand modern applications (Aharon 1991, Fairbanks et al. 1997, Thorrold et al. 1997). However, this 
temperature-dependent fractionation effect is small $\left(\sim 0.2 \%{ }^{\circ} \mathrm{C}^{-1}\right)$ relative to the processes of evaporation and precipitation that control ocean basin-scale variation in seawater $\delta^{18} \mathrm{O}$ values $\left(\delta^{18} \mathrm{O}_{\mathrm{sw}}\right)$. Rayleigh distillation plays an important role in determining the fractionation of oxygen isotopes in the hydrologic cycle (Gat 1996). These processes are largely the same as those regulating hydrogen isotopes, which can be seen in the meteoric water line (MWL):

$$
\delta^{2} \mathrm{H}=8^{*} \delta^{18} \mathrm{O}+d,
$$

where $d$ is the 'deuterium excess' ( $d=10 \%$ for the global MWL; Dansgaard 1964). As a result, $\delta^{18} \mathrm{O}$ values of seawater exhibit geographic variation in the world's oceans that typically covary with deuterium and salinity.

Many calcified tissues, including otoliths (Kalish 1991a, Thorrold et al. 1997), bones (Barrick et al. 1992), teeth (Kolodny et al. 1983), and shells (Mook \& Vogel 1968) are precipitated in oxygen isotope equilibrium with ambient water. Some biogenic carbonates, however, exhibit kinetic effects that result in $\delta^{18} \mathrm{O}$ values out of equilibrium with ambient water (McConnaughey 1989a,b).

\section{Oxygen isotope geographic variability}

Oxygen isotope values of ocean water on regional, short-term spatiotemporal scales can reflect a mass balance between evaporation $E$, precipitation $P$, advection $A$, mixing $M$, and river run-off $R$ (Figure 8), which can be modelled as (Benway \& Mix 2004)

$$
\delta^{18} O_{S W}=\frac{\left[\left(F_{p} * \delta_{p}\right)-\left(F_{E} * \delta_{E}\right)+\left(F_{A} * \delta_{A}\right)+\left(F_{M} * \delta_{M}\right)+\left(F_{R} * \delta_{R}\right)\right]}{\left[\left(F_{p}\right)-\left(F_{E}\right)+\left(F_{A}\right)+\left(F_{M}\right)+\left(F_{R}\right)\right]},
$$

where $F$ is the fraction, and $\delta$ is the isotopic value of each component contributing to the balance. $\delta^{18} \mathrm{O}_{\mathrm{SW}}$ values that are more positive are observed in highly evaporative subtropical gyres and low-latitude shallow seas, including the Mediterranean Sea (maximum $\delta^{18} \mathrm{O}_{\mathrm{SW}} 1.7 \%$; Rohling \& Rijk 1999) and the Red Sea (maximum $\delta^{18} \mathrm{O}_{\mathrm{Sw}}$ about $1.6 \%$; Ganssen \& Kroon 1991). The $\delta^{18} \mathrm{O}_{\mathrm{Sw}}$

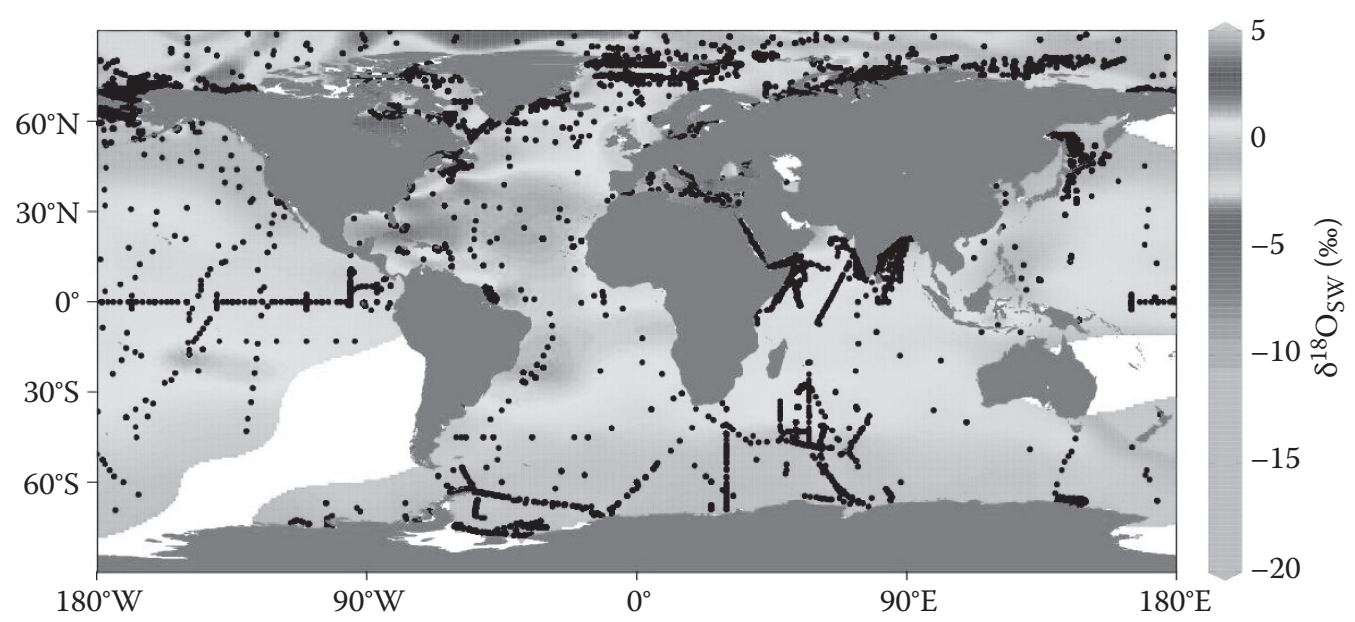

Figure 8 (See also colour figure in the insert) Horizontal isoscape of published seawater $\delta^{18} \mathrm{O}_{\mathrm{sw}}$ values in the surface waters (top $100 \mathrm{~m}$ ) of the world's oceans $(n=12,344$ data points). Data were collected from the Global Seawater Oxygen-18 database (Schmidt et al. 1999). Isoscapes were generated in Ocean Data View (Schlitzer 2011). Black dots indicate the sample locations. 
values that are most negative are found at high latitudes (nearly $-20 \%$ in the Arctic Ocean) and regions of extensive freshwater input. Freshwater discharge lowers $\delta^{18} \mathrm{O}_{\mathrm{SW}}$ values of coastal ocean waters and, in the case of large rivers like the Amazon and the Orinoco in the tropics and the MacKenzie and $\mathrm{Ob}$ in the Arctic, can produce anomalously low $\delta^{18} \mathrm{O}_{\mathrm{SW}}$ values that penetrate hundreds of kilometres into the ocean (e.g., Cooper et al. 2005).

There are several notable exceptions to the general pattern of decreasing $\delta^{18} \mathrm{O}_{\mathrm{SW}}$ values with latitude. Advection of ${ }^{18} \mathrm{O}$-depleted subpolar water towards the equator via the California Current results in anomalously low $\delta^{18} \mathrm{O}_{\mathrm{SW}}$ values along the eastern boundary of the North Pacific Ocean. Conversely, advection of ${ }^{18} \mathrm{O}$-enriched low-latitude water via the Gulf Stream causes the western boundary of the North Atlantic to have relatively high $\delta^{18} \mathrm{O}_{\mathrm{Sw}}$ values for its latitude. Vertical profiles of $\delta^{18} \mathrm{O}$ trend towards $0 \%$ with depth and typically show less variation than the horizontal isoscapes (Schmidt et al. 1999).

\section{Sulphur isotopes}

\section{Sulphur isotope fractionation}

Major sources of sulphur in the marine environment include hydrothermal processes and riverine input. Removal of sulphur in the marine environment is mostly through evaporite deposits, pyrite or organic compound burial and formation of carbonate compounds (Bottrell \& Newton 2006). Sulphate is the most common and biologically available species of sulphur in the open ocean. The fractionation of sulphate between minerals and dissolved sulphate is approximately zero; therefore, neither the creation nor the dissolution of evaporites has a significant effect on sulphate $\delta^{34} \mathrm{~S}$ values. Bacterial sulphate reduction, which takes place in sediments and other anoxic environments, is the major source of biological fractionation of sulphur in the marine environment (Bottrell \& Newton 2006), resulting in a 30\% to 70\% isotope effect (Peterson \& Fry 1987). Bacterial sulphate reduction is a kinetic process that produces sulphides and organic matter that are depleted in ${ }^{34} \mathrm{~S}$ relative to the sulphate being reduced. Rainwater sulphates are also potential sources of sulphur for intertidal plants (Fry et al. 1982). The equilibrium between oxidized and reduced sulphur species is typically only found at very high temperatures, characteristic of hydrothermal vent systems (Krouse et al. 1988).

The $\delta^{34} \mathrm{~S}$ values of phytoplankton, upland plants and marsh grasses are often quite distinct because of their use of different sources of inorganic sulphur (Peterson et al. 1985). Marine phytoplankton and seaweeds utilize marine sulphate (21\%o; Rees et al. 1978) and fractionate it little during uptake and assimilation into organic sulphur compounds. Upland plants in aerobic soils also fractionate sulphate little during uptake and assimilation, but they obtain sulphate from precipitation with a lower $\delta^{34} \mathrm{~S}$ value (2\%o to $8 \%$ ). Marsh plants and other primary producers living in anoxic conditions often use sulphides with much lower $\delta^{34} S$ values for at least some of their sulphur requirements, resulting in organic matter that is equally depleted in ${ }^{34} \mathrm{~S}$. The $\delta^{34} \mathrm{~S}$ signal established by primary producers is passed on to higher trophic levels in the food web because the essential sulphur-bearing compounds are typically incorporated into consumer tissues with little to no trophic fractionation (Peterson et al. 1986, Florin et al. 2011, but see Tanz \& Schmidt 2010).

\section{Sulphur isotope geographic variability}

Sulphur isotope distributions in the marine environment vary with distribution of sulphides and sulphates, quality of growing conditions (aerobic versus anaerobic), atmospheric deposition from natural sources and point sources from pollution. The residence time of sulphate in seawater is $2 \times 10^{7}$ years; thus, sulphate is well mixed in the marine environment, maintaining a relatively constant $\delta^{34} \mathrm{~S}_{\mathrm{SW}}$ value of $21 \%$ o throughout the open ocean (Rees et al. 1978). In general, benthic and nearshore habitats, including estuaries and marshes, are typically more anoxic than pelagic, offshore ecosystems and thus experience elevated levels of sulphate reduction with correspondingly 
higher $\delta^{34} \mathrm{~S}_{\mathrm{SW}}$ sulphate values. There can be times when ocean sulphate values do change significantly. For example, during periods of intense weathering, particularly of shales, ocean sulphate $\delta^{34} \mathrm{~S}$ can decrease significantly. Conversely, anoxic zones, such as parts of the Black Sea and regions of high primary productivity, may experience increased ocean sulphate $\delta^{34} \mathrm{~S}_{\mathrm{SW}}$ values due to elevated bacterial sulphate reduction (Neretin et al. 2003). On geological timescales, the isotope composition of seawater sulphate varies from $10 \%$ to $33 \%$ as a result of changes in the magnitude of sulphur fluxes into and out of the marine environment as well as changes in the isotope fractionation between sulphate and buried sulphide (Peterson \& Fry 1987). The $\delta^{34} S$ value of terrestrial sulphur is highly variable and dependent on rock type and climate-dependent weathering patterns (Krouse \& Grinenko 1991). The $\delta^{34} \mathrm{~S}$ value of river water sulphate (global mean 7\%o) varies regionally according to bedrock lithology, anthropogenic inputs and atmospheric deposition from natural sources (Thode et al. 1961). As a result, terrestrial run-off, rivers and groundwater inputs can be major sources of coastal $\delta^{34} \mathrm{~S}$ variability. Sulphur isotopes are thus most useful in coastal and estuarine environments, where highly variable freshwater inputs mix with relatively constant marine values to create steep gradients in sulphate $\delta^{34} \mathrm{~S}$ (Peterson \& Fry 1987, Fry 2002).

Human-induced perturbations to the natural sulphur cycle have markedly increased since industrialization, and the majority of sulphur emitted into the atmosphere is now likely of anthropogenic origin (Peterson \& Fry 1987). Anthropogenic sources of sulphur, most notably from fossil fuel burning, can overwhelm natural variability on small scales. These sources can produce unique point sources to track movement and residence patterns in the marine environment. In addition, eutrophication as a result of sewage inputs to coastal habitats can promote anoxic conditions, which support sulphate reduction and the generation of low- $\delta{ }^{34} \mathrm{~S}$ sulphides.

\section{Minor and trace elements in calcified tissues}

The chemical composition of oceanic minerals has been used to determine environmental conditions in palaeo-oceans for decades (Kastner 1999). More recently, ocean ecogeochemistry applications have focused on inferring movement patterns of fish and invertebrates from the elemental chemistry of aragonitic otoliths, shells and statoliths (e.g., Campana et al. 1999, Zacherl et al. 2003a, Arkhipkin et al. 2004, Becker et al. 2005, Elsdon et al. 2008, Walther \& Limburg 2012). While a number of elements are found in biogenic aragonite, most researchers to date have focused on some combination of six elements that both substitute for calcium in the aragonite matrix (and therefore are more likely to record ambient dissolved concentrations) and are sufficiently abundant and free from isobaric interferences to allow for quantification using inductively coupled plasma mass spectrometry (Thorrold \& Swearer 2009). These elements are characterized by conservative-type (lithium, magnesium, strontium), nutrient-type (barium) and scavenged-type (manganese, lead) distributions in the oceans and are most usefully reported as ratios to calcium in both ambient waters and in the calcified tissues.

\section{Minor and trace element fractionation}

Minor and trace element composition of calcified tissues are correlated with ambient dissolved concentrations in at least some instances. For instance, concentrations of strontium and barium in otoliths (Bath et al. 2000, Elsdon \& Gillanders 2004, Dorval et al. 2007) and gastropod protoconchs (Zacherl et al. 2003b) appear to reflect environmental parameters and serve as valuable tracers of juvenile movements and larval dispersal, respectively. However, strontium, barium and indeed almost all metals, with the notable exception of manganese (Elsdon \& Gillanders 2003), are found at significantly lower concentrations in calcified tissues than in the ambient environment (Campana \& Thorrold 2001). This fractionation is primarily controlled by biological processes that occur during ion transport from seawater to the internal fluid from which the calcified tissue 
precipitates (e.g., Melancon et al. 2009). Ion exchange across intestinal or gill membranes, ionic exchange between blood plasma and endolymph and the partition coefficients of ions at the otolith growth surface all likely play some role in regulating the composition of the precipitating fluid (Kalish 1991b).

Temperature typically has a positive influence on $\mathrm{Sr}: \mathrm{Ca}$ in low-strontium aragonite in fish otoliths and mollusc protoconchs (Bath et al. 2000, Elsdon \& Gillanders 2002, Zacherl et al. 2003b) and a negative effect on $\mathrm{Sr}: \mathrm{Ca}$ in high-strontium aragonite, including coral skeletons and mollusc statoliths (Beck et al. 1992, Zacherl et al. 2003b, Cohen \& Thorrold 2007). The effects of temperature on barium, manganese and magnesium are more variable and less conclusive (Elsdon \& Gillanders 2002, Zacherl et al. 2003b, Martin \& Thorrold 2005); a recent study found that the Li:Ca ratio was positively correlated with temperature in the otolith of the flatfish Solea solea (Tanner et al. 2013).

\section{Minor and trace element geographic variability}

The long residence times of conservative elements leads to generally uniform distributions throughout the world's oceans. For instance, lithium has a residence time of 1.5 million years and a global $\mathrm{Li}$ :Ca ratio of about $2.5 \mathrm{mmol} \mathrm{mol}^{-1}$ (Huh et al. 1998). Dissolved lithium values in river waters are considerably more variable and generally lower than in seawater, ranging from $30 \mathrm{n} M$ to $11.7 \mu M$, with concomitant Li:Ca ratios ranging from $77.8 \mu \mathrm{mol} \mathrm{mol}^{-1}$ to $15.7 \mathrm{mmol} \mathrm{mol}^{-1}$ (Huh et al. 1998). A significant correlation between otolith $\mathrm{Li}: \mathrm{Ca}$ and salinity suggests that lithium may be a useful tracer of movement between marine and freshwater habitats (Hicks et al. 2010), although the range of potential values in river waters means that freshwater end members would need to be characterized first. Magnesium is also conservative in seawater with a mean $\mathrm{Mg}: \mathrm{Ca}$ value of $5.14 \mathrm{~mol} \mathrm{~mol}^{-1}$ (Bruland \& Lohan 2004). Riverine water ratios are almost invariably lower than that of seawater. With a global average value for freshwater of $0.45 \mathrm{~mol} \mathrm{~mol}^{-1}, \mathrm{Mg}$ :Ca ratios are potentially a useful tracer of salinity (Surge \& Lohmann 2002). Finally, the global seawater Sr:Ca ratio is approximately $8.5 \mathrm{mmol} \mathrm{mol}^{-1}$ (de Villiers 1999) and is relatively invariant throughout the oceans. Dissolved strontium values in freshwater are largely controlled by surrounding bedrock geological composition, both rock type and weathering efficiency, and are often nearly an order of magnitude lower than seawater values (Bricker \& Jones 1995, Limburg 1995, Capo et al. 1998). Freshwater values show significant geographic and temporal variability, with Sr:Ca ratios ranging from 0.27 to $19.18 \mathrm{mmol}$ $\mathrm{mol}^{-1}$ (Brown \& Severin 2009). Strontium isotope values in ocean waters are relatively invariant with ${ }^{87} \mathrm{Sr}:{ }^{86} \mathrm{Sr}=0.70918$ (Ando et al. 2010), while fluvial ${ }^{87} \mathrm{Sr}:{ }^{86} \mathrm{Sr}$ ratios typically vary from about 0.704 in basaltic drainages to at least 0.75 in older, highly radiogenic granites (Barnett-Johnson et al. 2010, Muhlfeld et al. 2012). Biological fractionation of strontium isotopes is minimal; therefore, ${ }^{87} \mathrm{Sr}:{ }^{86} \mathrm{Sr}$ ratios represent an excellent tracer of movements between freshwater and ocean environments (McMahon et al. 2013).

Barium follows a nutrient-type distribution in seawater, with typical surface ocean values of 0.01 to $0.02 \mu M$, increasing to 0.03 and $0.09 \mu M$ at a depth of $3000 \mathrm{~m}$ in the North Atlantic and North Pacific, respectively (Bruland \& Lohan 2004). Barium concentrations in riverine and coastal areas are relatively high compared to slope and oceanic waters (Shen \& Stanford 1990), varying by nearly an order of magnitude globally around a worldwide riverine average of $0.10 \mu M$ (Gaillardet et al. 2003). Upwelling of cold, nutrient-rich deep water can be a significant secondary source of relatively high barium concentrations to the ocean surface waters (Lea et al. 1989).

Both manganese and lead are scavenged elements characterized by strong interactions with particles that lead to very short oceanic residence times of less than 1000 years (Donat \& Bruland 1995). Atmospheric dust is a major source of manganese and lead in oceanic environments. For example, peak concentrations of dissolved manganese in North Atlantic Ocean surface waters occur at $20^{\circ}$ north, which coincides with the zone of maximum dust deposition from the Sahara Desert 
(Bergquist \& Boyle 2006). However, in estuarine settings, manganese and lead fluxes from porewaters often overwhelm atmospheric and fluvial inputs (Rivera-Duarte \& Flegal 1994, Warnken et al. 2001). The vertical distributions of dissolved manganese in both the Pacific and the Atlantic Ocean are characterized by a surface maximum driven by atmospheric deposition and photoreduction of manganese oxides (Sunda \& Huntsman 1988), a subsurface minimum and a second maximum coincident with the oxygen minimum layer and presumably generated by redox dissolution (Landing \& Bruland 1987, Boye et al. 2012). Most of the dissolved lead in the oceans comes from anthropogenic sources, in particular from the use of leaded gasoline in the United States and Europe (Boyle 2001). The introduction of leaded gasoline in the 1920s led to a marked increase in dissolved lead levels in surface waters of the North Atlantic and, to a lesser extent, the North Pacific that peaked in the early 1970s. This lead spike provided a dated marker that was recorded in the skeletons of corals in Bermuda (Shen \& Boyle 1987), sclerosponges in the Bahamas (Swart et al. 2002), and bivalve shells in the North Atlantic (Krause-Nehring et al. 2012).

Previous studies have found little variation in manganese, strontium and barium concentrations from estuarine waters on monthly to seasonal timescales. However, water chemistry in dynamic environments with large tidal ranges may vary over shorter daily or tidal scales (Dorval \& Jones 2005, Elsdon \& Gillanders 2006). For example, Elsdon \& Gillanders (2006) found significant differences in manganese, strontium and barium concentrations between water samples collected on different days within three small $(<10 \mathrm{~km})$ tidal estuaries that accounted for up to $64 \%$ of the total variation on scales of days, weeks, months and seasons.

\section{Biological tissues}

Ecogeochemistry rests fundamentally on the assumption that the composition of a tissue will reflect the isotopic or elemental composition of the source from which an element is obtained and some degree of fractionation (Tieszen et al. 1983, Gannes et al. 1997). In the previous section, we discussed the processes that create geographic variability in stable isotope and trace element values and the resulting isoscapes. In this section, we address the issues of constraining tissue-specific isotope turnover rates and discrimination factors that control the offset between the baseline isoscape and the consumer isotope or element values.

\section{Element turnover rates}

Isotope turnover rate plays an important role in determining the temporal scales over which a tissue records an isotopic signature of residence or diet (Dalerum \& Angerbjörn 2005). Isotope turnover rates can vary from hours to years depending on a number of factors, including tissue type, the metabolic turnover or growth rate, and the taxa studied (Boecklen et al. 2011). Analysis of faeces or gut contents provides short-term information about an organism's diet, ranging from hours for zooplankton to a few days for large mammals. More metabolically active tissues, including liver and blood, typically have faster turnover rates (weeks) than less metabolically active tissues, such as muscle (months) or bone (years) (Tieszen et al. 1983, Buchheister \& Latour 2009, Malpica-Cruz et al. 2011). Similarly, the isotope composition of whole tissues represents an integration of the isotopic values of the tissue's constituents (e.g., proteins, lipids, carbohydrates), each with characteristic turnover rates that may differ from the bulk tissue turnover rate.

Tissues that are metabolically inert after formation, including hair, baleen, claws and otoliths, preserve a permanent record of source isotope composition (Rubenstein \& Hobson 2004). Calcified, accretionary tissues with density or optical bands corresponding to daily, seasonal or annual patterns, including otoliths, bivalve shells, teeth, claws, scales, vertebrae and baleen, may also provide a chronological record of lifetime animal diet and movement (Richardson 1988, Schell et al. 1989, Campana \& Thorrold 2001, Campana et al. 2002). Otoliths are particularly valuable tissues 
for retrospective studies of diet and movement because they grow continuously through successive addition of daily and annual aragonitic growth bands on a proteinaceous matrix, and they are metabolically inert postdeposition (Degens et al. 1969, Campana \& Neilson 1985, Campana 1999). Otoliths therefore preserve a chronological record of a fish's metabolic activity and the physical and chemical characteristics of the water in which the fish resided during the time of deposition (Thorrold et al. 1997). Researchers have similarly used the elemental composition of other calcified tissues, including bivalve (Becker et al. 2007) and gastropod shells (Zacherl et al. 2003a), elasmobranch vertebrae (Hale et al. 2006, Tillett et al. 2011), and squid statoliths (Arkhipkin et al. 2004), to determine movement patterns during specific life-history stages of a number of marine species.

Element turnover rate also varies by taxon. A literature review by Boecklen et al. (2011) found significant variation in tissue-specific carbon turnover rates among taxa. For example, the isotopic half-life (time for a tissue isotope value to change halfway from initial to its new equilibrium value) of muscle in mammals ( 1 to 3 months) was considerably longer than that for fish ( 2 to 8 weeks) and birds (1 to 3 weeks). One mechanism generating differences in isotope turnover rate among taxa can be seen in relative contributions of metabolic turnover rate and growth rate to isotope turnover rate in teleost fishes and elasmobranchs. Isotope turnover rates tend to be strongly correlated with growth rate and accretion of biomass in teleost fishes (Herzka 2005, Logan et al. 2006). Fish that are growing quickly (often during early life-history stages) tend to reach isotopic equilibrium with their diet much faster than older, slower-growing fish (Herzka 2005). Conversely, in elasmobranchs isotopic turnover rate appears to be closely linked to metabolic turnover rate (Logan \& Lutcavage 2010, Malpica-Cruz et al. 2011).

\section{Trophic discrimination factors}

We define trophic discrimination between diet and consumer to include kinetic fractionation associated with enzymatic reactions during metabolism as well as differences in stable isotope values due to differences in tissue composition. As with isotope turnover rate, trophic discrimination can vary widely among tissue types (Gannes et al. 1997, Vander Zanden \& Rasmussen 2001, McCutchan et al. 2003, Olive et al. 2003). In this section, we focus primarily on bulk trophic discrimination of carbon $\left(\Delta^{13} \mathrm{C}\right)$ and nitrogen $\left(\Delta^{15} \mathrm{~N}\right)$ between diet and consumer as they are the primary elements used to assess trophic dynamics in ecogeochemistry studies. However, it is important to note that other elements undergo varying degrees of trophic discrimination. For example, sulphur isotopes exhibit little or no trophic discrimination; thus, $\delta^{34} \mathrm{~S}$ values of consumers reflect the baseline signatures (Peterson et al. 1986). There are mixed results regarding the degree of trophic discrimination $\left(\Delta^{2} \mathrm{H}\right)$ in non-exchangable hydrogen. Some studies report significant differences between diet and consumer $\delta^{2} \mathrm{H}$ values, suggesting some degree of trophic fractionation (Macko et al. 1983, Birchall et al. 2005). However, other studies found that trophic fractionation was negligible and suggested that some non-exchangeable hydrogen in consumer tissue may come from ingestion or diffusion from ambient water (Solomon et al. 2009).

Marine carbon is typically thought to be conservatively fractionated $\left(\Delta^{13} \mathrm{C}=0 \%\right.$ o to $1 \%$ o) as it continues to move through food webs (DeNiro \& Epstein 1978). This small trophic discrimination is the basis for using $\delta^{13} \mathrm{C}$ to track diet sources and carbon flow through food webs as well as migration among isotopically distinct habitats (see reviews by Hobson 1999, Kelly 2000, Rubenstein $\&$ Hobson 2004). However, there can be significant variability in $\Delta^{13} \mathrm{C}$, from $-3 \%$ o to $5 \%$, among tissues and taxa owing to differential digestion or fractionation during assimilation and metabolic processing (Vander Zanden \& Rasmussen 2001, Post 2002, McCutchan et al. 2003). Trophic discrimination is typically larger for animals with higher rates of respiration relative to growth, such as birds and mammals, compared to fish and invertebrates. In addition, herbivores that must convert plant biomass into animal biomass often have higher bulk $\Delta^{13} \mathrm{C}$ values than carnivores and omnivores (Elsdon et al. 2010). The form of excreted waste may also affect trophic discrimination, as 
urea and uric acid contain carbon, while ammonia does not (however, this concept has received greater attention for its effects on $\Delta^{15} \mathrm{~N}$, discussed separately below). Analysing whole tissues often results in larger diet-to-consumer $\Delta^{13} \mathrm{C}$ values compared to muscle due to the inclusion of lipids during whole-body analysis. For example, Malpica-Cruz et al. (2011) found significant differences in tissue-specific $\Delta^{13} \mathrm{C}$ values for laboratory-reared leopard sharks (Triakis semifasciata). Liver, which had the highest lipid content, showed the lowest $\Delta^{13} \mathrm{C}$ values, fins and cartilage had the highest $\Delta^{13} \mathrm{C}$ values, and muscle and blood were intermediate. This variability can pose a significant confounding variable when comparing $\delta^{13} \mathrm{C}$ values from large consumers, typically analysed as muscle, and small consumers, which are often analysed whole.

The isotope value of consumer tissue may not always follow bulk diet isotope values, causing further complications for the interpretation of bulk stable isotope data in an ecogeochemistry context. Much of the variability among tissue-specific trophic discrimination factors is attributed to differences in tissue composition and lipid content (Malpica-Cruz et al. 2011). The carbon skeletons of different dietary components (proteins, lipids, and carbohydrates), which are often isotopically distinct from each other, can be routed to different tissue constituents in a process termed isotopic routing (Schwarcz 1991). Several studies have emphasized the problems that isotopic routing poses to the interpretation of bulk stable isotope data in diet reconstructions (Parkington 1991, Schwarcz \& Schoeninger 1991, Ambrose \& Norr 1993, Elsdon et al. 2010, McMahon et al. 2010). Studies have shown that changes in amino acid and lipid composition among tissues or ontogenetically within tissues can obscure changes in $\delta^{13} \mathrm{C}$ associated with diet or location shifts (Watabe et al. 1982, Murayama 2000, Hüssy et al. 2004). To control for tissue composition differences, it is often desirable to analyse the same tissue type across all samples. This is not always possible, particularly for large food web reconstructions that may require analysing a wide range of tissues.

Another common, although often debated, practice used to control for tissue composition differences is to normalize tissue lipid content, through either chemical extraction or mathematical correction (Post et al. 2007, Logan et al. 2008, Boecklen et al. 2011). While the change in $\delta^{13} \mathrm{C}$ values with lipid removal is expected, chemical extraction often affects nitrogen isotope values as well (Sotiropoulos et al. 2004, Logan et al. 2008). Given that most lipids do not contain nitrogen, these findings indicate that we do not fully understand the changes in tissue composition that occur during chemical lipid extraction. Several mathematical models have been developed to correct non-lipid extracted tissue isotope values for lipid contribution a posteriori (Post et al. 2007, Logan et al. 2008). Most models use elemental carbon-to-nitrogen ratios (C:N) of bulk tissue as a proxy for lipid content and a protein-lipid $\delta^{13} \mathrm{C}$ discrimination factor (Sweeting et al. 2006, Post et al. 2007). However, these parameters are not well constrained and may vary among species or higher taxa, resulting in a large range in the predictive power of the approach $\left(0.25<R^{2}<0.96\right)$ (Post et al. 2007, Logan et al. 2008, Tarroux et al. 2010).

Nitrogen isotopes typically exhibit a $3 \%$ o to $4 \%$ o trophic discrimination $\left(\Delta^{15} \mathrm{~N}\right)$ between diet and consumer (DeNiro \& Epstein 1981, Minagawa \& Wada 1984). This enrichment stems from a combination of fractionation during assimilation and protein synthesis as well as the preferential excretion of light isotopes as waste during metabolism (see review by Kelly 2000). As with carbon, there can be significant variability in trophic discrimination around the commonly accepted mean. Estimates of $\Delta^{15} \mathrm{~N}$ range from $-1 \%$ o to $9 \%$ as a function of dietary protein content, consumer species, tissue type, physiological stress and biochemical form of nitrogenous waste (see reviews by Minagawa \& Wada 1984, Michener \& Schell 1994, Vander Zanden \& Rasmussen 2001, McCutchan et al. 2003, Vanderklift \& Ponsard 2003). For instance, animals feeding on high-protein diets often exhibit significantly higher $\Delta^{15} \mathrm{~N}$ values compared to those feeding on low-protein diets (Vander Zanden \& Rasmussen 2001). Thus, diet quality and composition can have a significant impact on $\Delta^{15} \mathrm{~N}$ values within and among taxa. Vanderklift \& Ponsard (2003) reviewed nitrogen trophic discrimination in animals with a variety of forms of nitrogen excretion (e.g., ammonia, urea, uric acid). They found that animals excreting urea typically exhibited significantly larger mean trophic discrimination 
factors $\left(\Delta^{15} \mathrm{~N}=3 \%\right.$ ) than ammonia-excreting animals $(2 \%$ ). Many ureoletic elasmobranchs show relatively low $\Delta^{15} \mathrm{~N}$ values of $1 \%$ o to $2 \%$ (Hüssy et al. 2010, Malpica-Cruz et al. 2011), although this pattern is not ubiquitous (Logan \& Lutcavage 2010). These examples illustrate the complex contributions of the bulk trophic discrimination of nitrogen isotopes.

Nitrogen isotopes are commonly used to calculate the trophic position of consumers in the marine environment. The simplest model for calculating trophic position TP using bulk SIA is as follows:

$$
T P_{\text {bulk }}=\lambda+\left(\delta^{15} \mathrm{~N}_{\text {con }}-\delta^{15} \mathrm{~N}_{\text {base }}\right) / \Delta^{15} \mathrm{~N}
$$

where $\delta^{15} \mathrm{~N}_{\text {con }}$ is the nitrogen isotope value of the consumer, $\delta^{15} \mathrm{~N}_{\text {base }}$ is the nitrogen isotope value of the baseline consumer, $\lambda$ is the trophic position of the baseline consumer, and $\Delta^{15} \mathrm{~N}$ is the trophic discrimination between diet and consumer. Typically, $\delta^{15} \mathrm{~N}_{\text {con }}$ is measured directly, and $\Delta^{15} \mathrm{~N}$ is assumed to be between $3 \%$ and $4 \%$, despite the large range discussed previously. Choosing a suitable $\delta^{15} \mathrm{~N}_{\text {base }}$ is one of the most challenging, and thus limiting, factors in trophic estimation using bulk SIA. There can be significant temporal variability in $\delta^{15} \mathrm{~N}_{\text {base }}$ associated with the typically much faster turnover rates and thus shorter integration times of basal food web components relative to longer-lived consumers in the upper trophic level (Hannides et al. 2009). In marine environments, the microalgae that support marine food webs typically have $\delta^{15} \mathrm{~N}$ values that change spatially and seasonally due to incomplete utilization of nitrogenous nutrients (Altabet \& Francois 2001, Lourey et al. 2003) and differential utilization of nitrogen sources (nitrate, ammonium, $\mathrm{N}_{2}$ ) in space and time (Dugdale \& Goering 1967, Dore et al. 2002). Additional complications arise when organisms feed in multiple food webs with different $\delta^{15} \mathrm{~N}_{\text {base }}$ sources. As was the case for bulk $\delta^{13} \mathrm{C}$ interpretations, differences in tissue composition and metabolic processing can make interpreting bulk $\delta^{15} \mathrm{~N}$ values challenging. For instance, Schmidt et al. (2004) found that variability in bulk $\delta^{15} \mathrm{~N}$ values between euphausiid sexes and tissues (digestive glands and abdominal muscle) were driven by differences in the relative proportions of amino acids (up to $5 \mathrm{~mol} \%$ ) and their $\delta^{15} \mathrm{~N}$ variability (up to $11 \%$ ), as well as differences in tissue metabolism, primarily protein synthesis and degradation for energy supply. The authors showed that, despite the offset in bulk $\delta^{15} \mathrm{~N}$ values between female and male euphausiids $(1.3 \%$ ), both sexes were in fact feeding at the same trophic level, and the tissue composition and metabolism differences actually confound trophic-level interpretations of bulk $\delta^{15} \mathrm{~N}$ values.

One of the biggest challenges of interpreting bulk tissue stable isotope values is the confounding effect of changes in trophic position with variations in isotope values at the base of the food web $\left(\delta^{13} \mathrm{C}_{\text {base }}\right.$ and $\delta^{15} \mathrm{~N}_{\text {base }}$; Post 2002). It can be difficult to determine whether changes in a consumer's stable isotope value are due to changes in its diet or trophic position, changes in the baseline food web stable isotope value, or both. This can be particularly problematic when studying the diet and movement of highly migratory marine organisms that may change diet and trophic position as well as habitats throughout ontogeny (Graham et al. 2010, McMahon et al. 2013). The factors described can make interpretations of bulk tissue SIA challenging for studies of diet and migration. As a result, there have been calls for more studies to examine the biochemical and physiological basis of stable isotope ratios in ecology (Gannes et al. 1997, Gannes et al. 1998, Karasov \& Martínez del Rio 2007).

\section{Compound-specific stable isotope analysis}

Thanks in large part to advances in mass spectrometry, including gas chromatograph/combustion/ isotope ratio monitoring-mass spectrometry (GC/C/irm-MS) (Merritt et al. 1994, Meier-Augenstein 1999, Sessions 2006) and more recently the Finnigan LC IsoLink (McCullagh et al. 2006) and moving wire interface (Krummen et al. 2004, Sessions et al. 2005), it is now possible to obtain 
precise and accurate stable isotope measurements from individual biological compounds, including amino acids and fatty acids. Compound-specific SIA has the potential to increase the specificity of ecogeochemistry studies significantly and avoid many of the confounding variables that make it challenging to interpret bulk stable isotope values. Specifically, the metabolic and physiological processes that affect the isotopic values of individual compounds are better constrained and often better understood than the numerous variables affecting bulk tissue stable isotope values. While fractionation between bulk compounds is typically in the range of $1 \%$ o to 5\%o, fractionation between individual amino acids can be greater than 20\%o (Macko et al. 1987, Keil \& Fogel 2001, McMahon et al. 2010). While the use of compound-specific SIA in the marine environment is still relatively new, the technique has been applied to a variety of tissues, including blood, muscle, bone, and otoliths, to assess changes in diet and habitat use (Hare et al. 1991, Popp et al. 2007, Lorrain et al. 2009, McMahon et al. 2011a,b). In the following sections, we discuss the processes that result in fractionation of individual compounds (amino acids and fatty acids). We also highlight several key advantages of compound-specific SIA for ecogeochemistry studies, as well as current limitations and the direction of the field.

\section{Amino acids}

\section{Carbon}

Amino acids have conventionally been classified into two categories with regard to carbon metabolism, essential (indispensable) and non-essential (dispensable), relating to their synthesis by various organisms (Table 2). Borman et al. (1946) termed as indispensable those amino acids that cannot be synthesized by an organism from materials normally available to the cells at a speed adequate with the demands for normal growth. However, this definition emphasizes that there will be some variability in how amino acids are parsed into each category depending on the metabolic capabilities and demands of the organism. There are nine amino acids that are classified as truly essential, meaning that while plants and bacteria can synthesize them de novo, animals have lost the

Table 2 Classification of dietary amino acids according to their dietary requirements by animals

\begin{tabular}{llll}
\hline & & \multicolumn{2}{c}{ Carbon } \\
\cline { 3 - 4 } Nitrogen & Source & Lysinential (primary amine) & Non-essential \\
& & Phenylalanine (aromatic ring) & Glycine* \\
& Threonine (secondary alcohol) & Serine \\
& Methionine (secondary thiol) & Tyrosine* \\
& Isoleucine (branched aliphatic side chain) & Alanine \\
& Leucine (branched aliphatic side chain) & Aspartic acid \\
& Valine (branched aliphatic side chain) & Glutamic acid \\
& & Proline* \\
& Histidine (imidazole ring) & Arginine* \\
& Unknown & Aryptophan (indole ring) & Taurine* \\
& & Cystine* \\
\hline
\end{tabular}

Source: Modified from Karasov \& Martinez del Rio (2007).

Note: Amino acids are divided into essential, non-essential and conditionally essential (designated with *) for carbon isotopes and source, trophic and unknown for nitrogen isotopes. The structures that are likely to render certain amino acids indispensable are in parentheses next to the essential amino acids (Reeds 2000). 
enzymatic pathways to synthesize these amino acids and thus must acquire them directly from diet. Another seven amino acids are considered conditionally essential because their rate of synthesis is limited for certain species or conditions. Typically, the synthesis of these amino acids is limited by the availability of a precursor to donate carbon or accessory groups, such as sulphur. In some cases, synthesis is limited to certain tissues (e.g., proline and arginine in the intestines; Wakabayashi et al. 1994) or by physiological demands (e.g., arginine as a precursor for ornithine used to detoxify ammonia in some carnivores; Morris 1985). Non-essential amino acids can be synthesized by all species in sufficient quantities to maintain normal growth.

Modest bulk tissue $\Delta^{13} \mathrm{C}$ values often reflect little-to-no trophic discrimination for all essential amino acids and relatively large trophic discrimination factors for many non-essential amino acids (Hare et al. 1991, Howland et al. 2003, Jim et al. 2006, McMahon et al. 2010) (Figure 9A). As a result, essential amino acid $\Delta^{13} \mathrm{C}$ values between diet and animal consumers are typically near $0 \%$. Consumer essential amino acid $\delta^{13} \mathrm{C}$ values therefore represent the isotopic signature of primary producers at the base of the food web $\left(\delta^{13} \mathrm{C}_{\text {base }}\right)$ without the confounding variable of trophic discrimination. The inherent metabolic diversity within and among prokaryotes and plants generates distinct patterns of essential amino acid $\delta^{13} \mathrm{C}$ values and profiles that can be used to identify the origin of amino acids even when there is considerable variability in bulk $\delta^{13} \mathrm{C}$ (Abraham \& Hesse 2003, Scott et al. 2006). Unlike bulk SIA, which only relies on differences in $\delta^{13} \mathrm{C}$ value among end members, compound-specific SIA also makes use of differences in amino acid profiles, which can arise from different biosynthetic pathways used by various groups or from different isotope effects during the biosynthetic process. For example, plants and fungi have unique pathways for lysine and leucine biosynthesis, leading to isotopically distinct carbon isotope signatures compared to bacteria (Hagelstein et al. 1997, Hudson et al. 2005). Larsen et al. (2009) showed that the isotopic difference between isoleucine and leucine was much larger for plants and fungi (6\%o to $12 \%$ o) than bacteria ( $-3 \%$ o to $2 \%$ ), making them particularly valuable in distinguishing plant and fungal carbon from bacterially derived carbon. In contrast, the pathways for synthesis of alanine, valine, leucine and isoleucine in the pyruvate family are similar across fungi, bacteria and plants (Hagelstein et al. 1997), and it is the taxon-specific isotope effects associated with pyruvate dehydrogenase that cause differential enrichment of pyruvate available for biosynthesis (Blair et al. 1985). Amino acids in the pyruvate family can be useful for distinguishing the biosynthetic origin of amino acids in plants from fungi and bacteria (Larsen et al. 2009). Given the power of essential amino acid $\delta^{13} \mathrm{C}$ profiles to discriminate among key primary producers and the fact that those isotopic signatures are transferred to consumers at the upper trophic level with little to no trophic discrimination, compound-specific SIA provides a promising tool for identifying $\delta^{13} C_{\text {base }}$ values to track animal movement through isotopically distinct food webs and to trace carbon flow pathways in marine food webs.

McMahon et al. (2011a,b) explored the potential for otolith amino acid geochemistry in snapper (family Lutjanidae) to identify diet and residency patterns in juvenile nursery habitats. The technique relies on natural geographic variations in $\delta^{13} \mathrm{C}$ at the base of food webs among mangrove habitats, coral reefs and seagrass beds that are permanently recorded by otolith amino acids. McMahon et al. (2011b) found that while bulk inorganic otolith $\delta^{13} \mathrm{C}$ and $\delta^{18} \mathrm{O}$ values differed significantly between snapper from seagrass-dominated Red Sea coastal wetlands and the mangrove-dominated sites on the Pacific coast of Panama, it failed to distinguish nursery residence on local scales. Essential amino acid $\delta^{13} \mathrm{C}$ values in otoliths, on the other hand, varied as a function of habitat type and provided a better tracer of residence in different juvenile nursery habitats than conventional bulk otolith SIA alone. By targeting individual amino acids, McMahon et al. (2011b) avoided many of the confounding variables inherent in bulk otolith SIA, such as DIC masking dietary signatures. This study presented robust tracers of juvenile nursery residence that are crucial for reconstructing ontogenetic migration patterns of fishes among coastal wetlands and coral reefs. McMahon et al. (2012) used a compound-specific ecogeochemistry approach to identify essential coral reef fish habitats and 


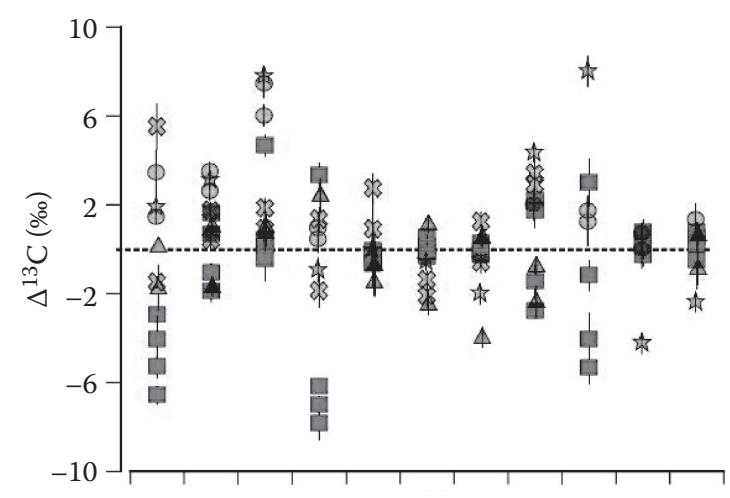

(A)

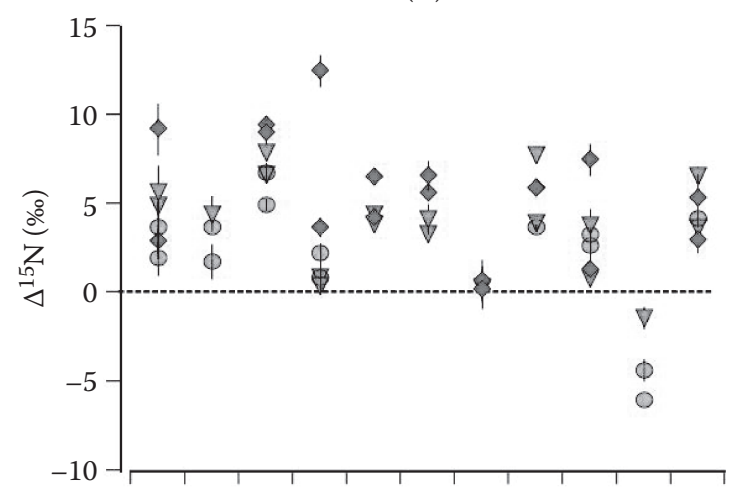

(B)

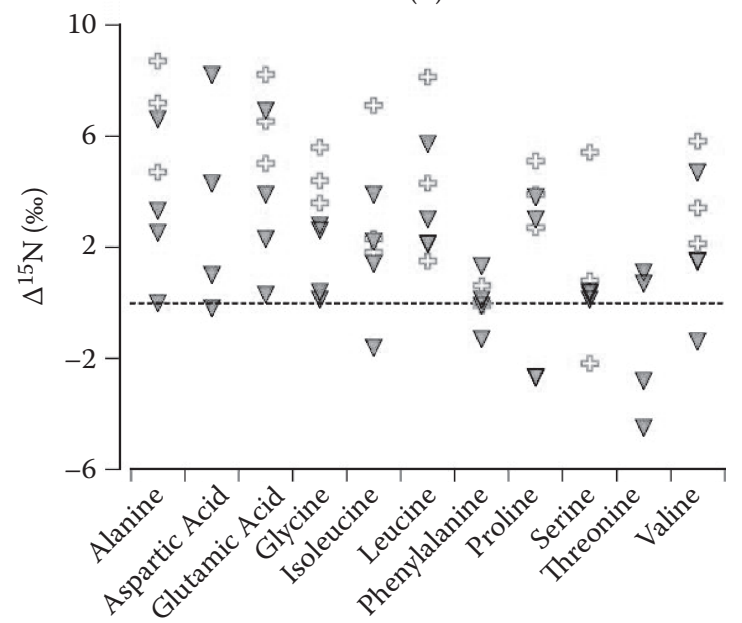

(C)

Figure 9 (See also colour figure in the insert) A compilation of individual amino acid fractionation factors between diet and consumer, including (A) $\Delta^{13} \mathrm{C}$ from controlled feeding experiments, (B) $\Delta^{15} \mathrm{~N}$ from controlled feeding experiments, and (C) $\Delta^{15} \mathrm{~N}$ from natural field samples. Data sources as follows: squares, McMahon et al. (2010); triangles, Fantle et al. (1999); X, Jim et al. (2006); circles, Hare et al. (1991); stars, Howland et al. (2003); inverted triangles, McClelland \& Montoya (2002); crosses, Chikaraishi et al. (2007); diamonds, Chikaraishi et al. (2009). Blue symbols: terrestrial vertebrates. Red symbols: aquatic vertebrates. Green symbols: aquatic invertebrates. Multiple symbols of the same shape and colour represent animals fed different diets. 
connectivity within a tropical Red Sea seascape. The authors characterized unique $\delta^{13} \mathrm{C}$ signatures from five potential juvenile nursery habitats by analysing five essential amino acid $\delta^{13} \mathrm{C}$ values from a commercially and ecologically important snapper species, Lutjanus ehrenbergii. The authors then quantified the relative contribution of coastal wetland and reef habitats to L. ehrenbergii populations on coastal, shelf, and oceanic coral reefs by classifying the juvenile core of adult fish otoliths to one of the five potential nursery habitat signatures using the multivariate amino acid $\delta^{13} \mathrm{C}$ data. The results provided the first direct measurements of the juvenile snappers' remarkable migrations of over $30 \mathrm{~km}$ between nurseries and reefs. This study found that seascape configuration played a critical but heretofore-unrecognized role in determining connectivity among habitats.

The correlation between consumer essential amino acid $\delta^{13} \mathrm{C}$ value and the carbon isotope value at the base of the food web is not always predictable, particularly for consumers with an extensive microbial gut community. Newsome et al. (2011) conducted a controlled feeding experiment on Nile tilapia (Oreochromis niloticus) reared on diets in which the percentage protein and $\delta^{13} \mathrm{C}$ value of macronutrients (protein, lipids and carbohydrates) varied significantly. The authors found that when tilapia were fed high-protein diets, the $\delta^{13} \mathrm{C}$ values of their essential amino acids closely resembled those of their diet, as expected. However, in the low-protein diet treatment, tilapia essential amino acid $\delta^{13} \mathrm{C}$ values were significantly higher than their corresponding dietary amino acids. This pattern indicated in vivo synthesis of essential amino acids from the bulk carbohydrate pool by microbes in the gut. The microbial contribution of essential macronutrients (vitamins and essential amino acids) to the host's nutrition has been well studied in ruminants (Kung \& Rode 1996, Karasov \& Carey 2008). It is becoming clear that non-ruminant consumers may also rely on microbial gut contributions under certain conditions. More research into the role of the gut microbial community in consumer amino acid metabolism is warranted, particularly for species such as sea turtles, dugongs and herbivorous fishes that are known to have extensive gut microbe communities (e.g., Mountfort et al. 2002, Andre et al. 2005).

Non-essential amino acid $\Delta^{13} \mathrm{C}$ values often exhibit significant deviations from $\Delta^{13} \mathrm{C}=0 \%$ and much greater variability among amino acids, diet types and species than essential amino acids (Hare et al. 1991, Howland et al. 2003, Jim et al. 2006, McMahon et al. 2010) (Figure 9A). This variability reflects the influence of the varied metabolic processes that shape the isotopic values of non-essential amino acids during metabolic processing. Patterns in non-essential amino acid $\Delta^{13} \mathrm{C}$ values are less clear than those for essential amino acids but show evidence of both de novo biosynthesis from bulk dietary carbon pools as well as direct isotopic routing from dietary protein. The relative contributions of isotopic routing versus biosynthesis of non-essential amino acids has been attributed to variability in protein content and amino acid composition of the diet as well as differential utilization of dietary constituents contributing to the bulk carbon pool (O'Brien et al. 2003, Jim et al. 2006, McMahon et al. 2010, Newsome et al. 2011).

Isotopic routing of individual amino acids from diet to consumer is an important contributor to the divergence of consumer bulk stable isotope values from those of its whole diet. If significant isotopic routing of dietary amino acids into consumer protein occurs, then consumer tissue $\delta^{13} \mathrm{C}$ values will significantly underrepresent the non-protein macronutrient content of the diet. Isotopic routing of non-essential amino acids is predicted to occur when consumers feed on high-protein diets, as this is far more energetically efficient than de novo biosynthesis. Jim et al. (2006) hypothesized that a threshold percentage of protein (5\% to $12 \%$ ) exists in the diet, with bone collagen $\delta^{13} \mathrm{C}$ values representing those contributed by dietary protein. Several previous studies have estimated a routing of $50 \%$ to $65 \%$ of dietary amino acids to bone collagen when the diet supplied an excess of each amino acid (Ambrose \& Norr 1993, Ambrose et al. 1997). Much of this work was conducted on terrestrial vertebrates, and several studies have found important deviations from these patterns in aquatic vertebrates. In a controlled feeding experiment rearing common mummichogs (Fundulus heteroclitus) on four isotopically distinct diets, McMahon et al. (2010) found a high degree of biosynthesis of 
non-essential amino acids, despite being fed high-protein diets. The authors suggested that since fish use a significant portion of dietary protein for energetic purposes (Dosdat et al. 1996), it is possible that they exhibit a lower degree of dietary routing than terrestrial vertebrates. Newsome et al. (2011) found a similar trend for Nile tilapia (Oreochromis niloticus) in the controlled feeding experiment discussed above. The authors showed that even when fed high-protein diets, non-protein dietary sources (carbohydrates and lipids) contributed a significant amount of carbon to the biosynthesis of non-essential amino acids in the proteinaceous tissues.

Variability in non-essential amino acid $\Delta^{13} \mathrm{C}$ values also reflects differences in utilization of the bulk carbon pool from diet (O'Brien et al. 2003, Jim et al. 2006, McMahon et al. 2010, Newsome et al. 2011). For example, catabolizing lipids as a significant energy source provides a very ${ }^{13} \mathrm{C}$-depleted carbon pool from which non-essential amino acids can be biosynthesized. McMahon et al. (2010) showed that the impact of a lipid-rich diet on the non-essential amino acid $\delta^{13} \mathrm{C}$ values of fish appears to be greatest near the source of carbon entering glycolysis and becomes diluted or altered as carbon flows through the tricarboxylic acid (TCA) cycle. Conversely, amino acids such as alanine that are synthesized from pyruvate become enriched in fish that are synthesizing large quantities of lipids (Gaye-Siessegger et al. 2011). This is because the pyruvate dehydrogenase complex heavily fractionates pyruvate when it splits acetyl coenzyme $\mathrm{A}(\mathrm{CoA})$ and $\mathrm{CO}_{2}$ as a precursor for lipid synthesis, thus leaving the remaining pyruvate enriched. Aspartate and glutamate are biosynthesized from oxaloacetate and $\alpha$-ketoglutarate, respectively, which in turn are generated by a variety of precursors in the Krebs cycle. Multiple cycling of metabolic intermediates through the Krebs cycle likely causes large fractionation during metabolic processing. As a result, Newsome et al. (2011) suggested that the $\delta^{13} \mathrm{C}$ analysis of aspartate and glutamate may be particularly valuable for reconstructing bulk diet. SIA of non-essential amino acids may provide better resolution of metabolic processing and carbon utilization than conventional bulk SIA. However, additional controlled feeding experiments to examine the underlying mechanisms behind non-essential amino acid fractionation are warranted. These studies are necessary to determine how much information on diet and metabolic processing we can glean from non-essential amino acid stable isotope values.

\section{Nitrogen}

As for carbon, amino acids have recently been classified into two categories, source and trophic (Popp et al. 2007), relating to the degree of $\delta^{15} \mathrm{~N}$ fractionation between diet and consumer during nitrogen metabolism. It is important to note that while source and essential amino acids all show little-to-no trophic fractionation between diet and consumer, they are not necessarily the same suite of amino acids, as is the case for trophic and non-essential amino acids displaying large trophic discrimination factors (Table 2). The dominant metabolic-processing routes of source amino acids do not significantly fractionate nitrogen because those reactions do not form or break bonds of nitrogen atoms. For example, there are no nitrogen-associated reactions in the conversion of methionine to $S$-adenosylmethionine or phenylalanine to tyrosine. As a result, $\delta^{15} \mathrm{~N}$ values of source amino acids in consumers reflect $\delta^{15} \mathrm{~N}_{\text {base }}$ without the confounding variable of trophic discrimination (McClelland \& Montoya 2002, Chikaraishi et al. 2007, Popp et al. 2007) (Figures 9B, 9C). Sherwood et al. (2011) examined historical nutrient regime shifts in the western North Atlantic Ocean using source amino acid $\delta^{15} \mathrm{~N}$ variability in deep-sea gorgonian corals. The authors were able to interpret coral amino acid nitrogen isotope values as a proxy for nitrate source and suggested that nutrient variability in this region was correlated with recent climate change events.

Trophic amino acids, on the other hand, undergo significant fractionation during nitrogen metabolism (Figures 9B, 9C). The removal and translocation of the amine functional group during deamination and transamination are the dominant metabolic processes in the formation of new amino acids via corresponding keto acids. These metabolic processes likely cause nitrogen isotope discrimination between the metabolized and remaining amino acids for many trophic amino acids, including alanine, valine, leucine, isoleucine, and glutamic acid (Macko et al. 1986). Variations 
in the magnitude of trophic amino acid fractionation between diet and consumer should reflect the isotope effect and relative flux of the deamination/transamination process for each amino acid (Gaebler et al. 1966). Amino acids such as arginine, lysine and histidine that contain multiple nitrogen atoms typically have more variable isotopic compositions due to their dependence on multiple nitrogen reservoirs and enzymatic inhibition reactions (Macko et al. 1987). Glutamic acid plays a key role in both the synthesis of several other amino acids (Lehninger 1975) and the excretion of ammonia in many marine taxa (Claybrook 1983). Nitrogen is transferred from glutamate via transamination to valine, isoleucine, leucine, tyrosine, phenylalanine and aspartic acid, leaving glutamate isotopically heavier. Thus, it is not surprising that glutamic acid exhibits a large $\Delta^{15} \mathrm{~N}$ between diet and consumer.

Compound-specific SIA provides an opportunity for more refined estimates of trophic position that avoid many of the confounding variables of bulk SIA, particularly variable $\Delta^{15} \mathrm{~N}$ values and uncertainty in $\delta^{15} \mathrm{~N}_{\text {base }}$. Compound-specific SIA makes use of the differences in fractionation of trophic and source amino acid to provide an internally indexed indicator of trophic position that normalizes for differences in $\delta^{15} \mathrm{~N}_{\text {base }}$. The general equation for trophic-level estimation with compound-specific SIA is as follows:

$$
\mathrm{TP}_{\mathrm{TA}-\mathrm{SA}}=1+\left(\delta^{15} \mathrm{~N}_{\mathrm{TA}}-\delta^{15} \mathrm{~N}_{\mathrm{SA}}+\beta\right) / \Delta^{15} \mathrm{~N}_{\mathrm{TA}},
$$

where $\delta^{15} \mathrm{~N}_{\mathrm{TA}}$ and $\delta^{15} \mathrm{~N}_{\mathrm{SA}}$ represent the nitrogen isotope values of the consumer trophic and source amino acids, respectively; $\beta$ represents the difference in $\delta^{15} \mathrm{~N}$ between the trophic and source amino acids of primary producers (e.g., $-3 \%$ o to $-4 \%$ o for aquatic cyanobacteria and algae, $+8.4 \%$ o for terrestrial $\mathrm{C}_{3}$ plants, and $-0.4 \%$ o for terrestrial $\mathrm{C}_{4}$ plants; McClelland \& Montoya 2002, Chikaraishi et al. 2010); and $\Delta^{15} \mathrm{~N}_{\mathrm{TA}}$ represents the trophic discrimination factor for the trophic amino acid. Phenylalanine consistently shows little-to-no fractionation across multiple marine and terrestrial taxa in feeding experiments and natural samples, making it an ideal source amino acid. Glutamic acid is typically the chosen trophic amino acid for trophic position calculations, although the magnitude of $\Delta^{15} \mathrm{~N}$ can vary among taxa.

McClelland \& Montoya (2002) and Chikaraishi et al. (2007) suggested that large ${ }^{15} \mathrm{~N}$ enrichment in trophic amino acids (e.g., glutamic acid $\Delta^{15} \mathrm{~N}=$ about $7 \%$ ) between diet and consumer provides a greater capacity for defining trophic level than moderate changes in bulk material $\left(\Delta^{15} \mathrm{~N}=\right.$ about $3.4 \%$ ). In addition, minimal fractionation of source amino acids (e.g., phenylalanine $\Delta^{15} \mathrm{~N}=0 \%$ ) provides information on $\delta^{15} \mathrm{~N}_{\text {base }}$, as discussed previously. Hence, a single analysis of amino acid $\delta^{15} \mathrm{~N}$ values from a consumer tissue provides concurrent information about trophic fractionation and $\delta^{15} \mathrm{~N}_{\text {base }}$ that is not possible using bulk SIA. However, it is important to note that, as was the case with bulk trophic position estimates, there are several important assumptions involved with the compound-specific trophic position equation. In particular, variability in $\beta$ and $\Delta \Delta^{15} \mathrm{~N}_{\mathrm{TA}}$ are not well constrained as yet. Additional controlled experiments to determine the variability in these two parameters is necessary to fully realize the potential of the compound-specific trophic position equation.

One of the biggest challenges of interpreting bulk tissue stable isotope values is the confounding effect of changes in trophic position with variations in $\delta^{13} \mathrm{C}_{\text {base }}$ and $\delta^{15} \mathrm{~N}_{\text {base }}$ (Post 2002). Compound-specific SIA provides an effective tool to tease apart these confounding variables. For instance, Dale et al. (2011) used a compound-specific ecogeochemistry approach, coupled with conventional stomach content analysis and bulk SIA, to examine the foraging ecology and habitat use of brown stingrays (Dasyatis lata) in Kane'ohe Bay, Hawaii. The authors found a counterintuitive trend of decreasing bulk $\delta^{15} \mathrm{~N}$ values as a function of size, with juvenile stingrays having significantly higher $\delta^{15} \mathrm{~N}$ values than adults. The authors posed two competing hypotheses to explain this trend: (1) Stingrays of all sizes were feeding in isotopically similar habitats but decreased in trophic position as they moved out of the bay as adults; or (2) the adult stingrays feeding outside the bay 
were feeding in a system with a distinct $\delta^{15} \mathrm{~N}_{\text {base }}$ value. Using the amino acid trophic position equation discussed previously, the authors showed that trophic position increased with size despite the decrease in bulk $\delta^{15} \mathrm{~N}$ value and confirmed a foraging habitat shift between the bay and deeper water coincident with the onset of sexual maturity.

Lorrain et al. (2009) used compound-specific SIA to examine trophic dynamics of penguins in the Indian and Southern Oceans. Conventional bulk stable isotope values suggested that king (Aptenodytes patagonicus) and Adélie (Pygoscelis adeliae) penguins occupied the highest trophic level, southern rockhopper penguins (Eudyptes chrysocome chrysocome) occupied the lowest trophic level, and northern rockhopper penguins (E. chrysocome moseleyi) were intermediate. The amino acid $\delta^{15} \mathrm{~N}$ data, however, indicated that king penguins had a higher trophic level compared to the other species than was predicted from bulk SIA. Furthermore, northern rockhoppers had a higher trophic level than the Adélie penguins. However, trophic position alone could not explain the patterns in bulk $\delta^{15} \mathrm{~N}$ values of penguins in this study. Significant differences were found in $\delta^{15} \mathrm{~N}$ values of a source amino acid (phenylalanine) among penguin species, suggesting that northern and southern rockhopper penguins were not foraging in the same oceanic regions, and that the differences in their bulk $\delta^{15} \mathrm{~N}$ values were due, in part, to $\delta^{15} \mathrm{~N}_{\text {base }}$ differences.

\section{Other elements}

The majority of compound-specific research in ecogeochemistry has been directed at carbon and nitrogen. However, recent work on $\delta^{2} \mathrm{H}$ of amino acids suggests that compound-specific deuterium analysis may be a valuable new avenue for studies of movement and foraging. Fogel et al. (2010) used bacterial cultures grown on deuterium-labelled water and growth media to show that $\delta^{2} \mathrm{H}$ of essential amino acids corresponded to the $\delta^{2} \mathrm{H}$ of diet, but the $\delta^{2} \mathrm{H}$ of non-essential amino acids reflected that of the supplied water (Fogel et al. 2010). The large geographic variation in hydrogen isoscapes suggests that $\delta^{2} \mathrm{H}$ analysis of amino acids may provide a valuable new tracer for studies of movement and foraging ecology.

\section{Fatty acids}

Fatty acids represent the main constituent of the majority of lipids found in all organisms. Unlike proteins that are broken down during digestion, fatty acids of carbon chain length 14 or more are not degraded once they are released from dietary lipid molecules during digestion. Once fatty acids have been incorporated into consumer tissue, they are either used for energy or reesterified and stored in adipose tissue, often as triacylglycerols. Thus, fatty acids are generally deposited into adipose tissue in predictable patterns with little modification, providing an integrated record of diet (Iverson et al. 2004). Marine organisms have a diverse suite of long-chain, polyunsaturated fatty acids that originate from various microorganisms, phytoplankton, and higher plants (Ackman 1980). A number of studies have shown that specific fatty acid patterns are passed from diet to consumer for a variety of taxa, from zooplankton and benthic macrofauna to pinnipeds and cetaceans (see Iverson et al. 2004, Budge et al. 2006 and references therein). Given that the pattern of fatty acids found in some plants and in many fish and invertebrates can be used to identify individual species accurately (Iverson et al. 1997, Budge et al. 2002), fatty acid profiles have become a powerful tool for quantitative assessment of predator diets (Iverson et al. 2004).

Much of the previous research using fatty acid signatures to examine spatial or temporal variations in diet and trophic ecology has been qualitative examination of changes in consumer fatty acid signatures alone (e.g., Iverson et al. 1997, McMahon et al. 2006). However, Iverson et al. (2004) developed a quantitative statistical model to estimate the contributions of prey species to the diets of predators using fatty acid signatures. This method computes the most likely combination of diet fatty acid signatures that matches the consumer, after accounting for consumer fatty acid metabolism (Budge et al. 2012). To be successful, this method requires that the fatty acid compositions of 
all important diet sources must be known, and there must be sufficient within-species sampling to assess variability in fatty acid signatures with ecological and demographic factors (e.g., Budge et al. 2002).

Compound-specific SIA of fatty acids has the advantage of providing both fatty acid profiles and isotopic information for dietary studies (e.g., Uhle et al. 1997, McLeod \& Wing 2007, Budge et al. 2008). Stable carbon isotope analysis of fatty acids shows similar patterns to those discussed for amino acids, with some fatty acids showing significant diet-to-consumer discrimination and others showing little-to-no isotopic change. While the $\delta^{13} \mathrm{C}$ value of pooled fatty acids is similar to that of the bulk carbon pool, individual storage fatty acids in consumers differ from dietary fatty acid due to chain elongation and dehydrogenation as well as metabolic turnover processes (Stott et al. 1997, Hammer et al. 1998). The kinetic isotope effect resulting from metabolic processing of non-essential fatty acids may hold valuable information about carbon utilization, similar to non-essential amino acids (Uhle et al. 1997). Conversely, essential fatty acids, such as omega fatty acids (e.g., linoleic acid 18:2n-6), are directly incorporated from diet into consumer tissue (Stott et al. 1997). Isotopic routing of essential fatty acids provides a record of the isotopic signature of the dietary source preserved in consumer tissues, much like essential amino acids.

Budge et al. (2008) found that ice algae and phytoplankton, the two dominant forms of primary production fuelling Arctic food webs, had distinct differences in fatty acid profiles and unique $\delta^{13} \mathrm{C}$ signatures of two individual fatty acids, $16: 4 \mathrm{n}-1(-24.0 \% \circ \pm 2.4 \%$ and $-30.7 \% \circ \pm 0.8 \%$, respectively) and 20:5n-3 (-18.3\%o $\pm 2.0 \%$ and $-26.9 \% \circ \pm 0.7 \%$, respectively). The authors used these differences in base of the food web end members to track carbon flow pathways to consumers at the upper trophic level, including fish, seabirds, pinnipeds and cetaceans. They found that although ice algae were only available to consumers for a short period of time (April-May), ice algae-derived carbon contributed up to $24 \%$ of the carbon passed on to upper trophic levels.

Cholesterol has also been shown to be an indicator of short-term, whole-diet $\delta^{13} \mathrm{C}$ values in several controlled feeding experiments on terrestrial vertebrates (Stott et al. 1997, Howland et al. 2003, Jim et al. 2004). Howland et al. (2003) found that pig bone cholesterol $\delta^{13} \mathrm{C}$ values were 3.4\%o depleted relative to whole diet, owing to a kinetic isotope effect resulting from oxidation of pyruvate to acetyl-CoA by the enzyme pyruvate dehydrogenase. This offset indicates that even though cholesterol was present in the diet, the bone cholesterol was biosynthesized from a bulk carbon pool rather than isotopically routed directly from the diet.

\section{Conclusions and future directions}

Ecogeochemistry relies, in large part, on isoscapes that integrate chemical, physical and biological processes that ultimately determine the isotope composition of marine animals. To enhance the use of isoscapes, we need continued efforts to collect and analyse isotope data throughout the world's oceans. Marine systems are inherently dynamic, and the generation of temporally explicit isoscapes will greatly enhance the accuracy and scope of ecogeochemistry studies. This is particularly important in light of the growing effects of climate change and ocean acidification on the biological, chemical and physical processes in our oceans (Bowen 2010). For example, the effects of temperature on productivity and the frequency and distribution of hypoxic events will potentially shift baseline isoscapes and change patterns of variability across spatial and temporal scales. In addition, we need increased modelling efforts that address the complex ecosystem processes driving geographic variability in isotope distributions. This requires new process-based research to help explain the underlying mechanisms driving spatiotemporal variability in isotopes (Schmittner et al. 2008, Somes et al. 2010).

Enhanced knowledge of isotopic routing, tissue turnover rates and fractionation factors is necessary to fully realize the potential of ecogeochemistry. We are confident that compound-specific SIA will improve the resolution of studies investigating trophic dynamics and movements. However, 
we clearly need additional controlled feeding experiments to understand the mechanisms that control non-essential and trophic amino acid stable isotope values. Improving instrument sensitivity is likely to reduce sample size requirements and increase temporal resolution from analyses of accretionary tissues. Gains in instrument sensitivity will be particularly helpful when applied to the analysis of individual compounds. Finally, we need improved networking to enhance the dissemination and exchange of data among ecogeochemists. This will require increased collaboration among geochemists, ecologists, geostatisticians and software developers, as well as the establishment of easily accessible public databases.

\section{Acknowledgements}

We were supported by funding from the National Science Foundation (Division of Ocean Sciences, 0825148 to S.R.T.), Award No. USA 00002 and KSA 00011 from the King Abdullah University of Science and Technology (to S.R.T.) and a National Science Foundation Graduate Research Fellowship (to L.H.). We thank all of the researchers who contributed published data to the meta-analyses used to generate our isoscapes, N. Lysiak and G. Lawson at Woods Hole Oceanographic Institution for providing unpublished zooplankton samples for the organic isoscapes, and B. Fry for constructive comments on the manuscript.

\section{References}

Abed-Navandi, D. \& Dworschak, P.C. 2005. Food sources of tropical thalassinidean shrimps: a stable-isotope study. Marine Ecology Progress Series 291, 159-168.

Abraham, W.R. \& Hesse, C. 2003. Isotope fractionation in the biosynthesis of cell components by different fungi: a basis for environmental carbon flux studies. Microbial Ecology 46,121-128.

Ackman, R.G. 1980. Fish lipids, part 1. In Advances in Fish Science and Technology, J.J. Connell (ed.). Oxford, UK: Fishing News Books, 86-103.

Aharon, P. 1991. Recorders of reef environment histories. Coral Reefs 10, 71-90.

Altabet, M.A. \& Francois, R. 2001. Nitrogen isotope biogeochemistry of the Antarctic Polar Frontal Zone at $170^{\circ}$ W. Deep-Sea Research II 48, 4247-4273.

Altabet, M.A. \& Small, L.F. 1990. Nitrogen isotopic ratios in fecal pellets produced by marine zooplankton. Geochimica et Cosmochimica Acta 54, 155-163.

Ambrose, S.H., Butler, B.M., Hanson, D.B., Hunter-Anderson, R.L. \& Krueger, H.W. 1997. Stable isotopic analysis of human diet in the Marianas Archipelago, Western Pacific. American Journal of Physical Anthropology 104, 343-361.

Ambrose, S.H. \& Norr, L. 1993. Carbon isotopic evidence for routing of dietary protein to bone collagen, and whole diet to bone apatite carbonate: purified diet growth experiments. In Molecular Archaeology of Prehistoric Human Bone, J. Lambert \& G. Grupe (eds). Berlin: Springer-Verlag, 1-37.

Ando, A., Nakano, T., Kawahata, H., Yokoyama, Y. \& Khim, B.-K. 2010. Testing seawater Sr isotopic variability on a glacial-interglacial timescale: an application of latest high-precision thermal ionization mass spectrometry. Geochemical Journal 44, 347-357.

Andre, J., Gyuris, E. \& Lawler, I.R. 2005. Comparison of the diets of sympatric dugongs and green turtles on the Orman Reefs, Torres Strait, Australia. Wildlife Research 32, 53-62.

Arkhipkin, A., Campana, S.E., FitzGerald, J. \& Thorrold, S.R. 2004. Spatial and temporal variation in elemental signatures of statoliths from the Patagonian longfin squid (Loligo gahi). Canadian Journal of Fisheries and Aquatic Sciences 61, 1212-1224.

Barnett-Johnson, R., Teel, D.J. \& Castillas, E. 2010. Genetic and otolith isotopic markers identify salmon populations in the Columbia River at broad and fine geographic scales. Environmental Biology of Fishes 89, 533-546.

Barrick, R.E., Fischer, A.G., Kolodny, Y., Luz, B. \& Bohaska, D. 1992. Cetacean bone oxygen isotopes as proxies for Miocene ocean composition and glaciation. Palaios 7, 521-531. 
Barth, A., Alvera, A., Troupin, C., Ouberdous, M. \& Beckers, J.M. 2010. A web interface for griding arbitrarily distributed in situ data based on Data-Interpolating Variational Analysis (DIVA). Advances in Geosciences 28, 29-37.

Bath, G.E., Thorrold, S.R., Jones, C.M., Campana, S.E., McLaren, J.W. \& Lam, J.W.H. 2000. Strontium and barium uptake in aragonitic otoliths of marine fish. Geochimica et Cosmochimica Acta 64, 1705-1714.

Beck, J.W., Edwards, R.L., Ito, M., Taylor, F.W., Rougerie, F., Joannot, P. \& Henin, C. 1992. Sea-surface temperature from coral skeletal strontium/calcium ratios. Science 257, 644-647.

Becker, B.J., Fodrie, F.J., Macmillan, P.A. \& Levin, L.A. 2005. Spatial and temporal variation in trace element fingerprints of mytilid mussel shells: a precursor to invertebrate larval tracking. Limnology and Oceanography 50, 48-61.

Becker, B.J., Levin, L.A., Frodie, J. \& McMillan, P.A. 2007. Complex larval connectivity patterns among marine invertebrate populations. Proceedings of the National Academy of Sciences USA 104, 3267-3272.

Bentaleb, I., Fontugne, M., Descolas-Gros, C., Girardin, C., Mariotti, A., Pierre, C., Brunet, C. \& Poisson, A. 1998. Carbon isotope fractionation by plankton in the Southern Indian Ocean: relationship between $\delta^{13} \mathrm{C}$ of particulate organic carbon and dissolved carbon dioxide. Journal of Marine Systems 17, 39-58.

Benway, H.M. \& Mix, A. 2004. Oxygen isotopes, upper-ocean salinity, and precipitation in the eastern tropical Pacific. Earth and Planetary Science Letters 224, 493-507.

Bergquist, B.A. \& Boyle, E.A. 2006. Dissolved iron in the tropical and subtropical Atlantic Ocean. Global Biogeochemical Cycles 20, GB1015, doi:10.1029/2005GB002505.

Best, P.B. \& Schell, D.M. 1996. Stable isotopes in southern right whale (Eubalaena australis) baleen as indicators of seasonal movements, feeding and growth. Marine Biology 124, 483-494.

Birchall, J., O'Connell, T.C., Heaton, T.H.E. \& Hedges, R.E.M. 2005. Hydrogen isotope ratios in animal body protein reflect trophic level. Journal of Animal Ecology 74, 877-881.

Blair, N., Leu, A., Munoz, E., Olsen, J., Kwong, E. \& Desmarais, D. 1985. Carbon isotopic fractionation in heterotrophic microbial-metabolism. Applied and Environmental Microbiology 50, 996-1001.

Bode, A.M., Alvarez-Ossorio, M.T., Carrera, P. \& Lorenzo, J. 2004. Reconstruction of trophic pathways between plankton and the North Iberian sardine (Sardina pilchardus) using stable isotopes. Scientia Marina 68, 165-178.

Bode, A., Alvarez-Ossorio, M.T., Cunha, M.E., Garrido, S., Peleteiro, P.B., Valdes, L. \& Varela, M. 2007. Stable nitrogen isotope studies of the pelagic food web on the Atlantic shelf of the Iberian Peninsula. Progress in Oceanography 74, 115-131.

Bode, A., Cerrera, P. \& Lens, S. 2003. The pelagic foodweb in the upwelling ecosystem of Galicia (NW Spain) during spring: natural abundance of stable carbon and nitrogen isotopes. ICES Journal of Marine Science 60, 11-22.

Boecklen, W.J., Yarnes, C.T., Cook, B.A. \& James, A.C. 2011. On the use of stable isotopes in trophic ecology. Annual Review of Marine Science 42, 411-440.

Boon, P.I., Bird, F.L. \& Bunn, S.E. 1997. Diet of the intertidal callianassid shrimps Biffarius arenosus and Trypea australiensis (Decapoda: Thalassinidea) in Western Port (southern Australia), determined with multiple stable-isotope analyses. Marine and Freshwater Research 48, 503-511.

Borman, A., Wood, T.R., Black, H.C., Anderson, E.G., Oesterling, M.J., Womack, M. \& Rose, WC. 1946. The role of arginine in growth with some observations on the effects of argininic acid. Journal of Biological Chemistry 166, 585-594.

Bottrell, S.H. \& Newton, R.J. 2006. Reconstruction of changes in global sulfur cycling from marine sulfate isotopes. Earth Science Reviews 75, 59-83.

Boutton, T.W. 1991. Stable carbon isotope ratios of natural materials: II. Atmospheric, terrestrial, marine and freshwater environments. In Carbon Isotope Techniques, D.C. Coleman \& B. Fry (eds). San Diego, CA: Academic Press, 173-186.

Bowen, G.J. 2010. Isoscapes: spatial pattern in isotopic biogeochemistry. Annual Review of Earth and Planetary Science 38, 161-187.

Boye, M., Wake, B.D., Lopez Garcia, P., Bown, J., Baker, A.R., Achterberg, E.P. 2012. Distributions of dissolved trace metals $(\mathrm{Cd}, \mathrm{Cu}, \mathrm{Mn}, \mathrm{Pb} \mathrm{Ag})$ in the southeast Atlantic and the Southern Ocean. Biogeosciences Discussions 9, 3579-3613.

Boyle, E.A. 2001. Anthropogenic trace elements in the ocean. In Encyclopedia of Ocean Sciences, J.H. Steel \& K.K. Turekian (eds). London: Academic Press, 162-169. 
Bricker, O.P. \& Jones, B.F. 1995. Main factors affecting the composition of natural waters. In Trace Elements in Natural Waters, B. Salbu \& E. Steinnes (eds). Boca Raton, FL: CRC Press, 1-20.

Broecker, W.S. \& Peng, T.H. 1974. Gas exchange rates between air and sea. Tellus 26, 21-35.

Broecker, W.S., Peng, T.H., Ostlund, G. \& Stuiver, M. 1985. The distribution of bomb radiocarbon in the ocean. Journal of Geophysical Research 90, 6953-6970.

Brown, M. 1998. Ocean data view 4.0. Oceanography 11, 19-21.

Brown, R.J. \& Severin, K.P. 2009. Otolith chemistry analyses indicate that water Sr:Ca is the primary factor influencing otolith $\mathrm{Sr}$ Ca for freshwater and diadromous fish but not for marine fish. Canadian Journal of Fisheries and Aquatic Sciences 66,1790-1808.

Bruland, K.W. \& Lohan, M.C. (2004). The control of trace metals in seawater. In Treatise on Geochemistry, H.D. Holland \& K.K. Turekian (eds). Amsterdam: Elsevier, 23-47.

Buchheister, A. \& Latour, R.J. 2009. Turnover and fractionation of carbon and nitrogen stable isotopes in tissues of a migratory coastal predator, summer flounder (Paralichthys dentatus). Canadian Journal of Fisheries and Aquatic Sciences 67, 445-461.

Budge, S.M., Iverson, S.J., Bowen, W.D. \& Ackman, R.G. 2002. Among- and within-species variation in fatty acid signatures of marine fish and invertebrates on the Scotian Shelf, Georges Bank and southern Gulf of St. Lawrence. Canadian Journal of Fisheries and Aquatic Sciences 59, 886-898.

Budge, S.M., Iverson, S.J. \& Koopman, H.N. 2006. Studying trophic ecology in marine ecosystems using fatty acids: a primer on analysis and interpretation. Marine Mammal Science 22, 759-801.

Budge, S.M., Penney, S.N. \& Lall, S.P. 2012. Estimating diets of Atlantic salmon (Salmo trutta) using fatty acid signature analyses; validation with controlled feeding studies. Canadian Journal of Fisheries and Aquatic Sciences 69, 1033-1046.

Budge, S.M., Wooller, M.J., Springer, A.M., Iverson, S.J., McRoy, C.P. \& Divoky, G.J. 2008. Tracing carbon flow in an Arctic marine food web using fatty acid-stable isotope analysis. Oecologia 157, 117-229.

Calvert, S.E. 2000. Stable isotope data from sediment traps and net tows in the Atlantic and Northeast Pacific Oceans. JGOFS Canada Data Sets 1989-1998. Vancouver, British Columbia, Canada: Marine Environmental Data Service, Department of Fisheries and Oceans.

Campana, S.E. 1999. Chemistry and composition of fish otoliths: pathways, mechanisms and applications. Marine Ecology Progress Series 188, 263-297.

Campana, S.E., Chouinard, G.A., Hanson, J.M. \& Frechet, A. 1999. Mixing and migration of overwintering Atlantic cod (Gadus morhua) stocks near the mouth of the Gulf of St. Lawrence. Canadian Journal of Fisheries and Aquatic Sciences 56, 1873-1881.

Campana, S.E., Natanson, L.J. \& Myklevoll, S. 2002. Bomb dating and age determination of large pelagic sharks. Canadian Journal of Fisheries and Aquatic Sciences 59, 450-455.

Campana, S.E. \& Neilson, J.D. 1985. Microstructure of fish otoliths. Canadian Journal of Fisheries and Aquatic Sciences 42, 1014-1032.

Campana, S.E. \& Thorrold, S.R. 2001. Otoliths, increments, and elements: keys to a comprehensive understanding of fish populations? Canadian Journal of Fisheries and Aquatic Sciences 58, 30-38.

Capo, R.C., Stewart, B.W. \& Chadwick, O.A. 1998. Strontium isotopes as tracers of ecosystem processes: theory and methods. Geoderma 82, 197-225.

Carlier, A., Riera, P., Amouroux, J.M., Bodiou, J.Y., Escoubeyrou, K., Desmalades, M., Caparros, J. \& Gremare, A. 2007. A seasonal survey of the food web in the Lapalme Lagoon (northwestern Mediterranean) assessed by carbon and nitrogen stable isotope analysis. Estuarine, Coastal and Shelf Science 73, 299-315.

Checkley, C.M. \& Entzeroth, L.C. 1985. Elemental and isotopic fractionation of carbon and nitrogen by marine, planktonic copepods and implications to the marine nitrogen cycle. Journal of Plankton Research 7, $553-568$.

Checkley, D.M. \& Miller, C.A. 1989. Nitrogen isotope fractionation by oceanic zooplankton. Deep-Sea Research 36, 1449-1456.

Chikaraishi, Y., Kashiyama, Y., Ogawa, N.O., Kitazato, H. \& Ohkouchi, N. 2007. Metabolic control of nitrogen isotope composition of amino acids in macroalgae and gastropods: implications for aquatic food web studies. Marine Ecology Progress Series 342, 85-90.

Chikaraishi, Y., Ogawa, N.O., Kashiyama, Y., Takano, Y., Suga, H., Tomitani, A., Miyashita, H., Kitazato, H. \& Ohkouchi, N. 2009. Determination of aquatic food-web structure based on compound-specific nitrogen isotopic composition of amino acids. Limnology and Oceanography: Methods 7, 740-750. 
Chikaraishi, Y., Ogawa, N.O. \& Ohkouchi, N. 2010. Further evaluation of the trophic level estimation based on nitrogen isotopic composition of amino acids. In Earth, Life, and Isotopes, N. Ohokouchi, I. Tayasu \& K. Koba (eds). Kyoto: Kyoto University Press, 37-51.

Cianco, J.E., Pascual, M.A., Botto, G., Frere, E. \& Iribarne, O. 2008. Trophic relationships of exotic anadromous salmonids in the southern Patagonian Shelf as inferred from stable isotopes. Limnology and Oceanography 53, 788-798.

Cifuentes, L.A., Sharp, J.H. \& Fogel, M.L. 1988. Stable carbon and nitrogen isotope biogeochemistry in the Delaware Estuary. Limnology and Oceanography 33, 1102-1115.

Claybrook, D.L. 1983. Nitrogen metabolism. In The Biology of Crustacea, Vol. 5. Internal Anatomy and Physiological Regulation, L.H. Mantel (ed.). New York: Academic Press, 163-213.

Cline, J.D. \& Kaplan, I.R. 1975. Isotopic fractionation of dissolved nitrate during denitrification in the eastern tropical North Pacific Ocean. Marine Chemistry 3, 271-299.

Cohen, A.L. \& Thorrold, S.R. 2007. Recovery of temperature records from slow-growing corals by fine scale sampling of skeletons. Geophysical Research Letters 34, L17706, doi:10.1029/2007GL030967.

Cooper, L.W., Benner, R., McClelland, J.W., Peterson, B.J., Holmes, R.M., Raymond, P.A., Hansell, D.A., Brebmeier, J.M. \& Codispoti, L.A. 2005. Linkages among runoff, dissolved organic carbon, and the stable oxygen isotope composition of seawater and other water mass indicators in the Arctic Ocean. Journal of Geophysical Research 110, G02013, doi:10.1029/2005JG000031.

Coplen, T.B., Hopple, J.A., Bohlke, J.K., Peiser, H.S., Rieder, S.E., Krouse, H.R., Rosman, K.J.R., Ding, T., Vocke, R.D.J., Revesz, K.M., Lamberty, A., Taylor, P. \& DeBievre, P. 2002. Complication of minimum and maximum isotope ratios of selected elements in naturally occurring terrestrial materials and reagents. United States Geological Survey, Reston, Virginia.

Corbisier, T., Petti, M.V., Skowronski, R.P. \& Brito, T.S. 2004. Trophic relationships in the nearshore zone of Martel Inlet (King George Island, Antarctic): $\delta^{13} \mathrm{C}$ stable-isotope analysis. Polar Biology 27, 75-82.

Dale, J.J., Wallsgrove, N.J., Popp, B.N. \& Holland, K.N. 2011. Nursery habitat use and foraging ecology of the brown stingray Dasyatis lata from stomach contents, bulk and amino acid stable isotopes. Marine Ecology Progress Series 433, 221-236.

Dalerum, F. \& Angerbjörn, A. 2005. Resolving temporal variation in vertebrate diets using naturally occurring stable isotopes. Oecologia 144, 647-658.

Dansgaard, W. 1964. Stable isotopes in precipitation. Tellus 16, 436-468.

Das, K., Lepoint, G., Yann, L. \& Bouquegneau, J.M. 2003. Marine mammals from the southern North Sea: feeding ecology from $\delta^{13} \mathrm{C}$ and $\delta^{15} \mathrm{~N}$ measurements. Marine Ecology Progress Series 263, 287-298.

Degens, E.T., Behrendt, M., Goddhardt, B. \& Reppmann, E. 1968. Metabolic fractionation of carbon isotopes in marine plankton II. Data on samples collected off the coast of Peru and Ecuador. Deep-Sea Research $15,11-20$.

Degens, E.T., Deuser, W.G. \& Haedrich, R.L. 1969. Molecular structure and composition of fish otoliths. Marine Biology 2, 105-113.

DeNiro, M.J. \& Epstein, S. 1978. Influence of diet on distribution of carbon isotopes in animals. Geochimica et Cosmochimica Acta 42, 495-506.

DeNiro, M.J. \& Epstein, S. 1981. Influence of diet on the distribution of nitrogen isotopes in animals. Geochimica et Cosmochimica Acta 45, 341-351.

Devenport, S.R. \& Bax, N.J. 2002. A trophic study of a marine ecosystem off southeastern Australia using stable isotopes of carbon and nitrogen. Canadian Journal of Fisheries and Aquatic Sciences 59, 514-530.

de Villiers, S. 1999. Seawater strontium and $\mathrm{Sr} / \mathrm{Ca}$ variability in the Atlantic and Pacific oceans. Earth and Planetary Science Letters 171, 623-634.

Dierking, J., Morat, F., Letourneur, Y. \& Harmelin-Vivien, M. 2012. Fingerprints of lagoonal life: migration of the marine flatfish Solea solea assessed by stable isotopes and otolith microchemistry. Estuarine, Coastal and Shelf Science 104-105, 23-32.

Donat, J.R. \& Bruland, K.W. 1995. Trace elements in the oceans. In Trace Elements in Natural Waters, B. Salbu \& E. Steinnes (eds). Boca Raton, Florida: CRC Press, 247-281.

Dore, J.E., Brum, J.R., Tupas, L.M. \& Karl, D.M. 2002. Seasonal and interannual variability in sources of nitrogen supporting export in the oligotrophic subtropical North Pacific Ocean. Limnology and Oceanography 47, 1595-1607.

Dorval, E. \& Jones, C.M. 2005. Chemistry of surface waters: distinguishing fine-scale differences in sea grass habitats of Chesapeake Bay. Limnology and Oceanography 50, 1073-1083. 
Dorval, E., Jones, C.M., Hannigan, R. \& van Montfrans, J. 2007. Relating otolith chemistry to surface water chemistry in a coastal plain estuary. Canadian Journal of Fisheries and Aquatic Sciences 64, 1-14.

Dosdat, A., Servais, F., Metailler, R., Huelvan, C. \& Desbruyeres, E. 1996. Comparison of nitrogenous losses in five teleost fish species. Aquaculture 141, 107-127.

Druffel, E.M. \& Linick T.W. 1978. Radiocarbon in annual coral rings of Florida. Geophysical Research Letters 5, 913-916.

Druffel, E.M. \& Williams, P.M. 1990. Identification of a deep marine source of particulate organic carbon using bomb ${ }^{14}$ C. Nature $347,172-174$.

Druffel, E.R.M. 1981. Radiocarbon in annual coral rings from the eastern tropical Pacific Ocean. Geophysical Research Letters 8, 59-62.

Druffel, E.R.M. 1987. Bomb radiocarbon in the Pacific: annual and seasonal timescale variations. Journal of Marine Research 45, 667-698.

Druffel-Rodriguez, K.C., Vetter, D., Griffin, S., Druffel, E.R.M., Dunbar, R.B., Mucciarone, D.A., Ziolkowski, L.A. \& Sanchez-Cabeza, J.A. 2012. Radiocarbon and stable isotopes in Palmyra corals during the past century. Geochimica et Cosmochimica Acta 82, 154-162.

Dugdale, R.C. \& Goering, J.J. 1967. Uptake of new and regenerated forms of nitrogen in primary productivity. Limnology and Oceanography 12, 196-206.

Dunton, K.H. 2001. $\delta^{15} \mathrm{~N}$ and $\delta^{13} \mathrm{C}$ measurements of Antarctic peninsula fauna: trophic relationships and assimilation of benthic seaweeds. American Zoologist 41, 99-112.

Dunton, K.H., Saupe, S.M., Golikov, A.N., Schell, D.M. \& Schonberg, S.V. 1989. Trophic relationships and isotopic gradients among arctic and subarctic marine fauna. Marine Ecology Progress Series 56, 89-97.

Elsdon, T.S., Ayvazian, S., McMahon, K.W. \& Thorrold, S.R. 2010. Experimental evaluation of stable isotope fractionation in fish muscle and otoliths. Marine Ecology Progress Series 408, 195-205.

Elsdon, T.S. \& Gillanders, B.M. 2002. Interactive effects of temperature and salinity on otolith chemistry: challenges for determining environmental histories of fish. Canadian Journal of Fisheries and Aquatic Sciences 59, 1796-1808.

Elsdon, T.S. \& Gillanders, B.M. 2003. Relationship between water and otolith elemental concentrations in juvenile black bream Acanthopagrus butcheri. Marine Ecology Progress Series 260, 263-272.

Elsdon, T.S. \& Gillanders, B.M. 2004. Fish otolith chemistry influenced by exposure to multiple environmental variables. Journal of Experimental Marine Biology and Ecology 313, 269-284.

Elsdon, T.S. \& Gillanders, B.M. 2006. Temporal variability of elemental concentrations in coastal and estuarine waters. Estuarine, Coastal and Shelf Science 66, 147-156.

Elsdon, T.S., Wells, B.K., Campana, S.E., Gillanders, B.M., Jones, C.M., Limburg, K.E., Secor, D.H., Thorrold, S.R. \& Walther, B.D. 2008. Otolith chemistry to describe movements and life-history parameters of fishes: hypotheses, assumptions, limitations and inferences. Oceanography and Marine Biology: an Annual Review 46, 297-330.

Estrada, J.A., Rice, A.N., Lutcavage, M.E. \& Skomal, G.B. 2003. Predicting trophic position in sharks of the north-west Atlantic Ocean using stable isotope analysis. Journal of the Marine Biological Association of the UK 83, 1347-1350.

Fairbanks, R.G., Evans, M.N., Rubenstone, J.L., Mortlock, R.A., Broad, K., Moore, M.D. \& Charles, C.D. 1997. Evaluating climate indices and their geochemical proxies measured in corals. Coral Reefs 16, S93-S100.

Fallon, S.J. \& Guilderson, T.P. 2008. Surface water processes in the Indonesian throughflow as documented by a high-resolution coral $\Delta^{14} \mathrm{C}$ record. Journal of Geophysical Research 113, C09001.

Fanelli, E., Cartes, J.E. \& Papiol, V. 2011. Food web structure of deep-sea macrozooplankton and micronekton off the Catalan slope: insight from stable isotopes. Journal of Marine Systems 87, 79-89.

Fanelli, E., Cartes, J.E., Rumolo, P. \& Sprovieri, M. 2009. Food-web structure and trophodynamics of meopelagic-suprabenthic bathyal macrofauna of the Algerian Basin based on stable isotopes of carbon and nitrogen. Deep-Sea Research I 56, 1504-1520.

Fantle, M.S., Dittel, A.I., Schwalm, S.M., Epifanio, C.E. \& Fogel, M.L. 1999. A food web analysis of the juvenile blue crab, Callinectes sapidus, using stable isotopes in whole animals and individual amino acids. Oecologia 120, 416-426.

Farquhar, G.D., Ehleringer, J.R. \& Hubick, K.T. 1989. Carbon isotope discrimination and photosynthesis. Annual Review of Plant Physiology and Plant Molecular Biology 40, 503-537. 
Florin, S.T., Felicetti, L.A. \& Robbins, C.T. 2011. The biological basis for understanding and predicting dietary-induced variations in nitrogen and sulphur isotope ratio discrimination. Functional Ecology 25, $519-526$.

Fogel, M.L. \& Cifuentes, L.A. 1993. Isotopic fractionation during primary production. In Organic Geochemistry, M.H. Engel \& S.A. Macko (eds). New York: Plenum Press, 73-98.

Fogel, M.L., Griffin, P. \& Newsome, S.D. 2010. Hydrogen isotopes in amino acids trace food and water. Presented at the 7th International Conference on Applications of Stable Isotope Techniques to Ecological Studies, August 2010, Fairbanks, Alaska.

Fontugne, M. \& Duplessy, J.C. 1978. Carbon isotope ratio of marine plankton related to surface water masses. Earth and Planetary Science Letters 41, 365-371.

Forest, A., Galindo, V., Darnis, G., Lalande, C., Pineault, S., Tremblay, J.E. \& Fortier, L. 2011. Carbon biomass, elemental ratios $(\mathrm{C}: \mathrm{N})$ and stable isotopic composition $\left(\delta^{13} \mathrm{C}, \delta^{15} \mathrm{~N}\right)$ of dominant calanoid copepods during the winter-to-summer transition in the Amundsen Gulf (Arctic Ocean). Journal of Plankton Research 33, 161-178.

France, R., Loret, J., Mathews, R. \& Springer, J. 1998. Longitudinal variation in zooplankton $\delta^{13}$ C through the Northwest Passage: inference for incorporation of sea-ice POM into pelagic foodwebs. Polar Biology 20, 335-341.

France, R.L. 1995. Carbon-13 enrichment in benthic compared to planktonic algae: foodweb implications. Marine Ecology Progress Series 124, 307-312.

Frederich, B., Fabri, G., Lepoint, G., Vandewalle, P. \& Parmentier, E. 2009. Trophic niches of thirteen damselfishes (Pomacentridae) at the Grand Recif of Toliara, Madagascar. Ichthyological Research 56, 10-17.

Friedman, I. 1953. Deuterium content of natural waters and other substances. Geochimica et Cosmochimica Acta 4, 89-103.

Fry, B. 1981. Natural stable carbon isotope tag traces Texas shrimp migrations. Fisheries Bulletin 79, 337-345.

Fry, B. 1988. Food web structure on Georges Bank from stable C, N, and S isotopic compositions. Limnology and Oceanography 33, 1182-1190.

Fry, B. 2002. Conservative mixing of stable isotopes across estuarine salinity gradients: a conceptual framework for monitoring watershed influences on downstream fisheries production. Estuaries 25, 264-271.

Fry, B. \& Quinones, R.B. 1994. Biomass spectra and stable isotope indicators of trophic level in zooplankton of the northwest Atlantic. Marine Ecology Progress Series 112, 201-204.

Fry, B., Scalan, R.S. \& Parker, P.L. $1983 .{ }^{13} \mathrm{C} /{ }^{12} \mathrm{C}$ ratios in marine food webs of the Torres Strait, Queensland. Australian Journal of Marine and Freshwater Research 34, 707-715.

Fry, B., Scalan, R.S., Winters, J.K. \& Parker, P.L. 1982. Sulphur uptake by salt grasses, mangroves and seagrasses in anaerobic sediments. Geochimica et Cosmochimica Acta 46, 1121-1124.

Fry, B. \& Wainright, S.C. 1991. Diatom sources of ${ }^{13}$ C-rich carbon in marine food webs. Marine Ecology Progress Series 76, 149-157.

Gaebler, O.H., Vitti, T.G. \& Vukmirovich, R. 1966. Isotope effects on metabolism of ${ }^{14} \mathrm{~N}$ and ${ }^{15} \mathrm{~N}$ from unlabeled dietary proteins. Canadian Journal of Biochemistry 44, 1249-1257.

Gaillardet, J., Viers, J. \& Dupré, B. 2003. Trace elements in river waters. In Treatise on Geochemistry, D.H. Heinrich \& K.T. Karl (eds). Oxford, UK: Pergamon, 225-272.

Galimov, E.M., Kodina, L.A., Stepanets, O.V. \& Korobeinik, G.S. 2006. Composition of phytoplankton and carbon isotopic composition of plankton and dissolved bicarbonate ions from the subsurface water layer along the Yenisei River-Kara Sea meridional profile $\left(70-77^{\circ} \mathrm{N}\right)$. Geochemistry International 44, 1053-1104.

Gannes, L.Z., Martínez del Rio, C. \& Koch, P. 1998. Natural abundance variations in stable isotopes and their potential uses in animal physiological ecology. Comparative Biochemistry and Physiology 119A, $725-737$.

Gannes, L.Z., O’Brien, D.M. \& Martínez del Rio, C. 1997. Stable isotopes in animal ecology: assumptions, caveats, and a call for more laboratory experiments. Ecology 78, 1271-1276.

Ganssen, G. \& Kroon, D. 1991. Evidence for Red Sea surface circulation from oxygen isotopes of modern surface waters and planktonic foraminiferal tests. Paleoceanography 6, 73-82.

Gat, J.R. 1996. Oxygen and hydrogen isotopes in the hydrologic cycle. Annual Review of Earth and Planetary Science 24, 225-262. 
Gaye-Siessegger, J., McCullagh, J.S.O. \& Focken, U. 2011. The effect of dietary amino acid abundance and isotopic composition on the growth rate, metabolism and tissue $\delta^{13} \mathrm{C}$ of rainbow trout. British Journal of Nutrition 105, 1764-1771.

Gearing, J.N., Hearing, P.J., Rudnick, D.T., Requejo, A.G. \& Hutchins, M.J. 1984. Isotopic variability of organic carbon in a phytoplankton-based, temperate estuary. Geochimica et Cosmochimica Acta 48, 1089-1098.

Goericke, R. \& Fry, B. 1994. Variations of marine plankton $\mathrm{d}^{13} \mathrm{C}$ with latitude, temperature, and dissolved $\mathrm{CO}_{2}$ in the World Ocean. Global Biogeochemical Cycles 8, 85-90.

Goering, J., Alexander, V. \& Haubenstock, N. 1990. Seasonal variability of stable carbon and nitrogen isotope ratios of organisms in a North Pacific bay. Estuarine, Coastal and Shelf Science 30, 239-260.

Goni, M.A., Monacci, N., Gisewhite, R., Ogston, A., Crockett, J. \& Nittrouer, C. 2006. Distribution and sources of particular organic matter in the water column and sediments of the Fly River Delta, Gulf of Papua (Papua New Guinea). Estuarine, Coastal and Shelf Science 69, 225-245.

Graham, B.S., Koch, P.L., Newsome, S.D., McMahon, K.W. \& Aurioles, D. 2010. Using isoscapes to trace the movements and foraging behavior of top predators in oceanic ecosystems. In Isoscapes: Understanding Movement, Pattern and Process on Earth Through Isotope Mapping, J. West et al. (eds). New York: Springer-Verlag, 299-318.

Griffin, M.P.A. \& Valiela, I. 2001. $\delta^{15} \mathrm{~N}$ isotope studies of life history and trophic position of Fundulus heteroclitus and Menidia menidia. Marine Ecology Progress Series 214, 299-305.

Gruber, N., Keeling, C.D., Bacastow, R.B., Guenther, P.R., Lueker, T.J., Wahlen, M., Meijer, H.A.J., Mook, W.G. \& Stocker, T.F. 1999. Spatiotemporal patterns of carbon-13 in the global surface oceans and the oceanic suess effect. Global Biogeochemical Cycles 13, 307-335.

Grumet, N.S., Abram, N.J., Beck, J.W., Dunbar, R.B., Gagan, M.K., Guilderson, T.P., Hantoro, W.S. \& Suwargadi, B.W. 2004. Coral radiocarbon records of Indian Ocean water mass mixing and wind-induced upwelling along the coast of Sumatra, Indonesia. Journal of Geophysical Research 109, C05003.

Hagelstein, P., Sieve, B., Klein, M., Jans, H. \& Schultz, G. 1997. Leucine synthesis in chloroplasts: leucine/ isoleucine aminotransferase and valine aminotransferase are different enzymes in spinach chloroplasts. Journal of Plant Physiology 150, 23-30.

Hale, L.F., Dudgeon, J.V., Mason, A.Z. \& Lowe, C.G. 2006. Elemental signatures in the vertebral cartilage of the round stingray, Urobatis halleri, from Seal Beach, California. Environmental Biology of Fishes 77, $317-325$.

Hammer, B.T., Fogel, M.L. \& Hoering, T.C. 1998. Stable carbon isotope ratios of fatty acids in seagrass and redhead ducks. Chemical Geology 152, 29-41.

Hannides, C.C.S., Popp, B.N., Landry, M.R. \& Graham, B.S. 2009. Quantification of zooplankton trophic position in the North Pacific Subtropical Gyre using stable nitrogen isotopes. Limnology and Oceanography 54, 50-61.

Hansson, S., Hobbie, J.E., Elmgren, R., Larsson, U., Fry, B. \& Johansson, S. 1997. The stable nitrogen isotope ratio as a marker of food-web interactions and fish migration. Ecology 78, 2249-2257.

Hare, P.E., Fogel, M.L., Stafford, T.W., Mitchell, A.D. \& Hoering, T.C. 1991. The isotopic composition of carbon and nitrogen in individual amino acids isolated from modern and fossil proteins. Journal of Archaeological Science 18, 277-292.

Harmelin-Vivien, M., Loizeau, V., Mellon, C., Beker, B., Arlhac, D., Bodiguel, X., Ferraton, F., Hermand, R., Philippon, X. \& Salen-Picard, C. 2008. Comparison of C and N stable isotope ratios between surface particulate organic matter and microphytoplankton in the Gulf of Lions (NW Mediterranean). Continental Shelf Research 28, 1911-1919.

Heaton, T.H.E. 1986. Isotopic studies of nitrogen pollution in the hydrosphere and atmosphere: a review. Chemical Geology 59, 87-102.

Herzka, S.Z. 2005. Assessing connectivity of estuarine fishes based on stable isotope ratio analysis. Estuarine, Coastal and Shelf Science 64, 58-69.

Hicks, A.S., Closs, G.P. \& Swearer, S.E. 2010. Otolith microchemistry of two amphidromous galaxiids across an experimental salinity gradient: a multi-element approach for tracking diadromous migrations. Journal of Experimental Marine Biology and Ecology 394, 86-97.

Hill, J.M. \& McQuaid, C.D. 2011. Stable isotope methods: the effect of gut contents on isotopic ratios of zooplankton. Estuarine, Coastal and Shelf Science 92, 480-485. 
Hinga, K.R., Arthur, M.A., Pilson, M.E. \& Whitaker, D. 1994. Carbon isotope fractionation by marine phytoplankton in culture: the effects of $\mathrm{CO}_{2}$ concentration, $\mathrm{pH}$, temperature and species. Global Biogeochemical Cycles 8, 91-102.

Hirch, S. 2009. Trophic interactions at seamounts. PhD thesis, Departments Biologie der Fakultät für Mathematik, Informatik \& Naturwissenschaften der Universität Hamburg, University of Hamburg, Germany.

Hobson, K.A. 1999. Tracing origins and migration of wildlife using stable isotopes: a review. Oecologia 120, 314-326.

Hobson, K.A., Ambrose, W.G. \& Renaud, P.E. 1995. Sources of primary production, benthic-pelagic coupling, and trophic relationships within the Northeast Water Polynya: insights from $\delta^{13} \mathrm{C}$ and $\delta^{15} \mathrm{~N}$ analysis. Marine Ecology Progress Series 128, 1-10.

Hobson, K.A., Barnett-Johnson, R. \& Cerling, T. 2010. Using isoscapes to track animal migration. In Isoscapes: Understanding Movement, Pattern and Process on Earth Through Isotope Mapping, J. West et al. (eds). New York: Springer-Verlag, 273-298.

Hobson, K.A., Fisk, A., Karnovsky, N., Holst, M., Gagnon, J.M. \& Fortier, M. 2002. A stable isotope $\left(\delta^{13} C\right.$, $\delta^{15} \mathrm{~N}$ ) model for the North Water food web: implications for evaluating trophodynamics and the flow of energy and contaminants. Deep-Sea Research II 49, 5131-5150.

Hobson, K.A. \& Montevecchi, W.A. 1991. Stable isotopic determination of the trophic relationships of Great Auks. Oecologia 87, 528-531.

Hobson, K.A., Piatt, J.F. \& Pitocchelli, J. 1994. Using stable isotopes to determine seabird trophic relationships. Journal of Animal Ecology 63, 786-798.

Hoch, M.P., Fogel, M.L. \& Kirchman, D.L. 1992. Isotope fractionation associated with ammonium uptake by a marine bacterium. Limnology and Oceanography 37, 1447-1459.

Hoekstra, P.F., Dehn, L.A., George, J.C., Solomon, K.R., Muir, D.C.G. \& O'Hara, T.M. 2002. Trophic ecology of bowhead whales (Balaena mysticetus) compared with that of other Arctic marine biota as interpreted from carbon-, nitrogen, and sulfur-isotope signatures. Canadian Journal of Zoology 80, 223-231.

Hoekstra, P.F., O'Hara, T.M., Fisk, A.T., Borga, K., Solomon, K.R. \& Muir, D.C.G. 2003. Trophic transfer of persistent organochlorine contaminants (OCs) within an Arctic marine food web from the southern Beaufort-Chukchi Seas. Environmental Pollution 124, 509-522.

Hoering, T.C. \& Ford, H.T. 1960. The isotope effect in the fixation of nitrogen by Azotobacter. Journal of the American Chemical Society 82, 376-378.

Hofmann, M., Wolf-Gladrow, D.A., Takahashi, T., Sutherland, S.C., Six, K.D. \& Maier-Reimer, E. 2000. Stable carbon isotope distribution of particulate organic matter in the ocean: a model study. Marine Chemistry 72, 131-150.

Holl, C.M., Villareal, T.A., Payyne, C.D., Clayton, T.D., Hart, C. \& Montoya, J.P. 2007. Trichodesmium in the western Gulf of Mexico: ${ }^{15} \mathrm{~N}_{2}$-fixation and natural abundance stable isotope evidence. Limnology and Oceanography 52, 2249-2259.

Horita, J. 1999. Abiogenic methane formation and isotopic fractionation under hydrothermal conditions. Science 285, 1055-1057.

Horita, J. \& Wesolowski, D.J. 1994. Liquid-vapor fraction of oxygen and hydrogen isotopes of water from the freezing to the critical temperature. Geochimica et Cosmochimica Acta 58, 3425-3437.

Howland, M.R., Corr, L.T., Young, S.M.M., Jones, V., Jim, S., van der Merwe, N.J., Mitchell, A.D. \& Evershed, R.P. 2003. Expression of the dietary isotope signal in the compound-specific $\delta^{13} \mathrm{C}$ values of pig bone lipids and amino acids. International Journal of Osteoarchaeology 13, 54-65.

Hübner, H. 1986. Isotope effects of nitrogen in the soil and biosphere. Handbook of Environmental Isotope Geochemistry 2, 361-425.

Hudson, A.O., Bless, C., Macedo, P., Chatterjee, S.P., Singh, B.K., Gilvarg, C. \& Leustek, T. 2005. Biosynthesis of lysine in plants: evidence for a variant of the known bacterial pathways. Biochimica et Biophysica Acta 1721, 27-36.

Huh, Y., Chan, L.-H., Zhang, L. \& Edmond, J.M. 1998. Lithium and its isotopes in major world rivers: implications for weathering and the oceanic budget. Geochimica et Cosmochimica Acta 62, 2039-2051.

Hüssy, N.E., MacNeil, M.A. \& Fisk, A.T. 2010. The requirement for accurate diet-tissue discrimination factors for interpreting stable isotopes in sharks. Hydrobiologia 654, 1-5. 
Hüssy, K., Mosegaard, H. \& Jessen, F. 2004. Effect of age and temperature on amino acid composition and the content of different protein types of juvenile Atlantic cod (Gadus morhua) otoliths. Canadian Journal of Fisheries and Aquatic Sciences 61, 1012-1020.

Iken, K., Bluhm, B.A. \& Gradinger, R. 2005. Food web structure in the high Arctic Canada Basin: evidence from $\delta^{13} \mathrm{C}$ and $\delta^{15} \mathrm{~N}$ analysis. Polar Biology 28, 238-249.

Iverson, S.J., Field, C., Don Bowen, W. \& Blanchard, W. 2004. Quantitative fatty acid signature analysis: a new method of estimating predator diets. Ecological Monographs 74, 211-235.

Iverson, S.J., Frost, K.J. \& Lowry, L.L. 1997. Fatty acid signatures reveal fine scale structure of foraging distribution of harbor seals and their prey in Prince William Sound, Alaska. Marine Ecology Progress Series 151, 255-271.

Jain, A.K., Kheshgi, H.S., Hoffert, M.I. \& Wuebbles, D.J. 1995. Distribution of radiocarbon as a test of global carbon cycle models. Global Biogeochemical Cycles 9, 153-166.

Jennings, S. \& Warr, K.J. 2003. Environmental correlates of large-scale spatial variation in the $\delta^{15} \mathrm{~N}$ of marine animals. Marine Biology 142, 1131-1140.

Jim, S., Ambrose, S.H. \& Evershed, R.P. 2004. Stable carbon isotopic evidence for differences in the dietary origin of bone cholesterol, collagen and apatite: implications for their use in palaeodietary reconstruction. Geochimica et Cosmochimica Acta 68, 61-72.

Jim, S., Jones, V., Ambrose, S.H. \& Evershed, R.P. 2006. Quantifying dietary macronutrient sources of carbon for bone collagen biosynthesis using natural abundance stable carbon isotope analysis. British Journal of Nutrition 95, 1055-1062.

Kaehler, S., Pakhomov, E.A. \& McQuaid, C.D. 2000. Trophic structure of the marine food web at the Prince Edward Islands (Southern Ocean) determined by $\delta^{13} \mathrm{C}$ and $\delta^{15} \mathrm{~N}$ analysis. Marine Ecology Progress Series 208, 13-20.

Kalansky, J.F., Robinson, R.S. \& Popp, B.N. 2011. Insights into nitrogen cycling in the western Gulf of California from nitrogen isotopic composition of diatom-bound organic matter. Geochemistry Geophysics Geosystems 12, Q06015, doi:10.1029/2010GC003437.

Kalish, J.M. 1991a. Oxygen and carbon stable isotopes in the otoliths of wild and laboratory-reared Australian salmon (Arripis trutta). Marine Biology 110, 37-47.

Kalish, J.M. 1991b. Determinants of otolith chemistry: seasonal variation in the composition of blood plasma, endolymph and otoliths of bearded rock cod Pseudophycis barbatus. Marine Ecology Progress Series 74, 137-159.

Kalish, J.M. 1993. Pre- and post-bomb radiocarbon in fish otoliths. Earth and Planetary Science Letters 114, 549-554.

Kang, C.K., Kim, J.B., Lee, K.S., Kim, J.B., Lee, P.Y. \& Hong, J.S. 2003. Trophic importance of benthic microalgae to macrozoobenthos in coastal bay systems in Korea: dual stable $\mathrm{C}$ and $\mathrm{N}$ isotope analyses. Marine Ecology Progress Series 259, 79-92.

Karasov, W.H. \& Carey, H.V. 2008. Metabolic teamwork between gut microbes and hosts. Microbe 4, 323-328.

Karasov, W.H. \& Martínez del Rio, C. 2007. Physiological Ecology. Princeton, NJ: Princeton University Press.

Kastner, M. 1999. Oceanic minerals: their origin, nature of their environment, and significance. Proceedings of the National Academy of Sciences USA 96, 3380-3387.

Keeling, C.D. \& Guenther, P. 1994. Shore based carbon analysis: duplicate carbon measurements made by the Carbon Dioxide Research Group during the 1983-1988 cruises, Scripps Institution of Oceanography, University of California, San Diego. Online. http://cdiac.esd.ornl.gov/ftp/oceans/keeling.data/. Carbon Dioxide Information Analysis Center, Oak Ridge National Laboratory, U.S. Department of Energy, Oak Ridge, Tennessee. doi:10.3334/CDIAC/otg.KEELING_DATA.

Keeling, C.D., Piper, S.C., Bacastow, R.B., Wahlen, M., Whorf, T.P., Heimann, M. \& Meijer, H.A. 2005. Atmospheric $\mathrm{CO}_{2}$ and ${ }^{13} \mathrm{CO}_{2}$ exchange with the terrestrial biosphere and oceans from 1978 to 2000: observations and carbon cycle implications. In A History of Atmospheric $\mathrm{CO}_{2}$ and Its Effects on Plants, Animals, and Ecosystems, J.R. Ehleringer, T.E. Cerling \& M.D. Dearing (eds). New York: Springer-Verlag, 83-113.

Keil, R.G. \& Fogel, M.L. 2001. Reworking of amino acid in marine sediments: stable carbon isotopic composition of amino acids in sediments along the Washington Coast. Limnology and Oceanography 46, 14-23.

Kelly, J.F. 2000. Stable isotopes of carbon and nitrogen in the study of avian and mammalian trophic ecology. Canadian Journal of Zoology 78, 1-27. 
Kelly, J.F., Bridge, B.S., Fudickar, A.M. \& Wassenaar, L.I. 2009. A test of comparative equilibration for determining non-exchangeable stable hydrogen isotope values in complex organic materials. Rapid Communications in Mass Spectrometry 23, 2316-2320.

Kendall, C. \& Coplen, T.B. 2001. Distribution of oxygen-18 and deuterium in river waters across the United States. Hydrological Processes 15, 1363-1393.

Key, R.M., Kozyr, A., Sabine, C.L., Lee, K., Wanninkhof, R., Bullister, J.L., Freely, R.A., Millero, F.J., Mordy, C. \& Peng, T.-H. 2004. A global ocean carbon climatology: results from Global Data Analysis Project (GLODAP). Global Biogeochemical Cycles, 18, GB4031.

Kilbourne, K.H., Quinn, T.M., Guilderson, T.P., Webb, R.S. \& Taylor, F.W. 2007. Decadal to interannual-scale source water variations in the Caribbean Sea recorded by Puerto Rican coral radiocarbon. Climate Dynamics 29, 51-62.

Kiriakoulakis, K., Fisher, E., Wolff, G.A., Freiwald, A., Grehan, A. \& Roberts, J.M. 2005. Lipids and nitrogen isotopes of two deep-water corals from the North-East Atlantic: initial results and implications for their nutrition. In Cold-Water Corals and Ecosystems, A. Freiwald \& J.M. Roberts (eds). Berlin: Springer-Verlag, 715-729.

Kohler, S.A., Connan, M., Hill, J.M., Mablouke, C., Bonnevie, B., Ludynia, K., Kemper, J., Huisamen, J., Underhill, L.G., Cherel, Y., McQuaid, C.D. \& Jaquemet, S. 2011. Geographic variation in the trophic ecology of an avian rocky shore predator, the African black oystercatcher, along the southern African coastline. Marine Ecology Progress Series 435, 235-249.

Kolasinski, J., Rogers, K., Cuet, P., Barry, B. \& Prouin, P. 2011. Sources of particulate organic matter at the ecosystem scale: a stable isotope and trace element study in a tropical coral reef. Marine Ecology Progress Series 443, 77-93.

Kolodny, Y., Luz, B. \& Navon, O. 1983. Oxygen isotope variations in phosphate of biogenic apatites, I. Fish bone apatite-rechecking the rules of the game. Earth and Planetary Science Letters 64, 398-404.

Koppelmann, R. \& Weikert, H. 2000. Transfer of organic matter in the deep Arabian Sea zooplankton community: insights from $\delta^{15} \mathrm{~N}$ analysis. Deep-Sea Research II 47, 2653-2672.

Krause-Nehring, J., Brey, T. \& Thorrold, S.R. 2012. Centennial records of lead contamination in northern Atlantic bivalves (Arctica islandica). Marine Pollution Bulletin 64, 233-240.

Krichevsky, M.I., Friedman, I., Newell, M.F. \& Sisler, F.D. 1961. Deuterium fractionation during molecular hydrogen formation in a marine pseudomonad. Journal of Biological Chemistry 236, 2520-2525.

Kroopnick, P.M. 1985. The distribution of ${ }^{13} \mathrm{C}$ of $\Sigma \mathrm{CO}_{2}$ in the world oceans. Deep-Sea Research 32, 57-84.

Krouse, H.R. \& Grinenko, V.A. 1991. Stable Isotopes: Natural and Anthropogenic Sulphur in the Environment. New York: Wiley.

Krouse, H.R., Viau, C.A., Eliuk, L.S., Ueda, A. \& Halas, S. 1988. Chemical and isotopic evidence of thermochemical sulfate reduction by light hydrocarbon gases in deep carbonate reservoirs. Nature 333, 415-419.

Krummen, M., Hilkert, A.W., Juchelka, D., Duhr, A., Schluter, H.J. \& Pesch, R. 2004. A new concept for isotope ratio monitoring liquid chromatography/mass spectrometry. Rapid Communications in Mass Spectrometry 18, 2260-2266.

Kung, L. \& Rode, L.M. 1996. Amino acid metabolism in ruminants. Animal Feed Science and Technology 59, 167-172.

Kurten, B., Painting, S.J., Struck, U., Polunin, N.V.C. \& Middelburg, J.J. 2011. Tracking seasonal changes in North Sea zooplankton dynamics using stable isotopes. Biogeochemistry doi:10.1007/s10533-011-9630-y.

Laakmann, S. \& Auel, H. 2010. Longitudinal and vertical trends in stable isotope signatures $\left(\delta^{13} \mathrm{C}\right.$ and $\left.\delta^{15} \mathrm{~N}\right)$ of omnivorous and carnivorous copepods across the South Atlantic Ocean. Marine Biology 157, 463-471.

Lamb, K. \& Swart, P.K. 2008. The carbon and nitrogen isotopic values of particulate organic material from the Florida Keys: a temporal and spatial study. Coral Reefs 27, 351-362.

Landing, W.M. \& Bruland, K.W. 1987. The contrasting biogeochemistry of iron and manganese in the Pacific Ocean. Geochimica et Cosmochimica Acta 51, 29-43.

Larsen, T., Taylor, D.L., Leigh, M.B. \& O'Brien, D.M. 2009. Stable isotope fingerprinting: a novel method for identifying plant, fungal, or bacterial origins of amino acids. Ecology 90, 3526-3535.

Laws, E.A., Popp, B.N., Bidigare, R.R., Kennicutt, M.C. \& Macko, S.A. 1995. Dependence of phytoplankton carbon isotopic composition on growth rate and $\left[\mathrm{CO}_{2}\right]_{\mathrm{aq}}$ : theoretical and experimental results. Geochemica et Cosmochimica Acta 59, 1131-1138.

Lea, D.W., Shen, G.T. \& Boyle, E.A. 1989. Coralline barium records temporal variability in equatorial Pacific upwelling. Nature 340, 373-376. 


\section{KELTON W. MCMAHON, LI LING HAMADY \& SIMON R. THORROLD}

Lehninger, A.H. 1975. Biochemistry. New York: Worth, 2nd edition.

Le Loc'h, F. \& Hily, C. 2005. Stable carbon and nitrogen isotope analysis of Nephrops norvegicus/Merluccius merluccius fishing grounds in the Bay of Biscay (Northeast Atlantic). Canadian Journal of Fisheries and Aquatic Sciences 62, 123-132.

Le Loc'h, F., Hily, C. \& Grall, J. 2008. Benthic community and food web structure on the continental shelf of the Bay of Biscay (north eastern Atlantic) revealed by stable isotope analysis. Journal of Marine Systems 72, 17-34.

Lesage, V., Hammill, M.O. \& Kovacs, K.M. 2001. Diet-tissue fractionation of stable carbon and nitrogen isotopes in phocid seals. Marine Mammal Science 18, 182-193.

Levin, I. \& Hesshaimer,V. 2000. Radiocarbon-a unique tracer of global carbon cycle dynamics. Radiocarbon 42, 69-80.

Libes, S.M. \& Deuser, W.G. 1988. The isotope geochemistry of particulate nitrogen in the Peru Upwelling Area and Gulf of Maine. Deep-Sea Research 35, 517-533.

Limburg, K.E. 1995. Otolith strontium traces environmental history of subyearling American shad Alosa sapidissima. Marine Ecology Progress Series 119, 25-35.

Limburg, K.E., Olson, C., Walther, Y., Dale, D., Slomp, C.P. \& Hoie, H. 2011. Tracking Baltic hypoxia and cod migration over millennia with natural tags. Proceedings of the National Academy of Sciences USA 108, E177-E182.

Linick, T.W. 1978. La Jolla measurements of radiocarbon in the oceans. Radiocarbon 20, 333-359.

Logan, J.M., Haas, H., Deegan, L. \& Gaines, E. 2006. Turnover rates of nitrogen stable isotopes in the salt marsh mummichog, Fundulus heteroclitus, following a laboratory diet switch. Oecologia 147, 391-395.

Logan, J.M., Jardine, T.D., Miller, T.J., Bunn, S.E., Cunjak, R.A. \& Lutcavage, M.E. 2008. Lipid corrections in carbon and nitrogen stable isotope analysis: comparison of chemical extraction and modeling methods. Journal of Animal Ecology 77, 838-846.

Logan, J.M. \& Lutcavage, M.E. 2010. Stable isotope dynamics in elasmobranch fishes. Hydrobiologia 644, 231-244.

Lorrain, A., Graham, B., Menard, F., Popp, B., Bouillon, S., van Breugel, P. \& Cherel, Y. 2009. Nitrogen and carbon isotope values of individual amino acids: a tool to study foraging ecology of penguins in the Southern Ocean. Marine Ecology Progress Series 391, 293-306.

Lourey, M.J., Trull, T.W. \& Sigman, D.M. 2003. Sensitivity of $\delta^{15}$ N of nitrate, surface suspended and deep sinking particulate nitrogen to seasonal nitrate depletion in the Southern Ocean. Global Biogeochemical Cycles 17, G1081, doi:10.1029/2002GB001973.

Lynch-Stieglitz, J., Stocker, T.F., Broecker, W.S. \& Fairbanks, R.G. 1995. The influence of air-sea exchange on the isotopic composition of oceanic carbon: observations and modeling. Global Biogeochemical Cycles 9, 653-665.

Lysiak, N.S. 2009. Investigating the migration and foraging ecology of North Atlantic right whales with stable isotope geochemistry of baleen and zooplankton. $\mathrm{PhD}$ thesis, Biology Department, Boston University.

Mackensen, A. 2001. Oxygen and carbon stable isotope tracers of Weddell Sea water masses: new data and some paleoceanographic implications. Deep-Sea Research I 48, 1401-1422.

Mackensen, A., Hubberten, H.-W., Bickert, T., Fischer, G. \& Fütterer D.K. 1993. The $\delta^{13} \mathrm{C}$ in benthic foraminiferal tests of Fontbotia wuellerstorfi (Schwager) relative to the $\delta^{13} \mathrm{C}$ of dissolved inorganic carbon in Southern Ocean Deep Water: implications for glacial ocean circulation models. Paleoceanography 8, 587-610.

Mackensen, A., Hubberten, H.-W., Scheele, N. \& Schlitzer, R. 1996. Decoupling of $\delta^{13} C_{\Sigma \mathrm{CO} 2}$ and phosphate in recent Weddell Sea deep and bottom water: implications for glacial Southern Ocean paleoceanography. Paleoceanography 11, 203-215.

Macko, S.A., Entzeroth, L. \& Parker, P.L. 1984. Regional differences in nitrogen and carbon isotopes on the continental shelf of the Gulf of Mexico. Naturwissenschaften 71, 374-375.

Macko, S.A., Estep, M.L.F., Engel, M.H. \& Hare, P.E. 1986. Kinetic fractionation of stable nitrogen isotopes during amino acid transamination. Geochimica et Cosmochimica Acta 50, 2143-2146.

Macko, S.A., Estep, M.L.F., Hare, P.E. \& Hoering, T.C. 1987. Isotopic fractionation of nitrogen and carbon in the synthesis of amino acids by microorganisms. Chemical Geology 65, 79-92.

Macko, S.A., Estep, M.L.F. \& Lee, W.Y. 1983. Stable hydrogen isotope analysis of food webs on laboratory and field populations of marine amphipods. Journal of Experimental Marine Biology and Ecology 72, 243-249. 
Mahaffey, C., Williams, R.G. \& Wolff, G.A. 2004. Physical supply of nitrogen to phytoplankton in the Atlantic Ocean. Global Biogeochemical Cycles 18, GB1034 doi:10.1029/2003GB002129.

Malpica-Cruz, L., Herzka, S.Z., Sosa-Nishizaki, O. \& Pablo Laso, J. 2011. Tissue-specific isotope trophic discrimination factors and turnover rates in a marine elasmobranch: empirical and modeling results. Canadian Journal of Fisheries and Aquatic Sciences 69, 551-564.

Martin, G.B. \& Thorrold, S.R. 2005. Temperature and salinity effect on magnesium, manganese, and barium incorporation in otoliths of larval and early juvenile spot Leiostomus xanthurus. Marine Ecology Progress Series 293, 223-232.

Matsura, Y. \& Wada, E. 1994. Carbon and nitrogen isotope ratios in marine organic matters of the coastal ecosystem in Ubatuba, southern Brazil. Ciencia e Cultura 46, 141-146.

McClelland, J.W., Holl, C.M. \& Montoya J.P. 2003. Relating low $\delta^{15} \mathrm{~N}$ values of zooplankton to $\mathrm{N}_{2}$-fixation in the tropical North Atlantic: insights provided by stable isotope ratios of amino acids. Deep-Sea Research I 50, 849-861.

McClelland, J.W. \& Montoya, J.P. 2002. Trophic relationships and the nitrogen isotopic composition of amino acids in plankton. Ecology 83, 2173-2180.

McClelland, J.W., Valiela, I. \& Michener, R.H. 1997. Nitrogen stable isotope signatures in estuarine food webs: a record of increasing urbanization in coastal watersheds. Limnology and Oceanography 42, 930-937.

McConnaughey, T. 1989a. ${ }^{13} \mathrm{C}$ and ${ }^{18} \mathrm{O}$ isotopic disequilibrium in biological carbonates: I. patterns. Geochimica et Cosmochimica Acta 53, 151-162.

McConnaughey, T. $1989 \mathrm{~b} .{ }^{13} \mathrm{C}$ and ${ }^{18} \mathrm{O}$ isotopic disequilibrium in biological carbonates: II. in vitro simulation of kinetic isotope effects. Geochimica et Cosmochimica Acta 53, 163-171.

McCullagh, J.S.O., Juchelka, D. \& Hedges, R.E.M. 2006. Analysis of amino acid ${ }^{13} \mathrm{C}$ abundance from human and faunal bone collagen using liquid chromatography/isotope ratio mass spectrometry. Rapid Communications in Mass Spectrometry 20, 2761-2768.

McCutchan, J.H., Jr., Lewis, W.M., Jr., Kendall, C. \& McGrath, C.C. 2003. Variation in trophic shift for stable isotope ratios of carbon, nitrogen, and sulfur. Oikos 102, 378-390.

McLeod, R.J. \& Wing, S.R. 2007. Hagfish in the New Zealand fjords are supported by chemoautotrophy of forest carbon. Ecology 88, 809-816.

McMahon, K.W., Ambrose, W.G., Jr., Johnson, B.J., Sun, M.Y., Lopez, G.R., Clough, L.M. \& Carroll, M.L. 2006. Benthic community response to ice algae and phytoplankton in Ny Alesund, Svalbard. Marine Ecology Progress Series 310, 1-14.

McMahon, K.W., Berumen, M.L., Mateo, I., Elsdon, T.S. \& Thorrold, S.R. 2011a. Carbon isotopes in otolith amino acids identify residency of juvenile snapper (Family: Lutjanidae) in coastal nurseries. Coral Reefs 30, 1135-1145.

McMahon, K.W., Berumen, M.L. \& Thorrold, S.R. 2012. Linking habitat mosaics and connectivity in a coral reef seascape. Proceedings of the National Academy of Sciences USA 109, 15372-15376.

McMahon, K.W., Fogel, M.L., Elsdon, T. \& Thorrold, S.R. 2010. Carbon isotope fractionation of amino acids in fish muscle reflects biosynthesis and isotopic routing from dietary protein. Journal of Animal Ecology 79, 1132-1141.

McMahon, K.W., Fogel, M.L., Johnson, B.J., Houghton, L.A. \& Thorrold, S.R. 2011 b. A new method to reconstruct fish diet and movement patterns from $\delta^{13} \mathrm{C}$ values in otolith amino acids. Canadian Journal of Fisheries and Aquatic Sciences 68, 1330-1340.

McMahon, K.W., Hamady, L.L., Thorrold, S.R. 2013. A review of ecogeochemistry approaches to estimating movements of marine animals. Limnology and Oceanography 58, 697-714.

Meier-Augenstein, W. 1999. Applied gas chromatography coupled to isotope ratio mass spectrometry. Journal of Chromatography 842, 351-371.

Melancon, S., Fryer, B.J. \& Markham, J.L. 2009. Chemical analysis of endolymph and the growing otolith: fractionation of metals in freshwater fish species. Environmental Toxicology and Chemistry 28, 1279-1287.

Merritt, D.A., Brand, W.A. \& Hayes, J.M. 1994. Isotope-ratio-monitoring gas chromatography-mass spectrometry: methods for isotopic calibration. Organic Geochemistry 21, 573-583.

Michener, R.H. \& Schell, D.M. 1994. Stable isotope ratios as tracers in marine aquatic food webs. In Stable Isotopes in Ecology and Environmental Science, K. Lajtha \& R.H. Michener (eds). Boston: Blackwell Scientific, 138-157.

Miller, T.W., Omori, K., Hamaoka, H., Shibata, J.Y. \& Hidejiro, O. 2010. Tracing anthropogenic inputs to production in the Seto Island Sea, Japan—a stable isotope approach. Marine Pollution Bulletin 60, 1803-1809. 
Millero, F., Lee, K. \& Wanninkhof, R. 1998. Carbon dioxide, hydrographic, and chemical data obtained during the R/V Ronald Brown in the Atlantic Ocean during WOCE Section AR01(A05) (23 January24 February, 1998). Online. http://cdiac.ornl.gov/ftp/oceans/ar01woce/. Carbon Dioxide Information Analysis Center, Oak Ridge National Laboratory, U.S. Department of Energy, Oak Ridge, Tennessee. doi:10.3334/CDIAC/otg.WOCE_A05_1998.

Minagawa, M. \& Wada, E. 1984. Stepwise enrichment of ${ }^{15} \mathrm{~N}$ along food chains: further evidence and the relations between $\delta^{15} \mathrm{~N}$ and animal age. Geochimica et Cosmochimica Acta 48, 1135-1140.

Mizutani, H., Kabaya, Y. \& Wada, E. 1991. Nitrogen and carbon isotope compositions relate linearly in cormorant tissues and its diet. Isotopenpraxis 27, 166-168.

Montoya, J.P., Carpenter, E.J. \& Capone, D.G. 2002. Nitrogen fixation and nitrogen isotope abundances in zooplankton of the oligotrophic North Atlantic. Limnology and Oceanography 47, 1617-1628.

Mook, W.G. 1986. ${ }^{13} \mathrm{C}$ in atmospheric $\mathrm{CO}_{2}$. Netherlands Journal of Sea Research 20, 211-223.

Mook, W.G. \& Vogel, J.C. 1968. Isotopic equilibrium between shells and their environment. Science 159, 874-875.

Morris, J.G. 1985. Nutritional and metabolic responses to arginine deficiency in carnivores. Journal of Nutrition 115, 524-531.

Mountfort, D.O., Campbell, J. \& Clements, K.D. 2002. Hindgut fermentation in three species of marine herbivorous fish. Applied and Environmental Microbiology 68, 1374-1380.

Muhlfeld, C.C., Thorrold, S.R., McMahon, T.E. \& Marotz, B. 2012. Estimating trout movements in a river network using strontium isoscapes. Canadian Journal of Fisheries and Aquatic Sciences 69, 906-915.

Mullin, M.M., Rau, G.H. \& Eppley, R.W. 1984. Stable nitrogen isotopes in zooplankton: some geographic and temporal variations in the North Pacific. Limnology and Oceanography 29, 1267-1273.

Murayama, E. 2000. Review of the growth regulation processes of otolith daily increment formation. Fisheries Research 46, 53-67.

Neretin, L.N., Bottcher, M.E. \& Grinenko, V.A. 2003. Sulfur isotope geochemistry of the Black Sea water column. Chemical Geology 200, 59-69.

Newsome, S.D., Fogel, M.L., Kelly, L. \& Martinez del Rio, C. 2011. Contribution of direct incorporation from diet and microbial amino acids to protein synthesis in Nile tilapia. Functional Ecology 25, 1051-1062.

Nydal, R. 1998. Carbon-14 measurements in surface water $\mathrm{CO}_{2}$ from the Atlantic, Indian and Pacific Oceans, 1965-1994. In Carbon Dioxide Information Analysis Center, A.L. Brenkert \& T.A. Boden (eds). Oak Ridge, Tennessee: Oak Ridge National Laboratory, ORNL/CDIAC-104, NDP-057A.

Nyssen, F., Brey, T., Lepoint, G., Bouquegneau, J.M., De Broyer, C. \& Dauby, P. 2002. A stable isotope approach to the eastern Weddell Sea trophic web: focus on benthic amphipods. Polar Biology 25, 280-287.

O'Brien, D.M., Boggs, C.L. \& Fogel, M.L. 2003. Pollen feeding in the butterfly Heliconius charitonia: isotopic evidence for essential amino acid transfer from pollen to eggs. Proceedings of the Royal Society of London B 270, 2631-2636.

Olive, P.J.W., Pinnegar, K.J., Polunin, N.V.C., Richards, G. \& Welch, R. 2003. Isotope trophic-step fractionation: a dynamic equilibrium model. Journal of Animal Ecology 72, 608-617.

Olson, R.J., Popp, B.N., Graham, B.S., López-Ibarra, G.A., Galván-Magaña, F., Lennert-Cody, C.E., Bocanegra-Castillo, N., Wallsgrove, N.J., Gier, E., Alatorre-Ramírez, V., Ballance, L.T. \& Fry, B. 2010. Food web inferences of stable isotope spatial patterns in copepods and yellowfin tuna in the pelagic eastern Pacific Ocean. Progress in Oceanography 86, 124-138.

O'Reilly, C.M., Hecky, R.E., Cohen, A.S. \& Plisnier, P.D. 2002. Interpreting stable isotopes in food webs: recognizing the role of time averaging at different trophic levels. Limnology and Oceanography 47, 306-309.

Ostlund, H.G., Doresy, H.G. \& Rooth, C.G. 1974. GEOSECS North Atlantic radiocarbon and tritium results. Earth and Planetary Science Letters 23, 69-86.

Ostrom, N.E., Macko, S.A., Deibel, D. \& Thrompson, R.J. 1997. Seasonal variation in the stable carbon and nitrogen isotope biogeochemistry of a coastal cold ocean environment. Geochimica et Cosmochimica Acta 61, 2929-2942.

Pajuelo, M., Bjorndal, K.A., Alfaro-Shigueto, J., Seminoff, J.A., Mangel, J.C. \& Bolten, A.B. 2010. Stable isotope variation in loggerhead turtles reveals Pacific-Atlantic oceanographic differences. Marine Ecology Progress Series 417, 277-285.

Pancost, R.D., Freeman, K.H., Wakeham, S.G. \& Roberston, C.Y. 1997. Controls on carbon isotope fractionation by diatoms in the Peru upwelling region. Geochimica et Cosmochimica Acta 61, 4983-4991. 


\section{OCEAN ECOGEOCHEMISTRY: A REVIEW}

Parkington, J. 1991. Approaches to dietary reconstruction in the Western Cape: are you what you have eaten? Journal of Archaeological Science 18, 331-342.

Pearcy, W.G. \& Stuiver, M. 1983. Vertical transport of carbon-14 into deep-sea food webs. Deep-Sea Research 30, 427-440.

Peterson, B.J. \& Fry, B. 1987. Stable isotopes in ecosystem studies. Annual Review of Ecology and Systematics 18, 293-320.

Peterson, B.J. \& Howarth, R.W. 1987. Sulfur, carbon, and nitrogen isotopes used to trace organic matter flow in the salt-marsh estuaries of Sapelo Island, Georgia. Limnology and Oceanography 32, 1195-1213.

Peterson, B.J., Howarth, R.W. \& Garritt, R.H. 1985. Multiple stable isotopes used to trace the flow of organic matter in estuarine food webs. Science 227, 1361-1363.

Peterson, B.J., Howarth, R.W. \& Garritt, R.H. 1986. Sulfur and carbon isotopes as tracers of salt-marsh organic matter flow. Ecology 67, 865-874.

Petursdottir, H., Falk-Petersen, S., Hop, H. \& Gislason, A. 2010. Calanus finmarchicus along the northern Mid-Atlantic Ridge: variation in fatty acid and alcohol profiles and stable isotope values, $\delta^{15} \mathrm{~N}$ and $\delta^{13} \mathrm{C}$. Journal of Plankton Research 32, 1067-1077.

Petursdottir, H., Gislason, A., Falk-Petersen, S., Hop, H. \& Svavarsson, J. 2008. Trophic interactions of the pelagic ecosystem over the Reykjanes Ridge as evaluated by fatty acids and stable isotope analyses. Deep-Sea Research II 55, 83-93.

Pinnegar, J.K., Polunin, N.V.C., Francour, P., Badalamenti, F., Chemello, R., Harmelin-Vivien, M.-L., Hereu, B., Milazzo, M., Zabala, M., D’Anna, G. \& Pipitone, C. 2000. Trophic cascades in benthic marine ecosystems: lessons for fisheries and protected-area management. Environmental Conservation 27, 179-200.

Polunin, N.V.C., Morales-Nin, B., Pawsey, W.E., Cartes, J.E., Pinnegar, J.K. \& Moranta, J. 2001. Feeding relationships in Mediterranean bathyal assemblages elucidated by stable nitrogen and carbon isotope data. Marine Ecology Progress Series 220, 13-23.

Pomerleau, C., Winkler, G., Sastri, A.R., Nelson, R.J., Vagle, S., Lesage, V. \& Ferguson, S.H. 2011. Spatial patterns in zooplankton communities across the eastern Canadian sub-Arctic and Arctic waters: insights from stable carbon $\left(\delta^{13} \mathrm{C}\right)$ and nitrogen $\left(\delta^{15} \mathrm{~N}\right)$ isotope ratios. Journal of Plankton Research 33, 1779-1792.

Popp, B.N., Graham, B.S., Olson, R.J., Hannides, C.C.S., Lott, M.J., Lopez-Ibarra, A., Galvan-Magana, F. \& Fry, B. 2007. Insight into the trophic ecology of yellowfin tuna, Thunnus albacares, from compound-specific nitrogen isotope analysis of proteinaceous amino acids. In Stable Isotopes as Indicators of Ecological Change, T.D. Dawson \& R.T.W. Siegwolf (eds). Amsterdam: Elsevier/Academic Press, 173-190.

Popp, B.N., Trull, T., Kenig, F., Wakeham, S.G., Rust, T.M., Tilbrook, B., Griffiths, B., Wright, S.W., Marchant, H.J., Bidigare, R.R. \& Laws, E.A. 1999. Controls on the carbon isotopic composition of Southern Ocean phytoplankton. Global Biogeochemical Cycles 13, 827-843.

Post, D.M. 2002. Using stable isotopes to estimate trophic position: models, methods, and assumptions. Ecology 83, 703-718.

Post, D.M., Layman, C.A., Albrey Arrington, D., Takimoto, G., Quattrochi, J. \& Montaña, C.G. 2007. Getting to the fat of the matter: models, methods and assumptions for dealing with lipids in stable isotope analysis. Oecologica 152, 179-189.

Quay, P., Sonnerup, R., Westby, T., Stutsman, J. \& McNichol, A. 2003. Changes in the ${ }^{13} \mathrm{C} /{ }^{12} \mathrm{C}$ of dissolved inorganic carbon in the ocean as a tracer of anthropogenic $\mathrm{CO}_{2}$ uptake. Global Biogeochemical Cycles 17, G1004, doi:10.1029/2001GB001817.

Quillfeldt, P., McGill, R.A.R. \& Furness, R.W. 2005. Diet and foraging areas of Southern Ocean seabirds and their prey inferred from stable isotopes: review and case study of Wilson's storm-petrel. Marine Ecology Progress Series 295, 295-304.

Rau, G.H., Karl, D.M. \& Carney, R.S. 1986. Does inorganic carbon assimilation cause ${ }^{14} \mathrm{C}$ depletion in deep-sea organisms? Deep-Sea Research 33, 349-357.

Rau, G.H., Mearns, A.J., Young, D.R., Olson, R.J., Schager, H.A. \& Kaplan, I.R. 1983. Animal ${ }^{13} \mathrm{C} /{ }^{12} \mathrm{C}$ correlates with trophic level in pelagic food webs. Ecology 64, 1314-1318.

Rau, G.H., Ohman, M.D. \& Pierrot-Bults, A. 2003. Linking nitrogen dynamics to climate variability off central California: a 51 year record based on ${ }^{15} \mathrm{~N} /{ }^{14} \mathrm{~N}$ in CalCOFI zooplankton. Deep-Sea Research II 50, 2431-2477.

Rau, G.H., Sweeney, R.E. \& Kaplan, I.R. 1982. Plankton ${ }^{13} \mathrm{C}:{ }^{12} \mathrm{C}$ ratio changes with latitude: differences between northern and southern oceans. Deep-Sea Research 29, 1035-1039.

Reeds, P. 2000. Dispensable and indispensable amino acids for humans. Journal of Nutrition 130, 1835S-1840S. 
Rees, C.E., Jenkins, W.J. \& Monster, J. 1978. The sulphur isotopic composition of ocean water sulphate. Geochimica et Cosmochimica Acta 42,377-381.

Richardson, C.A. 1988. Exogenous and endogenous rhythms of band formation in the shell of the clam Tapes philippinarum (Adams et Reeve, 1850). Journal of Experimental Marine Biology and Ecology 122, $105-126$.

Richoux, N.B. \& Froneman, P.W. 2009. Plankton trophodynamics at the subtropical convergence, Southern Ocean. Journal of Plankton Research 31, 1059-1073.

Riera, P. \& Richard, P. 1997. Temporal variation of $\delta^{13} \mathrm{C}$ in particulate organic matter and oyster Crassostrea gigas in Marennes-Oleron Bay (France): effect of freshwater inflow. Marine Ecology Progress Series 147, 105-115.

Rivera-Duarte, I. \& Flegal, A.R. 1994. Benthic lead fluxes in San Francisco Bay, California, USA. Geochemica et Cosmochimica Acta 58, 3307-3313.

Rodelli, M.R., Gearing, J.N., Gearing, P.J., Marshall, N. \& Sasekumar, A. 1984. Stable isotope ratio as a tracer of mangrove carbon in Malaysian ecosystems. Oecologia 61, 326-333.

Rohling, E.J. \& Rijk, S.D. 1999. Holocene climate optimum and last glacial maximum in the Mediterranean: the marine oxygen isotope record. Marine Geology 153, 57-75.

Rubenstein, D.R. \& Hobson, H.A. 2004. From birds to butterflies: animal movement patterns and stable isotopes. Trends in Ecology and Evolution 19, 256-263.

Sackett, W.M., Eckelmann, W.R., Bender, M.L. \& Be, A.W.H. 1965. Temperature dependence of carbon isotope composition in marine plankton and sediments. Science 148, 235-237.

Saino, T. \& Hattori, A. $1980 .{ }^{15} \mathrm{~N}$ natural abundance in oceanic suspended particulate matter. Nature 283, $752-754$.

Saino, T. \& Hattori, A. 1987. Geographical variation of the water column distribution of suspended particulate organic nitrogen and its ${ }^{15} \mathrm{~N}$ natural abundance in the Pacific and its marginal seas. Deep-Sea Research 34, 807-827.

Sato, T., Sasaki, H. \& Fukuchi, M. 2002. Stable isotopic compositions of overwintering copepods in the Arctic and Subarctic waters and implications to the feeding history. Journal of Marine Systems 38, 165-174.

Schell, D.M., Barnett, B.A. \& Vinette, K.A. 1998. Carbon and nitrogen isotope ratios in zooplankton of the Bering, Chukchi and Beaufort seas. Marine Ecology Progress Series 162, 11-23.

Schell, D.M., Saupe, S.M. \& Haubenstock, N. 1989. Bowhead whale (Balaena mysticetus) growth and feeding as estimated by $\delta^{13} \mathrm{C}$ techniques. Marine Biology 103, 433-443.

Schlitzer, R. 2002. Interactive analysis and visualization of geoscience data with Ocean Data View. Computers and Geosciences 28, 1211-1218.

Schlitzer, R. 2011. Ocean Data View. Paris: Alfred-Wegener-Institute for Polar and Marine Research. Online. http://odv.awi.de (accessed 1 August 2012).

Schmidt, K., Atkinson, A., Stubing, D., McClelland, J.W., Montoya, J.P. \& Voss, M. 2003. Trophic relationships among Southern Ocean copepods and krill: some uses and limitation of a stable isotope approach. Limnology and Oceanography 48, 277-289.

Schmidt, G.A., Bigg, G.R. \& Rohling, E.J. 1999. Global Seawater Oxygen-18 Database-v1.21. New York: National Aeronautics and Space Administration. Online. http://data.giss.nasa.gov/o18data (accessed 1 August 2012).

Schmidt, K., McClelland, J.W., Mente, E., Montoya, J.P., Atkinson, A. \& Voss, M. 2004. Trophic-level interpretation based on $\delta^{15} \mathrm{~N}$ values: implications of tissue-specific fractionation and amino acid composition. Marine Ecology Progress Series 266, 43-58.

Schmittner, A., Oschlies, A., Matthews, H.D. \& Galbraith, E.D. 2008 Future changes in climate, ocean circulation, ecosystems, and biogeochemical cycling simulated for a business-as-usual $\mathrm{CO}_{2}$ emission scenario until year 4000 AD. Global Biogeochemical Cycles 22, GB1013.

Schwarcz, H.P. 1991. Some theoretical aspects of isotope paleodiet studies. Journal of Archaeological Science 18, 261-275.

Schwarcz, H.P. \& Schoeninger, M.J. 1991. Stable isotope analyses in human nutritional ecology. American Journal of Physical Anthropology 34, 283-321.

Scott, J.H., O’Brien, D.M., Emerson, D., Sun, H., McDonald, G.D., Salgado, A. \& Fogel, M.L. 2006. An examination of the carbon isotope effects associated with amino acid biosynthesis. Astrobiology 6, 867-880.

Sessions, A.L. 2006. Isotope-ratio detection for gas chromatography. Journal of Separation Science 29, 1946-1961. 
Sessions, A.L., Sylva, S.P. \& Hayes, J.M. 2005. Moving-wire device for carbon isotopic analyses of nanogram quantities of nonvolatile organic carbon. Analytical Chemistry 77, 6519-6527.

Shadsky, I.P., Romankevich, E.A. \& Grinchenko, Y.I. 1982. Isotopic composition of carbon in lipids from suspended matter and bottom sediments east of the Kuril Islands. Oceanology 22, 301-304.

Shen, G.T. \& Boyle, E.A. 1987. Lead in corals: reconstruction of historical industrial fluxes to the surface ocean. Earth and Planetary Science Letters 82, 289-304.

Shen, G.T. \& Stanford, C.L. 1990. Trace element indicators of climate change in annually-banded corals. In Global Consequences of the 1982-83 El Nino, P.W. Glynn (ed.). New York: Elsevier, 255-283.

Sherwood, O.A., Lehmann, M.F., Schubert, C.J., Scott, D.B. \& McCarthy, M.D. 2011. Nutrient regime shift in the western North Atlantic indicated by compound-specific $\delta^{15} \mathrm{~N}$ of deep-sea gorgonian corals. Proceedings of the National Academy of Sciences USA 108, 1011-1015.

Sholto-Douglas, A.D., Field, J.G. \& James, A.G. $1991 .{ }^{13} \mathrm{C} /{ }^{12} \mathrm{C}$ and ${ }^{15} \mathrm{~N} /{ }^{14} \mathrm{~N}$ isotope ratios in the Southern Benguela ecosystem: indicators of food web relationships among different size-classes of plankton and pelagic fish; differences between fish muscle and bone collagen tissues. Marine Ecology Progress Series 78, 23-31.

Siegenthaler, U. 1989. Carbon-14 in the oceans. In Handbook of Environmental Isotope Geochemistry, P. Fritz \& J.C. Fontes (eds). New York: Elsevier, 3, 75-137.

Sigman, D.M., Altabet, M.A., McCorkle, D.C., Francois, R. \& Fisher, G. 1999. The $\delta^{15} \mathrm{~N}$ of nitrate in the Southern Ocean: consumption of nitrate in surface waters. Global Biogeochemical Cycles 113, $1149-1166$.

Simenstad, C.A. \& Wissmar, R.C. 1985. $\delta^{13} \mathrm{C}$ evidence of the origins and fates of organic carbon in estuarine and nearshore food webs. Marine Ecology Progress Series 22, 141-152.

Smith, S.L., Hendrichs, S.M. \& Rho, T. 2002. Stable C and N isotopic composition of sinking particles and zooplankton over the southeastern Bering Sea shelf. Deep-Sea Research 49, 6031-6050.

Solomon, C.T., Cole, J.J., Doucett, R.R., Pace, M.L., Preston, N.D., Smith, L.E. \& Weidel, B.C. 2009. The influence of environmental water on the hydrogen stable isotope ration in aquatic consumers. Oecologia 161, 313-324.

Somes, C.J., Schmittner, A., Galbraith, E.D., Lehmann, M.F., Altabet, M.A., Montoya, J.P., Letelier, R.M., Mix, A.C., Bourbonnais, A. \& Eby, M. 2010. Simulating the global distribution of nitrogen isotopes in the ocean. Global Biogeochemical Cycles 24, GB4019.

Sommer, F., Saage, A., Santer, B., Hansen, T. \& Sommer, U. 2005. Linking foraging strategies of marine calanoid copepods to patterns of nitrogen stable isotope signatures in a mesocosm study. Marine Ecology Progress Series 286, 99-106.

Sonntag, C., Münnich, K.O., Jacob, H. \& Rozanski, K. 1983. Variations of deuterium and oxygen-18 in continental precipitation and groundwater, and their causes. In Variations in the Global Water Budget, A. Street-Perrott \& A. Beran (eds). Amsterdam: Reidel,107-124.

Sotiropoulos, M.A., Tonn, W.M., Wassenaar, L.I. 2004. Effects of lipid extraction on stable carbon and nitrogen isotope analyses of fish tissues: potential consequences for food web studies. Ecology of Freshwater Fish 13, 155-160.

Sternberg, L.S.L. 1988. D/H ratios of environmental water recorded by D/H ratios of plant lipids. Nature 333, 59-61.

Stott, A.W., Evershed, R.P. \& Tuross, N. 1997. Compound-specific approach to the $\delta^{13} \mathrm{C}$ analysis of cholesterol in fossil bones. Organic Geochemistry 26, 99-103.

Stowasser, G., Atkinson, A., McGill, R.A.R., Phillips, R.A., Collins, M.A. \& Pond, D.W. 2012. Food web dynamics in the Scotia Sea in summer: a stable isotope study. Deep-Sea Research II 59-60, 208-221.

Stuck, U., Emeis, K-C., Vob, M., Krom, M.D. \& Rau, G.H. 2001. Biological productivity during sapropel S5 formation in the eastern Mediterranean Sea: evidence from stable isotopes of nitrogen and carbon. Geochimica et Cosmochimica Acta 65, 3249-3266.

Stuiver, M., Ostlund, H.G. \& McConnaughey, T.A. 1981. GEOSECS Atlantic and Pacific ${ }^{14} \mathrm{C}$ distribution. In Carbon Cycle Modeling, B. Bolin (ed.). New York: Wiley, 201-222.

Suess, H.E. 1955. Radiocarbon concentration in modern wood. Science 122, 415-417.

Sunda, W.G. \& Huntsman, S.A. 1988. Effects of sunlight on redox cycles of manganese in the southwestern Sargasso Sea. Deep-Sea Research 35, 1297-1317.

Surge, D.M. \& Lohmann, K.C. 2002. Temporal and spatial differences in salinity and water chemistry in SW Florida estuaries: effects of human-impacted watersheds. Estuaries 25, 393-408. 
Swart, P.K., Thorrold, S., Rosenheim, B., Eisenhauer, A., Harrison, C.G.A., Grammer, M. \& Latkoczy, C. 2002. Intra-annual variation in stable oxygen and carbon and trace element composition in sclerosponges. Paleoceanography 17,1045, doi:10.1029/2000PA000622.

Sweeting, C.J., Polunin, N.V.C. \& Jennings, S. 2006. Effects of chemical lipid extraction and arithmetic lipid correction on stable isotope ratios of fish tissues. Rapid Communications in Mass Spectrometry 20, $595-601$.

Sydeman, W.J., Hobson, K.A., Pyle, P. \& McLaren, E.B. 1997. Trophic relationships among seabirds in central California: combined stable isotope and conventional dietary approach. The Condor 99, 327-336.

Tamelander, T., Renaud, P.E., Hop, H., Carroll, M.L., Ambrose, W.G. \& Hobson, K.A. 2006. Trophic relationships and pelagic-benthic coupling during summer in the Barents Sea Marginal Ice Zone, revealed by stable carbon and nitrogen isotope measurements. Marine Ecology Progress Series 310, 33-46.

Tanner, S.E., Reis-Santos, P., Vasconcelos, R.P., Fonseca, V., Franca, S., Cabral, H.N. \& Thorrold, S.R. 2013. Does otolith geochemistry record ambient environmental conditions in a temperate tidal estuary? Journal of Experimental Marine Biology and Ecology 441, 7-15.

Tanz, N. \& Schmidt, H.L. 2010. $\delta^{34}$ S value measurements in food origin assignments and sulphur isotope fractionations in plants and animals. Journal of Agricultural Food Chemistry 58, 3139-3146.

Tarroux, A., Ehrich, D., Lecomte, N., Jardine, T.D., Bety, J. \& Berteaux, D. 2010. Sensitivity of stable isotope mixing models to variation in isotopic ratios: evaluating consequences of lipid extraction. Methods in Ecology and Evolution 1, 231-241.

Thayer, G.W., Govoni, J.J. \& Connally, D.W. 1983. Stable carbon isotope ratios of the planktonic food web in the northern Gulf of Mexico. Bulletin of Marine Science 33, 247-256.

Thode, H.G., Monster, J. \& Dunford, H.B. 1961. Sulphur isotope geochemistry. Geochimica et Cosmochimica Acta 25, 150-174.

Thorrold, S.R., Campana, S.E., Jones, C.M. \& Swart, P.K. 1997. Factors determining $\delta^{13} \mathrm{C}$ and $\delta^{18} \mathrm{O}$ fractionation in aragonitic otoliths of marine fish. Geochimica et Cosmochimica Acta 61, 2909-2919.

Thorrold, S.R., Jones, G.P., Hellberg, M.E., Burton, R.S., Swearer, S.E., Niegel, J.E., Morgan, S.G. \& Warner, R.R. 2002. Quantifying larval retention and connectivity in marine populations with artificial and natural markers. Bulletin of Marine Science 70, 291-308.

Thorrold, S.R. \& Swearer, S.E. 2009. Otolith chemistry. In Tropical Fish Otoliths: Information for Assessment, Management and Ecology, B.S. Green et al. (eds). Berlin: Springer, 249-295.

Tieszen, L.L., Boutton, T.W., Tesdahl, K.G. \& Slade, N.A. 1983. Fractionation and turnover of stable carbon isotopes in animal tissues: implications for $\delta^{13} \mathrm{C}$ analysis of diet. Oecologia 57, 32-37.

Tillett, B.J., Meekan, M.G., Parry, D., Munksgaard, M., Field, I.C., Thorburn, D. \& Bradshaw, C.J.A. 2011. Decoding fingerprints: elemental composition of vertebrae correlates to age-related habitat use in two morphologically similar sharks. Marine Ecology Progress Series 434, 133-142.

Tittlemier, S.A., Risk, A.T., Hobson, K.A. \& Norstrom, R.J. 2000. Examination of the bioaccumulation of halogenated dimethyl bipyrroles in an Arctic marine food web using stable nitrogen isotope analysis. Environmental Pollution 116, 85-93.

Uhle, M.E., Macko, S.A., Spero, S.A., Engel, M.H. \& Lea, D.W. 1997. Sources of carbon and nitrogen in modern plankton Foraminifera: the role of algal symbionts as determined by bulk and compound specific stable isotope analysis. Organic Geochemistry. 27, 103-113.

Urey, H.C. 1947. The thermodynamic properties of isotopic substances. Journal of the Chemical Society of London 1947, 562-581.

Vanderklift, M.A. \& Ponsard, S. 2003. Sources of variation in consumer-diet $\delta^{15} \mathrm{~N}$ enrichment: a meta-analysis. Oecologia 136, 169-182.

Vander Zanden, M.J. \& Rasmussen, J.B. 2001. Trophic fractionation: implications for aquatic food web studies. Limnology and Oceanography 46, 2061-2066.

van Woesik, R., Tomascik, T. \& Blake, S. 1999. Coral assemblages and physico-chemical characteristics of the Whisunday Islands: evidence of recent community change. Marine and Freshwater Research 50, $427-440$.

Villinski, J.C., Dunbar, R.B. \& Mucciarone, D.A. 2000. Carbon ${ }^{12} / \operatorname{Carbon}^{13}$ ratios of sedimentary organic matter from the Ross Sea, Antarctica: a record of phytoplankton bloom dynamics. Journal of Geophysical Research 105, 14163-14172. 


\section{OCEAN ECOGEOCHEMISTRY: A REVIEW}

Vizzini, S. \& Mazzola, A. 2003. Seasonal variations in the stable carbon and nitrogen isotope ratios. ${ }^{13} \mathrm{C} /{ }^{12} \mathrm{C}$ and ${ }^{15} \mathrm{~N} /{ }^{14} \mathrm{~N}$ of primary producers and consumers in a western Mediterranean coastal lagoon. Marine Biology 142, 1009-1018.

Wada, E. \& Hattori, A. 1976. Natural abundance of ${ }^{15} \mathrm{~N}$ in particulate organic matter in the North Pacific Ocean. Geochimica et Cosmochimica Acta 40, 249-251.

Wada, E., Terazaki, M., Kabaya, Y. \& Nemoto, T. 1987. ${ }^{15} \mathrm{~N}$ and ${ }^{13} \mathrm{C}$ abundances in the Antarctic Ocean with emphasis on the biogeochemical structure of the food web. Deep-Sea Research A 34, 829-841.

Wakabayashi, Y., Yamada, E., Yoshida, T. \& Takahashi, H. 1994. Arginine becomes an essential amino acid after massive resection of rat small intestine. Journal of Biological Chemistry 269, 32667-32671.

Walther, B.D. \& Limburg, K. 2012. The use of otolith chemistry to characterize diadromous migrations. Journal of Fish Biology 81, 796-825.

Warnken, K.W., Gill, G.A., Griffin, L.L. \& Santschi, P.H. 2001. Sediment-water exchange of Mn, Fe, Ni and $\mathrm{Zn}$ in Galveston Bay, Texas. Marine Chemistry 73, 215-231.

Waser, N.A.D., Harrison, W.G., Head, E.J.H., Nielsen, B., Lutz, V.A. \& Calvert, S.E. 2000. Geographic variations in the nitrogen isotope composition of surface particulate nitrogen and new nitrogen production across the North Atlantic Ocean. Deep-Sea Research I 27, 1207-1226.

Watabe, N., Tanaka, K., Yamada, J. \& Dean, J.M. 1982. Scanning electron microscope observations of the organic matrix in the otolith of the teleost fish Fundulus heteroclitus (Linnaeus) and Tilapia nilotica (Linnaeus). Journal of Experimental Marine Biology and Ecology 58, 127-134.

Weidman, C.R. \& Jones, G.A. 1993. A shell-derived time history of bomb ${ }^{14} \mathrm{C}$ on Georges Bank and its Labrador Sea implications. Journal of Geophysical Research 98, 14577-14588.

Weiss, R.F. 1974. Carbon dioxide in water and seawater: the solubility of a non-ideal gas. Marine Chemistry 2, 203-215.

Werstiuk, N.H. \& Ju, C. 1989. Protium-deuterium exchange of benzo-substituted heterocycles in neutral $\mathrm{D}_{2} \mathrm{O}$ at elevated temperatures. Canadian Journal of Chemistry 67, 812-815.

West, J., Bowen, G.J., Dawson, T.E. \& Tu, K.P. 2010. Isoscapes: Understanding Movement, Pattern and Process on Earth Through Isotope Mapping. New York: Springer-Verlag.

White, J.W.C. 1989. Stable hydrogen isotope ratios in planes: a review of current theory and some potential applications. In Stable Isotopes in Ecological Research, P.W. Rundel (ed.). New York: Springer-Verlag, $142-162$.

Wu, J., Calvert, S.E., Wong, C.S. \& Whitney, F.A. 1999. Carbon and nitrogen isotopic composition of sedimenting particulate material at Station Papa in the subarctic northeast Pacific. Deep-Sea Research II 46, 2793-2832.

Wyatt, A.S.J. 2011. Oceanographic ecology of coral reefs: the role of oceanographic processes in reef-level biogeochmistry and trophic ecology. $\mathrm{PhD}$ thesis, Oceans Institute and School of Environmental Systems, University of Western Australia, Perth.

Yamamuro, M., Kayanne, H. \& Minagawa, M. 1995. Carbon and nitrogen stable isotopes of primary producers in coral reef ecosystems. Limnology and Oceanography 40, 617-621.

Zacherl, D.C., Manríquez, P.H., Paradis, G., Day, R.W., Castilla, J.C., Warner, R.R., Lea, D.W. \& Gaines, S.G. 2003a. Trace elemental fingerprinting of gastropod statoliths to study larval dispersal trajectories. Marine Ecology Progress Series 248, 297-303.

Zacherl, D.C., Paradis, G. \& Lea, D.W. 2003b. Barium and strontium uptake in larval protoconch and statolith of the marine neogastropod Kelletia kelletii. Geochimica et Cosmochimica Acta 67, 4091-4099.

Zeebe, R.E. \& Wolf-Gladrow, D.A. 2001. $\mathrm{CO}_{2}$ in Seawater: Equilibrium, Kinetics, Isotopes. Amsterdam: Elsevier.

Zhang, J., Quay, P.D. \& Wilbur, D.O. 1995. Carbon isotope fractionation during gas-water exchange and dissolution of $\mathrm{CO}_{2}$. Geochimica et Cosmochimica Acta 59, 107-114. 



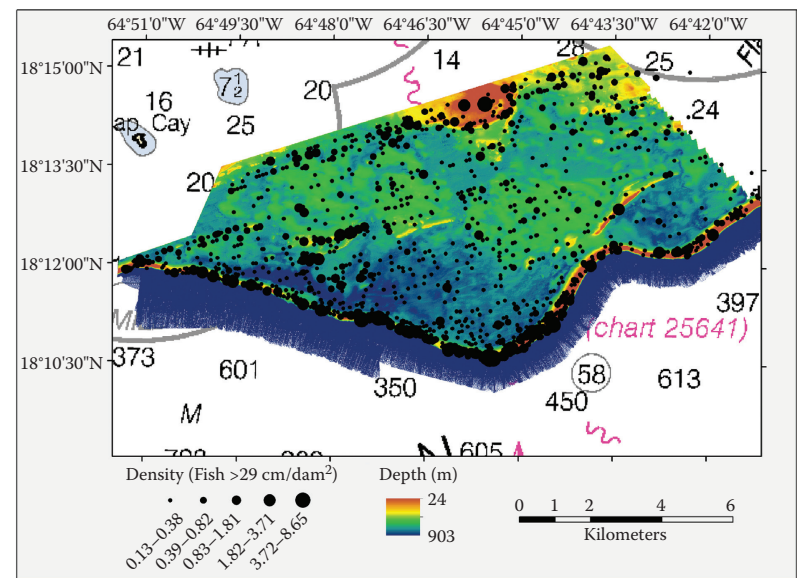

Colour Figure 10 (Kobara, Heyman, Pittman \& Nemeth)

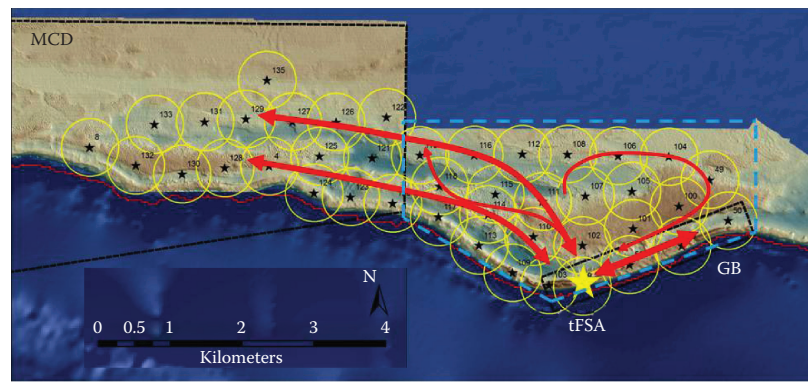

Colour Figure 11 (Kobara, Heyman, Pittman \& Nemeth)

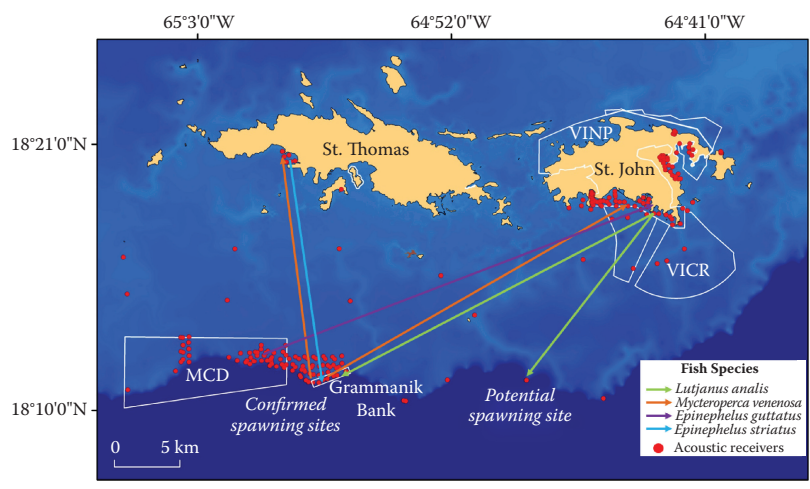

Colour Figure 12 (Kobara, Heyman, Pittman \& Nemeth)

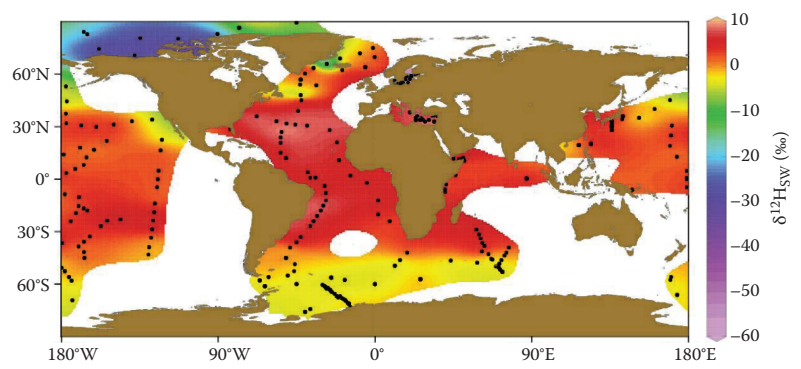

Colour Figure 1 (McMahon, Hamady \& Thorrold) 


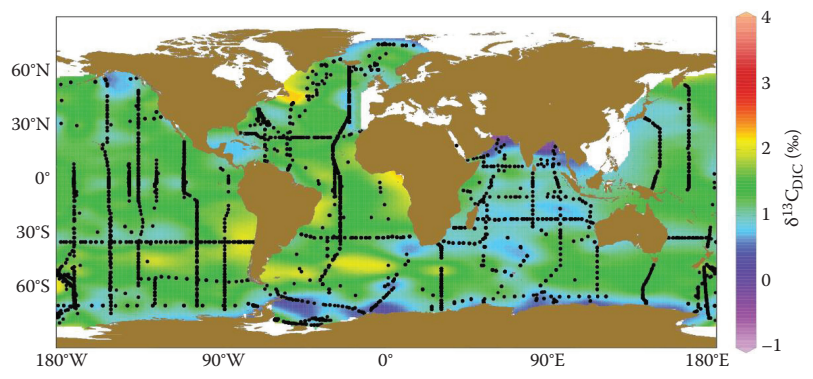

Colour Figure 2 (McMahon, Hamady \& Thorrold)

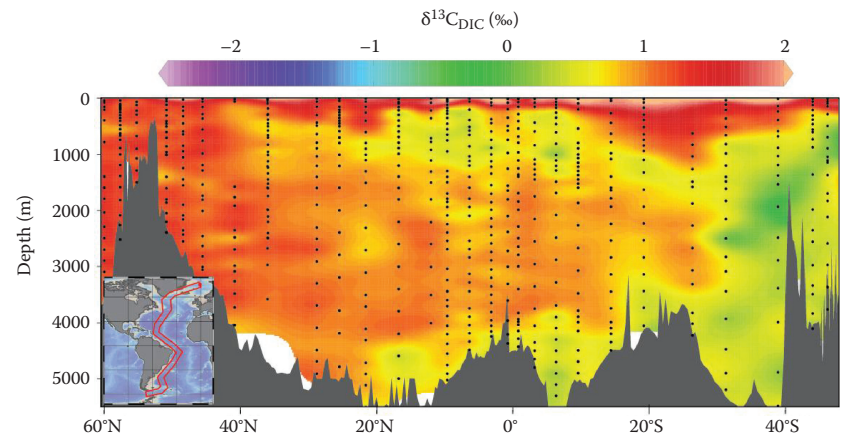

(A)

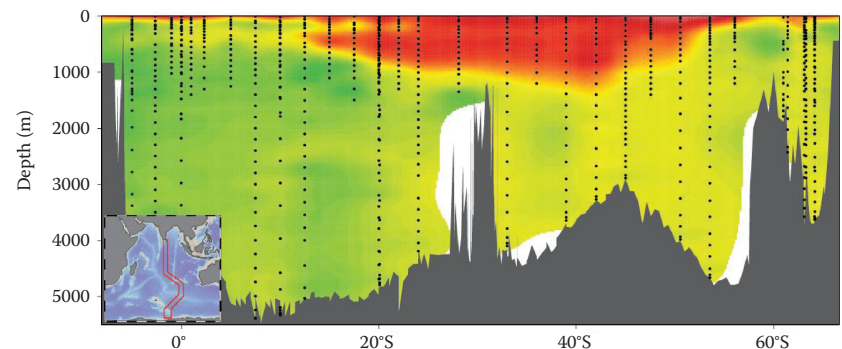

(B)

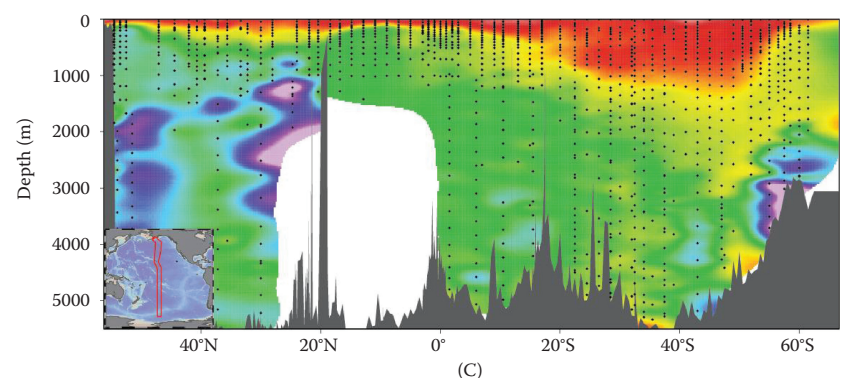

Colour Figure 3 (McMahon, Hamady \& Thorrold)

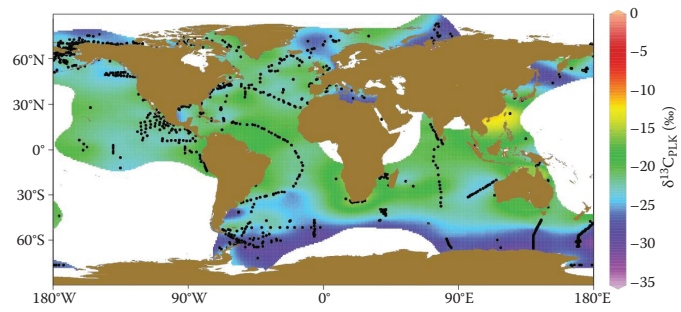

Colour Figure 4 (McMahon, Hamady \& Thorrold) 


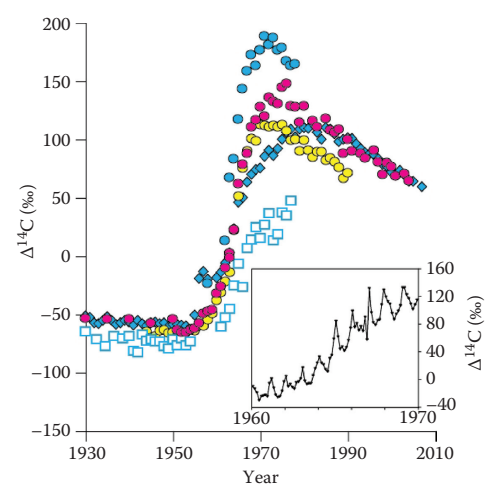

Colour Figure 5 (McMahon, Hamady \& Thorrold)
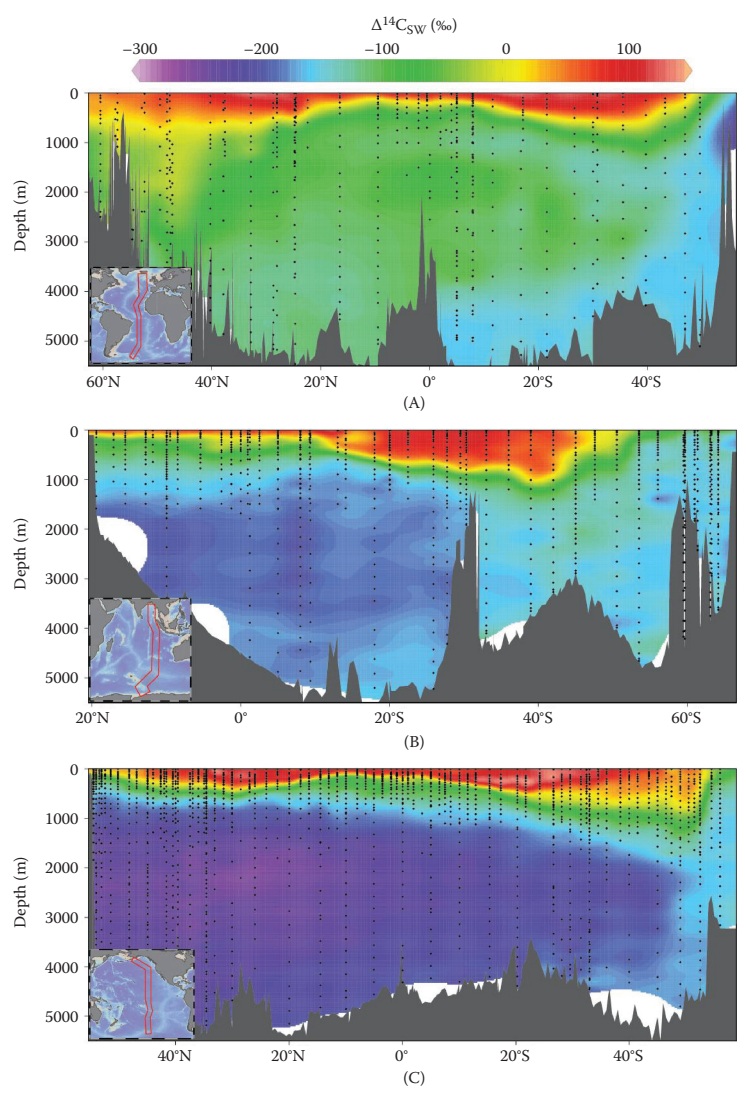

Colour Figure 6 (McMahon, Hamady \& Thorrold)

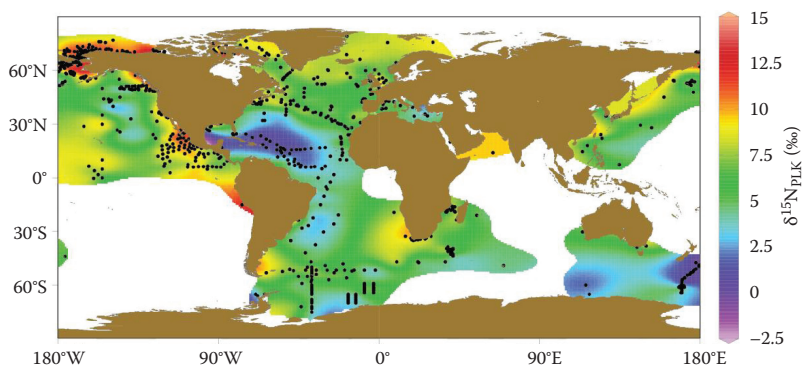

Colour Figure 7 (McMahon, Hamady \& Thorrold) 


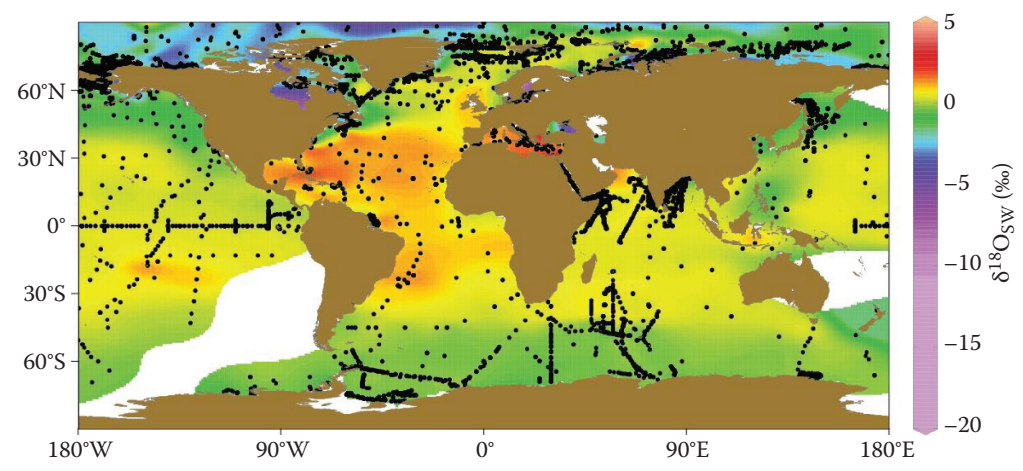

Colour Figure 8 (McMahon, Hamady \& Thorrold)

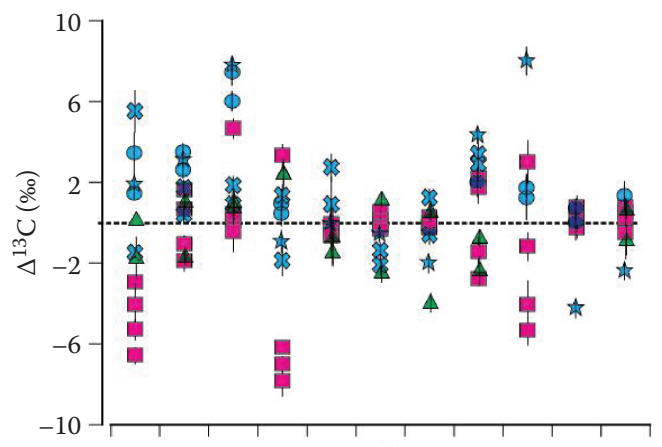

(A)

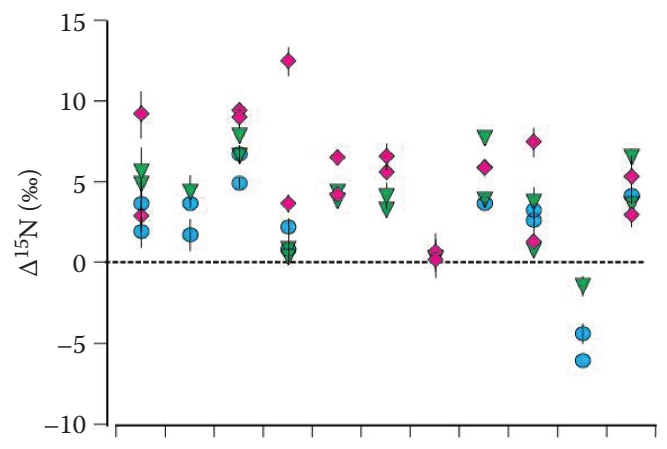

(B)

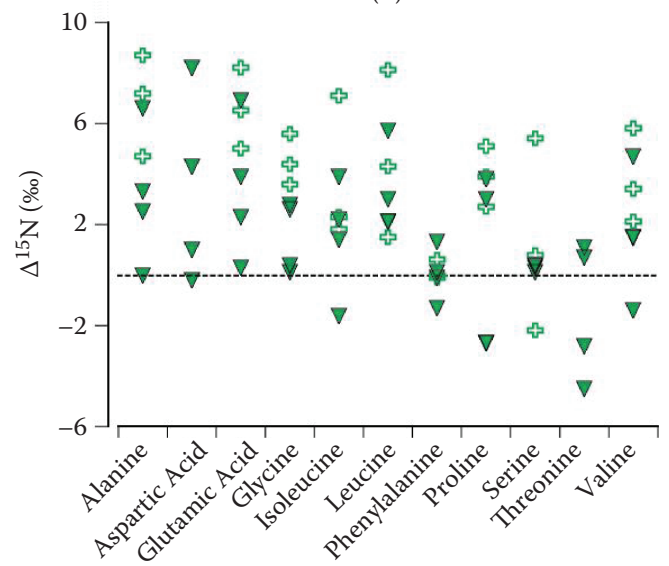

(C) 


\title{
APPENDIX THREE
}

Validated age and growth estimates for Carcharhinus obscurus in the northwestern Atlantic Ocean, with pre- and post management growth comparisons

\author{
Lisa J. Natanson \\ Brian J. Gervelis \\ USDOC/NOAA/NMFS, Narragansett, RI, USA \\ Megan V. Winton \\ USDOC/NOAA/NMFS \\ Woods Hole, MA, USA
}

Li Ling Hamady

Massachusetts Institute of Technology/Woods Hole Oceanographic Institution Joint Program in Oceanography/Applied Ocean Science and Engineering, Woods Hole, MA, USA

\author{
Simon J.B. Gulak and John K. Carlson \\ USDOC/NOAA/NMFS \\ Panama City, FL, USA
}

Reprinted with permission from Environmental Biology of Fishes @2013 Springer Science

Natanson LJ, BJ Gervelis, MV Winton, LL Hamady, SJB Gulak, JK Carlson (2013) Validated age \& growth estimates for Carcharhinus obscurus in the northwestern Atlantic Ocean, with pre$\&$ post management growth comparisons. Environmental Biology of Fishes

DOI 10.1007/s10641-013-0189-4 


\title{
Validated age and growth estimates for Carcharhinus obscurus in the northwestern Atlantic Ocean, with pre- and post management growth comparisons
}

\author{
Lisa J. Natanson • Brian J. Gervelis • Megan V. Winton • \\ Li Ling Hamady • Simon J. B. Gulak • John K. Carlson
}

Received: 9 April 2013 / Accepted: 23 September 2013

(C) Springer Science+Business Media Dordrecht (outside the USA) 2013

\begin{abstract}
Age and growth estimates for the dusky shark, Carcharhinus obscurus, were derived from vertebral centra collected in the northwestern Atlantic Ocean. Sample collection spanned the years prior to and following the implementation of management measures (19632010). Growth was compared pre- and post- population depletion and pre- and post- management to investigate the possibility of density-mediated shifts in age and growth parameters over time. There was no evidence of difference between periods for either sex. Additionally, bomb radiocarbon dating was used to determine the periodicity of band pair formation. Results support the traditional interpretation of annual band pairs up to approximately 11 years of age. After this time, vertebral counts considerably underestimate true age. Maximum validated ages were estimated to be between 38 and 42 years of age (an increase of 15 to 19 years over the
\end{abstract}

L. J. Natanson $(\bowtie) \cdot$ B. J. Gervelis

USDOC/NOAA/NMFS,

28 Tarzwell Dr., Narragansett, RI 02882, USA

e-mail: Lisa.Natanson@noaa.gov

M. V. Winton

USDOC/NOAA/NMFS,

166 Water St., Woods Hole, MA 02543, USA

L. L. Hamady

Woods Hole Oceanographic Institution,

Marine Research Facility 235, MS\#50, Woods Hole, MA

02543, USA

S. J. B. Gulak · J. K. Carlson

USDOC/NOAA/NMFS,

3500 Delwood Beach Road, Panama City, FL 32408, USA band count estimates), confirming longevity to at least 42 years of age. Growth curves estimated using only validated data were compared to those generated using band pair counts. Logistic growth parameters derived from validated vertebral length-at-age data were $L_{\infty}=$ $261.5 \mathrm{~cm} \mathrm{FL}, L_{o}=85.5 \mathrm{~cm}, t_{o}=4.89$ year and $\mathrm{g}=$ 0.15 year $^{-1}$ for the sexes combined. Revised estimates of age at maturity were 17.4 years for males and 17.6 years for females.

Keywords Dusky shark - Age and growth . Elasmobranch . Vertebrae $\cdot$ Bomb radiocarbon . Validation

\section{Introduction}

Density-dependent responses to population reduction in elasmobranchs are poorly understood (Walker 1998; Gedamke et al. 2005; Cortés 2007), although they potentially play an important role in a population's ability to sustain or recover from fishing mortality. Empirical data documenting such density-mediated shifts in age, growth and maturity in elasmobranchs are generally limited; to date, evidence of compensatory growth has been reported in two members of the United States (U.S.) coastal shark complex. Growth reportedly increased in both juvenile sandbar sharks, Carcharhinus plumbeus, in the northwest Atlantic (Sminkey and Musick 1995) and Atlantic sharpnose sharks, Rhizoprionodon terraenovae, in the Gulf of Mexico (GOM; Carlson and Baremore 2003) following fishery-induced decreases in abundance. 
The dusky shark is a common coastal pelagic carcharhinid that is widely distributed in the world's oceans (Compagno 1984) and considered a single, genetic stock in the northwest Atlantic and GOM (Benavides et al. 2011). It is considered one of the most vulnerable species to overexploitation due to its combination of slow growth, late age at maturity (19-21 years), small litter sizes (3-12 embryos), and tri-annual gestation (Natanson et al. 1995; Romine et al. 2009).

Along the eastern coast of the U.S., directed fisheries for large coastal sharks emerged in the 1970s and increased through the 1980s due to greater demand for shark products worldwide (NMFS 2011). Management was initiated for Atlantic and GOM sharks, including the dusky shark, in the Fishery Management Plan developed by National Marine Fisheries Service (NMFS) in 1993. Multiple stock assessments depict a decline in the northwest Atlantic and GOM dusky shark populations to as little as $15-20 \%$ of their mid1970s abundance by the late 1990s (Cortés et al. 2006; NMFS 2011). In response to such severe declines, dusky sharks were listed as a prohibited species in 2000 in both the northwest Atlantic and GOM (NMFS 1999). Additionally, a time/area closure was implemented off North Carolina in 2005 to help reduce the impact of fishing on an area where juvenile dusky sharks are known to congregate (NMFS 2003). Given the decline in abundance, dusky sharks in the northwest Atlantic may have experienced lower levels of intra-specific competition in the years following the peak of fishing activity, which may translate to changes in life history parameters over time.

Age and growth estimates were reported for dusky sharks in the northwest Atlantic during the period prior to management (Natanson et al. 1995). The observed maximum age for the species was 33 years; age at maturity for males and females was estimated at 19 and 21 years, respectively. While band pair deposition in the previous study was assumed to be annual, age estimates were not validated. Annual deposition of countable growth increments cannot be assumed through the complete lifespan because band pair deposition may stop or become irresolvable when somatic growth slows or ceases (Kalish and Johnston 2001; Francis et al. 2007; Andrews et al. 2011; Hamady et al., Bomb Radiocarbon Confirmation of Extreme Longevity in White Sharks (in review)). Such species can reach ages far older than that estimated by band pairs in vertebral centra. In recent studies where annual deposition has been validated in smaller specimens, longevities based on band pair counts have proven to be underestimates when validation is achieved over the entire size range (Andrews et al. 2011; Hamady et al., Bomb Radiocarbon Confirmation of Extreme Longevity in White Sharks (in review)).

The objectives of this study were to update age and growth parameter estimates for the dusky shark in the northwest Atlantic. Specifically, we investigate if any changes in growth have occurred over time due to potential density dependent effects. We also validate growth band deposition using bomb radiocarbon dating techniques.

\section{Materials and methods}

Vertebral preparation and interpretation

Vertebrae were obtained from dusky sharks caught using longline, trawl, and rod and reel gear on research cruises, commercial and recreational fishing vessels, and at sport fishing tournaments along the northeast coast of the U.S. between Florida and Cape Cod, Massachusetts, from 1963 to 2010. When possible, the $15^{\text {th }}$ through $20^{\text {th }}$ vertebrae were excised. If such precision was not possible, this section of backbone was approximated as the branchial region adjacent to the fifth gill arch. Vertebrae were cleaned and stored frozen or preserved in either $10 \%$ buffered formalin or $70 \%$ ethanol.

Only samples that had measured fork length (FL-tip of the snout to the fork in the tail, over the body) or total length (TL-tip of the snout to a point on the horizontal axis intersecting a perpendicular line extending downward from the tip of the upper caudal lobe to form a right angle) were used. All lengths reported are in FL $(\mathrm{cm})$ unless otherwise noted. For specimens with only a recorded TL, FL was estimated using the regression equation reported by Kohler et al. (1995):

$\mathrm{FL}=(0.8396 \times \mathrm{TL})-3.1902$

One or two whole vertebra from each sample obtained since the previous study were processed for histology as per Natanson et al. (1995). The resulting sections were digitally photographed with an MTI 
CCD 72 video camera ${ }^{1}$ attached to a SZX9 Olympus stereomicroscope using reflected light. Band pairs (consisting of one opaque and one translucent band) were counted and measured using Image Pro 4 software (Media Cybernetics) following the criteria from Natanson et al. (1995). The first opaque band distal to the focus was defined as the birth mark (the birth band radius; BR). A slight angle change in the corpus calcareum coincided with this mark. Measurements were made from the midpoint of the notochordal remnant to the BR and each opaque growth band along the internal corpus calcareum. The vertebral radius (VR) of each centrum was measured to the distal margin of the intermedialia along the same diagonal as band measurements. Samples used in Natanson et al. (1995) were not reprocessed, and the original age estimates were used; however, the BR and VR were remeasured as described above to provide consistency with the current digital analysis system. The identity of the birth band was confirmed by comparing BR values with the VR from young of the year (YOY) and full term embryos (Natanson et al. 2002).

The relationship between VR and FL was derived to determine the best method for back-calculation of size at birth to ensure the proper identification of the birth band. Initial scatterplots of VR and FL indicated a nonlinear relationship; therefore, a linear regression was fitted to log-transformed VR and FL data. Sex was included as a factor; an interaction term was also included to determine whether the slope of the relationship differed between sexes (Zuur et al. 2009). The regression model that best-fit the data was identified from all possible model subsets as the model containing only significant terms $(p<0.05)$ with the smallest second-order Akaike Information Criterion value $\left(\mathrm{AIC}_{\mathrm{c}}\right.$; Burnham and Anderson 2002).

The line did not pass through the origin so we used the Fraser-Lee equation modified for log-transformed data (Natanson et al. 2002) to back-calculate size-atbirth as:

$\ln \left(F L_{a}\right)=b+\ln \left(F L_{c}-b\right) \frac{\ln \left(V R_{a}\right)}{\ln \left(V R_{c}\right)}$,

where $a$ is age; $b$ is the intercept from the FL-VR regression; and $c$ is the age at capture. This and all

\footnotetext{
${ }^{1}$ Reference to Trade Names does not imply endorsement by NMFS.
}

subsequent analyses were conducted in $\mathrm{R}$ ( $\mathrm{R}$ Core Team 2012).

Age determination

Two readers (LJN, BJG) counted sections that were previously assigned ages by Natanson et al. (1995) to ensure consistency of band pair interpretation between studies. Once criteria had been established via intercalibration, each reader independently aged the majority of the samples twice. An additional 30 vertebrae were aged by only the primary reader ( $\mathrm{LJN})$ due to the lack of availability of the second reader. Quality control was maintained by the readers recounting earlier samples prior to initiating each reading and crosschecking the readings.

The consistency of age estimates between ageing rounds and readers was assessed using age bias plots and chi-square tests of symmetry (McNemar 1947; Bowker 1948; Campana et al. 1995; Hoenig et al. 1995; Evans and Hoenig 1998). To resolve discrepancies between readers greater than 2 years, a consensus was reached by reading the centra together. When counts disagreed by only 1 year, the primary reader's age estimates were used.

Bomb radiocarbon validation

Vertebrae from eight individuals were selected based on date of capture, size, and estimated age. Each vertebra was cut transversely through the focus using an Isomet ${ }^{\circledR}$ low speed saw (Buehler, Lake Bluff, IL, USA) equipped with diamond wafering blades which removed a $\sim 4 \mathrm{~mm}$ thick vertebral section. Sections were measured from the central focus to the outer margin and samples were cut along measured increments using a razor blade. Dusky shark vertebrae possess fine banding, making it problematic to extract enough material from individual band pairs in the corpus calcareum for $\Delta^{14} \mathrm{C}$ analysis. Therefore, a single sample consisted of several band pairs encompassing both material from the corpus calcareum and the intermedialia. To verify the location of the samples we compared the measured locations of the samples to measurements from photographs annotated with the band pair counts and then aligned the measured samples with their respective band pairs. 
Band pairs were initially assumed to be annual, and average age was assigned to sample sections based on calculation from catch date. Collagen extraction from vertebral samples was conducted following Tuross et al. (1988). For each sample, approximately $0.5 \mathrm{~g}$ of tissue was soaked overnight in a 3:1 chloroform methanol solution to remove lipids; it was then demineralized at room temperature in EDTA ( $\mathrm{pH}$ 8) for 7-20 days until the sample was soft. Following demineralization, samples were rinsed 10 times in Milli-Q water (with at least one overnight soak), dissolved in Milli-Q water at $110^{\circ} \mathrm{C}$, and filtered through muffled fritted glass filters. The filtrate was frozen and lypholized before the purified collagen was weighed prior to analysis by Accelerator Mass Spectrometry.

The samples for $\delta^{13} \mathrm{C}$ and $\Delta{ }^{14} \mathrm{C}$, with $\Delta{ }^{14} \mathrm{C}$ calculated as per Stuiver and Polach (1977) were analyzed at the National Ocean Sciences Accelerator Mass Spectrometry Facility at the Woods Hole Oceanographic Institution. The resulting dusky shark radiocarbon chronologies were compared to the $\Delta^{14} \mathrm{C}$ signal in the Atlantic as recorded by two reference chronologies, one from coral in Bermuda (Druffel 1989), and one from fish otoliths in the northwest Atlantic (Campana et al. 2008). Where reference chronologies and vertebral data differed, vertebral data were shifted back until they aligned with the reference data (Francis et al. 2007; Andrews et al. 2011). This was necessary for two specimens (DS51 and DS81).

\section{Growth curve estimation}

Length-at-age estimates based upon observed band pair counts were fitted using the Schnute (1981) growth model. The general model requires the specification of two reference ages, $t_{1}$ and $t_{2}$, and has the following four parameters:

\section{$L_{1} \quad$ length at age $t_{1}$,}

$L_{2}$ length at age $t_{2}$,

a a constant $\left(\right.$ time $^{-1}$ ) describing the constant relative rate of the relative growth rate,

$b$ a dimensionless constant describing the incremental relative rate of the relative growth rate.

Reference ages were set at $t_{1}=1$ year and $t_{2}=25$ year.
The general model is specified as:

$L_{t}=\left[L_{1}^{b}+\left(L_{2}^{b}-L_{1}^{b}\right) \frac{1-e^{-a\left(t-t_{1}\right)}}{1-e^{-a\left(t_{2}-t_{1}\right)}}\right]^{\frac{1}{b}}$,

where $a \neq 0, b \neq 0$.

The model takes several forms based on the values of $a$ and $b$. Not all of the forms (which include linear and exponential growth) were appropriate for our data; therefore we focused on three special cases, which are equivalent to the specialized von Bertalanffy (VBGF; von Bertalanffy 1938), Gompertz (Ricker 1975), and logistic growth models (Ricker 1979) commonly reported in elasmobranch age and growth studies. The general model is equivalent to the VBGF when $a>0$ and $b=1$; it takes the logistic form when $a>0$ and $b=-1$. The Gompertz function is expressed as:

$L_{t}=L_{1} e^{\ln \left(\frac{L_{2}}{L_{1}}\right) \frac{1-e^{-a\left(t-t_{1}\right)}}{1-e^{-a\left(t_{2}-t_{1}\right)}},}$

where $a>0, b=0$.

To investigate potential changes in growth parameters over time, samples were classified into population size periods based on date of capture as pre- or postpopulation depletion. Specimens collected between 1963 and 1989 (the year in which peak commercial landings of large coastal and pelagic sharks were reported; NMFS 2011) were categorized as pre-depletion; those collected from 1990 onward were considered post-depletion.

While selecting such an abrupt point in time does not take into account the long generation time of the species (Cortés 2002), we were constrained by our sample size. To account for potential lag time in the species' response given its life history characteristics, we also compared growth prior to (19631994; hereafter referred to as Period A, TPA) and postmanagement (2005-2010; Period B, TPB). These periods were based on obtaining a 10 year hiatus between collections to enable us to compare pre- and postmanagement.

Parameter estimates for each growth function were estimated using nonlinear least-squares regression methods in R ( $\mathrm{R}$ Core Team 2012). Models with common parameter estimates between sexes, population sizes (pre- or post-depletion), and management periods (TPA and TPB) were compared to those with separate 
parameter estimates to determine if there was evidence of difference. While this is typically presented as a two-part analysis in elasmobranch age and growth studies, it is really a question of overall model selection (e.g. Does the inclusion of separate parameter estimates for each sex improve model fit, or can growth be sufficiently described using common parameter estimates for both sexes?). If the inclusion of separate parameters produced a better fit than the model with common parameters, this was considered evidence of difference.

Final model selection was based on statistical fit and compatibility with known biological parameters. Model goodness-of-fit was evaluated by the small-sample, bias-corrected form of the Akaike information criterion $\left(\mathrm{AIC}_{\mathrm{c}}\right.$; Akaike 1973; Burnham and Anderson 2002). The $\mathrm{AIC}_{\mathrm{c}}$ provides a measure of model fit and complexity and allows for the simultaneous comparison of growth models and their subsets, with the model with the smallest $\mathrm{AIC}_{\mathrm{c}}$ value considered the "best" out of the suite of models considered. The $\mathrm{AIC}_{\mathrm{c}}$ difference $\left(\Delta_{i}\right)$ of each model was calculated based on the lowest observed $\mathrm{AIC}_{\mathrm{c}}$ value $\left(\mathrm{AIC}_{\mathrm{c}, \text { min }}\right)$ as $\Delta_{i}=\mathrm{AIC}_{\mathrm{c}, \mathrm{i}}-\mathrm{AIC}_{\mathrm{c} \text {,min }}$ to provide an estimate of the magnitude of difference between each model and the best model in the set. Models with values of $\Delta_{\mathrm{i}}>10$ were considered as having essentially no support and were omitted from further consideration. Models with $\mathrm{AIC}_{\mathrm{c}}$ values differing by $<2$ were considered indistinguishable; in such cases the most parsimonious model was selected (Burnham and Anderson 2002). To approximate model likelihood, the Akaike weight $\left(w_{i}\right)$ of each model was also calculated (Burnham and Anderson 2002).

Ninety-five percent confidence intervals were constructed for parameter estimates via bootstrap methods using the "nlstools" package in R (Baty and DelignetteMuller 2011). Residual plots were inspected to ensure the assumptions of homoscedasticity and normality of the error terms were met (Zuur et al. 2009). Parameter estimates typically reported for the three models (e.g. asymptotic size, $L_{\infty}$; theoretical size at birth, $t_{0}$; and the growth coefficient, $k$ ) were calculated following Schnute (1981) for comparison with other studies. Length-at-birth $\left(L_{0}\right)$ was estimated from the resulting equation for each growth model.

Growth curves using only validated data were generated for comparison with curves based on vertebral band pair counts. All samples over the highest age for which annual band pair deposition was validated ( 10.7 year; see
"Results") were removed from the dataset, leaving only three larger individuals with directly validated ages (2 male and 1 female). The limited number of older individuals precluded comparison of parameters between sexes, population sizes, or time periods.

\section{Results}

Vertebral interpretation

Vertebral samples from 251 free-living and 18 embryonic dusky sharks were used in this study. The 138 female and 113 male free-living sharks ranged in size from $74 \mathrm{~cm}$ to $300 \mathrm{~cm}$ FL. Embryos ranged in size from $48 \mathrm{~cm}$ to $66 \mathrm{~cm}$ FL. One hundred and sixty samples (63 male, 74-276 cm FL; 97 female, 76-287 cm FL) were collected during TPA and 63 (38 male, 78-264 cm FL; 25 female, 78-270 cm FL) during TPB; all 18 embryos were sampled in TPA. An additional 16 females (82$300 \mathrm{~cm} \mathrm{FL}$ ) and 12 males (85-260 cm FL) were obtained from 1995 to 1998 . When samples were categorized by population size, 127 samples were obtained pre- (51 male, 74-276 cm FL; 76 female, $77-287 \mathrm{~cm} \mathrm{FL)} \mathrm{and}$ 124 post-depletion ( 62 male, $77-264 \mathrm{~cm} \mathrm{FL}$; 62 female, 76-300 cm FL).

The location of the BR, between the VR of late term embryos and YOY, indicated the birth band was identified correctly $(\mathrm{BR}=4.55 \pm 0.05$ (mean $\pm 95 \% \mathrm{CI}) ; n=$ 186 ; VR=3.45 $\pm 0.10, n=18$ embryos; $\mathrm{VR}=4.77 \pm 0.16$, $n=34$ YOY). There was no evidence of difference in the FL-VR relationship between the sexes based on $\mathrm{AIC}_{\mathrm{c}}$ values $\left(\mathrm{AIC}_{\mathrm{c}} \mathrm{VR}=-746.56 ; \mathrm{AIC}_{\mathrm{c}} \mathrm{VR}+\mathrm{Sex}=\right.$ $-745.64 ; \mathrm{AIC}_{\mathrm{c}} \mathrm{VR}^{*} \mathrm{Sex}=-746.73 ; \Delta_{\mathrm{i}}<2.0$ in all cases). The FL-VR relationship was described for both sexes as follows:

$\ln (F L)=0.83 \ln (V R)+3.15\left(\mathrm{n}=248 ; r^{2}=0.99\right)$

The back-calculated size at birth based on the mean BR of the sample was $82.1 \mathrm{~cm} \mathrm{FL} \mathrm{(71.5-95.0} \mathrm{cm} \mathrm{FL)} \mathrm{(Fig.} \mathrm{1).}$

Age determination

Comparison of counts indicated that both readers were identifying the same band pairs. Sixty-six percent of counts agreed between readers and $89.5 \%$ were within one band pair. Only 11 counts differed by greater than 


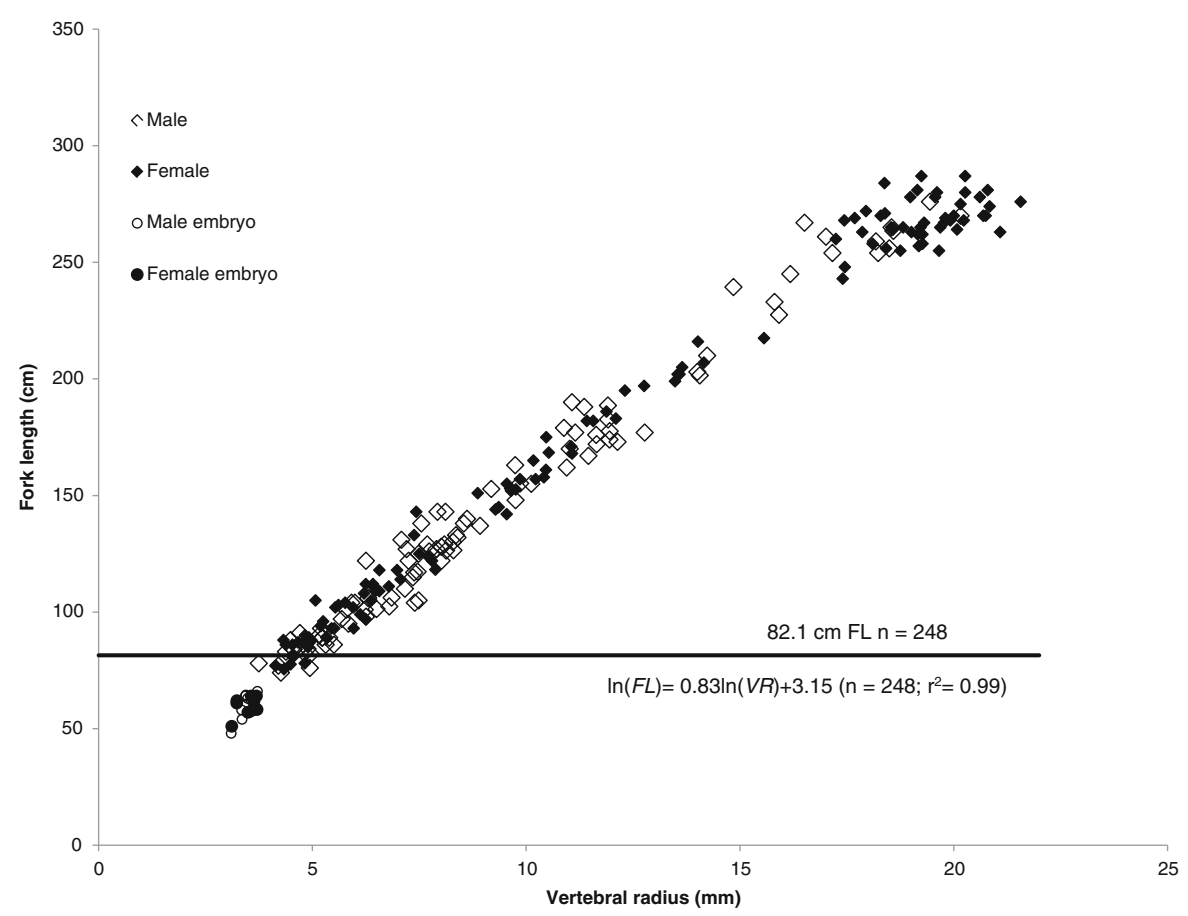

Fig. 1 Relationship between vertebral radius and fork length for male and female dusky sharks. The horizontal lines represents the size at birth

one band pair, with three samples needing to be aged by consensus. An age bias plot showed minimal variation around the 1:1 plot and no systematic bias (Fig. 2a). Additionally, the Bowker $\left(\chi^{2}=19.20, d f=23\right.$, $n=105, p=0.69)$, McNemar $\left(\chi^{2}=1.17, d f=4, n=105\right.$, $p=0.88)$ and Evans- Hoenig $\left(\chi^{2}=0.00, d f=1, n=105, p=\right.$ $1.00)$ chi-square tests of symmetry gave no indication that differences between readers were systematic rather than due to random error. Comparison of the first and second counts of the first reader also indicated no systematic bias Bowker $\left(\chi^{2}=25.00, d f=25, n=100, p=0.46\right)$, McNemar $\left(\chi^{2}=9.80, d f=6, n=100, p=0.13\right)$ and Evans-Hoenig $\left(\chi^{2}=\right.$ 3.46, $d f=1, n=100, p=0.06$ ) (Fig. 2b).

Bomb radiocarbon validation

A total of 30 samples were extracted from the eight sharks selected for radiocarbon analysis. The $\delta^{13} \mathrm{C}$ values (mean $\pm \mathrm{SE}=-12.68 \%{ }_{0} \pm 0.101 \%$ o) of the samples were typical of metabolically derived carbon (Kalish and Johnston 2001; Campana et al. 2002). Radiocarbon values ranged from $-84.2 \%$ o to $99.9 \%$ o $\Delta^{14} \mathrm{C}$, which correspond to the years 1949.5 and 1984 , respectively.
Vertebral data from the six smallest sharks appeared to line up with the reference curves (Fig. 3a), indicating that band pair counts were annual up to age 11 (Table 1). $\Delta^{14} \mathrm{C}$ values of two male sharks in the post-bomb period were intermediate between the Bermuda and northwest Atlantic radiocarbon curves (Fig. 3a). Though the DS234 chronology followed a reasonable declining trajectory, it recorded only post-bomb spike material (Fig. 3a), rendering it ineffective for validating counts.

The two largest sharks (DS51 \& DS81) appeared to be substantially under-aged, as their radiocarbon records were shifted to the right of the bomb radiocarbon spike in the reference chronologies (Fig. 3b). In order to align $\Delta^{14} \mathrm{C}$ values with the corresponding values from the reference chronologies and the other shark chronologies, age estimates were increased by 15 (DS51) and 19 (DS81) years, resulting in an estimated age at capture of 38 and 42 years, respectively (Fig. 3c).

Growth curve estimation

Based on $\mathrm{AIC}_{\mathrm{c}}$ values, the best fitting model for band pair counts of all samples collected throughout the course of the study $(n=251)$ was the logistic form of the Schnute model incorporating separate parameter 


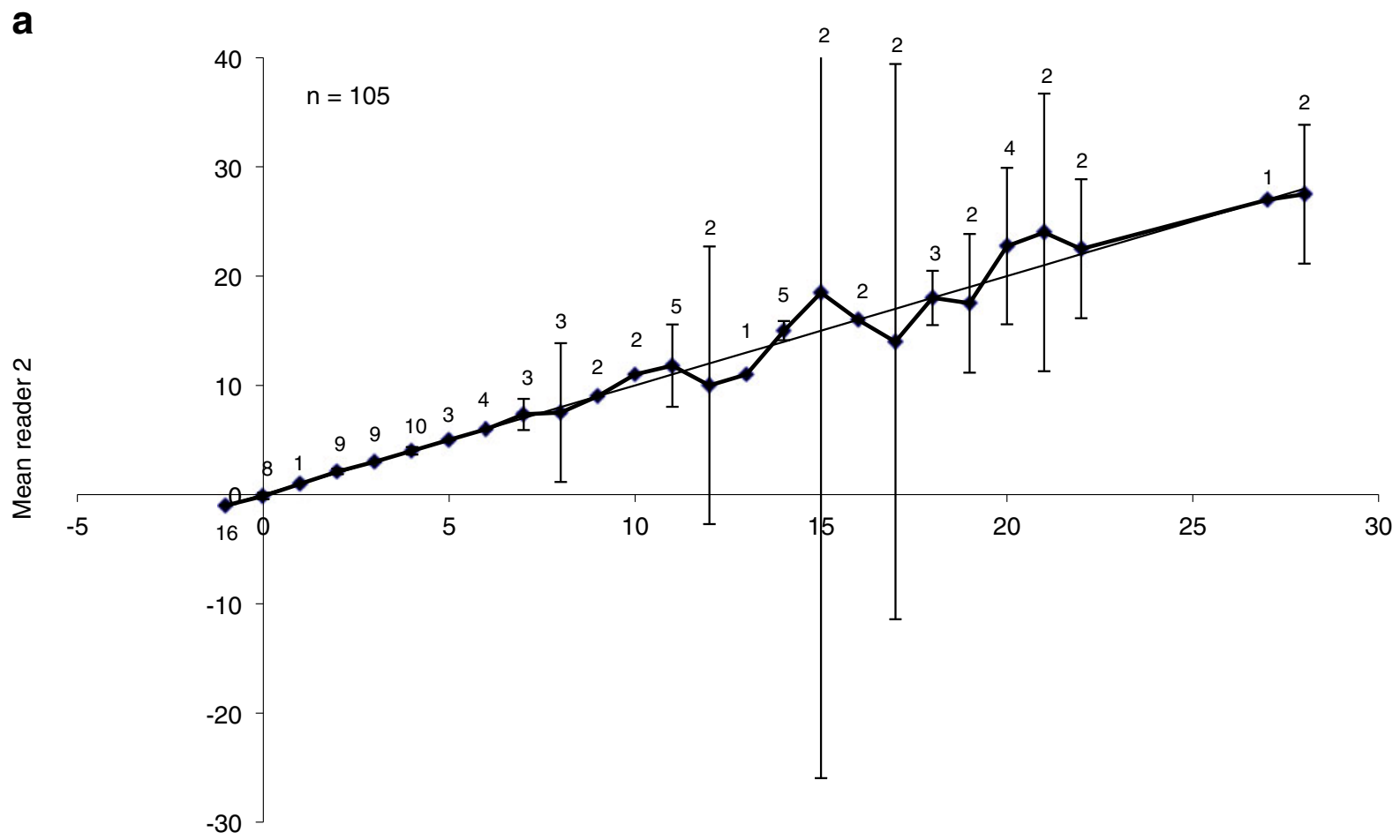

Reader 1

b

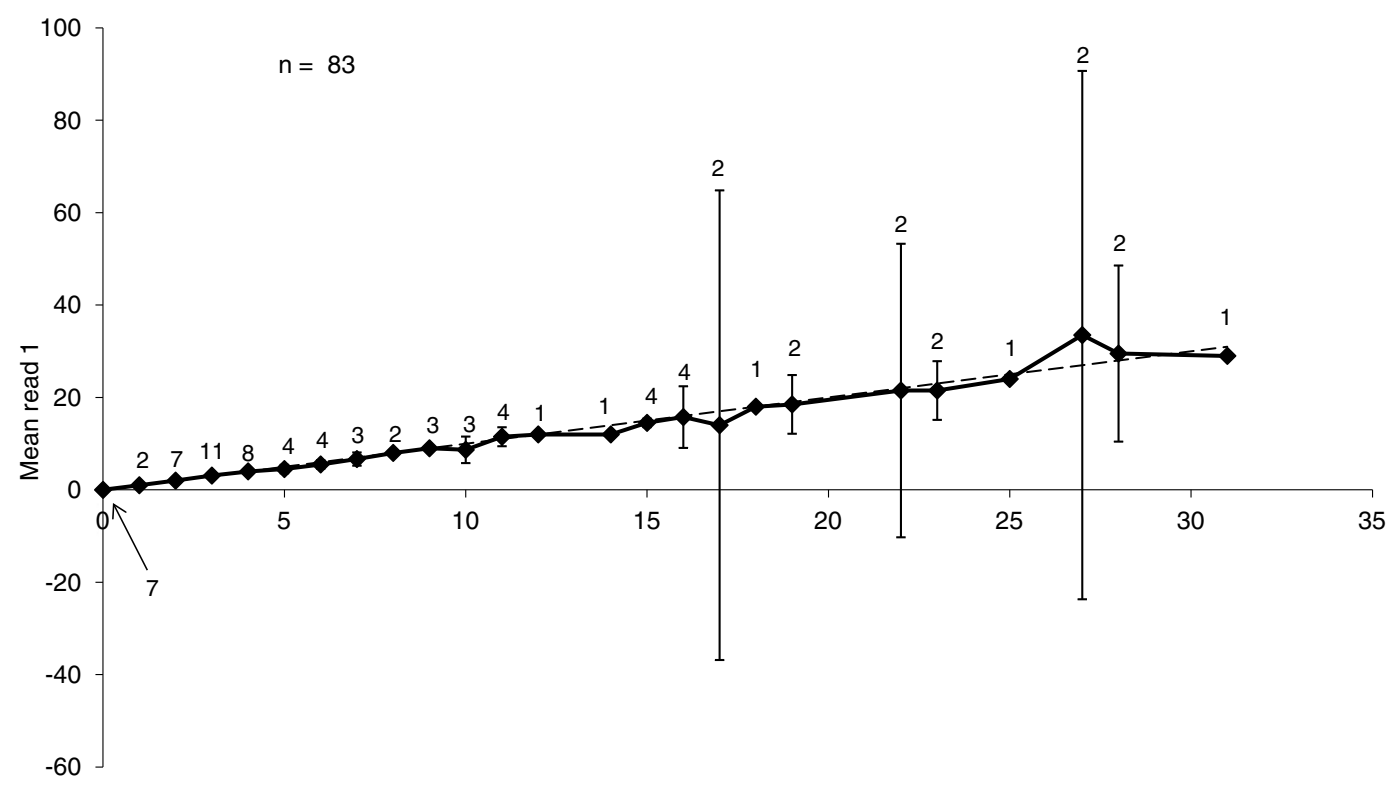

Read 2

Fig. 2 Age bias graph for pair-wise comparison of a) 105 dusky shark vertebral counts from the second count of two independent age readers. Each error bar represents the $95 \%$ confidence interval for the mean age assigned by reader 2 to all fish assigned a given age by reader 1; and b) 83 dusky sharks from the primary reader. Each error bar represents the $95 \%$ confidence interval for the mean age assigned on the first read to all fish assigned a given age on the second read. The one to one equivalence line is also presented 
Fig. 3 a) Bomb radiocarbon results from six dusky shark vertebrae that did not require shifting, the northwest Atlantic $\Delta^{14} \mathrm{C}$ otolith reference chronology, and the Bermuda $\Delta^{14} \mathrm{C}$ coral reference chronology. b) Bomb radiocarbon results from two dusky shark vertebrae and reference chronologies as in (a). Arrows indicate vertebral $\Delta^{14} \mathrm{C}$ curves that had to be shifted to line up with reference chronologies (dashed lines are initial data, solid lines are data shifted to align with the references). c) Bomb radiocarbon results from all 8 dusky shark vertebrae including adjusted chronologies as in (b), and reference chronologies as in (a) a

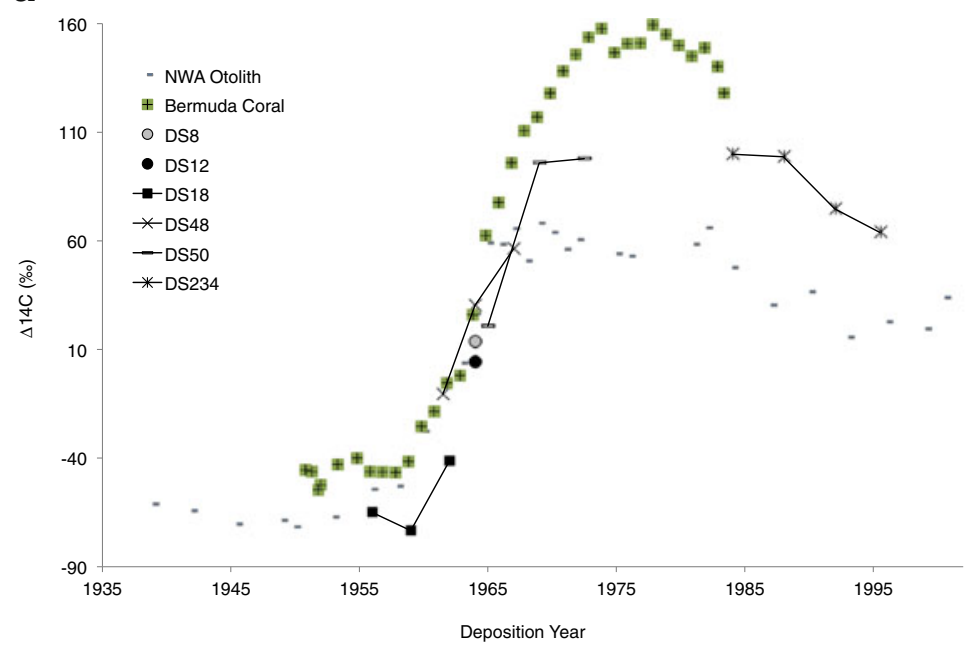

b

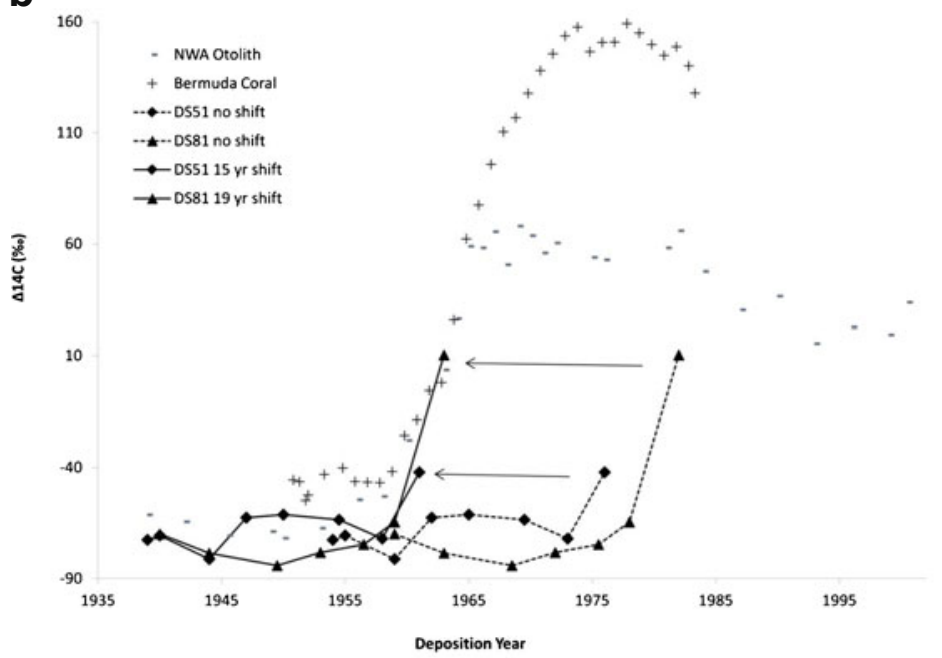

C

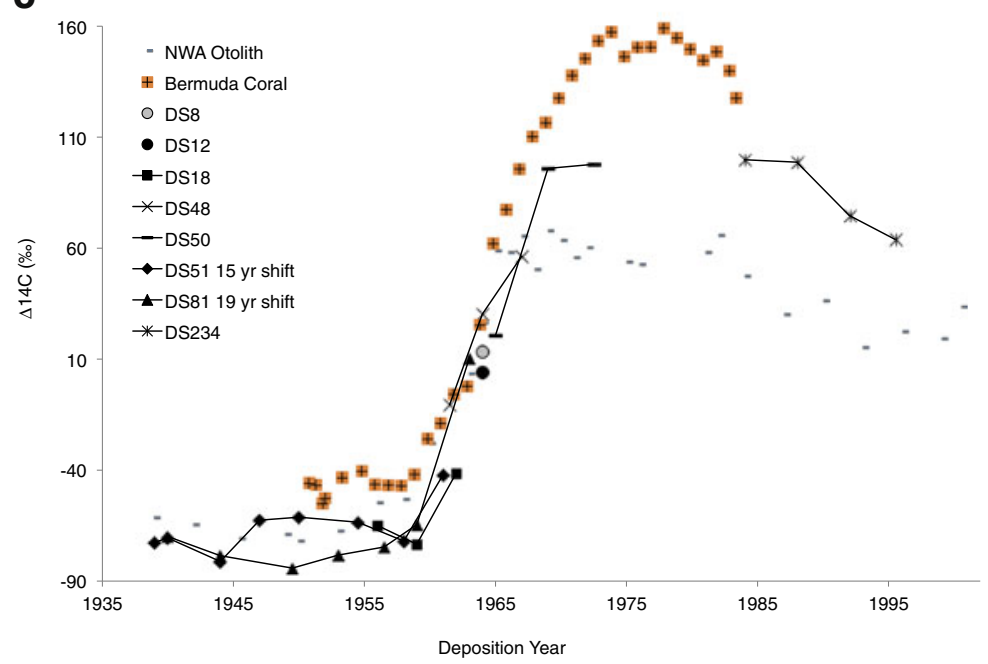


Table 1 Summary of individual shark information for vertebrae used for radiocarbon analyses

\begin{tabular}{llllll}
\hline Shark & Year collected & FL $(\mathbf{c m})$ & Sex & $\Delta^{\mathbf{1 4}}$ C Age & Band pairs \\
\hline DS8 & 1965 & 95 & M & 1 & 1 \\
DS12 & 1965 & 102 & F & 1 & 1 \\
DS18 & 1964 & 148 & M & 9 & 9 \\
DS48 & 1969 & 174 & M & 8 & 8 \\
DS50 & 1975 & 177 & M & 11 & 11 \\
DS51 & 1977 & 263 & F & 38 & 23 \\
DS81 & 1982 & 259 & M & 42 & 23 \\
DS234 & 1997 & 218 & M & 15 & 15 \\
\hline
\end{tabular}

Discrepancies between band pairs and $\Delta^{14} \mathrm{C}$ age indicate instances where a shift was necessary to align sample $\Delta^{14} \mathrm{C}$ values to reference curves (shaded rows). FL fork length

estimates for each sex (Table 2a). Including separate parameter estimates for each population size (pre- and postdepletion) did not improve fit over any of the models incorporating common parameter estimates, with the exception of the von Bertalanffy. However, $\Delta_{\mathrm{i}}$ values for all versions of the von Bertalanffy were $>10$, suggesting that the models had essentially no support (Burnham and Anderson 2002) and rendering the difference meaningless (Haddon 2001). More detailed analysis of the model subsets indicated that the best fitting models $\left(\Delta_{\mathrm{i}}<2.0\right.$; Table $3 \mathrm{a}$ ) contained common parameter estimates for $l_{1}$ and $l_{2}$ but separate estimates for $a$.

When the analysis was restricted to the samples collected during the pre-and post-management periods, the logistic model incorporating separate parameter estimates for each sex remained the best fitting (Table 2b). Including separate parameter estimates for each management period did not improve fit over any of the models incorporating common parameter estimates (Table 3b). Again, more detailed analysis of logistic model parameters suggested that $a$ was the source of difference between the sexes (Table 3b). Therefore, sexes were evaluated separately for the rest of this analysis but time periods were not, allowing us to use age estimates from specimens collected over the entire course of the study to generate growth curves.

Based on vertebral band pair counts, female growth was best described by the logistic model (Table 4; Fig. 4a) and male growth by the Gompertz (Table 4; Fig. 4b), although it should be noted that differences between models fit to male data were minimal. Validated growth $(n=152)$ was best described by the logistic function (Table 4; Fig. 5). The validated growth curve predicted a lower asymptotic length and correspondingly smaller sizes at age (Fig. 5).

\section{Discussion}

The under-ageing of long-lived elasmobranch species using band pairs on vertebral centra has become increasingly apparent. Since 2001, twelve studies have applied bomb radiocarbon dating to elasmobranchs (Kalish and Johnston 2001; Campana et al. 2002; Ardizzone et al. 2006; Campana et al. 2006; Kerr et al. 2006; Francis et al. 2007; Kneebone et al. 2008; McPhie and Campana 2009; Passerotti et al. 2010; Andrews et al. 2011; Tillet et al. 2011; Present study). Of these studies, five have shown that band pairs are deposited annually for only a portion of the life span of a species or could not validate the ages (Kalish and Johnston 2001; Kerr et al. 2006; Francis et al. 2007; Andrews et al. 2011; Present study). This finding calls into question the value of elasmobranch age determination based on band pair counts of vertebral centra.

Several possible explanations have been put forth to explain why the vertebral counts underestimate actual ages. These include difficultly discerning band pairs at the growing edge due to slower growth in older individuals, decreased or lack of band pair deposition following maturation, or deposition related to somatic growth and reproduction rather than seasonal cues (Natanson and Cailliet 1990; Natanson 1993; Francis et al. 2007; Natanson et al. 2008). Using histology, the 
Table 2 Relative goodness-of-fit for each growth model for Carcharhinus obscurus from the northwestern Atlantic for A) unvalidated band pair counts from 1963 to $2010(n=251)$ and B) unvalidated band pair counts from 1963-1994 to 2005-2010 ( $n=223)$

\begin{tabular}{llllll}
\hline Model & $\mathrm{k}$ & $\mathrm{AIC}_{\mathrm{c}}$ & $\Delta_{\mathrm{i}}$ & $\mathrm{w}_{\mathrm{i}}$ \\
\hline
\end{tabular}

A)

\begin{tabular}{lrrrr} 
Logistic + sex & 7 & 1942.27 & 0.00 & 0.76 \\
Logistic & 4 & 1945.70 & 3.43 & 0.14 \\
Gompertz + sex & 7 & 1946.87 & 4.60 & 0.08 \\
Logistic + population size & 7 & 1950.55 & 8.29 & 0.01 \\
Gompertz & 4 & 1951.17 & 8.90 & 0.01 \\
Gompertz + population size & 7 & 1954.23 & 11.97 & 0.00 \\
von Bertalanffy + sex & 7 & 1965.19 & 22.93 & 0.00 \\
von Bertalanffy + population size & 7 & 1971.50 & 29.24 & 0.00 \\
von Bertalanffy & 4 & 1973.14 & 30.88 & 0.00 \\
B) & & & & \\
Logistic + sex & 7 & 1722.42 & 0.00 & 0.69 \\
Logistic & 4 & 1724.71 & 2.29 & 0.22 \\
Gompertz + sex & 7 & 1727.94 & 5.52 & 0.04 \\
Logistic + time period & 7 & 1728.27 & 5.85 & 0.04 \\
Gompertz & 4 & 1732.69 & 10.28 & 0.00 \\
Gompertz + time period & 7 & 1737.25 & 14.83 & 0.00 \\
von Bertalanffy + sex & 7 & 1745.45 & 23.03 & 0.00 \\
von Bertalanffy & 4 & 1754.50 & 32.08 & 0.00 \\
von Bertalanffy + time period & 7 & 1756.69 & 34.27 & 0.00 \\
\hline & & & & \\
\hline
\end{tabular}

Models are ranked from best to worst fitting. + indicates the incorporation of a factor with separate parameter estimates for each level of the factor (Sex = male or female, Population Size = pre- or post-depletion, Time Period = pre- or post- management). Models without factors incorporated common parameter estimates for the entire dataset. If the inclusion of a factor produced a better fit than the model with common parameters, this was considered as evidence of difference in the parameter estimates between factor levels. See text for details. $-\mathrm{k}=$ total number of regression parameters, which includes the error term; $\mathrm{AIC}_{\mathrm{c}}=$ the small-sample, bias corrected form of the Akaike information criterion; $\Delta_{i}=$ Akaike difference, $\mathrm{w}_{\mathrm{i}}=$ Akaike weight

band pairs along the centra and at the edge are clear and easily countable; thus, difficulty discerning band pairs is not the underlying issue (James et al. 2013). In fact, in the current study and in Andrews et al. (2011) more band pairs could be counted; however, these "extra" band pairs did not meet the criteria whereby the ages of juveniles were validated. This indicates that a decrease in band pair deposition, whether related to somatic growth or maturity, is more likely the cause. While experimentation to determine these factors is difficult, it has been shown in two unrelated species that band pair deposition
Table 3 Relative goodness-of-fit with separate parameter estimates for each sex for the logistic growth model for Carcharhinus obscurus from the northwestern Atlantic for A) unvalidated band pair counts from 1963 to $2010(n=251)$ and B) unvalidated band pair counts from 1963-1994 to 2005-2010 $(n=223)$

\begin{tabular}{lllll}
\hline Model & $\mathrm{k}$ & $\mathrm{AIC}_{\mathrm{c}}$ & $\Delta_{\mathrm{i}}$ & $\mathrm{w}_{\mathrm{i}}$ \\
\hline A) & & & & \\
Common $l_{l}$ and $l_{2}$ & 5 & 1938.99 & 0.00 & 0.38 \\
Common $l_{1}$ & 6 & 1940.22 & 1.23 & 0.21 \\
Common $l_{2}$ & 6 & 1941.06 & 2.07 & 0.14 \\
Common $a$ & 6 & 1942.20 & 3.21 & 0.08 \\
Common $a$ and $l_{1}$ & 5 & 1942.23 & 3.24 & 0.08 \\
Separate & 7 & 1942.27 & 3.28 & 0.07 \\
Common $a$ and $l_{2}$ & 5 & 1943.51 & 4.52 & 0.04 \\
Common & 4 & 1945.70 & 6.71 & 0.01 \\
B) & & & & \\
Common $l_{l}$ and $l_{2}$ & 5 & 1718.22 & 0.00 & 0.48 \\
Common $l_{2}$ & 6 & 1720.28 & 2.07 & 0.17 \\
Common $l_{l}$ & 6 & 1720.33 & 2.11 & 0.17 \\
Separate & 7 & 1722.42 & 4.20 & 0.06 \\
Common $a$ and $l_{2}$ & 5 & 1722.48 & 4.27 & 0.06 \\
Common $a$ & 6 & 1723.88 & 5.67 & 0.03 \\
Common & 4 & 1724.71 & 6.49 & 0.02 \\
Common $a$ and $l_{1}$ & 5 & 1724.94 & 6.72 & 0.02 \\
\hline
\end{tabular}

Models are ranked from best to worst fitting. The 'separate' model incorporated different parameter estimates for each sex. The 'common' model incorporated the same parameter estimate for males and females. All other model subsets contained a mix of common and separate parameters as indicated. $a, l_{1}$, and $l_{2}$ are the logistic growth model parameters; $\mathrm{k}=$ total number of regression parameters, which includes the error term; $\mathrm{AIC}_{\mathrm{c}}=$ the small-sample, bias corrected form of the Akaike information criterion; $\Delta_{i}=$ Akaike difference, $\mathrm{w}_{\mathrm{i}}=$ Akaike weight

is related to somatic growth (Natanson and Cailliet 1990; Natanson et al. 2008). Additionally, in the little skate, Leucoraja erinacea, seasonal temperature cues had no effect on deposition rate but active reproduction did decrease band pair deposition (Natanson 1993).

Band pair counts for dusky sharks underestimated true age by as much as 19 years in individuals older than 11 years; other current studies suggest this phenomenon occurs more widely than previously assumed. Andrews et al. (2011) reported similar results for the closely related sandbar shark, finding band pair counts accurate only to $10-12$ years and resulting in underageing thereafter. For the white shark, Carcharodon carcharias, in the northwest Atlantic, Hamady et al., 


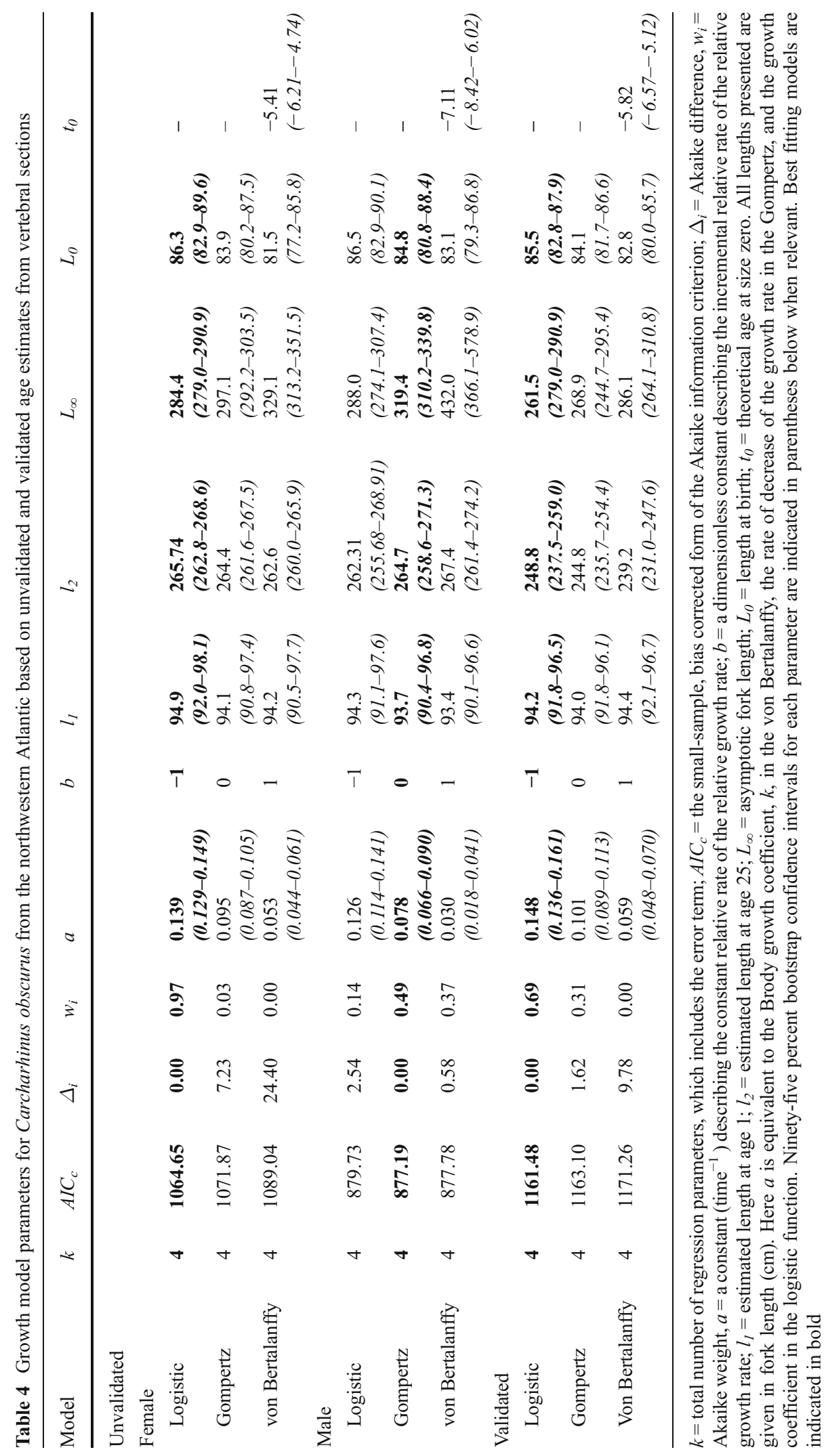




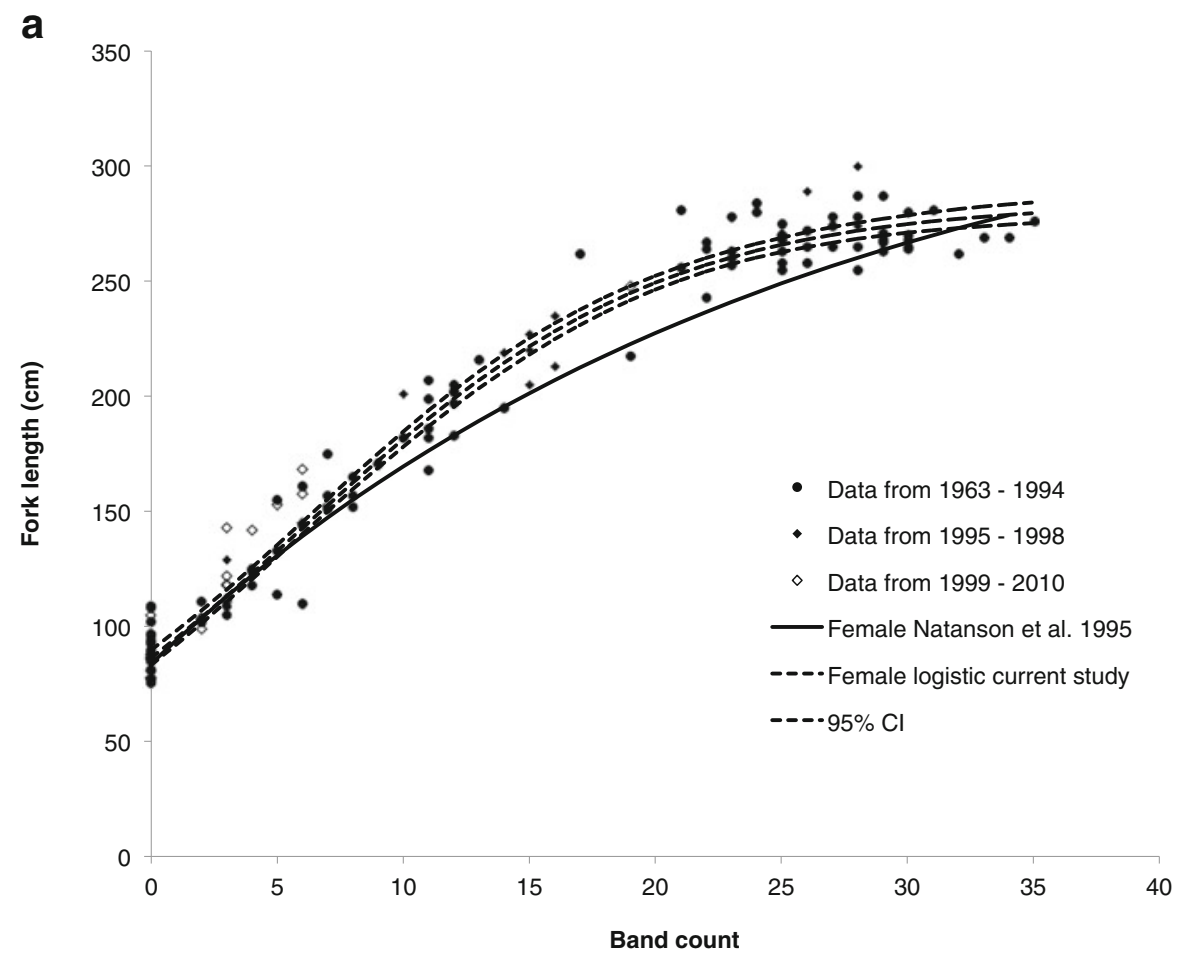

b

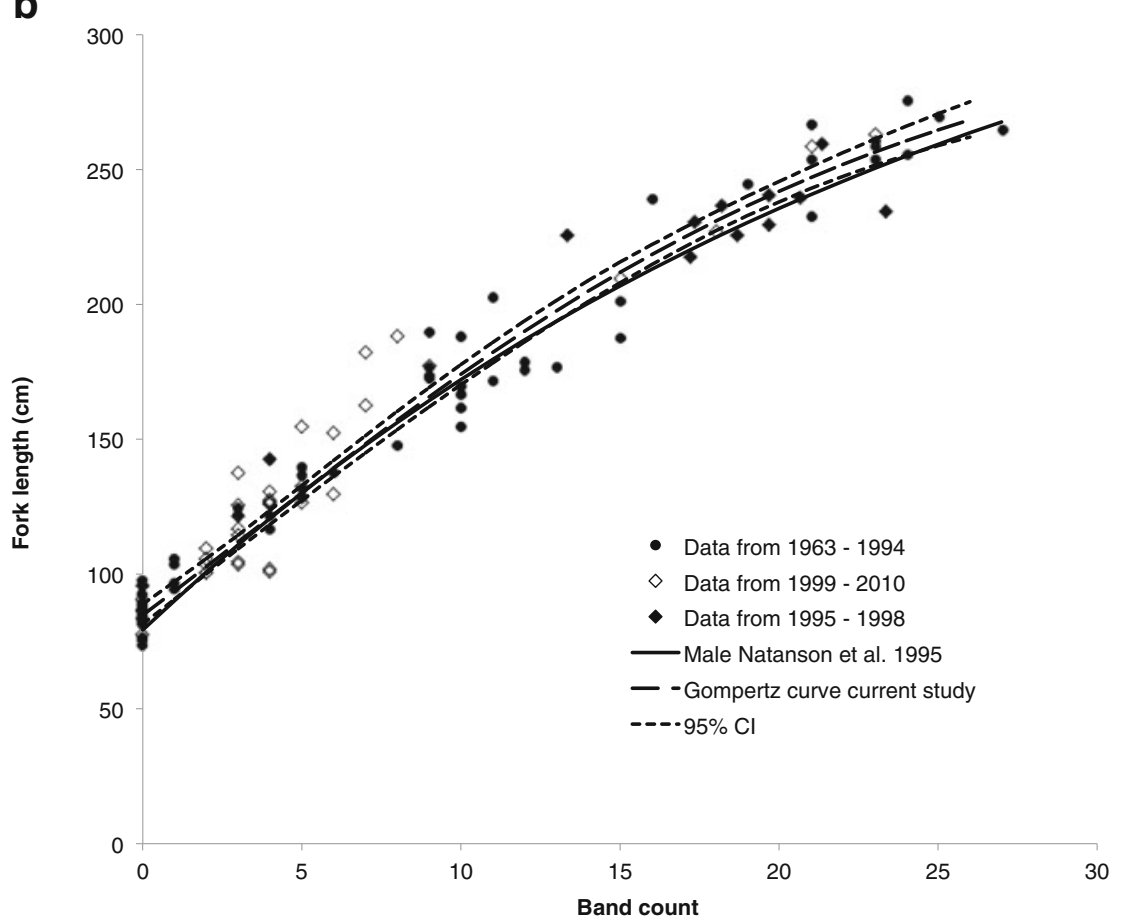

Fig. 4 Dusky shark growth data based on vertebral band counts. Logistic growth curve have been fitted to the female data (a) and Gompertz growth function has been fit to the male data (b). All data are presented as are growth curves from a previous study (Natanson et al. 1995) 


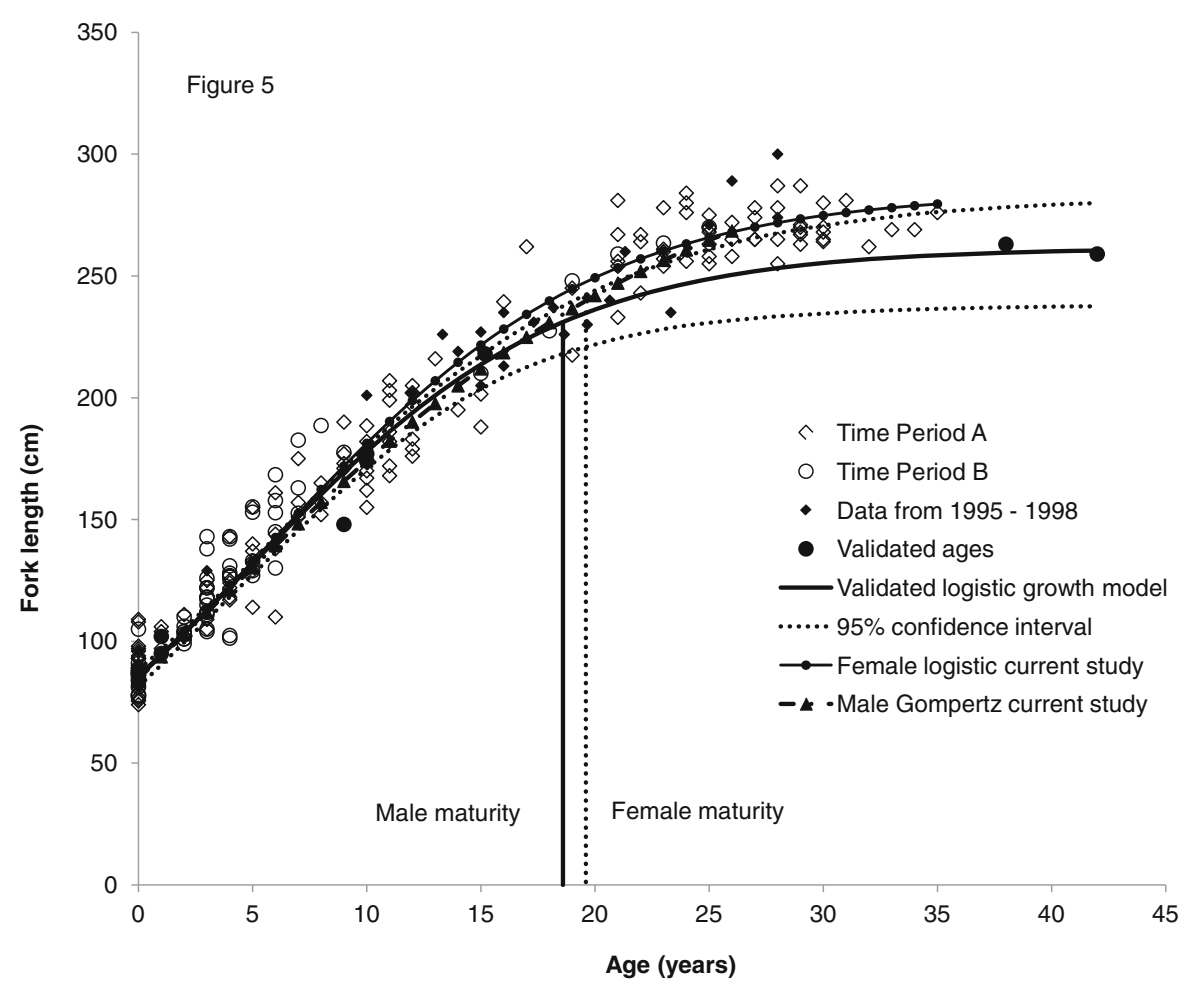

Fig. 5 Validated dusky shark growth data. Ninety-five percent confidence intervals and band pairs counts by period are also plotted

(Bomb Radiocarbon Confirmation of Extreme Longevity in White Sharks (in review)) found a similar result for male sharks. In contrast, female band pair counts overestimated age, indicating sexual dimorphism in band pair deposition (Hamady et al., Bomb Radiocarbon Confirmation of Extreme Longevity in White Sharks (in review)). Similarly, a study on porbeagle sharks, Lamna nasus, off New Zealand showed that validated ages were higher than band pair counts, suggesting deposition either stopped when somatic growth ceased or that band pairs were irresolvable at the vertebral margin (Francis et al. 2007). Little skates stopped depositing annual band pairs while reproductively active (Natanson 1993). More recently, Harry et al. (2013) showed that pregnant female $C$. sorrah did not uptake calcein on the growing edge, though male and nonpregnant females did, suggesting that the reproductively active females of this species may stop band pair deposition during pregnancy.

Given the importance of accurate age estimation to population assessment, validation of the periodicity of vertebral growth band deposition must be performed for all species of management interest. While the validated growth curve for the dusky shark is based on a small number of larger specimens, it represents the best available estimate at this time. The use of incorrect ages and resulting growth rates in demographic analyses can lead to errors in estimates of natural mortality rates, population growth rates, and management actions based upon those estimates (Beamish and McFarlane 1983; Cailliet and Andrews 2008). Given the high management profile of the species, age and growth parameters from the validated curves should be used as the basis for the species until more samples can be processed and the estimates refined.

When only validated age estimates were used for growth curve fitting, parameter estimates were not substantially different from those based on all band pair counts, reinforcing the conclusions of Natanson et al. (1995). These authors directly aged one dusky shark at $33^{+}$from vertebral band pair counts and estimated another at 39 years from tag/recapture analysis; theoretical longevities based on the von Bertalanffy growth model ranged from 40 to 50 years. They calculated that the largest reported dusky (308 cm FL female; Springer 1960) could be 51 years based on their growth curve. In this study, direct validation was obtained on a 38 year old female and a 42 year old male. These were the oldest 
of the validated samples but were not the largest individuals collected over the course of the study, suggesting that the species likely obtains higher ages.

The age at $50 \%$ maturity for females and males was estimated at 17.6 and 17.4 years, respectively, based on the validated growth curve and the estimated size at $50 \%$ maturity $(227 \mathrm{~cm} \mathrm{FL}$ and $226 \mathrm{~cm}$ FL female and male, respectively; J. Romine pers. comm. ${ }^{2}$ ). Refinements in both the maturity estimates by Romine (pers. comm. ${ }^{2}$ ) and the new growth curve have lead to a decrease in these estimates since the 19 and 21 year maturity estimates for males and females, respectively, by Natanson et al. (1995).

Given the severe decline in abundance experienced by the dusky shark in the northwestern Atlantic, one would expect to observe changes in life history parameters over time as a compensatory density-dependent response (Rose et al. 2001). However, the current study showed no evidence of difference in the size-at-age relationship between pre- and post- population depletion or management periods. By maintaining the same processing procedures, band pair criteria, and band pair reader between the two periods, potential bias associated with vertebral preparation and interpretation was minimized and, therefore, unlikely to effect the results (Cailliet et al. 1990).

Unfortunately, given the opportunistic nature of our sampling scheme, the potential for gear or area effects cannot be ruled out. However, the size range of the species was represented in all time periods, and geographic variation in parameters due to genetic effects is likely to be minimal; all samples used in this study were likely obtained from the same population of dusky sharks (Benavides et al. 2011). Thus, while we acknowledge that there are limitations to these analyses in terms of sample sizes and frequency distributions, we also feel it would have been remiss not to test for density-dependant differences due to the exploitation history of this species. Additionally, the use of unvalidated ages for the comparison may have confounded results; however, inspection of the plotted size-at-age data in the range of validated ages $(<10.7$ year, Fig. 5) indicates no obvious difference between periods.

While density-dependence is a common term in fisheries science, the ability to measure its magnitude in a population is highly controversial (Rose et al. 2001). Density-mediated changes in life history parameters

\footnotetext{
2 J. Romine 2013 Pers. Comm. 5501-A Cook-Underwood Road, Cook, WA 98605-9717
}

have been reported for four other shark species following extended exploitation. In the northwestern Atlantic, changes in both the growth rate and age at maturation were observed in the porbeagle (Cassoff et al. 2007). Evidence of change in the growth rate of juvenile sandbar sharks has also been reported (Sminkey and Musick 1995). Changes in life history parameters have also been documented for spiny dogfish, Squalus acanthias, in the northeast Pacific Ocean (Taylor and Gallucci 2009) and the Atlantic sharpnose shark in the Gulf of Mexico (Carlson and Baremore 2003). The relative lack of reported instances among elasmobranchs when compared to teleosts (Rose et al. 2001) illustrates the difficulty of documenting such effects in long lived species with correspondingly long generation times and recovery periods (Cortés 2002).

Differences in life history parameters and study timescales may explain why changes were observed over time in the above species but not in the dusky shark. The porbeagle and Atlantic sharpnose are both faster growing species with shorter life spans (Campana et al. 2002; Natanson et al. 2002; Carlson and Baremore 2003) and are likely able to more rapidly compensate for density related changes due to shorter generation times (Cortés 2002). The relatively broad periods defined as pre(1963-1989) and post- depletion (1990-2010) and pre-management for the purposes of this study (19631994) spanned the intensification, peak, and decline of the U.S. Atlantic coastal shark fishery and may have masked changes that occurred within those years; unfortunately, sample size constraints prevented us from splitting the data into smaller intervals. However, the long life span and generation time of the species would likely dampen the magnitude of any such short-term changes occurring within that period; multi-generational timescales may be required to detect density-related trends (Sæther et al. 2005; Taylor and Gallucci 2009). It is also important to note that environmental changes may also play a confounding role in discerning density-mediated changes (Rose et al. 2001); teasing apart the contribution of large-scale environmental and density-dependent effects to observed trends is an important and complicated area of future research (Taylor and Gallucci 2009).

The increasing evidence that band pair deposition does not remain annual throughout the life of many elasmobranch species makes examining density-dependent effects on growth difficult. Without known ages, it is not possible to look for changes in those ages; therefore, we suggest that no conclusions can be drawn without 
validation of the entire size range of a species. Since age estimates have not been properly validated for most elasmobranch species, future research needs to focus on first validating and then examining a species for the possibility of compensatory changes in age and growth parameters.

Acknowledgments We would like to thank the commercial and recreational fishermen who allowed us to sample their catches and all the scientists and observers, past and present, who obtained samples. We would also like to acknowledge the support of the Apex Predators Program staff. Jason Romine was very kind to spend time regenerating data to improve our age at maturity estimates. Allen Andrews and Simon Thorrold were excellent sounding boards for the bomb carbon analyses. In particular, we would like to thank Rich McBride; without his assistance we would not have obtained the initial funding for the bomb carbon work. He also provided valuable comments to our draft. This research was done consistent with applicable law.

\section{References}

Akaike H (1973) Information theory and the extension of the maximum likelihood principle. In: Petrov BN, Csaki F (eds) International Symposium on Information Theory. Academiai Kaido, Budapest, pp 267-281

Andrews AH, Natanson LJ, Kerr LA, Burgess GH, Cailliet GM (2011) Bomb radiocarbon and tag-recapture dating of sandbar shark (Carcharhinus plumbeus). Fish Bull 109:454-465

Ardizzone D, Cailliet GM, Natanson LJ, Andrews AH, Kerr LA, Brown TA (2006) Application of bomb radiocarbon chronologies to shortfin mako (Isurus oxyrinchus) age validation. Environ Biol Fish 25:355-366

Baty F, Delignette-Muller ML (2011) nlstools: tools for nonlinear regression diagnostics. $\mathrm{R}$ package version $0.0-11$

Beamish RJ, McFarlane GA (1983) The forgotten requirement for age validation in fisheries biology. Trans Am Fish Soc 112(6):735-743

Benavides MT, Horn RL, Feldheim KA, Shivji MS, Clarke SC, Wintner S, Natanson L, Braccini M, Boomer JJ, Gulak SJB, Chapman D (2011) Global phylogeny of the dusky shark Carcharhinus obscurus: implications for fisheries management and monitoring in the shark fin trade. Endanger Species Res 14:13-22

Bowker AH (1948) A test for symmetry in contingency tables. J Am Stat Assoc 43:572-574

Burnham KP, Anderson DR (2002) Model selection and multimodel inference: a practical information-theoretic approach, 2nd edn. Springer, New York

Cailliet GM, Andrews AH (2008) Age-validated longevity of fishes: its importance for sustainable fisheries. In: Tsukamoto K, Kawamura T, Takeuchi T, Beard Jr TD, Kaiser MJ (eds) Fisheries for global welfare and environment. 5th World Fisheries Congress 2008, p 103

Cailliet GM, Yudin KG, Tanaka S, Taniuchi T (1990) Growth characteristics of two populations of Mustelus manazo from Japan based on cross-reading vertebral bands. In: Pratt Jr. HL, Gruber SH, Taniuchi T (eds) Elasmobranchs as living resources: advances in biology, ecology, systematics and the status of the fisheries. NOAA Technical Report NFMS 90, pp 167-176

Campana SE, Annand MC, McMillan JI (1995) Graphical and statistical methods for determining the consistency of age determinations. Trans Am Fish Soc 124:131-138

Campana SE, Natanson LJ, Myklvoll S (2002) Bomb dating and age determination of large pelagic sharks. Can J Fish Aquat Sci 59:450-455

Campana SE, Jones C, McFarlane GA, Myklevoll S (2006) Bomb dating and age validation using the spines of spiny dogfish (Squalus acanthias). Environ Biol Fish 25:327336

Campana SE, Casselman JM, Jones CM (2008) Bomb radiocarbon chronologies in the Arctic, with implications for the age validation of lake trout (Salvelinus namaycush) and other Arctic species. Can J Fish Aquat Sci 65:733-743

Carlson JK, Baremore IE (2003) Changes in biological parameters of Atlantic sharpnose shark Rhizoprionodon terraenovae in the Gulf of Mexico: evidence for density-dependent growth and maturity? Mar Freshwat Res 54:227-234

Cassoff RM, Campana SE, Myklevoll S (2007) Changes in baseline growth and maturation parameters of Northwest Atlantic porbeagle, Lamna nasus, following heavy exploitation. Can J Fish Aquat Sci 64:19-29

Compagno LJV (1984) FAO species catalogue. Sharks of the world: an annotated and illustrated catalogue of shark species known to date. Part 2: carcharhiniformes. FAO Fish Synop 125. FAO, Rome 4, pp 251-655

Cortés E (2002) Incorporating uncertainty into demographic modeling: application to shark populations and their conservation. Conserv Biol 4:1048-1062

Cortés E (2007) Chondrichthyan demographic modeling: an essay on its use, abuse and future. Mar Freshwat Res 58:4-6

Cortés E, Brooks E, Apostolaki P, Brown CA (2006) Stock assessment of dusky shark in the U.S. Atlantic and Gulf of Mexico. National Marine Fisheries Service Panama City Laboratory Contribution 06-05 and Sustainable Fisheries Division Contribution SFD 2006-014

Druffel ERM (1989) Decade time scale variability of ventilation in the North Atlantic: high-precision measurements of bomb radiocarbon in banded corals. J Geophys Res 94(C3):32713285. doi:10.1029/JC094iC03p03271

Evans GT, Hoenig JM (1998) Testing and viewing symmetry in contingency tables, with application to readers of fish ages. Biometrics 54:620-629

Francis MP, Campana SE, Jones CM (2007) Age under-estimation in New Zealand porbeagle sharks (Lamna nasus): is there an upper limit to ages that can be determined from shark vertebrae? Mar Freshw Res 58:10-23

Gedamke T, DuPaul WD, Musick JA (2005) Observations on the life history of the barndoor skate, Dipturus laevis, on Georges Bank (western North Atlantic). J Northwest Atl Fish Sci 35:67-78

Haddon M (2001) Modeling and quantitative methods in fisheries. Chapman \& Hall/CRC Press, Boca Raton

Harry AV, Tobin AJ, Simpfendorfer CA (2013) Age, growth and reproductive biology of the spot-tail shark Carcharhinus sorrah, and the Australian blacktip shark, C. tilstoni, from the Great Barrier Reef World Heritage Area, north-eastern Australia. Mar Freshw Res 64(4):277-293 
Hoenig JM, Morgan MJ, Brown CA (1995) Analyzing differences between two age determination methods by tests of symmetry. Can J Fish Aquat Sci 52:364-368

James KC, Ebert DA, Natanson, LJ, Cailliet GM (2013) Age and growth characteristics of the Starry Skate, Raja stellulata, with a description of life history and habitat trends of the central California, U.S.A., skate assemblage. Environ Biol Fish

Kalish JM, Johnston J (2001) Determination of school shark age based on analysis of radiocarbon in vertebral collagen. In: Kalish JM (ed) Use of the bomb radiocarbon chronometer to validate fish age. Final Report, FDRC Project 93/109. Fisheries Research and Development Corporation, Canberra, Australia, pp 116-122

Kerr LA, Andrews AH, Cailliet GM, Brown TA, Coale KH (2006) Investigations of $\Delta^{14} \mathrm{C}, \delta^{13} \mathrm{C}$, and $\delta^{15} \mathrm{~N}$ in vertebrae of white shark (Carcharodon carcharias) from the eastern North Pacific Ocean. Environ Biol Fish 77:337-353

Kneebone J, Natanson LJ, Andrews AH, Howell WH (2008) Using bomb radiocarbon analyses to validate age and growth estimates for the tiger shark, Galeocerdo cuvier, in the western North Atlantic. Mar Biol 154:423-434

Kohler NE, Casey JG, Turner PA (1995) Length-weight relationships for 13 species of sharks from the western North Atlantic. Fish Bull 93(2):412-418

McNemar Q (1947) Note on the sampling error of the difference between correlated proportions or percentages. Psychometrika 12:153-157

McPhie RP, Campana SE (2009) Bomb dating and age determination of skates (family Rajidae) off the Eastern coast of Canada. ICES J Mar Sci 66:546-560

Natanson LJ (1993) Effect of temperature on band deposition in the little skate, Raja erinacea. Copeia 1993(1):199-206

Natanson LJ, Cailliet GM (1990) Vertebral growth zone deposition in Pacific angel sharks. Copeia 1990:1133-1145

Natanson LJ, Casey JG, Kohler NE (1995) Age and growth of the dusky shark, Carcharhinus obscurus, in the western North Atlantic. Fish Bull 93:116-126

Natanson LJ, Mello JJ, Campana SE (2002) Validated age and growth of the porbeagle shark (Lamna nasus) in the western North Atlantic Ocean. Fish Bull 100(2):266-278

Natanson LJ, Wintner SP, Johansson F, Piercy A, Campbell P, De Maddalena A, Gulak SJB, Human B, Cigala Fulgosi F, Ebert DA, Fong JD, Hemida F, Mollen FH, Vanni S, Burgess GH, Compagno LJV, Wedderburn-Maxwell A (2008) Preliminary investigation of vertebral band pairs in the basking shark Cetorhinus maximus (Gunnerus). MEPS 361:267-278

NMFS (1999) Final fishery management plan for Atlantic tunas, swordfish, and sharks. Volumes I and II. National Marine Fisheries Service, Silver Spring

NMFS (2003) Final amendment 1 to the fishery management plan for Atlantic tunas, swordfish, and sharks. National Marine Fisheries Service, Silver Spring

NMFS (2011) SEDAR 21 stock assessment report: sandbar, dusky, and blacknose sharks. SEDAR, 4055 Faber Place Drive, Suite 201, North Charleston, SC 29405. 415 pp
Passerotti MS, Carlson JK, Piercy AN, Campana SE (2010) Age validation of great hammerhead shark (Sphyrna mokarran), determined by bomb radiocarbon analysis. Fish Bull 108:346-351

R Core Team (2012) R: a language and environment for statistical computing. R Foundation for Statistical Computing, Vienna

Ricker WE (1975) Computation and interpretation of biological statistics of fish populations. Bull Fish Res Board Can 23:519-529

Ricker WE (1979) Growth rates and models. In: Hoar WS, Randall DJ, Brett JR (eds) Fish physiology, vol. VIII, bioenergetics and growth. Academic Press, pp 677-743

Romine JG, Musick JA, Burgess GH (2009) Demographic analyses of the dusky shark, Carcharhinus obscurus, in the Northwest Atlantic incorporating hooking mortality estimates and revised reproductive parameters. Environ Biol Fish 84:277-289

Rose KA, Cowen JH Jr, Winemiller KO, Myers RA, Hilborn R (2001) Compersatory density dependence in fish populations: importance, controversy, understanding and prognosis. Fish Fish 2:293-327

Sæther BE, Lande R, Engen S, Weimerskirch H, Lillegard M, Altwegg R, Becker PH, Bregnballe T, Brommer JE, McCleery RH, Merilä J, Nyholm E, Rendell W, Robertson RR, Tryjanowski P, Visser ME (2005) Generation time and temporal scaling of bird population dynamics. Nature 426:99-102

Schnute J (1981) A versatile growth model with statistically stable parameters. Can J Fish Aquat Sci 38:1128-1140

Sminkey TR, Musick JA (1995) Age and growth of the sandbar shark, Carcharhinus plumbeus, before and after population depletion. Copeia 1995:871-883

Springer S (1960) Natural history of the sandbar shark, Eulamnia milberti. Fish Bull 61:1-38

Stuiver M, Polach HA (1977) Discussion: reporting of ${ }^{14} \mathrm{C}$ data. Radiocarbon 19:355-363

Taylor IG, Gallucci VF (2009) Unconfounding the effects of climate and density dependence using 60 years of data on spiny dogfish (Squalus acanthias). Can J Fish Aquat Sci 66:351-366

Tillet BJ, Meekan MG, Field IC, Hua Q, Bradshaw CJA (2011) Similar life history traits in bull (Carcharhinus leucas) and pig-eye (C. amboinensis) sharks. Mar Freshwat Res 62:850860

Tuross N, Fogel ML, Hare PE (1988) Variability in the preservation of the isotopic composition of collagen from fossil bone. Geochim Cosmochim Acta 52:929-935

von Bertalanffy L (1938) A quantitative theory of organic growth (inquiries on growth laws II). Hum Biol 10:181-213

Walker TI (1998) Can shark resources be harvested sustainably? A question revisited with a review of shark fisheries. Mar Freshwat Res 49:553-572

Zuur AF, Ieno EN, Walker NJ, Saveliev AA, Smith GM (2009) Mixed effects model and extension in ecology with $\mathrm{R}$. Springer, New York 